
$\underline{z}$

$z$ IITIISN

(2nIIISN) 

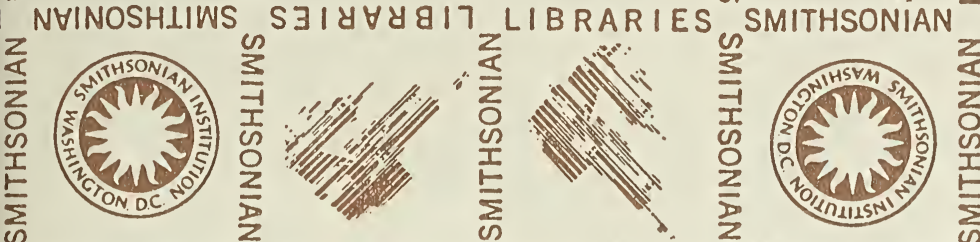
INSTITUTION

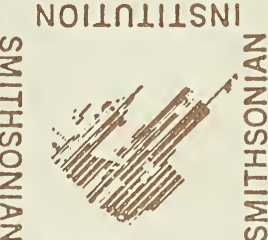

SMITHSONIAN
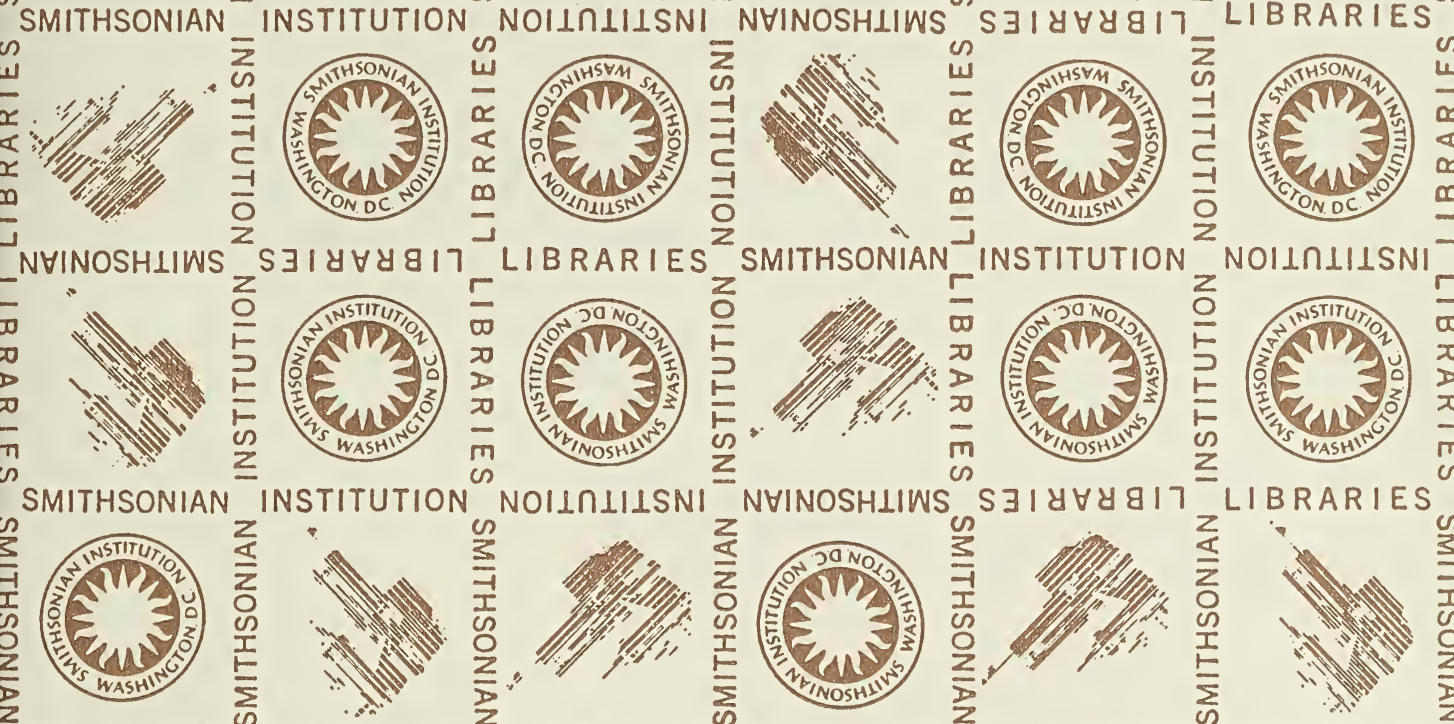

SI

NHINOSHLIWS S $\exists I Y \forall Y 817^{2}$ LIBRARIES SMITHSONIAN
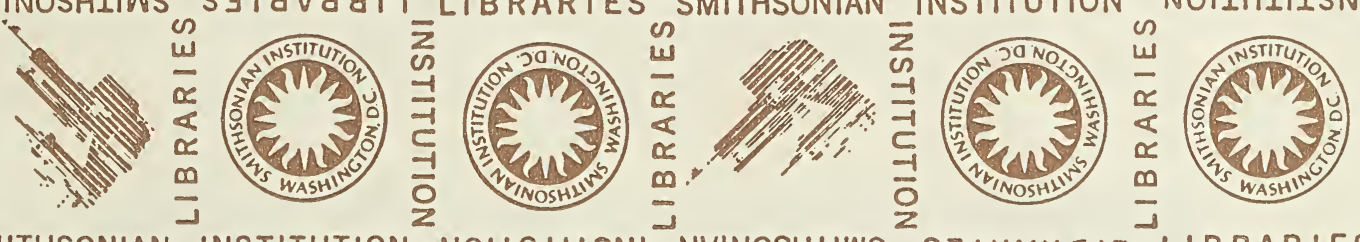

SMITHSONIAN INSTITUTION NOIINLIISNI NHINOSHLIWS
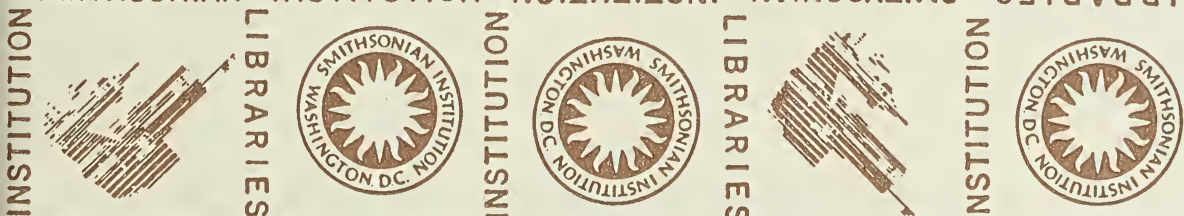

LIBRARIES

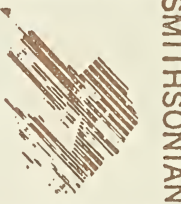

N
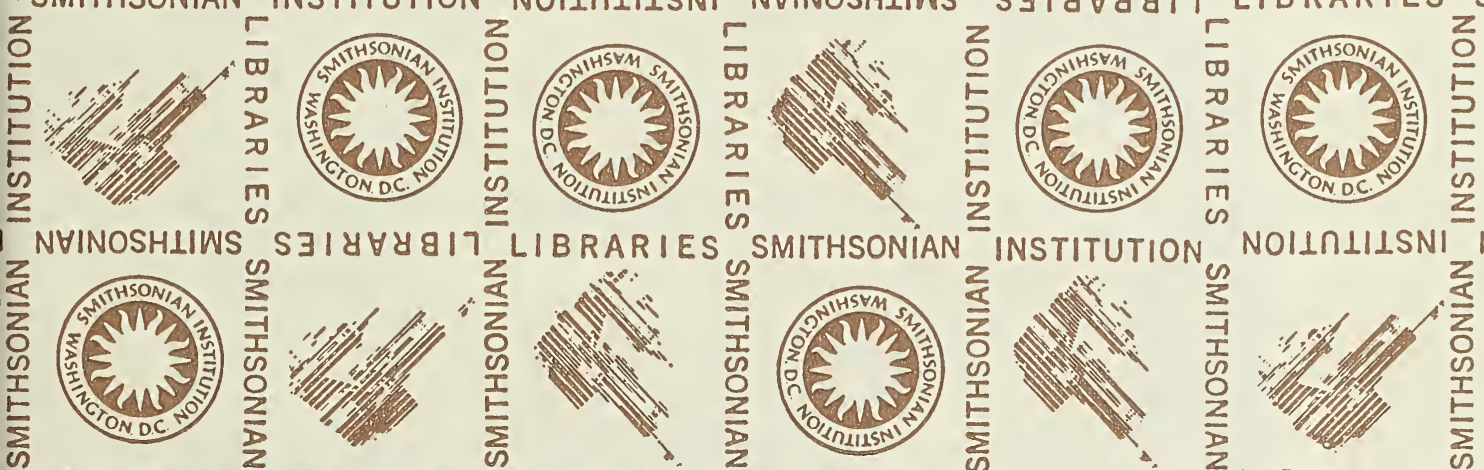

NOIINIIISNI N

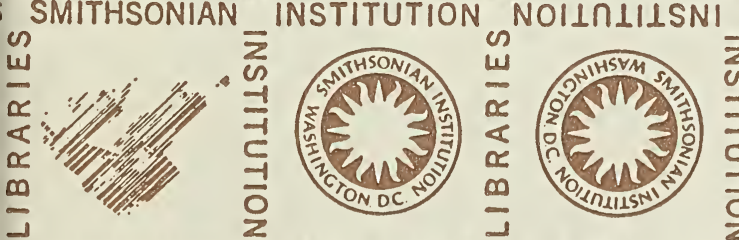

INUINOSHUWS
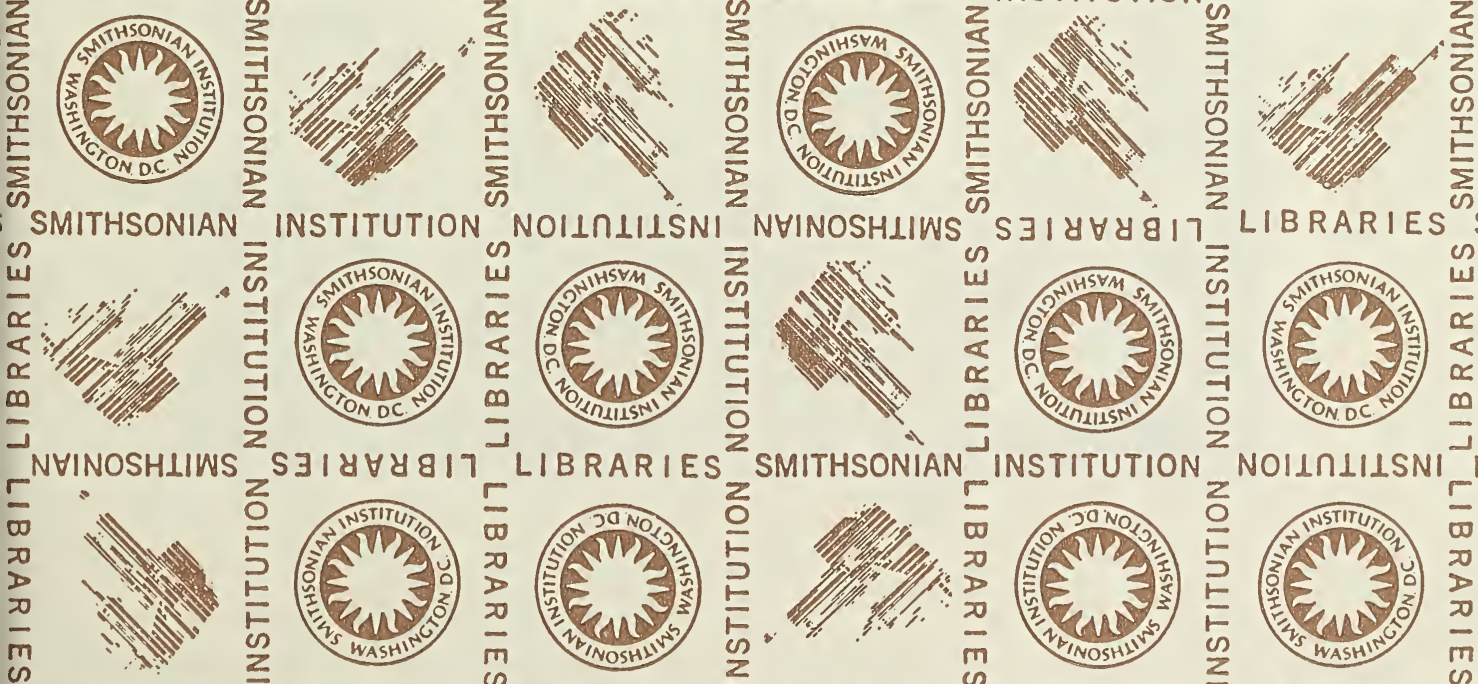

NSTITUTION
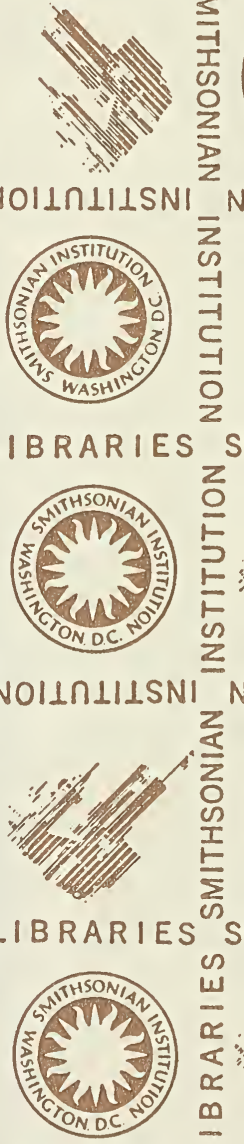

$S A$
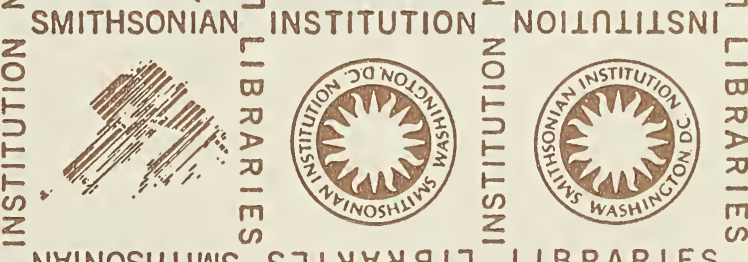



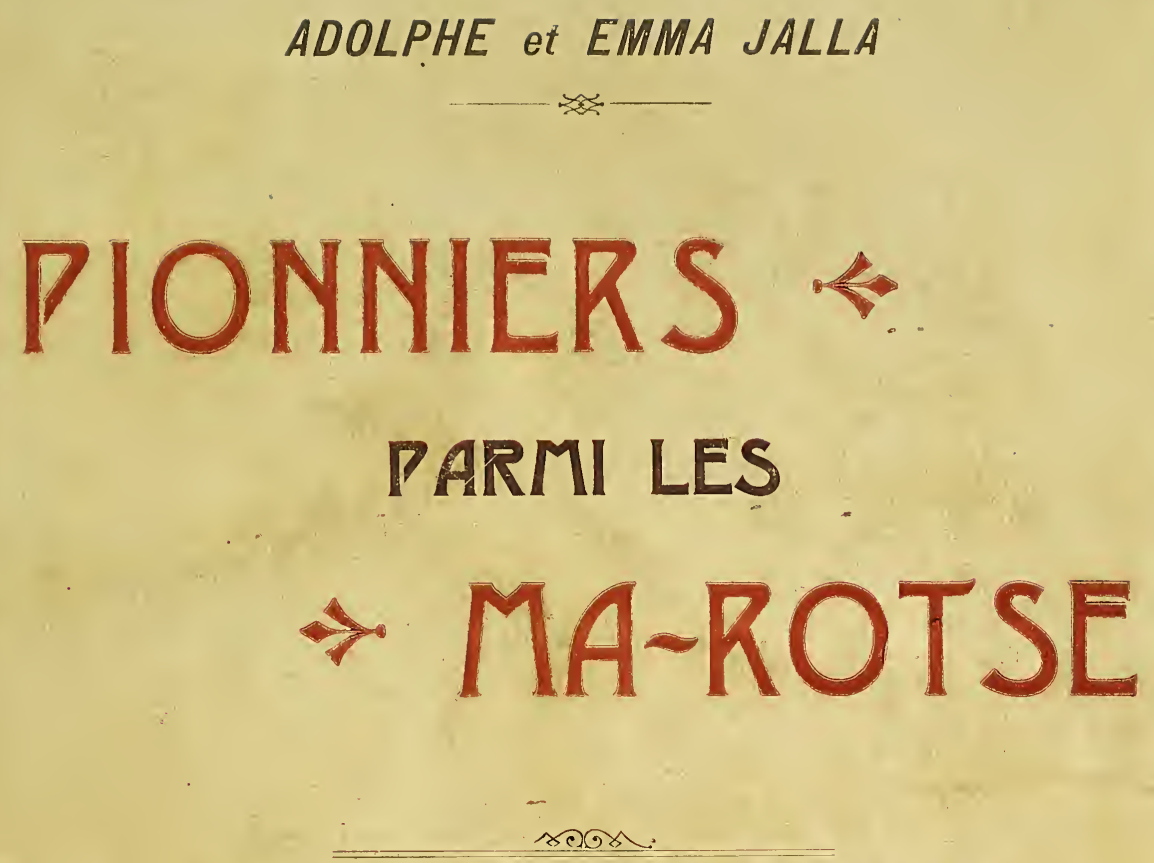

Avec 26 gravures et une carte du Barotsiland.

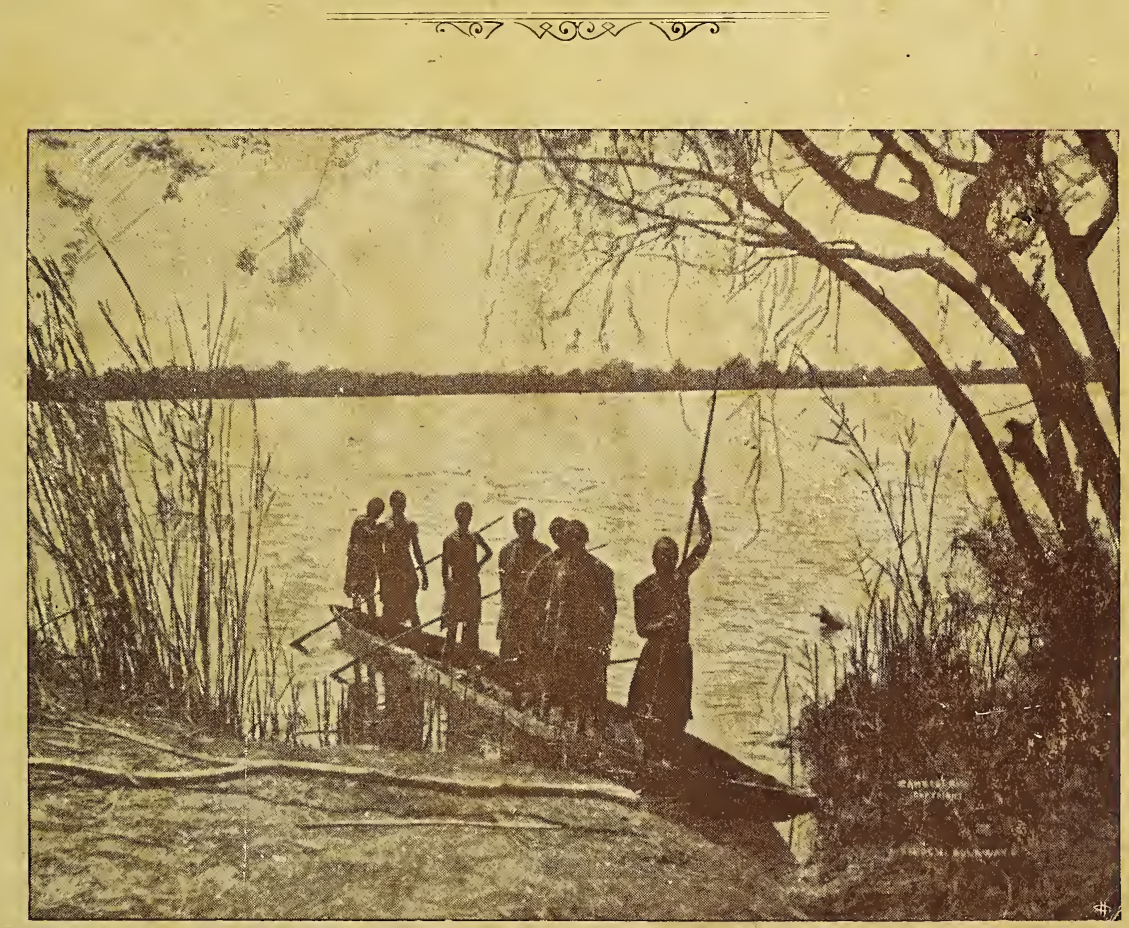

FLORENCE, 1904. - IMPRIMERIE CLAUDIENNE. 



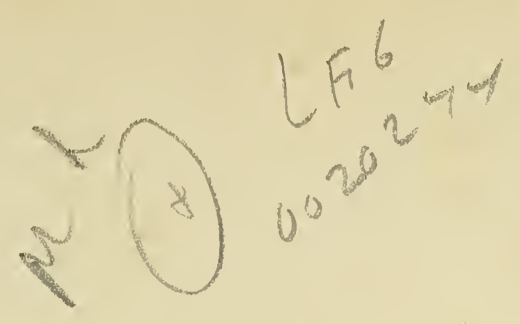

Pionniers parmi les Ma-Rotse.

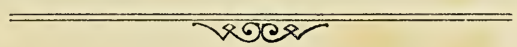





$$
\begin{gathered}
\text { À nos hôtes et amis } \\
\text { dont l'accueil chaleureux } \\
\text { a transformé notre séjour en Europe } \\
\text { en une source } \\
\text { de jouissances et de bénédictions. }
\end{gathered}
$$






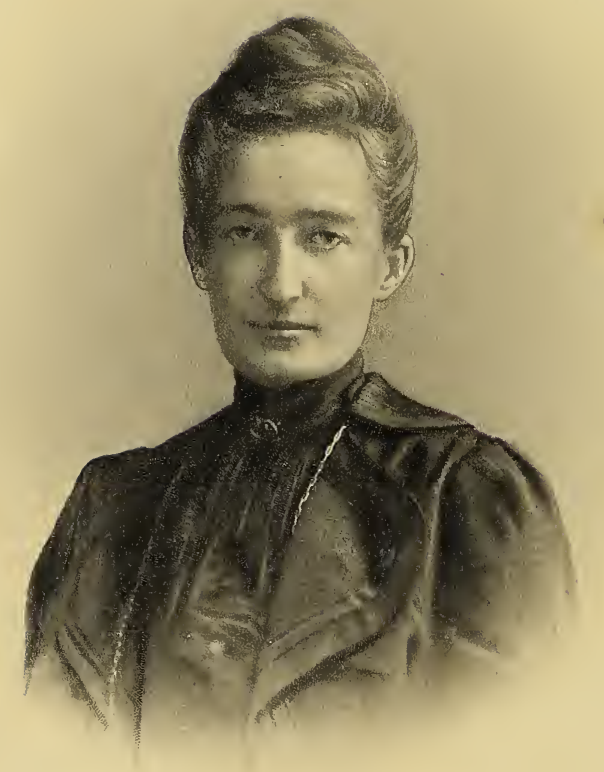

MADAME ADOLPHE JALLA NÉE EMMA PONS $1869-1902$ 


\section{LES MA-ROTSE}

PAR LE MISSIONNAIRE

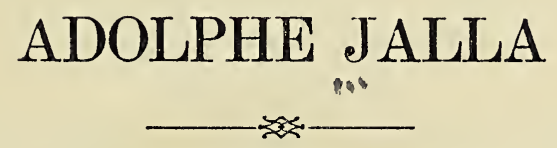

Avec de nombreuses gravures.
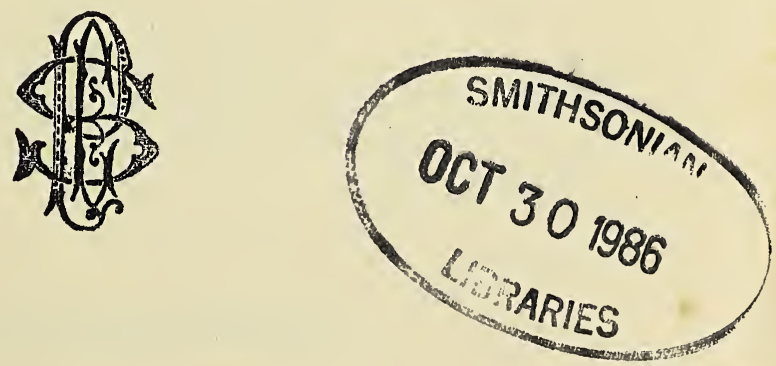

FLORENCE

IMPRIMERIE CLAUDIENNE

Via de' Serragli, 51

1903. 



\section{IN IMEIMORIAIM}

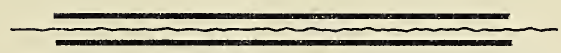

\̀ LA MÉMOIRE BÉNIE DE

CELLE

QUI A ÉTÉ POUR MOI

UN DON INAPPRÉCIABLE DU SEIGNEUR

ET POUR MON OEUVRE

UN AIDE D'ÉLITE

UNE FEMME MISSIONNAIRE DANS L'ÂME

PAR LA JOYEUSE CONSÉCRATION

DE SESQUALITÉS DU COEUR ET DE L'INTELLIGENCE

ELLE A FAIT BRILLER LA BEAUTÉ DE LA FAMILLE CHRÉTIENNE ET GAGNÉ DES ÂMES AU SAUVEUR

JUSQUE SUR LES RIVES DU ZAMBÈSE.

" Il m'appelle - Il m'accueillera."

Père, je veux que là où je suis, ceux que tu m'as donnés soient aussi avec moi, afin qu'ils voient ma gloire.

Jean XVII, 24. 



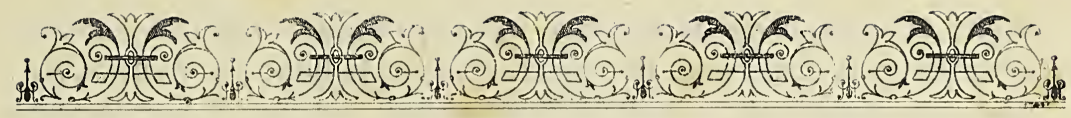

\title{
Avant Propos
}

\author{
du Directeur do la Société des Missions Evangéliques \\ DE PARIS
}

Un rare privilège est échu à la Société des Missions Evangéliques de Paris: elle groupe en une action commune les diverses branches du Protestantisme de langue française. En dehors des Missions, cette grande famille, si une dans ses origines, dans son histoire, dans son esprit, ne réalise sa solidarité que sur le terrain littéraire. Dans nos champs de conquête, son unitẻ s'est affirmée pratiquement. Aux représentants des vieilles églises huguenotes, aux fils du pays de Montbéliard et d'Alsace, se sont associés des missionnaires, toujours plus nombreux, de la Suisse française, jusqu'au jour où les enfants des Vallées vaudoises sont venus à leur tour prendre leur place dans les rangs de notre apostolat protestant.

Nulle part cette féconde coopération ne s'est accomplie plus pleinement que dans la Mission du Zambèze. Et nulle part l'apport de l'Eglise vaudoise n'a été plus riche et ne s'est produit plus à propos. L'histoire religieuse associera toujours au nom du fondateur de la Mission celui de Louis Jalla, qui après M. D. Jeanmairet, bientôt éloignẻ par l'état de sa santé, fut le premier compagnon de travail de M. Coillard; et celui de M. Adolphe Jalla qu'une collaboration plus étroite encore devait associer aux travaux de notre pionnier.

C'est cet auxiliare dévoué du vétéran de la mission qui, dans les pages qui suivent, va nous racontèr sa carrière. L'Eglise lui saura toujours grẻ d'avoir été, pour le vieux missionnaire et pour sa compagne de travail, non pas seulement un collaborateur actif et dévoué, mais un fils plein de respect et d'affection. Mais elle a d'autres 
raisons de l'aimer et de lui être reconnaissante: voilà des années qu'elle a vu en lui, sous les apparences de la douceur et de la modestie, un missionnaire plein d'ẻnergie, admirablement qualifié pour toutes les parties de sa tâche et possédé, ce qui vaut plus que tout le reste, par le plus pur esprit de la mission évangélique.

A ses côtés, le livre que nous présentons aux lecteurs fait apparaître une autre figure, pleine de force et de grâce, trop tôt, hélas, ravie à nos yeux: c'est celle de Madame Adolphe Jalla, que Dieu a rappellée à Lui l'an dernier, à l'heure où elle se préparait à reprendre avec son mari le chemin de l'Afrique. Que dire de cette jeune sœur qui n'ait été répété bien des fois, dans le concert de regrets et de témoignages d'affection qui s'est élevé autour de sa tombe? Dans l'émotion de cette heure, dans le saisissement d'une perte que rien ne faisait prévoir et que rien ne pourra réparer, nous avons essayé d'évoquer, tel qu'il nous est apparu, ce pur et noble visage, cette personalitẻ si pleine de charme et de vaillance. On nous pardonnera de nous citer nous-mêmes: il est des choses qu'on n'exprime bien qu'une fois.

«Ce qui, en Madame Jalla, l'emportait encore sur les qualités intellectuelles, c'étaient les dons de l'âme. On s'en apercevait bien vite dans sa société, dont nous voudrions pouvoir rendre tout le charme. L'enveloppe physique était frêle; mais l'énergie se lisait dans ses yeux au regard si pur et presque enfantin; sur ses traits, où la nettetẻ des lignes s'alliait aux plus délicates ceuleurs; sur tout ce visage transparent à l'intense vie intérieure. C'était là ce qui séduisait: cette droiture, ce naturel parfait qui excluait dans l'expression et jusque dans le ton, tout apprêt et toute affectation ».

Mais pourquoi nous attarder à une peinture forcément incomplète et dont les contours et les nuances n'ont de valeur que pour celui qui les trace d'une main malhabile, alors que notre jeune sœur se présente elle-même à nous au cours des pages qu'on va lire, dans la spontaneité de sa nature et dans le riche épanouissement du ministère qu'elle a partagé avec son mari ? - Les exigences de l'idéal littéraire eussent peut-être conseillé, dans le volume de M. Jalla, encore plus de suppressions qu'il n'en a été fait dejà dans le manuscrit primitif. Les amis des Missions, ceux qui désirent l'information abondante, la nuance exacte, la vie de pionnier dans sa réalité journalière, seront reconnaissants de posséder cet ouvrage et de prendre, en le lisant, une sorte de bain d'atmosphère missionnaire et zambézienne. Ce livre sera lu à la veillée dans les maisons où l'œuvre des Missions est en honneur; il alimentera l'intérêt et l'amour de ces humbles collaboratrices de la grande cause que groupe une modeste réunion de couture; il nourrira dans les églises le zèle pour l'évangélisation du monde. Et, qui sait? Par l'abon- 
dance des détails, par le retour d'incidents presque semblables, par l'accumulation de faits précis, peut-être atteindra-t-il plus sûrement son but que n'eût fait une composition plus limitée dans son étendue et plus mesurée dans ses proportions. Il donnera cette intuition directe des caractères, ce contact personnel avec des vies et des âmes qui, selon le mot célèbre, fait de l'histoire, et en particulier de l'histoire biographique, une résurrection.

Quoiqu'il en soit, au reste, de sa forme extérieure, la bénédiction de Dieu accompagnera ce travail. Écrit dans les larmes, traversé par un tendre et pur souvenir, inspiré par l'esprit du Maîtr ə, il fera son chemin et son œuvre dans nos églises, pendant que, de son côté, son auteur continuera de suivre son sentier et de faire son travail aux avant-postes de l'armée de Jésus-Christ.

C'est cette confiance, où se mêle une pensée de profonde et fraternelle affection, qui m'a donné le courage d'écrire ces lignes, si incapable que je me sente d'ailleurs de parler dignement de cet apostolat missionnaire que je n'ai pas exercé et dont j’ai seulement essayẻ d'être le serviteur.

\section{A. BCEGNER}

Directeur de la Société des Missions

Evangéliques de Paris.

PARIS, 1er Décembre 1903. 



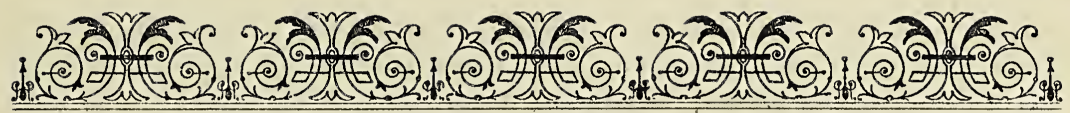

\section{PRERACE \\ -}

Des amis nous ont demandé d'écrire un livre sur notre vie de pionniers au Zambèze. Nous avons longtemps hésité. Bien des raisons nous en dissuadaient. Lq vie africaine ne nous a pas préparès à celte tâche. Cependant l'accueil que nous avons recu dans nos tournées missionnaires, les encouragements et l'affection que nous avons rencontrés partout, ont fini par faire taire les objections. Nous nous sommes dit que l'œuvre à laquelie Dieu nous a ap. pelés à travailler, n'est pas ḋ nous seuls, mais bien aussi $\dot{a}$ tous ceux qui, par leur sympathie, leurs dons, leurs prières, n'ont cessé de nous soutenir. Si le Seigneur nous a accordè des délivrances, si notre courage n'a pas défailli, si l'assurance de notre vocation n'a pas vacillé; si nous avons vu la lumière luire dans les tènébres, si l'ignorance, les superstitions, les atrocités sans nom se sont peu à peu dissipées sous l'infuence de l'Evangile, enfin, si nous avons pu cueillir quelques épis, n'est-ce-pas à nos amis que nous le devons en grande partie? Ne devons-nous pas, par reconnaissance, accéder $\dot{a}$ la demande qui nous a été faite et raconter no. tre vie missionnaire?

Nous décidâmes d'écrire pour nos amis. Pendant ma dernière tournée en France, ma femme traç le récit de la mort de notre petit Giulio et d'une partie de nos voyages....

Je suls restẻ seul pour cette oeuvre dont elle devait être le principal auteur! Ne devais-je pas renoncer à notre curre? Ce qui m'a poussé $\dot{a}$ la reprendre et $\dot{a}$ l'achever, c'est le désir qu'avait ma fernme de vivre encore, de travailler encore pour le Maître, de faire encore du bien.

Les pages que j'ai détachées de sa correspondance et qui seront la meilleure partie de l'ouvrage, seront, je crois, propres à attirer encore des âmes au Sauveur. Elle parlera encore, quoique morte. Qui dira la part d'influence qu'exerce la femme missionnaire, quand elle s'est consacrée au Seigneur, sans réserve, quand elle a connu quelque chose de cette joie de sauver les âmes, en vue de laquelle 
Jésus a soufferl la croix et méprisé l'ignominie, quand elle a compris que la grande auvre pour laquelle nous avons ètè rachetès c'est d'amener d'autres âmes au Rédempteur? Ce qui constitue la supériorité des Missions protestantes sur les catholiques, n'est-cepas la présence de la femme missionnaire, son ministère auprès des femmes et de la jeunesse, et la vie de famille dont elle est le centre?

Nos lettres à nos familles ont ètẻ la source presque unique $\dot{a}$ laquelle nous avons puisè; de là le style familier du récit et les dètails que l'on n'ose pas présenter au grand public, mais qui pour les proches ont un double prix. C'est à la famille agrandie des amis des missions que nous offrons ces pages.

Ils y verront que la vie missionnaire est surtout composẻe de petites choses et que, partant, elle est assez diffẻrente de l'idéal que beaucoup de personnes en ont. Sans doute le but est toujours de sauver les âmes, mais il s'agit aussi d'améliorer l'existence matèrielle et la vie individuelle et sociale, d'éclairer tes intelligences, de former les caractères, d'ouvrir de nouveaux horizons: charité, justice, sainteté. La prédication de l'Evangile a sa part dans cette cuvre complexe, mais l'enseignement scolaire, les conseils de toute nature, l'exercice de la médecine, les travaux manuels, la vie dans toutes ses manifestations, ont leur très grande importance. Cependant, que serait le changement des mceurs sans celui des coeurs? L'éducation sans l'instruction religieuse, ne peut qu'aboutir à d'amères déceptions: N'est-ce pas partout que nous devons chercher premièrement le royaume de Dieu et sa justice, dans l'église, dans la sociètè, ḋ l'école, dans la famille....? C'est ḋ cela que visent nos Missions et en particulier celle du Zambèze.

Si ces pages serviront $\dot{a}$ faire aimer le seigneur et son ceuvre, le but pour laquel elles ont èté écrites aura èté atteint.

Nous remercions Monsieur BERTRAND, qui a bien voulu prendre à sa charge les frais de la carte, $M$. Begner et $M$. Ed. FAVRE, qui ont bien voulu nous prêter un certain nombre de clichés, en plus de leur constante et précieuse coopération pour ce volume même. Je suis également reconnaissant envers mon frère, le pasteur EDOUARD JALLA, qui m'a offert d'être l'éditeur de cet ouvrage et rn'a déchargé de tout souci relatif $\dot{a}$ la publication.

Torre Pellice, 26 janvier 1903.

ADOLPHE JALLA. 
PREMIÈRE PARTIE

Non premier vogage all Pays des ma-Rotsi

Initiation à la vie missionnaire

1889-1891 




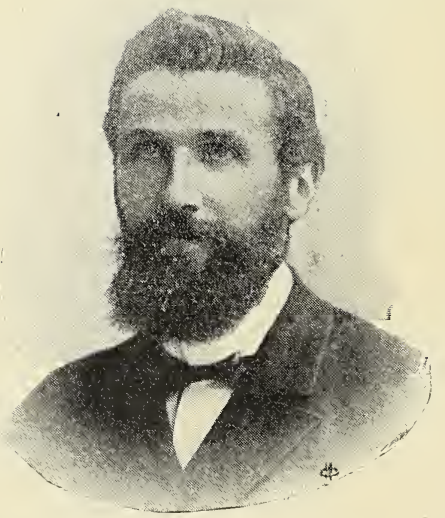

Adolphe Jalla (L'Auteur). 


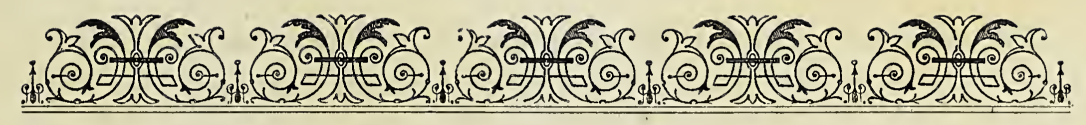

\section{PREMIÈRE PARTIE}

I.

\section{De Torre-Pellice à la Ville du Cap.}

Fiançailles. - Séparation. - sur ner.

C'était le 29 décembre 1888, quinze jours avant mon $\cup$ départ. Dans le déchirement de la séparation, un nouveau lien avait achevé de se former. J'allais partir seul, mais soutenu par le sentiment qu'outre ma mère, mes frères et soeurs, mes parents et amis, ma fiancée me suivrait par la pensée et par la prière, pendant le long voyage, puis sur les rives du Zambèze. Elle savait qu'en dehors de mon amour je ne pouvais lui offrir, après une séparation bien longue, qu'une vie de fatigues, de luttes, de peines, de dangers et de privations. Elle était pleine cependant de courage et d'entrain. Ce n'était pas seulement à partager ma vie difficile que notre Père céleste l'appelait, mais aussi à travailler avec moi dans son champ, et peut être à y ramasser une gerbe. J'avais la ferme confiance qu'll saurait la préparer pour son œuvre, la fortifier et la garder. C'était Lui qui me l'avait donnée, en réponse à mes prières. Son père m'avait dit: «Elle a été la meilleure des filles, elle sera la meilleure des femmes ». 
(1) Nos cœurs s'ètaient trouvès, compris, et maintenant ils étaient liès pour la vie. Le 11 janvier 1889 au matin, il partit, par une journẻe grise et neigeuse. Il étail parti, c'est vrai, les mers et les déserts nous sépareraient bientôt, mais Dieu voulant, nous nous retrouverions.

Le monde ne peut comprendre un départ de missionnaires, et même certains chrétiens, se refusant encore d'accepter l'ordre du Maître, blâment le fils qui quitte sa mère et l'accusent de n'avoir pas de cœur. Je me rappelle que ces voix étaient arrivées jusqu'à nous. Mais de quel droit parlaient-elles ainsi, tant que notre mère chérie n'avait rien dit? Elle souffrait, nous souffrions; mais n' offrirons-nous à l'Eternel que des sacrifices qui ne con̂tent rien? Nos coeurs se comprenaient et nous nous sentions d'autant plus près l'un de l'autre. Elle avait été si belle notre vie de famille, si douce, si libre, si joyeuse!

Le 15 février je m'embarquai à Dartmouth sur !e Garth Castle. Le 7 mars, vers midi nous étions en vue du Cap de Bonne Espérance. Bientôt la Montagne de la Table parut à l'horizon. À 5 h., grâces aux rayons du soleil couchant et à la limpidité de l'atmosphère, nous voyons distinctement, à notre droite, tous les détails du massif de la presqu'île du Cap, à gauche c'est l'île Robben (l'île des lépreux) et son phare blanc, la côte avec sa double bordure de sable blanc ed de collines, et plus loin, derrière celles-ci, les montagnes de La Perle. Nous faisons enfin notre entrée dans la rade à $6 \mathrm{~h}$. et la ville s'étale devant nous. J'aborde avec les autres passagers, je fais un petit tour, mais rentre au bateau pour la nuit.

J'étais heureux d'arriver sur ce continent vers lequel je m'étais senti attiré depuis bien des années; j'étais reconnaissant envers Dieu, mon Guide et mon Protecteur; j'éprouvais aussi un profond sentiment de tristesse en pensant aux ténèbres qui couvrent encore l'intérieur de l'Afrique.

(1) Tous les alinéas avec ce caractère d'imprimerie sont des citations tirées des lettres de Nadame Emma Jalla. 


\section{II.}

Séjour dans la Colonie du Cap.

Au Cap. - A Wellington. - Kimberley. - Chez M. Ashton de la L. Y. S.

A PRìs un court séjour à Cape Town, je partis pour Wel A lington. Le 15, j’arrivai, en chemin de fer, à Kimberley. Une lettre de M. Musson, chargé d'organiser mon expé. dition, m'y apprend que je ne pourrai me mettre en route qu'à la fin d'Avril.

Je fus particulièrement heureux de constater que, parmi les descendants de ces Boers qui ont trop longtemps été comnus comme les pires ennemis des noirs, une quinzaine de jeunes gens se préparaient au séminaire à continuer et étendre l'oeuvre missionnaire au Nord du Transvaal, et aux environs du Nyassa.

Je passai ensuite 39 heures dans un des confortables wagons de la ligne, destinée à devenir trans-africaine. Pendant la nuit nous franchissons les contreforts occidentaux de la grande chaine des Montagnes Noires. Je me réveille le lendemain en plein Karroo. Ce sont des plateaux et des collines où, à cette saison on ne voit que des touffes d'herbes grossières, des fougères, et quelques buissons épineux. Les troupeaux de brebis ont émigré; nous n'apercerons que de rares habitations dans les quelques endroits où il y a un peu d'eau. Dans quelques emplacements plus favorisés, mais très rares, on voit des villages. Le 15, à mon réveil, le train s'arrête à la station du fleuve Orange, où nous déjeûnons. À $11.45 \mathrm{~h}$. nous retrouvons la vie et le bruit à Beaconsfield, et bientôt après nous sommes à la station terminus de Kimberley.

Je ne savais pas en y arrivant que j'aurais le temps d'en faire longuement la connaissance. Hélas! le 17 mars, le jour même où je reçois mon premier courrier d'Europe, une lettre de $M$. Musson (chargé d'organiser mon expédition) m'annonce que je ne pourrai pas m'acheminer ver's le Zambèze arant la fin d'Avril! Que faire?

C'est l'Afrique. J'aurais pu l'oublier en entendant chaque jour le sifflet de la locomotive, le bruit des machines des mines, des voịtures et des chars, en voyant les Eglises, l'Armée du salut.... 
Ce délai me rappelle que je ne suis plus sur le continent où tout va à la vapeur. C'est encore la civilisation, mais ce n'est plus l'Europe. Toutes les maisons, sauf deux, n'ont qu'un rez de chaussée, et le fer blanc domine dans les maisons des riches comme dans celles des paurres, dans la cité des affaires, comme dans les rues bordées de villas. Les jardins de ces dernières ne sont que tracés. Les wagons, attelés de cinq ou six paires de boeufs, les noirs de toutes nuances que l'on rencontre à chaque pas, c'est aussi l'Afrique. Et la poussière! Au coucher du soleil la ville paraît comme enveloppée dans un brouillard de poussière. Je n'ai rien vu d'approchant en Europe.

Ce fut une joie pour mois de pouvoir quitter Kimberley et d'accepter l'hospitalité que m'offrait un missionnaire de la L. M. S. (London Missionary Society), M. Ashton, de Barkly là 39 kil. de Kimberley). M. Ashton est un vieillard à forte taille, à barbe et cheveux gris, à l'air bon. Il m'accueille comme si j'étais son fils. C'est un vétéran, un collaborateur de Moffat, un ami de Livingstone, à l'œuvre depuis quarante-six ans.

Les premiers mariages de noirs que je vis m'amusèrent. Les deux couples arec parents et amis étaient venus dès l'avantveille camper avec leurs wagons, près de la maison missionnaire. Pour la cérémonie les époux se présentèrent vêtus de noir avec chemises blanches et souliers luisants. L'un d'eux avait même des gants de coton blanc. Les épouses étaient en blanc, robes longues mais sans traine. L'une avait un beau voile de mousseline descendant jusqu'à la taille, trois ou quatre feuilles de chêne dorées, piquées le long de la robe, et des gants de coton jaune brun. L'antre avait des festons noirs autours de sa jupe; un voile bleu clair, épais et long, cachait complètement son visage: elle tenait à la main droite un foulard rouge. Après la lecture de quelques passages bibliques, et une courte allocution en sechwana, M. Ashton les invita successivement à se lever pour faire les promesses et recevoir la bénédiction. Ils devaient pendant ce temps se donner la main droite, mais quelle gaucherie! Suivit la signature des actes de mariage. Les deux époux et une épouse ne sachant pas écrire, firent la croix à côté de leurs noms.

Le 15 mai, je rentrai à Kimberley, espérant pouvoir en repartir bientôt. Hélas je dus encore y passer plus de trois semaines.

Ce second séjour dans la ville des diamants fut agrémenté par la rencontre des familles Creux et D. Keck. 
III.

De Kimberley à la ville du roi Khama.

Enfin en wagon à boeufs: - Un mo-Toka malade et premières expériences avec des Zambéziens. - Le Bechwanaland. - Rencontre avec M. Goy. A Ia capitale du rol Khama.

E 7 juin, à $6 \mathrm{~h}$. du soir, nos lourds chariots se mettent en branle! Trois mois après mon arrivée dans la Colonie!Enfin! nous sommes en route vers le Zambèze! Le wagon dans lequel je suis logé a été acheté pour M. Coillard, mais il est destivé au roi Lewanika.

Je ne tardai pas à trouver qu'un voyage en wagon a beaucoup de charme; c'est une longue suite de piques-niques, un tonique excellent pour le corps et un agréable repos pour l'esprit. Cependant je n'avais pas beaucoup de confort, mon wagon était trop rempli. La partie qui m était réservée avait 2.40 mètres de long, sur un m. de large à la base, et $0.48 \mathrm{~cm}$. de haut au centre. Je ne pouvais m'y glisser que sur le dos, ou à quatre pattes. La partie antérieure était occupée par ma couche, et le reste par les caisses, malles et sacs de voyage dont j'avais besoin. Aussi je ne m'enfilais dans ce boyau que pour y prendre des objets, ou pour y dormir. Quand le chariot était en marche, je le precédais, ou je m'asseyais sur la caisse d'avant. Jusqu'à Mafeking j'eus quatre agréables compagnons de route, blancs.

"J'essaie de donner des soins à mes compagnons indigènes quand ils sont indisposés. J'eus un cas grave. On m'avait dit qu'il ne s'agissait que d'une indigestion, mais je n'eus pas de peine à reconnaître l'erreur. Le malade était un mo-Toka bien chétif. M. Musson l'avait chargé de conduire deux chèvres, et sa tâche avec ces êtres capricieux n'était pas aussi aisée qu'on pourrait le croire au premier abord. Le pauvre garçon, qui toussait depuis longtemps, se déclara enfin malade le 15 juin. Il était brûlant de fièvre, son pouls était faible et rapide. Le soir, à la halte, il eut un crachement de sang. Je crus à une phthisie avancée. Je me sentis impuissant. Le pauvre garçon aurait eu besoin d'un 
bon lit, d'une bonne couverture, d'une nourriture appropriée à son état, au lieu de devoir dormir sur le sol, à peine couvert d'un vieux manteau de peau de mouton. J'aurais surtout voulu lui parler du grand médecin, de notre Sauveur, mais je ne pouvais guère me faire comprendre de lui. Je lui prêtai ma chaude couverture de voyage, et le recommandai aux soins de ses compagnons de service, tout en priant Dieu pour lui. Le lendemain le docteur de Vryburg le visita et se prononça pour une pleurésie. Il ordonna quelques médecines et le repos 》 (1).

Quand je m'éreillai, le dimanche 16 juin, nous étions campés à cinq minutes au $\mathrm{N}$. de Vryburg, la capitale du British Bechwanaland, le siège du gouvernement.

Vryburg était en 1889 une petite ville d'une centaine de maisons, sans industrie ni commerce. Non loin de là, se trouvait un petit fort et une caserne.

J'avais préparé une petite allocution en sessouto, je réunis notre monde, je lus quelques portions du Nouveau Testament sechwana, nous chantâmes ensemble et je leur dis ce que j'avais écrit. J'eus la joie d'apprendre qu'ils m'avaient tous bien compris.

Je n'étais pas malheureux lorsque je me trouvais au milieu des noirs. Le lendemain j'avais autour de moi deux des bergers de M. Musson, outre mon conducteur et son garçon; j'en profitai pour leur lire quelques chapitres du N.T. et pour prendre une leçon de langue, tout en leur montrant quelques gravures. Cela nous intéressa et nous fit du bien aux uns et aux autres.

Le 19 juin, on vint me dire: «Le pauvre Zambézien est mort et enterré dans votre couverture 》. Pauvre garçon, je l'avais trouvé bien bas la veille et je l'avais dit à ses compagnons de service; ceux-ci s'étaient mis à rire; le chef cuisinier m'avait dit d'un air moqueur: \& Il est mieux que jamais, ne le voyezvous pas à ses yeux? Et puis il a demandé de la bouillie 》. Le matin en arrivant ils le trouvèrent raide mort sur le wagon. Pauvre garçon! avait-il saisi quelques unes des paroles de vie que il avait écoutées à Vryburg? Cette nouvelle jeta sur moi un grand voile de tristesse, mais je me dis: «L'Eternel est bon envers tous, et ses compassions s'étendent sur toutes ses œuvres 》. Je m'étonnai de ce qu'il avait été si vite enterré. Ils auraient bien pu, me disais-je, attendre au moins mon arrivée,

(1) Tiré du Journal des Missions. 
j'aurais dit quelques paroles sérieuses à ces gens qui semblaient n'avoir été impressionnés en rien. Plus tard j'appris que ma couverture de voyage n'avait pas servi du tout à envelopper le cadavre de leur compatriote, mais avait été volée par l'un d'eux. Ce fut ma première expérience des dispositions de ces Zambéziens auxquels je désirais apporter l'Evangile d'amour et de sainteté. Ce n'était pas agréable de se sentir trompé de cette façon: j'espère au moins que le voleur n'aura pas hérité de la maladie qui avait emporté son compagnon.

Le 22 juin nous arrivâmes à Mafeking, qui est divisé en deux villes, celle des blancs et celle des noirs. La ville des blancs est bâtie au nord de celle de Montsioa sur un terrain parfaitement plat et nu; elle est fournie d'une place du marché assez grande mais déserte et de quelques rues se coupant à angle droit, et bordées de maisons. M. Appleby me dit avoir beaucoup plus de satisfaction avec les noirs que avec ses compatriotes.

Le 24 juin, en passant le lit à sec de la Ramatlabama, nous pénétrons dans le Bechwanaland Protectorate. Ce que nous avions vu du British Bechwanaland est ondulé, couvert d'herbe ordinairement haute et relativement dense, avec de très rares arbres. Les makatla, petits buissons odorants, servent de combustible. Que sera le British Protectorate? Peu après la Ramatlabama nous laissons à gauche la route de Kanye qu'avait suivie l'expedition de 1887, pour nous diriger vers le nord-est, par une route tracée récemment. Le pays est moins monotone. Nous avons toujours en vue des collines, nous en avons même franchi une chaîne qui sert de séparation entre le bassin de l'Orange et celui du Limpopo. La végétation est beaucoup plus variée. A côté du mimosa en parasol, seul arbre vu jusque là, croissent plusieurs autres espéces d'acacias, des saules, des hêtres et beaucoup d'autres dont je n'ai pu apprendre que les noms sechwana. L'herbe est haute et touffue.

Le 26 juin nous campons près du grand village de Ramutsa (1000 habitants). Le 1r juillet, nous passons la Notwani, et arrivons au village de Gaberone, une annexe de la Société de Berlin.

La lettre $u$ a le son de l' $u$ italien, de l'ou français.

La lettre w a le son du w anglais dans William, Edward.

Sh est semblable au sh anglais et au ch français. Ch du sessouto correspond au ch anglais (church).

Presque tous les mots des langues bantu ont l'accent sur la pénultime. 
Le 12 juillet, nous atteignons la capitale du ba-Mangwato. On m'y remit plusieurs lettres d'Italie et du Zambèze, attendues depuis des mois; mais j'étais si occupé que je ne pus qu'en parcourir quelques-unes, comme à la dérobée; je lus le reste au clair de lune: une éclipse vint encore m’interrompre.

A Shoshong comme dans tout le voyage j'éprouvai que le missionnaire est un chrétien privilégié. Quelle que soit la Société qui nous envoie, quelle que soit l'église dont nous sommes membres, nous appartenons tout à la même famille. De Wellington à Mangwato j'ai trouvé des frères aînés dans la personne de chacun des douze missionnaires que le Seigneur m'a fait rencontrer. Il me reste un délicieux souvenir des heures nombreuses, mais trop courtes, passées auprès de la famille de M. Hepburn et chez M. Lloyd, son collaborateur. J'en jouis d'autant plus que j'allais être privé de toute société pendant des semaines. Le dimanche 14 juillet, je participai à la $\mathrm{S}$. Cène avec les missionnaires, le chef Khama et environ 150 chrétiens noirs.

Léfi demeurait a deux pas de chez M. Musson; je le vis souvent. Sa femme se portait bien alors et ne semblait pas regret. ter le Zambèze; tandi que Léfi paraissait y avoir laissé une partie de son coeur.

\section{IV.}

A travers le désert.

Diflicnittés. - La poste: - Bushmen. - Les Macaricari. - La Nata. - Le pays aux mille étangs. - Ma-Tebele pilleurs. - Sans eau. - Vne oasis. La soir. - Arrivée : - Seul : - Délivrance.

TUsQU'A Mangwato le voyage en wagon s'était effectué très rapidement, on m'assurait qu'il en serait de même plus loin. Mais quand je constatai que mon wagon était aussi plein et plus lourdement chargé que pour la première partie du voyage, je commençai à craindre. La saison était très avancée et je savais par les lettres de mes devanciers que la route qui me restait à parcourir était plus pénible. 
Partis de Mangwato le 18 juillet, tout alla bien pendant la première étape; nous fîmes 16 kilom. en $2,40 \mathrm{~h}$.; cela promettait! Hélas! cela ne dura pas. Au trait du soir nous perdons une heure en passant une première fois le lit desséché de la Letloche. Quelques uns des bœufs ne sont qu'à demi dressés, ils sautent et gambadent comme de jeunes veaux; ils réussissent à briser non seulement des quantités de clés de joug et d'attaches de cuir, mais même deux fois la chaine de fer. Un des bœufs de timon du wagon de Viddleton s'agenouille chaque fois qu'il s'agit de faire un effort et ne se relève que lorsque le véhicule se remet en braule. D'autres enfin se sauvent chaque fois qu'on veut les atteler. Cependant nos conducteurs sont des hommes rompus au métier. Un peu plus tard, en repassant la Letloche, la chaîne de mon wagon se brise, nous n'en sortons qu'après demi-heure. Mais le second chariot dut y passer la nuit, et ce ne fut qu'à la suite de quatre heures d'effort que nous l'en retirâmes le lendemain matin. Cela alla mieux quand on eut pris des bœufs de M. Coillard pour remplacer les plus mauvais; mais les chariots étaient lourds et nous n'avancions que lentement.

Le 24 juillet, nous atteignons la Loale, à sec dans cette saison; sauf quelques dépressions où nous trouvons assez d'eau pour nous et nos attelages. Nous nous y établissons pour quelques jours, attendant l'arrivée du wagon promis. J'en profite pour faire différentes réparations, puis j'écris, j'étudie. Le wagon arrive enfin le 5 août au soir avec quatre bonnes lettres d'Europe. Malgré l'heure avancée je les dévore toutes le soir même et les relirai encore plus d'une fois à la clarté du soleil. Quelle joie procure un courrier en plein désert! Il vaut presque la peine de venir en Afrique pour l'éprouver. Dans mon isolement je revivais chaque jour, par la pensée, avec les êtres chéris que j'avais laissés bien loin.

Notre expédition est maintenant au complet: deux blancs, Middleton et moi; trois conducteurs métis, douze Zambéziens, trois wagons, chacun avec un attelage de 18 bœufs. De plus les 24 bœufs de $\mathrm{M}$. Coillard, douze chèvres et moutons, deux chevaux et quatre chiens.

Nous quittons enfin la Loale le 7 août. Nous franchissons plusieurs collines, les unes rocailleuses, d'autres sablonneuses, par des routes qui n'en sont pas. Dès le premier jour une caisse à compartiments, suspendue sous la partie postérieure du wagon 
de Middleton, se décroche en passant sur un buisson et trois marmites à pied qu'elle contient sont brisées. Une autre fois c'est le tour de la caisse à vaisselle; heureusement que le fer émaillé n'est que bosselé.

Le 9, nous faisons halte au bord de la Mokwe, un ruisseau limpide et frais entre de belles collines boisées. Nous nous la rappellerons souvent avec regrets. Déjà à la Misse, les 11 et 12, nous ne trouvons que peu d'eau, et quelle eau! couleur caféau-lait très foncé. Nous en remplissons quand même tous nos récipients. Nous ne devions retrouver de l'eau qu'à Halamabele après quatre jours de marche. Quand nous y fûmes arrivés, il fallut envoyer les boeufs s'abreuver quelques milles plus loin, à Linokaneng. Un des plus beaux boeufs de M. Coillard n'en revint pas. On le trouva mort le lendemain. Un Bushman l'avait frappé au coeur d'un coup de lance, mais il n'avait pas osé s'y attarder à le dépecer. Dès lor's et pendant trois semaines, nous eûmes presque chaque jour des visites de Bushmen arrivant toujours à l'improviste.

Quand je leur jouais des cantiques sur l'accordéon, ils étaient en extase et claquaient des mains. Leur langage est un étrange gazouillement, une cantilène dans laquelle dominent différentes espèces de clics. Khama s'est efforcé de fixer ces nomades en leur donnant du bétail à garder et en leur permettant de se servir du lait. Il a réussi à en grouper plusieurs là où l'eau est abondante, dans de misérables abris. Mais la plupart sont des rôdeurs incorrigibles. Ils ne travaillent ni ne filent, ils ne sèment ni ne moissonnent, et cependant Dieu prend soin d'eux. Le désert leur fournit des fruits, du miel, des tubercules, des racines et des herbes comestibles; ils abattent de temps en temps une pièce de gibier. Quelques uns ont des fusils. L'un d'eux vola le gros fusil de Yankee, mon conducteur.

Le matin du 25 nous arrivons à Simwane, le dernier poste de bétail de Khama. Nous en repartons après midi. En une petite étape nous sommes au grand bras du Macaricari que la photographie prise par M. Coillard a fait connaître. Avant d'y pénétrer nous trouvons un troupeau de springbocks paissant paisiblement. C'était charmant. Un coup de fusil en abat un et fait bondir les autres dans toutes les directions; ils s'éloignent en faisant des sauts prodigieux. Là-bas très loin nous voyons des centaines d'animaux; la lunette nous permet de distinguer 
diverses espèces d'antilopes, des zèbres et des girafes. Qu'elles sont étranges, et même grandioses, ces vastes solitudes des Macaricari, surtout quand on regarde vers l'Ouest, où cette mer de sable s'étend à perte de vue. A l'extrémité que nous traversons c'est sur plusieurs lieues d'étendue comme une lutte entre la vie et la mort. Ici c'est le sable blanc ou le gravier blanc qui l'emporte, là ce sont des touffes d'herbes qui résistent à l'invasion et poussent une pointe offensive. Toute cette partie des Macaricari est couverte d'eau chaque année, pendant quelques mois. Là où cette eau a séjourné, plus rien ne pousse.

Nous atteignons Shua, le cours inférieur de la Nata. Entre la Nata et le Zambèze la route est beaucoup plus sablonneuse; le sable est souvent si pénible que les boeufs doivent s'arrêter toutes les deux ou trois minutes, et nous ne faisons pas en moyenne trois kilomètres par heure.

Septembre est peut-être le meilleur mois pour la chasse, parce que le gibier se rassemble où il trouve de l'eau. Nous avons rarement été dépourvus de viande fraîche, depuis la Nata. J'eus l'occasion de manger du zèbre, de la girafe et de beaucoup d'espèces d'antilopes. Nous eûmes trois fois la visite du lion, et souvent celles de l'hyène et du chacal. Les abords des étangs étaient peuplés de toutes sortes d'oiseaux; les uns, bons chanteurs, nous faisaient chaque matin un gentil concert; beaucoup d'autres n'étaient que d'affreux criards. Au fort de la chaleur la nature entière semblait dormir, et avec elle nos boeufs, nos garçons, nos conducteurs, tout se taisait, on n'entendait que le vent dans les arbres.

C'est à ce moment de la journée (vers 1 heure) que le 15 Septembre, à Tama-setse surgissent une vingtaine de ma-Tebele et ma-Kakala, armés de lances et de massues, de hachettes et de fusils. Ils se présentèrent au nom de leur roi, soi-disant pour prélever un droit de passage. Puis, devenant de plus en plus importuns, ils demandèrent toutes sortes d'objets. Middleton en leur domnant de la viande de zèbre et quelques balles de fusil ne fait qu'augmenter leur convoitise, il appelle alors les conducteurs et fait atteler. Pendant que chacun est occupé, les ma-Tebele rôdent autour des wagons, essayant de s'emparer de tout ce qui est à portée de leurs mains. J'en surprends un qui ôte du sac un morceau de viande, je le lui fais poser. Peu après quatre ou cinq de ces gaillards entourent un de nos ma-Toka, 
le harcèlent de demandes, puis n'en pouvant rien obtenir, ils le menacent avec la hache. Ils sont prêts à déchirer ses vêtements, quand je leur fais lâcher prise. Ensuite un ma-Tebele d'une cinquantaine d'années, avec plusieurs jeunes ma-Kalaka, entoure un de nos ma-Subïa, le bousculent, arrachent son collier de perles bleues; ils commencent à déchirer ses vêtements et à le battre quand j'interviens.... Ils reculent.... mais saisissent leurs armes, les brandissent et les font entrechoquer.... Cependant, n'ayant pas réussi à nous effrayer, ils s'éloignent peu à peu. Middleton, en me voyant indigné, me dit en guise de consolation: 《Vous en verrez de pires avec vos Zambéziens 》. Tout le temps le Seigneur murmurait à mon oreille: «Même les cheveux de votre tête sont tous comptés, ne craignez donc point ».

L'eau de Deka à la mi-Septembre n'est ni douce, ni très abondante. Néanmoins, à peine arrivés, après nos cent kilomètres sans eau, nous nous hâtons de puiser celle qui nous est nécessaire. Les bœufs n'ont pas plus tôt été dételés qu'ils se précipitent vers le petit ruisseau et s'y vautrent, puis boivent, sans hésiter, cette eau troublée. Force nous fut de donner à ces pauvres bêtes epuisées, quelques jours de repos.

Le 21 septembre, nous arrivons à Panda-ma-Tenga. Quel bonheur de revoir des cultures, de l' eau en abondance, des habitations, du lait, du beurre, du pain, des œufs, des pois verts... C'est une vraie oasis dans le désert. Panda-ma-Tenga est encore à peu près tel que la photographie de M. Coillard le représente: au premier plan, les bâtisses des jésuites et celles de Westbeech, et derrière un petit village de huttes habité par sept métis, leurs familles et leurs serviteurs. Les femmes font le ménage et cultivent le jardin potager. Les hommes s'occupent de chasse, de pèche et cultivent des céréales: blé, maïs et sorgho. La Panda-ma-Tenga n'ayant là ni berge ni talus, il a été facile de dériver une partie de son eau pour l'irrigation des champs et des jardins. Le lendemain de notre arrivée était un dimanche. Nous eûmes un culte sous l'avant toit de ce qui avait été la principale maison des jésuites. Quelques-uns des nos garçons y prirent part, ainsi que presque toute la population du lieu. Ces pauvres gens sont bien à plaindre au point de vue intellectuel et spirituel. Nos garçons zambéziens se sont transformés, ils ont voulu se montrer à nous dans leurs plus beaux costumes: chemises, pantalons, habits, chapeaux, tout était battant neuf, une 


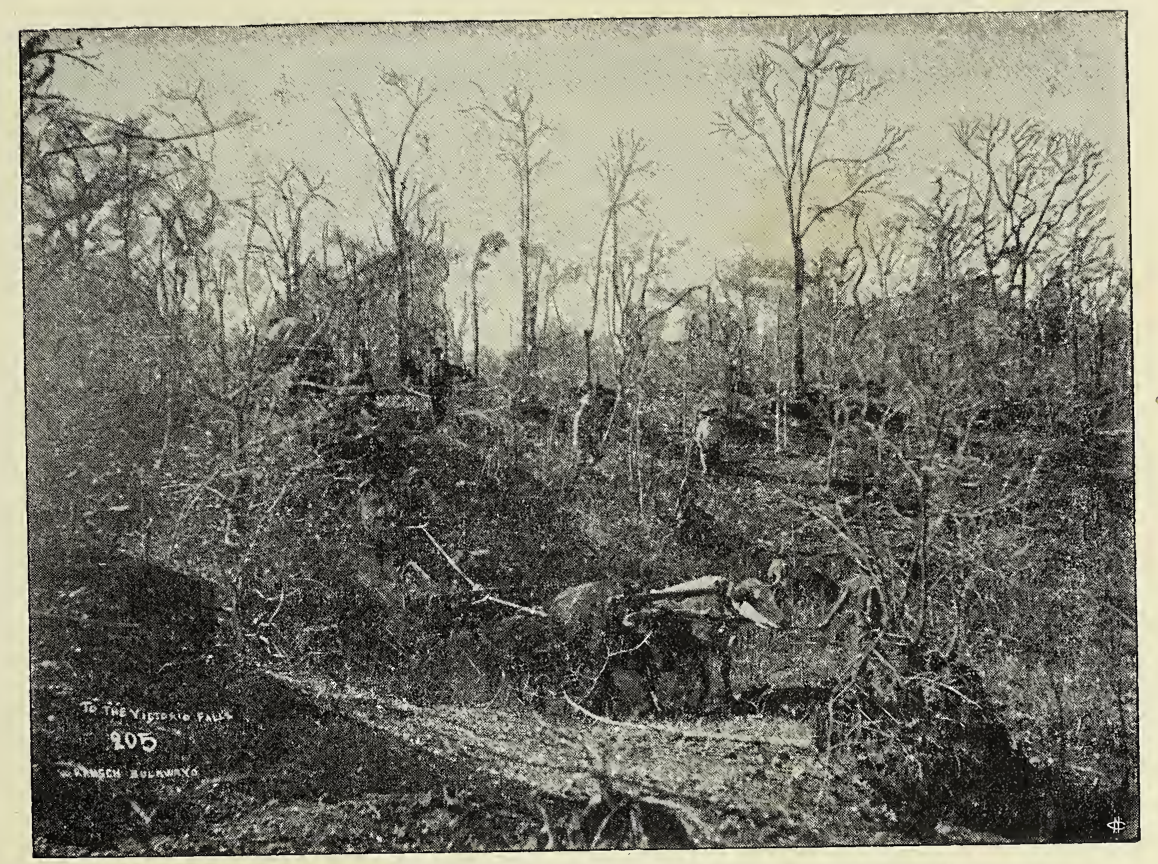

A travers les fourrés. 

vraie métamorphose. C'est ainsi qu'ils feront leur apparition dans leur pays. Y rentreront-ils meilleurs que quand ils en sont sortis? Sans doute, à la vue de l'industrie des blancs leur esprit s'est un peu ouvert, mais leur cour? Quels exemples ont-ils eus sous leurs yeux? Ont-ils du moins retenu quelque chose de ce que je leur ai dit à nos cultes, de Dieu et du Sauveur?

A Leshoma, où nous arrivons le 28 septembre, nous campons au pied de la colline, sur laquelle les membres de l'expédition de 1884 ont séjourné plus d'un an. Tout leur établissement a été détruit par le feu et les termites.

Le 21 septembre, j'avais envoyé un message à mon frère Louis Jalla à Sesheke, lui demandant de venir à ma rencontre à Kazungula. J'avais hâte d'y arriver. On décide que mon wagon y sera amené le même jour. Seulement comme la forêt qui nous en sépare est encore infestée par la tsétsé (1), nous devons attendre la nuit pour nous remettre en route. Enfin à 10 h., Yankee, qui connaît très bien ces lieux pour y avoir longtemps chassé l'éléphant, me dit: « Nous arrivons 》. Nous distinguons en effet d'abord le magasin de Westbeech, et au delà le fleuve, le grand fleuve. Arrivés! Mais personne ne nous attend. Nous allumons le feu, puis mes compagnons de route repartent avec les boeufs, pour refaire avant le lever du soleil, (c'est-à-dire avant le réveil de la tsetsé) les 14 à 15 kilomètres que nous venons de franchir depuis Leshoma.

Je reste seul, tout-à-fait seul, avec mon wagon, sous un arbre énorme. N'importe, je suis heureux et reconnaissant. Il est enfin là ce Zambèze après lequel j’ai souvent soupiré. Cependant je ne m'attarde pas à le contempler ce soir-là. Le lendemain est un dimanche. Je suis encore seul sur la rive droite, mais je ne m'y ennuie pas. Cette solitude me permet de repas. ser dans ma mémoire les bienfaits que le Seigneur n'a cessé de m'accorder. Kazungula n'est pas seulement pour moi l'eau et la verdure après le désert, c'est aussi le seuil du pays vers lequel j'ai été attiré, et où Dieu m'appelle à le servir. Je vais y revoir mon frère... J'y amènerai peut-être un jour ma fiancée. C'est aussi là qu'est la tombe de Dardier. Quel sérieux avertis-

(1) La tsétsé est une mouche dont la piqûre fait périr la plupart des animaux domestiques, les boeufs entre autres. L'humidité et le froid de la nuit l'engourdissent. 
ement! Que le fleuve est beau! Mes yeux, déshabitués d'un tel spectacle, ne se lassent pas de contempler cette eau bleue et ces belles rives, et mes oreilles se délectent à entendre le clapotement des vagues agitées par le vent.

Le soir, comme je faisais quelques pas après mon frugal souper, j'entends non loin de moi un frôlement dans les hautes herbes. Je savais qu'aucun Zambézien ne dormait sur la rive droite du fleuve, par crainte d'une invasion soudaine des MaTebele. Qu'est-ce? Je jette quelques brins d'herbe sur mon feu, pour le raviver et me retire prudemment dans le chariot. Après 11 h., je fus réveillé par le claquement du fouet; le wagon de Middleton arrivait, et ma solitude avait pris fin. Te lendemain nous découvrîmes les traces d'un lion qui avait passé à quelques pas de mon wagon, et avait été s'abreuver au fleuve. Une fois de plus le Seigneur m'avait délivré d'un danger, dont j’avais ignoré la grandeur.

V.

Sur l'eau et dans les sables.

boux revoir. - En canot. - Arrêtés par des hippopotames. - A Sesheke. Déanénagement et ensablement.

T E premier Octobre, las de regarder du côté de Sesheke, je 1 prends mon fusil et vais tâcher de tuer une perdrix. Quand je reviens au campement, Middleton me crie: Le canot est arrivé! En effet, Louis est là, prêt à aborder! Il est plus facile de se représenter ce revoir là-bas que de le décrire. Comme nos coeurs bondissaient! Mon frère m'apprit que M. Coillard était reparti pour Sefula depuis deux semaines.

La traversée des boeufs de M. Coillard fut une rude besogne. $\mathrm{Au}$ lieu de les saisir un à un pour les faire entrer dans le fleure et de les accompagner et soutenir jusqu'à l'autre rive, quelqu'un nous conseilla de les pousser à l'eau tous à la fois et de les faire nager en bande, ainsi qu'on le fait pour les boeufs et les raches des ma-Rotsé. Nos bêtes allèrent à la dérive dès qu'elles 
eurent perdu pied, et ne pensèrent plus qu'à revenir au point de départ. Plusieurs faillirent périr dans les roseaux qui bordent la rive. Quand nous essayâmes ensuite de les prendre un à un ce fut une lutte terrible. Plusieurs nous échappèrent bien des fois. Il y en eut un 'qui, à cinq reprises, réussit à se sauver bien loin sur la route de Leshoma, jusqu'à la forêt habitée par la tsétsé; une fois, il se précipita sur moi, les cornes en avant, comme un taureau furieux; je n'eus que le temps de me jeter à terre et il bondit par dessus moi.

Dès que le dernier boenf eut atteint la rive gauche, nous fîmes porter nos effets personnels dans les deux canots et nous nous embarquâmes. Ce n'est pas sans un sentiment de crainte qu'on se confie pour la première fois à ces troncs d'arbres creusës. Ils ne sont pas spacieux. Le mien, un des plus grands, ne mesurait guère que $0,60 \mathrm{~m}$. à l'endroit le plus large. Celui de mon frère était beaucoup plus étroit, bien que plus long. Le 3 octobre, à 11,30 h. nous partons. Nous abordons en dessous du premier rapide, le fusil en bandoulière, et trois petits chiens sur les bras, nous faisons à pied les trois quarts d'heure qui nous séparent de Manbova et nous allons faire une visite au chef Mokumba. Dès que les canots ont passé les rapides, nous nous rembarquons avec l'espoir d'avancer rapidement, mais à un tournant du fleuve nous sommes arrêtés par une grande bande d'hippopotames. J'en compte jusqu'à quinze à la fois la tête hors de l'eau. Quelle bande grotesque et bruyante! Les uns plongent, d'autres encore font la culbute. Une mère porte son petit (quel petit!) sur le dos ou le fait nager à ses côtés. D'autres ont l'air de se courtiser, mais sans beaucoup de grâce. Ne réussissant pas à les effrayer avec nos fusils à grenaille, nous nous voyons obligés, après avoir abordé, de camper là pour la nuit.

Le lendemain, peu avant le coucher du soleil, nous entrons dans le «seko》 (bras en cul de sac) de Sesheke. Ma bellesœur, M. et $\mathrm{M}^{\mathrm{e}}$ Jeanmairet et leurs maisonnées nous attendent sur la rive. Un beau cantique de bienvenue complète la réception. Nous fîmes honneur au souper: nous n'avions mangé que deux oufs durs, de toute la journée! Quelles bonnes causeries et comme je fus heureux de trouver ma belle-sœur fraîche, rose et bien portante! Mon frère m'avait bâti une jolie chau- mière, pensant que je passerais quelques mois avec lui à Sesheke. Je n'y restai que quelques jours: Louis avait été appelé par 
ses collègues à fonder la station de Kazungula. Le lendemain je fus conduit au Khotla pour y saluer les chefs. Nous en trouvâmes une douzaine.

Je fus étonné de voir dans les ruelles du village, qu'aucun homme ne sortait sans tenir quelque arme à la main, surtout la lance; la guerre civile avait cessé depuis quelques mois seulement, d'ailleurs les meurtres étaient fréquents.

Le dimanche, nous eûmes des cultes sous la vérandah des Jeanmairet. Il y vint très peu de monde. Au premier je dis quelques mots et mon frère Louis fit ses adieux.

VI.

Onze semaines sous la tente.

Fondation de la station de Kazungula. - Premières attaques de fiève. Adienx. - A travers les rapides.

Tous abordâmes à Kazungula le 12 octobre à $5 \mathrm{~h}$. du 1 soir, et y dressâmes nos tentes. Le dimanche 13 fut une journée de repos.

Le dimanche 20, mon frère inaugura les cultes; mais le personnel de la station y assista seul avec nous. Personne ne vint des quelques petits villages environnants. Nos seuls proches voisins, un Boer et sa femme noire, sont indifférents aux choses religieuses. Plus tard je remplaçai quelques fois mon frère pour les cultes.

La nuit du 23 au 24 octobre je ne dormis pas, j'avais la tête chaude; des idées saugrenues trottaient dans mon cerveau. Le matin je me levai encore plus tôt que d'habitude, ne pouvant supporter le lit. Tout le jour j'eus la tête lourde, une grande lassitude et de la somnolence. Je pus cependant terminer mon courrier; et bien que le fleuve fût agité, je le traversai pour porter le courrier à Middleton resté sur la rive droite. J'y arrivai épuisé, j'avais la fièvre. Elle alla en empirant jusqu'au 28 ; tête lourde et chaude, nuits blanches et somnolence pen- 
dant le jour; lassitude, soif, inappétence, rien ne manqua si ce n'est les douleurs articulaires et les maux de tête proprement dits. Enfin dans la nuit du 28 au 29 je pus retrourer un peu de sommeil; le 30 la fièvre me quitta, mais il me resta une grande faiblesse.

Le 31, la saison des pluies fut inaugurée par un violent orage. Malgré les intempéries je passai encore les deux mois suivants sous la tente. Des insectes de toutes espèces, ailés ou non, les moustiques entre autres, les araignées venimeuses, des scorpions, des serpents me firent d'assez fréquentes visites. J'eus encore quatre attaques de fièvre. La $2^{\mathrm{e}}$ (du 4 au 10 novembre) fut une attaque de fièvre tierce, sous sa forme classique, chaque accès étant composé des trois stages successifs de frissons, chaleur et sueurs. La $3^{\text {e }}$ (du 16 au 23 novembre) je pourrais l'appeler une attaque d'insomnie tierce, n'ayant plus eu que de très légers accès; mais ces insonnies! c'est là mon grand ennemi. Mon esprit court alors du nord au sud, traite les questions les plus diverses, d'histoire, de géographie, d'arithmétique, de langues, de médecine... Ou bien il est en proie aux cauchemars. La $4^{\mathrm{e}}$ attaque dura du 7 au 12 décembre et la $5^{\mathrm{e}}$ me tint la semaine de Noël.

Eussé-je du moins été le seul fiévreux; mais non, mon frère, ma belle-sœur surtout l'ont été autant que moi, et depuis mon premier accès, il ne nous est pas souvent arrivé de nous trouver tous trois à la fois en bonne santé. Malgré la fièvre, et pour réagir contre elle, nous consacrâmes beaucoup de temps au travail mauuel. Le campement changea peu à peu d'aspect. Une maisonnette rectangulaire à deux chambres s'éleva et put être inaugurée le 18 décembre:

Le matin du 30, arrivèrent les pagayeurs envoyés par M. Jeanmairet; Franz m'attendait à Sesheke. Il fallut partir le même jour. Les adieux sont tristes partout, mais au Zambèze les séparations sont particulièrement graves. Les distances sont décuplées par la rareté et la lenteur des moyens de communication, et l'on se sent entouré de dangers. Mais quelle grâce de pouvoir nous remettre réciproquement à Dieu!

J'ai Mokumoa-Kumoa comme chef batelier; il est à l'avant de mon canot et donne l'exemple; nous glissons sur l'eau, c'est un plaisir. Il me dit qu'il me fera passer en canot les rapides de Nkalata et de Mambova. J'accepte volontiers, car c'est la 
partie la plus belle du trajet entre Kazungula et Sesheke. Ailleurs le fleuve coule au milieu d'une plaine généralement nue. Les rives sont par-ci par-là bordées de roseaux ou de papyrus, et on longe souvent des berges arides ou des plages de sable animées il est vrai par des oiseaux de toute taille et de tout plumage. Mais la région des rapides est autrement intéressante. Les rives y sont plus boisées. La surface du fleuve devient de plus en plus agitée, on entend un bruit semblable à celui d'un puissant torrent de montagne. Le courant devient toujours plus fort, enfin le lit rocailleux apparaît. L'embarcation doit pour ainsi dire se faufiler entre les rocs, elle racle tantôt par le dessous, tantôt à bâbord ou à tribord, au milieu des flots bouillonnants. L'habileté des bateliers est admirable. On comprend que chaque année des canots chavirent et que des vies se perdent. Ma pirogue arrive la première au haut du second rapide. Tandis que sur la rive je contemple la belle nature, on vient nous annoncer qu'un canot a chaviré plus bas. Nous accourons, mais pour trouver qu'il a été remis à flot et que les gens en repêchent la charge. Ah, ma pauvre caisse de livres! Ils n'ont pas encore fini et nous voyons que le dernier canot est en danger. Mes bateliers se lancent à l'eau et le saisissent au moment où il allait pirouetter et se briser contre les rocs.

Le lendemain, 31 décembre, nous arrivons à Sesheke vers midi. J'y jouis de la bonne hospitalité des Jeanmairet. Le village était encore plus désert que trois mois auparavant; la plupart des chefs et des gens étaient aux champs.

\section{VII.}

\section{De Sesheke à Sefula en wagon.}

\footnotetext{
Voyage pendant la saison des pluies. - Incidents de voyage.

Letres de bienvenue. - Dephère etape. - Arrivée a sefula.
}

Tous partîmes le 3 janvier 1890 et employâmes 35 jours

1 pour franchir les régions aiternativement fluviales et lacustres qui séparent Sesheke de Sefula. J'achevai mon voyage dans le wagon du roi, le même qui m'avait amené à Kazun- 
gula. Notre expédition consistait en deux chariots, avec deux conducteurs et trois garçons. $\mathrm{Je}$ ne retracerai pas toutes les péripéties de ce voyage: roues cassées, boeufs et wagons embourbés, concerts de hyènes et de chacals, alertes nocturnes, chocs contre les arbres...

Voyager en pleine saison des pluies, cela offre quelques avantages, le sable est moins mouvant, la poussière est abattue, bois et prairies, tout est vert et l'on n'est pas éprouvé par la chaleur; mais d'autre part on finit par se lasser des averses continuelles (nous n'eûmes que trois jours sans pluie), les marais et les rivières sont pleins d'eau et retardent la marche.

J'avais espéré que la vie de voyage m'aurait aidé à surmonter la fièvre. Dieu ne permit pas qu'il en fût ainsi: j'eus trois fortes attaques qui durèrent trois à quatre jours chacune. Au Njoko et au Lumbe, lorsque j'étais le plus bas, j'entendais les gens dire en riant: "Il va mourir. Il va rejoindre Setwala 》 (le Morantsiane ou vice-roi de Sesheke qui avait péri tragiquement quelques mois auparavant). Il en curait été ainsi si ma vie avait été entre leurs mains; je n'entendis de leur part que des propos moqueurs. D'ailleurs ils ne faisaient pas grand cas des missionnaires, auxquels ils reprochaient de ne pas gaspiller leurs articles d'échange.

Le 4 février, j'envoyai à $M$. Coillard un billet lui annonçant notre arrivée prochaine. Le 6 , à la tombée de la nuit, le messager était déjà de retour avec deux délicieuses lettres de bienvenue de M. et M.e Coillard. Ils m'écrivaient: « Nous avons une certaine responsabilité de votre santé et de votre confort, et vous allez nous permettre de vous mettre autant at home que possible. Un enfant des Vallées ne doit pas nous considérer comme des étrangers, nous qui y avons été tant fêtés. Nous voulons vous posséder chez nous, pendant votre séjour ici, comme notre ami $»$.

Nous approchions enfin du terme de notre voyage. J'en étais heureux, car le bâton du pélerin commençait à me peser. Le 8 février, nous débouchâmes dans le vallon de Sefula. Je fus étonné de la masse de gens qui l'habitent, de l'étendue de leurs champs de sorgho et de maïs endigène. Nous fîmes une dernière halte à l'ombre d'un grand palissandre. Je venais d'y prendre mon déjeûner quand M. Coillard arriva à cheval, avec le prince 
Litia. Quoiqu'indisposé, il n'avait pas craint de braver le soleil et la fatigue. L'émotion me gagna et me coupa la parole au premier abord; nous causâmes ensuite longuement. M. Coillard repartit vers midi. Une heure plus tard nos wagons s'ébranlaient et bientôt nous aperçûmes le côteau boisé sur lequel est située la station de Sefula, les champs qui s'étendent à ses pieds, les petites bâtisses de M. Goy et les enclos du bétail construits à mi-côte, et un peu plus haut, vers l'ouest, le toit du temple. Je pus contempler tout cela tandis que les chariots avançaient péniblement dans le sable, le long de la Sefula canalisée.

Quand nous eûmes franchi la rivière et que je fus près du sommet de la colline, ie vis, à gauche des maisons, une cin. quantaine de personnes. C'étaient M. et M.e Coillard et M. Waddell qui avaient réuni là les élèves pour me saluer à mon arrivée à la station. Ils m'avaient préparé une réception princière, il y eut même une salve de coups de canon. La porte de la maison était surmontée d'un grand écriteau portant une parole de bienvenue encadrée des bannières française, anglaise et italienne. Pendant le thé les élèves entonnèrent un beau chant composé par M. Coillard pour la circonstance. Je sortis pour les remercier, ils me répondirent: «C'est nous qui te remercions $\%$.

\section{VIII.}

Débuts à Sefula.

A l'œuvre. - Lettre de Lewanika. - Sujets de tristesse.

E lendemain, dimanche, au culte principal, j'exposai à

1 environ deux cents personnes le but de ma venue, je développai aussi simplement que possible cette idée: Je suis un messager de Dieu venu pour vous annoncer le salut en Jésus. M. Coillard me servit d'interprète. Ce fut un beau dimanche.

Chez M. Coillard je me sentis aussitôt dans une bienfaisante atmosphère de prière. 


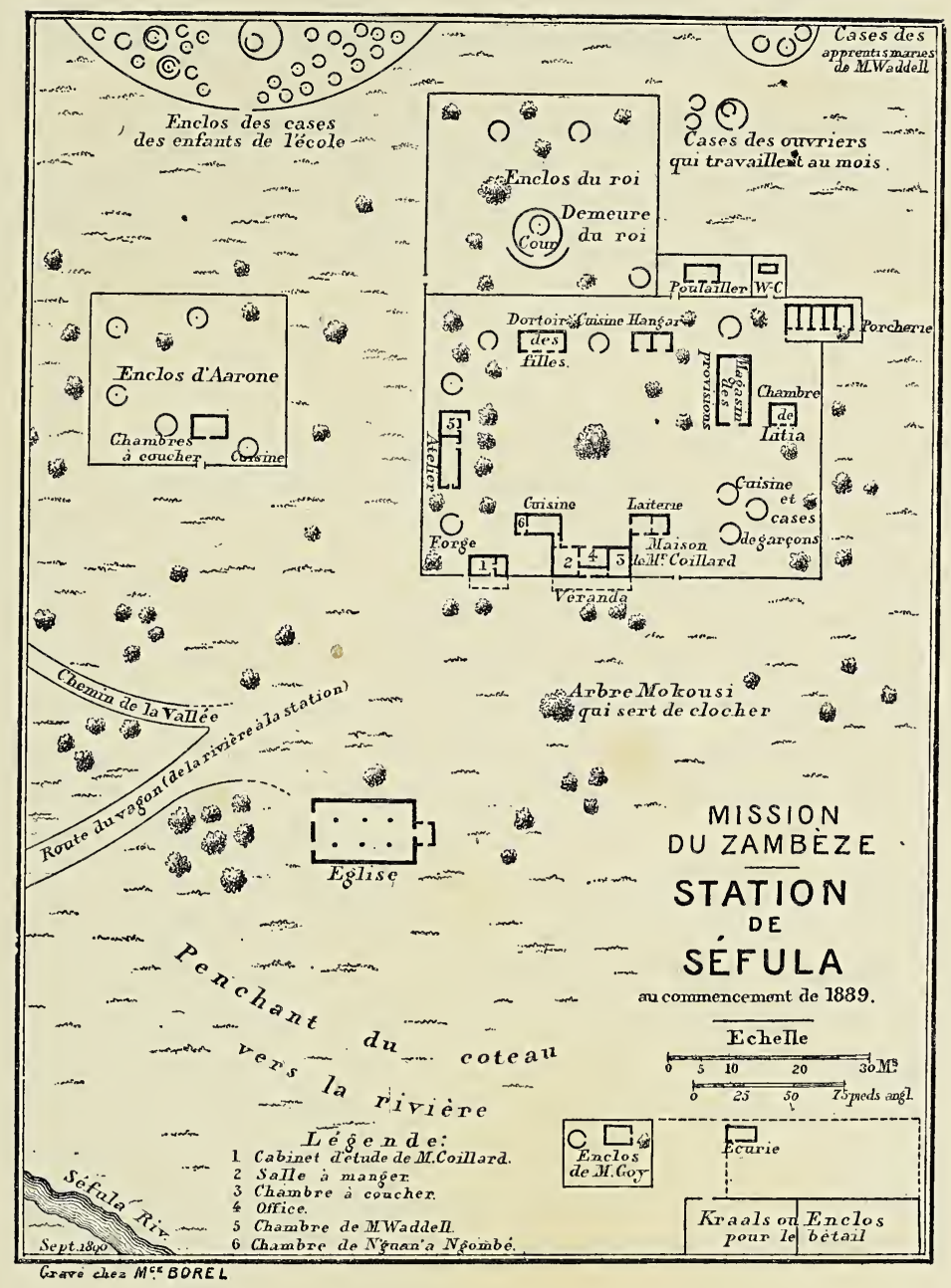



Le Lundi matin j'écrivis au roi une petite lettre en sessouto pour lui rendre hommage et lui exprimer mon désir de le voir bientôt. Le lendemain je reçus sa réponse:

《.Au nouveau missionnaire, salut! Viens bientôt avec la paix de ton Dieu. Je te remercie pour ta lettre, moi aussi je veux te voir at te saluer bientôt, nouveau missionnaire! je me réjouirai beaucoup en te voyant de mes yeux. Salut, salut, c'est moi qui t'aime.

\section{LEWANIKA 》.}

Dès la première semaine je remplaçai souvent M. Coillard au culte qui se fait au lever du soleil et auquel assistaient la plupart des élèves. J'écrivis une allocution en sessouto; $M$. Coillard y fit quelques corrections, mais m'exprima son étonnement du degré de connaissance de la langue auquel j'étais parvenu. Comme il me tardait de pouvoir bien manier cette arme! Il fut convenu que nous prendrions alternativement les services du dimanche. J'aurais aussi voulu soulager M. Coillard à l'école, dès mon arrivée, mais il ne me permit de le faire qu'au commencement de mars.

Les tournées d'évangélisation que nous faisions, tantôt dans une direction, tantôt dans une autre, me firent voir combien était nombreux le peuple à évangéliser. Mais que les huttes sont misérables et humides! Quoi d'étonnant que les maladies y soient fréquentes. Pauvres gens! s'ils rendaient leurs habitations plus confortables ils ne tarderaient pas à être accusés de vouloir se constituer chefs ou rois.

Le 27 février nous reçûmes la poste. C'était la première qui m'arrivait au Zambèze. Je n'avais plus reçu de lettres depuis le 5 août 1889 .

Dès le commencement de mars, je pris ma bonne part de l'école. J'avoue que je ne le fis d'abord que par devoir, mais bientôt j'y trouvai un grand intérêt.

L'oeuvre à Sefula était beaucoup plus encourageante qu'à Sesheke et à Kazungula. Nous avions chaque dimanche au culte 130 à 200 personnes; mais nos élèves et leurs gens constituaient la moitié de l'auditoire. Les gens des environs ne venaient guère que quand nous les avions conviés la veille.

Les sujets de tristesse étaient fréquents. Un jour un servi- 
teur du roi, qui était devenu un apprenti de M. Waddell, s'empara de la femme d'un de ses voisins. Le mari légitime, aux trois quarts divorcé, se contenta, comme compensation, des quelques lances que le ravisseur lui offrit, et renonça dès lors à tout droit sur celle qui avait été son épouse. Presque en même temps nous apprîmes qu'une femme qui demeurait au pied de la station, ennuyée des pleurs continuels de son petit enfant, l étouffa en lui remplissant la bouche de sable. Elle ne fut poursuivie par personne. Cet infanticide ne fit pas sensation parmi les indigènes! La vue de ce mal serait propre à nous décourager si elle n'était pas un stimulant à la prière et au travail.

\section{IX.}

\section{Première visite aux capitales.}

A travers la plaine submergée. - Première entrevue avec Lewanika. Son Khotla. - Salutation royale. - Vn culte sur la place publique. Chez Moliwae.

E 22 mars, bien que je sois un peu fiévreux, nous partons 1 pour la capitale, M. Coillard et moi, avec quatorze de nos élèves. C'est la saison de l'inondation. Mais le canal que l'on creuse aux frais de la mission n'étant pas encore utilisable, nous allons nous embarquer à trois kilomètres du pied de la colline, où quatre canots nous attendent. Une course à travers la plaine submergée offre peu d'intérêt, à moins qu'on ne collectionne des insectes: araignées, sauterelles, mantes, coccinelles, libellules, éphémères, pucerons, mouches, fourmis et cent autres espèces, semblent se donner rendez-vous dans nos étroites pirogues, et finissent par y grouiller. À part cela on ne voit guère que les hautes herbes dans lesquelles on disparait. Néanmoins, dans les lieux découverts les yeux peuvent se reposer sur des nénuphars roses, blancs, bleus de toute beauté, de grandes campanules lie de vin, des lys. Ailleurs ce sont des campanules, blanches comme neige, qui couvrent de grands espaces. Déjà une heure avant d'arriver à Léaluï nous en voyons 
les huttes qui se dessinent à l'horizon, comme des morceaux de terre, dominés par le grand ficus du roi.

Nous débarquons à $2,30 \mathrm{~h}$. aux abords de la Capitale et nous rendons à la hutte que le roi a fait construire pour les missionnaires. Nous sommes précédés par deux élèves et suivis par les autres. Après nous être fait annoncer à Lewanika, nous le trouvous dans sa salle de réception, assis sur une natte. Il se lève aussitôt, vient à notre rencontre et nous tend la main. Il nous fait asseoir à ses côtés, puis nous salue en nous exprimant sa joie de nous voir. Il nous offre une boisson à laquelle il donne le nom de thé et nous la fait servir dans des tasses en faïence. Il est grand, arec de larges épaules, bien bâti et vêtu à l'européenne, a les traits caractéristiques de sa race: le nez un peu épaté, la bouche assez large, les lèvres épaisses, de belles dents qui ressortent sur son teint shocolat très foncé. Son front est haut et droit. Il me pose beaucoup de questions intelligentes, sur mes parents, ma fiancée, mon pays, mon voyage etc. etc. À propos de l'école de Sefula il nous dit son désir que tous ses enfants y soient instruits et élevés par nous.

Son palais est une assez misérable chaumière rectangulaire, cette forme la distingue de toutes les autres; c'est le palais des courants d'air. La seule chambre digne de ce nom, celle où il nous reçoit, a les murs et le sol tapissés de nattes à dessins divers très primitifs et grotesques, représentant des hommes, des zèbres ou des crocodiles.

Nous allons ensuite faire visite à Ma-Marambura et à Longa, les deux premières des dix-sept femmes du roi, celles qui sont particulièrement chargées de nous pendant notre séjour à la capitale. Tout le grand établissement royal et les larges allées circulaires qui l'avoisinent, sont propres. Il n'en est pas de même des ruelles de la périphérie de Lealui, ni des cours et des huttes qui les bordent. Autour de la ville c'est encore pire : gare à qui marche à côté du sentier!

Vers $5 \mathrm{~h}$. nous nous rendons à la grande place du Khotla. Nous y trouvons le roi assis sur un petit fauteuil. Il a devant Ini une orchestre composé de deux joueurs de lirimba (xylophones) et de trois tambours; quelques oficiers royaux se tiennent à sa droite. En demi-cercle, mais à la distance respectueuse de vingt ou trente pas, sont accroupis plusieurs hommes. Nous prenons place à la gauche de Lewanika, sur des sièges que nos 
garçons nous ont apportés, et entamons la conversation avec lui. Voici deux hommes qui arrivent vers la gauche; ils avancent en battant des mains jusqu'à une quinzaine de pas du monarque, et crient: tau e tona! (grand lion!); puis ils s'agenouillent, plient leurs corps en avant, jusqu'à ce que leurs figures effleurent le sol; ils se tournent à droite, puis à gauche, redressent leurs bustes, lèvent les bras et crient: $o$ ! sho! o! sho! Ils répètent leurs révérences et leurs exclamations, enfin ils se lèvent pour aller s'agenouiller à leurs places. Pendant tout ce temps ils n'ont pas discontinué de battre des mains(1). Trois autres arrivent à droite, et s'avancent comme les précédents, mais au lieu de s'agenouiller quand ils sont à la distance voulue, ils se tiennent debout, alignés et font leurs salutations. Pourquoi cette différence? demandai-je. Le roi me répond que chacun peut le shwaelela comme il préfère, debout ou à genoux.

Bientôt après un vieillard à barbe et cheveux blancs s'avance jusqu'à cinq ou six pas de Sa Majesté, s'agenouille et bat des mains. J'apprends que c'est Marubutu, un homme sans titre parce qu'il n'en a pas voulu, mais dont l'avis a un grand poids. Il se lève ensuite et vient serrer la main à $\mathrm{M}$. Coillard et à moi. Le Ngambela (premier ministre), fait de même après avoir salué le roi. D'autres chefs et d'autres gens arrivent peu à peu, isolés ou par groupes. Comme ceux qui les ont précédés, ils ont tous leurs couvertures attachées autour du buste, en signe d'asservissement. Qu'il est pénible de voir tout ce monde s'avilir ainsi devant un homme, qui ne paraît pas même y prendre garde, à moins que ce ne soit pour se moquer de quelque gaucherie de ceux qui lui rendent de tels honneurs. En somme l'assemblée n'est pas nombreuse, car beaucoup d'hommes ont été au Lekwakwa, à environ 300 kilomètres au N. N.-E. de Léaluï, faire la guerre à des gens turbulents, car cette région septentrionale est le foyer des complots et des révolutions. Le Khotla est sans animation, pas de procès, pas de grave décision à prendre, peu de choses rapportées au souverain. Tout-à-coup il éternue, chacun cesse de causer et les joueurs battent quelques coups sur leurs instruments. Nous nous retirons au coucher du soleil ; le bruit des lirimba et des tambours nous dit que le roi ne tarda pas à imiter notre exemple.

(1) Les ma-Rotsé désignent cette salutation royale par le terme de shwaelela. 
Lewanika vint ensuite à notre hutte pour souper avec nous. Il y fit apporter un petit guéridon de sa confection, et les assiettes et tasses dont il avait besoin lui même. Il ne se tenait pas encore très bien à table, bien qu'il sût manier le couteau et la fourchette. M. Coillard m'assura qu'il avait déjà fait beaucoup de progrès à cet égard. Il était très difficile au sujet de ses assiettes; il en avait une pour la bouillie, une pour le poisson, une pour la viande et une pour le reste; il n'entendait pas qu'on les confondît. La fièvre me força à m'étendre sur ma couchette après le souper et je suivis ainsi la conversation.

Le lendemain, dimanche, j'allais de nouveau mieux; la fièvre devait revenir le soir. Au culte du matin, où je fus officiellement présenté aux grands de la nation, plusieurs choses me frappèrent. Notre cloche à main n'attira presque personne; ce ne fut qu'après que l'orchestre royal eut annoncé la venue de Lewanika que les gens commencèrent à s'assembler. Les femmes n'arrivèrent que plus tard; elle passèrent derrière nous presque inaperçues, et allèrent s'accroupir sous le petit abri du Khotla, hors de la vue des hommes. Leur présence avait déjà été une grande victoire remportée par M. Coillard. Le tout forma un auditcire d'environ 150 personnes. Le roi était entre ses deux missionnaires. Quand le culte commença les gens s'approchèrent de nous, tout en laissant un passage libre devant Sa Majesté, selon que l'exigeait l'étiquette se-rotsé, inspirée par la méfiance.

Nous vîmes beaucoup Lewanika pendant ce séjour, chez lui, au Khotla, chez nous. Nous prîmes tous nos repas en commun. Ma première impression fut bonne. Il avait été affable, il avait montré une grande déférence pour M. Coillard et beaucoup de confiance en lui; il appréciait l'œuvre missionnaire. Cependant il ne me fit pas l'effet d'un homme capable de gouverner une nation formée comme la sienne, de tant d'éléments disparates; il me parut manquer de décision et de fermeté. Je n'aurais pas non plus deviné que cet homme au regard plutôt doux eût pu être l'auteur de meurtres et massacres nombreux.

Nous vimes aussi plusieurs chefs et plusieurs personnes du peuple chez eux, et si je ne pus pas toujours admirer leur propreté, je fus frappé de leur intelligence. Je remarquai aussi la grandeur des huttes des principaux chefs et officiers royaux; je n'en avais vu de semblables dans aucun village indigène du Sud du Zambèze. 
Nous partîmes de Léaluï le mardi 25 mars, à 10.30 h., tantôt coupant à travers les herbes et roseaux de la plaine inondée, tantôt suivant le fleuve. Nous arrivâmes à Nalolo à $3.45 \mathrm{~h}$. Monde (actuellement appelée Akanangisoa), la fille de la reine, étant à Sefula, sa hutte nous fut assignee comme abri. Nous nous y établîmes et fîmes du thé en attendant qu'on vînt nous dire que Mokwae (1) était visible.

Vers 5.30 la reine arriva au Khotla, préeédée de ses tambours et li-rimba. C'est là que je lui fus présenté. Elle était entièrement habillée, mais avait la tête et les pieds nus. Tout se passe à son Khotla comme à celui de son frère le roi. C'est étrange de voir là une femme qui gouverne, tandis qu'à Léaluï aucune femme n'est autorisée à passer sur la place publique, pendant les séances administratives ou judiciaires. Cette reine, dont on a pu dire beaucoup de mal, se présenta à moi sous son beau jour, elle fut affable et hospitalière. Le 26, dès le matin, elle vint nous rendre sa visite, accompagnée de son mari Ishe Kwandu (2), et prit le thé avec nous. Puis, elle m'offrit de me faire visiter son palais. C'était la plus belle et la plus grande hutte circulaire que j'eusse vue jusqu'alors. Tout y était très propre comme chez Lewanika. Elle me fit aussi voir son atelier de nattes. Il y avait là plusieurs femmes achevant un magnifique tapis, dont le dessin représentait des crocodiles poursuivant un homme à la nage. C'était grotesque, mais il y avait progrès sur celle du palais du Léaluï. Mokwae eut soin de me dire qu'elle était l'aînée de la famille, et que par conséquent si elle avait été un homme, c'est elle qui serait roi. Comme son frère l'avait fait pour la Capitale, elle m'invita aussi à m'établir à Nalolo, comme son missionnaire. Je ne pus naturellement pas accepter. Elle me donna un mouton. Dans l'après-midi je lui apportai mon cadeau: un châle de laine à fond rouge et deux beaux colliers de perles de Venise. A 5 h., sur la place publique, eut lieu le culte, où je fus présenté à toute la population. Je leur parlai de ma vocation et du motif pour lequel javais accepté volontiers l'appel de Dieu: étant heureux je désirais que d'autres le fussent aussi.

(1) Toute femme ou jeune-fille appartenant par sa naissance à la famille royale, peut être appelée. Mokwae. Mais la reine de Nalolo est la Mokwae par excellence.

(2) Tout homme devenu le mari d'une Mokwae s’appelle Ishe, ou Mokwetunga. 


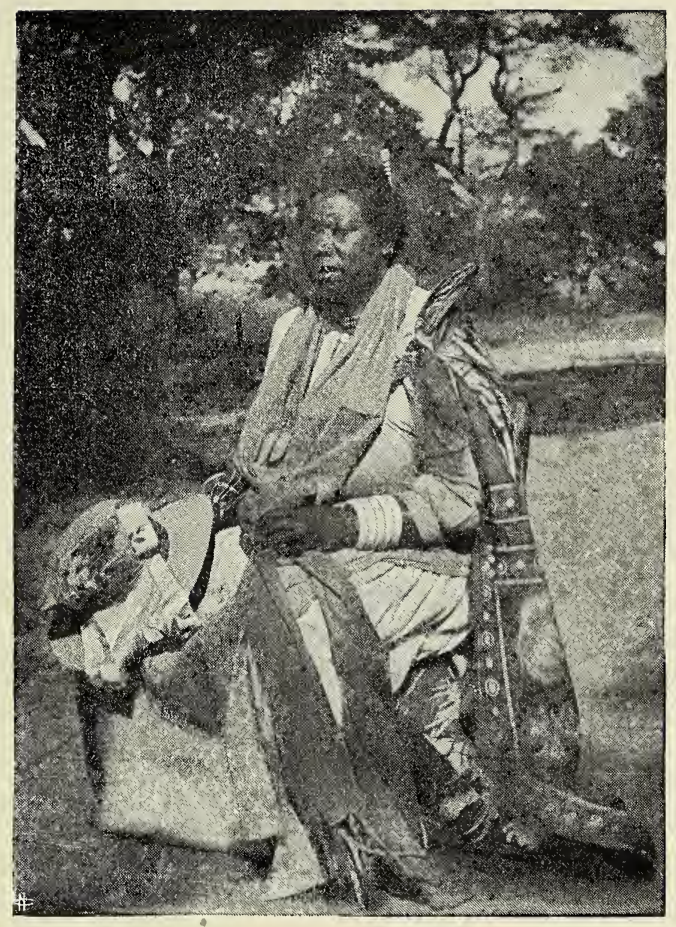

Mokwae. 

X.

Travaux missionnaires. Moeurs Zambéziennes.

Vie heurcuse. - Préoccupations politiques. - Ivrognerie. - Superstitions.

Corruption. - IIôtes royanx. - Strangulation.

TE lendemain, jeudi, nous rentrâmes à Sefula et $\mathrm{y}$ reprîmes

1 notre vie ordinaire. Le temps y passait vite et agréablement, malgré des visites de la fièvre tous les douze ou quinze jours. Heureusement qu'elle n'influe pas sur mon moral et que je m'en remets toujours assez vite, dès que la température est redevenue normale. Chez d'autres elle agit sur le foie ou la rate, sur le cœur ou l'estomac; il n'en était pas de même chez moi, alors.

Tour à tour maître d'école, capitaine, étudiant (pour le sessouto) et missionnaire, je puis bien le dire, je ne connaissais pas l'ennui. J'étais bien aise d'être très occupé et j'en remerciais Dieu. Les exercices militaires (sans fusil) que j'avais institués dès le commencement de mars, étaient censés enseigner la discipline à nos élèves garçons. Cela ne me donna pas mal à faire, surtout les premiers temps, bien que j'eûsses formé quelques caporaux, dont Litïa était le meilleur et le plus sérieux. Mais quel bavards que nos élèves! Au Zambèze les garçons n'ont rien à reprocher aux filles; il est difficile d'arrêter ces moulins à parole. Plus tard, quand nous pûmes commencer les marches et les différents mouvements combinés de pelotons, la discipline devint meilleure, parce que l'intérêt était plus grand.

Pour la prédication je progressais de semaine en semaine. Nous ne variions pas beaucoup nos sujets. Nos Zambéziens, très intelligents pour tant de choses, ont l'esprit peu ouvert pour tout ce qui sort du domaine matériel. C'était encore le temps du défrichement pénible.

Depuis quelques jours, un agent de la British South Africa Company, était arrivé à la capitale et les démarches pour établir le protectorat britannique sur le pays de Lewanika nous preoccupaient natureliement. Il y avait des obstacles et même une 
forte opposition venait de Sesheke. Le roi et son ngambela tournaient à tous les vents comme des girouettes. Lewanika en particulier désirait ardemment ce protectorat parce qu'il pensait par ce moyen être mis à l'abri des révolutions, et des invasions soit des ma-Tebele, soit des Portugais. Des lettres des Gouverneurs de la Colonie du Cap et du British Bechuanaland, ainsi que de Khama l'encourageaient à signer le Contrat qu'on lui offrait; mais il craignait l'intervention d'une puissance étrangère, dont l'envoyé qui ne cachait pas son mépris pour les noirs n'avait pas su gagner son estime. Tout cela nous empêchait de prévoir l'issue des négociations commencées. Ces questions ne sont pas directement de notre ressort, mais nous ne pouvons y être indifférents, puisque c'est le bien-être et même l'avenir de notre pays d'adoption qui est en jeu. Nous ne pouvions avoir confiance en aucun homme, mais nous regardions à Dieu qui régit les destinées des nations, et qui a, nous le croyions, des vues de miséricorde enver's ces tribus zambéziennes.

Le samedi 26 avril, quelle ne fut pas notre tristesse durant une course d'évangélisation, de trouver au village de Lengwalala une foule de gens ayant fait de grandes libations de bière indigène, et dansant; hommes, femmes et enfants étaient à moitié ivres. Quelle consternation de voir dans cet état quelques unes des femmes les plus assidues aux cultes!

Parmi nos élèves nous avions aussi bien des sujets de tristesse, quoique nous en̂ssions lieu d'être contents d'eux pendant les heures d'école. Hélas! l'exemple du mal venait des plus avancés et des plus haut placés, des neveux et cousins du roi: Sepopa, Likokwane, Sasa.... Monde, la fille de Mokwae, et la femme de Mokamba. Litia faisait exception, son amour du travail manuel et de l'étude, comme son amitié avec Nguanangombe les préservaient de bien des tentations. Dès lors l'œuvre de la grâce avait commencé en lui. Il avait déjà renoncé aux pratiques de ses compatriotes et ne priait plus que le Dieu de l'Evangile. C'était beau de le voir lui, prince héritier, en rapport intime avec Ngnanangombe (Andrease), un simple mo-Toka. Le baptême de celui-ci, qui eut lieu le 25 mai, dimanche de Pentecôte, fut une fête pour nous.

En juin notre station eut pour hôtes Lewanika, Mokwae, Katoka (la seconde sœur du roi) et trois femmes de Sa Majesté. Le Roi seul prit ses repas avec nous. Madame Coillard envoyait 
aux autres $d u$ thé ou du café. A cette occasion Lewanika me dit qu'il devait à Mr. Coillard les bonnes manières qu'il commençait à avoir.

Le 6 juin nous eûmes une fête. Je l'inaugurai en faisant exécuter à nos écoliers, des marches et des courses, par deux et par quatre, de côté et de front, ainsi que différentes évolutions combinées de pelotons. Le tambour marquait le pas ou la course. Cela ravit les nombreux assistants. M. Waddell prit les élèves après moi pour jouer au football. L'après midi fut consacré à des courses et des sauts, avec prix pour les vainqueurs. Le soir $M$. Cuillard fit une séance de projections et Waddell termina la journée en tirant une vingtaine de pièces d'artifice de sa confection. On parla bien longtemps de cette fête.

Le dimanche 8, sauf nos élèves, aucun de nos auditeurs ordinaires n'osa venir aux cultes, à cause du roi; cependant la chapelle se remplit, grâces à nos hôtes et à leurs suites.

Le jour même du départ de Lewanika et de Mokwae (11 juin; cinq des garçons de $M$. Coillard, arrètêrent un jeune mo-Mbunda, le serrèrent à la gorge au point de le faire évanouir, et s'emparèrent de la farine qu'il était venu vendre. Ce haut fait, dont ils étaient fiers, n'arriva aux oreilles de M. Coillard qu'assez tard dans la soirée. Le 12 il fit jeûner les coupables; puis à midi, à l'issue de l'école, il les fit comparaître avec leur victime, devant Litia et les autres chefs d'entre nos élèves. Litia déclara qu'il fallait les punir afin d'empêcher que ces scènes se renouvelassent. Selon la coutume du pays ils auraient dû être étranglés: œil pour œil, dent pour dent. La peine fut commuée dans celle de la fustigation. Cette strangulation odieuse est le châtiment le plus fréquent de ma-Rotsé, en public comme en privé. À la moindre dispute on les entend dire: Je t'étrangle! - C'est moi qui t'étrangle - puis presque sans bruit on voit les querelleurs porter leurs mains à la gorge l'un de l'autre et se serrer jusqu'à ce que l'un des deux tombe évanoủ. Quelquefois on laisse les étranglés revenir d'eux-mêmes à la vie, on les bat pour établir les fonctions vitales; d'autres fois l'évanouissement se prolonge.... et la victime ne se réveille plus. 


\section{XI.}

Traité de Lewanika avec la Compagnie à Charte.

Missionnaipes hôtes du roi. - Une convocation importante.

T E 21 juin, M. Coillard et moi, nous rendîmes à Léaluji. 1 Nous trouvâmes le roi au Kashandi, sa jolie chaumière du Conseil privé. Il nous reçut comme des amis, nous fit asseoir sur la même natte que lui et nous offrit du thé. Comme il avait fait abattre la hutte missionnaire, afin d'en construire une autre digne de lui et de nous, il nous offrit provisoirement une hutte d'où il avait fait sortir une de ses femmes; en nous recevant dans l'enceinte royale il nous fit sentir à nous, et il prouva à son peuple que nous n'étions plus des étrangers, mais en quelque sorte des membres de sa famille. Pendant tout ce séjour, c'est-à-dire jusqu'à la conclusion du traité avec la B. S. A. C. C. (1), il pourvut à nos besoins, prit ses repas avec nous et passa dans notre hutte toutes ses soirées. Le dimanche, aux deux cultes, nous eûmes de trois à quatre cents auditeurs. Ce fut là que j'improvisai mon premier discours en sessouto; je réussis assez bien, au dire de M. Coillard. Dans l'après midi, avec l'autorisation du roi, nous rassemblâmes nos élèves chez lui pour chanter.

Le grand pitso commença le 24.

Disposition du pitso:

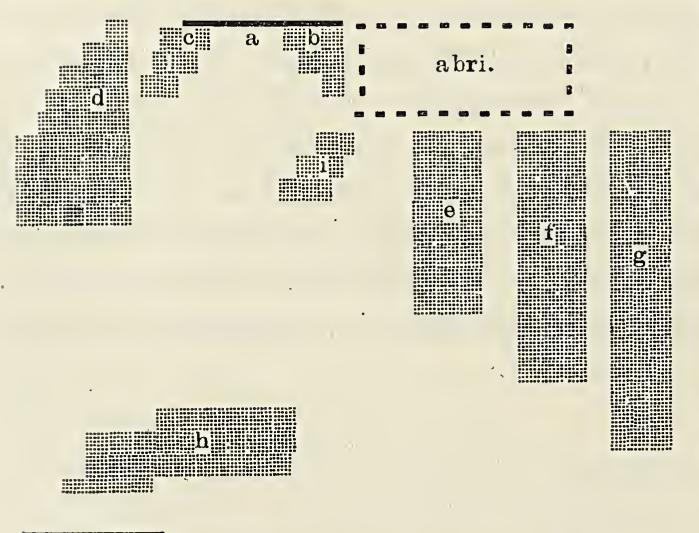

a. Le Roi. MM. Coillard et Ad. Jalla. M. Lochner.

$b$. Officiers royaux et serviteurs personnels.

c. Chefs du district de Léalui.

d. Gens du district. de Léalui.

$e$. Gens du districl du Motulo

(Libonda et le pays au Nord).

$f$. Gens de Nalolo et Mbala (pays au Sud de Nalolo). $g$. Gens de Sesheke et plus bas.

$h$. Gens du Linyanti.

$i$. Membres de la famille royale.

(1) British South Africa Chartered Company. 
Le Ngambela inaugura le pitso en allant s'agenouiller en $c$ et en présentant au Roi l'envoyé de la Compagnie qu'il appela 《ce soldat》, nom que les Zambéziens donnaient aux Anglais quand ils voulaient les distinguer des autres nations européennes. L'envoyé auquel M. Coillard servait d'interprète, raconta comment beaucoup d'autres tribus avaient accepté le Protectorat britannique, pour leur plus grand bonheur. Il dit en terminant: "Voulez-vous demeurer tels que vous êtes, ou bien désirez vous vous enrichir, faire des progrès, paître vos troupeaux et cultiver votre pays en toute sécurité? Choisissez! 》

Le lendemain, sur le conseil de M. Coillard, le roi dit à ses gens: «Questionnez sans crainte, n'acceptez pas tout aveuglément! 》Ils firent en effet à l'envoyé toutes sortes de questions sur les esclaves, les femmes, les champs, le bétail, le sol, les ouvriers, la chasse à l'éléphant et aux autres gros animaux, la pêche. Un vieux chef de Sesheke résuma la séance par ces mots: 《Les promesses sont belles, nous verrons les faits》.

Le 27 , le Traité fut signé, mais après avoir été encore traduit en sessouto, et expliqué une dernière fois.

Nous rentrâmes à Sefula le soir même, M. Coillard et moi, mais avec beaucoup de peine, car l'inondation avait baissé.

\section{XII.}

\section{Chasse au Léopard.}

DENDant notre absence à la Capitale, le léopard avait fait

des siennes: il avait penétré dans la cour de la station à différentes reprises et tué plusieurs veaux et des oies. Enfin un soir pendant le souper, il alla au piège, tendu dejà plusieurs fois en vain par Andréase (1) et il s'échappa sain et sauf en emportant l'appât. Aussi nos Zambéziens nous déclarèrent-ils aussitôt: 《Ce léopard n'est pas une bête, c'est une personne. 》

Le 14 juillet, au milieu de la nuit, je suis réreillé par un fort

(1) Un zambézien converti. 
bruit derrière la maison, où j'entendais crier une poule. Le léopard est dans le poulailler, me dis-je; j'y cours et y trouve Andrease avec son fusil. Au moment où j'ouvre la porte, le fauve bondit à mes pieds, et disparaît. Nous ne pûmes tirer, Andrease ayant fait la sottise de se placer vis-à-vis de moi. Nous pénétrons et trouvons quatre oies et une poule mortes. Mais le léopard n'avait eu le temps de rien dévorer. Un quart d'heure après, nouveau cri de poules, cette fois nous arrivons trop tard, l'animal a disparu avec sa proie. Il avait ouvert un large trou dans la palissade de roseaux. Peu après nous l'entendons miauler et hurler au village des élèves, se serait-il fait prendre à un lacet? En effet, mais nos courageux ma-Rotse s'enfuient et permettent ì l'animal de se dégager en rompant la corde.

Le 23 un élève vit le léopard (est-ce toujours le même?) dans les hautes herbes, au pied de la colline. A son appel, tous les hommes et grands garçons du village partirent armés de lances et de fusils, ils se divisèrent en deux bandes et entourèrent le léopard, en resserrant le cercle de plus en plus. Quand la bête commença à hurler, la panique s'empara d'une des troupes: la voilà qui s'enfuit et laisse partir l'ennemi!

Le premier octobre, le léopard recommença ses visites au poulailler. Le 2, j'allai boucher avec du bois le trou par lequel il nous avait échappé trois fois la nuit précédente, et ne laissai ouvert que celui du haut, par lequel il pouvait entrer mais non pas sortir. Le 3 , vers 3 h. du matin, je l'entends pénétrer dans le poulailler. Vite jaccours, je vois les deux yeux qui brillent dans l'obscurité, je tire. L'animal fait encore un bond de mon côté, mais il s'affaisse. Je l'avais frappé au cœur. Au bruit du coup de fusil des gens arrivent armés de lances. Je tire encore deux coups pour plus de sûreté. Quand nous entrons nous le trouvons mort et bien mort. C'était un léopard de taille moyenne. (Longueur du corps $1.15 \mathrm{~m}$. ; longueur de la queue $0.75 \mathrm{~m}$.; longueur totale $1.90 \mathrm{~m}$.). 


\section{XIII.}

Chef intérimaire de station.

M. Coillard part pour Kazungula. - M.e Coillard soufrante. Cécole. - Visite à la capitale. - Luene d'espoir. - Tristesse.

T 10 , M. Coillard avec Litia partit pour Sesheke en canot, 1 et le 18, M. Waddell pour la même destination, mais en wagon. Je restai seul auprès de Mme Coillard, seul pour tout le travail de la station, seul pour l'école.

Depuis mon arrivée à Sefula, Madame Coillard n'avait jamais été bien. Elle souffrait de paludisme chronique, et peut-être d'une maladie de cœur. Elle pouvait cependant encore vaquer aux soins du ménage et aux leçons de couture des fillettes qui lui avaient été confiées. Mais depuis l'incendie, et après le départ de M. Coillard, ses forces semblèrent encore décliner, l'anémie générale et celle du cerveau en particulier s'accentua, de violents maux de tête l'empêchèrent souvent de dormir. Elle souffrait d'une sensibilité physique et morale exagérée, la forte lumière, le moindre bruit, la moindre faute des 《filles》 aggravaient son mal. Hélas l'obéissance n'était pas le fort de ces enfants, et leurs cœurs n'étaient pas des plus tendres. Les sentiments de tendresse, de sympathie ou de pitié ne sont pas naturels aux Zambéziens; c'est la grâce de Dieu qui les fait naître et se développer.

Mes 50 ou 55 élèves me donnèrent de la satisfaction. Ils étaient respectueux, pas trop bruyants, et avaient envie d'apprendre, mais il ne fallait pas les perdre de vue un instant; ce qui rendait la tâche difficile c'était le nombre des classes. Lintérêt était général pour les leçons bibliques, il y avait de l'entrain dans les leçons de chant. Je formai une seconde classe d'anglais comme stimulant. Le 4 août, à la leçon d'anglais, je donnai pour la première fois à mes neuf nouveaux élèves, un exercice à faire chez eux. Les voilà tous se récriant: «Re phaletsoe! (nous sommes vaincus et en fuite). Ce mot, les Zambéziens l'aiment beaucoup, et l'emploient chaque fois qu'ils rencontrent quelque difficulté. Leur esprit, au lieu d'aimer les 
obstacles pour les surmonter, s'arrête tout court, et sans même essayer, il dit: Impossible! Ce mot nous le haïssons! Je tins bon et l'impossible devint possible; menacés d'être exclus de la classe, les uns après les autres m'apportèrent leurs thèmes faits.

J'allai passer le 15 août à la capitale avec une douzaine de mes élèves. Nous trouvâmes le roi au Kashandi, prêt à diner. Il m'invita. Il avait de la tortue et du thé. Il me reçut comme précédemment et vint prendre ses repas avec moi. Je fournis le café, le thé, le sucre, le pain et le lait. Nous eûmes de bonnes conversations et abordâmes toutes sortes de sujets civils, moraux, religieux, géographiques, astronomiques. Nous nous efforçons de répandre la semence à pleines mains, même dans la conversation. J'écrevais alors de Lewanika: «Il a l'esprit ouvert à toute instruction. Il déplore les ténèbres de lignorance et du mal dans lesquelles ils croupissent. Il me disait: Passeront-elles un jour ces ténèbres? 》

Le 18 , je rentrai à la station avec la fièvre. J'en étais déjà à ma $13^{\mathrm{e}}$ ou $14^{\mathrm{e}}$ attaque depuis mon arrivée à Sefula. Mais, Dieu merci, elle m'avait rarement empêché de faire mon œuvre de maitre d'école et de prédicateur.

Parmi les petites filles de la maison, Kumoio, la dernière venue, était ma préférée, bien qu'à l'école elle fût une tête de linotte. Elle avait la figure ouverte. Quelle joie quand j'appris que cette petite fiancée de Litia priait et demandait à Jésus de changer son cœur et de pardonner ses péchés. C'était un encouragement, un rayon de lumière au sein de l'obscurité, un gage du secours du Seigneur, bien nécessaire alors que la corruption souillait toutes choses autour de nous. Peu après nous apprenions la chute de deux jeunes filles au service de $\mathrm{M}$. Coillard, et celle encore plus grave d'Andrease lui-même! Quand nous fîmes part de notre tristesse à Seajika, il nous dit que c'était une chose toute naturelle, le seul malheur c'était que ce fût arrivé chez les missionnaires. 
XIV.

Dernières semaines de stage.

Prochain départ. - Rêves d’avenir. - Méthodes d'évangehisation.

Arrivéc de M.ne Kiener. - Etrange salutation. - Mdienx. - Retards.

$T^{\text {NFIN le }} 18$ septembre M. Coillard arriva accompagné de M.

1. Buckenham (1). Je fis sortir mes élèves en ordre, et nous reçûmes les voyageurs avec de beaux cantiques. Ensuite les élèves se hâtèrent d'aller rendre à Litia les honneurs princiers. Une semaine plus tard nous leur donnâmes quarante jours de vacance. Il me semblait qu'une partie de moi-même s' en allait avec eux. Je ne devais pas assister à leur retour.

Dès mon arrivée à Sefula, M. Coillard m'avait exprimé son regret que je ne fusse pas marié. Il aurait préféré me voir rester en Europe une année de plus, mais arriver avec ma femme. Il me dit: 《Plus tôt vous irez la chercher, mieux ce sera》. L' arrivée de M.lle Kiener rendait mon départ possible. Comme mon frère et ma belle-sœur avaient exprimé le vif désir de visiter Sefula et la Capitale, M. Coillard me proposa de partir le plus vite possible, afin d'aller occuper la station de Kazungula pendant l'absence de ses titulaires.

Dès que Litia eut vent de la chose, il vint me dire: - Quand partiras-tu? -- Dans quelques semaines; mais pourquoi cette demande? - C'est que si je jette les osselets dans mon cœur, je trouve que j'aimerais t'accompagner. - M. Coillard l'avait prévu.

Le 26 nous partîmes, M. Coillard, M. Buckenham, Litia et moi, tous quatre à cheval. Au lieu de couper à travers la plaine vers Léalui, nous longeâmes le pied de la colline qui la borde à l'est. Après une heure de trot nous atteignons Katongo, village bien connu à cause du tombeau de la mère de l'ancien roi Sepopa, où Serpa Pinto avait dressé son camp. Comme tous les tombeaux de la famille royale, celui-là est entouré de magnifi-

(1) Messrs Buckenham et Baldwin avaient été envoyés par l'Eglise des Méthodistes Primitifs à la recherche d'un champ de Missions. Ils s'établirent au bo-Shukulumbwe. 
ques ombrages. C'est une surface ronde de $2,50 \mathrm{~m}$. à $3 \mathrm{~m}$. de diamètre et tout-à-fait nue, sans le moindre brin d'herbe, ni de feuille morte. Un peu plus loin nous quittons le bord de la plaine pour gravir, à travers bois, la colline de Mongu, qui s'avance comme un promontoire dans le bo-Rotse (plaine basse et nue). Livingstone, puis les jésuites, avaient choisi cet endroit pour $y$ fonder une station. Nous descendons ensuite dans le vallon de Kanyongo (le petit), d'environ trois kilomètres de long, tout couvert de champs de manioc et de sorgho. Le fond en est marécageux et parcouru par un petit ruisseau. C'est là que M. Coillard pensait que je fonderais ma station à mon retour d'Europe. Aussi ce fut avec un intérêt tout spécial que j'examinai le vallon. Puis tout en galopant à travers la plaine je formais mille projets sur notre établissement, notre école, nos travaux de drainage, notre jardin; je pensais au bonheur avec lequel nous instruirions ces païens pour les amener au Sauveur. Avoir une station à nous, une œuvre à nous!

A Lealui le roi nous fit le bon accueil auquel il nous avait habitués. Il nous fit apporter de l'eau pour nous laver et nous rafraîchir, avant de nous offrir le thé. Une chose nous préoccupait: la présence à la Capitale de Middleton et ses menées et ses intrigues contre la Mission et contre la B. S. A. C. C. Il s'était établi à dix minutes de la ville, où il avait élévé cinq huttes. Nous rentrâmes à Sefula le 29 Septembre.

Comme nous chevauchions tranquillement, M. Coillard me dit:

《Si nous vous demandions de vous établir à Sefula pour $\mathrm{y}$ diriger un internat de garçons, qu'en penseriez-vous? Vous aimez l'enseignement, n'est-ce-pas? 》 Je restai interdit. Mes rêves de Kanyongo étaient si beaux! La question d'un internat s'était souvent posée à mon esprit. Comment évangéliserons nous la plaine du bo-Rotsi? Nous croyons alors ne pas pouvoir nous y établir. Qui irait à Lealui, à Nalolo, à Libonda et dans les nombreux villages grands et petits qui y sont parsemés? Pouvions-nous compter sur une bande d'évangélistes bassoutos? C'était douteux. Que restait-il à faire? Former des évangélistes indigènes, était pour nous la seule solution possible. Il faut que le pays soit évangélisé par ses propres enfants. Notre école ne suffisait pas pour cela. Le grand défaut c'était qu'en dehors des heures de leçons, nos élèves échappaient à notre influence, pour subir l'influence malsaine de leur village. Il convenait donc d'y 
soustraire ceux qui paraissaient bien doués et qui semblaient attirés vers l'Evangile, avec l'espoir d'en faire des évangélistes s'ils devenaient chrétiens. Pour cela il fallait un internat. Ce projet ne devait se réaliser ni dès mon retour, ni tel que nous l'avions formé.

En outre, au, point de vue de l'évangélisation faite par les missionnaires eux-mêmes, j'écrivais dejà à M. Boegner qu'il serait nécessaire de concentrer nos forces. Dans un pays malsain et dont les habitants n'inspirent pas une grande confiance, j'estimais qu'il était plus facile de rayonner quand on est à deux ou trois sur une station, que si chaque missionuaire occupe la sienne propre.

Le 3 octobre, nous eûmes le plaisir de souhaiter la bienvenue à M.lle Kiener, amenée en wagon par M. Waddell. Elle nous fit aussitôt la meilleure impression par sa confiance, sa joie et son amour des indigènes. Si on pouvait ne pas s'attacher aux Zambéziens, ou éviterait bien des tristesses, mais on se priverait aussi de beancoup de joies douces et pures, et on renoncerait à un des meilleurs ressorts, ì un des plus puissants leviers de toute activité. L'œuvre missionnaire est une œuvre de sauvetage, comme celles que l'on entreprend dans les bas-fonds des grands villes. On n'a pas besoin de loupe pour découvrir les défauts des Zambéziens. Ils ont peu de cour et il faut beaucoup de temps pour gagner leur confiance, car ils ne conçoivent pas le dévouement, eux dont l'égoïsme forme le fond du caractère. Cependant, à la longue, ils en viennent à apprécier ceux qui leur témoignent une vraie affection.

Le 10 octobre je retournai à la Capitale avec Litia. Chez Lewanika le missionnaire a libre entrée partout. Ne l'ayant trouvé ni au Kashandi, ni dans sa petite maison, je laissai Litia faire pied de grue et pénétrai dans la cour privée. Je trouvai le roi dans le corridor de sa grande hutte circulaire, accroupi sur une natte, et causant avec sa sœur Mokwae de Nalolo, accroupie vis-à-vis de lui sur une autre natte. Dehors près de la porte et sur une troisième natte, était Katoka, l'autre sœur du roi. Lewanika me fit aussitôt entrer et apporter un tabouret. J'étais arrivé à temps pour serrer la main à la reine et assister à sa salutation. Ma présence la gênait un peu. Elle allait se contenter de serrer la main de son frère, mais celui-ci dit: «Pas du tout, le missionnaire est des nôtres 》. Ils commencèrent alors 
à se crachoter mutuellement à la figure. C'est la salutation la plus tendre des ma-Rotse, celle qu'on réserve pour les membres de sa famille quand on les revoit après une longue absence.

Le Khotla s'était transformé en marché de bétail. Lewanika tient à surveiller les achats des ma-Mbari (noirs et métis de la province de Benguela), afin qu'ils ne puissent pas tromper les gens. En outre il a interdit la vente des vaches, et celle des bœuf de race se-shukulumbwe (plus petite).

Le 13 à l'aube, Lewanika, les princesses, et plusieurs autres élèves, répondirent encore à l'appel de la cloche et vinrent pour la prière. Le Roi resta avec nous jusqu'à notre départ. Il nous promit les canots pour le 20 octobre.

Lo 19 je fis à Sefula mon allocution d'adieu. J'étais ému en prenant congé de mes auditeurs. Il m'en coûtait de partir, javais donné mon cœur à l'œuvre, je l'aimais et j'aimais les indigènes malgré leurs défauts. Par la grâce de Dieu, on s'attache à eux en dépit de leurs misères, de leur corruption, de leur ingratitude, on en vient à se plaire dans leur société et on songe au bonheur que l'on éprouvera quand on en verra quelquesuns se donner au Sauveur. J'espérais leur revenir avec des forces multipliées. Le soir nous eûmes un service intime de S.te Cène, très bienfaisant. Nous fîmes entre nous une collecte pour la future église de Sefula.

Le 20 les canots promis n'arrivèrent pas. Middleton, un ancien artisan missionnaire qui nous avait quitté, excitait Lewanika contre nous. Le 23, en réponse à nos lettres, M. Coillard reçut du roi un message presque impertinent. Quant aux canots, il n'en était même pas question. Que faire? Je selle mon cheval et je pars. Le soleil allait se coucher quand j'arrivai à Léaluï. Lewanika siégeait au Khotla. Quand je vis le roi en particulier je le trouvai bouleversé, et très monté contre nous. Il nous accusa de l'avoir trompé et de nous être montrés favorables à la Compagnie à Charte parce que nous y avions notre profit. Il voulait annuller le Traite et exploiter lui-même son pays. Qu'est-ce que 2000 Livres sterling par an comme compensation des droits miniers qu'il a cédés? Son pays n'est-il pas plein d'or, puisqu'il est plein de sable... Je ne répète pas les autres absurdités, que je dus entendre. Battu sur chaque détail le roi ne s'avoua pas vaincu sur l'ensemble de la question. Nous nous séparâmes ce- 
pendant en bons termes, et il me promit les canots pour le 27 .

Lewanika tint parole, les canots arrivèrent au jour fixé.

Nous rentrâmes à Sefula le 3.

\begin{abstract}
XV.
Voyage en canot de Sefula à Kazungula.

Deprist. - De Nalolo à Seona. - Les chutes de Ygonye. - A Sesheke.

Le revoir.
\end{abstract}

$\mathrm{C}^{\mathrm{E}}$ fut le cœur très triste, que je quittai Sefula le 5 octobre

C 1890 et que je dis adieu à M. et à M.me Coillard, qui pendant neuf mois m'avaient comblé de bontés et initié à l'œurre missionnaire. Après trois heures de navigation nous abordons au port de Nalolo. Arrivés à la place du Khotla nos rameurs s'alignent et font la salutation royale. Quand nous sommes assis, les hommes de la ville saluent Litia leur à tour; puis les principaux chefs s'approchent pour me serrer la main et pour saluer le prince de différentes façons, selon qu'ils sont ou ne sont pas apparentés à la fanille royale.

À $5 \mathrm{~h}$. nous allons faire visite à Mokwae. Elle est accueillante. Elle veut que je constate qu'une paire de souliers que Mr Jeanmairet lui avait envoyée est trop petite. Le lendemain matin elle nous fait amener son veau gras, que nos bateliers ont bientôt tué d'un coup de lance au cour et dépecé. Quelques uns de mes éléves viennent me souhaiter bon voyage.

Le 8, c'est la chasse aux hippopotames qui nous retarde. Mokamba en tue un. À midi nous sommes à Senanga, où nous quittons la plaine proprement dite avec ses rives nues ou bordées de roseaux, et ses plages sablonneuses peuplées de volatiles. En aval la forêt arrive presque partout jusqu'au bord du fleure. Le 9, dimanche, nous passons la journée dans un lieu désert, ì l'ombre du mo-bula de Nanawa. Le matin j'ai un culte pour nos rameurs, puis avec mes sept élèves nous chantons. Le soir je partage mon repas avec Litia et Mokamba. Comme tous les 
soirs, avant de nous livrer au sommeil nous chantons encore un cantique, et je fais la prière avec tout le personnel de l'expédition.

Nous repartons le 7. Le 10 nous entrons dans la région des rapides. Mais en amont de Seoma il n'y en a point qui soient propres à causer de fortes émotions. Avant le coucher du soleil nous abordons à Seoma et campons au pied d'un magnifique sycomore.

Le 11 vers $7 \mathrm{~h}$. nous partons pour aller visiter les chutes de Ngonye: nos garçons y vont à pied; Litia, Mokamba et moi, nous y sommes amenés en canot, par des gens du lieu; nous passons à travers deux rapides et descendons le fleuve jusqu'à une cinquantaine de pas seulement des chutes, le bruit assourdissant et la vapeur qui s'en échappe nous disent qu'il ne ferait pas bon y être entraînés. Sautant ensuite de roc en roc, nous suivons le lit d'un petit bras du fleuve presque à sec à cette saison, puis nous tournons à droite et contemplons les chutes en face de nous. Dans l'amphithéâtre ou la marmite, comme l'appellent les indigènes, la plus rapprochée de la rive gauche sur laquelle nous nous tenons, l'eau se précipite de rocs en rocs avec un bruit épouvantable, en produisant une abondante vapeur que le vent pousse sur nous. Nous sommes trempés, n'importe: le soleil de novembre (le mois le plus chaud au Zambèze) aura bientôt tout séché; nous continuons à admirer. La chute en amphithéâtre est la principale, mais il y en a plusieurs autres. Le tout forme un tableau ravissant et saisissant à la fois, auquel les îles boisées qui sont en amont, servent de cadre. Nous passâmes là presque toute la journée. Je ne saurais dire combien je jouis escaladant des rochers, cela me donnait l'illusion d'être dans nos Alpes.

Pendant ce temps nos rameurs, aidés des gens de Seoma, étaient occupés au transbordement; pour cela ils amènent les canots sur le fleuve jusqu'à mi-chemin des chutes, là des gens les chargent sur leurs épaules, les portent ainsi une demi-heure et les déposent au bord du fleuve, d'où, à travers plusieurs mauvais rapides, les plus habiles les amènent au port de Nangwalu.

Mais voici qu'il faut «raccommoder》 un des gros canots de Litia. Ce n'est pas petite affaire. On tire le canot sur la rive, ou démanche huit à dix lances, on en enveloppe de feuilles de palmiers la partie tranchante, et on en chauffe au rouge la pointe 
inférieure. Puis, tandis que quelques rameurs prennent de l'écorce et la battent, en forme de bourrelet, d'autres font des trous avec les fers rouges, tout le long de la fente des deux côtés. Quand cette besogne est terminée, on étend un double bourrelet d'écorces par dessus la fente, un à l'intérieur du canot, l'autre à l'extérieur et l'on coud ensuite le tout avec soin.

Nous partons enfin! Surtout pendant la première heure les berges sont formées de roches basaltiques, de porphyre, de granit, de gneiss. Il en est qui ressemblent à de la lave. Qui sait quels bouleversements ont eu lieu dans ces parages? Le fleuve est si resserré et le courant si fort qu'à chaque coude il y a des remous violents. Malheur au canot maladroitement conduit! Les rapides proprement dits sont fréquents. Nous abordons à l'embouchure du Lumbe.

Le lendemain matin nous arrivâmes au grand rapide de Kale-là; comme à tous les rapides suivants, le fleuve est très large et se subdivise en plusieurs bras. Nous abordons à la rive droite. On décharge en partie les canots. Longer le rapide à pied c'est l'affaire de 5 minutes, il en fallut 25 à mon canot pour arriver en aval. D'autres plus lourds mirent encore plus de temps. Ce rapide n'a guères que 40 mètres de longueur, mais c'est un des plus dangereux. Les restes du canot de M. Coillard, échoué sur les rochers l'année précédente, sont là pour avertir de bien faire attention. Nos frêles embarcations ne passent qu'une à la fois; 8,10 , 15 bateliers se tiennent au milieu du courant pour les diriger ou les retenir par les cordes que l'on a attachées à la proue et à la poupe. Un canot est pris dans le rapide... la poupe est saisie par le courant, le canot est sur le point de tourner et de sombrer, vite tous les rameurs se jettent à l'eau et réussissent à grand'peine à le retenir et à le ramener dans la boune direction. Le soir au campement je dus faire sècher nos effets mouillés la veille. La fièvre me saisit et me tint quatre jours. Comme le canot devient fatigant quand on n'est pas bien!

Le 14 nous passons l'embouchure du Ndjoko, puis les rapides que les natifs appellent les enfants de Loshu, où les gros canots nous retardent passablement. À $2 \mathrm{~h}$. nous sommes à Loshu même, que nous passons sans trop de peine. Mais un de mes canots manque, ses rameurs ont été à un village de la rive droite pour demander de la nourriture. Le vent se lève, les nuages s'amoncellent, le fleuve est courroucé; nous campons et dres- 
sons nos tentes. Le lendemain, quand quelques-uns de nos hommes vont au haut de Loshu, ils voient le canot s'engager dans le rapide, mais par un mauvais chenal; ils crient aux bateliers de rebrousser.... c' est trop tard, le canot pirouette et enfonce! Vite chacun se jette à l'eau, on recueille les objets que le courant emporte et avec beaucoup de peine on remet le canot à flot, livres, provisions de bouche, articles d'échange.... la caisse des clichés de M. Coillard.... tout est ruisselant! Nous n'allons ce jour-là que jusqu'à Ngambwe, deux heures plus loin. La fièvre, le souci des clichés gâtés, m'empêchent de jouir de ce bout du fleuve, particulièrement beau, grâces aux innombrables arbustes qui le bordent. Ngambwe est plus qu'un rapide, c' est une série de rapides au milieu desquels se trouve une chute d'environ 2 mètres de hauteur. Il faut comme à Séoma faire le transbordement (mais c'est beaucoup plus court); on ne traîne les canots que sur un espace de 20 mètres, et on ne transporte les bagages qu'à un petit quart-d'heure en aval.

Le 19 à $4 \mathrm{~h}$., après une navigation accidentée nous faisions notre entrée à Sesheke. Mr. et M.me Goy m'y reçurent comme les missionnaires savent recevoir leurs collègues, et je jouis beaucoup des deux jours passés sous leur toit. J'eus bien du plaisir à faire la connaissance de Madame Goy, et comme j'admirai sa manière de parler le sessouto! Ces chers amis étaient bien inquiets pour leur petit Emile très souffrant. Nous ne pûmes nous arrêter chez eux que fort peu de temps.

Nous arrivâmes en vue de Kazungula le 22 après-midi. Je tirai un coup de fusil pour avertir mon frère de mon arrivée. Encore quelques coups de rame et je puis me jeter dans les bras de mes bien-aimés. Je m'y reconnais à peine. L'ancien établissement où j'ai passé près de trois mois sous la tente, est maintenant la propriété d'un Boer. La station est transportée un peu plus loin du port vers l'ouest. Ce qui y frappe les regards avant tout c'est une grande maison à deux ailes, dont la couverture est presque terminée. Derrière s'élèvent deux petites dépendances qui servent de maison d'habitation et de cuisine. Celle-ci fut mise à ma disposition, comme chambre à coucher. Après neuf beaux jours de communion fraternelle, j'accompagnai mes hôtes à la rive et les vis s'embarquer pour Sefula dans les canots qui m'avaient amené. 



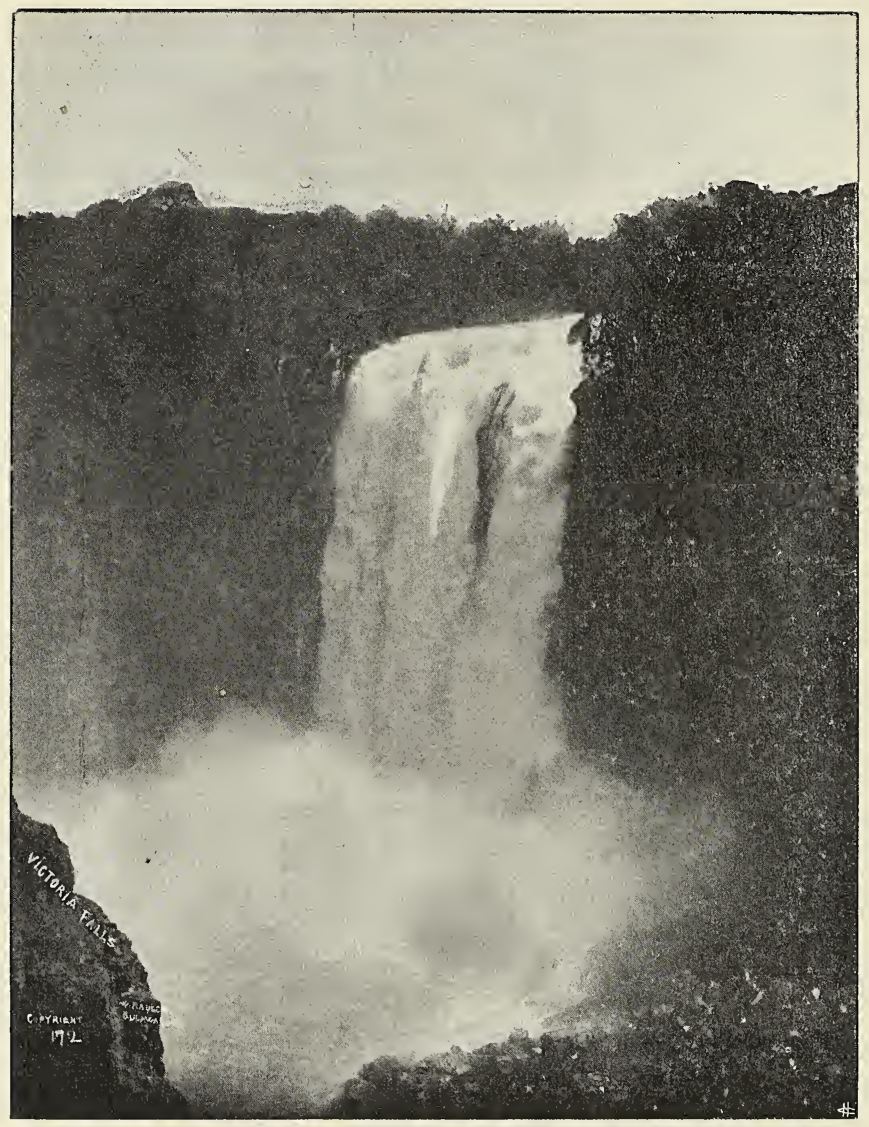

Chutes Victoria (Chute de droite). 


\section{XVI.}

\section{Laissé seul.}

Course aux Chutes Victoria. - Spectacle grandiose.

DESTÉ seul maître de la station, je travaillai tant que je 1 pus et ne me sentis pas malheureux du tout avec les natifs qui m'étaient laissés. Le ménage, l'école (j’avais 12 élèves, y compris Litia et ses cinq compagnons), les cultes du matin et du soir me donnaient assez à faire.

Quand javais un moment de loisir, je faisais avec mes grands élèves un tour de bâteau ou de chasse. Le dimanche je tenais aussi deux cultes; mais quelle différence avec Sefula! Sur la station ou au village de Mahaha je ne pus avoir plus de 27 auditeurs. Un jour en allant voir le tombeau de Dardier sur $\mathrm{la}^{\mathrm{t}}$ rive droite, nous trouvâmes un Bushman dont la lèvre gauche avait été broyée par un léopard. Il était très enflé, et des trois points où les griffes avaient pénétré il sortait beaucoup de pus et de temps en temps des esquilles d'os. J'allai le saigner plusieurs jours de suite.

Le 9 Décembre, laissant un garçon de confiance de mon frère responsable de la station, nous partons pour les Chutes Victoria. Litia, Mokamba et deux de leurs garçons ramant, nous allons en canot jusqu'au haut du rapide de Katomboro, à $1 \frac{1}{2} \mathrm{~h}$. de Kazungula, et là nous attendons les porteurs.

Vers 10 h. nous repartîmes, marchant à la file indienne. Nous étions une trentaine, dont vingt venus de chez Mahaha pour porter les effets de Litia, ou simplement pour grossir sa suite. On n'est pas prince pour rien! Je ne trouvais pas grand agrément à marcher à la file et à ne guères voir que le dos de mon prédécesseur. Un premier trajet de 3 heures, à travers bois et prairies. où courent des bandes de pintades et de perdrix et quelques antilopes, nous amène au village de Sepwapwa. Jusque là le sentier ne s'éloigne guère du fleuve, dont nous entendons le bruit sans le voir. Il y a par là de très mauvais rapides, qui rendent la navigation presque impossible. Encore un trajet d'une 
heure et demi, et nous campons pour la nuit au bord du ruisseau Mokasebanga. Litia et mes autres élèves, in'y préparent une hutte conique, toute recouverte de branchages. L'étape du lendemain est assez longue, environ 40 kilomètres sous un soleil ardent. Masoatane, le chef du village des Chutes, nous fit un excellent accueil. Nous entendions le bruit et voyons la vapeur du Mosi-oe-thunya. Grâces à la fatigue nous dormîmes malgré les piqûres des moustiques.

Le lendemain 11, nous fûmes bientôt sur pied. Conduits par Masoatane lui-même, nous atteignîmes le bord du fleuve, et nous trouvâmes trois petits canots dans lesquels vingt personnes purent avoir place. Heureusement le vent ne soufflait pas. Nous atteignîmes la rive droite sans accident. Pour voir les chutes il faut se résigner à être trempé jusqu'aux os, à passer sous des arbres ruisselants malgré le beau soleil, à s'enfoncer parfois dans une forêt vierge où pénètrent à peine quelques rayons de lumière... n'importe chacun veut aller se placer vis-à-vis de chacune des chutes et arriver jusqu'au point où on peut presque en avoir une vue d'ensemble. Comment décrire ces roulements de tonnerre constants, ces nuages qui sortent du gouffre béant qui s'étend sous nos pieds, et s'élèvent vers le ciel, ces vapeurs si denses parfois que nous ne pouvons rien distinguer à vingt pas, puis tout à coup le rideau se déchire pour laisser voir un des plus beaux spectacles qu'il soit donné à l'homme de contempler. Les chutes sont très variées. Ici, c'est tout un fleuve qui se précipite dans l'abîme avec fracas, là c'est un torrent, ailleurs un filet d'eau. Les uns se précipitent à pic du haut de ces immenses parois de rochers (ayant plus de 100 mètres de hauteur), d'autres rebondissent sur des saillies. Et cette rivière impétueuse que nous voyons de temps à autre là-bas à plus de cent mètres de profondeur, quand nous nous penchons sur le gouffre et que le vent chasse les vapeurs... C'est grandiose, c'est sublime. Tout notre être est saisi par la contemplation de ces merveilles qui chantent la gloire de leur Créateur.

C'était encore le moment des basses eaux. J'ai revu ces chutes quand le volume d'eau était peut-être dix fois plus grand: c'était plus terrible mais moins beau, parce que les aspects sont moins variés.

Le retour à Kazungula s'effectua rapidement. Dès avant no- 
tre course aux chutes nous avions eu de fréquentes visites de hyènes, elles s'étaient particulièrement acharnées sur le poulailler. Mais quelle ne fut pas notre consternation, à notre retour, en apprenant que trois chiens de mon frère avaient été pris par la hyène l'un après l'autre et que presque toute la basse-cour avait été annéantie! Nous guettâmes en vain l'animal, qui finit par se faire tuer à la trappe à fusil. Au coup nous accourons tous. Mes gens se mirent à railler cette hideuse bête, et à enfoncer leurs lances dans son corps. (Par ce procédé, les Zambéziens s’imaginent de se mettre à l'abri de la vengeance des mânes qui pourraient avoir hanté le fauve). Ils entonnèrent ensuite le chant spécial à cette sorte de victoire.

J'eus le plaisir de passer le jour de Noël à Sesheke, chez le roi, avec nos élèves. Mais nous rentrâmes à Kazungula dès le lendemain.

Mon frère et ma belle-soeur restèrent un mois à Sefula. Ce ne fut que le 31 janvier 1891 qu'ils revinrent à leur station.

\section{XVII.}

Du Zambèze en Italie.

Lmbourbés dans la région de la tsétsé. - Encore des fondrières. - Le désert fleuri. - Secours opportun. - Pertes et gloutonnerie. -- Distractions. Nostalgie - Disette. - Délivrance. - Chez Khama. - Diverses rencon. tres. - A la porte du tombeau. - Retour en Europe.

T ITIA, sa suite et moi, nous fìmes donc nos préparatifs de dé. L part. Du 11 au 13 février nous transportâmes le wagon, nos effets et les bœufs sur la rive droite. Le 13, après avoir une dernière fois ployé les genoux ensemble, nous nous disons adieu. A 7 h. du soir, Frantz fait claquer son fouet et nous voilà partis.

« Ma qui comincian le dolenti note» (1)

Nous ne tardons pas à atteindre le premier bourbier. «Si rous

(1) Mais ici commencent les notes tristes. 
le passez bien, nous avait dit un voyageur, vous pouvez compter vous tirer de tous les autres 》. Nos braves boufs, émoustillés par les cris et par les claquements du fouet, pataugent, enfoncent jusqu'au ventre, mais avancent, avancent toujours, bien que lentement. Nous sortons du bourbiei et en traversons plusieurs autres. Hélas, un peu après minuit, un tronc d'arbre pourri se trouve en travers des roues, qui s'enfoncent si bien dans l'argile, qu'il nous faut renoncer à aller plus loin cette nuit là. Nous envoyons les bœufs à Leshoma, hors de la région de la tsétsé, en recommandant aux gardiens de n'en repartir qu'à la nuit. Le lendemain samedi, nous dégageons les roues. Une demi-heure après le coucher du soleil, les boufs arrivent déjà à travers cette forêt infestée par la tsétsé! Nous fîmes une petite avance de demi-heure. A un certain endroit Frantz crut devoir laisser la piste, et nous fit embourber une seconde fois; il nous fallut renvoyer une autre fois les boeufs, grâces à cet accident.

Nous passâmes notre premier dimanche dans la boue. Hélas, ce ne devait pas être le seul! Nous pûmes cependant avoir notre culte. Mes onze auditeurs étaient assis ou perchés sur les roues, le timon, la caisse d'avant, comme ils le pouvaient.

Oh les péripéties de ce voyage! Oh ces fondrières! Nous n'arrivâmes à Leshoma que le 18 vers minuit. Six jours pour parcourir une distance d'environ seize kilomètres!

Les trois jours suivants, nous avançâmes sans encombres à travers des forêts sablonneuses. Les étangs, qui étaient complètement à sec quand j'y avais passé deux ans auparavant, débordaient tous. Nous passâmes le dimanche 22 au bord de la plaine de Kazuma. Ce fut une bonne journée de recueillement et de causeries sérieuses. Mais la pluie, qui avait commencé à tomber la veille, continua à détremper la vaste plaine argileuse que nous devions traverser.

Le lendemain, nous ne tardâmes pas à nous embourber. En six jours nous ne fîmes pas deux kilomètres. Nous n'en serions pas sortis si tôt, si à ma requête, M. Fraser (1) ne nous eût envoyé 14 bœufs de Panda ma Tenga. Le 2 mars nous attelons 20 bœufs et ramenons le wagon où nous avions campé le 21 février! De là, suivant la lisière du bois, nous contournons la plaine vers l'Est, et nous frayons une route dans la forêt, la hâche à la main.

(1) Un employé de la B. S. A. C. C. avec M. Bayly. 
Quand nous eûmes rejoint la piste de Kasibi, nous dûmes renvoyer les bœufs libérateurs à leurs propriétaires et continuer le voyage avec les nôtres, qui commençaient à se ressentir des piqûres de la tsétsé. Enfin après avoir à plusieurs reprises déchargé et rechargé le wagon aux plus mauvais pas, nous finîmes par atteindre Panda-ma-Tenga le 10 mars!

Nous trouvâmes ce village comparativement désert et les champs en friche. Plus de trace de la tannerie, plus de cris d'enfants, plus de chants. Sur l'ordre de Khama, Panda-maTenga avait dû être évacué par ses habitants. Nous y trouvâmes MM. Bayly et Fraser de la B. S. A. C. C. qui nous firent bon accueil. Ils venaient de recevoir du roi Lewanika une lettre que je dus leurs traduire, ainsi conçue: «Vous gens de la C.ie je ne vous veux pas, arrière de moi! Qui je veux c'est le Gouvernement de la Reine. Vous, vous venez pous voler et exploiter mon pays, je ne veux pas de vous! 》

Jusqu'au 18 mars la pluie tomba tous les jours. Comme nous avions déjà dû tuer trois bœufs et que d'autres présentaient des signes de dépérissement, j'envoyai demander à mon frère des bœufs de secours, le 19.

Le 20, nous nous remîmes en marche. Le 23, nous réussîmes après beaucoup de peine à nous tirer de la plaine argileuse de Deka, et le 26 nous laissâmes enfin derrière nous le dernier bourbier et arrivâmes à Joly's Vley. Nous n'avions pas encore dételé quand nous vîmes joindre nos messagers avec deux ouvriers de mon frère et quatre bøufs. Ce fut presque fête le soir: tous les bourbiers étaient enfin passés et le secours était venu!

Comme la région des Mille étangs est belle en cette saison! Sur les étangs fleurissent de beaux nénuphars et d'autres plantes aquatiques. Les bois, les prairies, tout est vert; on voit un peu partout comme des corbeilles de fleurs de toutes couleurs, une espèce de basilic parfume des bois entiers. Nous trouvons beaucoup de vigne sauvage et pas mal de raisin, dont nous nous régalons, bien qu'il n'ait que peu de jus et pas grand goût. Surtout dans la plaine des palmiers nous voyons des troupeaux de zèbres, de gnous, d'antilopes, et d'autruches.

Tout aurait été beau si nous n'avions pas vu nos bœufs dépérir de jour en jour. Quand le 11 avril nous atteignîmes la Nata, en la trouvant pleine d'eau courante, et en voyant notre attelage diminué et épuisé, nous craignimes de ne pas pouvoir 
passer cette rivière de longtemps. Si même nos bœufs réussissaient à atteindre l'autre rive, auraient-ils la force de nous en faire gravir la berge? Mais Dieu y avait pourvu, Lui qui nous avait amenés jusque là. Deux noirs arrivent à notre campement et nous annoncent qu'il y a sur la rive gauche plusieurs wagons chargés d'effets pour les missionnaires, et qu'ils vont essayer de passer la Nata à gué; c'est ce qui fut fait. Quand leur dernier chariot fut passé, les conducteurs attelèrent dix-huit de leurs bœufs au nôtre et nous amenèrent à la rive désirée, comme par enchantement. Ces beaux bœufs! cela nous faisait rêver.

Nous donnâmes quelques jours de repos à nos bœufs malades. Mes ma-Rotsi nous pêchèrent beaucoup de poissons avec des nasses de leur fabrication. Il y avait des quantités d'oiseaux pêcheurs, canards, pélicans. Mais que de moustiques!

Le 14 avril nous nous remettons en route.

Les Macaricari (1), grossis par la Nata, sont entièrement sous l'eau et débordent de toutes parts, ils forment une mer intérieure, mais dont l'eau est presque douce à cette saison. Il ne peut être question de passer par Shua. Nous rencontrons le wagon de provisions pour l'expédition qui nous a quitté. Le conducteur nous donne du courage, il nous assure qu'en contournant la mer vers l'Est et en suivant les traces de son chariot, nous arriverons sans trop de difficultés. Sur sa piste l'eau n'atteint pas plus d'un mètre. Ce trajet qu'on peut aisément faire en deux jours, nous en prit quatre, et nous coûta quatre bœufs! Ces pauvres bêtes servent encore après leur mort, nous gardons leur peau et mangeons leur chair. L'avidité avec laquelle mes compagnons de route les dépècent pour s'en gorger, me répugne. Chaque fois qu'un bœuf meurt c'est presque une fête pour eux, l'animation est extraordinaire, les langues sont plus déliées que jamais. Les feux ne risquent pas de s'éteindre ces jours-là, partout il y a de la viande en train de cuire, sur les braises, sous les cendres, enfilée à des broches de bois, dans les marmites... Je garde ma tristesse pour moi, à quoi servirait de l'exprimer? Je ne serais pas compris!

Nous arrivons a Linokaneng le 25 au soir. Nous dételons là, décidés à attendre le secours.

(l) Macaricari (comme mapaïpä̈ du se-rotsé) signifie: grande étendue d'eau agitée. C'est ainsi que nous les vîmes. 
Pendant tout le voyage, mes occupations préférées avaient été la correspondance, la prière du soir, les cultes du dimanche, l'étude et l'école. Chaque jour, presque sans exception, j'avais réuni mes élèves et leur avais donné des leçons. L'enseignement était devenu un besoin, et je savais que mes compagnons de voyage avaient une intelligence à développer et un cœur à donner à Dieu. À Linokaneng nous pûmes consacrer à cette œuvre de longues heures.

Mes Zambéziens avaient quelques fois la nostalgie du boRotsé. Il m'arriva de les entendre parler de leur plaine, de la capitale, de leurs condisciples, de leurs mères, avec une tendresse qu'ils ne montrent pas souvent. J'aimais particulièrement voir cette manifestation si rare de l'amour filial. Dans leur pays, j'en avais $v u$ un autre symptome dans l'affreuse habitude de maudire la mère de celui avec lequel on se dispute, pour le toucher au vif.

Nos provisions de route tiraient à leur fin. Depuis longtemps je n'avais plus de farine; la chasse, des fruits sauvages, quelquefois un peu de miel ou de lait que nous apportaient des Bushmen, nous aidèrent à ne pas mourir de faim.

Enfin le 2 mai, vers $8 \frac{1}{2} \mathrm{~h}$. du matin, nous entendons un bruit comme celui de bœufs marchant sur des cailloux. Les bœufs! les bœufs sont là! s'écrie chacun. Ils arrivaient en effet, amenés par un des garçons que j’avais envoyés de la Nata, et par un homme de Mangwato. Ce furent des transports de joie. Khama, M. Hepburn et la British Trading Association, s'étaient entendus pour nous secourir. Un antre sujet de reconnaissance était réservé pour moi seul: le courrier d'Europe.

Nous nous remettons en branle le 4 mai. Le 13 nous arrivons à Palapye et $\mathrm{y}$ campons près de la station missionnaire. M. Hepburn est absent, nlais Madame me reçoit comme un fils.

Je dus passer à Palapye beaucoup plus de temps que je ne l'avais pensé. Palapye, la nouvelle capitale des ba-Mangwato, ne ressemble en rien à l'ancienne, elle est surtout beaucoup plus étendue.

Le dimanche je fus invité à faire le culte dans le grand enclos à bétail de Khama (le Khotla). J'eus le joyeux privilège d'y annoncer l'Evangile à de beaux auditoires, et d'y entendre Khama prier pour son peuple.

Madame Hepburn et Khama me comblèrent encore de pro- 
visions de route. Je pris congé d'eux le 12 juin. Je laissai aussi Litia et ses compagnons. Las de voyager, ils voulaient attendre à Mangwato la prochaine occasion de rentrer au Zambèze. J'emmenai avec moi Mobiana, le brave garçon que Lewanika m'avait donné (un sien beau-frère), et le pauvre Frantz tout perclus. Mes nouveaux compagnons étaient des ba-Rolong de Mafeking ayant des besoins religieux: Avant même que j'eûsses eu le temps de les y convier, ils me demandèrent de prendre part à nos cultes du soir, et les dimanches ils m'aidèrent à convoquer des auditeurs occasionnels.

Le 17, en arrivant au Limpopo, nous trouvons la grande route à wagon du Mashonaland. J'eus le plaisir d'y rencontrer Vollet et le couple Pauluse Kamli se rendant au Zambèze.

Le 27, à Gaberone, je revois Jules Ellenberger, que j'avais déjà rencontré à Palapye.

Il m'amène au fort, puis chez M. Sermon, le magistrat où nous dînons.

Malheureusement en route je suis ressaisi par la fièvre, et c'est en cette mauraise compagnie que jarrive à Mafeking le 5 juillet. J'y suis reçu comme un vieil ami par MM. Whiteley et Musson. Je laissai là Frantz chez des connåissances et repartis le 9 au soir sur un autre wagon. Depuis lors j'eus la fièvre tous les soirs et toutes les nuits.

Le 17 juillet nous arrivons à Vryburg qui était alors le terminus du chemin de fer. J'ai de la peine à faire admettre Mobiana dans un compartiment de $\mathrm{III}^{\mathrm{e}}$ Classe, les blancs qui l'occupent refusant de voyager avec un noir.

Après une nuit blanche j’arrivai à Kimberley fiévreux, avec une forte amygdalite. Je confiai Mobiana à l'agent afin qu'il l'envoyât à Morija le plus tôt possible.

Le lundi 21, au lieu de partir pour le Cap, je dus faire chercher le Dr. Mackenzie qui me fit recevoir d'urgence à l'hôpital de la ville. J'y fus à la porte du tombeau pendant trois jours. Mais Dieu bénit les soins que me prodiguèrent le Dr. Mackenzie et les diaconesses. Le 28 le Docteur m'autorisa à prendre le train; il me fit conduire en voiture de l'hôpital à la gare et m'y recommanda à quelques connaissances.

Le 29, j'allai directement de la gare de la Ville du Cap au Dunottar Castle. Nous partîmes le soir même. J'étais encore très fatigué, mais, Dieu merci, la convalescence ne cessa de faire 
des progrès, en dépit du fort tangage dont beaucoup de passagers eurent à souffrir.

Le 16, j'étais à Paris, à la Maison des Missions, où M. Boegner ne tarda pas à me rejoindre, venant de St. Prix.

Le 18, je revois mon pays natal, ma fiancée, et ma mère! L'air des Vallées et l'affection de mon entourage firent des' merveilles. Au bout d'un mois je pus commencer à parcourir nos églises Vaudoises du Piémont et à y parler de la Mission du Zambèze.

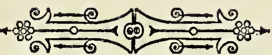





\section{Retour au Zambèze. - À deux.}

Semailles laborieuses.

Réveil de 1894 à 1895.

$$
\text { (1891-1895) }
$$





\title{
SECONDE PARTIE
}

\author{
XVIII.
}

Des Alpes à la Tele.

Mariage, - En Suisse et en France. - Ca traversée.

Itempux efret du mal de mer. - Le passé et l'avenir. - Arrivée à Last-London.

Une leçon de patience. - Patience mise à l'épreuve.

E 29 octobre 1901 fut l'heureux jour de notre mariage,

1 le couronnement de nos trois années de fiançailles et de correspondance. Ma fiancée avait été un don de Dieu, ma femme fut un don de Dieu. De ce jour sacré nos cœurs furent comme fondus en un seul, dans le Seigneur, et pour son service.

Le soir même du 29 nous dîmes adieu à nos mères, à notre père, à tous nos frères et sœurs, parents et amis.

En Suisse, où nous nous reudîmes pour saluer d'autres parents, nous continuâmes à éprouver combien était grand notre privilège d'appartenir à la famille missionnaire du Zambèze. Nous ne fûmes pas seulement les objets de la sympathie et de l'intérêt de nos amis: on nous avait aussi préparé des réunions. Il en fut de même à Lyon et à Paris.

$1^{\mathrm{r}}$ Novembre. -- Nous sommes heureux $\dot{a}$ la pensée de servir Dieu ensemble, heureux de l'affection qu'on nous tẻmoigne partout, heureux enfin parce que nous avons l'assurance que Dieu est avec 
nous et qu'll veillera sur nous partout où nous irons et tout le temps de notre vie. Si quelque chose trouble de temps en temps notre sérénité, c'est la pensẻe du chagrin de ceux que nous quittons.... Soyez heureux avec moi de ce qu'il a plu à Dieu de me choisir pour une si grande et belle oeuvre; priez pour que je sois rendue capable de l'accomplir avec fidèlité, avec toujours plus de joie et avec amour. Il agira pour moi et, par son Esprit, il suppleeera à tout ce qui me manque.

6 Novembre. - Nous recevons partout l'accueil le plus chaleureux qu'il soit possible d'imaginer.

28 NovemBRE. - A bord du petit vapeur qui nous amène au Scot. Nous sommes heureux, heureux malgré tout, malgré le sentiment de l'éloignement; heureux parce que nous sentons que Dieu est avec nous. Il est fidèle.

Il vaut la peine d'avoir à souffrir de la mauvaise humeur de l'Océan pour éprouver cette sensation exquise: c'est comme si l'on renaissait à une nouvelle vie! On prend intérêt à ce qui vous entoure, on s'occupe un peu du prochain que l'on coudoie et l'on ne pense plus que ce magnifique bateau n'est qu'un instrument de torture inventé pour la désolation des malheureux qui sont obligés d'y monter. Cette pauvre cabine que je haïssais si cordialement, revêt un tout autre aspect à mes yeux maintenant. Nous nous y sentons chez nous. clle n'est pas grande, est pleine comme un œuf, mais nous nous habituons très-bien à nous y mouvoir et nous finissons par nous y sentir au large.

Nous sommes reconnaissants de ce tempa de repos si complet, après les semaines fatigantes que nous venons de passer. Elles restent nẻanmoins gravées dans notre souvenir en traits indẻlẻbiles. Mais quelle jouissance de sentir que rien ne vous réclame, pas de courses dans les magasins, pas de visites, pas de questions sans cesse renouvelées, auxquelles il faut répondre.

Oh! ces soirées tranquilles sur le pont!

Nous ne pouvons nous lasser d'admirer les superbes teintes que laisse après lui l'astre du jour; puis nous voyons apparaître Vénus dans un rayon de lumière rosée, Jupiter brille au dessus du grand màt, et enfin une à une s'allument dans le firmament des myriades d'étoiles qui scintillent d'une lumière vive et douce. La lune aussi ajoute à ce beau spectacle et projette ses rayons dans la mer à l'azur sombre. Un petit groupe se forme autour de nous, et nous chantons des cantiques anglais...

Que de beaux jours... Que de sujets d'actions de grâces n"ai-je pas? Ma vie toute entière a étẻ si belle, si privilégiée, si heureuse. Ces 22 ans que j'ai vécus dans une maison comme la mienne, 
aimée, choyẻe par un père si tendre et par une mère si dévouẻe, avec un entourage d'amis précieux, sûrs, constants; puis cette période nouvelle que je viens de commencer. Oh n'y a-t-il pas lá de quoi bénir Dieu? Puissé-je le servir avec toute la fidélité qu'll est en droit d'attendre de moi, après toutes les grâces dont Il m'a comblée. Je me sens bien faible, bien indigne, bien peu apte à la grande tàche qui m'attend; mais je sais qu'il agira et qu'il manifestera sa force dans ma faiblesse. Plus j'avance vers l'Afrique et plus je suis heureuse de ce que le moment approche où je pourrai faire quelque chose directement pour le service de Dieu... Je crois que pour être femme missionnaire une seule chose suffit: l'amour, l'amour pour ces pauvres païens, l'amour pour ces êtres dégradès qui vous entourent, et cet amour-lá Dieu peut et veut le mettre dans mon cœur, dans une grande mesure.

Après avoir touchẻ au Cap le 15 dẻcembre nous nous arrêtons dans la Baie d'Algoa:

J'étais aguerrie désormais et me sentais le pied marin. Cependant ce fut avec une joie véritable que je me préparais à retourner sur terre ferme pour tout de bon. East London se présente sous un joli aspect: Des collines, couvertes de bouquets d'arbres; çà et là des groupes de maisons basses. Nous avançons toujours et arrivons enfin. Un petit vapeur arrive de la côte, il approche, il est à côtẻ de notre bâteau. On commonce alors á faire monter les gens venus de terre... dans un panier! Puis vint le tour des bagages et enfin celui des passagers. Nous fûmes des premiers à entrer dans le panier, où il y a un siège pour deux. Un filet placé au dessus nous oblige à nous tenir courbés en deux. La grue nous dépose doucement sur l'arrière du petit bâteau.

Nous étions de 25 à 30 passagers pour East-London. Dix minutes suffirent pour nous amener au quai: Après être sorti de la mer, on entre dans une large et paisible rivière, le Buffalo qui coule entre deux collines boisées et couvertes parfois de villages indigènes avec leurs petites huttes rondes, égayejes ça et là par des maisonnettes aux toits rouges qui annoncent la présence d'Européens.

Le chemin de fer nous amena à Aliwal North, le 19. C'est une petite ville à maisons basses, dispersées et cachẻes dans de vrais nids de verdure, "ce qui lui donne un aspect coquet et riant. Nous jouîmes de la charmante hospitalitẻ de la famille Daumas. Le soir nous écoutions les récits si vivants de madame Daumas sur les nombreuses aventures de sa vie missionnaire.

Nous partîmes d'Aliwal en «cart» à quatre chevaux. Quelles secousses! Mais nos braves bêtes ne se laissent arrêter ni par 
les ornières profondes de la terre argileuse, ni par les pierres, ni par les berges escarpées des cours d'eau; ils vont de l'avant d'un air qui semble dire: Nous y sommes habitués, allez! Ce ne sont pas leurs confrères d'Europe qui prendraient la chose si philosophiquement. Et notre cocher! il m'a donné une leçon, dont je crois que j'aurai à me souvenir plus d'une fois dans ce pays où la patience est la plus nécessaire de toutes les vertus. En vrai enfant de l'Afrique il en avait une dose qui dépassait toutes mes conceptions. Il a dû sauter à bas de son siège au moins vingt fois dảns le voyage. Tantôt c'était un cheval qui était sorti de sa place, une des brides qui se détachait, la lanière de son fouet qui se séparait du manche ou restait enchevêtrée dans les roues, ou bien enfin c'était le vent qui se mettait de la partie et l'obligeait à courir après son chapeau. À sa place jaurais murmuré, gémi, ou je me serais dédommagée en me mettant en colère. Lui, pas du tout, il descendait avec un sourire, remettait en ordre, et reprenait les rênes, prêt à recommencer au premier désordre qui se manifesterait dans l'attelage, au fouet ou sur sa tête. Eh bien, ce noir enfant de l'Afrique a raison, à quoi bon lutter contre cette force inerte mais puissante des petits contretemps?

Très vite je fus mise en demeure de constater que cette bonne leçon n'avait guères porté de fruits. En arrivant à Palmiet-Fontein, le 23 décembre, nous étions tout près de Massitissi (Lessouto). Mais la Télé, un fort torrent grossi par les dernières pluies, était infranchissable aux vẻhicules. Comment cela, m'écriai-je dans mon impatience européenne, il nous faut arriver à Massitissi demain. Des hôtes qui nous accueillaient avec l'hospitalitẻ si large du pays souriaient. - On ne peut pas traverser, répétaient ils. Il était tard, nous étions très fatigués après deux jours de voyage en cart, et nous fûmes henreux d'aller nous reposer après le souper tardif qui nous fut offert avec beaucoup de cordialité.

Le lendemain matin je crus que la plaisanterie de la veille aurait cessẻ et que sans tarder nous allions nous remettre en route. Mais non, le mème inexorable refrain: Impossible, il y a trop d'eau. Mon mari envoya un messager à $M$. Ellenberger pour lui demander s'il pouvait nous envoyer des chevaux. Et nous allâmes, en attendant, nous promener jusqu'ả la malicieuse rivière, dont l'eau coulait paisiblement, sans se douter de la révolte qu'elle soulevait dans mon coeur européen. Mon mari, lui, habituẻ à ces retards, prêt à toujours se souvenir de ce que j'apprenais lentement et à grand'peine, que l'Afrique est le pays des imprévus, souriait de mon impatience et me disait: «Ah! des Tele tu en trouveras encore avant d'être au Zambèze!» 


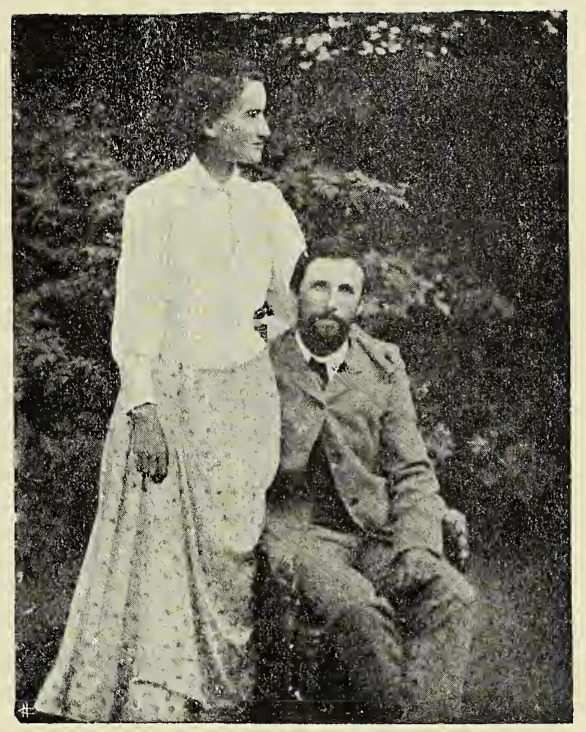

Ad. et En. Jalla (Morija, Février 1892). 

XIX.

Au Lessouto.

Première chevanchée. - Mort de Madame coillard. - Une mission modèle. E'école du Dimanche de Morija.

Dans l'après-midi enfin le messager arrivait. De l'autre côtẻ de la Télé nous attendaient deux chevaux. Ellenberger luimême était venu sur sa monture pour nous escorter. Avec quelle joie j'entrai dans la vieille barque qui nous traversa! J'eus vite enfilé l'amazone que m'apportait M. Ellenberger et me voilà à cheval pour la première fois de ma vie, tremblant dès que nous allions un peu vite, mais ne voulant jamais l'avouer, et surmontant ma frayeur, décidée à aimer ce nouveau genre de locomotion. Cette heure à cheval fut le prélude de bien des courses délicieuses dont je ne me lassais jamais.

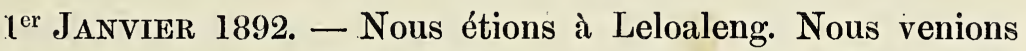
de nous lever, quand notre hôtesse me remit un billet de $\dot{M}$. Ellenberger, nous transmettant la depêche suivante: «Madame Coillard morte 》. (Elle était morte la veille même de notre mariage). Je ne pouvais en croire mes yeux. J'avais espéré la revoir à Sefula, et avec ma femme lui témoigner ma reconnaissance pour toutes les bontés qu'elle avait eues pour moi, pour ses soins, pour son affection maternelle, comme j'aurais voulu pouvoir dire à son mari toute notre ardente sympathie. Madame Coillard avait prévu sa mort prochaine; pendant le voyage de son mari à Kazungula en 1890, elle m'en avait parlé plus d'une fois, et m'avait dit qu'elle serait heureuse de mourir au Zambèze, au milieu de ceux qu'elle avait évangélisés. A mon départ de Sefula elle m'avait dit: «Au revoir, mais probablement pas ici 》.

Nous parcourûmes tout le Lessouto de Massitissi à Lalo. Nous jouîmes immensément de notre voyage: 'quel bienfait et quel privilège que la communion fraternelle! Et ces églises de noirs; ces centaines, ces milliers d'hommes arrachés au paganisme; ces stations avec leurs vergers propres à faire rêver un 
Zambézien; ces ouvres multiples qui en font comme des centres lumineux dans la nuit païenne; ce beau réseau d'annexes; ces catéchistes qui répandent la semence de l'Evangile jusque lans les coins les plus reculés du pays; ces anciens d'église et ces simples chrétiens qui ont compris leur responsabilité vis-à-vis le leurs frères encore plongés dans les ténèbres; ce commencement de pastorat indigène, les écoles du jour et du soir, l'école de jeunes-filles, l'école normale, l'école industrielle, l'école biblique, tout cela nous intéressa au plus haut degré, et nous démontra bien que cette mission du Lessouto est un corps vivant et vivifiant. La vue d'une mission qui a atteint de pareils résultats n'était pas seulement un encouragement pour nous, c'était une leçon de choses propre à produire des fruits pour notre ministère. Il restait beaucoup à accomplir, car le paganisme est vivace. Il a ses racines dans le cœur même de l'homme.

Sauf à Kana et à Lalo, où je me trouvai pendant la semaine, j'eus partout le privilège et le plaisir d'adresser quelques paroles d'exhortation et de parler de notre Mission du Zam. bèze; partout je trouvai de l'intérêt pour cette oeuvre. Nous gardâmes en particulier le souvenir des enfants de l'Ecole du dimanche de Morija: comme ils chantaient bien et de tout leur coeur! Mais ce qui fut le plus touchant, ce fut de les voir s'approcher de la table, les yeux étincelants de joie, ,pour apporter leurs pièces grandes ou petites, destinées à acheter des livres pour l'école de Yakobo Moshaqesha, un évangéliste marié, de Morija, qui s'était offert pour le Zambèze et devait s'y rendre avec nous. Cette collecte produisit environ 75 francs.

Que de noms se pressent sous ma plume! partout nous laissions une partio de notre coeur et de chers amis. Quel privilège, en nous enfonçant dans le centre de l'Afrique, de sentir qu'au sud battaient des coeurs frères des nôtres. 
XX.

Du Lessouto à Mafeking.

En cart. - A Mafeking dans l'attente.

i Vryburg il fallut, non sans quelque émotion, dire adieu au chemin de fer. Je me sentais un peu effrayée à l'idée d-une aventure dans les parages où les rails sont inconnus. De Vryburg à Mafeking nous fîmes le voyage en cart pour voyageurs, et non en voiture de poste.

Mon mari avait craint pour moi trop de fatigue. Notre attelage se relayait toutes les deux heures et se composait en général de 2 chevaux et de 4 mulets. Les deux chevaux placés en tête trottaient avec des évolutions savantes qui semblaient vouloir défier les mulets; ceux-ci, bien que plus pacifiques, trottaient eux aussi, secouant leurs longues oreilles quand le fouet les touchait.

À diffẻrentes reprises nous avons passé des marais où nos chevaux enfonçaient jusqu'au poitrail. La voiture enfonce! Nous allons rester en panne! Non, un coup de fouet, un coup de collier vigoureux de nos braves bêtes, une secousse à droite, une autre à gauche, quelques mouvements désordonnés, bon, nous voilà dehors! et nous recommençons notre course échevelée, à travers rivières et routes défoncées. Quelquefois après un soubresaut plus violent que les autres, nous nous demandons en riant si nous n'avons rien de brisé!

Nous arrivons enfin à Mafeking vers $1 \mathrm{~h}$. On nous conduit à l'hôtel Dixon. C'était le 26 mars.

On n'a aucune nouvelle du wagon des évangélistes. Le $1^{\mathrm{r}}$ avril nous apprenons qu'à quelques kimomètres de Vryburg un des wagons de leur chef d'expédition s'était brisé. Je demandai à M. Musson de les envoyer chercher dans un autre chariot. Nous quittâmes l'hôtel pour nous établir à notre ménage, dans notre propre wagon.

Vous auriez dû assister à notre installation. Je ne crois pas qu'une reine prenant possession de son palais, soit beaucoup plus contente que moi assumant mon rôle de maîtresse de maison, dans notre 
ètroite demeure. Mes premières expériences de cuisine en plein vent ne furent pas brillantes.

Enfin le 9 avril, Yakobo, Norea et Mobiana nous rejoignent. L'impatience leur a fait prendre les devants à cheval. Notre brave Mobiana s'acquitte de son service très convenablement et de la meilleure grâce du monde.

XXI.

De Mafeking à Kazungula en wagon.

En wagon. - Le talisman de la patience. - A Palapye.

Rencontre de M. Vollet - Soucis et gaite. - Ba-Mangwato et Buslimen.

Notre divin Berger. - In étrange plat. - Heureux dans les solitudes. - Epines.

T 12 au soir, le wagon des évangélistes étant enfin arrivé, $\triangle$ nous pûmes poursuivre notre voyage tous ensemble. Nous étions pour tout de bon en route vers le Zambèze!

Je jouis tellement du wagon! plus que je ne l'aurais cru possible. Les secousses? Oh! nous en avons eu et de bonnes, qui ont jeté sur la planche tout notre bagage et les mille petits objets que renferment nos sacs, suspendus de tous côtés. On rit de bon cœeur, tout en se hâtant de réparer les catastrophes et d'en prẻvenir de nouvelles.

17 AVRIL. Oh! si vous pouviez nous voir maintenant établissant notre bâche entre les deux wagons. Le petit baril à eau nous servira de table, nos chaises pliantes de sièges, nos genoux de table à écrire. Un magnifique ciel bleu sans un nuage, un beau soleil qu'un air frais et un vent assez froid nous font apprécier, des collines boisées, des prẻs, des arbres qui se groupent en jolis massifs, formant des cabinets de verdure naturels, tout cela en ce beau jour de Pâques nous remplit de paix, de joie et de reconnaissance envers ce Dieu si bon qui a répandu ses richesses un peu partout sur la terre.

Quel repos on ẻprouve en admirant la nature et en laissant ses yeux errer autour de soi!

Nous jouissons toujours beaucoup de leétape du soir. La lune brille alors d'un éclat doux et tranquille, qui donne un aspect fẻeri- 



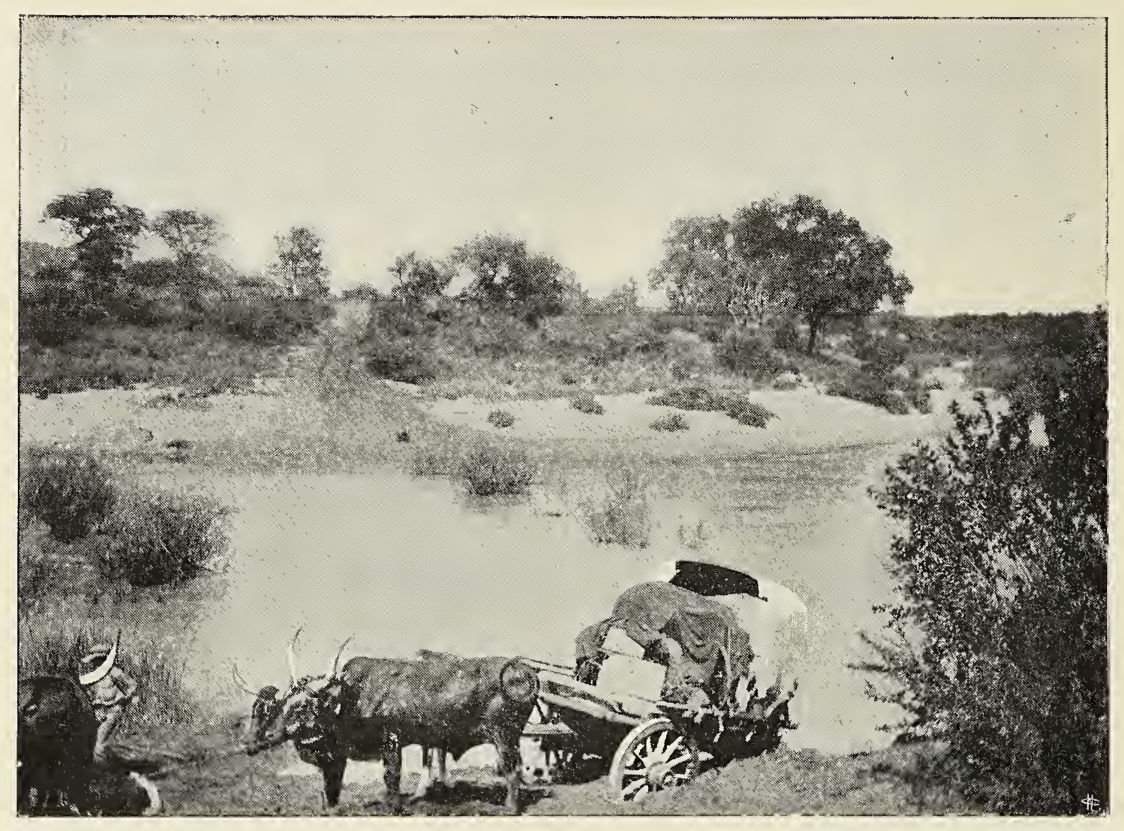

' agon embourbé

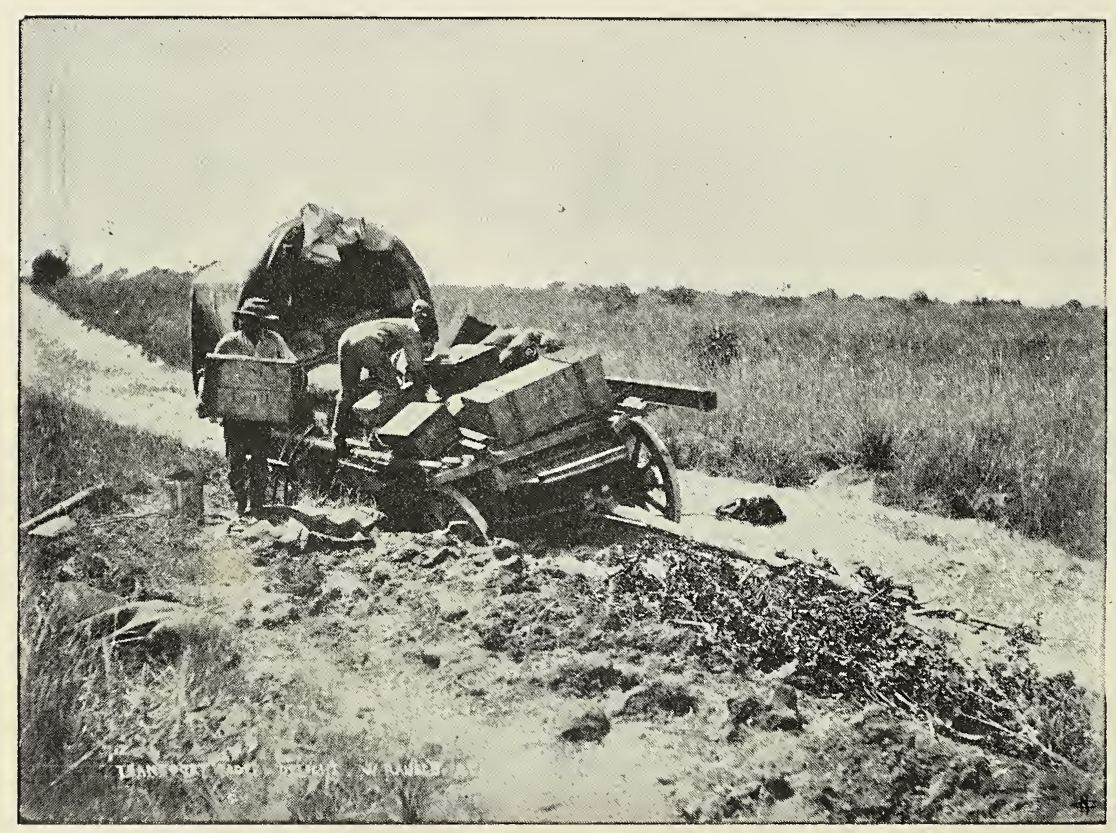

Wagon embourbé. 
que au paysage. Hier les teintes étaient superbes et nous admirions les nuages roses, le ciel bleu, les collines baignées dans ces riches couleurs du soir qu'aucun pinceau ne saurait rendre. Nous causons du passé, de l'avenir....

30 AVRIL. - Ce que j'admire toujours quand des obstacles nous arrêtent, c'est la bonne humeur inaltẻrable des conducteurs et de leurs aides, leurs patients et persévérants efforts pour surmonter la difficultè, les cris de joie sonores quand les roues se remettent enfin à tourner. Ah, vive la patience! c'est le talisman le plus précieux qu'un Africain puisse porter avec lui, à travers ces pays où les heures ne comptent pas. Vous croyez peut-être que je suis déjå une africaine parfaite. Détrompez-vous. Vous devriez voir de quel œil anxieux je suis les lents mouvements de notre boy qui lui, n'est jamais pressé. Quand je hasarde un phakisa! (hâte-toi) ou kapelepele! (vite. vite!), c'est bien en vain. Mieux vaut faire ce que d'autres ont fait avant moi: attendre. Et, bien que lentement, il vient à bout de son travail, sans jamais renverser quoi que ce soit, sans bruit. Si je pouvais imiter sa patience!

$I^{\mathrm{r}}$ MaI. - L'eau qui doit servir à notre ménage m'est comptée, je vous assure; on surveille chaque goutte avec un soin inquiet, quand il nous arrive d'avoir à passer un jour sans rencontrer ce précieux liquide. Je me réjouis d'arriver à Palapye où nous aurons de l'eau courante. Tout ce que l'on touche est si plein de poussière!

À Palapye, où nous arrivons le 3 mai, nous retrouvons Khama aimable et hospitalier. Il vient chaque matin saluer ma femme, bien que notre campement soit assez eloigné de sa résidence.

Le 4 au matin, quel ne fut pas notre étonnement en voyant M. Vollet venir à nous, lui que nous croyons au Zambèze! Hélas! pauvre ami, nous n'eûmes pas besoin de lui demander la raison de son retour: sa démarche incertaine, sa figure allongée et amaigrie, ses yeux presqu'éteints et toutes les autres marques de notre grande ennemie du Zambèze, nous en dirent assez. Nous fûmes heureux de l'avoir à nos repas et de lui témoigner notre sympathie. Il repartit pour le Sud, le 7, tandis que nous poursuivîmes notre marche en avant le 9 .

Depuis Palapye, je fus le directeur responsable de l'expédition. Comme nous voyagions à une bonne saison et que je connaissais parfaitement les distances entre les étangs ou cours d'eau, ce voyage se fit assez rapidement. Nous eûmes en Jacob et Norea sa femme, d'excellents compagnons de route. 
Vous voyez d'ici la scène: halte du soir, bon feu sur lequel sont une marmite et un coquemar. On va partir, il faut se hâter; je surveille ma soupe, je jette des regards pressés sur le coquemar. Enfin Mobiana dit: Il bout! Bonne nouvelle: je me précipite sur le devant du wagon et prends la tasse dans laquelle j'ai préparé le thé, puis, d'un pas délibéré, je cours vers ma marmite et... j'y jette le thé! Horreur! j'en eus le frisson. Madame! crie Mobiana consterné, oh Madame! Adolphe plus calme dit seulement: Qu'est-ce que tu fais, Emma? Ce que je fais? J'aurais voulu pleurer, mais il fallut rire et manger notre soupe au thé, assaisonnẻe de maints éclats de gaîté qui, j'en suis sûre, nous firent plus de bien que s`il en eût été autrement. Et Mobiana qui me dit: Mais, Madame, pourquoi est-ce que tu te hâtes toujours tant? C'était une remarque africaine au possible et bien digne d'un enfant de ce pays. En effet, pourquoi se hâter? Lui, il ne se hâte jamais, mais aussi il ne fait pas de pareilles méprises. Je sais aussi ce que c'est que d'offrir à son mari de la soupe et de ne trouver dans sa marmite que des pommes de terre, plus une goutte de bouillon. On passe ainsi du premier coup au second plat, et on a du légume au lieu de potage. C'est ce qui m'est arrivé jeudi parce que j'avais à côté de ma marmite le «baking pod » où cuisait mon pain, avec braises dessus et dessous. Les pommes de terre, les oignons et les courges, que nous avons achetés à Palapye, nous sont d'un précieux secours, et aident à varier la monotonie des boîtes de conserves; mais nous n'en avons plus pour longtemps. Les jours où nos garçons rapportent des canards, des oies ou des pintades, je suis enchantée, car alors mon dîner est tout trouvé.

A Missé des femmes et des enfants ont envahi notre campement presque tout le jour. Quelques-unes des femmes sont bien gentilles, elles ont un air timide et une voix très douce, avec de jolis sourires. L'une d'elles tenait dans ses bras un délicieux bébẻ de dix $\dot{a}$ onze mois, tout grassouillet, potelé, rondet et à la peau noire luisante que faisait ressortir le bleu des colliers de verroterie qui entouraient ses petits poignets, son cou et ses chevilles. C'était lá tout son habillement.

22 MaI. - J'ai là devant moi pendant que je vous écris, deux Bushmen que j'ose à peine regarder tant ils sont sales et dégoûtants. Leurs corps sont couverts de cicatrices faites par le feu qui leur sert de cuuvertures. Pauvres gens! Comme ceux que nous avons vus les jours passés, ils ont des membres grêles et décharnés et l'air souffreteux et affamé. Rien no los rond heureux comme une poignẻe de feuilles de tabac.

Vous auriez dû voir l'eau avec laquelle nous avons préparé notre 
porridge ce matin. Elle était littéralement noire, et, quand elle bouillait, si épaisse que nous l'avons écumée plusieurs fois et diminuée de la moitié. Ce ne fut pas trop mauvais. Ici même, l'eau était verte. Aussi verte que celle des canaux de Venise! Comme nous sommes contents à la perspective de retrouver de la vraie bonne eau ce soir à Linakaneng!

Jour de l'Ascension. 26 Mar. - «Mon âme, bénis l'Eternel, et n'oublie pas un de ses bienfaits ». C'est le verset que mon père m'a dit en m'embrassant le jour de ma confirmation. J'aime à y repenser souvent. Pas un seul, a-t-il insisté. C'est ce que nous essayons de faire chaque jour.

29 Mar. - À notre culte ce matin mon mari a médité le Psaume xxIII. Depuis que je possède des brebis je comprends mieux combien elles sont précieuses et quelle peine on se donne pour les retrouver quand elles s'égarent. «L'Eternel est mon berger», qu'avons-nous encore $\dot{a}$ redouter? Si seulement je savais mieux le glorifier. Je pensais autrefois que les missionnaires étaient des saints. Hélas! ici comme en Europe il faut lutter contre le péché, lutter et souvent succomber pour recommencer encore. J'aime mieux savoir que mes péchẻs me sont pardonnés à cause de Jẻsus, que de me persuader qu'ils n'existent plus en moi.

À la Nata. Une heure après le coucher du soleil, je vois mon mari revenir, son fusil sur l'ẻpaule, les mains vides. - Je ne reviens pas bredouille, me dit-il. Janavale porte le gibier. Il va arriver. - C'est un animal que nous retrouverons au Zambèze. Nous allons donc avoir un bon souper. Mais, qu'est-ce-donc?... Un énorme lézard d'eau! une hideuse bête à longue queue qui rappelle le serpent, mais un vrai lézard pour la forme, long d'environ un mètre, à peau noire et jaune. Deux Zambèziens se hâtent de le dẻpecer et leur figure s'ẻpanouit à la perspective du rẻgal qui les attend. C'est un gibier dur à cuire: nos hommes le laissent sur le feu toute la nuit et le matin ils l'apportent à leur maître. Cette viande rappelle le poisson... mais je ne puis oublier la forme hideuse de l'animal de la veille.

Ce qui m'a réjouie ici, c'est l'eau, la belle eau limpide et abondante. Quel luxe!

Nous nous sentons bien réellement dans le désert maintenant. Quand on a passé les Macaricari, on sait que l'on est bien loin du monde civilisé; mais ce sentiment n'a rien d'effrayant, je ne me sens pas du tout isolée ou perdue dans ces vastes so:itudes, je n'éprouve pas de sensation attristante comme je croyais que cela devait arriver quand on se voit si petit, si seul dans l'immensité. $\mathrm{Au}$ contraire, il semble qu'on est plus près de Dieu et que Dieu 
lui aussi se rapproche de nous, nous voit et nous suit avec une tendresse spéciale. C'est Lui sans doute qui remplit nos cœurs de cett's sérénite qui nous possédons et qui nous conserve notre entrain, avec l'heureux état de notre santé.

11 Juin. - Le voyage en wagon est charmant, c'est un pique nique dont nous jouissons à nouveau chaque jour. Monotone? mais non, chaque jour on se déplace. Les occupations quotidiennes toujours les mêmes, varient cependant dans les dẻtails; le tout a une poésie, un charme qu'on ne sent nulle part ailleurs, que n'offrent ni le chemin de fer, ni le bâteau, ni la diligence. Les soirées au clair de lune, les aurores aux doigts de rose, la cuisine en plein air, que d'attraits! Si seulement on pouvait bien se représenter notre vie, on ne nous plaindrait jamais. Je croyais que c'était bien plus difficile d'être heureuse en Afrique. Je savais que je le serais, mais je pensais que j'aurais besoin de bonne volonté, de constants efforts: pas du tout. Je suis heureuse tout naturellement et parceque je ne pourrais faire autrement.

16 Juin. J'ai accompagné mon mari à la recherche de l'eau. Nous avons presque tout le temps cheminé dans des prairies à hautes herbes, entre lesquelles nous disparaissions. Cela nous donnait l'illusion de champs de blé; mais point de bleuets, point de coquelicots ici. De temps à autre on voit des fleurettes roses ou rouges; mais ce qui attire l'attention a chaque pas se sont les fines épines qui se logent partout, et vous piquent à qui mieux mieux. C'est là leur mission, s'accrocher à tout et piquer. Triste mission, en vérité! Et les fourrés épineux dans lesquels les wagons pénètrent parfois à grand peine, et les longues branches garnies de pointes acérées qui raclent nos pauvres tentes et semblent vouloir les emporter!

Nous avons si bien entendu le rugissement du lion à Tamasetse le 12 courant, tout près de notre campement. C'étnit grandiose!

\section{XXII.}

A Kazungula.

A sevill ẩ bo-Rorsé.

E 25 juin, vers $11 \frac{1}{2}$ h. du soir, après la forêt de Leshoma

I nous prenons les devants à pied. En approchant du fleuve, nous voyons une tente dressée, mais pas de feux... Ce- 
pendant là-bas sur l'autre rive un feu brille, on entend des voix. L'une d'elles répond à mon coup de fusil.., Bientôt nous distinguons la voix de Louis Jalla (mon frère) qui appelle ses garçons et leur ordonne d'entrer dans le canot. Le calme de la nuit nous permet d'entendre la cadence des rames. Bientôt nous apercevons une longue ombre noire glissant sur la vaste nappe d'eau, et se rapprochant rapidement de nous. Que ce revoir fut beau, et comme nous en rendîmes grâces au Seigneur!

Dimanche 26 Juin. - Nous sommes chez Louis et Mario depuis ce matin. Aprés le déjeuner il y eut le culte sous la verandah. Enfin les causeries, les récits décousus, animés, les demandes et les réponses, les rires et les larmes, tous ces bavardages incohérents dont on jouit si fortement lorsqu'on retrouve des amis, des parents après une absence. Le petit Valdo contribue pour une large part à égayer le foyer missionnaire de Kazungula.

Ce n'est pas sans éprouver des sentiments très mélangès, de bonheur, de sérieuse émotion, de frayeur presque, que j'ai mis le pied sur cette terre païenne. De bonheur parce que c'est le but de longs mois de voyage, parce que j'allais y trouver des cœurs chauds, parce que mon home y sera, parce que j’ai une œuvre à y faire à côté de mon mari. De sérieuse émotion, car c'est une terre où la maladie et la souffrance nous attendent, nous le savons. De crainte, de frayeur, parce que nous avons une grande tâche ’̀ y accomplir, et que je sens toute ma faiblesse. Mais à tout cela j'ai trouvé une réponse: Le Seigneur est là. Il est avec nous, il sera toujours avec nous! L'amour pour les âmes, il l'augmentera dans mon coeur; la patience, le support, il veut me les donner. Dans la maladie, dans les épreuves, toujours sa main nous soutiendra.

Le lundi soir, nos 32 bøufs et les 6 chevaux dormaient sur la rive gauche du fleuve, et le mardi soir tous nos effets y avaient été amenés, et nos deux wagons étaient non seulement traversés, mais remontés.

$\mathrm{l}^{\mathrm{r}}$ JuILLET. - J'aime Marie (M.me Louis Jalla) comme si je l'avais toujours connue. J'admire son entrain, sa gaîté et la façon exemplaire dont elle tient sa maison et son ménage.

Dautre part on reparlait avec terreur d'une invasion probable des ma-Tebele. Une expédition de ma-Rotsé avait été envoyée punir les ma-Tomwe, une branche de la tribu des ma- 
Toka établie sur les rives du Zambèze en aval de l'embouchure du Gwae. Ces malheureux se trouvaient entre le marteau et l'enclume et essayaient de servir deux maîtres à la fois. A l'approche de la bande envoyée par Lewanika, les ma-Tomwe s'étaient réfugiés sur la rive Sud. Les ma-Rotsé les y avaient suivis et $\mathrm{y}$ avaient brisé leurs canots. Ils avaient par conséquent pé nétré sur le territoire des ma-Tebele. Voilà pourquoi ils s'attendaient à des représailles de leurs farouches voisins.

Sur ces entrefaites je reçus une lettre de Litia me confirmant la nouvelle de sa conversion et m' annonçant celle de quelques autres élèves de Sefula.

\section{XXIII.}

\section{De Kazungula à Sefula.}

Première lière et première séparation. - De Kazungula à Sesheke. Lions. Chevaux embourbés. - Bours piqués par la tsetse. Incidents divers. - Traversée lésastrense de la plaine alu Motondo.

A conférence devait avoir lieu à la station de M. Coillard.

$\triangle$ Nous décidâmes de nous y rendre en wagon. Mais la veille du jour fixé pour le départ, ma femme eut sa première attaque de fièvre. Je dus la laisser aux soins de sa belle-sœur et lui dire au revoir à Seheke, où elle serait amenée en canot dès que la fièvre l' aurait quittée. Je partis le 14 juillet, ayant Yakobo Mashabesha comme conducteur. C'était la première fois que je me rendais de Kazungula à Sesheke par cette route. Le voyage se fit assez rondement. Le premier trait nous amène à Mambova, au bout du troisième nous campons de l'autre côté du gué à berges escarpées du Nguezi.

Le 16 nous arrivons à Sesheke où les Goy nous accueillent.

Je retrouve la station agrandie et embellie. Mais la chapelle, bien que bâtie depuis peu, fait triste mine. Par un défaut d'agencement, le toit à pignons s'est affaissé d'avant en arrière. Aux cultes du lendemain faits par Yakobo et moi, nous eûmes 
très peu d'auditeur's, quoique nous fûssions à la porte d'un grand village.

Ma femme et mon frère arrivèrent enfin le 21 . Nous jouîmes de l'hospitalité des Goy jusqu'au 24, et le 25 à l'aube nous les quittâmes. Ce voyage ne manqua pas d'incidents intéressants. Nous eûmes plusieurs visites de lions: dès le premier jour une superbe lionne se leva à moins de 50 mètres du wagon. Une autre fois, par une sombre nuit, nous longions les marais du Loandja, quand tout à coup nos bœufs donnent des signes de frayeur, nos chevaux effarés se cabrent tellement que nous avons beaucoup de peine à les tenir. En même temps nous entendons un frôlement dans l'herbe. Nous tirons dans la direction d'où est venu le bruit. Il cesse un moment pour recommencer. Nous tirons encore et n'entendons plus rien. Un peu plus loin, ce même soir, le gardien des chevaux, auquel je venais de recommander expressément de ne pas s'écarter des wagons, s'imagine de couper court à travers une prairie détrempée. Après s'être longuement fatigués pour passer d'un bourbier à l'autre, harassés, nos chevaux enfoncent dans la vase jusqu'au poitrail. Alors leur gardien crie: Ne phaletsoè. (Je suis vaincu!). Nous faisons arrêter les chariots et accourons en apportant une lanterne. Il fallut les dégager les trois, tour à tour enfonçant nous mêmes parfois jusqu'aux hanches, et craignant de finir par disparaître dans la boue. Quel soupir quand au bout d'une heure nous pûmes en amener un aux wagons! Quant aux deux autres, après avoir essayé de tous les moyens, nous dûmes nous résoudre à leur lier les quatre jambes et à les tirer l'un après l'autre à force de bras. Je soulevais leur tête tandis que Louis nous précédait avec la lanterne. On comprend notre satisfaction quand le second, puis le troisième, arrivèrent eux aussi au campement. Mais les heures avaient passé, il y avait la tsétsé devaut nous comme derrière nous, la nuit était trop avancée pour espérer de pouvoir sortir de la région qui en est infestée, nous décidons de rester dans la clairière où nous sommes. Hélas! bien que nous n'ayons vu que très peu de ces mouches meurtrières, les faits prouvèrent par la suite que plusieurs boeufs en avaient été piqués.

Un jour une superbe lionne se leva à 50 mètres de notre wagon. Un autre jour un berger halluciné par la fumée du chanvre, nous fit escalader des termitières. Je ne parle ni des 
trous où il nous jette, ni des nombreux arbres contre lesquels nos wagons allèrent se heurter. Nous avions comme conducteurs deux Zambéziens nonchalants et peu expérimentés; aussi mon frère et moi devions nous payer de nos personnes pour exciter les boeufs et leur faire éviter les obstacles. Les gués n'offrirent pas de grandes difficultés. Si nous doublâmes les attelages à celui du Njoko, ce fut à cause de la berge assez rude de la rive droite.

La traversée de la plaine du Motondo, avec ses bourbiers et ses mares, fut plus compliquée. Nous pavâmes le premier bourbier de troncs de jeunes arbres; malgré cela la fatigue des boeufs fut si grande que deux de ceux que les piqûres de tsétsé avaient le plus affectés, succombèrent. Quand les deux chariots eurent franchi ce premier mauvais pas, nous en allégeâmes un. Je le dirigeai jusqu'à l'autre côté de la plaine, j'y fis déposer la charge; puis nous revînmes prendre le reste de la charge et une partie de celle du second. Ce même chariot repartit à $5 \mathrm{~h}$. avec ma femme et mon frère. Je restai avec le second wagon. J'attendis longtemps... j'entendis des cris, mais trop confusément pour que je pt̂sse comprendre; la nuit tomba.... Environ deux heures après je vis Mobiana venir vers moi avec un cheval. Il me raconta comment les conducteurs avait dévié, le wagon avait failli tomber dạs une mare, un des boeufs du timon s'y était noyé... mon frère et ma femme avaient été portés de là jusqu'à la lisière de la forêt.... Ce soir-là nous n'eûmes pas de souper et nous dormîmes à la belle étoile. Le lendemain il nous fallut passer des heures dans l'eau jusqu'à la ceinture, et luttant contre les sangsues qui s'acharnaient à nous piquer, pour décharger le wagon, le dégager et le recharger ensuite.

Déjà auparavant nous avions enlevé des chariots plusieurs caisses que nous avions confiées à des porteurs. Mais après les fatigues de la plaine du Motondo, l'épuisement de nos pauvres bêtes fut tel qu'il ne nous resta qu'à envoyer demander du secours à M. Coillard, à Sefula.

Au Luyi, le 26 août, nous trouvâmes la petite vérole; beaucoup de gens en étaient atteints. Sachant qu'elle sévissait au bo-Rotse où elle avait été importée par l'expédition du boLubale, la panique s'empara de nos gens, les deux conducteurs nous abandonnèrent et faillirent entrainer tous les autres. Le 


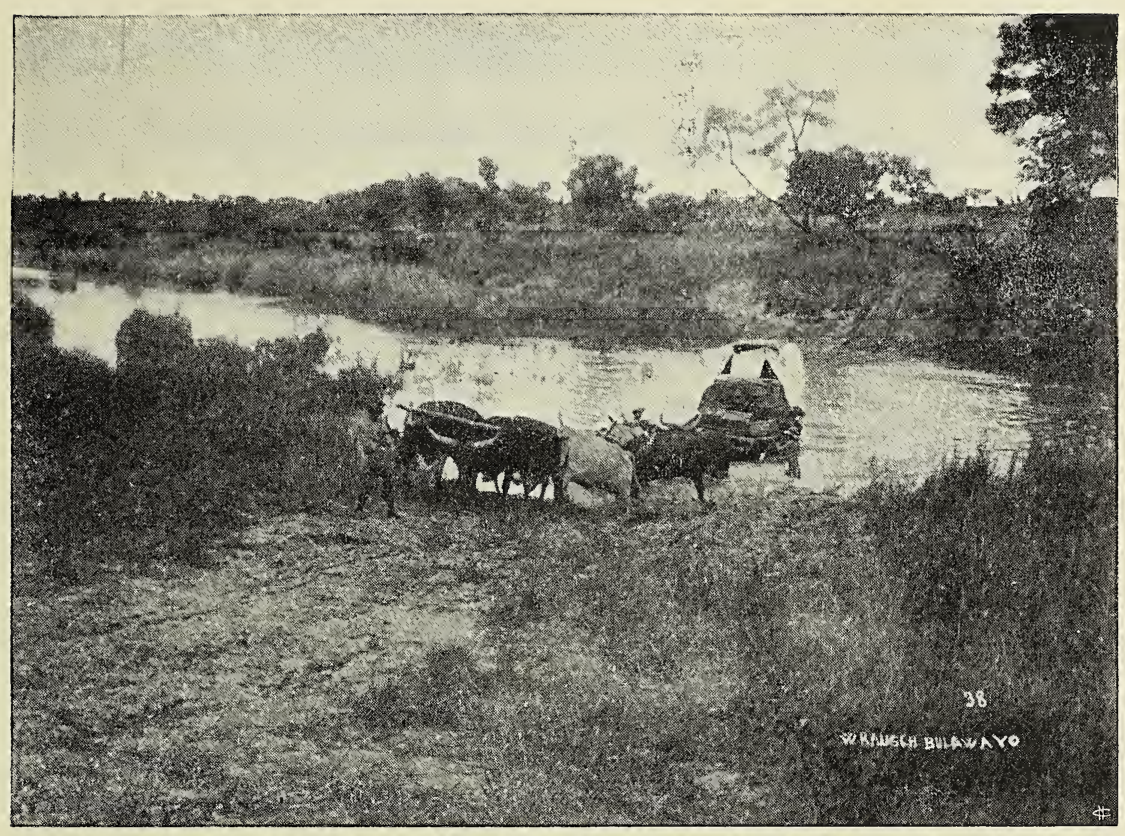

Boeufs en désordre. 

jeune homme qui nous amena les bœufs de secours, nous apporta du vaccin, et nous annonça la mort de Frantz.

Seonyi prit un fouet, Mobiana l'autre, et, non sans peine nous arrivâmes à Sefula le 5 septembre au soir.

\title{
XXIV.
}

Reprise du travail dans de tristes circonstances.

\author{
Arrivée à sefula. - denvie en soufrance. - La poste: \\ Lewanika mal disposé. - Séparations. - Tounnées dans les villages. \\ Notre home.
}

Nous sommes enfin dans ce Sefula, but de nos désirs et terme de notre long voyage. Dieu nous a conduits jusqu'ici sains et sauf's et nous y a fait trouver des cœurs pleins d'affection et un accueil chaleureux! Après le dîner, en terminant le culte, M. Coillard dit quelques paroles de bienvenue, pleines d'onction, et appelle les bénédictions de Dieu sur nous et sur notre ministère. * Que Dieu vous fasse comme à Joseph, me dit-il ensuite. Vous êtes venus dans un pays malsain, au milieu de gens corrompus et mauvais, loin de tous vos bien aimés; vous serez dans la solitude et privés des douceurs de la civilisation... mais Dieu est là!»

Voir M. Coillard c'est l'aimer, et je l'aime dejjà d'un amour respectueux et profond. Il est admirable dans son épreuve. Il ne s'efforce pas d'oublier; non, son deuil est toujours présent $\dot{a}$ son esprit, et sa souffrance est de tous les instants, mais il a accepté le coup qui l'a frappé comme une dispensation de son Père, toute mystérieuse et difficile à supporter qu'elle soit.

Un voile de tristesse couvrait la station. Tout nous parlait encore de Madame Coillard, mais elle n'y était plus. La petite vérole sévissait, on n'entendait parler que de malades et de morts; sur. la station même plusieurs étaient atteints.

La chapelle que javais vue se remplir presque chaque dimanche en 1890, semblait beaucoup trop grande pour la trentaine d'auditeurs qui s'y réunissait. La guerre et la variole avaient dispersé les gens, moissonné bien des vies et éloigné les gens de 
Dieu. L'école, jadis florissante, n'était plus qu'un beau souvenir: Andrease, qui avait été le sujet de tant de joie et de reconnaissance d'abord, avait quitté M. Coillard et était devenu le favori du roi. Il paraissait avoir complètement oublié Celui qu'il avait confessé comme son Sauveur, et semblait exercer une mauvaise influence sur Litia et Mokamba, ainsi que sur Lewanika lui-même.

9 Septembre. - C'est le cœur débordant de reconnaissance que je commence ma lettre, car hier nous sont arrivées vos chères, vos précieuses lettres d'avril et mai. Je cousais dans la salle à manger avec M.lle Kiener, quand nous entendons mon mari nous crier: Des lettres! Vous me voyez jeter mon ouvrage et courir à lui. Dès que le triage est fait, nous nous enfermons chez nous, pleins d'émotion. Nous voudrions tout lire à la fois. Qu'il fait bon recevoir des nouvelies de ses bien-aimés, et qu'un premier courrier au Zambèze est émouvant! si émouvant que j'en ai eu la fièvre!

11 Septembre. - Ces Messieurs sont partis hier à 3 heures pour Léaluï.... C'est M. Waddell qui nous fait le culte de famille pendant que nous sommes seules. Ses prières simples et ferventes partent du cœur et me font toujuurs du bien. Ce modeste ouvrier est un excellent homme, tout à son travail et fort attaché à M. Coillard.

Lewanika fut accueillant et aimable, mais beaucoup moins confiant et ouvert que je ne l'avais laissé. Tous, à Léalui comme ailleurs, réflétaient les mauvaises dispositions de Lewanika.

24 SePtEMBRe. - Adolphe est parti ce matin a 6 heures avec Louis (Jalla) pour la Capitale. M. Coillard est fatigué. Pauvre M. Coillard! que c'est triste d'achever ainsi seul une vie que l'on a partagée pen. dant de si longues années a vec un être aimé, et qui vous a devancé dans le ciel. Ne serait-ce pas beau si l'on pouvait partir ensemble?

28 SEPTEMBRE. - Louis est parti ce matin. Adolphe et moi avons ètẻ l'accompagner à cheval, à ses canots. Cette course m'a fait beaucoup de bien, cela m'a donné un entrain que je n'avais pas eu ces derniers jours, où j'avais eu une légère atteinte de fièvre. C'était délicieux de me sentir emportée par mon cheval.

Au commencement d'octobre j'eus une forte attaque de fièvre qui dura une semaine. - C'était la première depuis que j'étais sorti de l'hôpital de Kimberley.

Dimanche, 16 OCtobre. - Hier matin nous avons été, mon mari et moi, faire une tournée dans les villages pour inviter les gens à venir au culte aujourd'hui. A cheval, bien entendu, je ne pourrais pas 
marcher longtemps dans le sable et sous ce soleil ardent. Nos montures ne pouvaient pas aller jusque dans les villages. Nous les laissions à l'entrée de la rue principale et franchissions à pied les petits canaux d'eau noire et bourbeuse qui entourent les maisons, tantôt d'un bond, tantôt sur un tronc d'arbre. Quelquefois le sol est tellement humide qu'il est ẻlastique. On le voit céder sous les pas. Quels amphibies que ces Zambéziens! Ils aiment cela, eux, et dédaignent la colline qui n'est qu'à quelques minutes. « Demain c'est le jour de la cloche, leur disions-nous, venez au culte, tous $»_{0}$ - Ils acceptent notre invitation. Dans un village les hommes nous ont dit: * Ah nous, nous aimons qu'on nous invite ainsi chaque samedi, sinon nous n'allons pas». - «Mais ne savez-vous pas compter les jours?»-«Oui, il y en a sept, mais nous voulons être invitẻs». Terribles gens!.... Et que d'enfants! Ce petit peuple grouille partout. Nous leur avons dit de venir à l'école le mois prochain. Ils promettent tout ce que l'on veut, mais qui vivra verra. «Nous serons tes enfants quand M. Coillard sera à la Capitale », disaient les hommes à mon mari. Nous étions de retour ici à dix heures, satisfaits de cette première visite dans un quartier de notre paroisse.

19 OctoвRE. - Vers $21_{[} 2$ le petit gardien des chevaux est venu dire que notre cheval noir était couché et ne pouvait plus se relever. M. Coillard et Adolphe allèrent voir le pauvre animal et le trouvèrent mort! Avoir eu la peine d'amener cette précieuse et excellente bête jusqu'ici pour la perdre si tôt! Quel crève-cœur! Tout le monde a sympathisé avec nous. M. Coillard m'a dit: «Vous monterez encore. Votre mari prendra le cheval que vous m'avez amené. Il est à sa disposition ».

Nous avons eu notre réunion de prière habituelle. À propos de 2 Samuel XIV, et du désir ardent qui dévorait Absalom de revoir son père, M. Coillard nous parla du désir analogue que nous devons avoir de voir Dieu. C'est toujours une grande jouissance que d'entendre M. Coillard méditer la Parole de Dieu et prier.

24 OctoвRE. - Pauluse est parti avec deux wagons chargés pour Léaluï. Il était un peu inquiet à la pensée de devoir faire son ménage. M. Coillard l'a nourri toute l'année. C'est un brave homme qui gagne à être connu, il a une vie spirituelle développée, mais il n'a aucun goût pour les travaux manuels.

26 OctoвRE. - Que j'ètais heureuse hier en m'installant dans notre home bien modeste, bien simple, mais si coquet et confortable avec les rideaux à grands ramages, les portières en drap grenat, la caisse-armoire converte de cretonne assortie aux rideaux, la table que mon mari a montẻe hier. Elle est assez grande pour six personnes. Dans un coin une table à thẻ de la Zambézia de Vevey.... 
et puis tous ces bibelots que j'aime tant: des livres, des gravures, des photographies.... M. Coillard m'a dit: «Oh oui, rendez-la aussi confortable, aussi gaie que possible, votre maison. Il y a tant de choses tristes dans ce pays!».

27 OCTOBRE. - Le pauvre Sachono est encore fort malade, nous l'avons cru aveuglé par la variole. Hier soir il a aperçu la lanterne lorsque M. Coillard est allé le voir. Il a même pu discerner confusément ses traits. Les compagnons de Sachono n'ont pas partagé notre inquiétude. Que leur camarade perde la vue ou la recouvre, cela leur est fort égal. Pas un mot, pas un mouvement qui indique un sentiment quelconque de joie ou de regret. Ils sont impassibles. Oh! quand sentirons-nous battre le coeur des gens qui nous entourent!

XXV.

Chez nous et aux Capitales.

Fondation de la station de Lwatile. - Anniversaires.

Mort de Mobiana. - Nos "6 enfants". - Bonnes pages. - Un serpent.

A Lwatile. - Une perte. - Chez Mokwae. - Parmi les princesses.

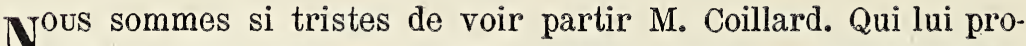
diguera désormais les mille petits soins que semblent ré. clamer son âge et l'état précaire de sa santé? Nous nous efforcerons d'adoucir sa solitude en lui procurant tout ce que notre attachement pour lui et nos moyens nous permettront. - L'oeuvre à été compromise par l'épidémie qui à sévi avec violence. Rendre à l'oeuvre sa première vigueur, sera faire un bien immense à notre doyen.

Plus tard: M. Coillard est parti à $4 \mathrm{~h}$. après avoir encore pris le thé chez nous et prié avec nous. Nous l'avons accompagné un petit bout de chemin, puis il est monté dans la wagonnette et nous sommes rentrés sur la station, qui nous semble déserte.

Nous avions proposé avec insistance, ma femme et moi, d'aller nous établir à Lwatile sur l'emplacement de la nouvelle station, d'y procéder au déblayage des broussailles et des fourrés épineux, et d'y bâtir quelques huttes, afin d'éviter ainsi à no- 
tre vénéré M. Coillard les premières fatigues de la fondation de la station de la Capitale; mais il n'en voulut pas entendre parler, il ne consentit pas même à ce que nous aillons l'aider. Le matin du 28 octobre il dressa ses tentes sur la termitière désolée, la termitière maudite de Loatile. C'était le premier jour anniversaire de la mort de Madame Coillard!

29 OctoвRE. -- Un an que nous sommes mariés!... Notre coeur est dẻbordant de reconnaissance envers notre bon Père céleste qui nous a abondamment bénis. Ces jours qui sont pleins pour nous de souvenirs doux, sont pour M. Coillard remplis de souvenirs déchirants: la plaie se rouvre et saigne.

Ce même jour mourait notre brave Mobiana. La nouvelle nous en fut communiquée le 31 par $\mathrm{M}$. Coillard. Il était revenu nous voir et avait été si gentil et si doux; il nous avait bien dit qu'il n'avait pas oublié ce qu'il avait appris et que chaque jour il faisait sa prière. Le 27 , en nous quittant tout triste, il nous avait demandé de pouvoir venir chez nous plus tard, «comme notre enfant»; à peine de retour à Lealui la petite vérole s'était déclarée. Selon la façon zambézienne, on l'avait porté dans l'eau froide du canal, et il avait succombé peu d'heures après. Le Seigneur voulut-il comme pour le fils de Jéroboan (1 Roi xIv), l'enlever à l'entourage corrompu des siens parce qu'il avait trouvé quelque chose de bon en lui ?

$1^{r}$ Novembre. - J'ai héritẻ de plusieurs petites filles de M. Coillard. Mes deux favorites sont Nosiku et Mathé. La première est une enfant gracieuse et prompte dans tous ses mouvements, intelligente et méthodique dans ses occupations. Quant à ma petite Mathé, c'est une tête de linotte pour laquelle je me sens une grande sy'mpathie. Je lui apprends à courir (les Zambéziens détestent cet exercice) et je ne réussis pas trop mal. Namokoro est notre marmiton, et vous la verriez tout le jour faire briller des bougeoirs ou des casseroles, frotter des pots et des marmites. La pauvre enfant est disgracieuse, lente et gauche dans ses mouvements, peu douée et a la mine ordinairement renfrognée. Elle m'a touchée l'autre jour en me donnant quelques fleurs blanches qu'elle avait cueillies. Nambula est une grosse fille, grondeuse mais pas méchante au fond, quoique boudeuse et colère. Que Dieu nous donne de les voir devenir ses enfants! 
Le soir du 2 novembre nous entendîmes nos enfants crier: Un serpent! J'accours avec Waddell. La trace conduit droit à notre maison. Nous pénétrons et entendons un souffle puissant derrière l'armoire. Nous blessons l'énorme reptile d'un coup de fusil; il essaie de sortir de sa niche, mais d'un coup de lance Mompisho le retient par le cou, avec une seconde lance je le transperce. Il dégage encore sa tête et se relève comme pour se jeter sur nous: cependant nous réussissons à le traîner dans la cour où on l'achève à coups de bâtons. Quelle délivrance! que serait-il arrivé si personne ne l'avait entendu glisser sur le sable?

Le 10 je retournai à Lwatile avec ma femme. Nous partageâmes la vie de M. Coillard pendant quelques jours, dormant sous la tente, envahis par toutes sortes d'insectes, chassés de nos lits par les fourmis guerrières, presque toutes les nuits; mais travaillant de toutes nos forces pour faire avancer les travaux et heureux d'apporter un peu de société à notre cher solitaire.

C'était la première visite de ma femme à la Capitale. Lewanika, ses femmes, ses chefs et ses officiers semblèrent heureux de lui souhaiter la bienvenue.

Hélas! le 17 nous dûmes rentrer à Sefula en wagon, nous aussi. Mon dernier cheval avait péri de cette maladie des poumons qui en emporte tant dans l'Afrique tropicale. Des six chevaux que j'avais amenés, il ne restait plus que celui de M. Coillard.

Le 26 novembre j'amenai ma femme à Nalolo, faire sa première visite à Mokwae. Elle nous y avait préparé une grande hutte dans l'enceinte royale. Elle fut très hospitalière et pourvut très abondamment à nos besoins. En revanche, fidèle à son habitude, elle mendia beaucoup, soit ouvertement, soit par insinuations. Le dimanche, les gens accoururent aux cultes en grand nombre, appelés par les tambours et les li-rimba de la reine.

Entre les deux services, je fis appeler les petites princesses dont l'éducation est confiẻe à Mokwae, et leur enseignai un cantique. Ce sont de gentilles enfants, mignonnes et intelligentes. Quand nous eûmes fini de chanter, une d'entr'elles me dit: «Donne-nous quelque chose de bon! $\gg$ Je leur fis une tartine de confiture, qu'elles mordaient chacune à tour de rôle. Vous auriez dû voir leurs yeux briller de plaisir et l'anxiẻtẻ avec laquelle les 
dernières surveillaient les autres. Quand le régal fut fini, elles dirent toutes en choeur: "Je te remercie, ma mère, c'est bon, c'est bon!»

Nous rencontrâmes Ma-Khosé chez Mokwae, une pauvre vieille femme qui doit rendre tous les hommages à la reine sa fille, Kandelela chaque fois que celle-ci parle, ne passer devant elle qu'en se pliant en deux. N'est-ce pas étrange et contre nature qu'une femme doive ainsi s'avilir devant son enfant?

Je retrouvai là plusieurs de mes anciens élèves, outre le prince Kaïba. Je fus particulièrement content de revoir Mpututu, son esclave de confiance, qui depuis quelques mois avait fait profession de servir le Seigneur. Il réunissait chaque dimanche les anciens écoliers et ensemble ils chantaient et priaient. Je lui permis de dire quelques mots l'après-midi, il le fit simplement, mais fidèlement, tout en tremblant un peu. C'était la première fois qu'il se tenait debout devant la reine.

\section{XXVI.}

Nos moyens d'action.

Nos dimanches, - Calomnies. - Programme de la semaine.

Travaux manuels. - $\mathbf{A}$ la table de Lewanika. - Kaieka leselave mo-Lubale. Encore une chevauchée.

Sefula nos dimanches étaient remplis, il y avait du A travail pour chacun. La journée commençait par l'école du dimanche pour les enfants de la maison, faite d'abord par M.lle Kiener. Ma femme s'en chargea dès le 10 septembre. Pendant ce temps M.lle Kiener essayait de réunir les femmes pour leur enseigner des cantiques. Les deux cultes principaux avaient lieu dans la matinée, à une demi-heure ou trois quarts d'heure d'intervalle l'un de l'autre. La plupart de nos auditeurs n'aurait pu revenir l'après-midi. Le village le plus rapproché de la station n'était qu'à environ deux kilomètres, mais il nous venait des gens de hameaux très éloignés. Le second culte était ordinairement une répétition du pre- 
mier, par demandes et réponses: une espèce d'école du dimanche pour adultes et enfants; souvent l'auditoire apprenait le texte par cœur. Entre les cultes, M.lle Kiener s'occupait des femmes et des jeunes filles, tandis que ma femme réunissait les enfants. L'après midi, outre le culte de famille, souvent célébré en anglais à cause de $M$. Waddell et de nos voisins les Méthodistes Primitifs, nous rassemblions encore les enfants de la maison pour chanter avec eux et leur montrer des images.

La fréquentation du culte ne tarda pas à être plus satisfaisante, cependant elle resta toujours sujette à de grandes variations d'un mois à l'autre et d'une semaine à la suivante, avec un minimum de 40 et un maximum de 150. La cause principale de cette irrégularité, ce n'était pas le beau ou le mauvais temps, mais la vie nomade que mènent nos Zambéziens: en effet, la culture des champs éloignés, les invasions de sauterelles, la pêche, des corvées sans fin, les éloignent sans cesse de leurs foyers. L'attention était généralement bonne, surtout au second service, mais les dimanches succédaient aux dimanches sans que nous voyons aucun signe de l'action du St. Esprit. Les calomnies dont nous avions été les objets de la part d'un ancien artisan missionnaire, qui après nous avoir quittés, s'était établi au Borotsé, s'étaient répandues dans le pays et avaient été bien accueillies par ces êtres foncièrement faux et incapables de concevoir le désintéressement. De toutes ces calomnies, voici celle qui nous a peut-être nui davantage: Nous serions venus nous enrichir aux dépenses des ma-Rotsé. Chaque auditeur, disait-on, chaque élève nous rapporte une somme, et cet argent que nos amis envoient en partie pour nos ouailles, nous l'amassons tout pour nous-mêmes. C'était surtout dans mes tournées que je pouvais toucher du doigt le mal que nous avait fait cet ancien missionnaire. A nous de montrer notre désintéressement. Mais il n'est pas facile de gagner des gens prévenus. Ces pénibles expériences, en nous convainquant toujours mieux de notre incapacité, nous faisaient élever nos yeux vers Celui qui seul peut convertir les pécheurs.

Durant la semaine, nous avions chaque jour, matin et soir, des cultes pour nos enfants et nos ouvriers. Le mercredi avant déjeuner j'avais une réunion à laquelle assistaient deux femmes et quelques élèves, outre les gens de la station. J'avais en 
plus une fois par semaine une classe pour quatre à six personnes chez lesquelles je pouvais constater de réels progrès dans la connaissance des vérités de l'Evangile, mais les progrès de la piété n'étaient pas aussi évidents. Nous avons toujours été étonnés de voir que le sentiment de la propre justice et l'orgueil spirituel se développe aussi aisément chez les pauvres païens qui font profession de christianisme que chez les chrétiens de partout, jeunes et vieux.

Les travaux manuels ne manquent jamais sur une station du Zambèze. Nous profitâmes de ce que l'inondation tardait à venir, pour activer le transport des matériaux de construction pour la station de Loatile, et des meubles et provisions indispensables pour Mr. Coillard et ses aides. Les premiers mois, je ne construisis qu'une hutte pour les ouvriers et une remise pour le wagon, mais nous fûmes sans cesse occupés à entretenir le canal, les toits des huttes, à 《smearer 》, les maisons et à renouveler les palissades. Il faut aussi mentionner les travaux d'irrigation et de jardinage, la culture du blé, les achats de nourriture et de matériaux pour Sefula et pour Loatile.

La fièvre compliquait aussi souvent notre tâche; ma femme en fut très affaiblie pendant de longs mois. Mais nous pûmes faire l'expérience que cette puissance aveugle est soumise elle aussi à celui sous l'abri duquel nous avons planté notre tente. Il mesure l'épreuve et accorde les délivrances.

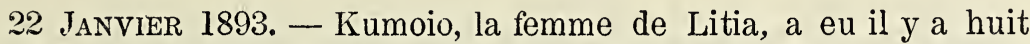
jours une petite fille. Hẻlas, son mari à dejjả pris une autre épouse, lui qui il y a un an avait promis solennellement de ne jamais le faire!

Chez Longa nous trouvâmes le roi. Il nous quitta après avoir causé un moment avec nous, disant qu'il n'avait pas encore dîné, mais qu'il nous ferait appeler quand il pourrait nous recevoir.... Quand nous allâmes chez lui nous trouvâmes le couvert mis pour nous aussi; du cafẻ, des oiseaux et du bœuf. Il n'est que 3 heures, mais comment refuser? et nous voilà à table, à table avec le roi ! Non mari à sa gauche, moi à sa droite, et M.lle Kiener vis-à-vis. C'est la première fois qu'il admet des dames à sa table! Il est aimable, poli, et manie avec aisance fourchette et couteau. Il me sert toujours la première et nous causons familièrement. Trois garçons servent le roi, à genoux toujours. Un tout près de la table, sert et dessert; les deux autres reçoivent les plats que l'on enlève 
un à un. Le roi nous dit, en nous passant nos tasses: «Je n'ai pas de sucre ». Etait-ce une insinuation, une suggestion? Nous répondìmes poliment que nous n'en prenons jamais, et il eut l'air de dire: « J'ai manqué mon but. Ces gens sont d'une simplicité exagérée ». Nous le quittons une heure plus tard en nous disant: Quel dommage qu'il soit si changeant. Il peut être si bon, si affable, et à l'air si bẻnin, lui qui peut être si cruel.

Nous avons beaucoup joui de notre séjour à Léalui, la fièvre nous a laissés parfaitement en repos cette fois, et nous croyons avoir fait du bien au cher Mr. Coillard. Il nous disait: « Pourquoi partez-vous! après le soleil viendront les jours sombres. Il n'y a plus d'épines quand vous êtes lả ».

Voilà deux matins que je prends Kaieka dans notre salon, pendant une heure environ. Je le fais lire et écrire et je lui raconte un peu d'histoire biblique. Nous en sommes naturellement au commencement. Le matin il sut très bien me répéter comment Dieu a fait l'homme. Kaieka est un pauvre petit mo-Lubale, ravi à sa mère il $\mathrm{y}$ a quelques mois et amené chez nous afin d'y gagner quelque chose pour son maître. Il boîte et il louche. Il a un petit air misérable; mais mon mari a découvert que sous cette pauvre enveloppe se cache une intelligence remarquable.

Du 9 au 17 février Mr. Coillard fut de nouveau sous notre toit. Ces rapports fréquents étaient pour nous une source de bénédictions et de force. Quel reconfort de pouvoir prier ensemble et de s'entretenir des difficultés de l'œurre!

25 FÉvrier. - Ce matin nous avons dẻjeuné à $6 \mathrm{l} / 2 \mathrm{~h}$. et tout de suite après je partis sur la fringante Grisette. Mon pauvre mari me suivait à pied. Il y avait longtemps que je désirais aller chez les deux femmes de la classe, mais mon courage faiblissait quand jo songeais à la distance et au sable du sentier. Un jour, mon mari me dit: 'Tu iras à cheval - A cheval ? sur cette Grisette toujours impatiente de partir? A cheval de nouveau? La brave bête, bien que vive, est douce comme un agneau. Les deux femmes furent si heureuses de nous voir! Manwendarubi nous fit voir sa hutte plutôt grande, mais très humide. Elle nous accompagna chez Mamwendabai qui nous reçut avec une figure rayonnante de joie, et nous fit asseoir sur une natte toute neuve. Puis elle courut chercher son livre et je les fis lire un moment. Elles nous firent donner du maïs frais en épis. L'heure de l'école approchant, nous dûmes bientôt nous lever et repartir pour la maison. Comme j'aimerais accompagner régulièrement mon mari chez nos paroissiens. Si seulement la fièrre ne m'avait pas tant affaiblie! 


\section{XXVII.}

Temps de crise.

Lorage gronde. - Il éclate. - Prières exancées. - Le ciel reste sombre.

C'animation revient. - Enconragements. - vn mois d'anxiété.

Deuil des ma-Rotsé. - Le calme après la tempête.

Tivrale semée prospérait: nos meilleures intentions, tous

1 nos mouvements ne rencontraient que défiance chez le roi et son entourage. Lewanika s'obstinait à nous considérer comme des marchands et aurait voulu nous mener selon son bon plaisir. La crise s'accentua. Nous sentions qu'on avait monté nos propres ouvriers contre nous; nous savions qu'à la Capitale l'excitation allait croissant et qu'il ent suffi d'un mot pour que la bande des vils flatteurs qui rampent devant le monarque se lançât sur nous comme une meute de chiens. Ce mot, Lewanika le dira-t-il ?

Dans la seconde moitié de février 1893, Mr. Buckenham ayant refusé à plusieurs reprises d'acheter à des prix exorbitants des bœufs de Lewanika, le roi s'irrita contre nous tous et décida de se venger ou de nous forcer la main, en nous affamant. Il envoya des ordres péremptoires dans les environs, interdisant à ses sujets tout rapport avec les missionnaires. Le marché, qui était très animé, cessa tout à coup le 27 février. Les gens qui venaient nous voir restèrent chez eux; l'école elle-même ne fut plus aussi fréquentée. Tout était calme sur la station, les seuls sons qui parvînssent à nos oreilles c'étaient le chant des coqs et le bruit des feuilles agitées par la brise. Etait-ce le calme qui suit la tempête ou celui qui la précède? Nous ne le savions pas. Ce qui était certain c'est que le vide s'était fait autour de nous. Nous fûmes obligés de renvoyer toutes les bou-. ches inutiles et de ne garder que les bergers, un ou deux élèves et nos fillettes. Mais le roi s'en tiendrait-il là ? Ne nous ferait-il pas piller, ou encore expulser?

Vers le soir du 5 mars, le roi nous fit chercher MM. Buckenham, Baldwin et moi. Nous nous rendîmes à Lwatile, en canot, 
le lendemain. Ce que Mr. Coillard nous apprit nous fit encore mieux comprendre que l'orage grondait autour de nous.

Le jeudi 9 , ce fut par la prière que nous nous préparâmes à comparaître devant Lewanika, accompagnés des évangélistes Pauluse et Yakobo.

Il vint à notre rencontre nous tendant la main. Il nous demanda avec un sourire des nouvelles de Sefula et de nos femmes. Mr. Coillard lui rappela que nous avions répondu à son appel. Dès lors ce ne fut plus de la part de notre hôte qu'injures et vilenies. Il nous traita de trompeurs, de menteurs, de voleurs, de vauriens dont on ne savait que faire en Europe, d'espions du gouvernement, de gens sans feu ni lieu comme sans foi ni loi. L'ancien ouvrier missionnaire aurait joui de constater combien ses leçons avaent été bien apprises. Le roi avait été excessivement blessé de ce que Mr. Buckenham avait déclaré qu'il achèterait des bœufs, mais non plus au roi. "Acheter à mes gens? Mais les bœufs de mes sujets ne sont-ils pas tous à moi ? Vous ne voulez pas acheter mes bœufs? Eh bien! vous n'achèterez plus rien! Tout le pays n'est-il pas à moi ? Tous ses produits ne m'appartiennent-ils pas? 》 Je lui rappelai que nous servons Dieu, que notre but n'est pas de nous enrichir: en faisant $d u$ commerce, mais d'appeler les gens à la repentance... 《Repentance de quoi ?》- «De vos péchés! Diras-tu qu'il n'y a pas de mal au bo-Rotsé, et qu'il n'y en a pas dans ton cœur? - $\&$ Mais pourquoi ne vous repentez-vous pas vous tous les premiers? 》 - Si vous servez Dieu, pourquoi ne vous contentezvous pas de prêcher? Ce Dieu, en qui vous dîtes avoir confiance, vous fera vivre. N'achetez plus ni farine, ni autre chose, il vous nourrira! Ne buvez plus de mon eau! ne brûlez plus de mon bois!» Je lui demandai alors quels étaient ses griefs contre moi personnellement. Rien de particulier, mais il recommença à déverser un flot d'injures contre nous. "Crois-tu nous faire trembler? lui demandai-je. Nous ne craignons rien, car nous avons le témoignage d'une bonne conscience, mais nons tremblons pour toi qui endurcis ton cœur 》. Pendant le plai. doyer de Mr. Buckenham, interprété par son collègue, il fit souvent des mouvements d'impatience et leur répondit par une grossière boutade. Il avait hâte d'en venir à Mr. Coillard. C'est contre lui qu'il a été le plus violent. Mais ce fut aussi son vieux missionnaire qui lui parla le plus fortement, lui reprochant sa 
conduite déloyale envers nous. Pauluse et Yacobo étaient horrifiés; le premier voulut interrompre $\mathrm{Mr}$. Coillard pour lui dire de parler plus doucement; il n'ouvrit pas la bouche quand vint son tour de parler. Yakobo dit bien quelques mots, mais uniquement sur le marché proprement dit, pas une parole pour relever notre nom de ministres de Dieu que Lewanika avait, trainé dans la boue.

Sur ce, nous saluons notre hôte, ne sachant pas quelles seraient les suites de cette entrevue; mais nous étions satisfaits d'avoir saisi cette occasion pour dire quelques vérités à ce pauvre homme qui n'entend jamais que des flatteries.

À Sefula nos femmes avaient passé la journée en prières.

9 Mars. - Ces quelques moments que nous avons passés à prier et à nous approcher ensemble de Dieu nous ont fait du bien. Oh qu'il fait bon pouvoir nous remettre entre les mains de ce Père tendre et bon! Les temps dans lesquels nous vivons sont faits pour nous rapprocher de ce Père toujours prêt à nous entendre, et à étendre sa main protectrice sur nous.

L'âme soupire tout naturellement après ce séjour céleste où il n'y aura plus de larmes, plus de séparation, plus rien de ce qui effraie et agite nos cœurs ici. Me voici presque au terme de cette journẻe que je redoutais et je n'ai pas trouvé une seule heure trop longue. Il remplit mon cœur d'une joie et d'une paix que je n'aurais pas crues compatibles avec mes inquiétudes. Je suis sûre qu'il veille sur mon mari et me le ramènera sain et sauf. Des actions de grâces sont sur nos lèvres, après ces jours d'angoisse.

Dieu voulut bien se servir de ce que nous avons dit pour faire rentrer le roi en lui-même. Comme nous l'écrivit Mr. Coillard quelques jours plus tard, le roi eut honte de sa conduite. Il rompit le silence et leva le blocus. La guerre ouverte était terminée, le marché reprenait peu à peu. Les tracasseries suivirent leur cours encore pendant plusieurs semaines. Beaucoup de gens aussi, sachant que nous n'étions pas bien vus à la cour, imitèrent l'exemple de leur souverain. Pas un paiement d'ouvrier ne se faisait sans contestations pénibles! Nous entendîmes bien des menaces et eûmes bien des vols à déplorer.

16 Mars. - Temps splendide, soleil radieux. La station est maintenant animée par tous nos enfants qui nous sont enfin revenus, 
même le batailleur Rubinda. Vous auriez ri avec moi de notre conversation d'hier. «Je rentre aujourd'hui », me dit-il de son ton décidé. Quand je lui fis mon sermon sur le tabac et les querelles, vous auriez dû voir son air sẻrieux et innocent quand à genoux devant moi il me disait: «Oh! oui, ma mère, tu as raison, le tabac c'est mauvais (il est un priseur enragé) et les chicanes, le bruit, oh ma mère, c'est si vilain! Et le voilà réadmis ce grand garçon, qui nous a vaincus par sa persévérance. Ils ne se déclarent pas vite «phaletsoe» (vaincus) nos Zambéziens quand il s'agit de mendier ou d'obtenir une grâce.

À midi les voici qui remplissent notre cour: «Salut, mon père, salut, ma mère». Les demandes suivent de près ces salutations. Une aiguille, du fil, du savon. Du savon surtout! Voila qui fait l'objet de la convoitise de tous. J'en donne quelquefois, mais non sans faire attendre mon quémandeur plusieurs jours. À la fin il arrive: «Et mon savon, où est-il? » Nous aimons tant ces pauvres enfants, malgrẻ tous leurs dẻfauts!

Nous eûmes aussi quelques encouragements dans l'œuvre. Une de nos chrétiennes m'amenait une femme en me disant que celle-ci voulait me «parler de son cœur 》. Ma-Wainyaio n'avait pas grand' chose à me dire de son cœur, elle était sous de sérieuses impressions qu'elle ne savait pas exprimer. Des lor's elle parcourut plusieurs fois par semaine les trois ou quatre kilomètres qui séparaient sa hutte de la station, pour venir apprendre à lire auprès de ma femme.

MM. Coillard et Waddell revinrent chez nous passer le Vendredi Saint et Pâques (2 avril). Mais le jour même de Pâques M. Coillard eut au poignet gauche une mauvaise piqûre; la douleur et l'enflure qui se manifestèrent aussitôt, nous firent penser à une pustule maligne, d'autant plus que des maux de tête et de la fièvre se déclarèrent dans la nuit. Nous ne fûmes rassurés que quand, après application de plusieurs cataplasmes de farine de lin, l'abcès s'ouvrit et qu'il sortit de la matière.

Mais tout le mois d'avril devait être pour nous une époque d'anxiété. Le 8 avril M. Coillard se plaignit de douleurs poignantes de la rate. Les symptômes devenant de plus en plus graves, nos angoisses allaient en augmentant. Notre frère ne se plaignait pas, mais il demandait à Dieu d'abréger la crise et de le prendre bientôt: "Nous invoquâmes le Seigneur, et il nous répondit 》. Le 12,M. Coillard put s'écrier: «C'est la délivrance! 
C'est à vos prières plus qu'aux miennes que le Seigneur a répondu. Le dernier pas coûte si peu, il en coûte davantage de revenir à la vie ». Hélas! ce n'était pas encore la délivrance complète. Des crises excessivement douloureuses revinrent. Nous fûmes encore ballottés entre l'espoir et l'appréhension pendant longtemps. Dieu bénit les moyens employés. «Il nous a délivrés, il a prolongé les jours de son serviteur, il nous a fait voir son salut 》.

Dieu nous exauça au delà de notre attente, car non seulement, Il nous remit notre frère, mais Il se servit de cette épreuve pour rapprocher de nous le roi et ses gens.

Les deuils qui frappèrent la maison royale accentuèrent cet heureux revirement. Le 2 mai, le jour même où nous ramenâmes M. Coillard à Lwatile, nous entendîmes des lamentations à la Capitale. - Qui est mort? Ce ne pouvait être qu'un membre de la famille royale, puisque Lewanika défend ces manifestations en toute autre occurrence. Nous ne tardâmes pas à apprendre que c'était Nymana-ngono, fils de Mokwae, qui était mort à Sesheke. Ce jeune homme avait été emporté en cinq jours par la variole! Dans quel état d'âme était-il, lui qui avait vécu dans la débauche?

L'étiquette exigeait ces pleurs, mais l'expression même que les ma-Rotsi emploient pour les condoléances, dépeint bien ces gens sans cœur et sans espérance. Cinq des principales femmes du roi, se rendirent à Nalolo auprès de Mokwae, dans des canots à pavillon. Pendant tous ces jours de deuil, la Capitale oldinairement animée et bruyante, était plongée dans un morne silence. Le roi abandonna sa grande maison pour se retirer dans une petite hutte, où deux ou trois de ses favoris ont seuls accès. Ses autres serviteurs et officiers passent leurs journées et leurs nuits, accroupis dans l'enceinte royale dans un silence presque complet. Le 5, Yakobo alla à Nalolo porter nos lettres de condoléances à Mokwae; elle se les fit lire par un de nos anciens élèves, mais elle ne permit pas à l'évangéliste de l'approcher, et ne l'autorisa pas à avoir de culte public. À Lwatile nous n'eûmes le dimanche qu'une vingtaine de jeunes-gens et de jeunes-filles, ainsi que les petits enfants du roi qui ne sont pas censés prendre le deuil.

Nous ne fûmes admis chez Lewanika que le 8. 
Le roi nous reçut drapé dans un grand morceau d'étoffe. C'était la première fois que je le voyais autrement que dans son correct habillement européen. Nous pûmes vite constater que toute la douleur des derniers jours était plus officielle que profonde dans le coeur du roi. Il parla très légèrement de la mort de son neveu; il croyait que sa vie immorale et l'abus de la bière avaient contribué à abréger ses jours. L'immoralité! nos cœurs saignent quand nous y arrêtons nos pensées. Dans le harem royal même, quels drames, quelles jalousies, quel péché!

Le roi sembla heureux de revoir ses missionnaires. Le surlendemain il accepta avec plaisir une invitation à dîner chez nous. Dès lors ses rapports avec nous furent aussi bons que dans les temps anciens. Il nous envoya chaque matin ses salutations en faisant demander de nos nouvelles. La maisonnée et ses sujets reflétèrent bientôt ses bonnes dispositions à notre égard. C'était enfin le calme après la tempête. Nous en bénîmes le Seigneur.

\section{XXVIII.}

Ombres et lumière.

Marais et fière. - Incompris. - Soucis de ménagère. - Lettres de la reine. Afrections naturelles. - Amis Zambéziens. - Sauterelles. - Voleurs. Pauvres enfants: - Abondance ou disette. - Médicament pour la paresse. - Amusements cruels. - Un serviteur joyeux. - - Des fiancés. - Evangélisation.

OATILE 13 maI. - Nos plans ont èté renversés par la visiteuse importune qui n'a pas l'air de vouloir encore me laisser tout $\grave{a}$ fait. Depuis deux jours je me sentais peu bien. Ce fut avant-hier surtout que la fièvre fut forte. Hier et arjourd'hui je suis encore faible et j'ai mal à la tête. Ce n'est pas étonnant qu'on soit malade ici. Le soir, des exhalaisons fétides nous arrivent de tous côtés. Ces miasmes s'échappent de la plaine, transformée en un marais empesté, en attendant que le soleil et le vent aient achevẻ leur oeuvre et fait de la plaine une prairie desséchée. Ne vous effrayez pas quand nous vous parlons des visites que nous fait la 
fièvre. Elle n'épargne pas les noirs non plus. Nos garçons et nos fillettes ont souvent, à tour de rôle, un ou deux jours de maux de tête par semaine ou de malaises, quand ce n'est pire.

Rentrés à Séfula, nous trouvâmes que l'évangélisation y était aussi plus facile. Nous essuyions moins de moqueries que par le passé. Nous fîmes de nouveaux efforts pour attirer les enfants à l'école. Nous en prîmes quelques-uns chez nous, mais quatre d'entr'eux nous quittèrent dès qu'ils eurent reçu quelque vêtement. Nous essayâmes de donner aux autres des primes de régularité, mais en vain. Les enfants avaient retenu la leçon donnée par les adultes et nous répondaient: «Qu'allons-nous faire chez vous? Vous ne nous donnez rien!»

Dimanche de Pentecôte. 21 mai. - Il s'est levé radieux pour nous, ce jour de Pentecôte. Pas un cœur qui nous comprenne et puisse se réjouir avec nous, de ce que l'Esprit de Dieu, ce Consolateur promis, a été envoyé. Mais comme nous demandons au Seigneur d'ouvrir les yeux de ces pauvres païens!

23 MAI. - Hier, Sébané et Ma-Wainiaio ont recrépi nos deux chambres, aussi fallut-il tout sortir. Il faut faire ce travail assez fréquemment pour abattre la poussière. Elle est partout cette poussière, elle tombe du toit, des murs, elle s'élève du sol, entre par la fenêtre, par la porte, elle pénètre partout, elle couvre tout, sans oublier nos personnes.

Mon autre souci de ménagère ce sont les fourmis... vous riez? Voilà deux soirs de suite que nous mangeons une soupe remplie de ces insectes. Il n'y a rien qui soit à l'abri de leurs pattes agiles. Et les mouches! dois-je vous en parler? Maman, aguerris-toi pour venir faire une visite à ta fille, mais en pensée tu frissonnes! Ne crains rien, j'en sers le moins possible; mais il faut bien faire bonne mine à mauvais jeu et se résigner à voir ces sottes bêtes se noyer dans votre tasse de thé, ou demander à partager votre lait et $\mathrm{y}$ tomber à six pattes, sans autre forme de politesse. On s'y fait et chacun enlève sa mouche de sang froid. On s'y fait à la longue!

Aujourd'hui de nouveau, Mokwae m'a envoyé deux messagers avec sa machine à coudre et une missive: «Je t'envoie ma machine pour que tu l'arranges, (elle est pleine de poussière et de rouille) et quand tu l'auras arrangée, viens m'enseigner à coudre; si tu n'en as pas le moyen, dis-le moi, et je t'enverrai un canot. Et mon pain, où est-il? Je t'avais envoyé de la graisse pour le cuire, 
mais le pain, je ne l'ai pas encore vu. Je t'en prie, donne-moi aussi un collier que je puisse porter».

Très peu de jours après notre arrivée à Sefula, en guise de bienvenue, la brave Mokwae nous avait fait tenir la lettre suivante: «Oh mon père, je t'en prie, aide-moi: j'ai du lait et du café, mais pas de sucre. Quant à mon mari,.il n'a pas de gilet ni de pantalon a mettre, il t'en demande. Nous sommes contents que tu sois revenu $»$.

10 Jusn. - J'ai plusieurs amis et la preuve c'est que chaque jour un nouvel individu arrive: «Je te demande un mouchoir». — « Je veux une aiguille ». - «Il me faut du fil ». Et si je fais mine de refuser: «Oh! n'es-tu pas notre mère? » - « Mais, je suis ton enfant! » Comment ne pas se laisser prendre à ces tendresses? Quelquefois cependant il faut être dur et renvoyer les mendiants à vide. Qui y tiendrait? et nous sommes loin de nager dans l'abondance.

Nous avons eu une invasion de sauterelles (1), il en a passé pendant une heure en nuages épais. Tout le monde est descendu au champ de blé où elles s'étaient posées et avec des morceaux d'ẻtoffe rouge et de la fumée on a pu les en chasser avant qu'elles aient fait des dẻgàts. Malheur aux champs sur lesquels elles se sont abattues pour la nuit.

L' œuvre se poursuivait sans trop de difficultés, nous étions mieux reçus chez les gens, les auditoires avaient grandi, à Nalolo nous étions toujours bien accueillis. Nous continuâmes cependant encore assez longtemps à subir de nombreux vols.

Ils ne commencèrent à diminuer que quelques semaines plus tard, quand le roi nous eut donné des gardiens chargés de faire la police sur la station.

Mais nous continuâmes cependant à surprendre plus d'un petit voleur ou petite voleuse, enfants de notre maisonnée, qui touchaient à la confiture, au sucre, au sel... à la viande dans la marmite, et cela pas toujours pour eux. Mamwendarubi ne nous avoua-t-elle pas plus tard avoir plusieurs fois poussé de nos fillettes à nous dérober du sel pour le lui donner? Paurres enfants! quelle perversité et quelles tentations dès l'âge le plus tendre!

(1) Quand en 1890 je vis moi-même les premières sauterelles voyageuses, elles étaient un objet de grande curiosité. Depuis lors elles se sont en quelque sorte acclimatées au Zambèze. 
Le mal persiste autour de nous, sous toutes ses formes, malgrẻ tous nos efforts pour éclairer ces pauvres consciences et gagner la confiance de ces cours que Satan tient sous sa puissante domination. Il y a des jours où on ne peut que se sentir triste, découragé: pas un de nos enfants qui se donne au Sauveur, rien qui montre que ces jeunes cœurs sentent le besoin de demander pardon de leurs péchẻs; rien toujours rien, que pẻchẻ, tromperie, mensonge et vol. Pauvres, pauvres enfants!

12 Septembre. - Il ne pleut jamais qu'on ne soit inondé. Vendredi, un de nos bœufs qu'un de nos boys dressait, tombe sur une de ses cornes et meurt sur le coup: la viande en est saine et excellente. Nous en mangeons tous les jours, quel dommage que cet animal ne se soit pas tué pendant nos jours de disette. En une semaine j'ai eu beaucoup plus de viande que nous n'en mangeons en un mois, et maintenant je suppose que je vais être de nouveau dans l'embaras pour quelque temps.

16 Septembre. - Mon mari est parti pour Nalolo ce matin... Je viens d'avoir un accès de gaietẻ à moi toute seule, aux dépens d'un des jeunes gens de la station. Il y a quelques jours, il se disait malade quand son missionnaire voulait l'envoyer chez Mokwae. Hier il boitillait, une jambe enveloppée d'un grand morceau de papier. Ce matin, après le dẻpart d'Adolphe, le bandage avait disparu. Il ètait revenu à la vie. Je le fis appeler: «Es-tu encore malade? - Non. - Alors c'est bien parce que je voulais te donner une médecine. - Oh, mais je la veux quand même ». Alors je lui prẻpare une bonne dose d'aloës et de rhubarbe, mélange supérieur que nous gardons pour les malades affligés de paresse. Il voit le noir breuvage et ne se sent pas rassuré: «Est-ce une mẻdecine pour le cœur? »- «Oui, aussi pour le cœur, rẻpondis-je d'un air savant. Avale, mais d'un trait». - « Cela me rendra malade, cela me tuera ». - «Avale ». Il prend le liquide et en boit une gorgẻe seulement, puis il se sauve en se tenant la bouche, et court boire de l'eau, au grand amusement de toute la galerie. - L'aurai-je guẻri? Hélas! j'en doute, car c'est une maladie chronique que la paresse, chez nos Zambéziens et chez ce jeune garçon en particulier. Seulement, peut-être ira-t-il raconter à d'autres qu'á moi ses infirmités imaginaires.

27 SePtembre. - Ce matin, j'étais encore chez moi, quand Mopoton arriva portant à Adolphe une poule que les deux plus jeunes parmi nos élèves avaient étranglée, juste assez pour la faire souffrir sans la tuer. Vilains enfants, dans des cas comme celui-ci ilsm'inspirent un vrai dẻgoût, une horreur que je ne surmonte qu'en songeant au milieu dans lequel ils vivent. Il y a quelque temps, 
c'étaient deux de mes fillettes qui avaient entièrement plumé une poule avant de la tuer. Les tortures que ces enfants font subir a des animaux sont le fruit des cruels exemples qu'ils ont eus sous les yeux dans leurs familles.

C'est pour moi une source constante de joie que de m'occuper de Kaieka. Boiteux, malingre, y voyant peu de ses pauvres yeux drôlement placés, ce petit garçon est le seul qui soit toujours de bonne humeur, toujours disposẻ à obẻir. Ai-je besoin de bois? « Kaieka!» Manquons nous d'eau? «Kaieka!» Voulons-nous faire porter un message? «Kaieka! » Toujours le petit homme arrive tout courant et s'empresse d'exécuter nos ordres. Il lit déjà assez bien pour apprendre des passages par cœur. Il me récite la parabole de l'enfant prodigue, avec des variantes bien à lui.

Nyondo a écrit aujourd'hui à sa fiancée. Comme celle-ci n'arrivait pas à bien lire sa lettre, je le fis pour elle. La voici: «Mathé, Je me porte bien. Oú en sont les choses de Dieu avec toi ? Est-ce que tu pries? Voilá que ce je te demande. Est-ce que tu te portes bien? Adieu, Mathé. - Nyondo ». C'est sobre. Pas de protestations superflues. Mais ces lignes respirent du sérieux.

Plus tard nous allons chez une vieille femme. Nous causons un peu, puis Adolphe lui demande de faire rassembler ses gens pour un culte. Il y avait une vingtaine de femmes, dix à douze hommes et plusieurs enfants, bien que tous ne fussent pas encore rentrés des champs. Je jouis tant de ces visites dans les villages, je voudrais pouvoir en faire une par semaine. Naturellement, je montais Grisette.

\section{XXIX.}

Crainte d'invasion de hordes ma-Tébélés.

\footnotetext{
Paix avec les ba-Lubale - Bruits de guerre. - Travaux de défense. Guerriers ma-Rotsé. - Litia chef d’armée. - Armée rebroussant chemin.
}

U mois de juin nous avions été réjouis par l'arrivée à LéaA lui de Mosongoandungu (un des grands chefs du bo-Lubale) et de la chéfesse Nyakametsi, qui étaient venus avec quelques uns de leurs principaux hommes demander la paix à Lewanika, en consentant à lui payer un tribut annuel. Lewanika ne leur avait 
pas seulement accordé la paix, mais il leur avait fait des cadeaux et leur avait rendu plusieurs de leurs parents, qui avaient fait partie du butin de la guerre de 1892 .

Hélas! Les cinq derniers mois de 1893 se passèrent dans la crainte d'une guerre avec les ma-Tébélés. Des rapports contradictoires nous arrivaient sans cesse des incursions faites dans le bo-Toka par ces brigands, et de leur invasion probable du bo-Rotsé. Les gros tambours de guerre battirent à plusieurs reprises. Des expéditions furent organisées puis abandonnées.

Le 21 septembre, peu avant le coucher du soleil, des roulements de tambours nous annoncent l'arrivée du roi au bas de la colline. Les gens des environs, avertis le matin, lui avaient construit deux belles huttes entourées d'une enceinte.

Naturellement je l' amenai à la station pour le souper. Il souffrait de maux de tête. Une dose d'antipyrine les fit disparâ̂tre comme par enchantement. Nous passâmes une excellente soirée avec lui. Il nous fit part des grands projets dont il était tout fier, des travaux stratégiques qu'il allait faire dans les plaines du Luyi et du Motondo. Il comptait y élever des remparts et inonder la rive gauche de ces deux rivières.

Il nous apprit que sa fille aînée avait abandonné son premier mari qu'elle trouvait trop âgé, pour devenir la femme de Mokamba, qui avait été promu au grade de Liomba. (Quelle déception pour Andrease qui avait espéré devenir lui le premier gendre du roi).

Il avait été décidé dès la mi-Octobre que je bâtirais à Loatile un magasin en vue de notre transfert probable à cette station. Je passai dès lors chaque semaine trois ou quatre jours à Loatile et retournais à Sefula pour le samedi et le dimanche. Il fallut commencer par un long travail de terrassement. Je ne pus achever cette bâtisse que dans le courant de février 1894.

Dès que les ma-Rotsé eurent appris que la guerre allait éclater entre les Anglais et les ma-Tébélé, ils pensèrent que ceuxci passeraient le Zambèse s'ils étaient battus. Aussi Lewanika et ses chefs décidèrent-ils d'aller garder les passages en aval des chûtes Victoria. Dans la nuit du 20 au 21 novembre les tambours de guerre firent entendre des sons lugubres, et le lendemain les gens des villages les plus rapprochés commencèrent à affluer à la Capitale dans les costumes de guerre les plus variés et les plus fantastiques. Nous fûmes étonnés de la 
quantité de fusils qu'il y arait dans le pays, c'est par centaines qu'ils se comptaient. C'étaient surtout des fusils à pierre et des pseudo-mousquets introduits par les ma-Mbari. Tous avaient des lances et une ou quelques hâches, et plusieurs tenaient de la main gauche des boucliers de peaux de bœufs bariolées. Les ma-Rotsé n'ont pas d'armée permanente, mais plutôt le système de la nation armée. Les gens craignirent de ne pas répondre à l'appel, car lors de la première panique on avait fouetté de cravaches en plein khotla tous ceux qui araient cru pouvoir rester tranquillement chez eux. Il fallut donner aux guerriers le temps de préparer leurs provisions de route.

J'étais à Sefula quand Litia et Kalonga y arrivèrent le 4 décembre à la tête d'une centaine de gens seulement. Ils $y$ passèrent trois jours pour donner à d'autres le temps d'arriver. Litia monta aussitôt nous saluer. Il avait posé son panache et ses armes et se présenta à nous, drapé dans une sorte de châle carré léger, formé de 8 mouchoirs à fond rouge cousus ensemble. Ma femme lui offrit du lait caillé et de la viande, puis nous causâmes de la guerre, tâchant de lui en faire saisir le sérieux. Nous lui recommandâmes de ne pas tolérer de pillage le long de la marche. Nous lui dîmes aussi combien nous étions tristes qu'ils fussent partis un dimanche, sans nécessité, et qu'ils eûssent été demander conseil et protection aux mânes, au lieu d'implorer le secours du Dieu vivant. Nous l'engageâmes à partager tous nos repas, et je constatai avec plaisir qu'il n'avait pas oublié les éléments de mantien que je lui avais enseignés pendant notre voyage à Mangwato. Il nous confirma qu'il était décidé qu'il serait installé à Sesheke ou à Kazungula. Il accepta avec empressement d'avoir un culte spécial avec ses guerriers. Il en amena environ cinquante. Nous eûmes l'impression que si on pouvait l'enlever à son entourage et le replacer sous l'influence de la Parole de Dieu, il ne tarderait pas à revenir à l'Evangile. Le jour même où ils allaient reprendre leur marche en avant, Litia et les principaux chefs vinrent à notre réunion de prière, à 6 heures du matin.

Le corps d'armée allait en grossissant de jour en jour. Somme toute, les ma-Rotsé out l'air peu martial, même avec leurs plumets et leurs boucliers, leurs fusils et leurs lances. Nous ne vîmes chez eux ni sérieux ni enthousiasme. Ils sont 
si légers que tout leur est un prétexte à plaisanterie, la guerre comme tout le reste.

Le 3 janvier 1894, l'armée de Litia était de retour. Ils avaient vu toutes sortes de mauvais pronostics. Des tortues et des lièvres trouvés morts, des fourmis guerrières entourant les lances sacrées! Enfin au Lumbe la fondre frappa une quarantaine d'hommes, dont trois moururent. La panique les saisit et ils se hâtèrent de rebrousser chemin. Pauvres superstitieux! Au fond, ce fut heureux, car il n'y eut pas d'invasion de ma-Tébélé, et les soldats n'auraient fait que piller les villages et les champs partout sur leur passage:

La saison des pluies était très en retard, le pays était menacé de la famine. Mais la pluie qui tomba abondamment au commencement de janvier, sauva la récolte.

XXX.

Paganisme Zambézien

\begin{abstract}
Aspirations. - Superstitions. - Joli tablean d'intérieur. - Fleurs et fruits.
Légèreté. - Manque de sens moral.
\end{abstract}

Mal prôné par la religion et par l'opinion publique. - Langage dénaturé, Sans Christ. - Mal ehez les professants. - A genoux:

10 DÉCEMBRE. - Que Dieu pardonne, que le sang de Jésus efface, lave, purifie! Si on a le sentiment de ses péchés, de sa misère spirituelle en Europe, ici il vous écrase; il y a des jours où avec Moïse on voudrait s'écrier: Seigneur, envoie, je te prie, qui tu dois envoyer! Comment, nous si pauvres, si pécheurs, si faibles, pourrions-nous amener d'autres âmes au pied de la croix? « Je serai avec ta bouche », rẻpondait l'Eternel au craintif Moïse, et c'est lá qu'est notre force. «Je serai avec vous jusqu'à la fin ». Pourquoi ces glorieuses promesses ne suffisent-elles pas toujours à calmer nos craintes, nos angoisses? Pourquoi sentons-nous tant malgré elles, le faix du jour, les épines de la route, les épreuves de chaque heure? Oh! que Dieu me donne ce calme, cette paix profonde et inaltérable, cette joie pure, sereine, toujours égale! 
20 DÉcembre. - Lwatile Trois femmes du roi sont venues nous voir vers midi. Quelle peine pour les accommoder! Nolianga (ma favorite avec Longa), s'est assise dans un coin, Matondo sur ma natte loin d'elle et Namabanda ne pouvait parvenir à se loger. "Assieds-toi donc là près de Matondo, lui dis-je. - Non. - Pourquoi? -- Je ne peux pas. - Comment cela? - Non, parceque Matondo allaite un enfant. - Oh, encore une de vos superstitions? Quelles gens vous êtes! Voici un tabouret. - Oh non, des gens s'y sout assis ». Elle finit par s'asseoir sur un morceau de toile. C'est ainsi que nous nous heurtons sans cesse à quelque superstition, ou coutume obscure et tenace.

22 DÉcembre. - Pendant que mon mari était sur le toit qu'on rẻparait, nous sommes allés au village, M. Coillard, M.lle Kiener et moi. Nous avons trouvé le roi chez une de ses femmes. Elle avait un bẻbé de près de deux ans, le plus gentil que j'aie encore vu, si mignon, si sociable, tout rondelet, avec des yeux brillants et vous regardant sans aucun signe de frayeur. Il venait vers chacun de nous avec un joli sourire, tenant à la main le chasse-mouches de son père, qui le regardait avec orgueil. C'ẻtait un joli tableau d'intérieur.

189.4 eut aussi ses ombres et ses lumières.

Sefula, 12 Janvier. - J'ai dans mon jardinet quelques légumes qui promettent. Les tomates grossissent à vue d'oeil. On m'apporte de notre autre jardin des radis, des navets, des choux, des aubergines. Les groseilles du Cap et le ananas que nous avons semés nous font espérer que ce ne sera pas en vain. Comme j'aime notre home. Je me surprends à jeter sur lui des regards admiratifs et à le trouver pittoresque, avec son toit de chaume sous les grands arbres qui paraissent vouloir le protéger. Ces temps-ci, notre maison est plus jolie encore aver le jardin suspendı que mon mari y a ménagé. Ce sont des caisses posées assez haut pour que les poules, les impertinentes ennemies de mes fleurs, n'y arrivent pas. Là ce sont mes volubilis qui montent en guirlandes gracieuses et nous donnent à peu près une fleur par jour; ici ce sont des capucines qui étalent complaisamment leurs fleurs aux vives nuances, puis des chrysanthèmes multicolores. Sur la fenêtre j'ai du réséda... J'jgnorais en Europe, où je vivais au milieu d'elles, la valeur vraie des fleurs.

À mesure que les semaines et les mois passaient, nous apprenions à mieux connaître nos élèves, nos ouvriers et nos ouailles. Nous comprenions mieux leurs moeurs, leurs ¿défauts, et 


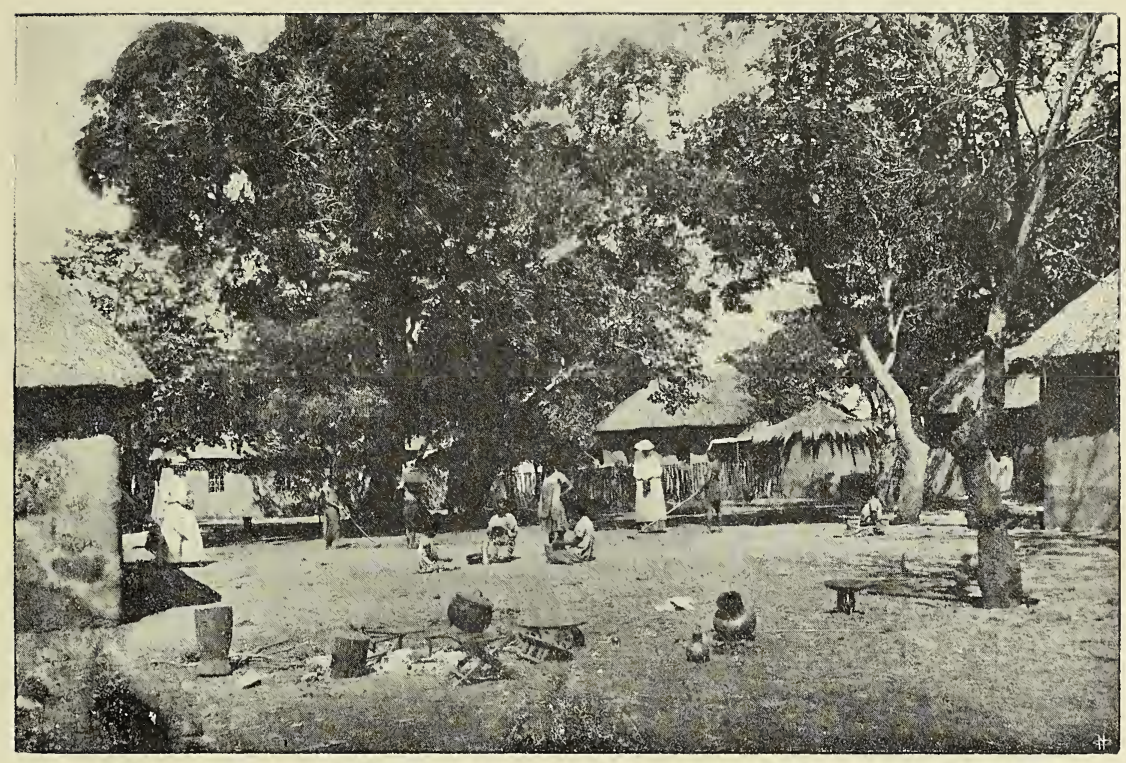

À Sefula (1891).

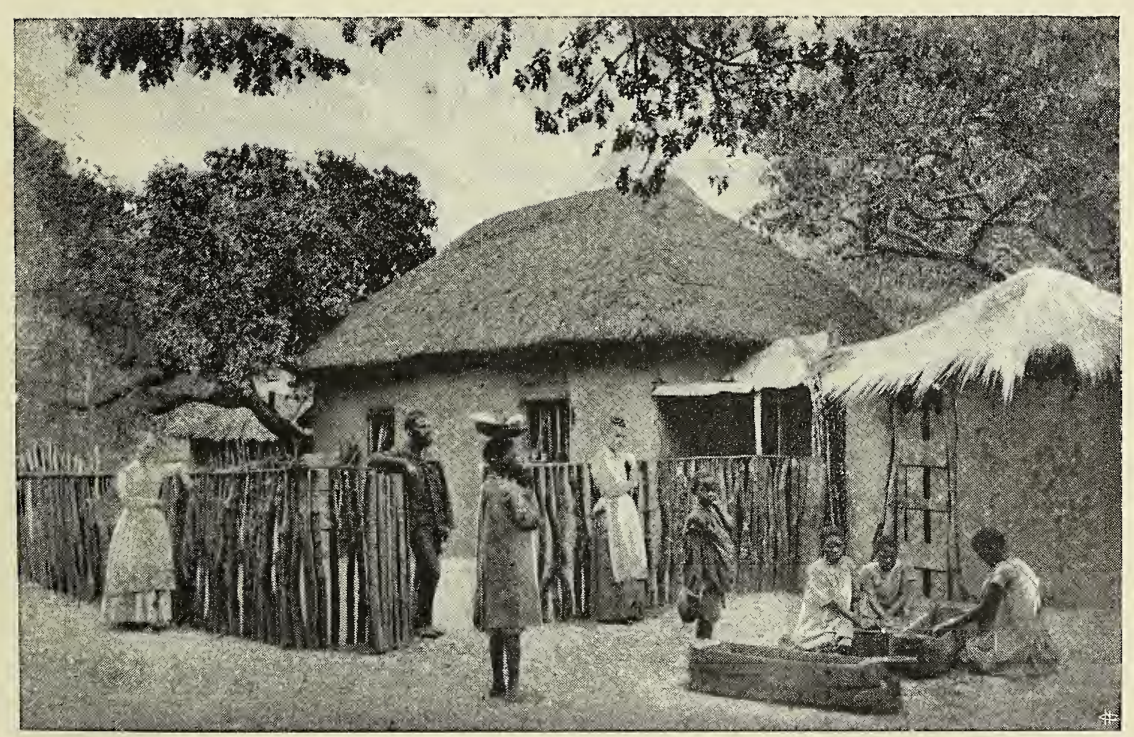

Devant notre chaumière (Sefula 1894). 

leur dépravation, et nous nous rendions mieux compte aussi du besoin qu'ils avaient du Sauveur.

Dans chacune de mes tournées j’apprenais quelque nouvelle superstition ou je voyais quelque autre fruit du paganisme zambézien. Un de nos voisins les plus intelligents eut une petite éruption ressemblant à celle de la rougeole. Qu'est-ce qui l'a produite? Personne n'a l'idée de rechercher les causes naturelles, hygièniques ou autres. S'il avait été un homme que ses voisins eûssent voulu perdre, ils auraient pu voir dans cet accident une preuve qu'il avait franchi un « lefunda 》 pour s'emparer du bien d'autrui. Non, les osselets divinatoires prouvèrent qu'il avait dû passer par dessus quelque fosse peu profonde d'un de ses esclaves dont on jette le cadavre n'importe où. Quand je le vis, il était encore considéré comme souillé. Il allait se faire des scarifications et $\mathrm{y}$ mettre quelque simple; mais pour bien se purifier il comptait se reudre deux ou trois mois plus tard de l'autre côté du fleuve, chez un docteur qui n'aurait pas manqué de lui 《manger 》 un boeuf.

Un de ses voisins, un homme qui avait été longtemps au service de M. Coillard, venait de rentrer chez lui, après un long séjour chez des docteurs, à quatre jours de marche au Nord. Sa lèpre semblait avoir diminué, mais le pauvre Moleta n'avait que la peau sur les os: il avait failli mourir de faim, et ses docteurs s'étaient emparés de son fusil comme paiement. Pour le racheter il devait leur amener une vache.

Un autre pauvre lépreux venait souvent nous voir, mais ses visites coïncidaient invariablement avec les jours où quelque animal mort avait donné l'abondance de viande à la station. «Seanga, pourquoi n'étais-tu pas là dimanche? - Je suis malade 》. Et il vous montre ses pauvres membres rongés par la terrible maladie. Vous saisissez l'occasion pour lui parler de la mort: "Mon pauvre ami, où iras-tu? 》 Pour toute réponse le malheureux part d'un grand éclat de rire qui fait expirer les paroles sur vos lèvres.

L'indifférence, la plus complète insouciance, et une légèreté dont on a peine à se faire une idée, voilà des obstacles contre lesquels nous nous heurtons à chaque pas. La vie est pour les Zambéziens un jeu, et la mort même ne les épouvante pas. Y aurait-il autre chose que l'insouciance? Leur fatalisme, la croyance à la métempsychose, ou encore leur idée qu'un certain 
tatouage au bras les fera passer de l'autre côté de la rivière, dans le pays des esprits, contribuent probablement à dissiper la terreur de la mort.

Leur dieu suprême, qu'ils appellent Nyambe, est pour le moins aussi impassible que celui des déistes. Il n'est pas étonnant dès lors qu'ils attribuent toutes leurs infortunes à des influences secrètes de morts ou de vivants. C'est ainsi que nos messagers revinrent après avoir fait naufrage, bien persuadés qu'on leur avait jeté un mauvais sort.

Nous étions aussi toujours plus péniblement frappés de l'absence presque absolue de sens moral chez nos Zambéziens. Ils nous ont bien dit qu'en leur expliquant les devoirs de l'homme envers son prochain, tels qu'il sont résumés dans la seconde partie du décalogue, nous ne leur avions rien apporté de nouveau, (en effet ils avaient des dictons pour réprouver les péchés qui y sont condamnés) mais ils n'en agissaient pas moins comme s'ils n'en avaient eu aucune notion. Hélas, l'atmosphère même qu'ils respirent est toute pleine de germes qui empoisonnent l'âme! Pour nous la notion de la divinité implique celles de beauté, de véracité, de justice, de sainteté. Il n'en est pas de même pour les païens, c'est plutôt le contraire. Dans leurs idées religieuses, le mal n'est pas seulement toléré, il est souvent encouragé et prôné, car ils ont prêté à la divinité toutes sortes de sentiments coupables; la jalousie, l'indifférence, la fausseté et même l'immoralité.

Quant à leurs ancêtres, dont le culte est beaucoup plus pratiqué que celui de la divinité, ils racontent avec complaisance leur cruauté, leurs haines et leurs actes immoraux.

Aussi nous ne pouvons nous étonner de trouver, que parmi les Zambéziens l'homme le plus admiré est celui qui tue le plus grand nombre de ses ennemis, le plus loué est celui qui réprimande ou punit le plus sévèrement, le plus envié celui qui a le plus de femmes. A leurs yeux la modestie est un défaut, le pardon une faiblesse, le dévouement une chose inconcevable. La guerre et tout ce qu'elle engendre de cruauté, le mariage à terme, la polygamie et sa suite inséparable de jalousies et de calomnies; l'esclavage qui détruit chez le maître les sentiments d'humanité, de douceur, et produit chez l'esclave la duplicité, la fourberie et la paresse; le mensonge sous toutes ses formes, l'immoralité, l'orgueil et la moquerie, l'égoïsme effréné, voilà quel- 
ques-uns des miasmes délétères dont est chargée l'atmosphère que le païen respire sans aspirer à la purifier et sans s'en plaindre, car elle lui semble presque normale. Nous nous rendîmes aussi compte peu à peu chez les enfants que nous élevions, comme chez tous, que le langage lui même est fréquemment dénaturé, que plusieurs des mots les plus usuels ont un double sens! Aussi quand nous faisions la triste découverte de cas d'immoralité parmi les enfants de nos stations, nous en étions peinés plutôt que surpris. Hélas il n'y avait pas de honte chez les coupables, pas de réprobation de la part de l'entourage. Si nous sévissions, l'opinion publique nous condanmait.

Plus tard, nous dûmes constater que chez les professants, l'atmosphère, tout en étant moins chargée, était cependant moins pure que celle dans laquelle nous vivons. Les effluves du paganisme arrivent si facilement jusqu'à eux! Plusieurs même de nos aides bassoutos ont dû être exclus du corps missionnaire pour des cas d'inconduite. Est-ce étonnant qu'un peu de boue reste attachée à ceux qui viennent de sortir de la fange? Avec tous ceux qui s'occupent d'œuvres de relèvement, nous sentons que ces chutes sont les épreuves les plus cuisantes de notre foi et de notre patience; mais sans les excuser, nous ne pouvons pas ne pas nous sentir remplis de pitié pour ceux qui tombent. Ah, nous comprenons le sens de ces paroles de St. Pierre: «La vaine manière de vivre, héritée des pères 》. Nous ne saurons peut-être jamais de quels abîmes de corruption nous sommes entourés, mais l'odeur nauséabonde qui s'en dégage nous en dit assez! Dieu est bon de nous accorder de respirer dans sa communion un air vivifiant.

Mon cœur se serre en pensant à ces enfants. Il n'y a pas d'enfants dans ce pays, les bẻbés sucent la corruption et le vice avec le lait de leurs mères... Nambula est bien coupable, mais quand on songe au milieu dans lequel grandissent ces filles avant d'entrer chè nous, la pitiẻ remplace le dégotit... Oh la prière, c'est là notre planche de salut. Accrochons-nous y. «Je ne te laisserai pas aller que tu ne m'aies béni ». L'œuvre que nous poursuivons doit se faire à genoux; ce ne sont pas nos paroles, notre amour, qui convertiront un seul de ces pécheurs, non, mais l'Esprit de Dieu que nos supplications appelleront sur eux. Cela faites-le avec nous. 


\title{
XXXI.
}

Oeuvre du Saint Esprit.

\begin{abstract}
Lueurs d'espoir. - Prière de Nosiku. - coenr devenu sensible. Leschavage et la famille. - coenr changé. - yokwae et Nolianga nos hôtes. Prières. - Pleurs.
\end{abstract}

$T^{N}$ même temps que ces tristes expériences, nous en fai1] sions d'autres. Grâces à Dieu, une œuvre s'accomplissait dans les cœurs. Les cultes étaient mieux fréquentés, l'attention et le sérieux y redoublaient, chez les petits comme chez les grands. Les réponses que plusieurs faisaient à mes demandes, prouvaient qu'ils suivaient la prédication et la comprenaient.

Les tournées que je pouvais faire plus d'une fois par semaine, grâces à la santé généralement bonne que Dieu m'accordait, me permettaient de constater que la connaissance de l'Evangile se répandait. Plusieurs personnes semblaient attirées vers 《les choses de Dieu 》, elles fréquentaient régulièrement les cultes et étaient parfois sous des impressions sérieuses.

En allant avec ma femme en tournée de visites nous arrivons chez Seanga. Nous le trouvons accroupi sur le sol humide de la hutte dans laquelle il est relégué, hutte si petite qu'il peut à peine s'y étendre. Nous lui parlons de l'amour du Sauveur et nous lui chantons quelques-uns de nos beaux cantiques. En nous remerciant, il nous dit qu'il prie le Dieu des missionaires. Il est très sensible à un morceau de viande que nous lui avons apporté.

Nos enfants de la station, plus dociles qu'autrefois, nous rendaient la tâche plus facile. Un dimanche d'avril Nosiku fut touchée au culte, elle pleura en sortant, et pleura de nouveau à la prière du lendemain. Elle, ordinairement orgueilleuse et brusque, était devenue douce et obéissante. Quand je l'invitai à prier avec moi, elle répéta avec émotion: «Oh Dieu, pardonnemoi, je t'ai offensé, j’ai commis tant de péchés qui ne sont connus que de toi et de moi. Oh Dieu, pardonne!». Mathé, sa 
compagne suivit bientôt son exemple. Elles commencèrent à s'entr'aider pour résister au mal.

De son côté, grâces à sa persévérance et à son excellente mémoire, Kaieka avait fait de réels progrès; son sérieux augmentait, nous rêvions déjà de le voir évangéliste un jour. Son maître apprit-il nos intentions? Un matin il vint le réclamer. Nous l'avions eu chez nous pendant seize mois. Et voilà notre Kaieka parti, privé de ces tranquilles heures du soir qu'il aimait tant. Il avait peine à retenir ses larmes en nous disant adieu. Ah! si ce n'avait été sanctionner l'esclavage, nous aurions volontiers payé son affranchissement, mais on aurait dit que nous l'avions acheté! Nous avions trouvé chez ce pauvre mo-Lubale des qualités qui n'existent pas chez la plupart des esclaves; ordinairement chez eux tout est mort, force de volonté, respect de soi, affections naturelles, l'esclavage brise tout en brisant la famille. La famille existait-elle au Zambèze? Un père, une mère peuvent-ils s'attacher à des enfants que le chef dont ils dépendent, ou le roi, vont leur enlever d'un jour à l'autre?

Cependant Kaieka revenait à la station chaque fois qu'il pouvait s'échapper; il avait toujours l'air si heureux de nous revoir. Et quelle joie il nous donna le jour où il annonça qu'il sentait que son cœur était sur le point d'être changé. Quand il ne pouvait venir lui même, il nous faisait dire par un compagnon auquel il apprenait à lire, qu'il n'oubliait pas ce que nous lui avions enseigné et qu'il priait pour nous! Une fois il nous demanda si Dieu entend les prières faites seulement dans le cœur, et non à haute voix.

En mai nous jouîmes beaucoup des cinq jours que Mokwae et Nolianga vinrent passer chez nous. La reine fut touchée de ce que nous l'invitâmes chaque jour à prendre au moins un repas à notre table. C'était la première fois qu'elle était l'hôte d'un missionnaire. Chose singulière, elle fut discrète. Quand nous lui parlions du Sauveur elle ne détournai pas la conversation, comme elle y était habituée. Quant à Nolianga, c'étaient ses besoins religieux qui l'avaient amenée à Sefula. Elle me demanda un Nouveau Testament, que je lui donnais après m'être assuré qu'elle avait appris à lire assez bien pour le comprendre. Elle gagna nos cœurs... mais à son départ nous nous dîmes avec tristesse «qu'il est difficile à un riche d'entrer dans le Royaume de Dieu 》. Mais ce qui est impossible à l'homme ne l'est pas 
à Dieu, et c'est à Lui que nous la recommandâmes dès lors encore plus ardemment qu'auparavant.

Ma femme continuait à avoir des attaques de fièvre assez fréquentes.

j'ai eu plus que ma part cette fois et cette attaque est plus tenace qu'aucune autre. Ordinairement elles se bornent à trois accès, j'en ai eu quatre déjà. La fièvre quarte, comme je l'ai cette fois (fièvre laissant deux jours d'apyressie entre les diffẻrents accès) est plus opiniâtre, dit-on, aussi ne faut-il pas s'étonner qu'elle me soit encore revenue.

LoATILE 2 Juin. - Chez Longa j'ai trouvé un joli ndondo (cruche à eau en terre), qu'elle m'avait promis. En mars, quand nous étions venus pour la dédicace de la chapelle de la Capitale, je l'avais trouvée un jour façonnant des pots et des cruches très jolies. «Oh, tu devrais m'en donner un, lui avais-je dit. - Mais oui, quand il sera cuit», et aujourd'hui elle m'en fit présent. «Tu sais, commença la malicieuse, tous les ndondo ont été cassés pendant la cuisson - Oh non, le mien est là. - Et, en effet, cinq minutes après, une jeune esclave me l'apportait. Longa était enchantée que son cadeau me fìt plaisir et puussa plus d'un de ses bons éclats de rire, secouant toute sa riche poitrine.

SEFula 13 Juin. - Aujourd'hui deux de nos fillettes sont parties pour Léalui, où M. Coillard désirait les avoir quelques jours. Nous étions tristes de devoir nous sẻparer d'elles. Nous les avons remises entre les mains du Père qui les aime encore bien plus et bien mieux que nous ne pouvons le faire. Nons avons prié avec elles Adolphe et moi, hier soir, en leur parlant sérieusement encore une fois. Toutes deux ont prié. Nosiku parle toujours de ses péchés et demande à Dieu de lui pardonner; Mathe demande à Dieu de leur donner des cœurs nouveaux et de faire en sorte qu'à notre retour de Kazungula nous les trouvions converties. Ce sera notre prière de tous les jours.

Ma petite Molca est toute enchantée de se trouver cuisinière en chef, elle est gaie comme un pinson et a l'air de trouver que c'est très amusant de prendre la place des grandes.

Voilà deux soirs que je m'endors en pleurant sur le sort de Kaieka. Plus de nouvelles de lui. Dieu veuille nous le rendre!

D'avril à juin je construisis à Sefula ce que nous appelâmes la Retraite, une chaumière rectangulaire à deux chambres, ò̀ 
nous comptions nous retirer quand l'inondation nous aurait chassés de notre station de la plaine (1).

Quand, le 25 juin, nous quittâmes Sefula, pour nous rendre à la Conférence, nous fûmes tristes de laisser en suspens l'œuvre qui semblait se développer.

\section{XXXII.}

\section{Voyage en canot.}

Premier campement. - Un voisinage désagréable.

Obstacles à la navigation. - Des pierres : - Arrivé à Kazungula.

\section{T voyage sur le fleuve avec $\mathrm{M}^{\mathrm{lle}}$ Kiener et MM. Coillard $\triangle$ et Waddell nous fit à tous beaucoup de bien.}

Nous arrivâmes ici à Nalolo vers 4 heures et campâmes assez loin du village, sur un terrain que les hippopotames avaient marquẻ de leurs pieds gigantesques. Nos bateliers eurent vite nivelẻ l'emplacement pour nos tentes. Une couche d'herbe, des nattes, une couverture, voilà notre lit fait. Mokwae nous avait envoyẻ du lait et $\mathrm{du}$ bois. Comme nous finissions de manger notre poulet froid, la nuit descendit toute noire, et au moment où j'exprimais le désir d'entendre un hippopotame, la puissante respiration d'un de ces amphibies nous fit frissonner (2). S'il allait escalader la berge et se précipiter sur les feux, qu'il prend plaisir, dit-on, à disperser avec son museau? Nous eûmes le culte avec nos gens, puis nous nous retirâmes dans nos tentes, et comme nous y dormîmes bien!

27 Juin. - C'est joli de voir notre flottille de neuf canots glisser sur le fleuve. Mais le vent se lève, il devient violent; des vagues trop fortes pour nos frêles embarcations nous forcent à aborder en toute hâte. On attend. «Le vent est-il encore trop fort? - Oui » répondent nos guides prudents, et nous attendons au grand soleil, sur uı terrain imbibé d'eau. Un des garçons de M. Coillard a un plumet blanc au bout de sa rame. "Ote-le, crie Semonja, le chef de notre expédition, tu appelles le vent!». Sans doute, ils en veu-

(1) Cette maison sert de salle d'école et de chapelle depuis 1900 .

(2) C'était le premier long voyage en canot que faisait ma femme. 
lent aussi a nos parasols ouverts, mais nosent le dire. Un autre garçon siffle un air de cantique. «Tais-toi, lui crie-t-on de tous côtés, tu appelles le vent! »... Enfin nous nous remettons en canot et pour trois heures nos gens rament avec vigueur.

SEOMa 30 JUIN. - Hier soir je m'endormis au sourd murmure des rapides, et rêvai à nos torrents de montagne... Nous partons après déjeuner pour visiter les chutes de Ngonye. On marche à la file zambézienne dans les petits sentiers faits pour un... nous avançons toujours et bientôt nous voyons des... pierres! Vous souriez? Je n'en avais plus vu depuis deux ans. Ce sont de vieilles amies qui me transportent de nouveau bien loin du Zambèze. L'illusion est complète quand je me trouve, sautant de roche en roche, glissant, grimpant. Qui n'est pas rassurẻ c'est notre guide, il est sur les épines. Sa peur se trahit par une humeur bourrue et noire. «Prenez garde! vous offensez le Dieu en regardant l'eau de trop près... Il vous attirera! (l). Ne regardez pas ce sable blanc là-bas, dit-il une autre fois, vous mourrez!».

Les chutes! Comment vous décrire ces beautẻs que seule la langue d'un poëte ou le pinceau d'un artiste pourraient rendre dignement. Nous ne pouvions que nous ècrier: Que c'est beau! et nous regardions de tous nos yeux, nous laissant asperger avec délices par la vapeur qui montait de l'abîme.

Un des rameurs de ma femme, qui n'avait jamais vu de rapides, commença à trembler comme une feuille dès que nous eûmes quitté le port de Naoguali, tellement qu'à chaque mauvais pas il fallut le faire asseoir!

Le 5 juillet, nous arrivâmes à Sesheke. Après y avoir passé deux nuits, nous y laissâmes nos compagnons de route, ayant hâte de retrouver mon frère et ma belle-soeur. Le 9 , à $5 \frac{1}{2} \mathrm{~h}$. nous les trouvâmes au port de Kazungula, avec nos neveux Valdo et Edouard Jalla, M. et $\mathrm{M}^{\mathrm{e}}$ Béguin et les évangélistes bassoutos (Willie et John et leurs femmes) qui venaient d'arriver.

Notre joie de retrouver nos chers Kazunguliens nous n'essayons pas de la décrire. $M$. et $\mathbf{M}^{\mathrm{e}}$ Béguin étaient pleins de l'entrain de la jeunesse, nous nous sentions vieux à côté d'eux. Nous fîmes vite bonne connaissance et nous réjouîmes de penser qu'ils seraient nos voisins.

Ce ne fut que le 12 au soir que M. Coillard et le reste de la famille missionnaire nous rejoignirent.

(1) Pour les Zambéziens le vertige est l'attrait exercé par une divinité. 


\section{XXXIII.}

Temps de rafraichissement.

« ToIcI, oh qu'il est agréable, qu'il est doux pour des frères de demeurer ensemble, car c'est là que l'Eternel envoie la bénédiction, la vie pour l'éternité. 》Nous le sentîmes dans nos séances de conférence, dans nos rapports mutuels, comme dans les cultes du dimanche et les réunions sur semaine. L'Esprit Saint agissait: ceux des Zambéziens qui s'étaient déjà décidés pour Jésus se sentirent fortifiés; d'autres, que nous savions bien disposés, se déclarèrent prêts à suivre le Seigneur; d'autres furent touchés, ébranlés dans leurs consciences, mais hésitaient encore. Que c'était réconfortant d'entendre nos garçons et nos filles rendre témoignage à l'amour et à la puissance du Sauveur; comme nous aurions aimé que plusieurs de nos Sefuliens eûssent été présents!

Ma belle-sœur, M.me Louis Jalla, nous confia pour quelque temps son fils Valdo, pour l'emmener avec nous à Séfula.

\section{XXXIV.}

\section{Retour à Sefula.}

VaIdo nous est confié. - Incidents de voyage. - En danger.

Rencontre des princes. - Un serpent dans la tente. - Chez Mokwaé.

T Es beaux jours de réunion de Kazungula furent trop 1 vite passés. Le 24 juillet, les Goy arec $M^{\text {lle }}$ Keck et II. Waddell nous précédèrent à Sesheke, nous les y suivîmes le surlendemain avec $M$. et $M^{\ominus}$ Béguin et Ernestine (la femme de Willie) que nous devions conduire à Sefula. M. Coillard alla aux Chutes Victoria avec mon frère. 
Avant d'arriver au port de Nangwalu, les bateliers de ma femme eurent à soutenir une lutte formidable contre le courant: pendant cinq longues minutes ils ne purent littéralement pas avancer, malgré tous leurs efforts, enfin ils se rapprochèrent $d u$ bord, et Moshoa qui était à la proue, put saisir un roc avec la rame et retenir le canot jusqu'à ce que mes rameurs arrivassent. Aucune autre pirogue n'affronta ce courant, on les hissa une à une en les tirant de la rive avec des cordes. Ce fut à peu près le seul danger que nous courûmes pendant tout le voyage de retour.

Le jeudi 16 août, vis-à-vis de l'embouchure du Loeti (1) nous rencontrons l'expédition de Litia et d'Akanangisoa. Un canot léger s'avançait en tête suivi par celui de Litia, puis viennent ceux des deux femmes du prince, ensuite celui d'Akanangisoa et de son mari. Quand nos bateliers et les bateliers et les gens du lieu eurent salué, jallai vers les princes. Litia se leva aussitôt pour saluer ces dames. Il donna à ma femme une bonne nouvelle: Il avait confié Kaieka au roi pour qu'il nous fût remis à notre arrivée!

Le 17, en arrivant à Senanga dès 8,30 du matin, nos gens purent saluer leur chère plaine du bo-Rotsé: Ouvre! ouvre! débouche! criaient-ils. C'était une hilarité et des transports de joie auxquels nos impassibles Zambéziens ne nous avaient pas habitués. Tout oiseau trouve son nid beau, même quand c'est la plaine nue du bo-Rotsé.

Le samedi 18, nous abordons à Nalolo, à 7 heures du soir. Comme la veille, c'est à la lueur de nos lanternes que nous plantons nos tentes. Nous envoyons saluer la reine et lui faisons demander du bois. À $9 \mathrm{~h}$. notre messager est de retour, et à $10 \mathrm{~h}$. nous pouvons enfin souper.

Le lendemain, que vois-je en sortant de notre tente, à l'aube? Un kaburwe-burwe (le serpent le plus venimeux du pays), dans la tente des Béguin sous leur matelas! Heureusement qu'il est engourdi par un froid de $+2^{\circ}$. Je charge mon arme à grenaille, je réveille nos amis et je les avertis que je vais tirer. Le coup de fusil tua net le reptile. Je n'avais pas dit à nos amis de quoi il s'agissait, de crainte que dans leur émotion il n'eûssent réveillé

(1) Le Loeti est le seul affluent important de la rive droite, entre le Lwanginga et le Linyanti, il n'est marqué sur aucune carte. 
le monstre. Ce fut la première chose qu'ils virent sur l'emplacement qui allait devenir leur station.

Mokwae ne tarda pas à nous envoyer un grand bidon de lait. Elle nous accueillit chez elle arec son bon sourire, malgré des douleurs névralgiques pour lesquelles elle s'était attaché fortement une ficelle autour de la tête. C'est en effet le remède généralement employé au Zambèze; que nos lecteurs en fassent l'expérience! Elle ne vint pas au culte, mais chargea le crieur public de convoquer les gens. Nous eûmes un auditoire de plus de quatre cents personnes. Plusieurs femmes entrèrent sous le hangar du Khotla et s'y accroupirent à côté des hommes. La reine et tous les Naloliens furent heureux de voir enfin et d'entendre leur missionnaire. Mokwae nous pressa de passer encore le lundi à sa résidence : elle voulait nous faire amener un boeuf gras, afin de mieux faire connaissance avec son missionnaire et sa Misisi. Le lundi matin, après avoir présenté M. Béguin aux principaux chefs, nous passâmes prendre la reine et son mari, et les conduisîmes à notre campement pour le diner.

\section{XXXV.}

\section{Le réveil à Sefula.}

\footnotetext{
Dien confond notre foi. - In Lazare plus riche que le riche. Les os desséchés en mouvenent, - Professions, confessions et classes. Mariage chrétien.
}

Rentrés à Sefula le 21 août, nous nous hâtâmes de déR ménager à la 《Retraite $\sharp$, et de céder aux Béguin les deux chambres dans lesquelles nous avions passé deux heureuses années. J'ajoutai à la Retraite ses dépendances: cuisine, chambre de bain, dépense et huttes pour nos enfants.

Pauluse ne nous avait précédés que de quelques jours. Nous craignions fort que l'oeuvre n'eût souffert. (Pauluse n'avait eu qu'une quarantaine de personnes aux cultes), mais le dimanche 26 août nous fûmes agréablement surpris en voyant une assem- 
blée de 130 personnes. La semaine suivante il y en eut 150; le mercredi, 70 personnes assistaient à la réunion de prières, la classe qui suivit fut sérieuse, nous y sentimes comme un souffle de l'Esprit qui poussa nos professants à s'humilier, l'un confessa son orgueil, un autre son manque de zèle, un autre des vols. Le dimanche suivant nous eûmes 330 auditeurs. La chapelle bondée offrait un spectable émouvant. Tous furent comme suspendus aux lèvres du messager de l'Evangile. Ce fut ainsi que Dieu confondit notre faible foi et nous convainquit de nouveau qu'il peut agir sans nous.

Ces joies furent une abondante compensation au crève-cœur que nous devions éprouver en ouvrant nos caisses de vêtements et de livres. Deux d'entre elles avaient particulièrement souffert: leur contenu n'était plus qu'une masse humide sans nom.

Le 12, nous conduisîmes les Béguin à Loatile, chez M. Coillard, où nous passâmes quelques heureuses journées. Tout le monde était bien disposé envers les missionnaires. Lewanika donnait le ton.

Kaieka, le cher enfant, était là aussi. Le 9, il avait publiquement raconté comment il avait trouvé le Sauveur chez les missionnaires. Il avait ensuite été libéré par le roi en plein khotla. En nous le remettant, le roi lui répéta qu'il était libre désormais; mais il lui recommanda l'obéissance à ses missionnaires et le zèle pour l'étude. Lewanika nous dit: « Ce garçon ne paie pas de mine, et je n'ai pas compris d'abord pourquoi les missionnaires s'étaient tellement attachés à lui; mais c'est un Lazare qui est plus riche que le riche de la parabole. C'est un homme, tout petit qu'il est! 》 Dès ce jour, Kaieka resta chez nous; par sa complaisance et sa fidèlité il devint un excellent aide pour ma fomme. À l'école il fit de rapides progrès.

Le 18 Septembre (1). - En arrivant à Sefula le matin au lever du soleil, nous fûmes accueillis par environ quarante personnes, des femmes surtout, venues pour la prière. Notre étonnement augmenta quaud Pauluse nous annonça que toutes ces personnes avaient déclaré l'avant-veille au culte, vouloir abandonner leur ancienne manière de vivre pour servir le Seigneur. Le lendemain nous passâmes une bonne partie de la matinée avec ces gens à les questionner et à entendre leurs confessions.

(1) Extrait du Journal des Missions. 


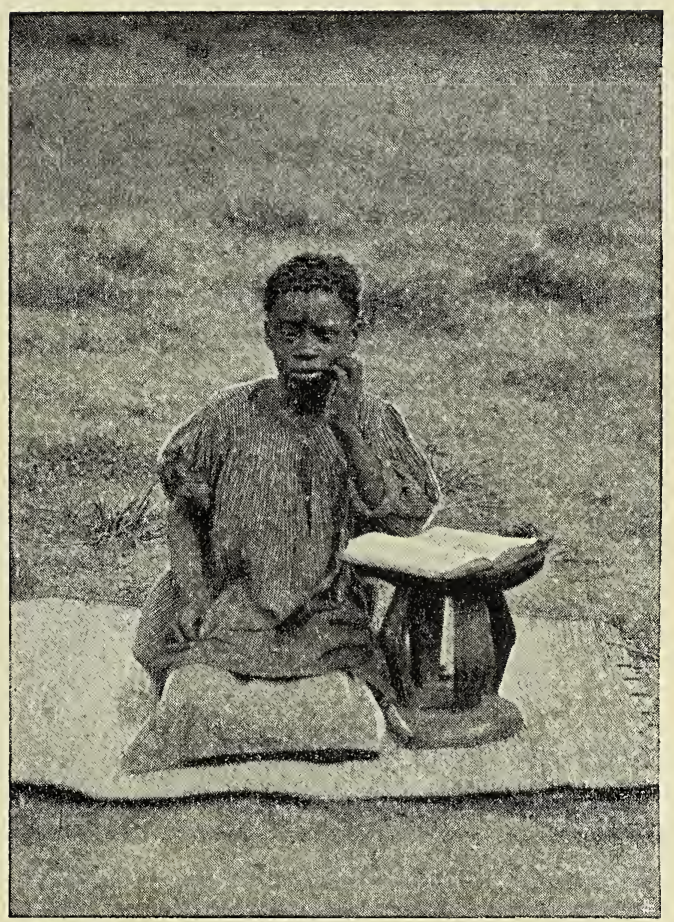

Kaieka. 

Quelle corruption ils nous dévoilèrent, comme Satan les avait enchaînés! Le nombre de ces personnes s'éleva bientôt à 80 . Nous savons bien que parnii eux plusieurs ont été entraînés par l'exemple des autres; il y a eu un désir de mieux faire, la crainte des jugements de Dieu, mais pas de vraie conversion, et en effet le zèle de plusieurs s'est bientôt refroidi. Mais il y en a quelques-uns qui nous ont fait une excellente impression, et dont la conduite témoigne de l'action du Saint-Esprit dans leurs consciences et sur leurs cœurs. Nous avons eu la joie de voir tous nos enfants se déclarer pour le Sauveur. Ce qui prouve en leur faveur c'est que nous n'avons plus que du plaisir avec eux, sauf quelques exceptions.

Nous avons ouvert la classe à toutes ces personnes, profitant de leurs bonnes dispositions pour les instruire et les exhorter.

Ce mouvement nous remplit d'espoir, les os désséchés se sont rapprochés, « il leur vint des nerfs, la chair crût et la peau les couvrit par dessus 》; mais nous ne les avons pas encore vus 《reprendre vie et se tenir sur leurs pieds »; nous attendons encore le souffle de l'Esprit de vie, mais nous l'attendons en implorant le Seigneur pour qu'il nous l'accorde.

L'école profita de ce mouvement. Nous eûmes jusqu'à 80 élèves réguliers.

Le 20 Septembre, M. Béguin se rendit à Nalolo avec Pauluse comme interprète, et fonda effectivement la station ce jour-là en dressant sa tente sur l'emplacement désigné par la reine.

LE 28 SePtembre. - Kaieka entra dans la chambre, l'air tout triste. «Qu'as-tu? lui demandai-je. - J'ai une nouvelle. Mais c'est une mauvaise nouvelle. - Vraiment! et de qui ? - De moi, ma mère. - As-tu peur de la dire devant nous tous? - Oh non, je la dirai: J'ai volé - Toi ? et quand? - Il y a bien des mois, plus d'un an ». Et il nous raconta comment, en compagnie de nos autres garçons, il nous avait pris des biscuits. Il ajouta: «Je veux tout te dire, tout te dévoiler », et il nous dit qu'il avait une fois volé du pain à sa mère, puis nié que ce fût lui. Pour un Zambézien, il n'avait pas beaucoup de vols sur la conscience.

À la veille de son mariage, Kosiku sentit aussi le besoin de venir nous confesser ses fautes. Elle n'a pas de ces souillures que nous avons entendu dévoiler à Lwatile par des enfants 
de sept à dix ans, mais quelle série de vols elle nous raconta! Nous pûmes lui donner une robe de noces blanche (toute simple). Son mariage avec Seonyi fut célébré le 4 Octobre, avec l'assistance d'une centaine de personnes. Quels horizons nouveaux ouvre le mariage chrétien! Tous prirent ensuite part au dîner de noces. Quelques-uns de nos voisins avaient apporté une dizaine de plats de nourriture cuite. Nous avions fait préparer de la viande, des légumes et des fruits sauvages. Les Zambéziens ont la belle habitude de faire part de ce qu'ils mangent, à toutes les personnes présentes. Ils comptent naturellement sur la réciprocité.

Le 14 Octobre nous eûmes à Nalolo l'installation officielle de M. Béguin et de Yakobo, à laquelle nous prîmes part, M. Coillard, le Ngambela, Lewanika et moi.

\section{XXXVI.}

\section{Dernières semaines à Sefula.}

Sage-femme et garde-malade. - Projet renversé. - Cherté des transports.

23 OcтовRE. - Voilà huit jours que je suis garde-malade, et il $\mathbf{y}$ en a six que je suis sans mon mari. Une petite Marguerite est venue réjouir le nid de nos amis Béguin, le 16 courant. Oh, si vous saviez quel soulagement ce fut pour moi quand je vis mère et enfant confortablement installés dans leurs lits! Quels moments solennels que ceux d'une naissance! Nous sans expérience, qu'aurions-nous fait s'il était survenu une complication? Mais notre Père savait notre impuissance, et il a conduit toutes choses avec un tendre amour... M. Béguin a la fièvre depuis hier, c'est sa première attaque. Je l'ai envoyé à la Retraite, et Valdo et moi avons couché près de Madame... Cher petit, il m'aide à ne pas avoir trop d'ennui, mais quand même, je commence à soupirer vraiment après mon Adolphe. Oh, que ferais-je si je devais vivre sans lui? Que cela doit être affreux d'être privẻe de celui qu'on aime comme soi-même. Que Dieu me refuse des enfants, je serais heureuse quand même s'il me laisse mon mari. Des enfants, c'est pourtant toujours le rayon de soleil, le sourire du ciel, l'oisillon du nid! 
29 OCTOBRE. - Trois ans que nous sommes ensemble! cela a passé vite et c'est toujours plus beau. Oh, Dieu veuille nous accorder encore beaucoup d'années ensemble à son service!

Le 18 Octobre. - M. Coillard devait quitter Sefula pour se rendre au Lessouto. Ce voyage avait été pour nous un grand sujet d'anxiété. Uue série de délais nous avait fait craindre qu'il ne pût réussir à atteindre Sesheke. Heureusement que par un accident survenu à sa voiture, à quelques centaines de pas seulement de la station, Dieu lui montra que ce projet n'était pas réalisable. Nous en fûmes bien heureux. Au lieu de remplacer notre doyen à la Capitale, nous n'aurons qu'à le seconder.

Je partis quand même pour Loatile, où m'attendaient les rameurs qui avaient amené les effets des missionnaires. Quelle affaire que de mesurer et couper 80 li-tsiba pour payer tout ce monde. Cela se passa sans la moindre réclamatiou. Mais comme ce genre de transport revient cher! 20 canots ne portent pas la charge de deux wagons, et voici ce que j’ai dî payer pour le trajet de Kazungula à Lealui:

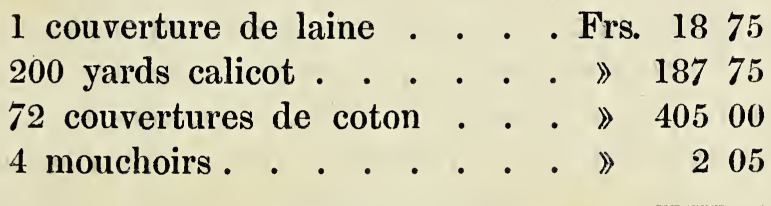

Total Frs. 61355

De Mafeking à Kazungula nous payons en raison d'un franc le kilog. pendant les bonnes années. Pendant les mauvaises, nous payâmes jusqu'à 2.50 francs le kilog. de Mafeking à Kazungula.

Le mardi 22 , M. Coillard revint à sa station, et le 24 je repartis pour Sefula, afin de hâter notre déménagement. Je trouvai ma femme très fatiguée. Depuis son retour de Kazungula, elle n'avait pas eu un jour de repos. Les déménagements et les smearages à surveiller, le ménage, le marché et les soins à donner à $\mathrm{M}^{\mathrm{e}}$ Béguin... c'était assez pour épuiser de plus forts qu'elle.

Nous jouîmes beaucoup des Béguin, et les liens qui se for- 
mèrent entre nous alors qu'il étaient nos hôtes, nous furent toujours très précieux.

Ce fut le cœur plein de tristesse que nous quittâmes Sefula. Si du moins nous avions pu confier l'œuvre à un missionnaire blanc!

\section{XXXVII.}

Nos débuts à Léaluï.

Désagrénents de Lwatilc. - Compensations. - Une journce remplic. - Travaux manuels. - Heureux. - Moqueurs. - be bons évangélistes. - Faut-il laisser son mari: - Evangélistes improvisés. - Lewanika bien disposé. Opposition des femmes.

Tous nous établîmes définitivement à Lwatile le 3 no1 vembre 1894. Nous fûmes vite attachés à nos nouveaux devoirs, heureux d'être auprès de M. Coillard, de lui prodiguer nos soins affectueux et de profiter de son expérience; heureux aussi de la tâche plus grande qui nous y attendait, ce qui nous fit oublier la plaine désolée et noire, ainsi que le vent qui la balaie et couvre tout de cendres et de poussière. Les sauterelles sont plus actives à Léalui qu'ailleurs. La vie y est beaucoup plus chère que sur n'importe quelle autre station; il est plus difficile de s'y procurer les provisions nécessaires pour notre maisomée; nous devons y acheter le bois et l'eau, tandis qu'ailleurs on les trouve à la porte; et quelle eau! Nous l'envoyons chercher à une distance de trois kilomètres. Le café ne parvient pas à en dissimuler le goût saumâtre. Pour avoir bu deux verres d'eau non bouillie ni filtrée, un vendredi soir, ma femme fut vingtquatre heures après saisie de terribles douleurs. L'intoxication ne fut complètement vaincue que le mardi. Une autre fois, ce fut M. Coillard qui éprouva ces mêmes effets à la suite de son café du matin. Mais tüus ces inconvénients sont largement compensés par l'œuvre. Nulle part au Zambèze il n'y a une telle agglomération de gens. Les étrangers et les tributaires venus de tous les coins du pays, semblent s'y être donné rendez-vous. 
6 Novembre. - Nous sommes ici pour tout de bon cette fois, sur notre termitière que vous connaissez dejà. Je suis pleine de joie et de reconnaissance en pensant que je pourrai avoir ici une large part dans l'œurre. Nous y sommes venus à cheval. Ce mode de locomotion me plait toujours beaucoup et me fait un bien réel. Nous pouvons lancer nos chevaux à fond de train à travers la plaine.

12 Novembre. - Aujourd'hui j'ai commencé la tâche que j'ai le bonheur de pouvoir accomplir ici. A 5 heures du matin tout le monde était sur pied. Bientôt après, la cloche de la prière se fait entendre. Tous ceux qui le peuvent lisent à leur tour un verset, puis chacun est invité à réciter un passage qu'il a appris chez lui. Voilà quelques matins qu'on fait cela et nos jeunes-gens semblent apprécier cette innovation. Suivent le chant et la prière. Ensuite on se disperse. Chacun va à son travail. Des femmes et des jeunes filles sont lả qui m'attendent, les unes pour smearer, les autres pour travailler à nos terrassements. Mon mari reprend sa hâche et sa scie. À $7 \mathrm{~h}$. on déjeûne, De 10 à midi je vais à l'école. Willie est débordẻ avec ses 150 ou 160 élèves. À 2 h. j'ai une leçon d'anglais avec les grands garçons de M. Coillard et quelques jeunes-gens de Léalui. Nous y allons de si bon cœur que je ne m'aperçois pas que l'heure a frappé. Je passe chez Ernestina que je trouve brisée après une nuit d'insomnie. En mon absence, les princesses et leurs fillettes n'ont pas perdu leur temps. Leurs aiguilles ont fait beaucoup de travail. Dans la soirée, mon mari s'occupe encore de gens dont les dispositions pour l'Evangile nous paraissent sérieuses.

15 Novembre. - Comme il me tarde que tous les travaux matériels de construction soient finis! Mon mari est maintenant en train de réparer la passerelle que l'inondation de l'an passé a endommagée. Demain il devra aller à Sefula réparer le toit de la scierie, qui a été en partie démoli par une grosse branche brisée par le vent... Je n'admets dans la classe de couture que les filles qui lisent couramment. Deux femmes du roi sont venues me faire visite. A $4 \mathrm{~h}$. un vent effroyable s'est levé et a duré plus d'une heure. Quand ces ouragans ont passé, on s'étonne de retrouver toutes les huttes debout.

Je me sens «at home » à Lwatilé, dans notre nouvelle sphère d'activitẻ! Les journées ne sont pas monotones, quoique toutes remplies par des occupations semblables.

20 Novembre. - Une lettre de M. Goy nous annonce que notre cheval a été happé par un crocodile. C'est un vrai chagrin!

J'at été à la Capitale de 4 à $6 \mathrm{~h}$. et, comme toujours, j'ai beaucoup joui de mes visites. La pauvre Ma-Morambwa broyait du 
noir. Elle m'a refait la description cent fois répétée de tous ses maux, avec une mimique des plus expressives! Je pressai le pas, je n'aimais pas à me sentir seule avec mes deux fillettes dans ce dédale de huttes. Des groupes de femmes oisives me saluaient en me criant des sottises. Pauvres créatures...

Ce matin, mes grands garçons à l'école ont èté rieurs et distraits. Je ne suis pas sûre de n'avoir pas èté quelquefois le sujet de leur gaîté intempestive. Cela aurait pu m'intimider à mes débuts de la vie africaine, mais maintenant j'y suis faite. D'ailleurs je ne permettrai pas que cela se répète. Ils sont génẻralement très polis et je n'ai que du plaisir pendant mes deux heures d'école chaque matin.

Le 6 décembre, ma femme fut appelée au secours d'Ernestina qui venait d'avoir un garçon. Norea, qui était venue l'avantveille pour la soigner, quoique mère d'un enfant, dut avoir recours à l'expérience de ma femme. Ma femme continua à la visiter chaque jour et à lui apporter fréquemment quelque gâterie. Le 17, quand elle parla de faire sortir le bébé, la mère se récria disant qu'il était encorre trop petit! Nous fûmes étonnés que des Bassoutos chrétiens et enfants de chrétiens observassent la coutume qui veut que les enfants aient un mois accompli avant de leur faire sentir le grand air. Est-ce une superstition qui se cache là dessous, ou une régle hygiénique? Ou bien, serait-ce pour cacher que ces petits sont presque blancs?

Le 18 je partis pour Sefula. Je fus heureux d'y trouver plus de 100 enfants à l'école, et 90 professants à la classe, pour la plupart des adultes pleins de zèle, tant pour la fréquentation des cultes, que pour s'efforcer d'y amener leurs voisins.

Ce qui me peina, ce fut ce que Pauluse me dit de ses malentendus avec Willie. Pendant que ma femme faisait son possible pour être bonne et prévenante pour Ernestina, et que Norea soignait la jeune mère, Willie écrivait à Sefula, qu'il étaient abandonnés, dans la détresse, dans un désert! Aussi il réclamait Elisa auprès de sa femme!

À la classe je répétai un mot de Nolianga: «Voyez, avait-elle dit à ma femme, Manwendarubi, vous la dites convertie, et pourtant elle vit avec un homme qui a d'autres femmes, et moi, pourquoi quitterais-je le roi?» Dans sa prière bien humble, notre brave Manwendarubi avoua qu'elle se sentait depuis longtemps dans une fausse position, et elle remercia Dieu d'avoir envoyé son 
serviteur pour le lui rappeler. Mais Ma-Waingaio ne voulut pas admettre la possibilité de laisser son mari.

À Lwatile pendant plusieurs semaines des auditoires de près de cinq cents personnes se pressaient dans le temple, et presque chaque dimanche nous entendions de nouvelles confessions de jeunes gens, jeunes filles ou enfants.

Nous aurions voulu les voir pleurer sur leurs péchés. Nous aurions voulu qu'il reconnussent mieux que, hors de Jésus, ils ne pouvaient rien faire.

Cependant, plusieurs d'entr'eux pleins de zèle, allaient évangéliser les villages voisins; l'opposition qu'ils rencontraient les fortifiait bien plus qu'elle ne les décourageait. Un simple esclave était le chef de cette bande d'évangélistes improvisés. Ils instituèrent spontanément una réunion d'édification mutuelle et d'évangélisation, qu'il tenaient au coucher du soleil, tantôt dans l'un tantôt dans l'autre des quartiers de li Capitale.

Toujours favorable à l'Evangile, Lewanika poussait ses gens à se convertir, il encouragea même publiquement sa femme Nolianga à déclarer tout ce qui était dans son coeur. Hélas, une invitation de quelqu'un ne pouvant que dire : allez, n'avait pas beaucoup de valeur.

Le pauvre homme nous disait qu'il serait très embarrassé s'il devait choisir sa femme parmi celles de son harem, car il n'y en avait aucune qu'il aimât assez pour l'avoir elle seule. Pauvre homme! et il en avait quinze!

Nolianga elle-même hésitait à faire le pas décisif: Se séparer"du roi et laisser cette position qu'elle sentait être contraire à la loi de Dieu. Elle tenait à sa position sociale, à ses aises, ̀̀ ses habitudes, et qui pourrait lui jeter la pierre? Les femmes étaient aussi opposées à l'Evangile que les chefs eux-mêmes. Elles ne sentent pas tout ce que leur situation a d'anormal. Non seulement elles ne savent pas tout ce qu'il y a dans le vrai mariage, mais elles ne comprennent rien à l'émancipation, à l'ennoblissement de la femme opéré par le christianisme. 


\section{XXXVIII.}

\section{L'opposition s'organise.}

\section{Dpposition des chefs. - Véhémente apostrophe de Pauluse. Cités devant les gouverucurs. - Accusations. - Menaces. réponses des accusés. - La Parole de Dieu blessera toujours. Lewanika notre défenseur.}

T 'opposition des chefs était plus naturelle, car ils sa$\perp$ vaient bien que l'Evangile visait à miner peu à peu celles de leurs institutions nationales qui étaient basées sur la raison du plus fort; ils craignaient que leur pouvoir ne fût bientôt ébranlé.

Le dimanche avant Noël nous eûmes à Lwatile les évangélistes Pauluse et Yakobo et leurs femmes, venus pour passer la fête avec nous. Ce furent de bonnes journées, Pauluse parla au culte avec l'aplomb et la force que lui donne l'intensité de sa vie spirituelle; mais il avait comptė sans la susceptibilité des gens. Les gros bonnets cherchaient un prétexte pour faire éclater leur haine, et ils le trouvèrent dans le discours même de Pauluse. Nous qui l'écoutions avec d'autres oreilles, nous le crûmes inspiré. Il parla avec feu et dit en montrant le roi de son index: «Toi, Lewanika, tu connais la vérité, tu l'entends depuis des années, mais tu la repousses. 'Tu périras. Tu ne rejettes pas le salut pour toi seulement, mais tu smpêches des gens de se convertir. Il regardent à toi, tu es responsable de ta nation $\gg$.

Pendant cette véhẻmente apostrophe, le roi semblait mal à son aise, et nous remarquâmes parmi l'assemblée une certaine agitation que nous comprîmes plus tard. Un des chefs aurait voulu se lever pour imposer silence à cet audacieux orateur, mais ses voisins l'en empéchèrent. Lewanika fut soulagé quand Pauluse s'assit. Yakobo parla à son tour, mais a vec plus de prudence. Le soir, le roi ne parut pas au culte. Son ministre et les chefs les plus importants l'imitèrent.

Au culte de Noël le roi seul et les élèves parurents. Le lendemain, mercredi 26 décembre, à dix heures du matin, des envoyés des chefs vinrent sommer les évangélistes et deux de nos garçons de comparaître au Khotla. Que voulait-on de nos garçons? Il ne 
s'agissait donc plus d'une simple discussion religieuse. L'air arrogant de ces messagers nous fit prévoir qu'il y aurait lutte, et M. Coillard eut peur pour nos garçons. Il était trop souffrant et trop faible pour aller à Léalui; il pria mon mari de quitter son travail et d'aller assister au débat, comptant que sa présence mettrait un frein aux passions surexcitées de ces sauvages. On sait que le missionnaire a le droit de servir de refuge aux condamnés, et d'intercéder pour eux. Il est un natamaio (ministre de grâce).

Voilà donc mon mari, les trois ẻvangélistes, et deux jeunes gens partis pour la capitale. Nous restons, M. Coillard et moi, en proie $\grave{a}$ une vague inquiẻtude, à la crainte que l'on ressent chaque fois que Satan livre une bataille dans ce triste pays où il domine encore. Et quels alliés il trouve dans ces ma-Rotsé! Les évangélistes et mon mari se rendirent chez le roi, qui fut très étonné de voir les jeunes gens qui les accompagnaient; il dit ne pas savoir qu'on les avait appelés et ignorer pourquoi les chefs avaient cru leur présence nécessaire.

Kalonga, un des principaux acteurs dans toute cette affaire, présent dans le kashandi, expliqua que le ngambela et lui avaient jugé à propos de faire comparaître ces garçons. Alors commença une contestation entre le roi et mon mari. Lewanika aurait voulu ne pas assister au débat, mais on lui représenta que, lui absent, personne ne saurait conduire la discussion impartialement. «Nous ne pourrons pas parler, on ne nous écoutera pas ». Le roi se rendit enfin à ces objurgations et tous ensemble ils s'acheminèrent vers la place du Khotla, où devait avoir lieu la discussion. On se réunit dans la maison-hangar qui vient d'être bâtie et qui doit servir aux assemblées politiques et judiciaires. Elle a $18 \dot{a} 20$ mètres de long sur 10 de large. Les poteaux extérieurs sont entièrement masqués par des nattes aux desseins multicolores. Le roi fit asseoir mon mari à sa droite, tandis que les évangélistes s'accroupirent à sa gauche.

Il était onze heures et demie quand le débat commença et ce fut Kalonga qui ouvrit le feu. Il exposa les griefs suivants: «Pauluse a manqué de respect envers le roi, et a voulu diviser le roi et son peuple. Nyondo et les autres garçons qui, le dimanche, s'asseyent près de notre roi, s'enorgueillissent et oublient qui il est et qui il sont».

« Ne sais tu pas, disent-ils à l'évangéliste, que si tu es auprès du roi maintenant, ce n'est qu'en ta qualité d'étranger? Mais, n'ẻtait ce roi même que vous insultez, vous ne seriez pas à cette place d'honneur. Nous pourrions vous ètrangler, vous chasser du pays. 
Vous ne savez pas enseigner. Ce que tu disais dimanche, Pauluse, où l'as-tu pris? Dans ton mauvais cœur!.... Nous menacer, prédire notre perte parce que nous ne nous convertissons pas tous ensemble! Nest-ce pas nous maudire, nous jeter un sort?... Ne rends pas le roi responsable de notre incrẻdulité; il n'empêche personne de se convertir. C'est nous qui ne voulons pas. Vous nous dégoûtez de l'Evangile par votre manque de respect. Pourquoi tant nous presser? Laissez-nous donc la paix! Vous nous reprochez sans cesse de ne pas croire, mais n'avons-nous pas cru depuis longtemps? N'est-ce pas nos enfants que vous enseignez? Qui vous a jamais empêchès de prêcher ce que vous voulez? Ne pensez pas que nous retournerons à vos cultes. Nous en avons assez désormais. Nous sommes trop âgés pour songer à changer nos coutumes. Occupez-vous des enfants et contentez-vous-en.... Pourquoi honorez-vous tant votre vieux missionnaire? Vous ne songeriez jamais à occuper sa place. Nous ne la lui disputons pas non plus, quand même vous le placiez au dessus de tous, et que vous en fassiez presque un Dieu. Mais pourquoi rabaisser notre roi? N'est-ce pas lui qui est un descendant des dieux, un dieu lui-même?»

«Et vous, Nyondo et Mompisho, vils ma-Shikulumbwe; parce que vous avez des vêtements des blancs, vous croyez pouvoir vous élever au dessus de nous tous, manquer de respect au roi! Comment avez-vous si vite oubliẻ d'où vous venez? N'est-ce pas vous que nous avons étẻ chercher dans votre pays, avec des bâtons? Qu'étaient vos pères et vos mères? Que sont-ils? Est-ce que parni tous vos compatriotes il y en a un qui ait un bout de vêtement sur lui? Vous asseoir près du roi! Quelle impudence! Mais vous ne retournerez pas chez vos ba-ruti, vous resterez ici, et nous vous rappellerons ce que vous êtes, puisque vous l'avez oubliẻ. Qu'est-ce qui nous retient de vous garrotter et de vous étrangler? ».

«Quant au marché des boeufs et des vaches, c'est une chose bizarre, disaient ces forcenés, que les missionnaires refusent d'acheter, sinon pour des livres. Si vous êtes venus enseigner le sagesse des livres, pourquoi ne les distribuez-vous pas? Ne les avez-vous pas reçus pour cela? Vous dites que c'est la Parole de Dieu. Mais que voulez-vous faire de ces vaches alors? Pouvez-vous les envoyer á votre Dieu? N'est-ce pas plutôt vous qui les gardez? Tous ces prêcheurs de l'Evangile en veulent à nos femmes. Mais lequel d'entr'eux est venu sans sa femme? Et nous ne pourrions pas garder les nôtres!.... Ah! outrager notre roi! Vous ne savez donc pas qu'il est un lion!.... Vous ne craignez donc pas d'exciter ses chiens? Nous nous serions dẻjá lancẻs sur vous s'il ne nous avait 
retenus. Mais prenez garde, nous pourrions ne pas toujours vaincre notre cœur ».

Voilà, pour autant que nous avons pu le résumer, ce qui a ètẻ dit pendant près de quatre heures. Nous ne pourrions pas vous répéter toutes les atrocités dont ces orateurs furibonds entremêlaient leurs discours. Tout cela était dit sans suite et sans ordre, dans un brouhaha indescriptible. L'un n'avait pas achevé de parler, que deux ou trois se disputaient pour prendre la parole.

Le tour des accusés vint enfin. La seule part que nos jeunes gens eùssent prise jusqu'alors au débat, avait été les battements de mains obligatoires, chaque fois qu'on s'adressait à eux. Une fois que Nyondo avait voulu prendre la parole pour protester contre les calomnies d'un orateur, la fureur d'un de ces forcenés sembla prête à se déchaîner et il dut se taire. Oser se dẻfendre! Qu'eût-ce été si le roi n'avait tenu tous ses chiens $\in$ n laisse par sa présence même? Cette scène faillit se répéter quand Mompisho fit signe qu'il voulait parler. Cette fois, le roi intervint en disant: «Laissez-le donc! ».

«Ma-Rotsé, vous nous accusez de beaucoup de choses. Qui n'a ses torts? Mais ne dites pas que nous manquons de respect envers le roi. Nous n'avons pas oublié qui nous sommes, ni qui est le roi. $\mathrm{Si}$, à la chapelle, nous nous asseyons derrière lui, c'est que nous avons été placés là par le Missionnaire ». Myondo répéta ces mêmes choses et ne craignit pas de relever certaines injures. Il interpella Semonja, qui, malgré sa profession de christianisme, avait cru devoir hurler avec les loups pour ne pas être dévoré par eux.

Pauluse, à son tour, se leva sur ses genoux, et expliqua comment, par son geste du doigt, il n'avait nullement eu l'intention d'offenser le roi. Il ignorait que ce simple mouvement pût être pris pour une insulte; il avait seulement voulu faire comprendre que nous ne nous adressons pas seulement aux esclaves, mais que notre Evangile est un Evangile pour tous.

Willie parla sur le respect et sur la vente des livres. Yakobo dit à l'assemblée de la part de M. Coillard, que les garçons n'avaient fait que lui obẻir à lui en s'asseyant derrière le roi, à la chapelle.

Mon mari prit enfin la parole: « J'avais pensé me borner à écouter, mais vos accusations m'obligent à ouvrir la bouche... Vous vous plaignez de ce que nous vous blessons par nos prédications, mais écoutez ce que je lis dans le Nouveau Testament: «La Parole de Dieu est une épée à deux tranchants ». La Parole de Dieu blessera toujours. Et nous ne pouvons pas ne pas vous la prêcher fidèlement. Ne nous en veuillez pas. Vous avez accepté 
les habitudes, les chants, les danses des ma-Mbunda sans aucune peine. Rien d'étonnant à cela, parce que tout cela est selon vos cours. Mais vous n'accepterez pas de même le christianisme, parcequ'il va à l'encontre des désirs de votre cœur. Ce ne serait plus le christianisme si on pouvait l'accepter sans luttes. Vous nous en voulez parce que nous vous pressons de vous convertir: mais comment pourrions-nous nous taire et rester impassibles, en vous voyant marcher vers la perdition, quand le salut est là pour vous aussi ?.. Vous insistez surtout sur un manque d'égards envers le roi; c'est ce qui m'a le plus étonné. Ecoutez une fois encore ce que nous vous prêchons à cet égard: Nous respectons le roi, et nous l'honorons surtout lorsque nous lui disons la vérité... Ces jeunes-gens n'ont commis aucune faute. Nous les avons placés à ce banc parceque nous avons besoin de nous entourer de chanteurs. Et si parmi vous, parmi les maîtres ou parmi les esclaves, nous trouvons quelqu'un de bien disposé envers l'Evangile et ayant une bonne voix, nous le placerons là aussi. Que cela ne vous fàche pas... Apaisez votre fureur à l'égard de Pauluse. Pauluse n'aurait pas montré le roi du doigt s'il avait connu vos mœurs, et je suis sûr qu'il ne le fera plus à l'avenir; tout comme je pense que ceux d'entre vous qui viennent chez nous; et que nous prions de ne pas priser dans notre maison, ne le feront plus. Mais pourquoi ne vous êtes-vous pas contentés de lui signaler ce manquement; à l'amiable? Pourquoi en faire une question d'état? Ne serait-ce point parce que vous cherchiez un prétexte pour vous soulever contre l'Evangile? Vous sentez qu'il est une puissance; mais songez-y de bonne foi, et vous avouerez que vos consciences nous donnent raison ».

Pauluse protesta de son regret pour le geste intempestif, auquel on avait attachẻ tant d'importance, mais il revendiqua hautement le libre et fidèle exercice de son ministère.

Ce fut alors le roi qui prit la parole. Qu'allait-il dire? Prendrait-il parti pour nos adversaires? Allait-il se tirer de cette affaire par un compromis?

«Mes ma-Rotsé, commença-t-il, les évangélistes et les élèves des missionnaires ne me manquent de respect en aucune façon. Ils ont pour moi tous les égards qui me sont dûs. Je sais très bien que si ces jeunes gens sont à cette place que vous leur disputez, c'est que le morriti les y a mis. Ne savez-vous pas d'ailleurs que Dieu est lui aussi un mo-rena, un maitre, un roi, un seigneur, et qu'il veut l'obéissance de ceux qui se disent ses sujets? Il peut et veut récompenser ceux de ses serviteurs qui font sa volonté et quelquefois Il élève les plus humbles; dans les cieux, 
des esclaves seront les ministres de leur Roi. Parmi nous, il est des chefs qui peut-être bientôt ne seront plus que de misẻrables esclaves, tandis que ceux que vous méprisez aujourd'hui pourront être un jour au dessus de nous. Vous n'aimez pas l'enseignement des missionnaires, mais vous aurez beau faire, ils n'en donneront pas d'autres. Vous aurez beau les menacer et les reprendre, ils ne changeront pas. C'est pour nous dire ces choses qu'ils sont venus ici. Mes ma-Rotsé, avouez qu'aujourd'hui vous n'avez choisi que des prétextes... Vous avez peur que je devienne chrétien, que je renvoie mes femmes, et que je ne vous oblige á en faire autant... Ma-Rotsé, prenez garde, une autre fois, quand vous instruirez un procès au Khotla, que vos griefs soient mieux fondés ou vous le perdrez, tout comme aujourd'hui ».

L'assemblée accueillit le discours du roi par le Kandelela obligatoire, et la séance fut close. Avant la dispersion de la foule, un de nos deux jeunes-gens dit encore: «Ma-Rotsé, vous nous critiquez amèrement. Nous saurez un jour que les enfants de Dieu sont les meilleurs serviteurs de l'homme. Avant d'être converti, l'on obẻit en grommelant. Après, lorsque notre maître nous dit: « Va!» On court!

$\mathrm{Au}$ moment où Nyondo et Mompisho accompagnèrent mon mari chez le roi, pour le remercier et prendre congé de lui: «Voilà, dit Lewanika à ses gens, des garçons que j'aime. Ils n'ont pas peur de dire franchement ce qu'ils pensent $\gg$.

L'après-midi était avancée quand nos enfants crièrent: «Voilà les évangélistes et le missionnaire! » Ils arrivaient en effet à grands pas, et nous nous sentîmes bien soulagés en apprenant l'issue du dẻbat. Ce jour-lá Lewanika nous parut inspiré.

Ce débat public avait bien marqué une victoire de l'Evangile; elle n'en fut pas moins suivie par une recrudescence de mécontentement parmi les chefs, à Léalui comme à Sefula et partout. On parlait beaucoup des conversions de Litia et d'Akanangisoa, et on redoutait celle du roi.

Nous retrouvâmes des échos de toutes ces rumeurs à Nalolo, où nous nous rendîmes pour passer avec les Béguin la fête du jour de l'an, et pour célébrer le baptême de leur petite Marguerite. 


\section{XXXIX.}

Lutte entre les ténèbres et la lumière.

senaine de prières. - Recrudescence du paganisme. - Meurtres. - Peu de valeur du sang humain. - Les "croyants" et les bals. - L'école en souffrance. - La classe est une pépinière. - Fête de la nouvelle lunc. - Une prenve de confiance. - Mokamba revient au Sauveur. - Méthode mission. naire. - Mamwudarubi résolue. - Inauguration de l'école du dimanche.

$\mathrm{M}$

AIs la lutte allait devenir plus dure. Le premier lundi de 1895 nous inaugurâmes la semaine de prières avec les sujets proposés par le Comité de l'Alliance Evangélique. Chaque soir entre $5.30 \mathrm{~h}$. et $6.30 \mathrm{~h}$. nous eûmes des assemblées variant entre 70 et 150 personnes. Lewanika y prit part quelquefois. Mokamba, rentré depuis peu du bo-Toka et sa femme Mpololoa (la fille aînée du roi), fréquentèrent régulièrement ces réunions.

Mais Satan ne se tenait pas pour battu. Quelques-uns de nos jeunes professants esclaves furent maltraités, et les bals nocturnes sur la place publique reprirent avec une ardeur nouvelle. Le matin du 8 janvier 1895 une jeune fille de 12 à 13 ans fut trouvée morte. Elle avait été étranglée pendant que les danses allaient leur train, par un esclare mo-Shukulumbwe qui lui avait ainsi fermé la bouche après l'avoir outragée.

Le 11, un esclave de Nolianga qui était venu vendre des ro. seaux à la station, eut le malheur au tournant d'une hutte, de blesser avec sa lance la jeune princesse Mofuekelwa qui courait pour venir à la réunion. Ce n'était qu'une égratignure près de l'œil, que je pansai anssitôt. Le lendemain matin en sortant de la prière, quelle ne fut pas notre horreur d'apprendre qu'on avait tué le malheureux esclave. Il avait été étranglé sans forme de procès par trois hommes que le roi avait envoyés pour le questionner. Le sang humain avait encore bien peu de valeur aux yeux de ces sauvages, et nous réalisâmes une fois de plus que Dieu avait chargé ses anges de nous garder! 
20 JANvier. - Avant hier, Willie me fit dire qu'il y avait peu d'enfants à l'école et que je pouvais l'y laisser seul. Accompagnée de Kaida, j'allai passer ces deux heures à la capitale. J'eus un long entretien avec Kamona, la femme du roi, mère de l'enfant blessée. Il ne restait à la fillette q'une petite marque à peine visible, et lui, le pauvre homme qúi l'avait faite, il est mort! C'est ce que je reprèsentai à Kamona, mais elle paraissait me dire que je faisais beaucoup de bruit pour rien! Un esclave de plus ou de moins, qu'est-ce que c'est? Mais blesser un enfant de sang royal!..

Dieu a mis quelques fleurs dans notre dẻsert. Quand on cherchait les meurtriers de la petite fille, ou commença par demander: Quels sont les habitués à danser? Qui ne danse jamais? «Oh, crièrent plusieurs: Tous les «Croyants » peuvent être exclus, nous ne les voyons jamais à nos danses ».

Hier, mon mari et moi avons parcouru les pauvres huttes d'un quartier de la capitale... Il nous tarde de connaître ces 2000 ou 3000 personnes qui vivent, souffrent et meurent à nos côtés. Priez pour que nos cœurs brûlent d'amour pour ces âmes profondément à plaindre.

25 JANVIER. - Il fait chaud dès le matin. Je souffre frẻquemment de violentes névralgies depuis quelques mois... Notre jardin est un parterre fleuri qui repose nos yeux, fatigués de se porter sur la plaine dẻsolẻe qui nous entoure.

Le 20 janvier, notre maison d'habitation était complètement terminée, sauf la couverture de chaume que des ouvriers promis par le roi devaient exécuter. Ce travail est un des premiers que les Zambéziens ont appris à bien faire. Je continuai à consacrer chaque jour plus d'une heure à des travaux manuels: (confections ou réparations). Je ne mentionne pas la surveillance qu'il me fallait exercer sur les ouvriers hommes et femmes, ni le temps consacré à prêter mes soins aux malades qui accouraient vers nous.

Mais je pus dès lors me vouer plus complètement à la tâche missionnaire proprement dite; et d'abord à l'école qui en avait grand besoin.

Willie était surchargé. Il n'avait de bonne méthode que pour l'enseignement $d u$ chant. Les enfants apprenaient par cœur les tableaux et les vocabulaires, comme des perroquets, mais n'étaient pas capables de lire. Ma femme avait la première classe, mais il en restait 7 à l'évangéliste, et il ne savait pas se faire aider par des moniteurs! Il avait comme principe de trop pousser les 
enfants, de les promouvoir dans des classes qu'ils étaient incapables de suivre, et cela pour les encourager ou leur plaire; triste système, c'était les laisser croupir en leur faisant oublier le peu qu'ils savaient. Ce qui était le plus en souffrance c'était l'écriture. Willie ne croyait pas à l'utilité des lignes, et ne commençait jamais par les bâtons, rarement par les lettres; il traçait comme modèles pour les nouveaux-venus des mots écrits en petits caractères. Il n'avait non plus de programme ni d'horaire; je commençai par en faire. Il faut ajouter à la décharge de Willie, qu'après M. Coillard, il fut celui de notre famille missionnaire qui eut le plus fréquemment la fièvre, il l'eut en moyenne un jour sur trois ou sur quatre, ce qui l'obligea plusieurs fois à nous laisser toute la charge de l'école, à ma femme et à moi.

Nos professants nous occupaient et nous préoccupaient aussi. Leur nombre augmentait sans cesse; mais l'interrogatoire que nous faisions subir aux nouveaux, et les leçons données aux autres, nous prouvaient que pour la plupart il ne s'agissait pas de conversion; hélas! plusieurs pensaient que d'avoir fait profession de 《croire 》, suffisait pour leur enlever toute crainte. Leur sûreté nons faisait trembler, car Jésus n'était ni le fondement de leur foi, ni la source de leur vie. Dans cette pépinière qu'était la classe, plus d'une plante périssait et d'autres végétaient et faisaient pressentir qu'elles n'auraient pas survécu à la transplantation. Mais il en était qui se développaient et promettaient de porter du fruit pour notre Maître.

La prière du matin, toujours bien fréquentée, continua à nous encourager. Beaucoup d'entre ceux qui y venaient s'étaient acheté des Bibles ou des Nouveaux Testaments; je leur en avais vendu pour 260 francs. Nous avions chaque matin une belle gerbe de 15 à 40 versets. Cet exercice les obligeait à lire et à fouiller la Parole de Dieu, et en enrichissait leur mémoire. Le choix des passages laissait quelquefois à désirer, mais il devenait de plus en plus intelligent.

Le 28 janvier, un des hommes préposés aux réparations de la Nalikwanda, qui n'avait probablement pas vu la nouvelle lune la veille, alla battre le tambour avec lequel on appelle les gens chargés de ce travail. « Comment, lui dit-on, tu irais travailler à la nouvelle lune? Ne crains-tu pas que tes plats et tes pots se brisent? 》 Cet homme persistant à battre le rappel, la 
chose vint aux oreilles de Lewanika. Il sortit vers ses sujets et leur dit: "Si hier on avait tué un hippopotame, n'en apporterait-on pas la viande aujourd'hui même? ne voyez-vous pas ces gens avec le tribut? Vous opposerez--vous à ce qu'ils le portent au Khotla et qu'il y soit distribué aujourd'hui? Viens donc, toi qui ne crains pas, allons au travail; quant à vous, restez puisque vous craignez de casser vos vases! - Non, non, nous irons aussi 》. Ils allèrent en murmurant et travaillèrent jusqu'à $4 \mathrm{~h}$. Dès lors, le jour de la nouvelle lune cessa d'être un jour de repos obligatoire.

Après leur travail ils n'en firent pas moins leur danse à la nouvelle lune. Nous vîmes sur la place une vingtaine d'hommes, les reins entourés d'une ceinture à laquelle sont suspendues des quantitès de queues de léopards et de chats sauvages, formant un cercle autour des tambours et exécutant toutes sortes de mouvements et de contorsions rhythmées, qui constituent leurs danses, a umilieu d'une foule d'hommes, de femmes, d'enfants. Même les femmes du roi sont autorisées ce jour-là à sortir sur la place publique et à s'y asseoir sur leurs nattes, entourées de leurs servantes.

Une femme du roi venait d'avoir un enfant. Quand nous nous présentons, ma femme et moi, on nous laisse aussitôt pénétrer dans l'enceinte qui lui sert de retraite, et où ne sont admises outre ses esclaves personnelles, que quelques parentes. La jeune mère va jusqu'à nous faire voir son nouveau-né, et cela avec la permission de Katoka qui se trouve là. Or tous les enfants de la famille royale sont soigneusement dérobés anx yeux $d u$ public jusqu'à l'âge de quatre ans. Pour nous il y avait longtemps qu'on faisait exception, mais c'était la premiére fois que nous étions autorisés à poser notre regard sur un tout jeune bébé. Nous fûmes très sensibles à cette preuve de confiance.

Le 30 janvier, Mokamba nous annonça qu'il avait renvoyé sa seconde femme et qu'il revenait vers son Sauveur. Il était travaillé depuis longtemps, il n'avait jamais été heureux depuis qu’il s'était séparé de nous, malgré tout ce qu’il avait fait pour s'étourdir. Il n'avait pas discontinué de lire son Nouveau Testament, pas même lorsqu'il nous combattait comme un ennemi acharné. Pendant le voyage au bo-Toka, qu'il venait de faire, quand son compagnon de route lui demandait de faire le culte, il répondait qu'il en était incapable: comment exhorter 
les autres quand lui même avait peine à lire la Parole de Dieu et à prier? Car, ajoutait-il 《taba li nyatsa 'na 》(i. e. les choses [vérités, récits] me blâment moi). Il nous dit que, ne pouvant résister plus longtemps, il se rendait en implorant grâce. Quand il alla annoncer au roi le pas qu'il venait de faire, celui-ci s'en réjouit beaucoup; il avait été affligé de son infidélité et de celle de Litia, mais il espérait que cette fois ils persévèreraient jusqu'à la fin.

31 JANVIER. - Je voudrais pouvoir exercer une influence durable sur les femmes, mais commes elles sont difficiles à atteindre! J'en ai dejjà cependant un certain nombre qui viennent assez fréquemment me voir. Nolianga, Ma-Njamqa... Nanjeke. Celle-ci je l'avais connue à Sefula, puis longtemps perdue de vue.

Il faut bien nous faire tout à tous, et bien que nous essayons de faire pénétrer nos idées dans leur esprit, il faut à notre tour entrer dans le leur et ne pas les juger en ne nous plaçant qu'à notre point de vue.

L'œuvre de Sefula s'était davantage ressentie du fait que les évangélistes avaient dû comparaître au Khotla et qu'ils y avaient été insultés. Le parti païen devint plus agressif et plusieurs défections eurent lieu parmi les professants.

Le dimanche 3 février, devant un auditoire de 550 personnes, aussitôt après ma prédication, Mokamba se leva et dit: «Je vous annonce, ma Rotsé et missionnaires, que je reviens à mon Sauveur, celui que j'avais déjà une fois fait profession de servir, mais dont je m'étais éloigné. Je m'humilie devant Dieu, et reviens à mon Sauveur pour le servir 》.

Ce même jour nous inaugurâmes l'ecole du dimanche, dont ma femme prit la direction. Nous divisâmes les 100 enfants présents en dix classes, et assignâmes à chacune d'elles un de nos catéchumènes plus avancés, comme moniteur.

4 FÉVRIER. - L'ouverture de notre école du dimanche répond à un de nus plus vifs désirs. Nous ne doutons pas qu'elle ne soit une source de bénédictions aussi grandes pour ceux qui y consacreront leurs efforts que pour ceux qui en bénéficieront directement. Ce n'est pas sans un tremblement intérieur que je ferai mes premières armes. Nẻanmoins je crois que Dieu m'appelait à cette tâche, et qu'il m'aidera à la remplir. Aujourd'hui le roi a été notre hôte. Il était d'une humeur charmante. 


\section{XL.}

Polygamie et divorce.

\footnotetext{
Procédure se-rotsé. - Opinions partagées. - La défense.
}

Verdiet du roj. - Mamwendarubi heureuse de porter sa eroix. - Joie à Sefula.

$\mathrm{I}$

E 5 février, après la distribution d'un tribut, composé d'une $\downarrow$ quinzaine de nattes et d'une quarantaine de pioches et de hâchettes, commença le pitso au sujet du divorce des femmes de polygames. Le roi y avait convoqué tout le ban et arrière-ban des chefs et officiers. Il me fit asseoir à sa droite, tout près de lui, à la place d'honneur." qu'il a toujours donnée aux missionnaires, même lorsqu'il nous était opposé.

Lengualala se plaça près des chefs et leur dit à voix basse: "J'ai trois femmes qui ont cru. Mamwendarubi, l'une d'elles, prétend maintenant me quitter, parce que, dit-elle, elle ne peut rester femme d'un polygame. Pourquoi cela? Je lui permets cependant de suivre tous les cultes du dimanche et de la semaine. Si elle me quitte et que les deux autres qui ont cru suivent son exemple, comment pourrai-je encore suffire aux travaux du roi? Elle voudrait que je renvoie mes autres femmes pour la garder elle seule, alors elle consentirait à rester, mais je ne le puis. D'ailleurs elle est mon esclave, est-ce qu'il lui suffit de croire pour s'émanciper de sou maître? 》

Nalonga expliqua à haute voix ce que Lengwalala venait de dire, et invita tous les présents à émettre leurs avis. Le premier qui prit la parole dit: « La condition faite à Lengwalala va vous être faite à tous; mais est-ce que vraiment toute femme qui croit va quitter son mari? 》Un autre: "Que cette femme retourne vers son mari! Puisqu'elle est son esclave, il a le droit d'en faire tout ce qu'il veut 》. "Qu'elle retourne vers son mari! dit $N d u i$, n'est-elle pas son bien, étant son esclave? 》 Un officier: "Mais pourquoi l'appelles-tu son esclave, sa propriété? Est-ce que toute femme est esclave parce qu'elle est femme?》Un autre: 《Je comprends que si je viens à croire, je devrai choisir parmi mes femmes celle que je préfère et renvoyer 
les autres, mais ce n'est pas la femme qui doit faire le premier pas 》. Un vieillard: "Pourquoi innover? D'où vient cet enseignement? 》 Tawira chef: 《La cloche nous appelle tous, elle dit: Hong! Hong! (venez! venez!). Si les femmes vont et que nous restions, c'est notre faute, si les femmes se convertissent et que nous refusions de le faire, c'est notre faute. Les missionnaires s'adressent à tous. Cette femme ne refuse pas de continuer à vivre avec son mari, mais à la condition d'être sa seule femme. Si vous voulez garder toutes vos femmes, chassez les missionnaires, car ils ne cesseront pas de proclamer la loi de Dieu 》. Un autre: « Le mariage est un accord entre l'homme et la femme. Si l'un des deux n'est plus content de vivre avec l'autre, il le quitte. Cette femme a donc usé de son droit 》. Kakulelielo chef: «Du tout, la femme n'est pas libre de quitter son mari sans son consentement 》. Moramata, serviteur personnel du roi: «Qu'elle cesse d'être sa femme, mais qu'elle continue à être son esclave 》. Un officier: "Que faire? Comment résister au courant? le cas de cette femme va se multiplier 》. Un chef: «Vous ne direz pas que nos femmes n'ont pas le droit d'aimer le roi tout comme nous. Il en est de même à l'égard de Dieu. Si cette femme insiste pour quitter son mari, ce n'est pas par esprit de dispute, mais pour servir Dieu 》.

Semonja avait déjà essayé de parler à deux reprises, au moment où son rang l'exigeait, mais le roi l'en avait empêché parce qu'en tant que professant, il était impliqué dans l'accusation. (Dans les procès, la défense suit naturellement l'accusation). Il parla et dit: "Lengwalala, si tes trois femmes qui ont cru veulent se séparer de toi, elles le feront, tu n'y peux rien. Ne fais pas l'étonné. Il y a longtemps que l'Evangile est annoncé dans ce pays, et surtout à Sefula. Tu devais savoir à quoi cela aboutirait. Si tu tiens à cette femme, renvoie les autres, sinon libère-la. Et toi, Kalonga, n'est-ce pas toi et d'autres qui essayez de vous asseoir dans deux canots? Pourquoi acceptezvous certaines choses des missionnaires, ou encore pourquoi ne les renvoyez-vous pas? 》

$J e$ parlai à mon tour et dis que nous ne demandons la monogamie qu'à des chrétiens; puis j'expliquai le passage qui avait d'abord troublé puis décidé Mamwendarubi. Quand Jésus dit à la Samaritaine: Celui que tu as maintenant n'est pas ton 
mari, c'était lui dire qu'elle était adultère, pourquoi? Parce qu'elle vivait avec un homme qui avait une autre femme.

Le roi: La question est complexe. D'abord l'esclavage. Avezvous jamais entendu un missionnaire prêcher la révolte aux esclaves? Ils leur prêchent l'obéissance et la soumission. Si vous vous convertissez, cesserez-vous d'être mes sujets? Est-ce que nos enfants qui ont cru, ont cessé d'être nos enfants? Quant à cette femme, pourquoi lui en voulez-vous tant? N'y-a-t'il pas sans cesse des divorces parmi vous? Si elle a cru, qui s'opposera à sa foi? Et si une des femmes du roi se levait à l'église, la tueriez-vous? Qu'auriez-vous à dire contre elle? La seconde femme de Litia est revenue de Kazungula, qui l'a insultée? Cette femme que vous jugez est une chrétienne; c'est tout, dit il: vous ne l'obligerez pas à agir contrairement à sa foi. Lengwalala, si tu crains de les perdre toutes, choisis celle qui tu préfères. Si elles sont tes esclaves, elles continueront à te servir. Où iraientelles? qui les ferait vivre? Les missionnaires ont-ils des champs à leur donner? ils ne s'emparent du bien de personne. C'est le dernier cas de ce genre que je jugerai, sachez-le bien. - Qui devient chrétien, devient chrétien et vit comme tel. C'est tout ce que j'ai à dire.

Le Ngambela, plein d'indignation, était sorti avant la fin pour ne pas avoir à approuver le jugement du roi par ses battements de mains. Lengwalala, lui, n'en croyait pas ses oreilles.

Mamwendarubi allait donc rentrer chez Lengwalala, non plus comme femme mais comme esclave, parce qu'on dit qu'elle lui avait été donnée autrefois par Sepopa. Mais son maître, n'abusera-t-il pas des droits sur elle? Ou bien, ne la maltraitera-t-il pas? Lewanika me promit que dans ce cas il affranchirait cette femme.

A Sefula, à l'annonce du pitso, les professants avaient tremblé; les païens étaient devenus insolents envers eux; on parlait même de menaces et de mauvais traitements. Chacun s'était attendu à ce que Mamwendarubi fût maltraitée et condamnée à la prison. Aussi le verdict du roi fut-il reçu avec joie par les membres de la classe. Le dimanche 10 février, Mamwendarubi se leva en pleine chapelle et dit: «Vous croyiez que jallais être condamnée par les ma-Rotsé, mais me voici au milieu de vous, on ne m'a fait aucun mal, au contraire, le roi m'a donné raison. Il a dit que toute femme qui se convertit est libre 
d'abandonner son mari s'il est polygame. Levez-vous, vous qui êtes dans ce cas, vous n'avez plus rien à craindre ".

Ma-Wainyayo se sépara aussi bientôt de son mari polygame. Comme elle n'en était pas l'esclave, elle le quitta tout-à-fait. Mais son village natal étant dans la région de Mboela (la partie méridionale de la plaine du bo-Rotsé), loin de nos stations, le roi lui donna un champ près de Sefula.

\section{XLI.}

Des progrès.

La directrice de lécole du dimanche. - Retours de fiève. - Nolianga repreat courage. - Nouvelles professions. -- Lewanika et lobservation du diman. che. - 11 Intte contre l'ivrognerie. - Mpololwa changée. - Course en Na. likwanda. - Station peu hospitalière. - Nonvean Béthel. - Nouveanx moyens d'action.

11 FÉVRIER. - Hier à $4 \mathrm{~h}$. prẻparation des moniteurs, et ce matin ma première école du dimanche. Ce n'est pas sarı appréhension que je pensais à cette première leçon que je devais faire devant un nombreux auditoire. Je crois que Dieu veut que je continue $\dot{a}$ présider ce culte. J'ai parlé aux cent dix enfants qui m'écoutaient. de l'école du dimanche d'Europe dans laquelle j'enseignais moi-même autrefois, et je leur ai dit que dans mon pays natal on aimait les enfants du Zambèze sans les avoir jamais vus.

4 MARS. - Je me remets de mon attaque de fièvre, mais elle m'a beaucoup affaiblie.

Le coin de l'Evangile pénétrait de plus en plus, bien que l'opposition fût toujours vive.

Le 1 mars, le Ngambela survint chez M. Coillard pendant une visite de Nolianga. Il fit à cette femme une réprimande grossière de ce qu'elle profitait de l'absence du roi pour faire des visites. (Le roi était en partie de chasse vers Nalolo). Malgré cela elle revint voir ma femme trois jours après, mais accompagnée par une autre femme du roi. La profession publique de Mpololoa et la fermeté de Mamwendarabi lui avaient 
rendu du courage. Elle nous réjouit par sa connaissance de l'Evangile. Elle continuait à lire régulièrement le Nouveau Te stament que je lui avais donné à Séfula.

Le 10 mars nous eûmes deux autres professions d'adultes, entr'autres celle de Tawira. Il avait été un de nos élèves à Séfula. Depuis longtemps sa conscience était troublée par ce passage: «Celui-là pèche qui sait faire le bien et ne le fait pas 》. Déjà auparavant, pendant un voyage, il avait été ébranlé dans sa tranquillité païenne par divers signes: une étoile filante, un tremblement de terre, et une éclipse de soleil. Il avait renvoyé sa seconde femme dès la mi-février.

L'inondation, qui chaque année transforme la plaine du boRotsé en un vaste lac, est une époque pleine de distractions. L'humeur de nos Zambéziens, toujours voyageuse, le devient alors au suprême degré. Pendant la crue, les femmes sont occupées à leurs champs de sorgho, qui vont être convertis en îlots, tandis que les hommes ne pensent qu'à la pêche ou à la chasse. L'école est en souffrance et les auditoires tombent à une moyenne de 300.

Un dimanche, au sortir du culte, Lewanika réprimanda vertement ses gens de ce qu'ils n'étaient pas venus aux cultes le dimanche précédent, parce que lui-même avait été retenu par une indisposition. "Vous vous croyez donc bien sages, leur dit-il entrautres choses, vous qui avez étẻ devancés par les autres nations, puisque vous vous souciez si peu de l'enseignement de vos missionnaires.

Bientôt après, voyant de nombreux canots glisser à travers la plaine, il fit fortement réprimander le chef de l'expédition: \& Allez-lui dire: Crois-tu donc me plaire en violant le jour de repos du Dieu qui nous fait vivre? Penses-tu que le produit de mon champ, que tu m'amènes, suffira pour me nourrir bien des jours avec ma maisonnée? Si le Dieu que tu méprises s'y refuse, peux-tu faire tomber la pluie et germer les grains? 》

Un jour il nous disait à propos de sa mauvaise humeur de deux ans auparavant, que le cœur est rusé et méchant comme un sorcier, et qu'il avait été comme un enfant qui pleure pour prendre du feu dans sa main, ne sachant pas que c'est pleurer pour une chose qui fait mal.

Déjà alors Lewanika avait renoncé pour lui-même à toute 
boisson enivrante (1) et il n'en faisait plus distribuer au khotla. Dès lors il n'a pas cessé de lutter contre l'ivrognerie, en dépit de l'opposition sourde ou manifeste de beaucoup de chefs et d'officiers. Il commença par réprimander les gens qui allaient au khotla dans un état d'ivresse; puis il menaça de punir toute personne qui serait trouvée ivre à la Capitale; ensuite il prohiba la fabrication de la bière capiteuse (interdiction qu'il étendit plus tard à tout le bo-Rotsé). Un jour il obligea le Ngambela à briser publiquement sa coupe, et à promettre de ne plus s'enivrer.

Pauluse et Elise, et nos chers amis de Nalolo, nous arrivèrent le jeudi-saint. En abordant à la station, ils furent surpris de voir une bande de jeunes femmes et jeunes filles qui avec Mpololoa à leur tête "recrépissaient»le sol de la chapelle. Cétait beau de voir l'entrain que la princesse donnait à tout son monde, en pétrissant elle-même l'argile et en entonnant des cantiques. Quelle transformation chez cette femme! Elle avait commencé à abandonner, entr'autres coutumes, celle qui ne permet pas à une femme de paraître avec son mari, et chaque matin, avant le lever du soleil, nous les voyons venir ensemble à la prière. L'un et l'autre étaient devenus si ouverts et communicatifs qu'il faisait bon les voir chez eux, causer, travailler, manger ensemble et lire ensemble la Parole de Dieu.

Le lendemain de Pâques (16 avril), Lewanika nous honora aux yeux de sa nation en nous invitant à prendre place dans sa Nalikwanda, M.M. Coillard, Béguin et moi. C'est un privilège dont aucun étranger n'avait encore joui. Le roi nous fit amener à la grande barque dans ses propres canots. Nous le trouvâmes établi sous le pavillon qui formait au milieu de la barque un joli petit salon d'environ 3 mètres de haut, sur autant de large et quatre de long, ouvert devant; de belles nattes en recouvraient le plancher, d'autres dressées contre les parois latérales étaient mobiles et servaient de rideaux. Les ma-Rotsé sont naturellement fiers, très satisfaits d'eux-mêmes et de leurs travaux, mais je crois que la Nalikwanda est ce dont ils sont le plus orgueilleux. Qui ne l'admirerait? Les blancs

(1) Il ne s’agit ici que de boissons indigènes, car dès 1890, il avait été convenu dans l'accord fait avec la B. S. A. C. quaucune boisson alcoolique ne serait importée dans son pays. 
eux-mêmes n'en seraient-ils pas ébahis? Pauvres gens, ils ne se rendent pas compte des progrès que l'art naval a faits depuis l'âge des habitations lacustres. Cependant la Nalikwanda leur fait bonneur quand on sait combien leurs outils sont primitifs; et la barque qui nous porte marque un grand progrès sur celles des années précédentes.

Malheureusement, ce n'est guères qu'un objet de luxe, puisque elle ne fait que 5 à 6 kilomètres à l'heure, tandis que les canots peuvent en faire le double. Et quelle peine pour la faire avancer! Au bout d'une journée les plus habiles sont épuisés de fatigue, bien qu'ils y soient une cinquantaine. Cependant personne ne se plaint, on en fait un point d'honneur. L'aristocratie du pays est seule admise à pagayer dans la barque royale. Ils ont alors un costume spécial. Sur la tête une espèce de bonnet d'étoffes bariolées, surmonté d'un panache en poils de lion ou de gnou. Un autre panache semblable pend de leur ceinture, sur les fourrures qui les couvrent. Cela leur donne un air grotesque et sauvage, d'autant plas qu'ils ne cessent d'imprimer à leur corps toutes sortes de mouvements rhytmés, en maniant leurs lourdes pagaies ornementées. Trois orchestres jouent à tour de rôle. Le premier, situé droit devant le pavillon, est composé des tambours de guerre, dont le bruit assourdissant s'entend à plus de 30 kilomètres. Les deux autres sont composés de chanteurs de se-rimba et de tambours; ils sont placés derrière le pavillon.

Dans cet étrange équipage nous avons royagé cinq heures sans la moindre halte. Quelles ovations à tous les villages près desquels nous avons passé! Le roi jouissait de ce spectacle et était content de nous y faire assister.

Enfin il donna l'ordre du débarquement. Tous ceux de l'avant descendirent et allèrent se ranger en demi-cercle pour saluer le roi au moment où il mettrait le pied à terre. À l'ombre d'un grand arbre on avait préparé un bel emplacement où le roi nous fit asseoir avec lui. Alors les rameurs de l'arrière descendirent et allèrent joindre leurs ovations à celles des autres. Les gens du lieu avaient apprêté une abondance de viande (don du roi), de légumes et de boissons non capiteuses; il y en eut même pour les rameurs des nombreux canots qui nous avaient escortés.

Après avoir fait le tour du village avec le roi, nous rentrons 
dans la Nalikwanda, où on nous sert viande, légumes et thé, offerts très aimablement comme notre hôte sait le faire. À $3 \mathrm{l}$. chacun ayant repris sa place, nous repartons au son des acclamations des assistants. Quelques-uns de ceux qui avaient semblé faiblir à l'aller, ne sont pas remontés. Nous avons à peine vogué une heure quand nous voyons les tambours se concerter, s'approcher tout doucement d'un cousin du roi, puis tout d'un coup le saisir par les jambes et le faire passer par dessus bord. Il y a un murmure parmi les rameurs, puis un nouvel élan, car gare à qui faiblit! Quant à notre homme, il ne perd pas sa présence d'esprit, il nage, en bon mo-Rotsé qu'il est, jusqu'à ce qu'il trouve le fond avec sa rame; alors l'enfonçant en terre, il s'y cramponne et attend qu'un canot vienne le recueillir.

Le soleil se couche pendant que nous traversons le Zambèze. Le roi met à notre disposition deux de ses canots, un pour $\mathrm{M}$. Coillard, l'autre pour M. Béguin et moi. Nous allons comme des flèches. La nuit nous surprend bientôt, une belle nuit étoilée, mais nos gens connaissent leur bo-Rotsé. Là où nous ne voyons qu'une plaine uniforme, ils distinguent toutes sortes de points de repaire... Enfin on aperçoit un feu dans le lontain. "Voilà le feu des missionnaires 》, s'écrient nos rameurs. Comment le savent-ils? Ils avancent désormais en droite ligne vers ce phare, et nous abordons pour trouver nos dames aux prises avec la fièvre.

Une demi-heure après, un messager de Lewanika vient s'informer si tout va bien, et nous annoncer l'arrivée du roi à Léalui.

Le lendemain matin Lewanika retourna à sa barque, car il tenait à faire une entrée grandiose à sa capitale. Il ne manque pas de faire faire un détour par la station pour se faire admirer. L'homme de la proue et celui de la poupe font toutes sortes de contorsions et de tours de force, au grand divertissement des assistants. On manœuvre dans tous les sens, on fait des évolutions savantes pour persuader aux spectateurs que les pagayeurs sont loin d'être fatigués. Enfin ils abordent au milieu des ovations frénétiques de la foule.

Nous jouîmes de la société des Béguin jusqu'au 24 avril, mais nous craignîmes qu'ils n'eûssent pas trouvé notre station très hospitalière: ils y avaient eu plusieurs accès de fièvre, et avaient participé plusieurs nuits à nos invasions de seurui. Pendant 
tous ces jours ces terribles fourmis ne nous avaient pas donné de repos, ni jour ni nuit. Nous avions beau en brûler, ou en échauder des milliers par jour, ces guerriers ne semblaient pas diminuer de nombre. Nous tuâmes aussi beaucoup de serpents, dont plus d'un dans les maisons.

Les couvreurs ayant enfin achevé leur ouvrage, nous pûmes le 25 avril, entrer dạs ce que nous appelons « la grande maison 》. Ce n'est ni un palais, ni un château, loin de là; cependant c'est plus que nous n'avious jamais rêvé d'avoir au Zambèze. Jusqu'alor's nous avions occupé la chaumière de 1894. Elle avait dû nous servir tout à la fois de magasin, de chambre à coucher, de salle à manger, de salon, de dispensaire médical, de salle de bain etc. Nous y avions été trop heureux pour jamais avoir eu l'idée de nous en plaindre. Mais c'est le cœur joyeux et reconnaissant que nous consacrâmes notre nouvelle demeure par la prière.

La plupart des matériaux de construction m'avaient été donnés par M. Coillard, et j'avais pu faire le comble avec des bois sortis de la scierie de Sefula. Quel secours que cette scierie, et combien notre travail aurait été facilité si elle avait continué à fonctionner. Hélas, le brave Waddell ne devait pas rentrer au Zambèse, à cause de la maladie qu'il y avait contractée.

Quel luxe d'espace dans notre grande maison: trois grandes chambres outre les dépendances, des murs de 4 mètres de haut, et une large vérandah faisant le tour de l'habitation, la proté. geant contre la pluie et contre les rayons du soleil. Ce confort nous fit oublier tout ce qu'elle nous avait cô̂té de travail et de fatigue.

Dès le lendemain nous y inaugurâmes pour notre maisonnée, les prières de chaque soir, indépendamment de la prière générale faite au coucher du soleil. Il nous tardait de voir nos enfants plus intimément, chose que nous n'avions pu faire auparavant, faute d'espace. Nous leur consacrâmes en outre une soirée par semaine pour des jeux.

Ma femme commença aussi dès le 2 mai une réunion de femmes du jeudi après-midi. On y causait et chantait, on y enseignait à lire, à coudre, et on y étudiait la vie des femmes de la Bible. 


\section{XLII.}

\section{Temps d'arrêt.}

Pas à plaindre. - Tont disciple un témoin. - M. Coillard va au bo-Lubale.

- Une diversion. - Agents destruetenrs. - Visite au harem royal. Exeuses et rires. - Description graphique. - Jenne mèe reeluse. - Les petits ennemis. - Mendiants. - Joic ou lamentations ? - Chasse anx jeunes sarcelles. - Retour de M. Coillarl. - Reeul à Sefula. - Premières col. lectes.

IA fin d'avril, le mouvement qui nous avait tant réjouis A sembla s'arrêter. La capitale entière nous avait paru, pendant un certain temps, être remuée par l'Esprit de Dieu, puis le calme plat était revenu. Nous avions annoncé l'amour de Dieu et proclamé sa loi; mais les gens d'abord émus, avaient fini par résister aux appels du Seigneur, leurs cœurs étaient redevenus insensibles, et ils s'étaient éloignés de nous.

MaI. - L'inondation baisse, nous croyons que dans cinq semaines nous pourrons faire revenir nos vaches. Quelle ressource que le lait dans un ménage! Comme nous l'apprécions quand nous en sommes privés. Les planches à moitié vides de ma dépense, nous commandent une stricte économie, si nous ne voulons pas être dénués de tout avant l'arrivée des provisions attendues. Ne croyez pas que nous soyons à plaindre. Pas du tout, et vous nous verriez souvent devant un maigre dîner ou souper, riant de bon coeur, et faisant de beaux plans pour l'avenir. Le roi nous a quelquefois envoyé du poisson ces derniers temps. Je vondrais qu'il le fît plus souvent.

Plusieurs de nos professants de Léalui continuèrent à nous donner du souci, nous dûmes aussi enrégistrer quelques défections; mais d'autres nous réjouirent par l'esprit missionnaire qui s'était éveillé en eux. Nous avions toujours insisté sur le devoir des professants de donner gratuitement à d'autres ce qu'ils avaient reçu gratuitement. Que de moyens d'évangélisation à leur portée! Les réunions, les conversations, la lecture de la Parole de Dieu, les chants... À Léalui nous avons à faire 
à une population très flottante. Nous n'avons pas deux dimanches de suite le même auditoire. Ce qui est un grand désavantage sous bien des rapports, doit devenir un moyen puissant d'évangélisation au près comme au loin. Il faut pour cela que tout disciple soit un témoin animé de l'esprit missionnaire.

Le 6 Mai, M. Coillard partit pour le Nord, emmenant une quarantaine de rameurs, et parmi eux onze de nos catéchumènes les plus avancés. Nous fûmes bien aises de le voir si bien accompagné, nous ne fûmes pas moins très inquiets, car depuis des mois notre cher doyen avait presque toujours été souffrant.

13 MaI. - Nolianga vint me voir. Je la fis entrer dans notre cabinet de travail et profitai de cet instant de tête-à-tête pour lui dire combien elle m'avait fait de peine dimanche en ne voulant rien me répéter de ce que nous avions entendu, quand, après le culte, j'avais rassemblé les femmes du roi pour chanter et causer avec elles. Elle m'avoua qu'elle avait compris qu'elle avait eu tort d'avoir eu honte, en quelque sorte, de faire voir qu'elle avait retenu et compris la prédication. Elle voudrait qu'on l'introduisît eu quelque sorte dans le ciel; qu'un autre fît ce qu'elle seule peut et doit faire pour plaire à Dieu.

19 MaI. - Adolphe devait aller à Sefula le 16 pour le mariage d'un catèchumène. Cette absence quelque courte qu'elle dût être, me hantait, puis j'avais, me sembiait-il, besoin de revoir les arbres, la forêt, autre chose que cette plate étendue, bien propre à faire broyer du noir. J'étais fatiguée, un petit changement me ferait du bien. Bref, jeudi matin, nous étions installés tous les trois dans le beau grand canot que le roi nous a donné; Valdo enchanté d'être du voyage et nos élèves, filles et garçons, aussi contents que lui, conduisant leur propre pirogue.

Sefula est bien isolé, la station est délabrẻe, mais quels beaux ombrages! Nous eûmes une réunion le soir, consacrée au mariage envisagé au point de vue chrétien. Je fis ensuite divers travaux manuels.

La station avait repris meilleure façon depuis que Pauluse avait fait défricher l'emplacement. Les maisons tombaient en ruines. Quant à notre «Retraite 》, bien qu'en bon état, elle avait l'aspect d'un lieu abandonné, la brousse voulait reprendre son domaine. Nous eûmes beaucoup de plaisir à revoir Pauluse et Elisa, et Manwendarubi aussi heureuse que jamais. 
Le mariage de Molonda, que nous célébrâmes le lendemain, attira plus de 130 personnes.

Le mariage célẻbré, le moment du départ était venu. L'ẻpoux (fils de Nalishua, le grand chef de la rẻgion), nous fit cadeau d'un morceau du boeuf de la noce. Vous devinez si cette viande fut la bienvenue pour moi, toujours en souci du: Que mangerons-nous? Le soir en rentrant à la maison je fis préparer du salpêtre, pour conserver une partie de cette viande. Le lendemain matin le morceau avait disparu! Le chien de Willie avait commis ce larcin.

Que de pertes de ce genre n'aurais-je pas à mentionner! Et, comme si tout cela ne suffisait pas pour compliquer notre travail, voila les charançons qui pénètrent eux aussi partout: l'autre jour, j'ouvre une boite de macaroni soudée. Ces atroces animaux y pullulaient!

Les termites avaient travaillẻ avec fureur, se croyant sans duute souverains maittres de notre domaine un moment abandonné. Oh, ces termites, ces infatigables termites, quels ennemis inlassables de notre repos! Ils travaillent sans relâche ces temps-ci, et avec rage, à dẻtruire notre belle maison, bien que nous leur livrions une guerre sans trève et sans merci (l).

(1) Autres insectes nuisibles, très communs, qui ne sont pas mentionnés dans notre récit.

Hannetons, courtilières, vers de terre, guêpes, taons; blattes (mangent les grains, la farine, le cuir, la laine); teignes (très actives); pous (très peu de noirs en sont exempts), puces communes...

La chique de puce pénétrante, est presque microscopique, elle pénètre dans la plante du pied ou dans les orteils, souvent sous les ongles, elle cherche un point tendre pour y déposer ses oeufs; aussi elle pénètre plus profondément chez les noirs. Elle pond ses oeufs dans un sachet. Elle produit une forte démangeaison mais insensibilise la partie qu'elle occupe. Si on ne l'enlève pas à temps avec ses oeufs, les vers qui en naissent produisent des ulcères dangereux. Elle envahit de plus en plus l'Afrique. Elle n'est au bo-Rotsé que depuis une vingtaine d'années, mais n'a pas encore atteint Sesheke.

Il y a plusieurs espèces de tignes. Des deux plus communes, l'une s'attaque surtout aux animaux domestiques; l'autre, le tampane, envahit les habitations et y tient lieu de punaise. Sa piqûre produit une démangeaison affreuse, et même de la fièvie.

Les punaises ne sont pas indigènes du bo-Rotsé, mais y sont peu à peu impertées par les ouvriers qui y retournent des mines du Sud.

Les scorpions (seulement dans les bois).

Les arachnides sont bien représentées, mais je n'en connais que deux espèces de venimeuses. Le tûvi et le se-bube. Leur piqûre produit des effets analogues à ceux de la piqûre du scorpion.

En 1898 nous eûmes à Lwatile une plaie de chenilles: ces bêtes couvraient les ricins dout nous avions orné la station. Les poils même qui s'envolaient produisaient une démangeaison insupportable que l'acide acétique seul parvenait à soulager un peu. Cela dura encore bien des jours aprës que les ricins eurent été abattus. 
Mon mari travaille avec entrain en dehors des heures de leçons $\dot{a}$ ses travaux de menuiserie, et fait si bien que ce soir il espère placer la porte de l'office. Pensez si je suis contente! Les festins des chats et des chiens seront bien finis!

25 MaI. - J'ai travaillé tout le jour, et les heures si remplies se sont envolées bien vite. Maintenant je puis m'asseoir et causer avec vous. Ce ne sera pas pour longtemps, car nous avons besoin de repos. Ce matin, après le nettoyage du samedi, toujours long, nous nous sommes dirigés vers Léalui, Adolphe et moi, mais nous avons trouvé le pont si abîmé qu'Adolphe m’a laissẻ continuer seule la route avec trois de nos enfants, pour retourner à la maison y prendre ses outils, et réparer les dégâts, afin que les gens n'aient pas une nouvelle excuse demain pour ne pas venir au culte. Hẻlas! ils en trouvent dẻjà bien assez. J'ai dû m'en convaincre une fois de plus dans le harem, où j'ai fait une tournée de visites. L'une ne viendra pas parceque son enfant est grognon; une autre a mal à la tête; une troisième dit: J'irai peut-être si.... Oh quelles gens! Écoute, dis-je à l'une de ces femmes qui ne vient jamais, sous prétexte qu'elle ne peut quitter son bébé, un gros garçon d'un an. Ecoute, Dieu te demandera compte de ta négligence. $\mathrm{Tu}$ te prives de la seule chose nécessaire bien légèrement.... Elle rit! C'est ainsi que les Zambéziens se tirent toujours d'un mauvais pas.... ils rient. Oh! ces rires, comme ils nous poursuivent et comme nous les dẻtestons.

Longa me fit une description graphique de tous ses maux, avec force gestes que je ne puis rendre, à mon grand regret. J'ai manqué éclater de rire deux ou trois fois au moment le plus palpitant. « Vois-tu, dit-elle, j'ai maigri cıs temps-ci. - Vraiment, je ne m'en serais pas aperçue. - Écoute, reprit-elle d'un ton tragique, tu ne sais pas combien j'ai mal. Vois-tu, ça fait comme-ça ici au côtẻ (et elle y appuie fortement la main), ça fait tou! tou! tou! tou! touah!.... Et dans la tête quelquefois ça me fait zou! zou! zou! zum! Alors je me couvre de ma couverture et je me mets au soleil.... Peu à peu, je me sens mieux. Et ma jambe! ça commence à la cheville et ça va jusqu'à la hanche. De toute la nuit je ne dors pas!» Mettez cela dans leur jargon expressif et pittoresque, regardez cette mine épanouie et ces joues rebondies où la santé éclate, voyez ces grimaces et ces contorsions, et dites-moi si vous pouvez garder votre sérieux.

Rentrée à la maison vers midi, j'y étais accueillie par Valdo qui arrive toujours en courant á ma rencontre. Mon mari avait fini son travail au pont, et achevait de placer la porte de l'office. Mon après-midi a été employẻe à arranger ce cher petit domaine, où je 
suis reine et maîtresse maintenant, et d'où toute la gent fẻline et canine a été bannie. Elle n'a plus rien à y voir. Mais les fourmis ! elles ne se laissent pas intimider par une porte, et elles continuent à tout envahir. J'ai essayé de mettre de l'ouatte aux pieds des étagères; les rouées petites bêtes passent au travers à grand'peine, mais elle passent! La poudre insecticide elle-même ne les arrête pas longtemps. Il m'a fallu avoir deux grands plats pleins d'eau dans lesquels nous avons posé de vieilles boîtes de conserves renversées. Sur le tout nous avons mis une planche. C'est là que je garde mes provisions. Mais je tremble toujours que nos fillettes maladroites ne renversent mon échafaudage, comme cela arrivait souvent à Sefula. Que de complications dans ce pays!.... et par dessus tout cela, l'eau qu'il faut aller chercher à plus d'une heure d'ici.... On s'habitue à tout, et nous sentons tout cela moins que vous ne le pensez, j'en suis sûre.

Nous avons eu les Willie à dìner hier soir; leur petit Henry est toujours plus mignon. Il me regarde comme s'il comprenait que j'ai une autre couleur que sa maman, bien jolie cependant dans sa peau noire.

Dimanche 26. - Journėe calme, rafraîchissante. Qu'elle nous prẻpare au travail, aux tentations, aux ennuis de la semaine, $\dot{a}$ ses joies aussi.

Pendant notre course à Sefula, le roi était parti pour une nouvelle chasse. Il avait été précédé ou suivi par la majorité des hommes du village, plusieurs écoliers et une douzaine de nos catéchumènes. La plupart des femmes de ces gens quittèrent aussi la capitale pour aller à leurs champs ou à leurs villages. C'est la mode, et il est probable qu'il faut en chercher la cause dans l'affreuse corruption de Léalui.

Je profitai de la diminution de la tâche missionnaire pour hâter la bâtisse de la cuisine et pour la confection des chassis de fenêtre, et de la porte vitrée. Je dus aussi veiller aux travaux de terrassements et faire réparer les brèches faites à la chaussée par l'inondation.

27 MaI. - J'ai eu la visite de Nolianga cet après-midi, elle a pris le thé avec nous. Mokabai, le vieux crieur public, est venu aussi: «Il fait froid, mon Seigneur, il fait si froid! mon Seigneur, il fait si froid! mes oreilles gèlent. Oh! une couverture, mon maître. Je suis venu pour cela. - Froid? Tu nous parles du froid du Zambèze à nous? » Mais il persiste, il serre ses épaules dans son vieux 
gilet de peau. «Mon Seigneur et mon maitre, il fait froid! Je te demande une couverture, et tous les jours pendant un mois, je viendrai te la demander, je la demanderai jusqu'à ce que je la reçoive». Il le fera et par son insistance, il obtiendra ce qu'il veut. Ils nous donnent de grandes leçons, ces Zambéziens, dans leur ignorance.

Le 6 juin, le roi rentra à Léalui.... À l'arrière plan, ses femmes en couleurs voyantes, font entendre un chant plaintif, du moins il nous semble tel. La joie! les pauvres africaines la connaissent-elles? Joie! et pourquoi? parceque leur époux est revenu? - Oui, mais l'époux de qui? De ces 15 femmes. Je comprends pourquoi leurs démonstrations de joie ne nous semblent à nous que des lamentations.

Il y a des vacances qui s'imposent à nos écoles, ce sont entr'autres les jours où l'on va pêcher à la lance et le jour de la chasse aux jeunes sarcelles et aux cigognes pêcheuses. Les jours qui suivent sont des jours de liesse puisqu'on est dans l'abondance. Ce sont des milliers de poissons ou d'oiseaux qui sont tués chaque fois, tellement que tous les gens de la capitale, et de tous les villages à 10 ou 15 kilomètres à la ronde, en ont leur part.

Les sarcelles et les cigognes pêcheuses, au moment de pondre, se rassemblent en grandes bandes dans de vastes champs de roseaux. En juin ou juillet, selon la durée de l'inondation, des hommes chargés de les épier; en apportent quelques unes au roi. Celui-ci dit à ses gens en plein khotla: "Demain vous irez briser les ailes des oiseaux, de crainte qu'ils ne nous échappent en s'envolant 》. Le lendemain matin, le crieur public crie: "Que tous aillent, que personne ne reste!》 Hommes et garçons, libres et esclaves partent, quelques-uns en canot, la plupart à pied. Le lendemain, sur un ordre, tout ce monde, armé de bâtons, se précipite dans les roseaux - sur les jeunes oiseaux. Quand le massacre est achevé, de nouveau sur un ordre, tous se rassemblent, tenant à la main leur butin. Les chefs qui en sont chargés, prélèvent la part du roi, le tiers ou le quart. Dès lors, chacun est libre d'en cuire sur la braise et de rapporter le reste chez lui, où il en fera part à ses parents, aux chefs et à ses amis. On cuit aussi ceux qu'on ne peut manger aussitôt, puis on les fend et on les fait sécher au soleil. On en conserve ainsi pendant 10 et 15 jours. Les villages en sont parfumés.

Le 11 juin, Mokwae arriva en grande pompe, et fut reçue 
avec tous les honneurs royaux. Bien qu'elle fût toujours affable avec nous, nous savions qu'elle avait été pressée de venir par Katoka afin de s'opposer aux progrès de l'Evangile, et surtout à la conversion de Nolianga. Déjà d'autres fois ses séjours à Léalui avaient été suivis d'une recrudescence de paganisme.

Le 14, nous croyons M. Coillard encore très loin vers le Nord, quand nous reçûmes de lui un billet nous annonçant son retour pour le lundi 17. Nous eûmes une nouvelle surprise le 15 après-midi, quand nous entendîmes nos enfants crier: Voilà le missionnaire! Tous ses compagnons de voyage et lui étaient en effet là, encore pleins de la délivrance merveilleuse que le Seigneur leur avait accordée chez Kakenge, et de l'œurre qui s'était faite chez quelques-uns des rameurs. Le lendemain fut un dimanche d'actions de grâces.

19 MaI. - Nous avons eu Mokwae à dîner. Elle est arrivée tout haletante, emmitouflée dans une houppelande et un capuchon. Elle est comique avec son énorme embonpoint et sa démarche incertaine. Les bottines trop étroites semblent la faire souffrir. Mais que n'endure-t-on pas gaîment lorsque la vanité est en jeu ! - La reine a étẻ fort convenable. Décidèment elle fait des progrès.

Le 20 juin, je retournai à Séfula y bénir un noureau mariage. Je constatai avec tristesse qu'il y avait recul. Non seulement les cultes étaient moins fréquentés, mais la foi de plusieurs des professants avait sombré. La crise avait été causée par la question du mariage. Se lier pour la vie à une personne consterne les Zambéziens et leur paraît chose impossible. Ils disent à leur manière: «Si telle est la condition de l'homme avec la femme, il ne convient pas de se marier $\gg$. Comme on pouvait s'y attendre, cet état de choses fut la pierre de touche qui nous permit de discerner les vrais disciples de Christ d'entre ceux dont le cœur ne lui avait pas été entièrement gagné.

Une nouvelle réconfortante ce fut qu'en cette année de disette, une vingtaine de professants de Sefula avaient collecté un sac de grain pour l'évangélisation du pays. Ce n'était pas beaucoup, mais c'était un commencement. 


\section{XLIII.}

Encouragements, secours et difficultés.

u $y$ a plus de bonheur à donner qu'à recevoir. - Cours froids.

Petits persecuteurs. - Disette.

D $\mathrm{k}$ s le lendemain matin je parlai à nos professants de DLéalui, de la collecte faite par ceux de Sefula. Peu après, à notre insu, Mokamba rassembla nos gens et les pressa de porter chacun sa quote-part. Le 24, ma femme découvrit que nos enfants de la station se privaient de leur déjeuner tous les matins, afin de pouvoir contribuer à la collecte. Ils se renoncèrent ainsi eux-mêmes jusqu'à ce que chacun d'eux eut mis à part un plein plat de sorgho.

Et ils étaient si heureux! Le 28, Mokamba inaugura la collecte en amenant un jeune bœuf pour sa contribution. Tous nos enfants apportèrent alors chacun leur plat. Leurs yeux brillants nous disaient que des Zambéziens avaient enfin compris qu'il y a plus de joie à donner qu'à recevoir. Ils appelaient ces dons leur « témoignage de reconnaissance 》. Les contributions arrivèrent jour après jour. La plupart apportèrent des plats de grains, d'autres donnèrent des nattes, des plats en bois, voire même une pioche. Semonja donna 2 shellings croyant que c'était beancoup.

22 JoIn. - Nous avons fait, mon mari et moi, une course pastorale à Léalui, passant de cour en cour, nons asseyant partout où nous voyions quelques personnes réunies... Comme on se sent souvent petit, incapable, ignorant, devant ces cœurs durs, froids, fermés au choses spirituelles. Plus je vis la vie missionnaire et plus je comprends combien grand est le privilège de ceux qui depuis leur enfance sont élevés dans la connaissance de Dieu. C'est si difficile de faire comprendre l'amour de Dieu, le besoin du Sauveur, à des gens qui ont toujours vécu de la vie animale, préoccupés uniquement des choses passagères, ignorant presque qu'ils ont une âme. 
24 Juin. - J'ai été à la capitale avec quelques-uns de nos élèves. Nous avons été nous asseoir dans la grande cour de Moshukula. J'y ai passé quelques beaux moments entourée de plusieurs vieilles femmes et d'enfants. Nous avons causé, chanté, regardé des images... « Viens encore nous enseigner », me dirent ces bonnes femmes quand je partis. Nous passâmes alors chez plusieurs autres. Je n'eus garde d'oublier le vieux Narubutu. D'abord il causait tout le temps que nous chantions, mais sur une observation que je lui fis, il se tut, ferma ses paupières et écouta d'un air recueilli. «J'écouterai toujours », me dit-il, en me saluant.

En rentrant à la maison je rencontrai Ma-Rhosi, la vieille mère du roi. Elle revenait de ses champs. «Mais comment, tu as des jambes aujourd'hui? » lui dis-je. Elle se mit à rire et à me faire un discours se-Rotsé, que je devinai plus que je ne le compris. Aller à ses champs, ou venir à l'église, ce sont deux choses touta-fait diffẻrentes. L'impotente d'hier retrouve aujourd'hui ses forces.

A la fin de juin, ce fut avec recoinnaissance que nous reçumes une première partie des provisions attendues depuis si longtemps. Dieu avait pourvu à notre pain quotidien et à celui de notre maisonnée, eu veillant sur ces caisses et ces ballots. i Loatile nous avons rarement l'occasion d'acheter des légumes indigènes. Nous ne pouvons guère en cultiver nous-mêmes que quatre à cinq mois par an.

A Sefula par contre, les légumes verts, indigènes (1) ou non, faisaient partie de notre menu ordinaire. Aussi à Loatile apprécions-nous d'autant plus ce que nous recevons de l'Afrique Méridionale ou de l'Europe.

Trois des canots de l'expédition avaient été attaqués par des hippopotames, et un sac de sucre de Pauluse avait été au fond de l'eau. En guise de consolation nous lui envoyâmes une partie de notre petite provision de 24 kilogr., ne nous doutant pas que nous ne devions plus en recevoir avant novembre 1898. Afin d'associer nos enfants à notre joie, nous leur fîmes le soir même une distribution de sucre candi que nous avions commandé dans ce dessein. Nous envoyâmes aussi au roi, une boîte de biscuits, de la confiture et une ombrelle, en le remerciant pour les canots qu'il avait bénévolement mis à notre disposition.

(1) Nous avons mangé de six à sept espèces de légumes indigènes, apprêtés comme les épinards ou accommodés en salade. 
5 IUILlet. - Les heures du soir sont si douces après le travail de la journẻe, ses tracas et ses ennuis. Qu'il fait bon s'asseoir dans notre salle à manger et causer à cœur ouvert, écrire, lire et travailler, presque sûrs que personne ne viendra nous déranger. Tenir un ménage africain, ce n'est pas une sinécure. Le soir on est harassé sans avoir beaucoup fait. Le temps s'émiette en mille petites occupations et on peut rarement mettre à son avoir une grande somme de travail suivi. Tautôt c'est les soins à donner à la laiterie qui réclament ma surveillance, tautôt c'est le levain qu'il faut confier aux jeunes filles chargées de pétrir le pain, enfin ce sont les nettoyages toujours à recommencer, et au milieu de tout cela que d'imprévus! À midi nous sortons de l'école. Je me précipite alors à l'office pour voir ce que nous aurons pour le dîner. Pendant ce temps les enfants entourent la maison. C'est un véritable siège! $\mathrm{A}$ toutes les ouvertures il $\mathrm{y}$ en a un: "Je demande de la médecine pour les yeux! - Je mendie du savon. Ma mère, où est mon morceau de toile? - Mon livre se gâte, il me faut le couvrir au plus tôt ». - « Ma mère, tu m'as promis un chiffon pour mon gilet. - Il me faut du papier ». Ah! les terribles petits persécuteurs!.. Enfin nous nous mettons à table; mais lá encore on vient nous assaillir. Alors je suis impitoyable. "Nous mangeons » fais-je d'un ton solennel, et ils comprennent cela, car eux, ils ne se dérangeraient pas pour un empire, quand ils remplissent cette fonction importante.

Nos élèves, que nous considérons comme nos enfants, travaillent beaucoup, mais les pauvrets ne font que ce que je leur dis: ils n'ont aucune initiative. Un objet quelconque pourrait se trouver toute une semaine sur leur chemin sans qu'on les voie prendre la peine de l'enlever. Il faut avoir des yeux pour tous. Cette tension d'esprit continuelle est fatigante.

Depuis le 10 juillet nous avons installẻ nos fourneaux dans la grande cuisine. Kaieka est enchantẻ de son nouveau domaine. Son zèle est à la hauteur des circonstances. C'est grâces à mon mari que mon fourneau fonctionne, car l'agent de Mafeking en nous l'expédiant, a oubliẻ d'y joindre les tuyaux. Adolphe en a fabriqué avec des feuilles de zinc et tout cela marche à souhait. Au premier essai, nos enfants ont été émerveillés de voir la fumée sortir du dernier tuyau. Ils se sont écriẻs: Mosi wa thunya (1).

(1) «La fumée se lève », voilà très probablement le vrai sens du nom donné par les ma-Kololo aux Chutes Victoria. 


\section{XLIV.}

\section{Emancipation et profession de Nolianga.}

\section{Nolianga émancipée. - Echappée du filet des oiseleurs. - Sa profession.}

Déclaration de Lewanika. - Jole de Nolianga

T E 13 juillet, Nolianga vint nous annoncer que le roi avait $\perp$ enfin enlevé les derniers obstacles à son émancipation! Que la puissance de la grâce du Seigneur est admirable! Combien sa longanimité est merveilleuse! Il a touché cette conscience endormie, et s'est glorifié de cette nature sensible, mais peu capable de détermination. Elle va sortir du harem et se dépouiller d'honneurs enviés par tous, mais Dieu le lui rendra au centuple: ella saura ce qu'il $\mathrm{y}$ a de bonheur à être où le Seigneur nous veut, à abandonner quelque chose pour Celui qui s'est livré pour nous, et à être débarrassée de ses péchés, sauvée, libre de la liberté des enfants de Dieu.

17 Julllet. - Ce matin à l'aube nous avons rassemblé tout le personnel de la station devant la fenêtre de M. Coillard. Nous avons chanté les quatre strophes d'un cantique qu'Adolphe avait composẻ pour la circonstance. Cher M. Coillard, il ètait si faible qu'il ne put maîtriser son émotion.

Nous avons passé la journée ensemble. Mon bouquet de fête, deux capucines et quelques pointes de réséda, était bien beau pour le Zambèse! Mon abricotier mesure environ 8 centimètres. Pensez si je rêve en l'arrosant chaque soir avec amour! Perrette est connue au Zambèze.

Le 20, Lewanika crut devoir annoncer sa décision au sujet de Nolianga, à ses principaux chefs et officiers. Il les appela un à un dans son kashandi, pensant qu'ainsi ils n'oseraient pas manifester leur désapprobation. Malgré cela il ne trouva un peu d'appui que chez deux ou trois.

Le dimanche 21 juillet, dès le matin, quelques-uns allèrent chez Nolianga pour essayer de la dissuader. Afin d'échapper à leurs obsessions elle vint se réfugier à Loatile longtemps avant l'heure du culte. 


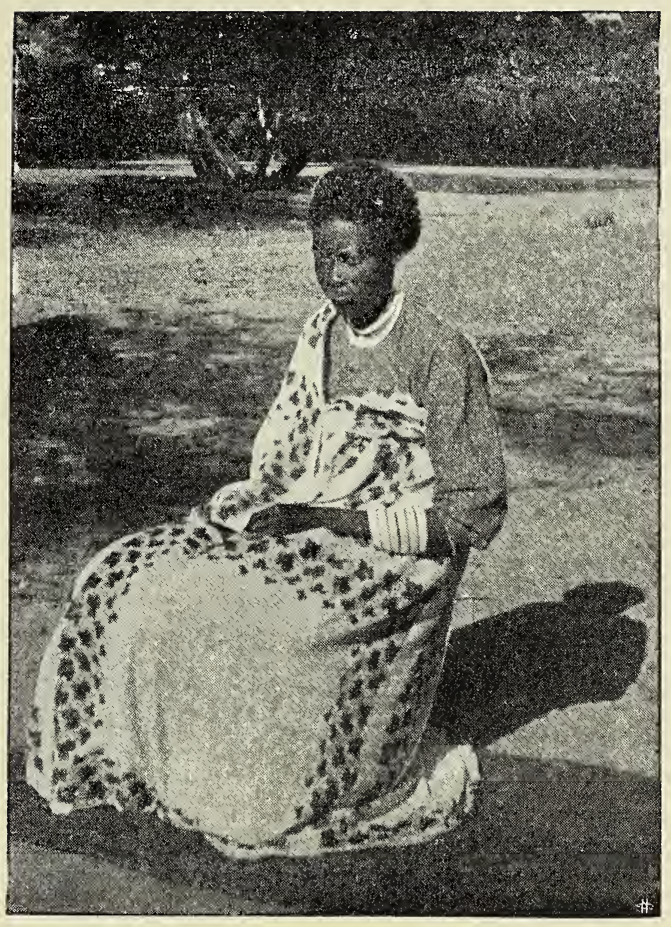

Elizabetha (Nolianga). 

Aussitôt après ma prédication, elle se leva et parla avec un calme et une assurance qui nous étonnèrent. "Ma-Rotsé, ditelle, vous le savez, j'ai longtemps résisté au S. Esprit; maintenant vous pouvez me désapprouver, mais je ne puis résister plus longtemps, je veux suivre Jésus qui est mort pour moi 》.

Elle s'assied. Après un moment de profond silence, Lewanika se lève et dit: « $\mathrm{Ne}$ regardez pas cette femme si fixement, ce qu'elle vient de faire, elle l'a fait avec mon approbation. Le mouvement va en progressant et ne s'arrêtera plus $\sharp$. Après une pause, il ajouta: "Quiconque parmi vous sent la puissance de ce que nous annoncent les missionnaires, est libre de se déclarer. Qu'on ne dise pas que c'est moi qui empêche les gens de se convertir! 》.

Je laissai à M. Coillard le privilège de répondre; l'émotion l'obligea à le faire brièvement. "Mon père, dit-il au roi, j’ai été triste en t'entendant, nous t'attendions toi-même ». J'entonnai: 《Chantez, anges du ciel» (en sessouto) et terminai par la prière.

Dès le lendemain matin à l'aurore, Nolianga vint à la prière, elle revint nous voir l'après-midi. Cette femme, que nous avions presque toujours vue mélancolique, était radieuse maintenant. Elle avait dû beaucoup souffrir pendant ces mois de luttes, pour être si joyeuse, en dépit de tout ce à quoi elle venait de renoncer.

$\mathrm{XLV}$.

L'opposition gagne du terrain.

Lewanika calcule la dépense.

II est arrêté par la menace d'une révolution et par des craintes superstitieuses. Nombreuses défections.

T E roi vint ce même jour nous parler des transformations qui s'imposeraient s'il se convertissait. Qu'il nous sembla près à ce moment! Il était attiré vers Dieu, mais une lacune nous frappait chez lui, il ne nous parlait jamais de ses péchés, 
de sa misère. Ah! s'il avait senti la conviction du péché, il aurait moins calculé la dépense. Il aurait aussi méprisé la menace de troubles politiques que les chefs du parti païen firent parvenir à ses oreilles.

Kalonga était la tête et l'âme de ce parti. De colère il n'était pas venu aux cultes du 21 juillet, et pendant des jours et des semaines il vomit des calomnies contre tous ceux qui s'étaient déclarés chrétiens, il les traitait de fous, et il menaçait d'étrangler la première femme qui ferait mine de suivre l'exemple de Nolianga. Il prétendait que les femmes du roi sont les prêtresses de ses ancêtres et que d'ailleurs elles sont le don de la nation au roi; par conséquent celui-ci n'a pas le droit de les libérer sans le consentement du peuple.

Ainsi Kalonga et les gens de son parti firent passer devant les yeux de Lewanika le spectre d'une nouvelle révolution, et réveillèrent les craintes superstitieuses qui n'étaient qu'assoupies au fond de son cœur.

D'après leurs traditions, Mbuyamwamba, la première reine ma-Rotsé, la mère de toute la race royale, était une femme de Nyambe, le dieu des ancêtres, le dieu par excellence. C'est d'elle que descend Lewanika en ligne directe, il est donc fils de la divinité et dieu lui-même. C'est de Nyambe que sout issus tous les membres anciens et récents de la dynastie royale, dont les tombeaux, parsemés dans la plaine du bo-rotsé, sont encore entretenus et révérés comme des lieux de pélerinage. Les mânes de ceux qui y furent enterrés, «les maîtres des tombeaux 》 comme ils sont appelés, sont encore redoutés de beaucoup. Ils sont le principal objet du culte indigène bien plus que Nyambe, dont on ne tient guère compte.

Ainsi que nous l'avons dit, le palais royal s'appelle Kwandu, du nom du tombeau de Ngalama, un roi guerrier, farouche, cruel, vindicatif, celui de ses ancêtres que Lewanika avait choisi comme protecteur spécial. Sa première femme, Ma-Morambwa, en est en quelque sorte la prêtresse. Chacune de ses autres femmes, l'est d'un autre de ses ancêtres. Lewanika est très superstitieux à cet égard. S'il y a une chose qu'il lui répugne de nous voir battre en brèche, c'est le culte de ses ancêtres, cette croyance qui constitue sa plus grande objection à l'abandon de la polygamie. En y faisant appel, les chefs du parti con- 
servatemr employèrent un levier presqu'aussi puissant que la menace de la révolution.

Les adversaires du christianisme gagnèrent du terrain, l'opposition s'étendit, il y eut des gens qui refusèrent de nous recevoir chez eux, nos écoliers devinrent moqueurs et indisciplinés.

Plusieurs de nos professants subirent cette influence démoralisante. Ils abandonnèrent leur premier zèle. On n'entendait plus Léalui retentir de leurs chants, on ne les voyait plus guère presser les gens d'ouvrir leur cœur au Sauveur; ils ne nous parlaient plus aussi souvent de bonnes tournées dans les villages environnants, ils n'accouraient plus aussi régulièrement à nos classes et à l'école; plusieurs abandonnèrent la foi chrétienne. La plupart des renégats furent des jeunes gens, des jeunes filles ou des enfants qui s'étaient fait illusion, prenant des impressions et de bons désirs pour la conversion. Le joug du Maître, si doux pour qui le porte volontiers, meurtrit les autres. Nos cœurs en saignèrent: et cependant nous savions que ce triage était salutaire.

\section{XLVI. \\ M. Bertrand, un hôte apprécié ef regretté.}

son conrt séjour à Lwatile. - Sa promesse.

L 17 août, M. le Capitaine Alfred Bertrand, de Genève, l'explorateur bien connu, nous arrivait vers midi, à la tête de ses gens. Vite mon mari court à sa rencontre, pendant que je me hâte de préparer des rafraîchissements que je lui envoie. Il faut qu'il paie ses porteurs et qu'il les congédie, car nous n'avons point de nourriture pour eux.

Bientôt nous considérions notre hôte comme un ami. Aver quel intérêt il suivait toutes nos occupations, posait mille questions, nous accompagnait dans nos visites à Léaluï... Oh, les bonnes soirées que nous passâmes avec lui, causant de l'Europe, de la Suisse, de notre vie africaine... Le 12 septembre, M. Bertrand nous quitta définitivement. Son sẻjour chez nous avait été coupé par une courte visite à Nalolo. 
En lui disant adieu, nous nous sentions tristes. " Penserez-vous encore à nous en Europe? » lui demanda quelqu'un. Depuis 1895 M. Bertrand n'a cessé de travailler pour notre Mission, et de lui gagner des amis. Toutes les Zambézias fondées, ces courants de sympathie, ces foyers d'amour et d'intẻrêt que son témoignage a créés, disent qu'il a tenu parole.

\section{XLVII. \\ La traite interdite au bo-Rotsé.}

Lewanika et la traite. - Un blane avili.

$T^{\mathrm{N}}$ Portugais de la côte occidentale (Benguela), arrivé le

U 3 août, annonça sans la moindre honte, qu'il était venu demander à Lewanika l'autorisation de traverser son pays de l'ouest à l'est pour aller au ba-Shukulumbwe et au bo-Nkoia acheter des esclaves.

La traite avait été organisée dans le pays pendant la domination des ma-Kololo et $\mathrm{y}$ avait été maintenue, bien qu'arec moins de vigueur, sous Se-popa. Mais Lewanika s'y était opposé depuis plusieurs années.

Les présents offerts par le marchand de chair liumaine (fusils, poudre, plomb, toiles aux brillantes couleurs), faisaient bien envie au roi et à son conseil, mais la présence des missionnaires, ces sentinelles incommodes parfois, et, nous osons l'espérer, un peu de conscience, leur conseillaient fortement de ne rien accorder à cet homme. Après 9 jours d'hésitations et de pourparlers, ils appelèrent le Portugais et en pleine assemblée publique ils lui interdirent de faire la traite. A l'ouie de ce refus, le marchand se mit dans une colère furieuse: Au grand amusement des Zambéziens, il se leva, jeta à terre chapeau, mouchoir, ombrelle, pleura, se dit ruiné, puis il se retira précipitamment en se frappant la tête. Quand il revint, le roi lui dit: « Nous avons des bœufs et de l'ivoire, fais un commerce honnête 》. Ce conseil fut suivi, mais en quittant Léalui, le blanc 
alla au bo-Lubale, où la traite est encore en vigueur (1), Lewanika n'y ayant que juste assez de pouvoir pour se faire payer un tribut dérisoire.

\title{
XLVIII.
}

La cinquième conférence de la mission.

\author{
Grave maladic de $\boldsymbol{M}$. Coillard, - Communion fratevelle. \\ Fondation de l'école d'évangelistes, - Adieux.
}

CEPTEMBRE fut pour nous un temps de rafraichissement $D$ dont nous garderons toujours de beaux souvenirs, assombris néanmoins par celui d'une grave maladie de M. Coillard. Nous avions déjà été dans l'anxiété à son sujet tout le mois d'août. Ses douleurs étaient si vives, qu'elles lui arrachaient des génissements que nous entendions de chez nous, la nuit comme le jour. Il n'avait un peu de repos que lorsque je lui administrais du chloral. Je passais auprès de lui une bonne partie de mes journées et toutes mes soirées.

Nous jouissons beaucoup de la visite de nos frères et amis du Bas et de Nalolo, et de M. Davit, venus pour la Conférence. Notre station est pleine de bruit, de roix joyenses, de cris et de pleurs d'enfants, de leurs rires aussi. Je jouirais plus encore de tout cela si j'étais tout-à-fait bien. Je souffre d'une lassitude générale qui m'accable, et de terribles névralgies.

La cinquième conférence de la mission du Zambèze dura assez longtemps à cause de la maladie de M. Coillard. Notre doyen présida chacune de nos séances, malgré l'état précaire de sa santé, et il est inutile de dire combien nous fûmes heureux de ne pas être privés des lumières de son expérience.

La décision la plus importante, prise par la Conférence, fut

(1) La traite se fait encore dans une grande partie du bassin de ll'Okuvangu et du Kwito, du Lungwebunge et du Zambèze au nord de la résidence de Kakange, favorisée et entretenue par les Portugais. 
celle de la fondation de l'école d'évangélistes. Nous sentions tous que nous devions bâtir notre édifice spirituel avec les matériaux du pays, et donner, des l'abord, un caractère essentiellement missionnaire à notre œuvre. Il fallait que nous mîssions d'emblée l'évangélisation du pays sur la conscience et sur le cœur de nos congrégations, qu'elles en sentissent la responsabilité, qu'elles en fournissent les ouvriers et les fonds.

La création de l'école d'évangélistes me fut confiée. Le 16 septembre je fis un dernier appel à ceux qui désiraient se vouer à l'évangélisation, et je leur laissai trois jours pour réfléchir encore au sérieux de leur vocation. Sept jeunes gens se déclarèrent prêts à y entrer.

Kajata, un jeune garçon de Kazungula, amené par mon frère, compléta cette première classe. Le 21 , nous eûmes une réunion de prière spéciale pour eux. Le 23 , il furent présentés à la conférence. Après un examen qui ne portait que sur la lecture, l'écriture, l'orthographe, les connaissances bibliques, et un exposé des motifs qui les poussaient à s'enrôler au service du Maître, ils furent acceptés.

Les bonnes causeries, les excellentes soirées prirent fin le 4 octobre, quand nos amis nous quittèrent pour rentrer dans leurs stations.

5 OCTOBRE. - Nous voici de nouveau seuls. Nos amis sont partis nous laissant tout tristes, si surpris que ce mois ait si vite passé. Heureusement que M. Davit nous reste. La maison est vide depuis que Valdo nous a quittés.

\section{XLIX.}

\section{Dernières semaines passées à Lwatile avec M. Coillard.}

Duverture de l'école d'évangélistes. - Une alerte. - Adienx de M. coillard. Son départ. - Mort tragique de Seonji.

T 7 Octobre nous ouvrîmes l'école d'évangélistes, et jusqu'ì $\triangle$ la nouvelle année je visai surtout à les habituer au travail individuel. La conférence avait insisté sur la nécessité d'unir le travail manuel aux études proprement dites. Que pouvions- 
nous faire de mieux que de bâtir la maison qui devait leur servir de dortoir? Ils consacrèrent leurs après-midi à ces travaux. Nous jouissions de voir l'entrain avec lequel ces jeunes gens apportaient du sable pour niveler le sol, puis préparaient et plaçaient les pieux, le toit et les roseaux. Enfin je leur enseignai à faire. le couvrage de chaume.

23 OCTOBRE. - Vers 4 h. j'étais dans notre chambre, M. Davit dans la sienne, et Adolphe sur le toit du dortoir des élèves évangélistes, plaçant les solives. J'avais mal à la tête et voulus aspirer un flacon de sels; mais le bouchon en verre tenait si fort que je dus allumer une bougie et l'y faire chauffer. C'était sur une petite caisse qui nous sert de table, près du lit et contre une fenêtre. Par une distraction dont je ne me rends pas compte, et dans un moment de totale absence, j'avais évidemment jeté l'allumette allumée entre la caisse et le rideau.... bref, un instant après je vois le rideau flamber! J'essaie de l'éteindre, mais je ne réussis, pas! J'appelle M. Davit. Il accourt et joint ses efforts aux miens mais la flamme montait, montait toujours, se communiquait à la moustiquaire.... L'alerte est donnée, tout le monde accourt, le feu a pris au chaume du toit!.... Je crus que la maison toute entière allait y passer. Oh quelle angoisse!.... Mais non, Dieu a eu pitié de nous. L'eau, le sable qu'on jeta sur le foyer de l'incendie eurent enfin raison de ces flammes qui semblaient se hâter pour dévorer la proie qu'elles auraient si aisément engloutie! Le feu avait déjá pris au cabinet de toilette. Il y a lá une grande tache noire dans l'herbe du toit qui, avec celle de la chambre à coucher, nous parlent de la nécessité de veiller et de la délivrance qui nous a été accordée.

Le moment approchait où M. Coillard devait nous quitter. Sa présence seule était une force, et, comme chacun de nous était heureux de le sentir à la tête de la Mission et de chercher auprès de lui les conseils dont il avait besoin! Si tous avaient senti cela, ma femme et moi nous l'àvions éprouvé d'une façon très spéciale.

Dimanche sOIR, 27 OCTOBRE. - Nous avons eu une journée triste, mais bienfaisante. M. Coillard a fait ses adieux. Ce matin il a retracé l'histoire de notre mission. Il a rappelé la bonté de Dieu envers le ma-Rotsẻ et il leur a reproché leur endurcissement. Après midi il a fait de sérieux appels au roi, aux chefs, à nos catéchumèness, 
aux femmes, à tous enfin. Puis il a donné la parole á ceux qui pouvaient avoir quelque chose à dire.

Moka, un de nos ẻlèves évangélistes, se lève: « Mon père, je n'ai rien à dire, tu dois partir, pars en paix. Nous avions cru que tu mourrais ici. Pars et pense à nous et prie pour nous!» Sesoaïra, un autre élève évangéliste: «Les choses de Dieu auraient dû ètre acceptées par les grands de la nation; ils les unt rejetées, nous les croyons. On nous appelle des enfants, on se moque de nous; cela ne fait rien. Pars en paix, mon père!» Sewakutilibebe, un troisièms élève évangẻliste: «Oui, mon père, tu pars et nous pleurons. Dans la tribu il y a des gens qui se rejouissent de ton départ. Ils disent: Oh! qu'il parte, il nous ennuyait avec ses choses de Dieu, il veut troubler notre nation, nous empêcher de faire ce que nos cœurs désirent. Lan passé, quand tu es revenu, au lieu de partir pour le Lessouto, ils étaient tristes, maintenant ils sont contents, mais nous, nous te pleurons, mon père, nous penserons à toi ». - Tawira: «Je n'ai rien à ajouter. J'aj reçu ton message, je sais qu'il y a un Dieu ». Après Willie et Adolphe, Lewanika, le pauvre cher homme, voulut aussi rendre son témoignage. «Quel est le roi mo-Rotsé qui ait eu tout ce que j'ai eu: Un missionnaire, un temple? Il n'y en a point. Je suis triste que tu partes. Jai dit». Il faisait nuit quand nous sommes sortis de la chapelle.

Ce fut douloureux de voir notre cher doyen nous quitter le 30 octobre. Ce qui rendait ce départ encore plus pénible, c'était la froide indifférence de nos Zambéziens, des principaux chefs surtout, vis-à-vis de celui qui avait compromis sa santé en se consacrant à eux, et qui avait été, dans les mains de Dieu, un instrument de salut pour la nation.

Nous accompagnâmes M. Coillard, ma femme et moi, jusqu'à Seoma. Durant le trajet, le $1^{r}$ novembre nous eûmes la douleur de perdre Seonji d'une façon subite et terrible. Il se tua par accident, avec son fusil. Nous l'ensevelîmes à Nalolo le 2. C'était un jeune homme vif et colère autrefois, mais que l'œuvre du St. Esprit avait transformé. C'est avec l'assurance que c'était un racheté que nous confiâmes sa dépouille à la terre. 



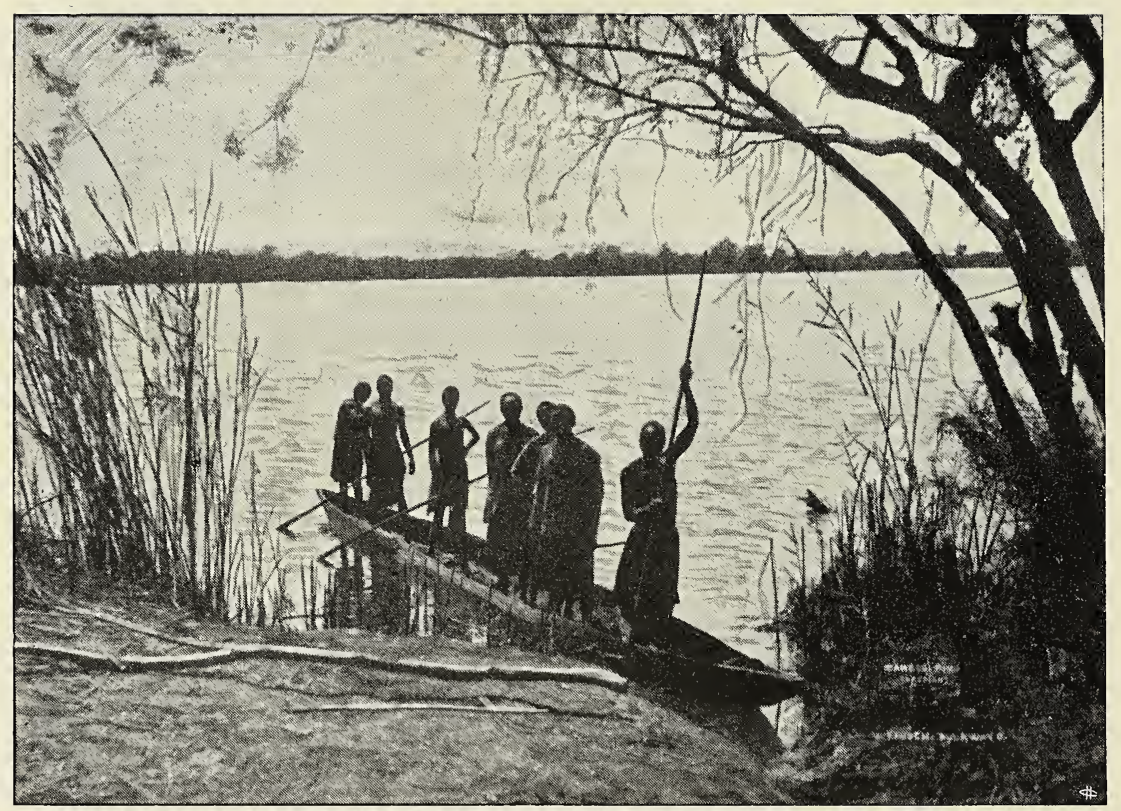

Le Zambèze vis-à--vis de la station de Mosi-wa-thunya. 
L.

De Nalolo à Séoma avec M. Coillard. Retour à Léalui.

\begin{abstract}
Leau du fleuve. - Bonté de Dien daus la création.
bernières henres avec M. Coillard. - Evangélisation. - Un naufrage.

Litia le prince chrếtien.
\end{abstract}

Nalolo 2 Novembre. - Nous sommes ici depuis hier soir. Ce qui fait le charme de cette station c'est sa situation au bord du fleuve. De l'eau fraîche et limpide! Savent-ils bien ce qu'ils pos sèdent ceux qui ont ce précieux liquide en abondance? Nous laver dans de l'eau claire, mais cela nous semble presque un gaspillage, et parfois il nous vient un scrupule: $Y$ en aura-t-il assez? Nous sommes tellement habitués à la mesurer, à compter les gouttes. Notre puiseur d'eau inspecte son tonneau tout le long du jour, puis éclate en injures s'il se doute qu'il y a gaspillage: «Ne savez-vous pas qu'elle vient de loin?.... » Mais voilà que je m’ètends sur les misères de Loatile au lieu de vous parler de ce beau fleuve sur lequel nous arrêtons nos yeux avec délices.

Nous eûmes le privilège de pouvoir accompagner et soigner M. Coillard jusqu'à Seoma.

Le 11 novembre, après avoir encore ployé les genoux ensemble, nous lui dîmes: À Dieu! puis nous le regardâmes s'en aller porté dans un canot, sur les épaules de huit hommes robustes. Notre prière ardente était que Dieu lui accordât d'atteindre la Colonie du Cap, puis l'Europe, où il recevrait les soins réclamés par son état, et qu'un beau ministère lui fût réservé dans les églises, où sa présence même ne manquerait pas d'éveiller l'intérêt en faveur du Zambèze.

Ce furent les élèves évangélistes qui conduisirent notre canot pour l'aller et le retour. Notre dessein avait été de profiter de l' occasion pour évangéliser plusieurs villages avant de rentrer sur notre station, mais le manque de vivres hâta notre retour. Cependant, tant à Seoma qu'à Nguanamâ et à Hufa, nous pûmes parler du Sauveur à d'assez nombreux auditoires, et nos élèves évangélistes y rendirent leur témoignage. Les 
chefs de ces villages nous envoyèrent leurs dons d'hospitalité, des grains, des patates sèches ou du lait caillé.

Le 13, le vent se leva subitement avec une violence extraordinaire. Le flots devinrent furieux; en un clin d'œil toute la surface du fleuve fut couverte de moutons blancs. Nous nous hâtons d'aborder. Quand nous nous retournons nous voyons le petit canot des bagages se remplir d'eau et disparaître. Vite j'envoie mon canot au secours des naufragés, et nous nous empressons de vider celui de ma femme pour qu'il y aille aussi. Dieu merci, tous furent saufs. Une fillette de douze ans put se tenir sur l'eau jusqu'à ce qu'on allât la repêcher.

À Nalolo, chez nos amis $M$. et $M^{e}$ Béguin nous rencontrâmes Litia. À l'issue d'un culte, en nous faisant ses adieux, il adressa quelques bonnes paroles à nos élèves évangélistes, leur recommandant d'être zèlés pour l'étude et de confesser courageusement le nom du Sauveur. 
TROISIEME PARTIE

Seuls pour une tâche sans cesse grandissante

1895-1897 



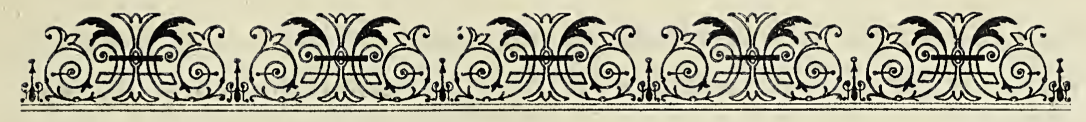

\section{TROISIĖME PARTIE}

LI.

Heureuses dispositions de Lewanika

Bon accueil. - Un hôte étrange. - Divorces an harem royal. - Bonnes têtes. séance de promodions. - Petits sujets de joie.

Echange de bons procélés. - Installation de M. Davit à Sefula.

LWATILE, où nous rentrâmes le 18 novembre 1895 nous A étions attendus par les évangélistes Willie et Théodore et leurs femmes. Il avaient étendu les nattes dans la maison, les tasses pour le thé étaient sur la table, la bouilloire sur le feu... Quelques heures après, Nolianga et Mpololoa avec quelques autres professants vinrent nous souhaiter la bienvenue. Le roi étant absent, j'envoyai nos salutations au Ngambela qui vint lui même le lendemain nous faire une visite très cordiale. Lewanika fit de même peu après son retour et pártagea notre repas du soir.

Le lendemain de notre arrivée nous vîmes paraître devant nous un blanc, maigre, pâle et misérablement vêtu. C'était $M$. Roth, un jeune Bavarois catholique qui avait vécu quelque temps au Damaraland où il avait subi des revers de fortune. Obligé de s'enfuir au Bihé, il avait été l'hôte de M. Sanders de la mission américaine. Il arrivait de là à pied, et pendant les quinze derniers jours, il avais vécu à la merci des natifs, 
sans un grain de verroterie, ni un bout de toile avec lequel il pût acheter de la nourriture ou payer les porteurs de ses effets.

Quand je le lui présentai, Lewanika fut touché de son histoire et promit de lui venir en aide.

M. Roth se faisait comprendre sans peine en français, en italien, en anglais, en portugais et en se-mbunda. Il avait un vrai talent pour le dessin. Ce pauvre jeune homme, qui semblait avoir des besoins religieux, et qui parut prendre un véritable intérêt à nos travaux, fut massacré par les Matébélés à son passage dans leur territoire. - Le 3 décembre, Lewanika nous annonça qu'il venait de renvoyer deux de ses femmes. Il le fit sans formuler aucune accusation contre elles, de son propre mouvement comme de sa propre autorité, sans consulter aucun de ses chefs et de ses officiers. Nous ne savions pas si nous devions nous en réjouir. Nous nous prîmes à espérer que ce serait le commencement de la dissolution du harem. La conversion de la jeune reine Nolianga avait fait bien autrement battre notre cœur.

Le 6, une des deux femmes renvoyées par le roi, passa par la station en se rendant chez des parents. Elle était vêtue comme une simple femme de chef subalterne, dépourvue des bracelets d'ivoire et des autres ornements qui sont l'apanage de. la famille royale; une seule esclave l'accompagnait; personne ne se prosternait sur son passage, on n'entendait pas un claquement de mains. Pauvre femme, elle si hautaine, si moqueuse, quelle dégringolade!

Elle ne put retenir quelques larmes quand ma femme lui parla. Elle qui s'était tant moquée de Nolianga, comme elle était plus à plaindre, même à un point de vue tout humain, tout matériel!

Nous eûmes de bonnes fêtes de Noël avec M. Davit et les Bé guin. M. Davit fit le jour même de Noël sa première prédication en sessouto. Après midi nous rassemblâmes nos enfants et les élèves évangélistes autour du sac à surprises, contenant des cadeaux pour chacun d'eux (robes, nécessaires de couture, livres, calicot, couteaux). Personne ne fut oublié et tous manifestèrent bruyamment leur joie.

Le lendemain ce fut le tour de l'école de station. Nous avions demandé au roi et à ses principaux chefs et officiers de pren- 
dre part à la séance. Après un examen sommaire de chaque classe, nous donnâmes 15 prix aux plus réguliers et aux plus appliqués. Les discours suivirent. Il $\mathrm{y}$ en eut une douzaine! Qu'on se rassure, ces ma-Rotsé sont sobres de paroles eu public. Quelques-uns des orateurs faillirent se quereller, s'accusant réciproquement de ne pas avoir soutenu l'école. (L'invective est leur forme oratoire de prédilection). Après dîner nous distribuâmes aux 114 élèves la viande cuite d'une tête de notre bétail, égorgée par une hyène.

Les trois derniers jours de l'année furent marqués chacun par un fait réjouissant. Le 29 par la naissance d'Eugène, l'enfant premier-né de Théodore et Alita. Le 30 je reçus un présent, le premier témoignage de gratitude qui m'eût été offert pour mes soins médicaux. La reconnaissance est une fleur rare. Son parfum en est d'autant plus exquis. Le Jour de l'An, Léwanika nous donna, en guise d'étrennes, quelques nattes artistement tressées, qui nous furent d'une grande utilité. Mais au Zambèze, accepter un cadeau c'est s'engager à en offrir immédiatement au donateur.

Il y avait bien des mois que j'avais fait mon dernier marché avec le roi. Et encore n'avais-je consenti à entrer en pourparlers avec lui que parcequ'il avait voulu acheter une Bible et un recueil de cantiques pour sa fille Sanana.

Une longue et pénible expérience m'avait contraint à dire au roi que pour demeurer bons amis il nous fallait renoncer à toute négociation, nous n'eûmes plus dès lors que des échanges de bons procédés.

Le 4 janvier 1896, M. Béguin et moi, accompagnés de Mokamba, allâmes rejoindre à Sefula M. Davit. Le lendemain, 250 personnes assistèrent à son installation. Le 6 , je le présentai à la classe, ensuite je célébrai le mariage d'un professant avec une païenne, et enfin nous procédâmes à la réouverture de l'école. Elle n'était plus fréquentée que par trois ou quatre enfants. L'école se rouvrit avec 44 élèves. Quelques jours plus tard leur nombre doubla.

Nous dûmes laisser M. Davit faire ses premières armes tout seul. Panluse et sa femme étaient de bons voisins et des aides précieux pour le nouveau missionnaire. 
LII.

Inauguration officielle de l'école d'évangélistes.

Séance d'inanguration. - Détails biographiques sur les élèves.

Horaire - Programme.

T $\mathbf{8}$ janvier eut lieu l'inauguration officielle de l'école

1 d'évangélistes. Le roi, tous nos professants et beaucoup d'élèves de l'école de station y furent présents, avec quelques chefs et officiers. Nos amis Béguin étaient encore des nôtres jusqu'au lendemain matin. Je lus quelques versets et parlai du sérieux et de la beauté de la vocation des évangélistes. M. Béguin leur parla principalement de la nécessité d'apprendre avant d'être à même d'enseigner. Willie insista sur les difficultés que tout évangéliste peut s'attendre à rencontrer.

Mokamba leur dit: "Nous sommes heureux de vous voir vous vouer à l'évangélisation du pays de nos pères, persévérez. Vos compagnons ne manqueront pas de se moquer de vous. Persévérez comme Moïse, qui a préféré être méprisé avec le peuple de Dieu, plutôt que d'être appelé le fils de la fille de Pharaon, parce qu'il pensait que les richesses d'Egypte étaient périssables, tandis que Dieu lui en réservait d'éternelles. Veillez sur vous-mêmes, car désormais on ne vous appellera plus seulement croyants, mais évangélistes 》. Semonja lenr dit: «Mes frères, sachez que dès aujourd'hui on se moquera de vous, en disant: Vous voulez imiter les blancs, tout en étant noirs comme nous, où avez-vous trouvé ces choses? N'importe, prenez courage. 》

Le roi ajouta: «Moka, c'est toi qui étais à mon service personnel avec Sewakutilibebe. Pensez-vous que par le fait que vous sortez de ma capitale, elle cessera de subsister? Si je viens ici et que j'apprenne que l'un de vous trouble les missionnaires en disant qu'il veut retourner à la capitale... cela ne se fera pas tant que je serai roi. Si j'avais le droit de le faire, j'établirais une loi pour punir ceux qui deviennent renégats. Vous 
avez désormais un autre roi. Votre seule affaire est de vous appliquer à vos études 》.

Sesoaîra termina par la prière, une prière de consécration au Seigneur, faite au nom de tous ses condisciples. La séance fut écourtée par la réunion qui devait suivre. (C'était la semaine de prières de l'Alliance évangélique). Le soir je fis des projections lumineuses.

Nos jeunes gens firent leurs adieux à leurs chefs, parents et amis. $\grave{A} 4 \mathrm{~h}$. ils se rassemblèrent sur la place publique pour prendre officiellement congé de tous et remercier le roi qui les avait libérés. Dès $5 \mathrm{~h}$. ils faisaient partie de notre maisonnée.

Les élèves de la classe la plus avancée ( $1^{\text {re }}$ classe) étaient: Sewakutilibebe, Nawa, Kuibisa, Selwendo, Leaco, Semocheta et Nyondo. Ceux de la classe préparatoire: Moka, Sesoaïra, Rajata.

Nyondo, que les pages précédentes et le livre de M. Coillard ont déjà fait connaître, n'était pas à l'ouverture de l'école; il avait accompagné 《son père 》, notre cher doyen, jusqu'à Kazungula. Mo-Shukulumbwe de naissance, il avait été enlevé à ses parents lorsqu'il était encore jeune garçon, et était devenu un des esclaves personnels de Lewanika, attaché au service du Kwandu, le palais royal. En 1889 il avait obtenu du roi la permission de demeurer chez M. Coillard, en vue de l'école. C'ètait un garçon de confiance, assez bien doué, converti depuis 1892.

Ra-Botale, le père de Leaco, était mo-Mbowe, mais établi tout près de la station de Sefula. Léaco en avait fréquenté l'école. Il avait ensuite été domestique de Pauluse et de M. Coillard, et était professant depuis 1894. Comme Nyondo, il avait fait partie de la classe préparatoire de M. Coillard.

Semocheta était déjà chez M. Coillard quand j'y arrivai en février 1890. C'était un esclave libéré, un mo-Toka, qui entra dans l'école d'évangélistes sans aucun enthousiasme, comme à son corps défendant.

Sewakutilibebe est mo-Subiya, de Mambova. Jeune garçon de 12 à 13 ans il avait été à Johannesburg et en était revenu avec le nom de Pikinini. Lewanika ayant entendu parler de sa vive intelligence, l'avait fait venir à Léalui, lui avait donné le nom de Sewakutilibebe, et l'avait attaché à sa maison. Entré à l'école de Loatile en 94, ce garçon avait appris à lire et à écrire comme par enchantement, n'avait pas tardé à devancer 
tous ses condisciples, et à devenir le premier élève de l'école. Il avait été un des premiers fruits du réveil de 1894.

Nawa et Kuibisa, nos seuls ma-Rotsé, sont tous deux originaires de Mbaela. Le premier est fils de Mokena, la $3^{\text {e }}$ femme du roi, le second est frère de Ma-Morambwa (la $1^{\text {re }}$ femme du roi). Les deux étaient parmi les meilleurs élèves de l'école de station, et avaient fait profession de christianisme vers la fin de 1894. Ils araient de 17 à 19 ans.

Selwendo est issu d'un ma-Rotsé et d'une ma-Totela. Au temps de Ngolama, un de ses aïeuls avait été envoyé au Njoko (dans le bo-Totela) avec les ma-Ntumelete, (gens chargés de la garde des gués). Son grand-père fut tué par les ma-Kololo, lorsqu'ils envahirent le bo-Rotsé. Son père, considéré comme un mo-Totela, était un petit chef de village à Nanjeko (dans le bo-Kwangwa). C'est là que Selwendo passa la plus grande partie de son enfance. Il nous racontait que quand il refusait d'obéir, ses parents le privaient de nourriture, bien qu'ils eûssent des esclaves. Après la mort de son père, il fut pris par le roi, amené à Léalui et placé à Moshukula, une des dépendances de l'établissement royal. Quand en octobre 1893 le roi fit annoncer que tous les garçons étaient libres d'aller à l'école des missionnaires, il s'y rendit. C'était un garçon timide de 16 à 17 ans, que ses compagnons n'aimaient guère; mais grâce à sa persévérance, il se fit peu à peu remarquer de nous par ses progrès. Il était dans la $2^{\mathrm{e}}$ classe quand il demanda à être accepté comme élève évangéliste. Sa conversion date aussi de la fin de 1894.

Moka eut une enfance assez heureuse. Son père était un bo-Tebele qui s'était réfugié chez les ma-Rotse pour échapper à la tyrannie de Lobengula. Il avait gagné la confiance du roi. Ses malheurs commencèrent à la mort de son père. Lewanika déposséda les enfants, et prit Moka à son service personnel. C'était vers 1883. Quand la révolution éclata, il échappa au massacre. $\dot{A}$ son retour, Lewanika le reprit, et ne tarda pas à remarquer le soin avec lequel il faisait son service. Quand il se convertit (en 1894), il était gardien d'une antilope d'eau que le roi élevait. Au commencement, il avait eu pea de zèle pour l'école, et aucun désir de fréquenter les cultes. Il fut frappé un jour par les paroles du cantique «Chantez, anges du ciel $\gg$. Il se dit: Qui sont ceux que l'on fêtera au ciel ? Est-il possible 
que cela puisse s'appliquer à moi ? Ce fut le commencement de sa conversion. Depuis lors, il prit intèrêt à l'école et aux cultes. Il fit profession publique en même temps que Salwendo.

Sesoaïra est un mo-Shukulumbwe, né vers 1870, ravi à ses parents quand il était encore jeune garçon. Il fut attaché à la personne de Litinyana (un neveu du roi). Pendant la révolution, il passa d'un maitre à l'autre, dut servir conıme porteur pendant les combats de Mongu (commencement de 1885), il fut entraîné vers le Lekwakwoi, revint au bo-Rotsé; au retour de Lewanika, il redevint esclave de Litinyana, dont le père avait péri au commencement de la révolution. Sesoaïra entra en contact avec l'Evangile en 1889, à Sefula, où il fut pendant quelques mois ouvrier de M. Coillard. Il fit profession de christianisme en septembre 1894. Il se fit remarquer par son zèle, mais il était peu doué intellectuellement. Lui et Moka n'étaient que dans la $4^{\mathrm{e}}$ classe de l'école de station, quand ils entrèrent dans la classe préparatoire. Ils pouvaient comprendre ce qu'ils lisaient, mais ne savaient pas écrire et n'avaient aucune notion ni de arithmétique, ni de géographie.

Kajata enfin, le $3^{\text {e }}$ élève de la classe préparatoire, venait de Kazungula, dont il avait fréquenté l'école. Il avait de 16 à 17 ans. Sa conversion datait aussi de 1894.

Voici quelle était la distribution de nos heures d'études pour la semaine :

Exégèse cursive de l'A. T. $3 \mathrm{~h}$. Grammaire $\quad \mathrm{l} \mathrm{h}$.

Exégèse de la Genèse

$2 》$ Composition

$2 》$

Exégèse de Luc (manuel)

$2 》$ Improvisation

1 )

Catéchisme

$1 》$

Dictée

$1 》$

Histoire de l'Eglise

1 )

Ecriture

$1 》$

Exercices homilétiques

$2 》$

Lecture

$1 》$

Chant

$1 》$

Total 11 L.

Arithmétique

$2 》$

Géographie

2 》

Anglais

Le samedi était consacré à l'évangélisation.

Tout en nous efforçant de donner à nos élèves évangélistes un 
développement général, nous visions surtout à leur rendre la Parole de Dieu attrayante et familière. En outre ils avaient en commun avec les autres catéchumènes plus avancés, les classes que nous faisions avant déjeuner et les exercices de chant. Ils avaient aussi quelques heures de travail manuel, et devaient préparer, à tonr de rôle, leurs repas.

Ainsi commencèrent ces leçons et ces rapports constants avec nos élèves évangélistes. Ce fut un privilège que de nous occuper de ces jeunes gens, l'espoir de l'église zambézienne. Ils apportèrent beaucoup de vie à la station. Chaque semaine les élèves venaient passer une soirée avec nous. L'école devait être pour nous une source de grandes joies et de cuisantes douleurs.

\section{LIII.}

Sujets de préoccupations et objets de nos soins.

\footnotetext{
La disette. - Menace de guerre. - Lewanika semble prêt. willie malade. - Protestation couragense de Moka.

Classe pour les professantes.
}

T 'Approvisionnement pour notre maisonnée eût été des 1 plus laborieux si M. Béguin ne nous était venu en aide très activement et de grand cœur.

Les sauterelles, qui avaient menacé de tout dévorer et qui avaient longtemps nui à nos cultes, en retenant les gens dans les champs, avaient enfin disparu, Dieu merci, pour un temps du moins, et la récolte du maïs put se faire. C'est ainsi que la disette prit fin. Que de fois depuis août (95) nous avions donné à nos gens la dernière tasse (1) mais Dieu avait toujours envoyé à temps ce qui était nécessaire pour la journée. Nous avions vécu au jour le jour. Mais, nous l'avouons, nous respirâmes plus librement quand nous pûmes avoir le pain du lendemain assuré.

1) Une grande tasse en fer émaillé nous sert de mesure. 
Un autre sujet de préoccupations survint alors: une menace de guerre. Les ma-Tawana du lac Ngami, avec Sekomi à leur tête, avaient envahi le territoire d'un allié de Lewanika et à certains égards son vassal. Quand les esprits se furent un peu calmés, les ma-Rotsé suivirent mon conseil, et décidèrent d'arranger le différend par la voie diplomatique. Nous en bénîmes Dieı.

19 JANVIER. - Comme toujours le dimanche, Lewanika vint dîner avec nous. Au sortir du second service, il s'assit encore sous notre vèrandah pour causer. Il parla de ses femmes qui suivent irrégulièrement le culte, de la dureté des femmes en général, et tout cela comme un parfait chrétien. "Mais, que puis-je faire? nous dit-il. Quand je presse les gens de venir au culte, il se disent: Et lui, pourquoi ne se convertit-il pas? » Mon mari avait pris pour texte: Qu'as-tu fait de ton frère? et le Roi en avait été impressionné. Lersque nous nous séparons de cet homme, nous nous sentons toujours émus et nous disons: Mais, pourquoi donc ne fait-il pas le pas décisif? Quelquefois en l'entendant parler nous oublions qu'il n'est pas chrétien. Qu'est-ce qui le retient? Intercédez avec nous en sa faveur.

2 FÉvRIER. - Les moustiques nous tourmentent, le soir nos chambres en sont envahies.

Willie est sorti pour la première fois depuis 8 jours, pour venir au culte de ce matín. La fièvre l'a amaigri et rendu tremblant. Je lui envoie souvent une soupe, un buuillon ou des œufs battus. Ce soir, je leur ai envoyé deux canards. "C'est ce que nous désirions, me fit dire Ernestina, Misisi n'oublie pas les petits oiseaux $\gg$.

Les immortelles sont très belles, mais toutes d'une même nuance, Les balsamines et les zinnias sont dans toute leur gloire, et quelle richesse de teintes!

Les termites sont plus actifs que jamais, par contre les fourmis guerrières nous laissent bien tranquilles cette année: la guerre sans relâche que nous leur avons faite n'a pas été inutile.

Le 12 février, Moka nous réjouit par un acte courageux. Il osa s'opposer à plusieurs chefs et à des centaines de gens, lui tout seul, protestant qu'il ne fallait pas aller au tombeau de Lirundu implorer l'aide des mânes, pour faire traverser le fleuve du bétail. Il ne réussit pas, mais il n'en rendit pas moins son témoignage.

À la fin de février, ma femme inaugura une classe pour les 
fummes et jeunes filles professantes. Là elle pouvait leur dire bien des choses qu'on ne peut aborder dans les classes mixtes ou les réunions ordinaires, et les habituer à fixer leur attention.

\section{LIV.}

À la grande chasse royale.

Départ du roi pour la chasse. - A Libonda, objets de curiosité. - Souvenirs de Livingstone. - Un arbre sacré. - An campement royal. - Bonté de Lewanika. - Autant qu'Elie. - Honneur à Misisi. - En canot sous la pluie - Envahis par le seurui. - L'avant-dernière allumette.

T Es bonnes dispositions di Lewanika, quelques nouvelles $\perp$ professions, les magnifiques auditoires des derniers mois, nous firent croire qu'un nouveau réveil approchait.

En partant pour la grande chasse le 2 mars, le roi recommanda au Ngambela et aux autres chefs laissés à la capitale, de rassembler les gens pour les cultes. Lui qui l'année précé. dente m'avait éconduit, lorsque je m'étais offert à aller présider un crite à son campement, nous pressa cette année de ne pas les laisser sans prédicateur un seul dimanche. Il était désireux que l'Evangile fût annoncé aux foules qui allaient se rassembler.

Nous allâmes le saluer à son canot, lui apportant quelques petites provisions de route, des choses qu'il aimait trouver à notre table. En nous quittant, il fit encore crier aux élèves évangélistes qui montaient notre canot: «Adieu, et apprenez beaucoup 》. Nos jeunes gens nous étonnèrent, nous n'en entendîmes pas un seul regretter sa liberté, en voyant partir ses anciens compagnons pour la chasse. Leur entrain à l'école allait en augmentant.

Le 11 mars, laissant la garde de la station à Leaco et Ngambo nous partons à $7.30 \mathrm{~h}$. vers le Nord, à travers la plaine submergée. À 10,30 h. nous passons près du grand village de Namakala, une heure après nous sommes vis-à-vis de Libonda. Nous traversons les deux bras du fleuve et arrivons au dé- 
barcadère. Libonda est à environ 2 kilomètres du Zambèze, mais pendant linondation on aborde au pied même du village. Le mamelon sur lesquel il est bâti est alors un grand ílot élevé au dessus du niveau de la plaine. Katoka, qui en est la chéfesse, nous avait autorisés à dresser notre tente dans sa cour, que nous trouvâmes très-bien entretenue.

Tous les hommes sont à la chasse, sauf cinq ou six, mais les femmes et les enfants sont en grand nombre. Ils viennent nous saluer les uns après les autres ou par groupes de vingt à trente. Pour quelques uns d'entr'eux je suis une merveille, parce que tous ne m'ont pas vue à Léalui. Je suis la première femme blanche qui ait fait son apparition dans ce village, aussi accourt-on de tout côté pour me voir. Quand nous croyons que tout le monde est parti, nous nous apercevons que les issues de la cour sont encore bien garnies. Je voudrais me reposer un peu sous notre tente, mais c'est impossible. On y étouffe. Nous sortons accompagnés des élèves évangélistes, pour voir le village et inviter les gens à venir à la « prière », au coucher du soleil. Plus de 120 personnes écoutèrent mon mari leur expliquer l'oraison dominicale. Nyondo ajouta quelques exhortations. Le village est grand, mais les huttes sont assez misérables. Peu ou point de passages entre elles. Tout l'espace disponible a été utilisé pour la culture du maiis. Ca et là des planches bien entretenues de tabac et de chanvre. De tous côtés les enfants sortent pour nous voir, et s'enfuient effrayés à notre approche, quelques-uns en criant et en cachant leur figure dans leurs mains. Ce n'est pas flatteur! Nous demandons du bois pour notre feu et on nous en appporte bientôt. Un brave vieux, qui traîne deux grosses bûches, a vu Livingstone lors de son premier voyage à travers le pays et a été l'un de ses bateliers. On nous dit que c'est Livingstone qui a introduit au Zambèze les chats domestiques, ainsi qu'une qualité supérieure de tabac que l'on appelle maroboto (du nom de Madame Livingstone: Ma-Robert, la mère de Robert). Un ficus séculaire se dresse pas bien loin de notre campement. Si on jouit à l'ombre de ses énormes branches, on se garde bien d'en brûler jamais les rameaux desséchés. On les jette. Les brûler, ce serait irriter celle qui l'a planté, nous explique un indigène, car elle $\mathrm{y}$ a déposé son cour. (Mbwanikana, est le nom de la sœur du premier roi enterrée sous cet arbre). Des centaines de tourterelles ont établi domicile dans ses branches et nous entendons leur roucoulement.

Un accès de fièvre, la chaleur accablante et les moustiques devaient la nuit nous empêcher de prendre du repos. 
Le lendemain nous avons une cinquantaine de persounes au culte. Nous continuons vers le nord. La plaine est plus accidentée qu'à Lealui, on y voit plus d'arbres et de buissons. Dans toutes les directions de hauts panaches de palmiers nous rappellent, ce que d'ailleurs le soleil ne nous laisse pas oublier, que nous sommes sous les tropiques. Trois heures et quart de navigation nous amènent au campement de chasse.

Lewanika nous reçut avec une grande courtoisie. Nous passâmes ainsi environ deux semaines auprès de lui, le suivant dans ses déplacements.

Les occasions d'évangéliser et de prêcher, des soins médicaux aux malades, ne nous manquèrent pas. L'exercice de la médecine est un moyen de plus, que nous avons à notre portée, pour attirer les indigènes.

Que de gens qui nous connaissent pour nous avoir vus ou entendus à Léalui et dont nous n'avons aucun souvenir! Par contre, il en est plusieurs qui n'ont pas encore la moindre notion de notre mission, et qui se demandent ce que nous sommes venus chercher à cette chasse. Ils ne se doutent pas que nous sommes venus les chercher eux-mêmes au nom du Dieu qui veut les sauver.

Lewanika vint à diverses reprises passer quelques moments, ou même des heures, près de notre tente.

15 MaRs. -- Après le culte nous sommes allẻs dans l'enceinte royale où Lewanika nous a suivis. Il nous fit entrer dans sa hutte qu'il appelle son trou (elle a pourtant 2 mètres de hauteur sur 6 ou 7 de longueur). L'heure de conversation, que nous avons eue avec lui, s'est bien vite écoulée. Dans nos entretiens avec le roi nous n'oublions jamais de lui parler de ses intérêts éternels.

Nous étions à peine de retour à notre campement qu'un garçon venait de la part du roi nous porter une moitiẻ d'antilope.

«Voilà la viande de Misisi, dit le porteur, celle de l'autre jour ètait pour le moruti, celle-ci est pour Misisi, et le roi lui fait dire que c'est une bête tuẻe de sa propre main ». N'est-ce pas joli ?

L'épizootie n'a pas encore fait de victimes ici. Le gibier abonde. Mais pourrons-nous recevoir des approvisionnements? «Nous aurons autant qu'Elie au Kérith, en tous cas », me disait mon mari aujourd'hui. Cette pensée m'a fortifiee et a banni tout souci de ma pensée.

22 Mars. - Nous sommes toujours plus enchantés de l'humeur 
du roi. Il nous comble d'égards. Hier soir, comme il faisait dejjà nuit et que nous finissions notre souper, il arriva à l'improviste et passa une grande demi-heure avec nous.

$\mathrm{Au}$ retour, la pluie battante nous accompagna jusqu'à Libonda, plus de 50 kilomètres; mais nos rameurs avancèrent avec un entrain admirable. Nous repartîmes de Libonda ̀̀ 2.20 h. et regagnâmes le Zambèze, que nous descendîmes.

Nous arrivons à Namayula à $4.45 \mathrm{~h}$. Le tombeau est submergé, mais le hameau, bâti sur un mamelon élevé autrefois par des travaux de terrassement, est complètement à sec. Hélas, c'est nous qui ne le sommes pas; tente, matelas, drap, châle... tout est mouillé et trempé. Nous dressons la tente sur la petite place du Khotla. Kaieka réussit enfin à allumer son feu avec $d u$ bois mouillé et nous fait du thé, dont nous faisons part à tous. Nous assemblons les gens pour la prière. Nos élèves nous y récitent un joli choix de versets, nous chantons et prions. Les moustiques s'abattent sur nous et nous obligent à rentrer dans la tente pour le souper.

Vers minuit je suis réveillé en sursaut par les fourmis guerrières. La tente en est pleine. Dehors tous nos gens déménagent. J'essaie d'allumer une bougie... mais nos allumettes ont senti l'humidité, j'en frotte une vingtaine en vain... enfin, l'avant-dernière prend feu. Tout le sol est noir de fourmis, tous nos effets en sont couverts, nous en tuons beaucoup qui avaient déjà grimpé sur nos lits. Nous nous isolons de notre mieux... Mais la bougie ne durera pas jusqu'au matin. Peut-être qu'au besoin la dernière allumette ne refusera pas de s'allumer. $\grave{A}$ $5 \mathrm{~h}$. nos gens viennent nous réveiller pour nous prier de partir au plus tôt. Ils nous donnent de la lumière.

Tout le monde aide à enlever la tente et à secouer nos innombrables ennemis. Nous chargeons les canots, nous rassemblons encore les gens pour le culte et nous voilà filant à travers la plaine. C'est à qui arrivera le premier. Nous abordons à Loatile à 8.30 h. En 2 h. nous arons parcouru 23 kilomètres! 
LV.

Cernés par l'inondation.

nats, serpents, termites et crocodiles, - Cultes au chotla.

Chez les Béguño.

Comme l'inondation a diminué la superficie de notre station! L'eau a atteint les huttes de quelques-uns de nos gens et les a rendues inhabitables. Il y a des rats partout, il ne se passe pas de jour où l'on ne tue plusieurs serpents dans le jardin potager, et parfois jusques dans la salle à manger ou dans la chambre à coucher.

Que de choses à faire quand on rentre à la maison! Les termites avaient travaillé pendant les quinze jours qu'a duré notre absence. Leurs nids couvrent nos murs. Dans notre chambre à coucher il y a 14 trous béants! N'est-ce pas affreux que ces termites gâtent ainsi notre jolie maison?

À Léalui la moitié de la place du Khotla était sous l'eau, jabordai au hangar du tribunal. La plupart des maisons étaient inondées, et les gens étaient chassés de chez eux. Les esclaves qui devaient garder les cours de leurs maîtres s'y étaient fait des échafaudages pour y dormir.

Le niveau de l'eau s'éleva jusqu'au 27, et atteignit une hauteur moyenne d'un mètre et quatrevingt-quatre centimètres.

L'accès de la station était désormais très dangereux. Déjà à la fin de février, notre puiseur d'eau, un homme grand et gros, y avait été mordu par un crocodile. Mais les terribles sauriens étaient devenus de plus en plus audacieux, et plus d'un porc était resté leur proie. Personne n'osait s'aventurer sur la chaussée à moitié submergée. D'autre part il n'était pas resté à la capitale assez de canots pour nous amener de nombreuses personnes.

Je proposai au Ngambela et à Katoka de tenir les cultes sous le hangar du Khotla, ce qu'ils acceptèrent avec reconnaissance. Nous nous en félicitâmes. Le dimanche 29 mars, et le ven- 
dredi Saint (3 avril), nous y eûmes environ 300 personnes, surtout des femmes, car la plupart des hommes étaient avec le Roi.

Nous rentrîmes à Lwatile le 13 avril.

LVI.

Influences pernicieuses.

Letour de la chasse. - La soif de l'or. - Le paganisme s'afiche. - Le tabac.

E.retour de la chasse se fit avec plus de pompe que ja1 mais. Tous ce qui était resté à Léalui d'hommes capables de ramer, avait amené la Nalikwanda à la rencontre du roi, à Libonda. Nous la vîmes arriver le 27 avril, pavoisée avec beaucoup de soin: Pour la première fois un drapeau (blanc et bleu) flottait au dessus du pavillon. Jamais nous n'avions assisté à un accueil aussi frénétique, jamais nous n'avions vu dans ce pays tant de gens rassemblés.

Lewanika était épanoui. Il était fier de montrer sa gloire, uon seulement à nous qui y sommes habitués, mais aussi à deux marchands anglais qui se trouvaient justement à Léalui.

La vue de ces marchands et les fréquents entretiens qu'il eut avec eux, même le dimanche à l'heure des cultes, réveillèrent le démon de l'avarice, qui n'était qu'assoupi dans le cœur du roi Ils lui firent espérer qu'il recevrait bientôt de la B. S. A. C. C. les 50,000 francs annuels qu'elle lui avait promis en 1890; ils offrirent de lui payer le caoutchouc plus de $5 \mathrm{fr}$. le kilogr. et promirent de lui apporter toutes sortes d'objets à acheter. Il est facile de deviner le reste: Lewanika ne pensa plus qu'à l'or. Pendant un temps il aurait voulu que nous lui payions argent comptant chaque petit service qu'il nous rendait. Avec quelle facilité il manqua les cultes depuis lors: un mal de tête, moins encore, tout lui servit de prétexte pour éviter la «maison de Dieu $》$.

Cependant nos rapports personnels furent toujours faciles, et même agréables. Il nous traita en amis comme précédemment et fit bien des choses pour favoriser l'œurre. Il ne s'offusqua pas 
des observations que je lui fis. «Continue, me dit-il un jour, continue à nous avertir et à nous reprendre, ne te lasse pas, ton travail ne sera pas vain $\nabla$.

Malgré les cultes célébrés tous les dimanches aux campements de chasse, cette vie de distractions avait nui à l'œuvre de Dieu dans d'autres cœurs que dans celui du roi. Le paganisme s'affficha avec plus d'éclat; tous les soirs nous fûmes affligés par le bruit des chants, des tambours et des danses.

Cependant les cultes furent fréquentés. Nous eûmes une moyenne de 275 auditeurs. Le nombre des élèves se maintint à une moyenne de 95 depuis la réouverture de l'école. Nos classes et la prière du matin continuèrent à être bien suivies par les professants. Malgré les moqueries des païens qui ne les appelaient plus guères que 《les fous 》, ils tinrent bon.

Notre école d'évangélistes nous donna aussi des soucis. Il fallut interdire l'usage du tabac aux élèves évangélistes, comme nous l'avons toujours fait à nos «enfants 》 qui sont souvent appelés à entrer dans notre maison ou dans la cuisine. Saisissant comme prétexte qu'ils ne pouvaient abandonner le tabac, deux d'entr'eux déclarèrent être fatigués de leurs études, et vouloir rentrer à la capitale. "Moi, disait l'un, ce que j'aime, c'est d'aller et venir comme je l'entends, chasser quand bon me semble, et me reposer quand cela me plait». Quant à l'autre, nature renfermée, peu appliqué à son travail, nous sentions depuis longtemps que son cœur était ailleurs. Il avait plusieurs fois fait des démarches pour quitter M. Coillard et devenir domestique $d u$ roi, il ne voyait rien de plus beau.

Mais la réception qui leur fut faite à Léalui ne fut pas telle qu'ils l'avaient espérée; le roi, très vexé, leur fit dire: «Que venez-vous faire ici? Je n'ai pas besoin de vous!» Pendant le temps qu'ils couchèrent à la capitale, ils vinrent tous les jours rôder sur la station conıme des âmes en peine. Le fils de maRotsé n'avait peut-être pas grand'chose à craindre de la colère du roi; l'autre, pauvre esclave libéré, avait eu vent que Lewanika se proposait de le châtier vertement et même de lui enlever sa fiancée, une gentille enfant qui était chez nous. Enfin je me rendis à leurs supplications et les repris les deux, tout en doutant de leur repentir. Il vaut mieux pécher par excès de miséricorde que par trop de rigueur. 


\title{
LVII.
}

Deuil et autres épreuves.

\begin{abstract}
Mort de ma mère et de I. Goy. - D'où viendra le secours?
\end{abstract}
La maladie. - Révolte des ma-Tebele.

T 9 mai nous reçûmes un douloureux courrier, nous ap$\perp$ prîmes la mort de ma mère bien-aimée (décédée le 23 décembre 1895). Il nous resta le souvenir béni de sa vie de prière, d'humilité et de dévouement, et le ciel eut un attrait de plus. Comme l'arrivée de mon frère, Louis Jalla, à la maison paternelle avait dû être assombrie!

La même poste nous apporta la nouvelle encore plus inattendue, de la mort de notre ami A. Goy ( +26 avril). Si nous ne savions par expérience que le Seigneur ne se trompe pas, mais qu'il fait contribuer toutes choses au bien de ceux qui l'aiment et à l'avancement de son règne, nous aurions été découragés et abattus. Pourquoi pendant l'absence du fondateur de la mission et du plus ancien de ses collaborateurs, pourquoi enlever à notre œuvre, à Sesheke, à sa jeune femme et à ses enfants, cet ami dont l'activité était si indispensable? Pourquoi cette perte? Notre frère possédait bien la langue, il avait appris à connaître les Zambéziens, il avait acquis beaucoup d'expérience, cela nous avait frappés pendant la dernière conférence, nous avions tous beaucoup joui de lui. Pourquoi? Nous le saurons un jour et nous en bénirons Dieu, mais le ciel nous paraissait sombre.

Cependant quelle belle mort que la sienne, enlevé après une tournée d'évangélisation, mort à la brèche! Il avait quitté cé pays de fièvre, de légèreté, de mensonge, de corruption, de larmes, il était auprès de notre Sauveur. Mais cette paurre Madame Goy, veuve après 6 ans de mariage et veuve au Zambèze, loin de tous ses parents et de sa fille aînée et dans l'impossibilité d'aller auprès d'eux; veuve à Sesheke avec une cheffesse comme Akanangisa, renégate, folle! Nous la pressâmes fortement de venir attendre chez nous que la porte du pays se rouvrît. 
Chère M.me Goy, n'est-ce pas la fournaise ardente, le creuset? Malheur à qui doit y passer sans la foi qui triomphe de tout! Elle m'ẻcrit: « La solitude dans laquelle je suis est terrible, je ne puis m'y habituer ». On peut tout supporter à deux, mais qu'est-ce que cela doit être, laissẻe seule, seule dans ce pays désolé. Nous ne pouvons ni ne devons pénétrer les mystères de l'au-delá, mais ne nous est-il pas permis de supposer que nos bien-aimés qui nous ont tant aimés ici-bas, continuent à nous suivre des régions célestes où ils ont pénétrẻ avant nous?

Le même courrier du 9 mai confirma la nouvelle apprise précédemment, des désastres produits par l'epizootie dans toute l'Afrique Méridionale. Dans ce pays où le transport se fait par le moyen des bœufs, nous nous trouvâmes dans l'impossibilité de recevoir nos approvisionnements. Nos articles d'échange, nos provisions de tous genres tiraient rapidement à leur fin.

Surchargés de travail, réduits en nombre, nous n'avions pas d'espoir de renfort. Je tremblais en pensant que j'étais alors l'ainé de la Mission.

Une des leçons que le Seigneur voulait nous enseigner c'était de regarder toujours à Lui. Au milieu de nos afflictions et de nos détresses, il nous répétait: Ma grâce te suffit, ma force s'accomplit dans ta faiblesse 》. Notre prière était qu'il nous donnât d'être «fidèles jusqu'à la mort».

Vers le 12 mai, Lewanika nous avait déjà communiqué la nouvelle de la révolte des ma-Tebele, mais comme il l'avait apprise par des rapports verbaux, nous en avions douté. Hélas, plus tard des lettres et des journaux nous annoncèrent des massacres! Comme nous bénîmes Dieu de ce que cette révolte n'avait pas éclaté quelques semaines plus tôt. Le Seigneur avait accordé à nos frères une délivrance semblable à celle dont ils avaient été les objets à leur départ de Kazungula. L'eûssent-ils retardé, ils n'auraient pas trouvé de quoi former un seul attelage, tant l'épizootie avait fait de ravages.

22 MAI. - Ma correspondance dẻjà passablement ètendue, va être encure augmentẻe. Que faire, par exemple, quand dans une excellente lettre de Genève on me dit: «Vous ne serez pas étonnée si je continue avec vous la correspondance que nous avions ma mère et moi avec M. Coillard.... Je sais que vous avez beaucoup à faire, 
mais si vous pouvez nous faire le plaisir de succéder à notre cher M. Coillard pour la correspondance, nous vous en serions très reconnaissantes ». Comment rẻsister à ces appels?

\section{LVIII.}

Dix jours au chevet de M. Davit.

M. Davit mourant. - Lente résurrection.

T a nuit du $1^{r}$ au 2 juin fut pour moi une nuit de fièvre. U J'eus quand même mon école le 2. J'avais cédé la place à ma femme pour sa leçon d'anglais, quand je vis paraître les messagers envoyés la veille avec notre poste pour Sesheke et l'Europe. Il nous apportèrent la foudroyante nouvelle, confirmée par une lettre d'Elisa, que M. Davit était mourant! Dans la matinée, Pauluse inquiet de ne pas le voir, était entré dans sa chambre et l'avait trouvé à terre, couvert de poussière et de meurtrissures, sans mouvement, sans autre signe de vie qu'un léger souffle. Nous partîmes demi-heure après, Willie et moi, chacun dans un canot. Mais c'est un mauvais moment pour aller à Sefula, la plaine a encore trop d'eau pour être traversée à pied ou à cheval, et le canot doit faire un grand détour et ne peut avancer que péniblement. Le soleil se couche avant que nous ayons atteint le Nokana. Plus loin un hippopotame nous barre le passage pendant trois quarts d'heure. Enfin à $7.30 \mathrm{~h}$. nous abordons, mais très loin de la station, car, hélas! le canal n'a pas été déblayé. Guidés par un jeune homme de l'endroit nous avançons à travers marais et fondrières, ayant quelquefois de l'eau jusqu'à la ceinture, et cela dure des heures. Enfin nous passons une dernière flaque d'eau et arrivons au village de Narumangu; une demi-heure après nous sommes à Sefula.

Il est minuit. Nous tremblons de fièvre et d'émotion en franchissant le seuil de la maison. Davit est là sur un matelas, toujours muet, les yeux fermés. Pauluse est à son chevet, trois jeunes hommes (des ouvriers de notre malade) sont aussi accroupis dans la chambre. Je donne quelques soins à mon ami, 
mais sans effet apparent. $\dot{A}$ une heure je vais me coucher, mais une fièvre ardente et l'angoisse m'enlèvent tout sommeil. Le matin (3 juin), je retrouve Davit dans le même état, son pouls est assez régulier, sa température au dessous de la normale.

Vers le soir ses idées s'éclaircissent encore, bien qu'il ne nous reconnaisse toujours pas. Dans ses rêves il prononce des prières touchantes.

Le 5 vers $10 \mathrm{~h}$. du matin ses idées recommencent à se brouiller.

Nous décidons de transporter notre cher malade à Lwatile, oì il sera plus facile de lui donner les soins que réclame son état.

Le 6 il continue à divaguer pendant que nous le mettons avec son matelas sur une civière, et que nous le faisons porter jusqu'à l'embarcadère, où nous arrivons après deux heures de marche pénible. Mon canot recouvert d'un pavillon nous $\mathrm{y}$ attend. M. Béguin, que j'avais prié l'avant-veille de venir nous aider, nous quitte pour rentrer chez lui.

Nous nous embarquons nous-mêmes bientôt. Je veille sur mon ami pendant que les élèves évangélistes rament avec entrain. Enfin à 4,45 h. nous atteignous le port de Lwatile, nos jeunes gens le portent sur un lit. Nous le laissons avec les évangélistes; je suis rendu, épuisé bien plus par les émotions constantes de tous ces jours que par les veilles et la fatigue.

Quelques-uns des élèves évangélistes le veillent la première nuit. Mais il nous reconnait et avec nous il est devenu doux comme un agneau, il remercie pour tout ce que nous lui donnons. La nuit suivante est bonne.

Le lundi 8 , quand je retourne vers lui après le déjeuner, il revient enfin à lui-même, il se sent à Lwatile, soigné par nous et ne cesse de répeter: «Que je suis content que mes terreurs ne fussent que des rêves! 》 Lui dont la force nous avait étonnés les jours précédents, se sentit dès lors faible comme un petit enfant. Ce même jour nous cessâmes de le veiller. Sa convalescence fut assez rapide, il put recommencer à se lever le 11.

Pendant ces semaines d'angoisses, plusieurs professants et le roi nous manifestèrent beaucoup de sympathie. Pendant que j'étais à Sefula, au chevet de Davit, Lewanika avait procuré à ma femme plusieurs messagers. Il envoya demander des nouvelles tous les jours. 
13 Juin. - Nous avons trouvé Nolianga chez Longa, accroupie sur une natte dans la cour; elle salue humblement etjoyeusement comme une esclave. Elle vient tous les jours écrire sur son cahier. Qu'il fait bon la voir toujours si gaie, si ouverte, elle autrefois toujours mélancolique. En la voyant nous oublions qu'un des traits caractéristiques de nos pauvres Zambéziens est la légèreté, et nous nous reprenons à croire que Dieu saura se choisir de fidèles témoins au sein de cette tribu.

\section{LIX.}

\section{Encore des difficultés.}

\footnotetext{
Henace d'invasion des ma-Tebele. - Fievre bilicuse hématurique. recrudescence de paganisme. - Un prince le-Tebele. -.- Procès de Matindo.
}

T 21 juin, j'allai lire au roi une lettre di M. Bagly lui $\perp$ annonçant que des hordes de ma-Tebele battues par les Anglais, cherchaient des canots pour traverser le fleuve. À Kazungula la panique avait fait évacuer tous les villages, même les Boiteux se préparaient à se réfugier sur l'île de Mpalira.

Or, tandis que l'épizootie avait décimé les troupeaux de la plupart des tribus environnantes, et même ceux du chef chrétien Khama, et des états boers et anglais, elle avait épargné ceux du bo-Rotsé proprement dit. Cette nouvelle preuve de la miséricorde de Dieu, loin de les attirer vers lui, ne servit guères qu'à enorgueillir ces paurres aveugles, et ramener la foule aux tombeaux des ancêtres qui tendaient à être abandonnés.

Mokwae revint passer cinq à six semaines dans sa résidence de Léalui, à partir du 30 juin. Ce séjour fut comme d'habitude accompagné et suivi d'une recrudescence de paganisme et d'un renouveau de superstitions. Les femmes du roi et celles des principaux chefs dûrent, selon l'étiquette, passer toute la première nuit sur pied, pour faire à la reine une sérénade accompagnée de marches rhytmées, tout autour de son établissement Le soir du samedi 4 juillet et toute la nuit, Léalui retentit du 
bruit de danses effrénées. Naturellement, nous ne vîmes aux cultes du lendemain ni Mokwae, ni Lewanika, ni ses femmes. Nous fûmes même émerveillés d'avoir un auditoire de 180 personnes.

J'en parlai au roi et à la reine, leur faisant toucher du doigt la triste influence qu'ils exerçaient sur leurs sujets. Lewanika en sembla effrayé. Les dimanches suivants ils précédèrent la foule aux services et nous eûmes des assemblées de 330 et 380 personnes. La capitale regorgeait de monde. Car si plusieurs étaient partis pour empêcher l'invasion des ma-Tebele, et si d'autres avaient été envoyés par Lewanika chercher du caoutchonc ou délimiter les frontières, d'autre part beaucoup de gens avaient été conviés pour des corvées à Léalui même. On bâtissait et on rebâtissait de tous côtés, entr'autres choses on construisait une grande maison rectangulaire et on élevait la chaussée.

Sur ces entrefaites un frère cadet de Lo-Bengula arriva à Léalui. Il était venu chercher refuge auprès de Lewanika. Il n'en fallait pas tant pour gonfler d'orgueil des gens qui ne sont jamais sortis de leur trou. Il en est qui allèrent jusqu'à dire: «Les ma-Tebele font leur soumission aux ma-Rotsé, bientôt les blancs eux-mêmes viendront en faire autant 》.

Un procès important se débattait au tribunal de la capitale. Lewanika décide de rendre le chef Matindo responsable d'un meurtre commis dans son village, de faire saisir tout son grand troupeau de vaches et de bœufs et de le distribuer (Matindo était un ancien réfugié). Le roi avait déjà sévi auparavant contre les meurtriers, mais en rendant les chefs responsables des meurtres commis dans leurs villages et dont on ne pouvait découvrir les auteurs, il obligea les chefs à faire eux-mêmes la police. Depuis lors la sécurité devint à peu près complète. Les indigènes ne s'arment plus que pour les voyages en prérision de rencontre avec des fauves. 


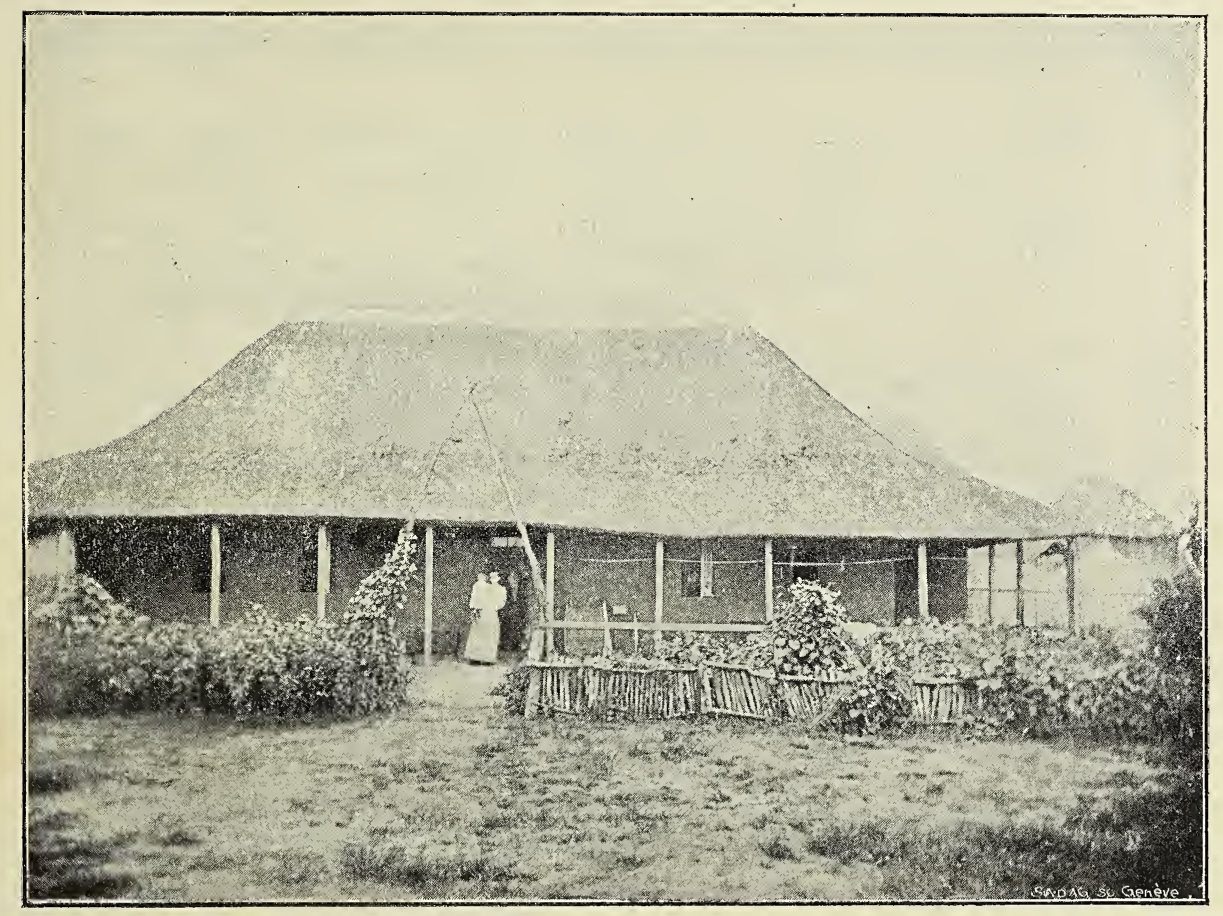

À Lwatile. 

LX.

Naissance de notre premier-né.

Henreux père et mère. - Lewanika encore superstitieux.

$\mathbf{V}^{\mathrm{E}}$ voici mère depuis le 20 juillet. Qui dira toute la joie que l'enfant qui nous est donné a apporté dans notre demeure.

Madame Béguin est arrivée quarante heures après la naissance. Un enfant! quel rayon de soleil! quel trésor! quelle fleur sur notre sentier, parmi les épines de notre route.

13 Août. - Notre cher Giulio nous regarde déjà de ses jolis yeux profonds. Madame Béguin m'a quittée la semaine passée, elle a soignẻ Bébẻ avec amour et m'a tenu compagnie, mon mari, toujours occupé, ne pouvant guère rester auprès de nous. Notre cher enfant prospère à vue d'œil et devient (sommes-nous bons juges?) chaque jour plus mignon. Il sourit souvent, et il a une abondance de ravissants cheveux blonds dorés.

28 Août. - Lewanika est toujours affable et nous envoie de temps en temps du poisson grillé sur la braise. Nous vivons surtout de patates et du produit de la chasse des gens de la station. Les Boiteux ont appris, je ne sais par qui, que nous sornmes à court de sel et nous en ont envoyé une boîte. Quant à nos boîtes de viande conservée, elles touchent à leur fin.

\section{LXI.}

Princesses mises à l'épreuve.

Nawina vaincue, puis vietoriense. - Ses soeurs ânées succombent.

DE tous les enfants du roi, Nawina, la fille de Nolianga, est notre préférée. Elle se convertit une des premières à Léalui (en septembre 1894). Sa douceur, sa timidité, la propreté de sa personne et de ses vêtements nous l'avaient déjà faite re- 
marquer précédemment. Depuis lors, son application à l'école, sa régularité aux classes, aux réunions, aux cultes, à l'école du dimanche nous la firent apprécier encore davantage. Cependant en juin 1896 elle se laissa tatouer. Sa mère désolée nous l'amena, elle considérait cet acte comme un retour au paganisme. $\mathrm{Na}$ wina était toute en pleurs. Je la réprimandai et lui recommandai de mieux veiller et de prier, afin qu'elle ne fût pas entrainée loin du Sauveur, ayant enfreint quelqu'une des règles imposées pas les superstitions païennes.

On voulait l'obliger à se purifier. Elle refusa. J'allai trouver le Roi, qui finit par me promettre qu'on n'userait pas de violences envers sa fille.

Ce même jour on amène Nawina devant le plat contenant le liquide purificateur. On la presse de s'en laver et d'en mettre aux poignets, aux chevilles, au front etc. Elle refuse. - Mais sache que si tu ne te purifies pas tu ne grandiras plus, (elle avait alors une dizaine d'années seulement), tu auras tant de crises nerveuses que tu en mourras... - Je ne crois plus à ces «médecines 》, répond-elle, je sais que Dieu garde ses enfants... N'allez pas dire que si j'agis ainsi c'est que j'y suis poussée par ma mère, non, c'est de moi-même. - Mais c'est ta tante, c'est le roi qui l'ordonnent. - Je n'y consentirai pas. - Eh bien, nous allons t'asperger de force. - Mais la brave enfant s'enfuit chez nous, et selon la promesse du roi on la laisse tranquille dès Jors.

Craignant le ressentiment de Katoka, quelques gardiens auraient voulu lui laisser croire que la purification avait été faite. « À quoi bon, répondirent d'autres, Nawina ne le cachera pas! 》

Katoka inspirée par sa sœur aînée Mokwae, poursuivit ses efforts pour détourner les autres professants de la famille royale. Les deux filles aînées du roi, consentirent même à se laisser laver avec tous leurs frères et sœurs (sans Nawina que l'on ne tenta même plus), avec je ne sais quelle drogue. On leur atta. cha des cordonnets destinés à leur donner de la vigueur et bien d'autres vertus.

Quand Mokamba vit sa femme rentrer arec ses amulettes, il les lui coupa, l'avertit qu'il l'abandonnerait si elle reniait le Sauveur, et la réprimanda si fortement qu'elle s'en alla se cacher. On ne la retrouva que tard dans la soirée.

Mokamba alla se plaindre au roi de ce qu'il avait induit sa 
femme en tentation. Son beau-père s'excusa en disant que si elle s'y était opposée, personne ne l'aurait obligée à subir ces pratiques.

\section{LXII.}

\section{Docteur's zambéziens.}

oflicier tué par ses docteurs. - La chirurgie et la núdecine au bo-Rotsé. Des chapues mexveilleux.

$T^{N}$ ce même temps les docteurs indigènes firent une de ces C opérations dont ils sont coutumiers. Moranda, un des officiers royaux était revenu du bo-Shukulumbwe (où son maître l'avait envoyé chasser) avec une douloureuse fluxion à la joue. C'est un nerf, lui dit-on, il faut le couper. On appelle un docteur. Celui-ci s'imagine couper un nerf dentaire, mais enfonce son bistouri jusqu'à la carotide externe et la perce. Ils essaient de tous les moyens pour arrêter l'hémorragie, mais en vain. Le pauvre homme a perdu beaucoup de sang quand on a recours à moi. J'arrêtai l'hémorragie et j'insistai pour qu'on apportât le patient à la station, mais ses parents n'y consentirent pas. Je le soignai plusieurs jours de suite. L'enflammation et l'enflure diminuèrent au point qu'il pouvait causer et manger sans trop de peine. Mais un jour ne s'avisèrent-ils pas d'enlever le pansement? (Les Zambéziens croient que nos remèdes doivent agir comme des charmes, instantanément). Quand j'arrivai, l'homme exsangue allait expirer, je ne pus plus rien pour lui que de lui parler du Sauveur, et prier.

Cela donne une idée de la chirurgie des noirs!

Les docteurs du bo-Botsé n'amputent jamais, ils n'arrachent même pas de dents; mais ils ouvrent des abcès, il font des ligatures, et surtout ils usent et abusent de la saignée.

La science médicale n'est pas l'apanage d'une caste. Les docteurs plus recherchés sont les étrangers; on fait de longs voyages pour aller chez eux, ou bien on les fait venir à grands frais. Il n'y a pas d'école de médecine, mais ceux qui ont longtemps servi les docteurs, deviennent médecins à leur tour. 
Pour découvrir les causes des maux, comme pour savoir par quels moyens il faut les combattre, ils se servent tous des osselets divinatoires et de toutes sortes de pratiques superstitieuses (aspersions de sang ou d'eau...) et de tours d'adresse avec des cerceaux et des morceaux de bois. Ils ne considèrent pas que la plupart des maux ont comme cause la transgression de quelque loi de la nature, ou de quelque règle d'hygiène. Pour eux la cause des maladies et des accidents ou des malheurs est toujours occulte, c'est la vengeance des mânes (soit qu'ils aient été délaissés, ou qu'on ait passé sur leurs tombes) ce sont des sortilèges, ou de mauvaises rencontres de gens ou de bêtes. Les Zambéziens sont sans cesse poursuivis par quelque crainte semblable.

Les remèdes sont des simples végétaux (racines, écorces, feuilles, herbes ou fleurs) qu'ils administrent intérieurement en décoctions, et extérieurement en compresses, ou en fumigations. Ils connaissent des purgatifs et des vomitifs, des sudorifiques. Ils ont des spécifiques même pour la lèpre.

Mais tout en administrant ces médicaments, ils font leur possible pour faire croire à leurs patients que l'essentiel ce sont les purifications, les offrandes aux mânes, les amulettes et les charmes. Il est des charmes que l'on porte sur soi, ou que l'on suspend dans les habitations, d'autres qu'on enterre; on en lance d'autres aux personnes sur lesquelles on veut agir etc. Les docteurs dispensent ainsi couramment des charmes ou des amulettes propres à gagner la faveur des chefs, du roi ou de toute autre personne, pour donner aux chasseurs de l'habileté au tir, pour attirer le gibier, pour préserver de la foudre, et des sortilèges pour rendre invulnérables ou invisibles. Hélas, ils connaissent aussi plusieurs poisons dont l'effet est mortel, et ils les ont longtemps mis à la disposition de qui les payait bien. Ils se font d'ailleurs toujours bien payer; il est rare qu'ils se contentent de verroterie ou de calicot, ils exigent souvent un bœuf, un fusil, ou même un esclave. 


\section{LXIII.}

Sur la station.

Retour des élèves évangélistes. - La première désertion. - Biographies missionmaires. - Première fievre de Ginlio. - Un rayon de soleil. - Méchan. tes gens: pauvres gens : - Le major Goold Adams. -- Ineendie de prairic. - Travaux manuels et autres occupations. - Dimanche rempli et bien. faisant.

T 2 septembre nous recommençâmes nos leçons aux élèves évangélistes. Quelques uns avaient été au Nyengo (ì l'Ouest), d'autres jusqu'à Kazungula et au bo-Toka. Ils s'étaient efforcés de porter partout avec eux la Parole de vie et d'enseigner des cantiques, tant pendant le voyage qu'après être arrivés à destination. Moka et Sesoaïra étaient particulièrement enchantés de l'accueil que leur avait fait Nguana-ngombe, cheffesse importante du Nyengo. Elle les avait chargés de demander un missionnaire pour son grand village et son district. (C'est une partie des plus peuplées des états de Lewanika, où jamais missionnaire n'a mis pied, bien qu'elle ne soit qu'à quelques jours de distance de Léaluï).

Cependant l'école n'était pas au complet, il nous manquait Sewakutilibebe, notre meilleur élève, un garçon sérieux, appliqué et sur lequel nous comptions. Après bien des hésitations et des détours, il nous avoua que sa femme d'un côté et les chefs de l'autre lui avaient montré qu'il ne pouvait être à la fois évangéliste et gendre du roi. Il devait s'occuper des affaires du pays. Il aurait voulu fréquenter l'école, mais sans se lier à le faire régulièrement, ni à devenir un jour évangéliste; mais je ne pouvais le garder dans ces conditions.

La question de l'après-midi du dimanche de nos enfants et des élèves évangélistes nous préoccupa beaucoup. Il y avait eu un temps où ils allaient régulièrement à la capitale ou dans d'autres villages chanter des cantiques et répéter la prédication du matin. Mais peu à peu leur zèle s'était refroidi, et au lieu de faire $d u$ bien ils subissaient la mauvaise influence ambiante. Ce 
n'était pas assez de continuer à les faire chanter une partie de l'après-nidi. Nous n'aurions pas voulu les garder de force à la station, sans leur donner quelque intérêt, estimant que pour de jeunes adeptes, il ne faut pas que le jour du Seigneur risque de devenir ennuyeux. Nous décidâmes de leur exposer des biographies missionaires, une par dimanche. Ils y firent tous si bon accueil, ils manifestèrent un intérêt si vif, que nous nous sentîmes très encouragés. Nous nous faisions du bien à nous--mêmes dans la société des grands serviteurs de Dieu.

Mes fillettes m'aident beaucoup pour les travaux à l'aiguille, mais il faut préparer chaque ouvrage et faufiler. Cédant enfin aux instances de mon mari, et à la nécessité de me dẻcharger de tâches secondaires pour ne pas négliger les plus importantes, je leur laisse taire beaucoup plus que par le passé, ainsi les plus avancées plient le linge et repassent.

Depuis la naissance de Giulio je me sens plus forte que je ne l'ètais auparavant. Pourquoi de nos jours la femme veut-elle chercher partout ailleurs que dans son foyer une tâche digne d'elle? N'est-ce pas assez que de former de jeunes cours, d'y semer la semence divine, d'en étouffer les mauvaises pensėes, de suivre arec amour le développement de ces êtres chéris que l'on aime comme soi-même? Est-ce trop peu que d'être l'aide semblable à l'homme dont celui-ci a besoin pour trouver du soleil et des fleurs sur son sentier, parfois si épineux, si difficile?....

Oh! le village de la capitale, comme il est décourageant. L'indiffẻrence et les moqueries $\mathrm{y}$ règnent. Le harem est plus impénétrable que jamais, le roi plus païen, plus enduré, plus éloigné que par le passẻ des choses de Dieu. Notre point lumineux c'est l'école d'ẻvangẻlistes.

4 OCTOBRE. - Notre fils, hélas! a dẻjà fait la connaissance de la fièvre. Son corps était brûlant, il ne pouvait dormir que dans nos bras, se réveillant à tout instant. Et malgré tout, le cher enfant nous faisait par moments de si jolis sourires, avec un regard si doux et si triste, comme pour nous demander pourquoi nous le laissions souffrir.

Heureusement que le voilà tout-á-fait bien de nouveau. Nous oublions tous nos soucis en le regardant sourire; auprès de lui, les chagrins semblent moins gros, les nuages disparaissent quand ce rayon de soleil brille de sa clartẻ si douce et si pure. On oublie en serrant dans ses bras ce petit être innocent, dont le regard profond semble plonger encore dans les régions cẻlestes, que la cor- 
ruption et le mensonge nous entourent. Quand l'ingratitude et le manque de cœur de nos Zambéziens serrent nos cœurs, un regard jetè sur notre enfant nous parle de ce grand amour dont le Père nous a aimés, et la reconnaissance nous envahit tout entiers. Un enfant! c'est un trésor en Europe, mais ici c'est une bẻnédiction plus grande encore, une compensation à tout ce que nous avons à souffrir moralement, dans ce pays où l'amour est chose presque inconnue. C'est navrant de penser qu'on a si peu de prise sur le cœur des gens et de se dire que si nous partions demain, nous serions aussitôt oubliẻs; et cependant nous leur consacrons notre temps, nos forces, notre vie, nous leur donnons notre cœur. Voila pourquoi nous souffrons de ne pas atteindre le leur. Oh! ils se récrieraient si je leur disais cela. Il prétendent nous aimer. Nous aimer, oui, comme on aime ceux dont on attend des bienfaits. Ils ignorent ce que c'est que l'affection vraie. Ils sont souvent arrachés à leurs mères tout enfants encore. L'amour, où l'apprendraient-ils dans ce triste pays où il n'y a pas de famille? Quand je songe à ce qu'a été notre enfance et que je la compare à la leur, un profond sentiment de pitiẻ s'empare de moi, et, après m'être écriẻe: « Méchantes gens!» je soupire: «Pauvres gens!»

Le 5 Octobre, arriva à Loatile le Major Goold Adams (1) envoyé par le gouvermement britannique pour faire le relevé de la frontière occidentale du royaume de Léwanika. Il avait passé par le lac Ngami, qu'il avait trouvé entièrement desséché. Sur la demande du roi nous le reçûmes chez nous. C'est un homme aux manières agréables et au cœur chaud, gai et sérieux à la fois, en bon Irlandais protestant. Pendant les 5 semaines qu'il passa chez nous il fréquenta régulièrement, non seulement notre culte de famille, mais aussi les cultes pour les indigènes. $\mathrm{Ce}$ fut un grand plaisir pour nous que cette visite.

$\mathrm{Ne}$ pouvant laisser l'école d'évangélistes à tout instant, et évitant de me mêler de politique, après la première entrevue, je me fis remplacer par Ben comme interprète du Major et du roi. Cependant les affaires ayant été sur le point de se gâter, je fus appelé à les raccommoder officiellement. Lewanika avait dit qu'il ne croyait pas que son hôte fût un envoyé du gouvernement, il avait été presque grossier envers lui et lui avait refusé la permission de poursuivre son voyage. Quelques heures après, il rappela le Major et tout fut réglé à l'amiable.

(1) Actuellement gouverneur de la Colonie de l'Orange. 
Généralement en octobre ou novembre, pendant toute une semaine, nous pouvions admirer chaque soir des feux de prairie, formant des illuminations féériques. Cette année 1896, pour sauver la chapelle de l'incendie, nous dûmes brûler en toute hâte les abords de notre termitière, et enlever ainsi tout aliment aux flammes que le vent poussait vers nous et qui approchaient rapidement, avec des crépitations formidables. Nous fûmes parfois enfumés au point de risquer d'être suffoqués. De jaune qu'elle était, la plaine devient toute noire, et chaque coup de vent amène jusque dans la maison une poussière sombre qui couvre tous nos effets. Après 1896 nous ne vímes plus ce spectacle grandiose. Les ma-Rotsé remarquèrent que les sauterelles ne déposent leurs œufs que là où l'herbe manque, ou bien où elle est courte, aussi défendirent-ils de brûler la plaine avant que la nouvelle herbe eût poussé.

À part ces incidents, la vie de station allait son train habituel: écoles, prières, classes, préparation de cours et corrections de tâches, travaux de ménage, distribution de médecines, achats, surveillance de travaux, tournées, outre la correspondance et les mille et un détails de tous les jours.

Dimanche 25 OCtobre. - Mon mari continue à avoir mal à la gorge. C'est ennuyeux que son indisposition traîne ainsi. Il guérirait plus vite s'il pouvait garder le silence, mais comment faire quand on est professeur, pasteur et prédicateur! Figurez-vous qu'aujourd'hui il m'a chargée de sa réunion de missions pour toute notre maisonnẻe et pour les évangélistes. J'ai parlé de John Williams, le martyr d'Erromanga.

Notre dimanche est bien rempli. À $7 \mathrm{~h}$. le déjeuner, à $8 \mathrm{~h}$. le culte avec tout le personnel de la station, ensuite l'ẻcole du dimanche, puis le service principal, le dîner. À 2 h. notre culte missionnaire, à $3.30 \mathrm{~h}$. exercice de chant avec nos gens et plusieurs personnes de la capitale; le second service indigène a lieu à $5 \mathrm{~h}$., et le souper à $7 \mathrm{~h}$. Ce n'est qu'à $9 \mathrm{~h}$. que nous pouvons nous retirer dans notre petit salon. Il ne faut pas croire que cette journée soit fatigante quoique remplie, non, c'est bien une journée à part, une oasis, una halte bienfaisante dans la vie si occupée, et parfois agitẻe de tous les jours.

Ce n'est pas sans un certain tremblement intérieur que le lundi on reprend la vie habituelle, que l'on rentre dans l'ornière. Tout l'engrenage se remet en mouvement, mais toutes les pièces mécani- 
ques marcheront-elles? La machine ne grincera-t-elle pas trop souvent? Quelles tentations, quels ennuis nous réserve cette semaine? Le chéri que nous possédons nous redit par sa chère petite figure épanouie, confiante et gaie: "Ne vous inquiétez d'aucune chose, ne soyez pas en souci pour le lendemain ».

....Etre mère, que c'est grand, que c'est beau, que c'est solennel! 11 faudrait d'abord et toujours travailler à son propre perfectionnement, pour pouvoir mieux élever ces petits êtres.

\section{LXIV.}

A la Capitale.

unstitution d'un corps de police. - Nanjeke frappée. - Progrès. - Visites à domicile. - Diférences entre tribus. -- Corruption générale. - Le roí reconmande le travail manuel. - Il tient au culte qles ancêtres. - Akauan. gisoa, - Retour du Major Goold Adams.

TEAlur avait longtemps eu un mauvais renom dans le pays, en parler c'était parler d'un nid de brigands et de débauchés, comme ma-Rotsé avait longtemps été synonime de fourbe et de cruel. Cela avait un peu changé; sous l'influence du christianisme le roi et quelques chefs avaient commencé à réagir et à tâcher de guérir les plaies de la capitale. Lewanika m'en parlait assez souvent avec tristesse.

Le $1^{r}$ octobre, il institua un corps de police. Les «ma-pölisa》 furent d'abord chargés d'empêcher les gens de courir le village, la nuit. Quelques jours plus tard ils furent autorisés à frapper de coups de cravache toute femme ou jeune fille qui serait trouvée seule dans les rues. Une autre de leurs attributions ce fut d'obliger les enfants à aller à l'école, et même de rassembler les gens" pour les cultes du dimanche.

Le 14 octobre, je dus apprendre à mes dépens qu'une autre de leurs tâches était de barrer les entrées de la grande enceinte royale. Un agent de police armé de cravache et de lance m'arrêta: «Tu plaisantes, fis-je. - Personne n'entre sans y être appelé. - Va donc m'annoncer. - Ce n'est pas mon affaire ». Je 
fais volte-face et retraverse la place. Un officier du roi arrive alors en courant et me dit d'entrer. Je vais droit à la salle de réception. Après les salutations je raconte à Lewanika la scène de tout-à l'heure. Il s'excuse aussitôt de ne pas m'avoir pré venu, puis me dit en terminant: "Continue à considérer ma maison comme la tienne ». Quand je repars il m'accompagne jusqu't̀ l'enceinte et dit au chef de la police: «Sachez que le missionnaire est maître ici comme moi-même, il peut entrer et scrtir en tout temps et aller partout où il veut 》.

Le surlendemain, notre brave Nanjeke passe tranquillement dans la rue et y rencontre deux de ces gardiens des bonnes mœurs. "Va-t'en, ou je te frappe 》 lui dit l'un d'eux. Elle répond: «Si je m'enfuis tu me frapperas encore plus fort». Sur ce, il lui donne trois coups de cravache. Avertis de la chose, nous allons la voir chez son oncle, où elle s'est refugiée et la trouvons couchée, l'oeil droit très enflé. Nous portons aussitôt plainte au roi, il mande les deux agents de police, et les gronde en notre présence. Il leur dit qu'ils ne doivent frapper personne, mais amener les coupables au Khotla, et ajoute qu'ils n'ont rien à faire avec les gens qui passent tranquillement leur chemin. Il était temps que cet ordre sortît de la bouche du monarque, car ces hommes frappaient à tort et à travers. Il y avait beaucoup de murmures, mais personne qui osât faire parvenir une plainte à qui de droit. Nanjeke en eut pour près d'une semaine avant de pouvoir ouvrir l'œil.

Plus tard, quand Lewanika défendit les danses à sa Capitale, après les premiers battements de tambours de la garde nocturne (entre 9,30 et $10 \mathrm{~h}$. du soir), ce furent encore les agents qui durent faire respecter cet ordre.

Grâces à ces diverses mesures, Léalui fit de réels progrès. Tout le mal n'en a pas disparu, loin de là, mais ce n'est plus la ville corrompue d'autrefois.

Ma femme et moi et les élèves évangélistes, nous consacrions chaque semaine plusieurs heures aux visites à domicile; nous allions tant chez les habitants de Léalui, que chez les nombreux étrangers. C'est un puissant moyen de répandre la lumière et de faire tomber les préjugés. On apprend assez facilement à distinguer les représentants des divers groupes de tribus, car il y a entr'eux de grandes différences, sinon de type tout au moins d'habillement et de coiffure, comme aussi de langue: 
Groupes des principales tribus, d'après los dialectes.

I.

Ma-Rotsé (au centre)

ma-Kwangwa

ma-Mbowe

ba-Moenyi

ba-Nyengo

ba-(Kwa)-Makoma

ba-Imelangu

IV.

Ma-Nkoya (au Nord-Est) ba-(Kwa)-Kaonde

ba-Mashasha

ba-Morundumina
II.

Ma-Mbunda (au Nord)

(et à l'Ouest)

ma-Wiko

ba-Chivokwe

ba-(Kwa)-Lubale

ma-Lunda

(plusieurs autres tribus au

Nord-Ouest des états de

Lewanika se rattachent

à ce groupe).

III.

$M a-T o k a$ (à l'est)

ma-Totela

ma-Shukulumbwe

ma-Tomwe

ma-Subija

ma-Lea

ma-Nanza.

VI.

$M a-K w e n g u$ (Bushmen)

ma-Mpukushu

ma-Yei

VII.

ma-Kalaharé

ma-Kwangari

Il y a d'assez grandes différences dialectiques entre les différents membres de chacun de ces groupes, cependant ils se comprennent réciproquement. Mais il n'en est pas de même entre un groupe et l'autre, il s'agit bien là de langues différentes; cependant, sauf les ma-Kwengu, ils se rattachent tous à la grande famille bantu.

$\begin{array}{llll}\begin{array}{l}\text { Français } \\ \text { homme (homo) }\end{array} & \text { sessouto } & \text { se-kololo } & \text { se-rotsé } \\ \text { pain } & \text { bo-tho } & \text { mo-tu } & \text { mo-nu } \\ \text { lance } & \text { le-rumo } & \text { bo-hobe } & \text { ndima } \\ \text { forêt } & \text { mo-ru } & \text { le-rumo } & \text { mbinji } \\ \text { homme (vir) } & \text { mu-nna } & \text { mo-situ } & \text { mu-sithu } \\ \text { femme } & \text { mo-sali } & \text { mo-sadi } & \text { mo-lume } \\ & & & \text { mo-kati } \\ \text { se-toka } & \text { se-subiya } & \text { se-mbunda } & \text { se-nkoya } \\ \text { mo-ntu } & \text { mu-ntu } & \text { mo-nu } & \text { mo-nu } \\ \text { nsima } & \text { nkoko } & \text { bilia } & \text { shima } \\ \text { li-sumo } & \text { Kera } & \text { li-kunga } & \text { mo-linga } \\ \text { mu-situ } & \text { mu-zuka } & \text { munda } & \text { lu-shiaka } \\ \text { mu-alume } & \text { mu-kuame } & \text { mo-nalume } & \text { mo-rume } \\ \text { mu-anakatsi } & \text { mu-anakazi } & \text { mo-nakazi } & \text { mo-kati }\end{array}$

Les mieux vêtus sont ceux du groupe des ma-Rotsé et ceux du groupe des ma-Mbunda qui ont eu des rapports avec les Portugais. Si l'on voit des gens particulièrement sales, graisseux, et avec de longs cheveux entremêlés de perles, on peut être à peu près sûr qu'on a devant soit des gens appartenant au 
groupe des ma-Mbunda, ou à celui des ba-Mashi. Les ma-Shukulumbwe qui ne portent chez eux aucun vêtement, ni les hommes ni les femmes, n'osent pas se présenter ainsi à leurs maitres les ma-Rotsé ; ils doivent avoir au moins un petit tablier de peau ou de toile. Plusieurs se sont dépouillés de leur long chignon. Mais il leur reste un autre signe caractéristique: il leur manque les quatre dents incisives supérieures. Ils tiennent it cette marque, car, disent-ils, s'ils y renonçaient ils ne trouveraient plus de femmes. Ils ne sont pas les seuls à avoir une marque aux dents. Les ma-Toka, ma-Tomwe, ma-Lea et ma-Totela s'arrachent les deux incisives moyennes supérieures. Les maNkoya se les liment en pointe, tandis que les ma-Rotsé se les liment à peine. Nous trouvons les ma-Rotsé corrompus, mais ils ne sont pas au dernier degré de l'échelle morale, ce que nous avons appris de la plupart de leurs tributaires nous l'a prouvé.

Il serait facile de se rendre compte des progrès accomplis par Lewanika et les ma-Rotsé en général, en parcourant les parties de leur vaste empire où leur autorité n'est assez grande que pour exiger le paiement des impôts ou tributs. Au bo-Shukulumbwe, au bo-Nkoya, au bo-Lunda, au bo-Lubale, au Wiko, au Mashi... on ne verrait aucun chef qui puisse... être comparé à Lewanika: On y trouverait encore en pleine vigueur, l'ivrognerie, la sorcellerie, la traite des esclaves, toutes ces plaies du paganisme que, grâce à l'Evangile, Lewanika a si efficacement combattues dans le bo-Rotsé.

L'affluence de ces tributaires des ma-Rotsé grandit d'année en année. Plusieurs ne comprennent pas le se-kololo, mais nous n'avons guère de peine pour trouver des interprètes, car la plupart des gens demeurant au bo-Rotsé sont polyglottes; même s'ils ne comprennent rien au message de salut que nous annonçons aux services du dimanche, ils voient quelque chose de leurs yeux, ils reçoivent des impressions que Dieu peut bénir, et dont il peut se servir pour le développement de notre mission.

1 Novembre. - Après le dìner, mon mari a fait comparaitre les èlèves évangélistes devant le roi. Ils ne veulent pas balayer la cour chaque samedi, à tour de rôle. Ceux qui sont mariés prétendent que cela ne leur sied guère, et les autres refusent avec raison d'ètre seuls à le faire. Lewanika leur a très-bien parlé. «Pourquoi ne feriez-vous pas ce petit travail? leur a-t-il dit. Est-ce que moi 
je ne travaille pas? Et cette maison, n'est-ce pas votre missionnaire qui l'a bâtie de ses propres mains? Et la Bible ne dit-elle pas que nous devons gagner notre pain à la sueur de notre front? Quand vous serez évangẻlistes et envoyẻs de tous côtẻs, que ferez-vous si vous ne voulez pas travailler de ros mains? Vous donnera-t-on des esclaves pour vous servir? » Les jeunes gens á chaque interpellation claquaient des mains en disant: «Shangwe».

Ce même jour, au moment d'entrer au second culte, je reçus une lettre du Roi, conçue en ces termes: "Moruti, mon cœur « est peiné de la façon dont tu prêches, tu parles de choses « honteuses telles que le divorce et l'adultère. De plus, pour«quoi nous parles-tu des tombeaux des vieux rois? Non, mo« ruti, enseigne ce qui est écrit dans le livre de Dieu. Aujour《d'hui je ne retourne pas là-bas, mon cœur est peiné, c'est 《moi Lewanika 》. Ce fut comme un coup de foudre dans un ciel serein. Je lui répondis après le culte, par écrit: «Roi, je suis peiné de ta lettre et surpris. Dis-moi comment nous pouvons déraciner ce qui retient les gens loin du Sauveur. Ne fautil pas pour cela montrer parfois la vanité de vos croyances, et de vos superstitions? Que ne m'as-tu dit cela de ta bouche, tandis que nous étions ensemble? Cependant tu sais bien que je te respecte. S'il est sorti de ma bouche une parole inconvenante, je suis prêt à la rétracter. (J'avais combattu le culte des ancêtres). Mais que le roi ne m'en veuille pas, qu'il pense plutôt au Seigneur qui le cherche par le trouble que la prédication d'aujourd'hui a produit 》. Le mardi j'allai chez lui, nous causîmes longuement du sujet. Quand je pris congé de lui, il me dit: «Je te remercie d'être venu, tout est oublié 》.

Le 12 novembre Akanangisoa arriva à Léalui, elle y fut reçue avec la salutation royale, la salutation la plus noble, comme Litia l'avait été l'année précedente. Ce sont les seuls qui aient droit à cette salutation en dehors du roi et la reine, de Nyambe et des ancêtres de la famille royale. Quand elle vint chez nous et que nous allâmes chez elle, elle fut très aimable, tellement que nous aurions pu croire qu'on l'avait calomniée. Etait-ce bien elle qui avait fait tant de misères à M. et Madame Goy, depuis qu'elle avait renié sa profession de christianisme?

Dès que je vis qu'il y avait pour M. ${ }^{\text {me }}$ Goy quelque possibilité d'entreprendre le voyage vers le Lessouto, j'achetai, avec l'appro bation de mes collègues, l'attelage de M. Coillard pour le compte 
de la Mission et l'envoyai à Sesheke, à la disposition de notre sœur si éprouvée.

Le Major Goold Adams nous revint du bo-Lubale le 26 no vembre. Comme M. Coillard en 1895, il n'avait pas pu dépasser le territoire de Kakenge, il n'avait pas même réussi à voir ce chef farouche. Par contre, il avait été très-bien reçu par l'officier portugais qui gardait le fort de Kakenge avec ses 24 soldats.

S'intéressant à tout ce qui se faisait sur la station, il comprit aussi quelques unes de nos joies. Il fut frappé de l'application des élèves évangélistes et de leur développement intellectuel. Notre petit trésor toujours bien portant, gagna très vite le cœur du Major.

Ce ne fut pas sans regret que nous le vîmes partir le 14 décembre. Il devait se rendre à Seoma en canot, de là il comptait aller à pied au Mashi, et au Luyana, où il devait retrouver d'abord son cheval, puis son wagon.

\section{$\mathrm{LXV.}$}

Les évangélistes s'éloignent.

Plaintes des évangélistes bassoutos. - Mort de Théodore Pibso.

T ES évangélistes bassoutos nous donnèrent de nouveau du

$\triangle$ souci. À la conférence de 1895 Yakobo avait demandé une augmentation de salaire, au nom de tous ses collègues. La Conférence avait répondu par la bouche de M. Coillard qu'elle estimait que mille francs constituent un grand salaire d'évangélistes.

Après un échange de lettres assez vif de leur part, ils nous dirent que si au bout de douze mois leur demande ne leur était pas accordée, ils donneraient leur démission.

L'un d'entre eux, Théodore, eut une seconde attaque d'hématurie du 26 au 29 novembre, bientôt suivie de la troisième le 6 décembre. 
Il s'éteignit sans agonie, la nuit du 9 au 10 décembre, lui le plus jeune, le dernier venu. Un seul évangéliste était à son chevet, personne ne s'était douté que ce fût déjà la fin.

J'apportai un drap et aidai à l'y arranger; je priai avec sa femme, la pauvre Alita qui sanglotait, et rentrai chez nous. Dès le matin j'envoyai aunoncer la mort à la capitale, recommandant de n'en faire part au roi que quand il serait. sorti au Khotla, car je savais qu'on ne doit jamais annoncer un décès au roi, dans son enceinte privée: les missionnaires seuls osent prononcer le mot de mort. Je fis creuser la fosse derrière la chapelle par nos ouvriers, aidés des élèves évangélistes. D'autres élèves nous firent une civière.

À 2.30 h. M. Davit arriva, et à 3 h. nous commençâmes le service à la maison mortuaire. Les principaux chefs et officiers royaux étaient là, suivis d'une grande foule. A ces gens qui redoutent la mort et sont scandalisés quand elle frappe l'un de nous, nous parlâmes surtout d'espoir, de résurrection et de vie. Je rappelai aussi comment sur son lit de souffrance, Théodore avait pensé avec tristesse à la dureté de cœur des Zambéziens, et dit: « Le roi est bon, il favorise l'œuvre, mais lui-même il ne se convertit pas!

\section{LXVI.}

Vacances et fêtes agitées et assombries.

\footnotetext{
Nos hôtes. - Lewanika meurtrier. - Prix exorbitauts. - Contrat avec le rol.

Des réchappés de galère. - Noèl. Baptême de Giulio.

Bous cxamens de l'école d'évangélistes. - Ine recrue.
}

Tos fêtes commencèrent par deux mariages d'élèves évangélistes, celui de Moka avec Nanjeke, et celui de Kuibisa avec Ngambe, celle-ci encore païenne hélas!

La première chose qui frappa les Béguin et M. Davit quand ils vinrent chez nous pour Noël, ce furent les corbeilles toutes resplendissantes de fleurs que nous avions devant la maison. Ils apprécièrent vivement nos légumes frais. 
Mais quel triste message nous reçûmes le 26 décembre! Lewanika lui-même me fit annoncer qu'il venait de faire tuer une de ses femmes qu'il avait chassée pour mauvaise conduite trois ans auparavant. Après l'avoir humiliée de bien de façons il l'avait donnée comme femme à un de ses sujets; mais ayant appris qu'elle s'en était réjouie et se préparait à se sauver au Lekwakwa le refuge des mécontents), il avait envoyé deux hommes la lier, et la faire disparaître sous les longues herbes qui recouvrent l'eau comme d'un tissu inextricable. Lewanika avait fait cela sans aucune forme de procès. Il ne nous en parla à ses chefs et à moi qu'après coup.

Quand jallai lui représenter que cette exécution illégale était un horrible meurtre, il sembla d'abord interdit, mais il ne manifesta ni honte ni remords, au contraire, il en paraissait satisfait. C'est Dieu qui fait le bien et le mal, me dit-il, l'homme ne saurait résister; les cours des rois sont dans la main de Dieu, qui les dirige comme il veut. Faut-il en face du mal se con tenter de croiser les bras et craindre Dieu? Pourquoi nous a-t'il donné la lance? Pendant huit semaines Lewanika ne remit pas les pieds sur la station.

Bien que nous sachant à court de tout, les indigènes exigeaient de nous des prix impossibles. Comme nous ne pouvions les donner, ils nous affamaient. Et cependaut pour qui achetionsnous de la nourriture? Pour leurs enfants, que nous élevions, et particulièrement pour des jeunes gens que nous essayons de former pour l'évangélisation du pays; le seul travail que j'avais fait faire depuis l'inondation avait été d'élever la chaussée dont le peuple profite infiniment plus que nous. Kalonga, dont nous élevions la fille, n'eut-il pas l'audace de venir nous demander une pleine corbeille de verroterie en échange de deux corbeilles de sorgho? Le roi, duquel j'aurais voulu acheter trois ou quatre vaches pour les Boiteux, me demanda 250 franss par tête, pour des bêtes qui n'ont du lait qu'un an sur trois, en moyenne, et qui au meilleur moment n'en donnent qu'une tasse deux fois par jour.

Nous manquions de tout, nourriture, vêtements et objets d'échange, comment nous en procurer? Comment amener le renfort qu'on nous promettait de Paris? Le dernier courrier du Sud nous avait appris que pour le transport de Palapye à Bulawayo on payait en raison de fr. 3,30 le kilog. Que serait-ce pour le 
Zambèze? Notre agent, M. Whiteley, nous avait écrit que si nous n'envoyons pas des bœufs à Palapye, il ne pourrait rien nous faire parvenir de longtemps.

Malgré les difficultés que nous prévoyons, nous décidâmes de proposer à Lewanika le contrat suivant: « Nous les missionnaires, nous nous engageons à payer au roi en raison de 2 francs 66 cent. le kilogr. pour tout objet amené à Kazungula dans le wagon du roi; c'est-à-dire que si le wagon $d u$ roi nous amène une charge de $1800 \mathrm{Kg}$. nous lui paierons $3.000 \mathrm{fr}$. En outre, nous nous engageons à payer en raison de $\mathrm{I} \mathrm{fr}$. $33 \mathrm{le} \mathrm{Kg}$. pour tout effet amené à Kazungula par les bœufs du roi, mais dans des wagons et par des conducteurs qui seraient à notre charge. C'est-à-dire que pour tout attelage du roi qui amènerait $1.800 \mathrm{~kg}$. nous paierions 1.500 francs. - Moi, le roi Lewanika, je m'engage ì ne pas réclamer des missionnaires de paiement ni pour des conducteurs que j'envoie, ni pour les bœufs qui viendraient à périr; mais je ne demanderai que le prix du transport, tel que les missionnaires me l'ont promis par ce contrat $\gg$.

La pensée de faire de l'argent fit briller les yeux de Lewanika. Après une calme discussion, il accepta le contrat et le signa avec nous.

Nous acceptâmes avec reconnaissance l'offre que nous fit M. Davit d'aller lui-même organiser l'expédition de ravitaillement.

Le 30 décembre nous arrivèrent deux Portugais et un Espagnol. Ils étaient dans un dénuement extrême. Venant du NordOuest et étant dépourvus d'objets d'échange, ils avaient dû se défaire ici d'un gilet, là d'un couteau etc. pour se procurer de la nourriture, ou pour la traversée des rivières. L'un n'avait pas de chemise, deux étaient sans souliers, ils n'avaient pas un gilet entre les trois. Ils prétendaient avoir quitté la côte occidentale pour aller chercher du travail à Quilimane, ou à Mozambique. Les ma-Rotsé les prirent d'abord pour des espions, mais la désolation qu'ils manifestèrent quand on parla de les ramener à la frontière occidentale, prouva bien ce que nous avions soupçonné, que c'étaient des convicts évadés. Nous obtînmes qu'on leur permît de poursuivre leur voyage vers l'Est. En effet, après quelques jours ils partirent pour Sesheke avec quelques provisions de bouche que nous leur donnấmes et 4 mètres de calicot qu'ils reçurent de M. Béguin.

Malgré tout, nous eûmes avec nos amis de bonnes fêtes. À 
Noël nous eûmes de beaux auditoires, une prédication de M. Béguin, et le Gloria de Bost, parfaitement exécuté par ceux qui avaient été assidus aux exercices de chant.

Dimanche 27 DÉcembre à 3 h. les Béguin, M. Davit, les Willie, nous et toute notre maisonnée, nous nous réunissons dans notre salle à manger pour le baptême de Giulio. Il était si mignon dans sa jolie robe de satinette crême que je lui avais faite, et tout souriant. Pendant que M. Béguin parlait, il le regardait d'un air amusé et plein de sourires, il était à croquer. Après l'avoir baptisé, M. Béguin nous fit une bonne méditation sur: «Mon âme, bénis l'Eternel, et n'oublie aucun de ses bienfaits », texte approprié à la circonstance: et qui répond bien à nos sentiments.

Je n' avais pas seulement convié mes collègues pour passer les fêtes avec nous: pendant toute une semaine nous eûmes les examens de l'école d'évangélistes. Ce fut presque une fête, nos chers jeunes gens se firent honneur et prouvèrent à leurs examinateurs qu'ils n'avaient pas perdu leur temps. C'était une précieuse promesse d'avenir, surtout alors que les évangélistes bassoutos menaçaient de uous quitter en bloc. Tous furent promus. sauf Semocheta, qui d'ailleurs se préparait à nous quitter définitivement.

Nous eûmes aussi une recrue, Mpututu. Il avait tenu bon depuis sa profession faite cinq ans auparavant; mais parce qu'il était esclave (de Kaïba) et surtout parce qu'il est peu doué d'intelligence, il n'avait guère fait de progrès. Il savait à peine lire. Mokwae et le roi le libérèrent.

Les réunions de la semaine de prières se ressentirent du mauvais vouloir du parti rétrograde, elles ne furent guère suivies que par nos professants et quelques écoliers.

Le 11 janvier les Béguin nous quittent. Nous passons toute la journée à examiner les 7 classes de l'école de station. Le surlendemain nous faisons devant plusieurs chefs les promotions arec distribution de prix. Nous constatons un progrès remarquable chez Willie, au point de vue pédagogique. Il s'était occupé de l'école avec amour et le résultat était satisfaisant. La moyenne de fréquentation avait été de 90 élèves. 



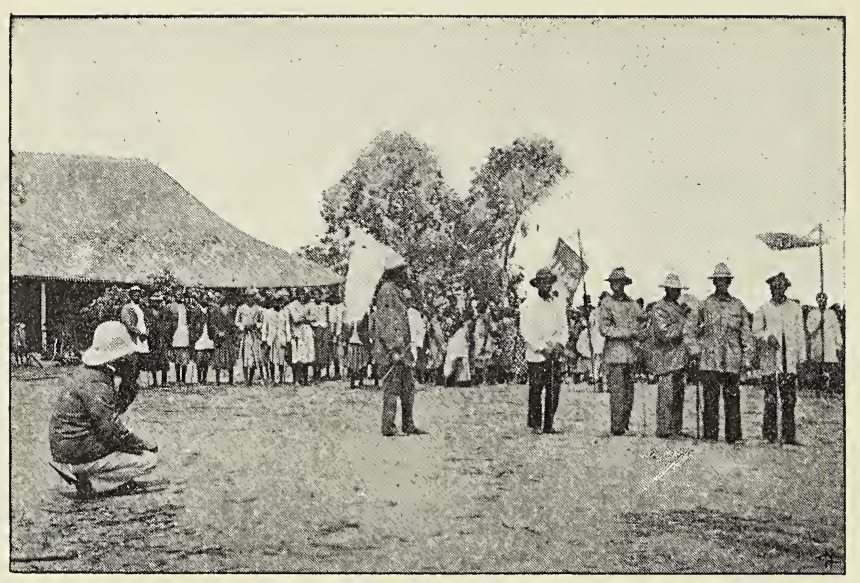

Nos six évangélistes du bo-Rotsé et leurs écoles.

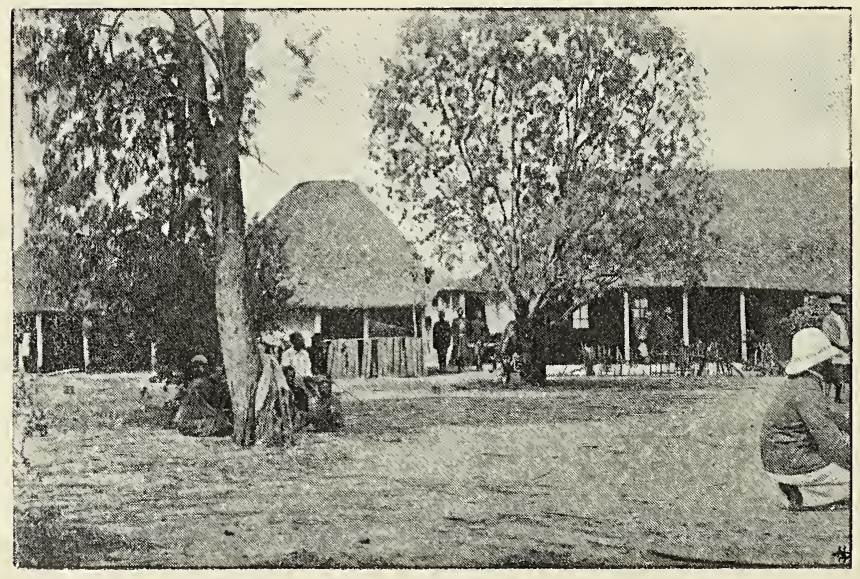

À Lwatile. 


\section{LXVII.}

Toujours la lutte entre le bien et le mal.

Départ de M. Davit. - Un encouragement inattendu. - Fondation de l'école des femmes d'évangélistes. - Pendant l'orage. - Menaces de guerre. - Chefs et officiers au bane des accusés. - Devins pris en fiagrant. - Leur châtiment. - Petites afruires d'état. - Sensations et foi. - La famine.

E 12, le roi fit partir les boufs de la grande expédition 1 de ravitaillement. M. Davit, qui avait été à Sefula le 4, afin d'y mettre ses effets à l'abri des termites et de faire ses préparatifs de voyage, revint plein d'entrain espérant partir sans délai. Mais Lewanika n'était pas pressé. Cédant néanmoins aux instances de notre ami, il lui procura enfin le canot et les rameurs promis et notre collègue nous quitta le 18. Mai dès avant son arrivée à Nalolo il eut des difficultés avec ses bateliers.

Je dus disperser les élèves évangélistes et les envoyer en canot acheter de la nourriture pour eux et pour toute notre maisonnée. Ils se dirigèrent vers Lukoma, un grand vallon agricole à l'Ouest du Zambèze. Ils revenaient le 21 avec plusieurs sacs de sorgho. Détail intéressant et qui fit tressaillir notre cœur de joie, nos jeunes gens avaient rencontré dans l'intérieur des terres un petit garçon aux connaissances bibliques remarquables et qui s'était empressé de leur aider à rassembler les gens pour des cultes.

Le dimanche 24 janvier, avant le jour, un orage effrayant s'abattit sur Léalui. Le matin personne n'osa sortir du village pour venir au culte. En telles circonstances tout mo-Rotsé est tenu d'aller chez le roi «pour mourir avec lui 》 si la foudre venait à tomber sur sa maison. La foudre incendia une hutte. Il y en eut qui sortirent au plus fort de l'orage pour maudire le tonnerre; d'autres voulaient que l'on allât déposer des offrandes sur les principaux tombeaux royaux afin d'obtenir la faveur des mânes. On ne les écouta pas.

Depuis longtemps nous déplorions la paresse et l'ignorance de 
la plupart des femmes ou fiancées de nos élèves évangélistes. Les jeunes femmes en particulier trouvaient au dessous d'elles de fréquenter l'école de station. Elles avaient bien une leçon de conture tous les après-midi, mais elles se dispensaient trop facilement de la fréquenter. Il fallait faire quelque chose pour elles.

Le 26 janvier ma femme inaugura la classe des futures femmes d'évangélistes, à laquelle elle consacra désormais deux heures par matin.

Le 3 février, après l'école, pendant une tournée à la capitale, je vis le Ngambela, tous les chefs et officiers du roi agenouillés sur le banc des accusés, en plein soleil - une véritable torture. Les principaux chefs de Nalolo, Sesheke et Kazungula leur reprochaient d'avoir négligé les travaux du roi. (la Nalikwanda, les maisons du harem, le grand filet...) Il sem blait qu'on en voulût surtout au Ngambela et au premier officier royal. Plusieurs des accusés affirmaient que s'ils n'avaient pas été plus actifs c'était la faute de ces deux hommes. Il était évident que c'était un coup monté par Lewanika. Il n'y avait personne là pour rappeler le passé et dire comment, après Dieu, c'était grâce au Ngambela que Lewanika était rentré au pouvoir en 1885.

J'allai trouver le roi à son atelier, et lui représentai ce que d'autres n'osaient lui dire. Pourquoi cette recrudescence d'absolutisme? Puis je retournai au Khotla, et allant droit à Sampi, le Ngambela de Nalolo, le président du tribunal, je lui dis: « N'as-tu pas peur d'être bientôt traîné au supplice? Êtes-vous capables de prendre la place de ceux que vous condamnez à un cruel châtiment avant même que leur culpabilité ait été prouvée?

J'étais à peine rentré à la station quand on vint m'annoncer que le roi avait ordonné que l'on renvoyât tous les accusés absous.

Le 5, je retournai à Léalui. Lewanika m'y apprit que pendant la nuit il avait fait arrêter à Lienenu (village situé à environ 10 kilomètres à l'ouest) deux hommes qui par leurs chants et leurs danses nocturnes et par les osselets divinatoires, prétendent découvrir les sorciers. Il les avait fait saisir en flagrant délit, et conduire garrottés à la capitale.

Le roi luttait depuis quelques années contre les accusations de sorcellerie. Il avait commencé par défendre qu'on fît boire le poison aux accusés et avait fondé des 《villages de sorciers》, où 
ceux-ci pouvaient se réfugier. Il avait ensuite puni les empoisonneurs.

Les deux devins en question étaient appelés dans différents villages, ils s'y informaient secrètement de celui ou de ceux que l'on voulait perdre, puis par voie d'éliminations successives, ils en venaient à ceux qu'ils voulaient désigner. Le roi les fit comparaître devant le tribunal. "Vous savez découvrir les sorciers, leur dit-il, eh bien, quel est celui qui est la cause des maladies et des morts qui surviennent à ma capitale? 》. Ils furent naturellement interdits. Alors le roi de se moquer d'eux. «Ah! les bons devins qui n'ont pas même deviné qui'ls allaient être saisis et condamnés à faire un vil service dans les rues de Léalui! 》

Ils alléguèrent alors pour leur défense que leur métier de musiciens ambulants n'étant pas assez lucratif, ils s'étaient faits 《sorciers 》 pour ne pas mourir de faim.

Au bout de 10 jours de travaux forcés, Lewanika fit briser les instruments des deux devins en plein Khotla et les congédia par ces mots: «Allez, parcourez le pays, et dites à tous vos compères les devins, que s'ils continuent à tromper les gens, ils seront punis plus sévèrement que vous ne l'avez été vous-mêmes 》.

Il y eut des mécontents qui pensèrent que prohiber la divination c'était favoriser la sorcellerie. Ah! comme les ténèbres sont encore épaisses! Nous ne saurons peut-être jamais combien la superstition fait partie de la vie sociale et privée de nos Zambéziens, sa disparition sera l'œuvre de plusieurs générations.

Plus tard Lewanika fit faire un nouveau pas à la question en décidant que désormais en matière de sorcellerie ce ne serait plus l'accusé mais l'accusateur qui serait puni.

Le 19 je trouvai Lewanika et quelques-uns de ses principaux officiers, occupés à la confection d'un matelas de camp qu'ils voulaient recouvrir de peaux de léopards. C'est ainsi que tout ce qui touche au monarque devient une affaire d'état. J'arrivai à temps pour les tirer d'embarras. Il n'avaient plus de ficelle, j'en envoyai quérir à la station.

Un jour Lewanika me dit que la conversion est entièrement l'œuvre de Dieu, nos cœurs sont entre ses mains, l'empressement comme les retards et les hésitations viennent de Lui. C'est Lui qui doit produire en nous des sentiments nouveaux (je devrais traduire sensations). Le dimanche suivant, le sujet de ma prédication (la guérison d'Enée) me donna l'occasion de lui 
dire que la foi est quelque chose de plus simple. Cet appel pressant ne devait pas encore produire une de ces sensations dont il parlait! Il en a déjà tant eu et chaque fois il a de nouveau endurci son cœur. Il a peur de se sentir remué, et se tient alors loin de la prédication de l'Évangile. Ne serait-ce pas pour cela qu'il ne revint pas l'après-midi? Oh que Dieu le trouble tellement qu'il ne trouve de paix qu'au pied de la croix!

Le dimanche suivant il empêcha tous ses chefs et officiers de travailler à la Nalikwanda, et les amena au culte du matin. Il nous dit avoir appris par des rapports que $\mathrm{M}^{\mathrm{e}}$ Goy avait d̂̂ aller à pied depuis la Nata, à cause de la Rinderpest qui sérissait encore à Mangwato. Il était très inquiet pour les bœufs qu'il y avait envoyé.

Nous apprîmes aussi que la famine sévissait dans tout le bo-Toka, et qu'à Kazungula même plusieurs personnes étaient mortes de faim. Les Boiteux étaient menacés eux-mêmes de souffrir de la famine. Nous leur envoyâmes aussitôt trois messagers avec provisions, puis un canot de nourriture; le roi $y$ contribua en nous donnant pour eux un sac de sorgho et de haricots indigènes. Nous mêmes n'étions pas dans l'abondance, d'autant plus que l'inondation nous avait de nouveau obligés à nous séparer de nos vaches. Notre troupeau semblait atteint lui aussi. Lewanika nous sachant à court, nous envoyait de la viande une fois par semaine.

\section{LXVIII.}

Dernières semaines et mort de Giulio.

\footnotetext{
La fière. - Progrès. - Afrection de Lewanika. - Mort d'Bugène Pisso. Coups d'épingle. - Jours d'angoisse et de lutte. - Soumis mais brisés. Ensevelissement. - Fruits de l'épreuve. - Lettre de condoléance de Lewar nika. - Sympathie. - Muri pour le diel.
}

NoTRE petit garçon n'ẻtait pas bien depuis le mois de janvier, il avait de fréquentes attaques de fièvre. Nous étions inquiets, mais nous ne pensions pas que notre doux rayon de soleil nous serait enlevé. 
Avec le 15 mars la dispersion des élèves évangélistes commença. L'époque des vacances était arrivée pour nous comme pour toutes les écoles. Le 18 la capitale parut déserte. En passant en Nalikwanda, près de la station, le roi ne manqua pas d'en descendre pour venir nous saluer. Il avait toujours témoigné beaucoup d'affection à nutre garçonnet et il s'était même attaché à lui d'une façon émouvante. Il ne perdait pas une occasion de demander de ses nouvelles, se réjouissant de chacun de ses progrès.

Le lendemain Léaco et Nyambo partirent pour le bo-Lubale. De tous nos élèves évangélistes il ne nous resta que Kajata, et notre grande famille fut réduite à neuf personnes. Nous avions bien besoin d'un peu de repos et de détente.

L'état du petit Eugène va en empirant malgré nos soins. - Le soir du 19 il expirait presque dans mes bras pendant que je lui prodiguais les soins qui nous paraissaient devoir mieux le soulager. Quelques minutes plus tard, alors que rentrés chez nous, nous finissions de souper, on vient nous chercher: L'enfant est mort! Nous accourûmes; la pauvre mère effarée dans un coin murmurait: «Il respire encore, dites qu'il respire encore». Hẻlas il fallut la détromper, son petit garçon n'était plus. Son esprit était allé rejoindre le père, que dans ses visions d'enfant mourant, il avait appelé: Père! Père! avait-il dit en tendant ses petits bras vers une figure imaginaire. Nous veillâmes auprès du petit corps lent à se refroidir après la brûlante fièvre qui l'avait consumẻ. Nous l'habillâmes d'une des longues robes blanches de Giulio. La mère ne voulut plus le voir, et nous roulâmes le petit cadavre dans une natte.

En rentrant chez nous, la vue de la tête blonde reposant dans le berceau rose nous serra le cœur et la même pensée nous traversa. l'esprit. Oh! et si c'était lui!

Le lendemain on ensevelissait le petit Eugène. La santé de notre bébé nous inquiétait. Oh! comme je le serrais sur mon cœur en regardant le pauvre mère desolée.

Le lendemain Dimanche, Pauluse, venu pour l'enterrement, était encore là et prêcha avec son ardeur ordinaire. À un moment donné il désigna mon enfant, couchẻ et dormant sur mes genoux. «Et celui-là aussi n'est qu'un prêt, dit-il, il vous sera redemandẻ». J'en eus le coeur douloureusement serré. Le dimanche suivant notre petit bien aimé, était auprès de Celui qui nous l'avait donné, mais seulement pour un peu de temps, ici-bas.

C'était le 24 mars. La méningite se déclara. 
La nuit point de sommeil pour le pauvre petit, pas de repos pour sa tête fatiguée! Oh! la longue nuit d'angoisse! Le jour suivant le mal empira, pas un sourire n'éclairait le petit visage qui en était souvent naguère illuminé au milieu de sa plus forte fièvre. Il disait: Maman! ma maman! comme pour me demander pourquoi il souffrait tant.

Le vendredi, le voyant toujours plus mal, je dis a mon mari: «Dimanche nous n'aurons plus notre bẻbé». Mon mari voulait espérer. Mais c'est en vain que je regardais ce beau texte suspendu à la muraille: «C'est dans le calme et la confiance que sera votre force ». quelque chose me disait que notre bébé aliait nous être redemandé ». - «Ma grâce te suffit». Ce passage monta ḋ mon cœur comme murmurẻ pas une voix mystérieuse. Je compris: «Ma grâce te suffit», sans ce bébé que tu croyais nécessaire à ton bonheur.

Encore une nuit d'angoisse. À l'aube je me lève, je vais à la salle à manger avec notre enfant dans mes bras. Je touche sa menotte et je sens avec terreur qu'elle est glacée. «Oh! la fin arrive», dis-je en retournant auprès de mon mari qui essayait de prendre un peu de repos. J'écrivis à nos amis Béguin à Nalolo, leur disant l'épreuve qui nous menaçait.

A 5 heures je crus que notre enfant expirait dans mes bras, déjà son regard était vitreux. «Regarde, criai-je à mon mari, il s'en va! » Oh l'angoisse de cet instant! Mais non, il se ranima, alors nous crûmes que Dieu voulait faire un miracle et nous nous mîmes à le supplier de nous conserver notre enfant. Comme nous criâmes à Lui! Nous voulions croire qu'Il nous le laisserait. Il eut un moment de calme, presque de sommeil: Dieu voulait-Il nous exaucer? Mais peu auprès survinrent de terribles spasmes et nous devions reconnaître, avec des larmes amères, que Dieu redemandait l'enfant. Nous ne voulions pas le retenir de force, non. Si le bon Berger voulait son petit agneau, nous le Lui donnerions. Tu ne nous l'arraches pas, nous consentons à le voir partir! Et alors un peu de calme rentra dans nos pauvres cours brisés. C'était le sacrifice demandẻ et accepté. Nous sentions Dieu tout près de nous, parceque notre volonté était d'accord avec la sienne.

À 11,15 h. quand notre trésor s'envolait, nous étions soumis mais brisés. La lutte nous avait prẻparés. Il nous avait amenés à dire: Que ta volonté soit faite, quand même nous ne la comprenions pas.

À 5.15 h. nous nous réunîmes dans la vẻrandah auprès du petit cercueil recouvert diun drap. Mon mari lut quelques passages et quelques mots, et Willie pria. On chanta deux cantiques. Puis nous nous acheminâmes vers la fosse, où l'on allait descendre le petit corps. L'assurance que ce n'était pas notre enfant qu'on mettait dans 
ce trou, nous a soutenus. Nous voyons, par la foi, notre petit Giulio au ciel, à l'abri de tout mal, auprès du Seigneur.

29 MARs. - Je ne puis dire toutes les consolations que Dieu a fait descendre dans nos cours depuis que nous sommes dans la fournaise ardente de l'épreuve.... Et maintenant que l'ẻpreuve porte ses fruits, que nous soyons plus complètement dévoués au service de Dieu, que nous aions plus d'amour, de zèle, de foi, et que, les cœurs en Haut, nous poursuivions notre carrière, la main dans la main du Sauveur, jusqu'à ce que nous entrions nous aussi dans les demeures éternelles.

La première lettre de condoléance qui nous parvint fut celle de Lewanika. En voici la traduction littérale:

《Missionnaire, mon ami, je suis profondément triste. Qui est 《 malheureux c'est moi, car dans ce pays Dieu avait voulu me 《donner du bonheur par votre moyen à vous ses serviteurs et 《désormais tous les missionnaires diront: C'est un mauvais pays, « un pays meurtrier. En outre les gens d'ici diront: Voilà les 《 choses de Dieu sont petites, car ils ne connaissent pas la puis«sance de Dieu. Je suis très malheureux de ce que la main 《de Dieu s'est appesantie sur ses serviteurs. Je ne sais que « dire, je suis très triste. Adieu. Oh! que Dieu te soit en aide! «Je suiș ton ami qui t'aime toujours. Je pleure vraiment, mon 《 cœur souffre. Lewanika 》.

La triste nouvelle lui avait été communiquée durant le culte. Il s'était aussitôt levé en disant: «Ce qui touche le missionnaire me touche, il est un autre moi-même. Je ne suis bien que s'il est bien 》.

Plusieurs autres personnes nous témoignèrent leur sympathie. Quelques unes vinrent de Sefula. Cependant, qu'ils ont peu à dire les Zambéziens! C'est à nous de leur faire part des consolations que le Seigneur répand dans nos cœurs. Mais chez eux l'intention était bonne et elle nous fit du bien.

Pour beaucoup d'autres, hélas! notre deuil devint un sujet de moqueries. Ils magnifièrent la puissance de leurs ancêtres et bafouèrent celle du Dieu des missionnaires. 


\title{
LXIX.
}

Dieu nous accorde des consolations.

\begin{abstract}
Arrivée de h.he Kiener. - Chez les Béguin. - A sefula pour mariage et baptême. - La paix de Pâques. - Nouvelles professions. - Donnez-nous des missionnaires: - Existences vides. - Incendie chez le roi. - La cour rentre à Léalul.
\end{abstract}

L nous tardait de voir arriver $M^{\text {lle }}$.Kiener. Surchargés de 1 besogne et sans cesse débordés par une tâche grandissante, nous avions demandé que $M^{\text {lle }}$ Kiener nous fût adjointe. Nous avions appris qu'elle avait accepté notre appel et qu'elle était partie de Kazungula, en canot, le 4 mars. L'école de Kazungula avait dû être dissoute, Litia abandonnant ce village.

$M^{\text {lle }}$ Kiener arriva enfin le 3 avril 1897, mais fiévreuse, amaigrie. Après un voyage de 31 jours, au cours duquel elle avait couru mille dangers, manquant du nécessaire, son système nerveux avait été fortement ébranlé. Elle était si faible qu'elle en était presque devenue sourde et aveugle, elle ne pouvait rien voir à vingt pas. Arrivée la veille à Nalolo elle avait aussitôt poursuivi, apprenant notre épreuve et notre impatience de la voir. Elle pleura avec nous et sa présence nous fit du bien; obligés de sortir de nous-mêmes pour nous occuper d'elle, sentant sa profonde sympathie, nous bénîmes Dieu de nous l'avoir envoyée. Au bout de huit jours de repos et d'un régime fortifiant, elle recommença à prendre des forces.

Nolianga nous apprit ce même jour qu'on lui avait enlevé la petite princesse Matanka qu'elle élevait. L'enfant était malade et les ennemis de l'Evangile avaient fait dire par un devin que Nolianga avait été désignée par les osselets divinatoires comme cause de cette maladie, par le fait qu'après avoir été dans une maison de deuil (celle de Théodore) sans nécessité, elle n'avait fait aucune purification.

Le 12 j'allai rejoindre ma femme. Nous passâmes Pâques chez nos amis, les aidant et jouissant de leur sympathie. De là je dus aller à Sefula administrer le baptême à l'enfant de Pau- 
luse. J'y trouvai une centaine de personnes assemblées. Je fis le service et je parlai sur mo-hau, nom de l'enfant de l'évangéliste, signifiant la grîce. L'auditoire fut recueilli quand je montrai que la grâce de Dieu suffit toujours au racheté, à l'enfant comme à l'adulte. Pauluse reprit plus tard cette pensée et avec délicatesse et affection il me l'appliqua.

Pauvre station, cela me serrait le cœur de voir l'herbe envahissant tout, les maisons toutes décrépies et plusieurs menaçant ruine, et de me sentir impuissant parce que depuis des mois j'avais les mains vides. Spirituellement c'était un lumignon fumant.

À Nalolo nous occupions une chaumière bâtie récemment, où nos hôtes pensaient s'installer bientôt, pendant qu'on réparerait la toiture de leur grande maison déjà pleine de gouttières. Là comme à Loatile nous vivions principalement des produits du pays: patates et autres tubercules rappelant les pommes de terre.

Comme tout nous semble monotone! Notre enfant est dans le beau ciel, avec les anges, heureux, et nous sommes restés dans le désert aride. Pour lui les chants, la joie, les sourires, pour nous les larmes, le deuil, le vide affreux, toujours plus grand à mesure que le temps passe. Le cher petit nous avait fait la vie si belle. De nos cœurs s'élevait sans cesse un hymne de reconnaissance. C'est Lui, le Pẻre d'amour qui l'a fait, nous ne murmurons pas, mais nous pleurons. Nous balbutions chaque jour, ce que Dieu dans sa bonté nous a accordé de dire au moment suprême de la séparation: Que ta volontẻ soit faite, quelque mystérieuse, quelque sévère que elle nous paraisse parfois.

Pâques, c'est la fête des cœurs en deuil, nous pouvons répandre des larmes sur nos bien-aimés envolés, mais la paix descend aussi dans nos âmes, comme dans celles des disciples. Il ne faut pas que l'épreuve qui nous a été dispensée demeure vaine pour nous. Il faut que le départ de notre enfant nous rapproche de Dieu, nous fasse vivre tous près du ciel. Le Seigneur nous redonnera l'entrain et la joie nécessaires pour reprendre la vie de Loatile. Jésus qui a pleuré sur le tombeau de Lazare, pleure avec nous et nous aide jour après jour à porter notre croix. Dieu est bon, il permet qu'au sein de la plus grande douleur, des joies nous soient réservées, il nous conserve encore l'un à l'autre et il nous fait sentir que c'est un privilège qu'il nous accorde en nous permettant de travailler encore pour Lui. 
Le 23 avril nous rentrions chez nous. $\mathrm{M}^{\text {.le }}$ Kiener avait tout préparé. Un bouquet de fleurs avait été posé près du berceau vide. Ma femme était souffrante, elle ne reprit des forces que après une semaine.

Le 25 nous eûmes 150 auditeurs. Comme j'allais commencer la prédication, une femme à cheveux gris, courbée par des rhumatismes, se leva et, d'une voix tremblotante, déclara avoir trouvé le Sauveur dans sa vieillesse, Après ce fut notre brave Nanjeke qui déclara s'être donnée à Jésus. Le soir encore une autre profession, celle d'une pauvre fille que nous n'avions que trop connue à Sefula en 1890, et qui depuis avait vécu dans l'immoralité. Nous ne pouvions oublier tous les renégats des mois passés. Mais nous voulions espérer que ceux-ci chercheraient en Dieu la force pour persévérer.

Le 28 Moka et Sesoaira revinrent chez nous. Ils étaient retournés au Nyengo. Ils y avaient approché beaucoup de gens, et presque tous les jours ils avaient pu en rassembler pour la prière; dans deux villages surtout on les avait retenus quelques jours pour entendre encore l'Evangile, et on nous avait envoyé dire: «Donnez-nous des missionnaires! 》Ủn homme qu'ils avaient vu en 1896, avait observé le dimanche depuis lors. Tous les ba-Nyengo comprennent le se-kololo. Quand répondronsnous à ces appels?

Les autres élèves évangélistes nous apportèrent des messages analogues. Que n'y a-t'il un missionnaire à tel et tel village, disent-ils, il y serait bien accueilli; et les ténèbres y sont si épaisses!

Pour les gardiens et gardiennes de Léalui nous aurions voulu que la cour n'y rentrât pas trop tốt, ils venaient aux cultes si volontiers! Nous les voyons beaucoup chez eux; Nolianga en assemblait un certain nombre chaque soir pour la prière. Ces gardiens sont surtout des femmes et des jeunes filles qui, en temps ordinairè, ne peuvent que difficilement assister aux services.

DIMANCHE 2 Mar. - Nous nous embarquons, mon mari et moi, ả $5 \mathrm{~h}$. du matin: M. ${ }^{\text {lle }}$ Kiener éprouve encore une légitime répugnance à remonter en canot. Nous arrivons aux Mafulo vers $8 h$. Nous nous faisons annoncer à Lewanika. Nous le trouvons dans son Kashandi, salle du conseil qui lui sert aussi de salle à manger. Il nous reçut avec son amabilite coutumière et nous parla de notre cher enfant. 
La sympathie qu'il nous exprima me fit du bien. Lewanika est le seul, avec quelques professants, qui ait pris une part vẻritable à notre deuil. La plupart croient sans doute que pour nous la perte d'un enfant n'est pas plus que pour eux. Au culte qui suivit notre visite au roi il y avait plusieurs chefs et officiers, puis des esclaves et des gens du peuple, et une quinzaine seulement de jeunes filles ayant Mpololoa à leur tête, en tout 130 personnes.

Après le culte nous allâmes chez quelques femmes du roi. Chacune d'elles était dans sa hutte. Les unes avaient leurs enfants auprès d'elles, d'autres étaient assises seules sur leurs nattes, inoccupées. Quelle existence vide et monotone! Mais cette vie leur plait: elles ont une belle position, des esclaves, des champs, du bẻtail, des honneurs... Cela leur suffit. Elles se moquent de vous quand vous essayez de faire briller devant leurs yeux quelque chose de plus èlevè. Pendant que nous ètions chez Ma-Morambwa un messager vint nous prévenir que le roi nous attendait.

Nos couverts étaient mis à la table de Lewanika. Le repas fut excellent; une oie rôtie, du lait caillé, du maïs bouilli, du thé pour arroser le tout. Lewanika fut d'une exquise amabilité, simple et bon comme un véritable ami.

À 3 h. second culte: Une cinquantaine d'auditeurs. Nous saluâmes encure chez eux le roi, Mokamba et Mpololoa, et nous repartîmes. Nos rameurs avaient un entrain remarquable. Le retour au soleil cuuchant, dans le crépuscule doré ensuite, enfin dans la nuit noire, fut reposant.

Quatre jours après, le soir, nous vîmes une lueur d'incendie aux Mafulo. Le lendemain un messager du roi vint nous annoncer que six maisons de son établissement avaient été réduites en cendres et que Kwandu avait failli être aussi consumé. Nous nous empressâmes de lui exprimer notre sympathie par écrit en attendant de savoir lesquels de ses objets détruits nous pourrions remplacer. C'est ainsi que la coutume des ma-Rotsé voudrait qu'on «consolât» les incendiés. Mais en réalité on ne le fait guères que pour les grands du pays.

Le 13 Lewanika nous annonça son arrivée pour le lendemain. Il nous envoya encore un message le 14 avant midi. ̇̀ $2 \mathrm{~h}$. nous commençous à entendre les mahoma (tambours de guerre), à 4,20 h. la Nalikwanda est devant la station. Lewanika rentre à Léalui avec toute la pompe et les ovations habituelles.

Il ne nous oublia pas au milieu de tout ce bruit: dès le premier soir il nous envoya trois poissons rôtis sur la braise, don 
qu'il répéta le lendemain. Bien que les troupeaux n'êtssent pas encore été ramenés, et que lui-même ne fût pas dans l'abondance, il nous laissa jusqu'à la fin la jouissance du lait qu'il nous avait donné pour Giulio.

\section{LXX.}

Reprise de l'œuvre en plein.

Deux nouvelles défections à l'ćcole d'évangélistes.

Réouverture des écoles. - Vol légal. - Nouvelles de nos voyageurs.

T E roi ramena la vie à Loatile comme à Lealui. Il n'y eut 1 de nouveau plus de limite à notre activité, si ce n'est nos forces, et l'impossibilité de nous dédoubler. C'est un privilège pour les enfants de Dieu, surtout lorsqu'ils sont dans le deuil. Nous eûmes de bons auditoires, nous reprîmes nos classes de catéchisme et nos écoles.

Mais tout ne fut pas joie. Nawa et Kuibisa, les seuls de nos éléves évangélistes qui eûssent passé leurs vacances aux Mafulo du roi, ne rentrèrent à leur école que pour nous montrer que leurs cœurs n'y étaient plus. Ah l'influence du paganisme de la cour! Ils n'osèrent pas me le dire ouvertement, mais ils firent savoir au Souverain qu'ils étaient fatigués d'étudier. Lewanika en fut attristé, il se dit confus de voir combien ses sujets manquent de persévérance et de fonds. Me voyant affligé par ces défections, il me demanda s'il ne faudrait pas fustiger ces jeunes gens. "Ne nous les renvoie pas de force, lui répondis-je, ils ne feraient plus aucun progrès quand même, et ne deviendraient jamais des évangélistes 》. Nous avions craint que ces deux jeunes gens, issus de l'aristocratie du pays, ne pûssent s'astreindre à la discipline et à la régularité de l'école. Cependant ils avaient semblé s'être attachés à leurs leçons et avoir de l'affection pour nous. Il ne nous restait qu'à demander qu'il nous fût épargné la douleur de les voir abjurer le Christianisme. 
Nous rouvrîmes l'école des futures femmes d'évangélistes le même jour; M. ${ }^{\text {lle }}$ Kiener leur consacra de 9 à $10 \mathrm{~h}$. et ma femme les garda de 10 à midi. Le matin avant déjeûner elle avait repris sa classe de professantes.

Le 19 ce fut la rentrée de l'école de station, avec 70 élèves auxquels je présentai M. ${ }^{\text {lle }}$ Kiener. Le lendemain il y eut plus de 100 enfants, et encore davantage les jours suivants.

Nous réapprîmes le sens de ce que les Zambéziens appellent $K u$ funda et qui n'est autre chose qu'un vol légalisé. Déjà en 1890 à Sefula, un neveu de Lewanika avait été une belle nuit à l'une des bergeries royales, il y avait égorgé un boeuf, et en avait emporté la viande. Quand on l'avait accusé il avait répondu qu'il n'avait pas volé mais funda. C'est un droit de parenté et d'hospitalité, ou même d'amitié, droit réciproque. Le 18 mai donc, Moka reçut la visite d'un sien cousin à la mode du Zambèze. Mon élève ne s'y fiant guère, courut à sa hutte après la première leçon, mais pour découvrir que sa plus belle couverture de laine avait disparu. Que faire? le voleur avait usé de son droit.

Le roi rassembla tous les enfants au Khotla; en leur présence il remit à Amba une cravache, en lui disant: «Si tu ne frappes pas les enfants qui refusent d'aller à l'école, c'est toi qui seras frappé 》. Le nombre des élèves monta bientôt à 153 .

Le matin de l'Ascension (27 mai) nous eûmes un service bien fréquenté. L'après-midi notre long Mompisho arriva avec trois garçons. Ils revenaient de Palapye jusqu'où ils avaient accompagné M.me Goy. Ils nous apportèrent de bonnes nouvelles de notre soeur, et nous dirent sa vaillance, mais ce qu'ils nous racontèrent de M. Davit nous donna beaucoup de souci. Ils l'avaient rencontré à Kwaliba fiévreux, éclopé, sans provisions, et presqu'abandonné de ses compagnons de voyage.

Nous avions espéré que le tombereau ramené à Kazungula par Mompisho aurait contenu quelques-unes de ces provisions qui nous semblaient indispensables, mais il n'y avait pour nous qu'une petite caisse de lait condensé.

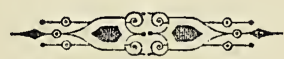





\section{QUATRIÈME PARTIE}

\section{Periode Critique}

1897-189S 



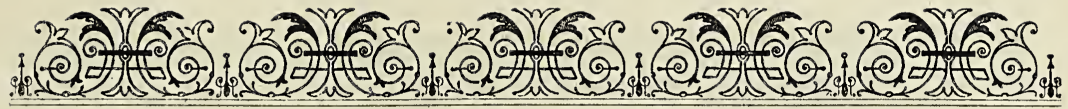

\title{
QUATRIÈME PARTIE
}

\author{
LXXI.
}

Causes de la Crise.

Le roi fâché. - Ses raisons pour l'être. - L'Eternel règnc.

E dimanche 23 mai, Lewanika avait semblé moins heu-

1 reux de nous voir, nous l'avions trouvé silencieux à table et l'air préoccupé. Il n'était pas revenu l'après-midi, ni le jeudi de l'Ascension.

Quand je l'avais vu chez lui le 24, j'avais compris qu'il avait quelque chose sur le cœur. Enfin le 28 je crus sentir qu'il y avait de l'orage en l'air. En rentrant de la capitale je passai chez Willie qui avait été gravement malade et lui fis part de l'impression produite sur moi par le roi. L'évangéliste me dit alors que Lewanika était en effet fâché contre nous, à cause de M. Davit, et qu'il avait dit: «Vous êtes mauvais, vous les missionnaires 》.

On avait en effet rapporté à Lewanika que M. Davit l'avait fortement blâmé devant ses gens de ne pas observer le contrat relatif au transport de nos provisions, et qu'il avait même menacé d'avoir recours contre lui à l'autorité anglaise. J'eus toutes les peines du monde à le calmer. A la fin pour me prouver qu'il ne m'en voulait pas, Lewanika me fit demander de la toile en couleur, pour un se-tsiba qu'il voulait donner à Sekufele. Il continua à nous envoyer de la viande une fois par semaine. 
Le roi est revenu aux cultes, il est aimable comme toujours, mais nous sentons qu'il ne nous ouvre pas son cœur et qu'il nourrit contre nous du ressentiment et de l'amertume. Tout cela éclaterra peut-être un jour. Le ciel est noir et nous paraît chargé d'électricité. Mais l'Eternel règne, et pas un cheveu de notre tête ne tombera à terre sans sa volonté. Nous ne sommes pas dans les mains des ma-Rotsé.

\section{LXXII.}

Au jour le jour.

Dieu envoie ses copbeaux. - Princesse renégate.

Candidats au baptême.

T $\mathrm{E}$ 10. Au lever du soleil tout est couvert d'une épaisse

1 couche de gelée blanclıe. Le thermomètre marque $+1^{\circ}$ centigrade. Nos derniers messagers reviennent avec notre poste, ils ont été effrayés par des lions entre le Luyi et le Lumbe.

Dimanche 13 JUIN. Dieu continue à pourvoir à nos besoins d'une façon merveilleuse. Les corbeaux qu'il nous envoie ont la couleur de ceux d'Elie. Que de fois ils sont venus au bon moment. Aujourd'hui c'est Mokwae qui nous envoie une magnifique oie.

LE 17. Nous recevons du roi et de Semonja une douzaine d'oiseaux tués dans leurs nids, presque aussi gros que des pigeons. Leur viande est délicieusement tendre et délicate. Comme nous venons de tuer un petit porc, et que nous avons pu acheter quelques patates, nous sommes dans l'abondance pour quelques jours. Nous passons de notre abondance aux évangélistes (Willie). Au bon moment les corbeaux reviendront.

La princesse Samana est retournée au paganisme et s'est séparée de Sewakutilibebe, qu'elle a enlevé à notre école d'évangélistes il y a 10 mois Le roi en est si fâché qu'il oblige sa fille à abandonner sa hutte, et la menace de lui enlever tous ses esclaves; tandis qu'il laisse son gendre à son poste et lui promet une autre de ses filles. 
LE 16. J'inaugure la classe des candidats au baptême. J'en ai cinq. Les catéchumènes et les élèves évangélistes sont le point lumineux de notre ciel, malgré leurs misères.

\section{LXXIII.}

Esclavage et guerre esclavagiste.

Préoccupations des ma-Rotsé. - Doù viennent les esclaves. - Leur triste sort.

Emancipations individuelles. - Guerre à la guerre. - La guerre est cunlée Nyondo et la bonne guerre. - Corvée. - Tributs vivants.

T A venue prochaine du résident britannique fit surgir 1 toutes sortes de préoccupations sociales et politiques. Les esclaves s'en réjouirent pensant que le jour de leur émancipation allait luire. Les ma-Rotsé commencèrent à trembler. En attendant ils firent leur possible pour raffermir et étendre leur domination, et pour augmenter le nombre de leurs esclaves proprement dits. De là des projets de razzias, et d'expéditions faites chez leurs vassaux. Seulement ils n'osent plus employer tous les moyens d'autrefois, et le roi réprimande ceux qui sont trop violents.

Peut-être ne sera-ce pas hors de propos de dire quelque chose sur l'esclavage au bo-Rotsé.

Au bo-Rotsé personne n'est complètement libre. Etre libre c'est ne dépendre que du roi, c'est 《être au roi 》. Les chefs sont esclaves du roi, qui a tout pouvoir sur eux, leurs enfants et leur propriété. De son côté le roi est esclave de ses chefs, sa conduite de 1895 l'a bien prouvé. Cependant cet esclavagelà est relatif.

Il en est un autre hélas! bien pire. Et au bo-Rotsé proprement les trois quarts de la population sont composés d'esclaves. D'où viennent tous ces esclaves? Les uns sont le produit des guerres ou incursions, d'autres ont été amenés comme tribut. D'autres encore ont servi à payer des amendes ou des dettes. Quelques uns ont été achetés (on payait 7 pioches pour un garçon, et 14 pour une jeune fille, prix moyen!. Mais la plupart 
des esclaves actuels sont des enfants d'anciens esclaves, nés chez leurs maîtres.

Pour tous c'est l'esclavage domestique. Ils sont ou deviennent plus ou moins membres de la famille, souvent même par le mariage. Mais ils sont la propriété de leurs maitres et font partie de leur héritage.

Autrefois les esclaves ne pouvaient manger ni sorgho ni millet. Il leur était interdit de se bâtir des huttes convenables, de porter de beaux vêtements, ou même de posséder de beaux objets qu'il se seraient faits. Les maîtres avaient droit de vie et de mort sur eux.

Ceux dont la condition est la plus misérable ce sont les esclaves qui sont tout-à-fait au bas de l'échelle; car en ce pays d'esclaves les esclaves peuvent avoir des esclaves à eux!

Mais même au bo-Rotsé l'esclavage n'est pas nécessairement perpétuel. Il y avait beaucoup de ma-Rotsé esclaves, il n'y en a plus maintenant. En 1894 Lewanika a déclaré que toute personne pouvant prouver qu'elle est née ou issue de ma-Rotsé serait affranchie. Des parents peuvent payer la rançon des membres de leur famille.

Le roi émancipe qui il veut. Il a élevé des esclaves aux plus hautes dignités, il en a allié d'autres à sa famille. Il en a libéré plusieurs, simplement parce qu'ils étaient maltraités par leurs maîtres. 1)'autres enfin ont été affranchis pour devenir des « enfants des missionnaires 》, ou des évangélistes.

Sous l'influence de l'Evangile, le sort des esclaves a été adouci, les lois restrictives sont tombées en désuétude, et les propriétaires n'ont plus sur eux droit de vie et de mort. En outre, les guerres, qui étrient parmi les principales sources de l'esclavage, ont été abandonnées.

Les gens de Sembula mokoa (1) ne reçurent pas bien les messagers des ma-Rotsé, et se moquèrent de leur sommation. Ils répondirent: "Nous n'êtes pas nos maîtres, restez chez vous, comme nous restons chez nous $\gg$.

A l'ouïe de ces paroles, les chefs et les officiers de Léalui déclarèrent qu'il fallait châtier ces insolents de ma-Shukulumbwe. Le 11 juin j'allai chez Lewanika essayer de le dissuader d'appeler ses guerriers. Mais je sentis que pour lui le parti

(1) Voir p. 197. 
de la guerre était pris. En effet le 16 nous entendîmes les lugubres mahoma (tambours de guerre) et dès le lendemain nous vîmes des gens armés accourir de tous côtés. Le 18 je retournai vers Lewanika et allai chez quelques chefs parler contre leur projet, mais je m'en retournai triste et découragé. Cependant on ne battit plus les tambours la nuit suivante. Le samedi 19 il vint peu de monde à la réunion de prières de $5 \mathrm{~h}$. Nous y exposâmes à Dieu notre douleur.

Le 20 juin, il y eut 350 personnes au culte du matin. Le roi et la plupart des chefs étaient présents. On s'attendait à ce que je parle de la guerre. Je ne leur cachai rien. Je leur montrai par des exemples bibliques comment on ne se joue pas des avertissements de Dieu, et je répétai avecinsistance qu'ils devaient renoncer à cette entreprise inique. La seule guerre permise est celle de défense; mais ce n'est pas leur pays, ce ne sont pas leurs foyers qui sont menacés, ils ne rêvent que pillage, massacre, et esclaves! Une telle guerre ne peut être bénie de Dieu!

Dieu me soutenait. Tous avaient l'air étonnés de ma hardiesse, les yeux de certains lançaient des flammes; mais la plupart ne manifestaient qu'un vif intérêt.

A la sortie il y eut beaucoup d'animation, on ne parla que de la prédication. Des chefs l'approuvèrent, d'autres étaient furieux. Qu'en résulterait-il?

Pendant le dîner, Lewanika parut ébranlé dans sa résolution. Nous fûmes étonnés et contents de le voir revenir pour le culte de l'après-midi. Le lundi il nous envoya quatre oies vivantes.

Le 23 j'appris par Mokamba que les chefs, le Ngambela en tête, avaient demandé au roi la veille de renoncer à cette expédition; 《le moruti a raison》 disaient-ils.

Le 25 nous pûmes nous écrier: Il n'y aura pas de guerre! Les chefs et le roi y avaient renoncé d'un commun accord. C'était, je pense, la première fois que les ma-Rotsé abandonnaient une expédition pour laquelle ils avaient déjà fait tous les préparatifs. Ils avaient simulé des combats et désigné ceux qui devaient commander les troupes. Ils durent envoyer des messagers à Nalolo et à Sesheke pour arrêter les bandes de guerriers qui allaient se mettre en marche. Comme nous en bénîmes Dieu!

J'eus plus tard la conviction que le roi avait été le principal 
promoteur de cette razzia esclavagiste; avec Amba et quelques autres officiers, il fut très vexé d'avoir dû renoncer à l'expédition; tandis que la plupart des gens et des chefs en furent contents.

Nyondo, revenu juste alors du bo-Shukulumbwe, nous parla d'autres travaux. Au départ de son village natal, ses jeunes concitoyens pouvaient chanter tout seuls le cantique qu'il leur avait enseigné aux prières du soir.

Même après la dispersion des guerriers, Léalui regorgea de gens rassemblés pour la construction du nouveau palais royal et pour l'exhaussement de tout le harem. Nous ne pouvions que difficilement voir chez eux ces centaines et ces milliers d'hommes et de femmes, occupés comme ils l'étaient toute la semaine. Le dimanche ils se reposaient, ou bien ils vaquaient ì leurs propres affaires. Aussi l'augmentation de la moyenne de nos auditoires était-elle dûe au grand nombre des écoliers.

Le $1^{r}$ juillet Sasa arriva avec le tribut des ma-Toka: des ballots de belles couvertures (gagnées par les ma-Toka aux mines de diamant, ou d'or) et 88 esclaves qui furent distribués le lendemain. Quelles iniquités! Pauvre bo-Toka décimé par la famine et l' esclavage! De semblables tributs avaient été amenés à Nalolo et à Sesheke.

On nous rapporta que les percepteurs de tribut envoyés par Litia dans le ba-Tomwe, s'étaient conduits en vrais sauvages. Les gens fuyaient à leur approche. Ceux d'un village restèrent, mais refusèrent de payer un tribut en enfants. Ils auraient dit: "Nous mourrons plutôt que de laisser prendre nos enfants! 》 On les attaqua avec l'aide d'un transfuge, on tua le chef du village et 9 de ses hommes, et on prit tout le reste. Plusieurs femmes se seraient jetées dans le Zambèze, et $y$ auraient péri, pour échapper à l'esclavage. Certains dirent qu'elles y avaient été précipitées. Il y a des sauvages ailleurs que parmi les maTebele! Qu'arriverait-il si on laissait un libre cours aux instincts de ces populations! 


\section{LXXIV.}

La crise s'accentue.

Désastre à palapye. - Lewanika suscite des difficultés. - On travaille le IDimanche. - Refus de nous aider. - Nouveaux griefs. - Fûcheuse infuence de Séajika. - Le repos dominical. - Mauvais vouloir des chefs. - Les services rendus par la Mission. - Brave Lewanika. - Poste difficile.

E 12 août nous reçûmes par la poste la terrible nouvelle 1 de la mort de tous (1) les bœufs envoyés à Palapye par Lewanika et Mokwae. Nous crûmes à l'effondrement de nos espérances de secours pour 1897. Dès le lendemain j'allai annoncer au roi la terrible nouvelle. $\grave{A}$ mon grand soulagement il ne manifesta aucun ressentiment. Mais ne cachait-il rien? Il est lui aussi noir et zambézien, et par conséquent habile à dissimuler. Pauvre homme, je l'ai plaint de tout mon cœur. Au lieu de réaliser une fortune par cette expédition, il n'avait que des pertes! J'aurais voulu lui manifester notre sympathie autrement que par des paroles, mais je n'y fus pas autorisé.

Le 15 , je portai plainte au roi contre les derniers messagers, qui avaient volé 8 yards de calicot à M. Béguin. Il refusa de s'en mêler, parceque nous ne passons pas par lui pour la poste.

Le 16, il envoya Mokamba me dire que désormais les missionnaires paieraient les frêts des canots, comme les marchands, ceux-ci prétendant être traités comme nous. Je répondis que le roi se trompait, car chacun sait que dans l'Afrique Méridionale on accorde plusieurs privilèges aux missionnaires et aux pasteurs, en considération de leur ministère; ainsi nous ne payons rien pour le passage des fleuves sur les ponts et les bacs, et ne payons que peu sur les chemins de fer. Il suffit que le roi déclare qu'il veut nous accorder ces mêmes faveurs. Lewanika dit: Ce que le missionnaire dit est bien.

Le 18 fut le quatrième dimanche où le Roi ne mit pas les pieds sur la station depuis ma prédication contre la guerre.

(1) Nous apprîmes plus tard qu'ils n'avaient pas tous péri. 
Tout le jour il y eut des gens apportant des balles de roseaux ou d'herbe, à Léalui. En sortant du culte de l'après-midi, je dis aux chefs et officiers: Faites cesser ce trafic le dimanche, et je me promis de prêcher sur le quatrième commandement, le dimanche suivant. Ce jour-là le roi assista au culte avec 340 de ses sujets, mais à la Capitale Katoka dirigeait les travaux, et la grosse moitié de nos 150 élèves y avait été retenue.

Le 22, Lewanika reçut du Gouverneur de la Colonie du Cap une lettre annonçant pour la fin de juin, l'arrivée à Kazungula du Résident Britannique en la personne du major Coryndon. On demandait des canots pour lui et son escorte. On prévenait les ma-Rotsé que cet officier ne devait ni domner ni accepter de cadeaux, ni vendre, ni acheter quoi que ce soit, sauf pour sa subsistance et celle de ses gens.

Le courrier du 28 nous apporta deux bonnes nouvelles: L'arrivée chez les Boiteux d'une partie de nos caisses, et le départ de Palapye le $1^{\text {er }}$ juin de Davit, des Coïsson, des Mercier et de Léfi. Le 29 j’allai rapporter ces nouvelles à Lewanika et lui parler de la grave maladie de M. Boiteux (hématurie). Il ne manifesta ni joie, ni tristesse. Quand je lui demandai des canots, il me dit ne plus en avoir. Tous étaient retenus pour le résident et pour le marchand qu'Andrease amène. J'insiste. Il me dit alors qu'il ne veut plus nous prêter de canots, parcequ'une lettre d'Andrease lui apprend que M. Davit a refusé de l'aider à vendre les boeufs qui avaient échappé à l'épizootie, en lui disant qu'il n'avait plus rien à faire avec lui. J'eus beau affirmer que M. Davit nous avait écrit tout l'inverse, qu'il avait offert ses services, mais qu'Andrease lui avait tourné le dos... tout fut inutile. Je dus rentrer sans avoir obtenu la promesse d'un seul canot.

Cependant le 3 août Lewanika me promit quelques pirogues, mais il m'avertit qu'il serait inutile d'en demander aux chefs. Il me raconta ensuite qu'à Palapye M. Davit aurait voulu faire emprisonner les Zambéziens qu'il avait pris comme serviteurs. Il me dit: "Noirs et blancs peuvent faire profession de christianisme et devenir des fauves... Le christianisme ne vaut pas mieux que nos religions à nous. Nous connaissons Dieu les uns comme les autres, nous ne différons que par les lois et les moeurs. Nos coeurs sont tous les mêmes. Qui les connait si ce n'est Dieu? Nous sommes comme des voleurs, ajouta-t-il dans 
le cours de la discussion, nous sommes comme des voleurs qui savent qu'ils font mal et en seront punis, mais ne s'amendent pas ». De la façon dont il prononçait le nom de M. Davit, je sentais qu'il le haïssait, qu'il avait soif de s'en venger... et M. Davit était en route vers le Zambèze!

Les temps étaient sérieux, oh comme nous sentions le besoin d'être revêtus de l'esprit de sagesse, de force et d'amour! Que se passait-il dans le cour de notre royal voisin? Méditait-il un mauvais coup? Ou bien ses paroles étaient-elles l'effet des aiguillons contre lesquels il regimbait?

Seajika avait de nouveau beaucoup d'ascendant sur lui, et son influence était pernicieuse; non content d'être en scandale par sa polygamie et dêtre la principale cause des malheurs des ma-Toka, quoique ma-Toka lui-même, il aurait encore voulu bannir du pays l'Evangile auquel il devait pourtant le peu de bon qu'il eût.

Nous acceptâmes les canots $d u$ roi, mais nous envoyâmes quand même Mompisho avec le wagon à Sesheke. Oh cette question des transports! Elle devenait plus difficile d'année en année. Ce que j'écrivais alors je le pense encore maintenant. Ce qui serait le plus pratique et le moins coûteux, ce serait le chameau ou le dromadaire. Une dizaine de ces bêtes ferait sans peine tous nos transports entre Kazungula et le bo-Rotsé.

Le $1^{\text {er }}$ août nous eûmes d'assez bons auditoires, malgré l'absence du roi: 330 le matin et 160 l'après midi. La prédication sur le repos dominical avait servi à quelque chose, nous ne vîmes que très peu de gens par les chemins.

Le 7 aout Mokamba m'amena les 4 canots promis par le roi. Nous avions décidé qu'Alita en profiterait pour se rendre à la porte du pays. Le 8 , je lui donnai la parole à la fin du service, pour ses adieux, le 13 elle nous quitta. Willie l'accompagna jusqu'à Kazungula.

Le 11 , j'eus une longue discussion avec Lewanika et plusieurs de ses principaux chefs et officiers. Ils avaient décidé de demander pour le trajet de Kazungula à Léalui le prix de transport que nous payions de Palapye à Kazungula. Je m'efforçai de leur faire comprendre qu'ils ne pouvaient comparer leurs canots aux wagons. Seraient-ils prêts à avoir les rameurs à leur charge, et, surtout, pourraient-ils, comme on le fait pour les wagons, payer toutes les pertes et avaries? Ne serait-ce 
pas une source perpétuelle de disputes? Je ne savais pas ce que les marchands et les voyageurs en penseraient; quant à nous missionnaires, nous préférions renoncer à recevoir nos effets, plutôt que de consentir à ces conditions, quittes à venir vers le roi mendier notre pain. Je demandai qu'on nous fît les faveurs dont nous jouissons sur les bateaux et les chemins de fer (le rabais du 25 ou de $50 \%$ ), considérant ce que nous faisons pour la nation, si vraiment on ne veut plus nous aider comme des amis. Chefs et officiers, Mokamba et Semonja en tête, s'opposèrent à l'établissement de prix de faveur pour les missionnaires, prétendant que le premier venu voudrait en jouir aussi. Le Ngambela parla grossièrement des missionnaires en bloc.

Alors je leur rappelai quelques-uns des services que nous leur rendons gratuitement : écoles et livres scolaires, médecines, chaussée, canal, enseignenient de divers travaux manuels; c'est à nous qu'ils doivent de pouvoir élever un palais royal qui sera la merveille du pays. Je leur rappelai aussi que ce que nous achetons c'est pour leurs enfants que nous nourrissons et habillons. Le Ngambela n'eut-il pas l'effronterie de me répondre que c'était notre affaire, qu'ils ne nous devaient rien en retour! Dieu merci, je pus parler très calmement, tout en leur disant quelques vérités.

Il était près d'l h. quand je les quittai, les laissant discuter. Je n'entendis plus parler de rien jusqu'au 14 au soir, quand Mokamba vint m'informer du tarif adopté pour les marchands: 1 à 2 livres st. par canot. Je le chargeai de demander au roi si pour nous missionnaires ce serait la même chose. Le 15 au matin il vint me donner la réponse. «Le roi continuera à vous prêter ses canots comme par le passé, bien que d'autres ne voient pas, lui il sait que vous l'aidez 》. Comme nous bénîmes Dieu pour cette grâce! C'était lui qui avait incliné le cœur du roi en notre faveur. Les chefs disaient que plutôt que de prêter leurs canots pour si peu ( 1 ou $2 \mathrm{~L}$. st.), ils préféraient les garder.

Le message de Lewanika nous a fait grand plaisir. Il nous fait oublier bien des choses; d'ailleurs, dans ses plus mauvais moments, le roi excite notre pitié et nous l'aimons quand même. Que le poste de mon mari est difficile! Ce n'est pas avec de grands mots et de grandes colères qu'on aura raison de nos Zambéziens. C'est une fête pour eux que de voir quelqu'un perdre son sang-froid. Ils n'ont plus aucune considération pour lui. 


\section{LXXV.}

Parmi nos ouailles.

Arête dans l'osophage. - Supercherie d'un docteur. - Kajata moribond.

Hospitalíté de ma-Toka. - Nouveanx rouages. - Heureuse petite mère.

vEc l'espoir d'ouvrir les yeux des élèves évangélistes, A j'avais entrepris déjà depuis quelques mois un cours que nous appelions: Merveilles et inventions. Au commencement d'août je le trasformai en: Leçons élémentaires d'anatomie humaine, à cause d'un incident survenu.

Le 21 matin, Kajata avait eu une arête de poisson à l'oeso. phage. Il avait été passer sa journée à Léalui chez un homme qui fait sa spécialité d'enlever les corps étrangers; niais notre élève était revenu à $5 \mathrm{~h}$. dans le même état. Je l'entrepris alors, et réussis à faire descendre l'arête dans l'estomac, n'ayant pu l'enlever.

Mais le lendemain, comme le point blessé était encore douloureux, Kajata crut que je m'étais trompé. Conduit par Mompisho, il alla à Leikwanywa pour se faire enlever son arête par un docteur indigène. Celui-ci aspira très fortement par l'oreille et prétendit avoir retiré la cause de son mal! Notre jeune homme vint en effet me montrer une arête. Les niais! malgré cela l'état de Kajata alla en empirant. Le 27 à minuit, puis le 28 à $6 \mathrm{~h}$. du matin je le trouvai presque étouffé par un affreux abcès à l'oesophage. L'inflammation ne semblait pas vouloir céder à mes soins. Il alla en empirant tout le jour. Il n'avait plus rien mangé depuis 36 heures, et avait aussi toutà-fait perdu la voix. Enfin le soir l'abcès perça, et à $8 \mathrm{~h}$. nous pûmes lui faire prendre du lait et de l'eau. Dès qu'il fut rétabli, je fis à mon école la description de l'oreille. Ce fut la première leçon d'anatomie. Que de grossières erreurs, même chez nos jeunes gens les plus avancés, et quelle fourberie chez ces docteurs indigènes!

11 aoùt. - J'ai un autre cuisinier. Kaieka était fatigué, puis ses devoirs à la cuisine l'enlevaient trop souvent à l'ẻcole. J'espère avec 
de la patience et de la fermeté former son successeur, un drôle de petit original, $\dot{a}$ la mine éveillée. Je lui enseigne à lire et $\dot{a}$ écrire le matin quand je suis à mon école de jeunes femmes, augmentée ces temps-ci, depuis le départ de Willie, de la $1^{\text {re }}$ classe de l'école de station.

Dans notre tournẻe au village, vendredi, nous sommes entrés dans la cour d'un mo-Toka. À notre apparition la femme s'enfuit effrayée dans la maison. Lui plus sociable nous reçut aimablement. Le jour suivant nous voyons notre homme arriver à la station suivi de sa femme, l'un portant un plat de viande, l'autre un plat de sorgho. "Tu n'as plus peur de nous? dis-je à la femme-Non». Ils nous prẻsentèrent leurs cadeaux et insistèrent jusqu'à ce que nous les eûssions acceptés. «Hier j'ai étẻ trop triste, nous dit l'homme, de ne pas pouvoir vous faire un cadeau de bienvenue, mais je n'avais rien à vous offrir ». Et nos braves gens s'en allèrent tout contents.

Le 19 août $M^{11 e}$ Kiener organisa avec une grande partie des professantes une Union chrétienne. Elle avait déjà institué à la capitale, alternativement chez Nolianga et Mpololoa, une réunion pour femmes païennes, le jeudi après midi; 8 à $10 \mathrm{y}$ assistaient. À la même heure la princesse Navina rassemblait chez elle de 30 à 40 enfants, surtout de ceux qui ne pouvaient fréquenter l'école, et ma femme leur faisait l'école du jeudi. A son école du dimanche le nombre des enfants variait entre 70 et 150 .

En outre les professants de Léalui se réunissaient encore souvent pour la prière au coucher $d u$ soleil. C'est ainsi que nous faisions notre possible pour alimenter la flamme chez les convertis, et pour l'allumer chez les autres. Les classes et tous les autres cultes suivaient naturellement leur cours.

Notre situation actuelle n'est pas gaie. Le roi, bon pour nous, est loin, plus loin que jamais de Dieu, et médite on ne sait quoi pour se venger. Les chefs et officiers sont hostiles à l'Evangile et durs comme des pierres. Demandez que notre foi reste ferme. 


\section{LXXVI.}

Délivrance. - Sinistre. - Démissions.

Enfin des approvisionnements. - Incendie de la station de Nalolo.

Démissions d’évangélistes. - Le parti rétrograde relève la tête.

Arrivée du wagon.

T $\mathbf{E} 20$ septembre Willie fut de retour de Kazungula. Des 1 natifs revenant des mines lui avaient dit que notre expédition de renfort était encore à Lénokaneng. Il nous apporta aussi une lettre d'insultes d'Alita, qui nous fit croire que la pauvre femme était devenue hystérique. Elle avait déjà eu plusieurs crises nerveuses depuis la mort de son mari.

Le 21 ce fut fête chez nous. À $8 \mathrm{~h}$. du soir il nous arriva enfin 3 caisses : une petite de lait condensé (amenée à Kazungula par le tombereau), une caisse de provisions contenant des viandes conservées, du vermicelli, du macaroni! toutes choses dont nous avions oublié le goût. Nous n'en serons donc plus réduits aux patates le matin, à midi et le soir! C'était le commencement de la délivrance. Il y avait aussi une caisse de pétrole. La lumière nous est assurée pour les veillées de bien des mois! Quel luxe! Le tour des vêtements et des objets d'échange viendra.

Mais comment payer les rameurs? J'allai demander conseil à Lewanika. Il sympathisa avec nous et me dit de promettre le paiement. Afin que les pagayeurs ne fîssent aucune difficulté, il me donna un garçon avec un message pour eux.

Le 26, Lewanika nous fit l'agréable surprise de venir déjeuner chez nous à $7 \mathrm{~h}$. du matin, afin de devancer le vent. Il goûta alors pour la première fois du lait frais. Nous eûmes plus de 400 personnes au culte, dont seulement 95 femmes.

Le 28 nous reçûmes une pressante invitation des Béguin à aller, M. ${ }^{\text {lle }}$ Kiener et nous, passer quelques jours chez eux. Nous acceptâmes avec plaisir, car nous sentions le besoin d'un peu de repos, loin du théâtre de nos travaux et de nos luttes.

Le 29 entre la prière et la classe de catéchumènes, un billet 
de M. Béguin nous apprend que la station de Nalolo est en cendres depuis le 27 au soir! Et dix heures après nous voyons arriver nos amis dans le tombereau que j'avais envoyé à leur rencontre! Pauvres amis, quel dénuement que le leur, et quelle perspective pour M. Béguin qui croyait en avoir fini avec les travaux de construction! Et cependant ils ne se plaignaient pas, leur entrain nous édifiait.

Le 30, Lewanika vint tout exprès pour leur exprimer sa sympathie.

Le 4 octobre, Willie nous donna sa démission pour fin novembre, mais sans la motiver; c'est par le roi et Mokamba que nous apprîmes qu'il pensait devenir interprète du roi. Trois jours après Yakobo vint me dire qu'il quittait la mission, voulant retourner au Lessouto dès la fin du mois, à cause des deuils de Borea (dont la mère et un frère venaient de mourir) et de leur fatigue.

Le 5, un courrier d'Europe nous apporta les premières lettres de condoléance de nos parents et amis. Nous apprîmes aussi la triste nouvelle du retour à Palapye du renfort que nous avions si longuement attendu, ainsi que l'assassinat de M. Minault et de mon cher Escande. M. Béguin repartit pour commencer le déblaiement de sa station.

Le 7, Lewanika demanda à ses chefs et officiers de formuler certaines lois qui avaient été en vigueur depuis deux ou trois ans, surtout celles sur l'adultère et les boissons enivrantes. II voulait les faire sanctionner par le résident le plus tôt possible. Mais tous, sauf huit, furent d'avis de réclamer le droit de fabriquer et de boire ces boissons fortes, et d'abolir la prison pour les adultères; une amende aurait suffi. Le parti rétrograde relevait la tête.

Le 12, il nous fallut faire un dernier marché avec le dernier objet d'échange qui nous restât, et pétrir notre dernier litre de farine.

Le 15 soir, le wagon arriva Quel soulagement pour nous tous et particulièrement pour la maîtresse de maison. Comme nous fùmes reconnaissants que Dieu nous eût fait parvenir ce secours! Du blé, de la farine, des légumes, du sucre... quelle richesse. Mais il nous manquait encore bien des choses qui nous semblaient nécessaires: les objets d'échange, les vêtements des élèves évangélistes, café, riz, chapeaux, chaussures, et tous mes 


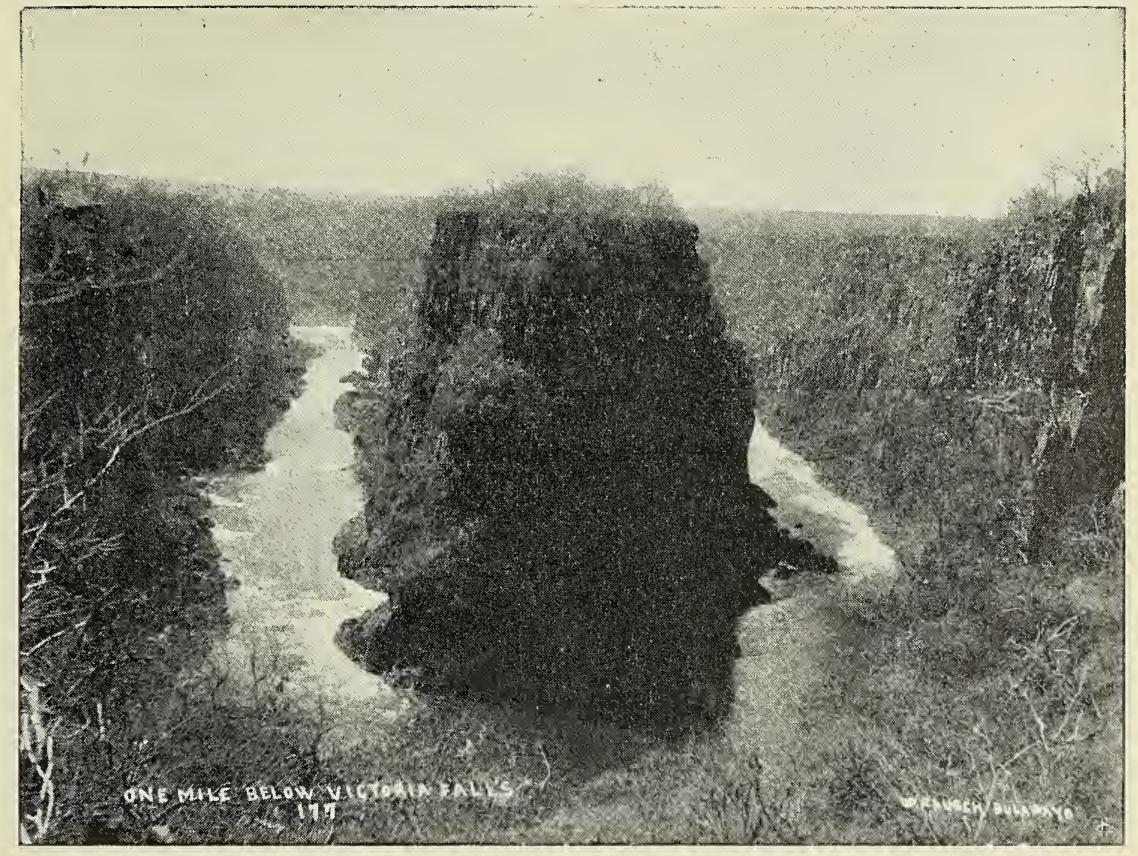

Brusque tournant du Zambèze à environ $2000 \mathrm{~m}$. en aval des chntes lictoria. 

vêtements, sauf une paire de pantalons et un habit. Heureusement que M. Béguin put me prêter 5 pièces de calicot (de 36 yards).

\title{
LXXVII.
}

Etablissement du Protectorat Britannique.

\begin{abstract}
Arrivéc du Résident Britannique. - Entrevues préliminaires. Déclaration et acceptation du protectorat. - Les déçus.
\end{abstract}

T 19 octobre Lewanika dîna avec nous. Litia et le Rési$\checkmark$ dent Britannique vinrent camper à 45 minutes de la station.

Le 20 dès $7.30 \mathrm{~h}$. ils arrivent à la passerelle. Nous allons les y saluer, M. Béguin et moi. Le Major Coryndon, son secrétaire et son escorte de cinq hommes étaient en petite tenue militaire, mais sans armes. On ne les avait pas attendus de si bonne heure. Cependant les femmes viennent bientôt en foule, accompagnant leur salut des cris saccadés de rigueur en pareilles circonstances. Les hommes n'arrivent que plus tard en 7 régiments compacts, 3 d'un côté de la chaussée et 4 de l'autre. Le Ngambela et les principaux chefs marchent sur la chaussée, Litia et le résident les attendent à la passerelle, assis. Il devait $\mathrm{y}$ avoir près de 10.000 personnes.

Quand on a fini de saluer, nous nous acheminons vers la capitale. Le roi siège au Khotla, ayant à sa droite tout ce qu'il a pu rassembler de vieillards, une quarantaine d'hommes à cheveux gris, et à gauche, mais à une certaine distance, les hommes et jeunes gens attachés au service de sa maison. Il nous fait asseoir à côté de lui et souhaite la bienvenue au résident. Les régiments arrivent l'un après l'autre, défilent et font la saIutation royale. Ils terminent la cérémonie par un salut général.

Nous nous rendons alors au Kashandi, de part et d'autre on exprime la joie de s'être rencontrés.

Peu après $11 \mathrm{~h}$. nous quittons le Roi et conduisons chez nous le major Coryndon et M. Worthington son secrétaire, pour le 
dîner. Nous jouîmes de faire leur connaissance. Ils nous dirent qu'ils espéraient nous aider, adopter nos prix pour les marchés des indigènes, et nous promirent la poste mensuelle.

Le 21, Mokwae arriva dans toute sa pompe.

Le 22, nouvelle entrevue avec le roi. Je sers de nouveau d'in. terprète. Lewanika prétendit ne pas croire que le major Coryndon fût le représentant du gouvernement britannique, mais seulement celui de la B. S. A. C. C. Le résident le quitta fâché. Venir si loin pour être l'objet de tels doutes! Je réussis à les réconcilier.

Le 25 fut le grand jour de la déclaration explicite et de l'acceptation du Protectorat Britannique sur le pays de Lewanika. Le major Coryndon me pria de remplacer encore une tois son interprète. Nous trouvâmes le roi dans la maison du Khotla, où il avait fait apporter des chaises et des tabourets pour nous et les évangélistes. M. Béguin était aussi présent.

En vrai militaire, le résident parla simplement, allant droit au but. Il dit qu'il était cet envoyé de la Reine qu'ils araient réclamé à bien des reprises, et le représentant de.la B. S. A. C. C. à laquelle une concession avait été accordée sept ans auparavant. Sa mission c'est d'aider le roi par ses conseils, de veiller à ce que la concession soit observée, de faciliter les rapports du roi avec les étrangers qui vont venir. Par lui le pays de Lewanika est définitivement déclaré Protectorat Britannique. Cependant il n'est pas venu se mêler des rapports du roi et de ses sujets, ni de leurs petites affaires. Le pays continue à appartenir au roi, il n'a été acheté par personne. Sa mission est toute pacifique, pour le prouver il n'a amené qu'une petite escorte.

J'interprétai phrase par phrase pour les principaux chefs et officiers assemblés dans la maison; ensuite Yakobo fit le résumé du discours pour les foules accroupies sur la place. (Nous sûmes alors qu'il avait renoncé à partir pour le Lessouto, et qu'il était devenu l'interprète du roi).

Lewanika chargea encore le Ngambela de Nalolo de répéter les points principaux au peuple. Mais celui-ci se contenta de dire à peu près ceci: "Voici la substance de ce qui a été dit: Rien n'est changé à nos mœurs ni à nos lcis. Vous êtes encore nos esclaves, vous nous devez encore obéissance, et malheur à qui regimbe! » 
Quatre des principaux chefs remercièrent ensuite le résident pour ses paroles. C'était justement ce qu'ils désiraient. Le roi approuva et ajouta qu'il ne lui manquait qu'une lettre répétant les mêmes choses. Alors le major Coryndon la lui présenta. Yakobo la traduisit.

Semonja fut chargé de dire à la foule: «Vous vous êtes assemblés à la capitale sur l'ordre du roi, vous avez bien fait. Vous pouvez maintenant rentrer chez vous. Vous avez entendu la parole du résident, vous continuez à être nos sujets \%. Nalishua l'appuya. Sur ce, toute la foule se lève, salue à plusieurs reprises et se disperse. Nous ne tardons pas à imiter son exemple.

Quelles seront les conséquences de cette journée? Elles seront probablement grandes; mais cette séance en a déçu plusieurs. Là sur la place du Khotla des milliers d'esclaves avaient attendu la proclamation de leur émancipation, d'autres milliers plus nombreux en attendaient la nouvelle aux quatre coins du pays... Non, ce bienfait ils ne pouvaient l'obtenir si facilement, cela viendra par évolution, et l'Evangile en sera probablement le plus puissant agent.

Yakobo étant devenu l'interprète du roi, Willie retira sa démission.

\section{LXXVIII.}

L'épidémie d'influenza et ses fruits.

Plaie saignante. - L'infiuenza à Lwatile et au palais.

Retraite salutaire. - Misères navrantes à Léalui. - Dareté de cœur. Itecruflescence de paganisme. - Sefula en soumrance. - Malades à la Résidence.

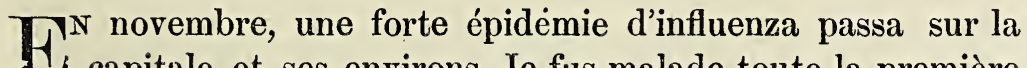
capitale et ses environs. Je fus malade toute la première moitié du mois.

10 Novembre. - Aujourd'hui nos amis Bẻguin nous ont quittés pour retourner sur leur station desolée. Ils vont occuper l'établissement de Yakobo. La petite Eglantine avait pris elle une large 
place dans nos affections. Elle nous prodiguait ses jolis sourires. Voilà huit jours que mon mari a presque toujours la fièvre. Aujourd'hui il se sent moins bien que jamais. Levé tôt pour dire adieu à nos amis, il a dû s'aliter tout de suite après leur départ. La fièvre m'effraie doublement depuis qu'elle nous a enlevẻ notre précieux enfant!

Avant que je fûsses bien rétabli, je dus m'installer au chevet de ma femme, tombée malade à son tour. Ensuite ce fut le tour de $\mathrm{M}^{\text {lle }}$ Kiener.

À la capitale plusieurs en moururent. Le roi fut aussi gravement malade et on fut inquiet à son sujet quelques jours. Le 22, j'eus le privilège d'être admis auprès de lui, privilège qui n'était accordé qu'au Ngambela et à trois ou quatre officiers. Il était accroupi sur une natte, dans un endroit si abrité, que je m'y sentais étouffer. Mais c'est ce qu'il aime, que pas un souffle d'air n'arrive jusqu'à lui. Enfin le 26, quand pour la première fois il put se représenter au Khotla, toute la population masculine de Léalui l'accueillit avec des acclamations de joie.

Sur la station personne n'échappa à l'épidémie, ni enfant. ni adulte. Ce temps de retraite forcée nous fit du bien. Il est nécessaire de rentrer en soi-même de temps en temps, et de se retremper dans la communion du Sauveur, loin de tout bruit. Mais ce qu'il y a de pénible c'est de sentir que tout le poids de l'œuvre retombe sur ceux avec lesquels on le partage habituellement. Il y a tant à faire que dans ces cas on ne peut suffire à tout. Notre tâche fut compliquée par la distribution de médecines à 20 ou 30 personnes par jour, tant il y avait de malades.

Que de souffrances à la capitale! Nous aurions voulu donner des secours aux abandonnés, mais notre grenier était souvent vide. Les misères que nous pouvons contempler nous navrent. Ici c'est un pauvre enfant brûlant de fièvre et altéré, dont personne ne s'occupe, là c'est une vieille femme dont on dit en riant: "Elle se meurt ». Dans toutes les cours ce ne sont que corps étendus, haletants, enfants, hommes et femmes, toussant, fiévreux, quelques-uns souffrant la faim. Les symptômes ne sont pas les mêmes chez tous: points de côté, maux de tête, de gorge, de poitrine, saignements de nez ou crachements de sang. Et au dessus de toute cette misère, il y a le gros point noir, l'égoïsme des grands, leur froide indiffé- 
rence, leur rebutante dureté. Un jour, on emportait pour le «jeter » (lisez: ensevelir), un jeune garçon mourant. Craignant qu'il n'expirât dans une cour dépendant du harem royal, on se hâtait de s'en débarrasser. Un de nos professants aperçut le cortège et le corps où demeurait un reste de vie. Il s'opposa à ce que l'horrible dessein fût accompli jusqu'au bout. Comment nos Zambéziens en sont-ils encore là après tant d'années d'évangélisation?

Nous avions beaucoup demandé à Dieu que cette épreuve contribuât à l'avancement de son règne, mais nous dûmes constater une nouvelle recrudescence du paganisme avec railleries et sarcasme redoublés. Paurres aveugles pour lesquels tout est occasion de chute! Santé et maladie, abondance et disette, tout semble les éloigner de Dieu.

La station de Sefula se délabrait de plus en plus. Je dus y envoyer le wagon et faire amener à Loatile tout ce qui aurait pu être enfoui sous les ruines. Pauvre Sefula! Il perdit encore la brave Mamwendarubi que le roi enleva aux tracasseries de son maître Langwalala. Lewanika l'affranchit et l'appela a Léa. lui, afin qu'elle élevât une de ses filles, la gentille princesse Wabei. Notre œuvre profita de cette bonne acquisition.

Nous eûmes dans le résident un très agréable voisin. Elles furent fréquentes les occasions de nous rendre des services réciproques très appréciés. L'établissement que le roi lui avait préparé était à environ 1,500 mètres au sud de la station, de sorte que nous étions à mi-chemin entre la «Résidence»et la capitale. Cependant il ne pouvait y rester longtemps à cause de l'inondation. Il choisit Mongu, cette espèce de promontoire s'avançant dans la plaine, que Livingstone puis les jésuites avaient considéré comme propre à l'établissement d'une station. Le major Coryndon s'y fit bâtir une grande maison. Cela devint la vraie 《Résidence \%. Il craignait beaucoup la plaine. Il avait déjà eu de graves cas de fièvre parmi sa suite et le 26 novembre, un de ses soldats était atteint de la même maladie que d'autres blancs avant eux avaient eue à des degrés divers (perte de connaissance, mouvements désordonnés suivis d'hallucinations, et enfin une longue période de faiblesse). Chose étrange, ce ne fut qu'alors que nous apprîmes qu'il y avait eu des cas semblables parmi les natifs, entr'autres un jeune chef dont la guérison était considérée comme un miracle opéré par nos médecines. 


\section{LXXIX.}

\section{Nos fêtes}

Travaux et joics en commun.

Les nouveaux nons. - Baptêmes d'aduites. - Mouvenent parmi les cnfants.

Trois espèces de blanes. - Secomrs avariés.

Tous eûmes de nouveau le plaisir de posséder les Béguin

1 pour les fêtes, et de nous les adjoindre pour les examens de nos diverses écoles. Nous eûmes encore le mariage d'un élève évangéliste, Salwendo, avec Lumba, una jeune professante élevée par les Willie. Par des cadeaux nous associâmes nos maisonnées à la joie de nos fêtes. Des élèves évangélistes allèrent remplacer $M$. Béguin à Nalolo pour les cultes de Noël et du dernier dimanche de l'année. Les progrès de mes jeunes gens furent moins sensibles qu'ils ne l'avaient été la première année. C'était naturel. Alors on avait constaté un grand saut en avant, de l'école de station à l'école d'évangélistes, ils ne pouvaient guère que maintenir leur avance.

Un évènement important vint nous réjouir, évènement auquel nos élèves evangélistes tenaient à assister: Le baptême de quatre adultes. Le seul qui en̂t été administré au Zambèze, avait été celui d'Andrease à Sefula en 1890. Presqu'aucun de nos professant actuels n'y avait été présent.

Les candidats étaient: Nolianga, qui choisit le nom d'Elizabetha, et trois élèves évangélistes : Selwendo, Sesoaïra et $\mathrm{Mpu}-$ tutu, que nous appellerons désormais: Samuele, Pauluse et Gideone.

Au point de vue zambézien l'admission dans l'église par le baptême exige un nouveau nom. Le passage d'un âge à l'autre, d'un état à un autre, d'un maître à un autre, est toujours marqué par un nouveau nom. On nous a souvent demandé pourquoi nous n'observons pas cette coutume à l'égard des enfants et des ouvriers qui entrent chez nous.

Nous avions examiné les candidats avec l'assistance de ces dames, des évangélistes Willie et Pauluse Kaneli. J'avais com- 
posé la liturgie le 5, et avais lu aux intéressés les promesses que j'allais leur demander de faire.

Les baptêmes se firent le 6 janvier 1898 devant une assemblée assez nombreuse. $\Lambda$ près la partie liturgique proprement dite, les promesses et le baptême, je serre la main à chacun de ces nouveaux membres de l'église, l'appelant par son nouveau nom, disant à chacun un mot d'exhortation. Je leur adresse encore quelques paroles de l'estrade et invite M. Béguin, Pauluse et Willie, à en faire de même. Le tout intercalé de beaux cantiques d'occasion, dura environ deux heures. Nous offrîmes enfin une agape aux baptisés. Ces baptêmes furent le point culminant de nos fêtes.

M. Béguin repartit seul pour Nalolo le 7 , nous laissant Madame et ses deux fillettes.

19 JANVIER 1898. - Notre œuvre, qu'en dire? Les cœurs sont encore rebelles. Cependant il s'est produit parmi les enfants un mouvement qui nous encourage, et pour lequel nous remercions Dieu. Nous en avons une vingtaine qui disent vouloir servir le Seigneur, et bien que ce désir soit parfois vague, nous ne les repoussons pas ces «petits» que Jésus aime. Mon mari leur défend en gènéral de faire une déclaration publique. On les reçoit dans les classes et aux cultes. Nous nous efforçons d'éclairer leurs consciences, et de leur donner une idée plus précise de ce qu'est le Sauveur, et de ce qu'Il attend de ceux qui se disent ses serviteurs.

Un des employés du résident avait porté plainte contre quelques-uns des pagayeurs que le roi lui avait procurés. $\grave{A}$ re propos Lewanika dit aux gens assemblés au Khotla: «Il y a trois espèces de blancs, ceux du gouvernement, les marchands et les missionnaires. Ceux du gouvernement, craignez-les, ils ont le pouvoir; les marchands, mangez-les, car ils sont venus pour vous manger. Quant aux missionnaires, ils sont des nôtres, ils sont de chez nous》. Le roi exprima ainsi sa confiance en nous, et le devoir de nous traiter comme des amis.

Le 24 janvier il nous arrive quatre canots chargés de nos effets. Quelle tristesse de voir que toutes les caisses sont mouillées et de constater que tout le contenu est trempé; nous devons jeter bien des choses complètement avariées, et d'autres, surtout des objets d'échange, ont perdu la moitié de leur valeur. Et ce sont des objets pour lesquels nous avons payé un 
transport excessif (à raison de 2,80 fr. le kilogr.), de Mafeking à Kazungula. Cependant ce fut un secours dont nous fûmes reconnaissants.

\section{LXXX.}

Naissance de notre second enfant.

T $\mathrm{E} 6$ février, un dimanche, nons reçûmes avec bonheur no1 tre petite Graziella (un témoignage de la grâce de Dieu), oisillon qui venait égayer le nid resté vide depuis 10 mois et demi.

Le résident et son secrétaire, le roi, les évangélistes et quelques professants, s'empressèrent de nous envoyer leurs félicitations, quelques-unes accompagnées de cadeaux.

Pauvre petite Graziella, pendant de longs mois nous pûmes dire d'elle: «L'homme naît pour souffrir, comme l'étincelle pour voler. 》 M. ${ }^{e}$ Béguin resta avec nous jusqu'au 19 février.

Les élèves evangélistes et leurs femmes furent aussi très heureux de voir notre enfant, lorsqu'ils rentrèrent, les uns après les autres. L'amour pour les enfants est un des beaux traits de caractère des Zambéziens.

J'ai fait plusieurs visites à Léalui avec bébè. La vieille mère du roi (Ma-Rhosé) nous reçut avec enthousiasme. Une autre fois nous lui apportâmes ce qu'on appelle ici une couverture de jour, c'est un châle léger fait de mouchoirs aux brillantes couleurs, que les ma-Rotsé hommes et femmes aiment beaucoup. La bonne vieille n'en détachait pas les yeux, se demandant si après tout ce ne serait pas pour elle, aussi me hâtai-je de lui en faire hommage. Elle nous en exprima sa reconnaissance en disant à plusieurs reprises: Que le bébé vive longtemps, qu'il vive longtemps! et elle lui faisait ses plus doux sourires. Pauvre vieille femme, elle a su apprécier la toile et les mouchoirs des blancs, leur thé et leur sucre... mais elle n'a pas accepté l'Evangile. Lorsque nous lui parlons des cultes où elle n'est jamais venue, elle montre piteusement ses jambes, qui pourtant savent bien la porter aux champs, quand elle veut $y$ aller diriger sa bande de piocheuses.

Puis nous passons au harem royal, chez la grosse Longa à la 
face réjouie et aux grands éclats de rire; chez Ma-Morambwa aimable et accueillante, mais prête à vous parler de sa maladie chronique, et de son fils épileptique, si vous l'exhortez à regarder à Dieu. Nous allons ensuite voir Ma-Sanana, aux longues dents déchaussées, qui s'absorbe dans la contemplation de Graziella pour nous fermer la bouche; Maondo, la petite mijorée dont les airs affectés et langoureux semblent déplacés dans ce pays; j'avais cru que ces défauts-lá étaient le produit exclusif de la civilisation. Puis Matondo, une belle femme, jadis bien disposée et qui vient d'être très malade. «C'est Dieu qui t'a rendue à la vie, dit mon mari».«Oui, je le sais, c'est lui qui fait vivre et mourir», mais sa tête n'en est pas moins couverte de médecines et d'amulettes. Ces femmes du roi ne veulent pas se convertir, et elles s'y prennent de la bonne manière pour ne pas laisser la bonne semence tomber dans leurs cœurs, elles passent des mois entiers sans mettre le pied à la chapelle.

Le 18 mars, Sekota, un des serviteurs de confiance du roi (venu avec lui en Europe), nous amena une fillette d'environ 12 ans et nous l'offrit comme petite bonne pour bébé.

\section{LXXXI.}

\section{L'œuvre pendant l'inondation de 1898.}

zires de Nanjeke. - Mevanche de Mosonguandungu. -- Emotion donnée au roi. Triste anniversaire. - Correspondance. - Evangélisation.

communion. - Infanticide. - Professions encouragées par Lewanika.

CAUF Nyondo qui prit cinq mois de vacance, nos chers Loa$\$$ tiliens revinrent tous avec une nouvelle collection de faits intéressants, et un nouvel entrain pour leurs études.

Nanjeke avait passé ses vacances chez des parents, et y avait été malade. C'est en de telles occasions que plusieurs de nos professants ont renié leur foi. Elle refusa de participer à toute pratique superstiticuse. On persista à jeter les osselets divinatoires, on le fit loin d'elle, et on vint lui annoncer que les fourmis guerrières l'avaient rendue malade. Elle qui n'en avait plus 
été mordue depuis des années, accueillit cette déclaration avec des éclats de rire, dont nous eûmes les échos quand elle nous raconta la chose. Elle hâta son retour chez nous pour accélérer sa guérison.

Le roi qui est toujours à la recherche de quelque chose de nouveau, et aussi toujours désireux de faire des progrès, avait fait construire denx Nalikwanda au lieu d'une: une selon l'ancienne coutume avec des planches unies les unes aux autres par des 《coutures 》 et des bourrelets semblables à ceux qu'on fait pour réparer les canots. L'autre, plus grande, est formée de planches unies par de très longs clous: les fissures en sont bouchées avec de la résine. Son pavillon était recouvert d'un éléphant de grandeur naturelle, très bien réussi, entouré d'une gaze bleu-clair que je lui avais donnée pour cet objet.

La veille du départ pour les Mafulo, je fis demander au roi si $\mathrm{M}^{\mathrm{lle}}$ Kiener et ma femme pouvaient aller voir ses grandes barques de près. Nous trouvâmes Lewanika sur l'emplacement. Quel ne fut pas son effroi, quand il vit nos dames s'apprêter à aborder! Il prétendit qu'elles ne sauraient où poser les pieds, a cause de la boue. Je compris et essayai de les retenir, mais Moka dit: «Elles marcheront en choisissant leurs pas, mon père 》. Nous mîmes tous pied à terre, nous approchant de la Nalikwanda sacrée, qu'aucune femme n'est admise à voir de près, tant qu'elle n'a pas servi. Tremblant, sans doute, que nos dames ne poussassent l'audace jusqu'à demander d'entrer, Lewanika s'éloigna de nous et se donna l'air très affairé. Il parut profondément soulagé quand nous reprîmes place dans le canot, et nous dit: «Ah! oui, allez vite, il fait froid pour cet enfant 》.

Le lendemain il passa chez nous en partant, et dîna avec nous pendant que les Nalikwanda se poursuivaient escortées et suivies de centaines de canots. Nous restâmes longtemps avec lui sous la vẻrandah, admirant ce joli spectacle, lui enchanté, ravi, rayonnant comme un enfant. Il mangea peu, il était tout excité et fatigué, car il nous dit avoir étẻ le premier debout le matin, pour donner le branle à toute son escorte. Nous lui rendîmes bientôt sa liberté et il entra dans son petit canot, que six rameurs firent rapidement glisser à la poursuite des Nalikwanda.

Voilà un an que notre petit Giulio s'envolait. Comme tous les détails de ces jours d'angoisse, de ces dernières heures déchirantes 
de lutte avec Dieu, remontent à nos cœurs, mais sans amertume! Notre enfant est heureux auprès du Sauveur, il y a èté porté avant que les souillures de la terre aient pu flétrir sa petite âme, et lá il chante les louanges de l'Agneau en nous attendant, en sètonnant peut-être que nous versions encore des pleurs en regardant sa place vide. L'enfant que Dieu nous a donné a sa place bien distincte dans notre cour. Elle n'a pas pris celle de son frère.

Je ne puis me rẻsoudre à confier Graziella aux domestiques. Un bẻbẻ est trop précieux poür qu'on le donne à n'importe qui, et on le possède parfois pour si peu de temps!

Si dans les mains de Dieu notre correspondance peut aider a l'avancement de son règne, ce sera pour nous un grand sujet de reconnaissance... Si l'on savait la peine que nous avons souvent $\dot{a}$ trouver une heure de tranquillité à passer à notre table à écrire! Mon mari est toujours très occupé, plus occupé que je ne saurais le dire, avec ses tâches multiples et complexes.

Avec la collaboration habituelle de Willie, et l'aide des élèves évangélistes, nous pûmes chaque dimanche avoir des services sur la station, aux Mafulo, et même au campement de chasse du roi. Nous fîmes aussi plusieurs services sur semaine dans les villages environnants. Léalui ne fut pas négligé. Nous y fîmes de fréquentes visites, $M^{\text {lle }}$ Kiener y continua ses réunions du jeudi, et ma femme y rassembla les enfants tous les mercredis.

Le vendredi saint (8 avril) après avoir eu dans la maison du Khotla un culte pour 180 personnes (surtout des femmes), nous allâmes l'après midi en famille à Lirundu, le célèbre tombeau de Morambwa, grand père de Lewanika. Nous y assemblâmes une cinquantaine de femmes et quelques hoinmes.

Nous eûmes la sainte cène à Pâques (1890) et y admîmes les quatre membres d'église baptisés le 6 janvier. Norea, Mpololoa et Nawina vinrent exprès des Mafulo pour y assister. Ensuite nous les eûmes tous à notre table avec Willie et Ernestina, pour leur montrer qu'en effet nous avons communion les uns avec les autres.

À Likwangwa, tombeau royal entouré d'un petit village, que je visitai avec quatre de mes élèves, le 15 avril, je trouvai un enfant dont les incisives supérieures avaient poussé avant les inférieures. Son père, désireux de le soustraire au sort terrible qui attend de tels enfants, l'avait caché pendant huit ans. Mais 
un ennemi dénonça la chose à Kalonga, prétendant que cet enfant était la cause des maladies et des morts survenues dans le village. Willie présent intercède et demande que l'enfant soit élevé sur la station missionnaire. On lui dit que ce n'est pas nécessaire, le petit sera sauf à cause de son intercession. Quand je vis le père, je lui dis de nous amener quand même son enfant, le plus tôt possible. Hélas! quelques jours plus tard, le pauvre père désolé venait nous annọncer qu'on avait jeté son garçon au lac, après l'avoir étranglé. Sort qu'il aurait dû subir huit ans auparavant, car c'était une victime, ou un sacrifice réclamé par les mânes de céans.

Le 26 avril 1898 nous arriva enfin la première poste 《 via Bulawayo 》, longtemps attendue. Ce n'était encore rien de merveilleux, la lettre la plus récente d'Europe était datée du 31 décembre 1897 ! mais c'était le commencement, et il y avait lieu d'espérer que désormais notre poste mensuelle était établie. Il nous manquait encore toutes les lettres de septembre et d'octobre.

Nour apprîmes que le Capitaine Lawley, l'administrateur de la Rhodesia, avait quitté Bulawayo pour venir s'aboucher avec Lewanika au sujet de la Convention qu'on voulait modifier. Comme il ne comptait pas venir plus loin que les Chutes Victoria, il priait le roi d'aller l'y rencontrer.

Le 29, deux femmes préposées à la grande dépendance royale de Moshukula, femmes que nous savions travaillées dans leur's consciences, vinrent me parler de leur conversion. Elles avaient fait informer le roi de leur désir de déclarer publiquement leur foi. Il leur avait répondu par lettre: «Déclarez-vous, mais faites-le d'un cœur sincère et tenez bon. J'aime qu'on se convertisse, ce que je n'aime pas c'est qu'on revienne en arrière 》. Ce brave Lewanika était toujours le même, exerçant une influence tantôt salutaire tantôt pernicieuse. Il n'avait pas séjourné aux Mafulo, mais avait été pour des semaines à la grande chasse, dans la vallée du Luena. (Les ma-Rotsé ne retournent jamais chasser dans la même région avant trois ou quatre ans). De là il avait maintenu de très bons rapports épistolaires avec nous, et nous avait envoyé de temps en temps du produit de sa chasse. Il y avait très bien accueilli Willie, un dimanche, et lui avait fait avoir près d'un millier d'auditeurs.

Le $1^{\text {er }}$ mai, après la prédication, et comme en réponse au 
chœur: «Qui est pour le Seigneur? 》 Makatete (ou Liapabeng) dit: «Ah! je me rends, il y a longtemps que je résiste, maintenant je suis convaincue. Je me confie à Jésus qui effacera tous mes péchés $》$. C'est une femme que l'on reconnait facilement comme une mo-Kololo, à son teint clair et à son bon sessouto. Makabeta, sa compagne, se lève ensuite: «Ce sont les mêmes choses qui me poussent à me lever. Je suis vieille, que demanderais-je encore au monde? »

\section{LXXXII.}

Grave maladie de Graziella.

\footnotetext{
Une syncope. - Départ pour Mongu. - Chez Lewanika aux Mafulo. Une bonne réponse pour M. Davit. Vacances abrégées. - Un serpent dans la chambre à coucher.
}

TOTRE chère enfant eut cinq accès de fièvre tierce du $\tau$

1 au 16 avril. Même quand l'attaque fut terminée, elle eut peu d'appétit, des sommeils agités la nuit, presque pas de repos le jour; elle tressautait au moindre bruit. Nous étions inquiets.

Le 21 avril, peu après le lever du soleil, la petite poussa un cri; bientôt ses traits s'altèrent, elle devient blême, ses yeux se fixent... je tiens un corps inerte. Oh l'angoisse de ces minutes! Cependant je me dis que c'était peut-être une syncope. Je portai notre enfant au grand air, mais inutilement; nous la frictionnons tout en criant au Seigneur. Elle se mit bientôt à pleurer. Quelle musique à notre oreille! $M^{\text {lle }}$ Kiener était survenue et en un instant notre maisonnée ahurie et affligée avait entendu la terrible nouvelle, bientôt démentie par les cris même de Graziella. En quelques minutes $M^{\text {lle }}$ Kiener et nos jeunes gens avaient preparé un bain chaud, qui sembla aussi contribuer ì faire du bien à notre ressuscitée. Peu à peu ses traits reprirent leur expression habituelle et la chérie nous faisait de délicieux sourires une heure après l'accident.

La matinée fut assez bonne; mais vers midi elle eut en moins 
d'une heure trois demi syncopes. Cette fois encore Dieu nous exauça. Nous comprîmes que le lait condensé ne convenait pas à notre enfant. Nous essayâmes du lait frais bouilli. Depuis lors elle reprit ses forces d'une façon étonnante.

Dieu a eu pitiẻ de nous. Il nous a épargné un nouveau déchirement, que son nom soit béni! et que notre foi, mise à une si rude épreuve, en soit fortifiée. Que lui rendrons nous pour ce bienfait? Dieu qui a pris l'enfant fort et prospère, peut conserver à ses parents la délicate petite créature qui fait leur bonheur...

Un esprit de douceur, de travail et de soumission plane sur tout notre personnel. La femme de Gideone s'est convertie.

Nous pensâmes qu'un changement d'air ferait du bien à notre petite. Moi-même j'étais peu bien depuis des semaines; je continuais à vaquer à mes multiples devoirs, mais javais un peu de fièvre toutes les nuits, et une lassitude qui ne m'était pas habituelle. Le Major Coryndon, avant de partir pour le Bas, nous avait pressés de faire un séjour dans sa résidence. Nous en écrivîmes à son secrétaire M. Worthington, qui nous offrit aussitôt sa propre chambre.

LE 3 MAI à 8 h. nous nous embarquons, mon mari, Graziella et moi, et à $9,30 \mathrm{~h}$. nous abordons an pied de la colline de Mongu. M. Worthington nous y reçoit et m'offre de me faire porter, mais j'aime mieux marcher. C'est une rude affaire sur ce sable noir et profond. La résidence et ses alentours offrent un charmant coup d'œil. La maison est mise toute entière à notre disposition et nous nous y installons. Il y a longtemps que nous n'avons pas respiré d'air aussi frais et pur.

Sachant que je désirais voir le roi le plus tôt possible, mes élèves, qui étaient retournés à Loatile l'après-midi, et y avaient entendu les tambours annonçant le retour du monarque aux Mafulo, revinrent le soir même, afin de m'y amener.

Le lendemain je m'y rendis en effet avec M. Worthington. Nous y abordâmes vers 9,30 h., au moment où le roi se rendait au Khotla. La place était toute noire de gens; après un quart d'heure Lewanika nous introduit chez lui. Nous le trouvons tout décidé à répondre à l'invitation du Capitaine Lawley. M. Worthington lui parle de prolonger son voyage jusqu'en Angleterre. Apprenant que nous devons descendre à Kazungula 


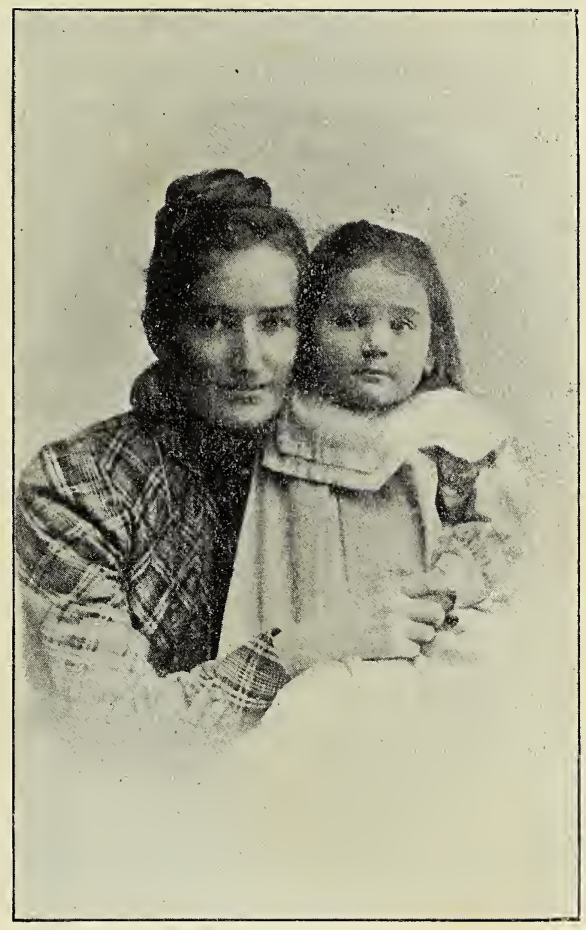

Madame E. Jalla et Graziella. 

pour y rencontrer mon frère et $\mathrm{y}$ avoir la conférence, il me promet un grand canot pour ma femme.

Nous fûmes de retour à la Résidence à 5 heures.

Le lait que nous avions à Mongu ne convenait pas à Graziella. En plus les moustiques la dévoraient. Nous nous demandions s'il ne valait pas mieux rentrer chez nous. Nous avions fait les plus beaux projets pour ces journées de repos. Nous désirions les consacrer à la préparation des cours, à des lectures et à la correspondance. Mais la santé de la chère petite devait passer avant le reste.

$\mathrm{Au}$ moment où nous commençons à faire notre culte, j'entends un souffle puissant, et je m'écrie toute épouvantée: «Qu'est-ce que c'est? » Je commence à me rassurer quand le souffle reprend plus fort et plus continu. C'est un serpent, sans doute. Pendant que ja cours appeler nos garçons, mon mari cherche l'animal, mais la chambre est encombrée, et toute tapissée de nattes. Je rentre avec Kajata, Kaieka et Kwalela avant qu'il ait rien découvert. Enfin entre une des cloisons et la natte on aperçoit le reptile. « Misisi, me crie Kajata, c'est un mauvais, prends bébé et sors! J'arrache de son berceau ma fillette qui dort tranquillement, je l'enveloppe et je me précipite sur la vérandah. La chasse fut longue et difficile, l'animal dressait sa tête à un mètre du sol, menaçant ceux qui le persécutaient de ses crocs envenimés. On parvint enfin à le transpercer d'un coup de lance. Quand il fut achevé, on le porta dehors.... c'était un monstre de deux mètres de long!... quelle délivrance!

Le lendemain matin, avant de partir, M. Worthington me fait admirer le jardin potager contenant une variété de légumes inouie pour ce pays.

Notre brusque retour à la station surprit tout le monde, surtout $\mathrm{M}^{1 \mathrm{He}}$ Kiener. Nous trouvâmes notre maison sens dessus dessous pour le crèpissage, qu'on voulait faire en notre absence. Ces sortes de rẻparations indispensables et si fréquentes sont une rraie épreure pour les maîtresses de maison au Zambèze. 


\section{LXXXIII.}

Fragments de notre journal.

M.Ile Kỉner soufrante. - Départ du roi pour Mosi-wa-thnuya.

La fidèle Mamwendarubi. - Des livres.

Dien pourvoit à nos besoins. - Epreuves chez les Pauluse.

Tous réussîmes à décider $\mathrm{M}^{\text {lle }}$ Kiener à descendre aussi

1 à Kazungula, prévoyant la possibilité d'un retour en Europe. Elle avait pensé attendre que nous allions nous-mêmes en congé, nous aurions beaucoup aimé la garder jusqu'alors et faire profiter l'œuvre de son activité, son expérience, la maturité de sa piété et sa sympathie pour toutes les misères, nous sentions que nous ne nous passerions pas facilement de son concours; mais depuis des mois, certains symptômes inquiétants et un affaiblissement général nous faisaient parler de la nécessité de son retour en Suisse.

Le 6 mai le roi arriva avec ses deux Nalikwanda.

Il partit le 10 mai à $3 \mathrm{~h}$. et passa encore quelques minutes chez nous. Nous demandâmes à Dieu de tout diriger afin que les décisions qui allaient se prendre fûssent pour le bien de cet homme et de son peuple. La plupart des chefs et officiers suivirent leur souverain, emmenant des dizaines et des centaines de rameurs.

Nos auditoires s'en ressentirent; ils oscillèrent entre 160 et 140. Mais il nous resta une grande partie des professants.

Mamwendarubi nous faisait toujours du bien. Elle continuait à faire briller sa lumière dans la nouvelle position où elle avait été placée. Aux Mafulo elle avait refusé de manger de la bouillie dont la farine avait été faite le dimanche. Dès lors dans la cour de Matondo (la mère de la princesse Wabei) on pila le samedi les grains qui devaient servir à la nourriture du lendemain. Notre brave professante réunissait chaque soir les escla ves pour la prière, et souvent la femme du roi, sa maîtresse, lui demandait de faire le culte avec elle.

Le 16 nous rouvrîmes l'école de station. 


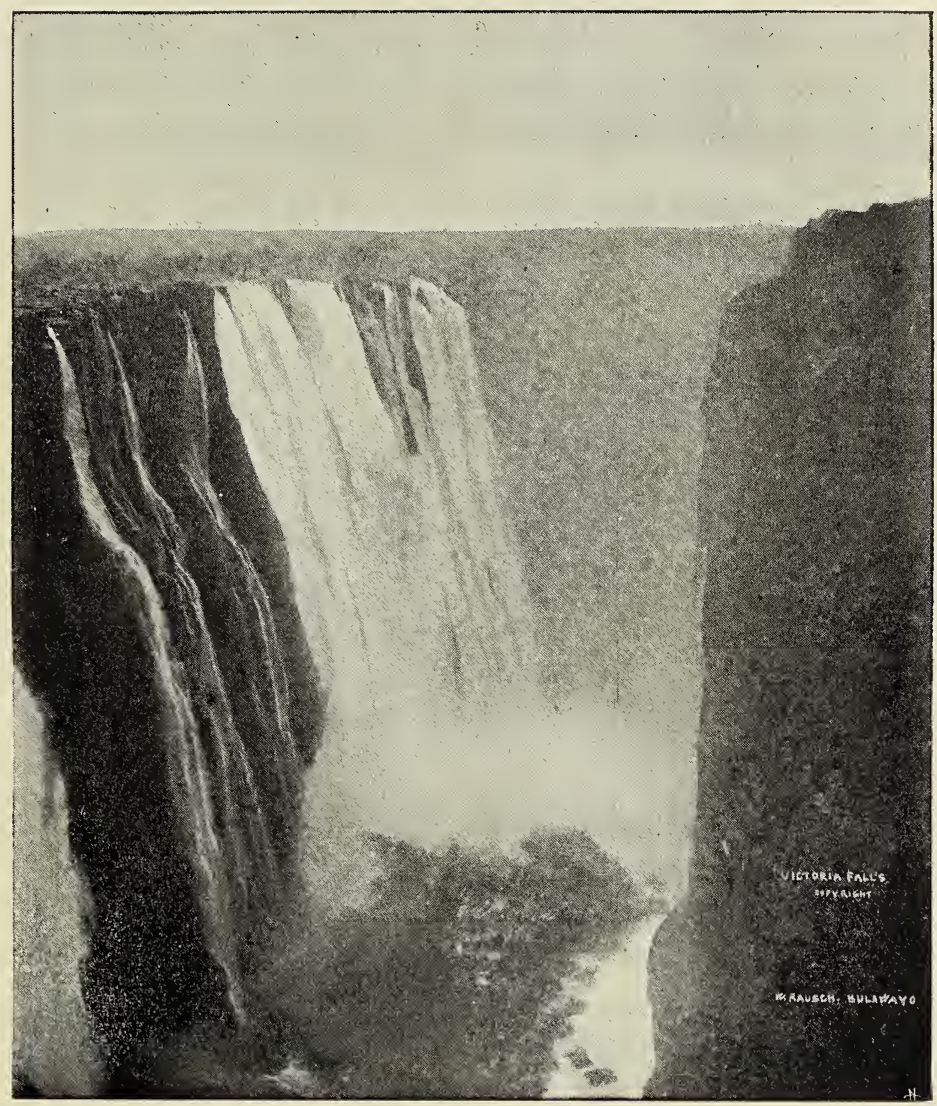

Chutes Victoria (Chute de gauche). 

Le 26 ma femme reprit sa classe de professantes. L'après midi elle offrit une collation à 45 enfants de son école du jeudi.

29 MaI. - Les livres que parents et amis nous envoient nous font un grand plaisir. On a quelquefois besoin de sortir de soimême, de ses occupations, des soucis et des travaux quotidiens. Comment exprimer notre reconnaissance à nos amis chrètiens, qui nous enveloppaient ainsi d'une chaude atmosphère d'amour dont les souffles bienfaisants vont droit à nos cœurs. Vous peuplez notre solitude et vous fortifiez nos mains affaiblies.

Voyez comme Dieu est bon! Cette année ancore il se sert de nouveaux instruments pour nous venir en aide. Les quelques provisions que nous avons reçues tirent rapidement à leur fin, et il nous a fallu en jeter une grande partie. La pluie et l'eau du fleuve les avaient avariées. Eh bien, voila de longs mois que nous recevons chaque semaine des légumes provenant du jardin de la Résidence. Des tomates en abondance, des haricots, des laitues, des navets apportent dans notre menu une variété qu'il ne connait guère et donnent à notre table un aspect civilisé qui fait du bien. Nous nous demandons parfois ce que nous ferions sans ce renfort inespéré. De temps à autre il nous arrive un cadeau de poisson ou de volaille; nous avons beaucoup de patates. Les oeufs et le lait ne nous manquent pas non plus. Nous serions des ingrats si nous nous plaignions de ce qui nous manque.

Le 31 je reçus un billet du roi, dans lequel il me demandait mon avis sur le projet qu'il nourrissait d'aller faire une visite à la Reine Victoria, après l'entrevue avec l'administrateur de la Rhodesia. Il insinuait qu'il aimerait que de l'accompagnasse. Je lui répondis que je ne croyais pas le moment opportun.

\section{LXXXIV.}

Une mort et un mariage.

Mort d'Wisa. - Que Leoco onblie Ngambo: - Ses fançailes avec Elizabetha.

keur mariage marque nu progres.

T E 13 juin, un messager de Pauluse nous annonça qu'Elisa 1 était gravement malade. Nous prêtâmes à Ernestina notre unique canot, arec des rameurs, afin qu'elle accourât. Le 
14, une lettre nous dit qu'Elisa était mourante. Nous réussîmes, Willie et moi, à avoir les deux chevaux du roi restés à Léalui pendant l'inondation, et nous partîmes à $11 \mathrm{~h}$. Mais la plaine étant encore en bonne partie submergée, nous n'arrivâmes à Sefula qu'à $4 \mathrm{~h}$. Avant même d'y entrer nous apprenons qu'Elisa n'est plus. Nous royons une centaine de personnes dans la cour de la station. Pauluse vient à notre rencontre en sanglotant. Dans la hutte mortuaire nous trouvons Ernestina et Norea. Pauluse nous dit qu'il va être obligé de fonder un troisième foyer. Le corps de sa femme est enveloppé dans un drap cousu, et recouvert d'une couverture en laine. Elisa avait eu une pneumonie avec une fièvre violente. Dans son long délire elle m'avait souvent appelé. Elle avait encore reconnu Ernestina dans un moment de lucidité et lui avait dit qu'elle était fatiguée et allait se reposer. Je fis un culte pour les présents, puis avec Willie nous fîmes la bière.

Le lendemain, près de 200 personnes accoururent. Depuis longtemps la station n'en avait vu autant. Les professants avaient aidé à soigner et à veiller Elisa pendant sa maladie, ils la veillèrent encore après sa mort et aidèrent à creuser la fosse. Quel progrès depuis la mort de Madame Coillard!

Dès notre retour à Loatile j'envoyai notre canot prendre Pauluse et Mohau, afin qu'ils passassent quelques jours avec nous.

Léaco était toujours sans nouvelles de Nyambo. Dès le commencement de mars le roi m'avait dit qu'il n'y avait plus d'espoir de revoir cette jeune femme, et il m'avait annoncé qu'il donnait Leaco comme fiancé à Elizabetha. On aurait même voulu que le mariage se fît aussitôt. Je m'y étais opposé. Il n'y avait alors que huit mois que Nyambo avait été laissée an bo-Lubale, qui savait qu'elle ne pensât encore à son mari, mais qu'elle ne fut empêchée de communiquer avec lui même par lettre? Il fallait attendre de savoir quelque chose de plus précis. La réponse de Mosongoandungu revint catégorique: «Que Leaco oublie Nyambo, il ne la reverra jamais $\gg$.

En partant pour le Mosi-oa-thunya Lewanika avait chargé Katoka de faire toutes les démarches nécessaires pcur le mariage de Leoco et Elizabetha.

Le mariage put être célébré le 17 juin. Il ramena sur la station jusqu'aux femmes du roi qui n'y avaient plus mis les pieds depuis longtemps. Il y eut près de 600 personnes. Je pris comme texte 
de l'exhortation: II Corinthiens v. 17. Je commençai par relever la nouveauté de ce qui se passait: une femme du roi libérée par le roi lui-même, à laquelle on permet de prendre comme mari un jeune homme fils d'esclaves, et qui s'rnit a lui pour la vie devant Dieu et devant les hommes. Qui aurait cru que tant d'infractions aux mœurs du pays se feraient un jour avec le plein consentement du roi et même avec sa participation? Le secret de tout cela c'est que Christ a renouvelé toutes choses pour qui a cru en Lui.

M'adressant ensuite aux époux, je leur dis comment leur maison et leur vie conjugale devaient montrer qu'en effet les choses vieilles sont passées et que toutes choses sont devenues nouvelles. Pour cela il faut demeurer en Christ.

Willie ajouta quelques bonnes exhortations. Tout se passa très bien: les chants, les réponses des époux, le recueillement de cette grande assemblée. Tous deux étaient bien quoique simplement.

Katoka avait fait apporter une vingtaine de plats de nourriture, de la part du roi.

Ernestina et Willie, qu'Adolphe avait fait chercher pour venir voir le festin, se sont crus invités chez nous pour le dîner; et faisant bonne mine à mauvais jeu, il fallut les avoir à table. Ils ne se sont doutés de rien, et nous avons joui d'eux. Willie a si bon coeur que nous l'aimons beaucoup; malgrè toutes les difficultés et les ennuis que nous avons eus avec eux, nos rapports sont restés très bons.

\title{
LXXXV.
}

Voyage à Kazungula et retour.

\author{
Nautrage. - Froid. - Hippopotanes. \\ Accueil des évangelistes, des princes et du roi. - Henreux revoir.
}

Incidents de voyage.

Tous dûmes partir pour Kazungula le 28 juin, sans avoir 1 assez de rameurs. Au bo-Toéa un de nos canots de bagages chavira. Nos plongeurs réussirent à tout retirer, mais 
nous ne pûmes atteindre Nalolo que le lendemain matin. Nous en repartîmes le 30 avec la famille Béguin.

À Seoma nous apprîmes la naissance de Jeanne Boiteux.

Le samedi 9 juillet nous eûmes froid tout le temps de Ngambwe à Nalisa. Le soir à $9 \mathrm{~h}$. le thermomètre marquait $0^{\circ}$. Le lendemain à notre réveil nous trouvons 15 centimètres de glace dans nos seaux, et le thermomètre n'a que $-8^{0}$ ! Toutes les feuilles des arbres sont gelées. Malgré des feux immenses, nos rameurs ne commencent à se réchauffer qu'après $10 \mathrm{~h}$.

Le 11 matin, un peu en amont de Katongo, nous voyons un troupeau de plus de cinquante hippopotames. À l'île des maTebele, où nous abordons vers le soir, nous trouvons de nos bonnes connaissances de Léalui qui tirent à la rive un hippopotame femelle et son veau qu'ils ont tués.

À Sesheke, où nous arrivons le 12 à $9,30 \mathrm{~h}$. du matin, ce sont Aarone et Alina qui nous souhaitent la bienvenue; mais tout nous parle encore des Goy. Akanangisoa fut très accueillante. Litia était tout à la construction de sa belle maison. De chez lui nous nous rendîmes au campement de Lewanika, où nous fûmes accueillis en amis. Le roi était de retour du Mosi-oa-thunya, fier de la façon dont il y avait été traité, et heureux d'avoir obtenu ce qu'il désirait. Il avait renoncé à son voyage en Angleterre, suivant mon conseil. Il mit à ma disposition 9 canots de transport et nous donna un morceau d'hippopotame.

Le 13 nous retrouvâmes le roi à l'endroit où ses canots étaient amarrés; il y était venu tout exprès pour saluer ces dames qu'il n'avait pas vues la veille. Nous passâmes une petite demi-heure avec lui.

Le 14 à midi et demi, nous sommes salués à Kazungula par des salves. Toute la famille missionnaire est là prête à nous accueillir, à mesure que nous sortons des canots. Quel bonheur de revoir mon frère et ma belle-sœur si bien portants et rajeunis par leur séjour en Europe, où cependant ils ont dû laisser leurs deux jeunes fils. Qu'il fait bon souhaiter la bienvenue à de nouveaux collaborateurs: $M$. et M. Coïsson, M. et $M^{\circ}$ Mann, $M^{110}$ Specht, M. Mercier, Léfi et sa femme, ce renfort après lequel nous avions si longtemps soupiré dans notre isolement! Nous sommes heureux de voir $M$. et $\mathbf{M}^{\mathrm{e}}$ Boiteux, que nous ne connaissions que par lettres. Nous demandons à voix 
basse des nouvelles de la petite Jeanne, dont nous avons appris la maladie à Sesheke. Mais on nous répond qu'elle est ensevelie depuis la veille! Pauvres amis!

M.M. Pickering et Chapman, missionnaires au bo-Shukulumbwe, étaient depuis quelques jours sur la station.

Que de bons souvenirs nous gardons des semaines passées à Kazungula, et de la visite faite aux chutes Victoria avec la plupart de nos frères et scurs. Nous nous y rendîmes en corps pour choisir l'emplacement de la station dont nous venions de décider la fondation, en la confiant à $\mathrm{M}$. et $\mathrm{M}^{\mathrm{e}}$ Coïsson.

Le 24 juillet nous eûmes le baptême de notre Graziella et d'Emilie Coïsson. Le 27 nous dîmes adieu à $M^{\text {lle }}$ Kiener dont la Conférence avait jugé nécessaire le retour en Europe.

Le 10 août commencèrent les adieux à ceux que nous laissions à Kazungula: les Boiteux, les Coïsson, Mercier. Cinq jours plus tard à Sesheke nous nous séparâmes de Louis Jalla.

Le retour au bo-Rotsé fut assez animé. Outre les Béguin nous avions $M$. et $M^{\mathrm{e}}$ Mann et $M^{\text {lie }}$ Specht, que la Conférence nous avait donnés comme collaborateurs à Léalui. Les incidents ne firent pas défaut. Le canot de M. Béguin, qui avait souffert pendant le voyage d'aller, chavira de nouveau aux rapides de Katimamolilo et n'était plus sûr. Je lui laissai le mien et fis le reste du voyage dans le même canot que ma femme et Graziella. Le 25 nous faillîmes être renversés par un hippopotame, qui d'un banc de roseaux se jeta dans le fleuve à un mètre de la proue de notre canot. Dieu nous garda!

Nous passâmes le dimanche 28 à Senanga, au pied de l'emplacement où les Boiteux devaient quelques mois plus tard fonder leur station. Nous y eûmes un culte avec les gens $d u$ lieu outre nos rameurs, que nous assemblions naturellement tous les jours.

Les derniers jours ont été fatigants. Graziella en avait assez de cette petite embarcation couverte, où nous nous sentions nousmêmes un peu comme en prison. Le 30 soir nous arrivons à Nalolo, et nous passons chez les Béguin la journée du 31 . 


\title{
LXXXVI.
}

Triste retour sur notre station.

\begin{abstract}
Mort d'Enestina. - Notre hone quand mêne. - Désagréments et compensation. Arrivée de nos collaborateurs. -- Lewanika de mauvaise humeux. Fiançailles.
\end{abstract}

I E $I^{\mathrm{r}}$ septembre $\dot{a} 4,20 \mathrm{~h}$. du matin nous nous embarquons, $\checkmark$ mon mari, Graziella et moi, devançant les autres afin de leur prẻparer un pied à terre. À midi nous reçûmes une lettre de Willie nous apprenant que sa femme était mourante! Quelques heures après, un autre message nous apportait la nouvelle de sa mort. Nous en fûmes navrés. Quel mystère que le départ de cette jeune femme enlevẻe à son mari et à ses deux petits enfants!

Nous dûmes faire á pied le dernier bout, car le canal fait un grand détour, et il y avait si peu d'eau que nous ne serions arrivẻs qu'à une heure très avancẻe de la soirée. Nous arrivâmes à temps seulement pour qu'Adolphe pût faire une prière. Le pauvre Willie sanglotait en nous saluant.

Quel retour lugubre sur notre station! Représentez-vous une termitière perdue dans la plaine comme une oasis dans le désert, plantez-y quelques maisons, quelques eucalyptus, et vous avez notre «home ». Eh bien oui, c'est notre «home», et la première impression passée, je pus, du fond du cœur, dire une fois de plus: "Casa mia, casa mia, per piccina che tu sia, tu sei sempre casa mia!». Et puis, comment ne pas être heureux et reconnaissants? Quand je vois des mẻnages brisés, des couples mutilés, je ne puis que demander à Dieu de nous épargner et de nous garder les uns aux autres.

Ernestina a étẻ emportẻe en six jours par l'hématurie. Dès l'abord elle a senti qu'elle s'en allait et a dit: «Je suis prête, si le Maître me veut, je n'ai plus souci pour mes enfants. Mais, disaitelle à son mari, tant que je suis là ne sois pas triste; je veux voir des visages heureux ». Elle aurait voulu nous revoir et quand elle a su que nous étions à Nalolo, elle a dit: «Ils arriveront trop tard! $\gg$ Son mari ne pouvait croire qu'elle s'en allait, tant son visage était serein et joyeux. 
Dès son arrivée en 1894 elle avait secondé Willie à l'école, surtout pendant la dernière année où elle avait travaillé avec zèle à l'évangélisation des femmes. Elle avait été pour nous une amie sur laquelle nous pouvions compter, particulièrement précieuse aux moments de l'épreuve. C'était une fille de l'évangéliste mossouto Asser, bien connu de tous ceux qui sont au courant des premiers travaux missionnaires des Bassoutos.

Nous ne trouvâmes chez nous, ni bois à bruler, ni nourriture pour nos gens. Notre compensation ce fut le lait, ce lait qui nous avait beaucoup manqué pendant le voyage et le séjour à Kazungula.

Le 2 nous eûmes beaucoup de besogne à abattre, mais à $4 \mathrm{~h}$., à l'arrivée de nos collaborateurs, non seulement la salle à manger était présentable, mais encore nous pûmes conduire nos hôtes dans des chambres très habitables.

Les Loatiliens et tous les professants furent heureux de nous revoir. Il y eut moins d'empressement de la part des païens.

Le paganisme avait gagné du terrain. Avant même de revoir sa capitale, Lewanika, sans conseiller fidèle et cédant à la pression de son entourage, s'était rendu aux tombeaux de Lirundu et de Katuranuva, pour rendre hommage aux mânes qui avaient fait prospérer (?) son entrevue avec le représentant de la $B$. S. A. C. C. et l'avaient protégé pendant son voyage. Il n'était pas étonnant que les nombreux tombeaux des environs fussent de nouveau soignés et fréquentés. Le roi était trop éclairé pour ne pas avoir de remords de sa conduite, mécontent de lui-même il ne pouvait nous recevoir avec effusion, nous qui lui tenons un peu lieu de conscience. En temps ordinaire il aurait applaudi aux décisions de la Conférence, surtout à celle de la fondation de deux stations; il aurait publiquement manifesté sa joie à la vue des aides que nous amenions; mais non, il ne montra que sa mauvaise humeur, et critiqua tout.

Cependant il me promit de faciliter la fondation de la station de Senanga. Je retournai chez lui le 12, fixer le frêt des canots que les gens de Mboela devaient conduire à Kazungula pour le déménagement de la famille Boiteux. Nous convînmes de payer une chemise, une couverture de coton, ou une couverture de laine, selon la grandeur des canots.

L'après midi nous fûmes agréablement surpris par l'arrivée de MM. Pickering et Chapman. Ils avaient fait à pied, en 17 jours, 
les 450 kilomètres qui séparent leurs stations de la nôtre. Le 23 nous apprîmes officiellement les fiançailles de M. Pickering et de M. ${ }^{\text {lle }}$ Specht.

25 Septembre. - Nos hôtes du bo-Shukulumbwe sont repartis, mais nous avons encore chez nous les Mann et M. ${ }^{110}$ Specht. Il y a plusieurs blancs dans les environs et nous tenons à être hospitaliers quand ce sont des gens comme il faut. Nous les aurons aussi pour un culte anglais.

\title{
LXXXVII.
}

Mort du Ngambela.

\begin{abstract}
Descendrait-il seul au séjour des morts : Enterrement du grand chef. - Actes symboliques.
\end{abstract}

T $\mathbf{E}$ vieux Ngambela Mwauluka tomba gravement malade. L'allai le voir fréquemment. Le 29 je passai encore des heures à son chevet. $\dot{A} 4 \mathrm{~h}$. des lamentations nous annoncèrent sa mort.

Pendant ma visite de condoléance, j'entendis des gens dire: «Descendra-t-il seul au séjour des morts, n'aura-t-il personne pour l'y servir? 》 Je tendis l'oreille. On parlait d'accuser de sorcellerie une de ses femmes, et de la tuer! Je me dirigeai chez le roi. Me recevra-t'il, moi qui viens d'auprès d'un cadavre? J'entrai sans le consulter et lui dis qu'il devait faire acte d'autorité et empêcher qu'on ne consommât le sacrifice humain dont il était question. Il me le promit et tint parole. Mais je fus triste de voir que Lewanika dissimulait à peine sa satisfaction d'être débarrassé de cet homme, auquel il devait pourtant beaucoup.

Le soir même, son corps enveloppé de couvertures et de nattes fut posé sur un petit canot, surmonté d'un pavillon. Le lendemain avant le jour on perça par derrière le mur de sa hutte pour faire passer le cadavre, puis un interminable convoi sortit de Léalui et décrit un grand demi-cercle autour de la 
capitale, avant de prendre la direction de la fosse que l'on a creusée très loin, vis-à-vis de Sola. Le mort porté dans son canot par plusieurs de ses anciens serviteurs, est précédé seulement par les veuves, chacune desquelles porte un objet do mestique destiné à être mis dans la tombe. Il est suivi immé. diatement par une femme portant une cruche, puis par les enfants du défunt, et les chefs. La fosse est très longue et profonde.

Le canot y est posé avec beaucoup de soin, de telle façon que le cadavre soit tourné vers l'orient. On y place les objets de ménage apportés par les femmes, on recouvre le tout d' une natte, ensuite les membres de la famille viennent chacun à son tour y jeter des brins d'herbe qu'ils brisent. La terre versée avec des plats en bois est bien tassée; quand elle a atteint le niveau du pavillon on place encore deux gourdes dans la fosse, puis on achève l'enterrement. On jette sur le tertre des plats cassés, ainsi qu'un vase en terre et une pioche.

Le convoi se reforme, mais dans l'ordre inverse. Il rentre à Léalui vers $9 \mathrm{~h}$. par le même sentier et en refaisant le même grand tour. On va égorger les bœufs qui seront sensés servir de viatique. Le deuil officiel durera une semaine. Puis le vieux serviteur du roi et de la nation sera 《hlobohile》, et on en parlera le moins possible.

\section{LXXXVIII.}

Difficultẻs et encouragements.

\footnotetext{
Leaco abandonne l'école d'évangélistes. - Joies de famille. - Malales. - où est ton frère? - Comment traiter les serviteurs? - Toi seul tu me dis la vérité. - Pour Sefula. - Nos enfants anx Missionnaires : - Sacrifice humain : - Arbre de Noël.
}

Nous avons un nouveau sujet de tristesse dans notre école d'èvangẻlistes. Léaco, un garçon studieux et appliqué, ne veut plus devenir évangéliste depuis qu'il a épousẻ Elizabetha. Il a été pris lui aussi au filet, alléché par la gloire et les honneurs qu'il peut trouver au pied du monarque, révéré comme un Dieu dans ce pays où l'on vit encore du régime du moyen âge. De cette école 
objet de tant de sollicitude, de patient labeur et de larmes, qui sortira fidèle, et prêt pour le travail?

13 OстовRE. - Ce matin les élèves évangélistes et toute notre maisonnée, dirigés par Adolphe, ont chantẻ à notre porte un beau cantique sessouto qui parle de l'enfant de Dieu comme d'un prince gardé par des armées d'anges. Ce chant m'a fait du bien et c'est le cœur joyeux que je me suis empressée d'aller saluer ces amis et les remercier.

3 NOVEMBRE. - Mes mains sont plus que remplies par d'anciens et par de nouveaux devoirs, mais je bénis Dieu de ce qu'il me donne une si bonne santé, malgré mon teint jaune et ma maigreur. L'état assez satisfaisant de ma santẻ est d'autant plus remarquable que tout le monde autour de nous a été malade. Nous avons eu tous les jours à soigner sur la station, trois ou quatre cas de fièvre, maux de gorge, et des vingtaines de malades à la capitale. C'est un mauvais moment de l' annẻe et Adolphe s'en est toujours ressenti. Il recommence à traîner de l'aile comme l'année passée.

Ce soir en rentrant de Léalui, où j'ai eu ma réunion de femmes, Nanjeka me dit: «Je veux toujours venir avec toi, et appeler moi aussi des femmes. - C'est bien. - Tu vois, notre affaire à nous c'est de travailler, de dire, si on ne croit pas, qu'au moins ce ne soit pas notre faute. Autrefois, dit-elle, nous avions du zèle, nous parcourions la capitale et causions avec nos compagnes, avec toutes les femmes, mais maintenant je ne le fais plus. Il faut recommencer. - Oui, il le faut, nous devons penser à cette parole: Qu'as-tu fait de ton frère? $\gg$ Brave fille, quel bien elle m'a fait! Je me suis sentie toute réchauffée par cette petite conversation toute simple, sans prétention, et qui partait d'un cœur ému. Le bon esprit qui règne dans notre maison nous réconforte, et Dieu nous donne bien des sujets de joie dans ces enfants, jeunes gens et jeunes femmes dont nous nous occupons. Ils sont l'àme de nos diffẻrentes unions chrétiennes. Il y a aussi un mouvement de réveil à l'école, et une quinzaine d'ẻlèves, surtout des jeunes filles, ont déclarẻ vouloir se donner au Sauveur. Notre pauvre roi est préoccupé de tout, sauf de la seule chose nécessaire.

Le 5 novembre, dans une conversation avec un marchand, j'appris que je n'étais pas en odeur de sainteté auprès des blancs. Si les ouvriers n'obéissent pas à leurs maîtres, c'est ma faute, disent-ils, parce que je me suis opposé à ce qu'on les maltraite. Cette dernière affirmation est vraie, mais mes 
ouvriers m'obéissent parce qu'ils me respectent et je n'ai jamais le moindre désagrément avec eux.

Lewanika lui-même traite ses serviteurs personnels avec bonté. Hélas il est souvent très dur envers d'autres! Il avait ordonné aux habitants des régions de Katongo et de Kanyongo et Makoko, de bâtir certaines maisons pour lesquelles il avait reçu et empoché une assez forte somme; ceux-ci le firent en maugréant. Ils faisaient volontiers, disaient-ils, les corvées pour le roi, c'était leur devoir, mais ils ne voulaient pas servir les blancs sans eu être payés; les missionnaires paient toujours leurs ouvriers. L'ouvrage fut mal fait. Après avoir été constater la chose sur les lieux le 11 novembre, le roi fit subir la strangulation à une centaine d'hommes et de femmes (1).

Trois jours après, je me rendis vers Lewanika et lui exprimai mon horreur de l'iniquité qu'il venait de consommer; je lui fis aussi remarquer quelle erreur il avait commise en s'aliénant ses sujets. Si des troubles surgissaient, est-ce que ces gens qu'il venait de maltraiter, feraient un pas pour lui servir de boucliers? Lewanika m'écouta, il reconnut ses torts et me remercia pour mes conseils. "Je suis environné de flatteurs, me dit-il, toi seul tu me dis la vérité 》.

Le 12 novembre, après avoir accompagné ma femme et Graziella jusqu'à Batuke (l'embarcadère), je me rendis au Khotla avec M. Mann, Pauluse et Willie. A ma requête le roi avait mandé les chefs des environs de Sefula. Il n'en était venu que quinze. Il s'agissait de ressusciter l'école de Sefula, morte depuis des mois. J'ouvris le feu en faisant brièvement l'histoire de cette école, et insistai sur la nécessité d'un effort durable. Je fus suivi d'une dizaine d'orateurs, évangélistes, chefs et officiers. Mokuba fut le plus original de la bande. Une troupe de maMbunda venus de l'ouest, dansaient et chantaient au son de deux étranges tambours, au milieu de la vaste place publique. «Voyez-vous quelque beauté, ou quelque utilité à ces danses? C'est là ce que nous recherchions autrefois. Mais maintenant nous savons mieux que cela. Nous avons de meilleurs plaisirs: c'est l'instruction apportée par les missionnaires. Ils sont

(1) On se rappelle que la strangulation c'est l'étouffement par compression de la gorge, jusqu'à évanouissement complet, suivi de la fustigation pour rétablir les tonctions vitales. 
venus nous ouvrir les yeux et nous donner la vie. C'est à eux que nous devons confier nos enfants $》$. On décida de reconstituer l'école en question. Les coupables furent réprimandés, et un homme fut placé comme surveillant de l'école avec pouvoir d'obliger les enfants à la fréquenter.

Ce même jour Lewanika s'opposa à ce que les propriétaires des huit derniers canots venus, réclamassent quelque frêt que ce fût. Il leur dit: Les missionnaires ne font que nous donner, instruction, conseils, médecines... ce n'est que juste que vous les aidiez!

Cette année-là, bien que Noël fût un dimanche, nous eûmes de très petits auditoires, point d'adultes. Léalui était en deuil d'Akalemwa, le fils de Litia par sa seconde femme. On nous rapporta qu'un de ses petits esclaves fut couvert de colliers de perles blanches, et enseveli avec le petit prince. Mais nous ne pûmes en être sûrs.

Le 26 nous eûmes notre arbre de Noël, un blanc palmier illuminé pour notre maisonnée.

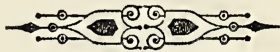




\section{CINQUIÈME PARTIE}

L'œuvre progresse. Deuils. Renforts.

1898-1900 



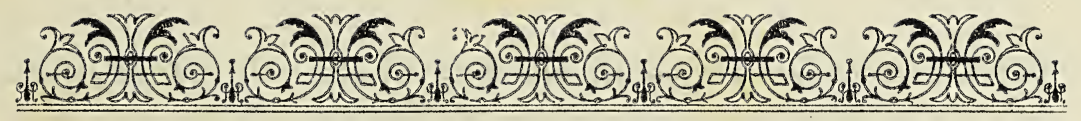

\title{
CINQUIĖME PARTIE
}

\author{
LXXXIX.
}

L'œurre missionnaire. Les rouages.

\begin{abstract}
Visites à domicile. - Cultes du dimanche et de la semaine.
\end{abstract}
classes. - Unions chrétiemmes. - Les écoles.

Tous avons continué, Willie, ma femme et moi, à visiter

1. aussi fréquemment que possible les gens de Léalui chez eux. M. Mann m'a souvent accompagné dans ces tournées. Nous avons pu constater avec tristesse l'ignorance extrême de plusieurs, mais aussi voir combien est répandue la connaissance de la vérité. Les indifférents et les moqueurs sont légion, mais il en est plusieurs parmi les hommes et les femmes, et même parmi les officiers et les chefs, qui ont ressenti quelque chose de la puissance de l'Esprit luttant avec eux. Il y a des dormeurs parmi les morts.

Autant que nos autres occupations nous l'ont permis, nous avons visité les nombreux étrangers noirs qui affluent à la capitale. Bien que la plupart ne comprennent pas le sessouto, il se trouve toujours quelqu'un pour leur interpréter nos salutations et nos exhortations.

Les auditoires du dimanche, qui avaient beaucoup diminué pendant notre absence, se reformèrent peu à peu. La pluie, le vent, les sauterelles, les travaux des champs et les corvées sont tonjours des obstacles à la fréquentation de nos services reli- 
gieux. L'attention est habituellement bonne. Willie m'a aidé pour la prédication. L'expérience et l'épreuve l'ont mûri aussi pour cette partie de la tâche missionnaire.

Plusieurs villages éloignés de la station de 7 à 16 kilomètres ont été visités le dimanche, surtout par les élèves évangélistes. Il y a eu des assemblées variant entre 30 et 135 personnes, et on nous a souvent pressés d'y retourner.

L'école du dimanche, toujours sous la direction de ma femme, avec les élèves évangélistes comme moniteurs, ou même, à l'occasion, comme remplaçants, a toujours eu plus de 100 élèves (maximum 150).

La répétition après le culte principal, inaugurée par M. ${ }^{\text {Ile }}$ Kiener pour les femmes, a été faite par Norea jusqu'à son départ le 21 novembre, et continuée par quelques-unes de nos professantes plus avancées. Hélas, le plus souvent il n'y a guères que nos femmes et jeunes filles de la station.

Le second culte général a toujours comme sujet celui de la prédication du matin. Nous nous efforçons cependant d'en varier la forme. Il se fait souvent en partie par demandes et réponses, et l'exhortation y devient parfois un appel. Il est ordinairement fréquenté par la moitié de l'auditoire du matin.

La réunion de missions du dimanche après-midi a continué à vivement intéresser nos Loatiliens. Ma femme et moi nous alternons pour la direction.

Parmi les cultes sur semaine, il n'y en a qu'un fait expressément pour les païens. Il se fait le jeudi à $4 \mathrm{~h}$., alternativement chez Elizabetha et Mpololoa. Ma femme y a eu bien des encouragements. Jusqu'à 80 femmes ou jeunes filles y ont été présentes.

Nos professants continuent à se réunir régulièrement au coucher du soleil pour un service, consistant en chant et prière, et quelquefois exhortation. Souvent bien des païens se joignent à eux. Un culte semblable se fait le soir à la station.

La prière du matin, qui ne se faisait qu'à Lwatile, est maintenant dédoublée les jours où il n'y a pas de classe de catéchumènes, et se fait simultanément à Léalui et à Lwatile.

Des classes, celle du lundi pour les catéchumènes les plus récents, et confiée à Willie, laisse à désirer pour la fréquentation. La classe générale du mercredi est par contre bien suivie. Celle du jeudi, faite par ma femme pour les professantes, a des 
hauts et des bas, mais elle donne de bons résultats. La classe du vendredi est pour les candidats au baptême.

Après le départ de Norea (21 novembre), ma femme hérita encore de la direction de l'Union Chrétienne de femmes.

Deux nouveaux rouages ont été inaugurés. $1^{\circ}$ Une union cadette de jeunes filles, fondée le 4 octobre. $2^{\circ}$ L'Union Chrétienne de jeunes gens, fondée le 14 octobre 1890, avec douze membres. Je n'en ai que la haute surveillance. Le président est nommé par les membres. Ils sont bien entrés dans l'esprit de la chose, ils font à tour de rôle une méditation, et se font réciproquement part de leurs expériences d'activité chrétienne. Ils n'ont pas craint de s'engager à lire la Bible et à faire le culte de famille tous les jours, comme à s'efforcer d'évangéliser les paiens.

Nous avons eu le mariage de Kajata et Nasirele (élevée d'abord par M.e L. Jalla, puis par nous).

Une chose nouvelle, ce fut la confirmation à l'église de deux mariages contractés à la paienne avant la conversion des époux (Fawira et Nyonga, Gideone et Moangala).

Willie a continué à avoir la direction de l'école de station. $\mathrm{M}^{\text {lle }}$ Specht en a pris deux classes sur sept, et M. Mann a donné surtout à la $1^{\text {re }}$ classe les quelques heures que l'école primaire supérieure lui laissait libres. La moyenne de fréquentation a été de 112 élèves (maximum 139).

La conférence de Kazungula, en décidant le placement de M. Mann à Léalui, lui avait demandé de s'occuper, pour la première année, de l'école de station, sans exclure l'Ecole d'évangẻlistes. Nous nous sommes tenus à l'esprit de cette décision: M. Mann s'est en effet partiellement occupé des deux écoles mentionnées (il a donné aux élèves évangélistes les leçons d'anglais, arithmétique et géographie, en tout $5 \mathrm{~h}$. par semaine). Cependant l'œuvre à laquelle il a consacré la meilleure partie de son temps, c'est une cuvre nouvelle. Il y avait autour de nous plusieurs jeunes gens ayant reçu de l'école de station tout ce qu'on pouvait en attendre; d'autres avaient quitté l'école biblique, ne se sentant pas de vocation pour devenir évangélistes; ils étaient désireux de s'instruire encore, quelques-uns songeaient à partir pour la Colonie. - N'y avait-il rien à faire pour eux? Le moment n'était-il pas venu de poser le fondement de ce qui pourra devenir l'école normale du Zambèze? 
Le 21 septembre nous fîmes en présence du roi l'examen de ceux qui devaient composer la première volée. Sept jeunes gens et une jeune fille (Nawina) furent admis d'emblée. D'autres se représentèrent à un sezond examen, fait un mois plus tard, lors de l'inauguration des leçons; quatre y furent admis, d'autres en furent écartés.

Dans le programme l'anglais domine, mais la Bible, l'histoire naturelle et l'histoire proprement dite, l'arithmétique et la géographie y ont leur place, ainsi que le chant et des exercices de composition en sessouto. M. Mann a 16 des 25 heures, les autres sont réparties entre Willie, ma femme et moi. Les progrès furent réjouissants, comme nous pûmes le constater aux examens de la fin de l'année. Cependant un élève fut exclus pour irrégularité, et un autre passa à l'école d'évangélistes. Nous finîmes par y admettre Léaco.

Il y a deux écoles de couture, celle des jeunes femmes et filles de la station, tenue par ma femme, et celle des jeunes filles plus avancées de l'école de station, tenue par $M^{\text {lle }}$ Specht (deux après-midi par semaine).

L'école des femmes évangélistes a continué sous les soins de ma femme, aussi régulièrement que les circonstances l'ont permis. Les élèves aident très fréquemment leur 《mère 》 pour des travaux de ménage ou de station.

L'école d'évangélistes (25 heures par semaine), a été rouverte le 19 Septembre. Les examens de fin d'année ont prouvé une fois de plus, qu'un travail sérieux a été fait par nos jeunes gens. Ils nous ont souvent aidés et même remplacés pour l'école de station, les prières et classes, l'école du dimanche, les visites à la capitale et surtout les cultes dans les villages de la plaine.

Nous avons en outre soigné de 8 à 9 patients par jour, en moyenne. 
XC.

Sujets de joie et sujets de tristesse.

\footnotetext{
Baptêmes. - Recrues. - Agréable surprise.

Pardonuc-nous comme nous pardonnons. - Maisonnée aiméc. Ecole mouvenentée. - Ienreux.
}

TE retournai à Sefula le 3 janvier 1899, avec M. Béguin cette fois, pour y étayer à nouveau la scierie. Nous bouchâmes aussi avec du chaume un gros trou au toit de la grande maison, et mîmes à l'abri des termites le seul wagon en bon état qui nous restât au bo-Rotsé.

Le 5 janvier tous les professants valides de Sefula et de Léalui assistèrent à Loatile, au baptême de deux hommes et de deux femmes. Ce fut une belle fête, pleine de sérieux et de recueillement. Nous leur donnâmes les nouveaux noms de Filippi, Abrahama, Ruthe et Sara.

Vers 5 h. nous reçûmes deux nouvelles recrues à l'école d'évangélistes: Setumba, le frère cadet de Moka, professant depuis 1894 - qui vient d'être près de trois ans l'homme de confiance des Béguin. C'est un garçon sérieux qui nous dit simplement, mais d'une manière touchante, qu'il veut servir le Seigueur, et donner à d'autres ce qu'il a reçu. Il nous ramena Nosiku, sa femme. L'autre fut Kaïeka. Il nous parla de la grâce de Dieu qui a agi en sa faveur, et de la reconnaissance qu'il veut lui témoigner en le servant comme évangéliste.

Le soir nous avons dans la chapelle une répétition de l'arbre de Noël. Il y a foule, 8 à 900 personnes. Grâce aux objets reçus de Genève, Neuchâtel, et des Vallées Vaudoises, nous pouvons donner un cadeau à chacun des professants de Léalui et de Sefula. Tout se passe avec entrain et avec ordre.

A $4.30 \mathrm{~h}$. nous avons la très agréable surprise d'accueillir II. et M. ${ }^{e}$ Boiteux qui arrivent avec leur petite Marie.

Nous qui trouvions que notre maisonnée marchait si bien, et qui en bénissions Dieu, ne dûmes-nous pas (le 17 janvier) séparer Kajata et Mathe (la femme de Filippi) qui se battaient? 
Nous craiguîmes la colère de Filippi quand nous le vîmes ap. procher... Non, il prêta l'oreille à ce que je lui dis, et bientôt après, quand Kajata s'humilia et lui demanda son pardon, Filippi lui tendit la main en disant: «Bénis le Seigneur qui nous a enseigné à dire: Pardonne--nous comme nous pardonnons. N'était cela, j'aurais déjà mis le feu à ta maison! 》

Les Boiteux nous quittèrent le 18, pleins d'entrain pour la fondation de leur établissement. Sur nos stations de la plaine, et surtout à Loatile, ils avaient pu se rendre compte des privilèges de Senanga. Bois, eau, pâturages pour toute l'année, ils ont tout cela à la porte, et des marchés plus faciles. Tout était cher à Léalui depuis notre retour de Kazungula. Mais l'œuvre toujours empoignante, nous faisait oublier toutes ces misères.

23 JANVIER. -- Nos journées s'écoulent avec une rapidité étonnante: on est toujours à la fin de la semaine et du mois. C'est que nos mains sont pleines et nous bénissuns Dieu qui nous donne jour après jour la force de vaquer à nos occupations. Et il nous donne de la joie dans l'accomplissement de cette tâche. Nous aimons toujours plus notre grande maisonnée, ces jeunes gens, ces jeunes femmes, ces fillettes et ces garçons qui sont nos sujets de préoccupations et nous donnent, avec les plus grands soucis, aussi les plus grands encouragements. Mon mari a repris son école et j'ai recommencẻ celle des femmes de ses élèves. Mais quelle école mouvementée que celle-ci! Presque toutes les écolières ont un bébé, et ce sont parfois des cris, des piaillements à effaroucher la science. Graziella n'aide pas au maintien de l'ordre et du silence, elle touche à tout, renverse l'encrier, dẻchire les livres et détourne sans cesse l'attention de ces jeunes mères (il $\mathrm{y}$ en a qui n'ont que de 16 à 18 ans). Mais je ne puis assez remercier Dieu en voyant ces jeunes femmes autrefois boudeuses, paresseuses, récalcitrantes, maintenant douces et respectueuses et toujours prêtes à me rendre service. Depuis quelques mois un esprit de soumission a règné dans notre maisonnée et a singulièrement facilité toutes choses. Si de temps à autre une faute grave est venue nous montrer que le mal n'a pas perdu tout son empire sur ces cœurs, nous avons pu constater aussi que l'Esprit de Dieu est à l'œuvre en eux et qu'il y porte ses fruits bénis.

Du 8 au 20 nous eûmes la visite de notre ami Georges Mercier. Quel homme précieux à avoir sur une station! Avec l'entrain de la jeunesse, il a su mettre la main à tout, et nous a réparé bien des choses. 
XCI.

Un nouveau Ngambela à Léalui (1).

Les caudidats. - Mokamba le chrétien. - Investiture.

Discours des ma-Rotsé. - Snjet de louange et d'intercession.

Tous vous rappelez la mort de l'ancien Ngambela, survenue le 29 septembre dernier. En signe de deuil, les affaires publiques furent suspendues pendant une semaine. Plus tard, le roi envoya des messagers à Seshéke et à Nalolo et dit aux chefs d'ici de désigner le successeur. On mit en avant plusieurs candidats.

Il y a un mois, ou les avait tous éliminés, sauf trois:

$1 .^{\circ}$ - Namoyamba, mari de Katoka, la sœur cadette de Lewanika;

$20^{\circ}$ - Katema, ami d'enfance du roi, conseiller avant la révolution, promu, au retour de Léwanika, à la dignité de $\mathrm{Na}$ lishua;

$3 .^{\circ}$ - Mokamba, celui que les lettres de M. Coillard vous ont fait connaitre, le grand ami de Litia, premier gendre du roi, fait Liomba depuis quelques années.

Plus tard, on élimine Namoyamba; il a été élevé loin de la capitale; on le trouve cassant... Chaque fois que le roi m'a demandé mon avis, j'ai écarté Mokamba, l'estimant trop jeunetrente et un ans - pour cette charge de premier chef du pays après Léwanika et Mokwaé. Cependant, le 9 courant, le roi m'annonce que c'est Mokamba qui va être installé le lendemain comme Ngambéla. C'est encore un secret pour la nation et pour les candidats. Le roi motive son choix en me disant que Katéma ne manquerait pas de faire tous ses efforts pour favoriser le paganisme, tandis que Mokamba est un chrétien dont l'esprit est ouvert à tous les progrès. Cette observation vous fera comprendre toute l'importance que cette nomination a pour nous. Comme je n'y étais pour rien, je pus me réjouir d'autant

(1) Extrait du Journal des Missions. 
plus sans arrière pensée. Mokamba est, depuis le commencement de janvier, un candidat au baptême.

Nous comptons le recevoir au baptême le Vendredi-Saint. Le 16 février, nous donnons congé à nos quatre écoles de Loatile et, dès neuf heures, MM. Mann et Mercier, Willie et moi, nous nous rendons à Léalui. Devant le hangar du tribunal, on a mé. nagé un demi-cercle libre, d'une trentaine de mètres de rayon. Tout le reste de la vaste place est couvert d'hommes accronpis, accourus pour la cérémonie. Dans le beau hangar, à la place d'honneur, à gauche de la natte royale, quatre chaises nous attendent. La plupart des chefs y sont, ainsi que plusieurs membres de la famille royale... Léwanika nous envoie dire de prendre patience, car il n'est pas encore tout-à-fait prêt.

En effet, ce n'est qu'à dix heures et demie qu'il sort de son établissement, vêtu comme un "gentleman 》, précédé par son fauteuil et sa bande de 《li-rimba》 et de tambours, et suivi par une foule de conseillers et d'autres serviteurs. Il commence par choisir, dans le groupe des gens de l'ancien Ngambéla, quatre ou cinq hommes qui passeront à son service personnel. Il fait ensuite sortir du groupe les parents du défunt, qui ne doirent pas devenir la propriété du successeur. Ceux qui restent, une centaine d'hommes, serrent les rangs et occupent l'extrêmité de l'espace resté libre vis-à-vis du hangar.

Alors, sur un signe du roi, les principaux conseillers présents se lèvent, s'approchent de Mokamba et, le prenant chacun par un bras, s'efforcent de le faire mettre debout. Celui-ci résiste.

De divers côtés on crie: «Lève-toi! obéis! 》 Il cède, il est conduit devant ses futurs serviteurs. Deux autres conseillers, deux chefs de Nalolo et de Katéma, sont désignés par le roi pour le suivre. Ils vont s'accroupir à sa gauche, perpendiculairement aux serviteurs. Deux hommes de Naturamda s'approchent à leur tour de Mokamba, par derrière; ils lui attachent sur la tête le moshukwé, parure faite avec la crinière d'un lion, ils jettent sur son épaule une peau de mo-tobo, espèce d'antilope, et mettent dans sa main le ngonyé, instrument de musique rappelant le triangle, avec lequel on appelle les gens aux corvées.

Les quatre conseillers délégués commencent la série des discours et donnent le ton. L'un après l'autre, ils s'adressent successivement à Mokamba, aux chefs de Léalui, aux serviteurs du Ngambéla et à la nation, rappelant à chacun son devoir. 
Awami menace d'être long; Sémonja l'arrête court par ordre du roi. Nous entendons ensuite une trentaine d'allocutions. Ils doivent croire que repetita placent; nous nous serions contentés de beaucoup moins. C'est que l'éloquence n'est guères développée ici; l'esclavage et le mensonge lui ont trop longtemps coupé les ailes. Je vous donnerai, cependant, les paroles les plus saillantes; elles ont quelquefois une saveur locale qui leur prête une certaine originalité.

Jmboa, chef de Nalolo: «Que chacun fasse son devoir! Chefs de Léalui, cessez de vous porter envie les uns aux autres! Devenez solidaires et aidez-vous réciproquement! 》

Katema: «Regardons tous à lui!... Ne dites pas: C'est un enfant, nous le ferons tourner à notre gré! 》.

Sampi, Ngambéla de Nalolo: «Le Ngambéla, c'est un canot: il ne saurait avancer seul. Aidez-le, vous, les principaux chefs, ne vous laissez pas aller à critiquer toujours ses paroles et ses actes! 》

Le dernier délégué a parlé. Ils laissent Mokamba au soleil et viennent reprendre leur place sous le hangar. Les autres orateurs parlent de devant le hangar; les chefs à droite, les officiers et autres à gauche de la porte principale. Tous font leurs discours à genoux. Voici les principaux chefs de Léalui:

Sémonja, notre professant, que vous connaissez peut-être sous le nom de Sébého: «Mokamba, tu es notre Séopé (autre nom pour Ngambéla). Ne t'enorgueillis pas. Tu es le taureau qui conduit le troupeau à l'autre rive: Avance toujours; en revenant en arrière, tu nous noierais. Vous, chefs, rappelez-vous que vous n'avez pas soutenu l'ancien Séopé comme vous l'auriez dû. So. yez le bouclier du nouveau!»

Muimui, cousin germain du roi, considéré comme chef des chefs de la famille royale: - « C'est une lourde tâche que l'on te donne; tu portes le pays sur ta tête et la nation sur ton épaule. - Malheur à vous, chefs, si vous ne vous conduisez pas bien envers lui! Souvenez-vous qu'il est des nôtres et même le gendre du roi, bien qu'il soit devenu Séopé! Auriez-vous encore quelque idée de détrôner Léwanika?»

Likokosane, neveu du roi, notre ancien élève de Séfula, s'emporte contre tout ce qui n'est pas de la famille royale.

D'autres cousins, neveux, gendres parlent plus ou moins sur le même ton. 
Sewakutilibebe, gendre du roi et professant, cache sa bannière: «Mokamba, ne t'enorgueillis pas, sois fidèle au roi!»

Léaco, le nôtre, prend la parole en sa qualité de mari de Nolianga, cousine du roi : - $\& \mathrm{Tu}$ es chrétien, ne l'oublie jamais. Dis toujours la vérité, même à ton maître. Sers le roi, mais sers avant tout Dieu! 》

Il est une heure; les orateurs se pressent à la tribune. Je demande la parole, devant rentrer à la maison avant la fin. Le roi fait faire silence. Je sors à mon tour, le parasol ouvert à la main: - «Mokamba, je te salue en ta dignité de Ngambéla. Voulant t'épargner, je ne t'ai pas donné ma voix. Tu as été élu, agis en homme! Que la justice et la vérité soient ta parure. Sers le roi, honore tout le monde, même les esclaves, crains Dieu! N'aie pas trop confiance en ta propre sagesse, recherche les conseils, mais surtout demande à Dieu lumière, sagesse et force. Qu'est-ce qui t'a élevé? C'est l'Evangile. Qui t’a élevé? C'est Dieu. Agis donc en chrétien. Ne regarde qu'en avant et en haut. Sois un conseiller fidèle du roi, aide-le à réformer les mours de la nation 》.

A ce qu'on nous a dit, les discours ont continué sans interruption jusqu'à trois heures. Mokamba, la tête brûlante, est ensuite conduit à l'eau; on l'asperge, on le revêt d'une belle peru de léopard et d'un magnifique pagne. Ainsi paré, il retourne à la place publique. La foule, les chefs en tête, lui rend la salutation royale (shwaelela), il salue le roi à son tour. Il est conduit au petit khotla de l'ancien Ngambéla, il y siège quelques instants et peut enfin rentrer chez lui.

Le lendemain, samedi, le roi m'envoie un messager pour me remercier d'avoir pris part à l'installation du Ngambéla par la présence et par la parole. A cinq heures, à la réunion de prières, jinvite tous nos professants:

$1^{\circ} \mathrm{A}$ bénir le Seigneur de ce qu'il a honoré son Eglise en appelant ua de ses membres à cette haute fonction de Ngambela;

$2^{\circ} \mathrm{A}$ intercéder afin que, en Mokamba, se réalisent ces paroles:- «Si quelqu'un administre, qu'il le fasse selon la force que 1)ieu lui fournit, afin qu'en toutes choses Dieu soit glorifié par Jésus Christ 》.

Louez Dieu avec nous, mais intercédez pour ce jeune homme; qu'il surmonte les tentations et honore l'Evangile! 


\title{
XCII.
}

Quelques fleurs et quelques fruits.

\begin{abstract}
Afrection pour les jeunes. - Ratification du mariage du Ngambela. - Premier évangélistes zambéziens à l'cuvre. - Baptêmes, - La petite église de LéaIni. - Intimité entre collègues. - Départ de rauluse et wille. - Gens bien disposés. - Rénnions de prières, - De la pitié. - Leçon de géographie.
\end{abstract}

23 Mars. - Nous avons fêté les Mann: c'est leur anniversaire de mariage. M. Mann est à peine remis d'une fièvre de huit jours et M.lle Specht en est au troisième jour de sa première attaque.

Mon cuisinier a été voir un sien parent malade. C'est Kwalela qui le remplace. C'est un gentil garçon, lent mais soigneux dans tout ce qu'il fait, et propre. Depuis que nous l'avons (février 1893), je ne l'ai jamais surpris disant un mensonge, et jamais, que je sache, il n'a volé. Il est doux et respectueux. Je dois bien rarement le réprimander.

Marumo, un jeune homme qui avait grièvement offensé sun ami, est venu s'humilier devant Kajata qui lui a répondu: «Je t'attendais. Quelques-uns me disaient: Que lui feras-tu? Le laisseras-tu comme cela? Je n'ai pas voulu me venger. 'Tu as offensé Dieu et attristé les missionnaires, tu as fait couler leurs larmes. Maintenant fais comme David, qui après s'être humilié a fait son possible pour plaire à Dieu. Que ceux qui t'ont connu comme un garçon de mauvaise vie, s'écrient: Où sont les façons de faire de Marumo? 》 C'est une grande victoire que Kajata a remportée, car il est naturellement boudeur et violent; c'est une victoire que l'Evangile a rapportée en lui.

Le 22 mars eut lieu à l'église la ratification du mariage de Mokamba et Mpololoa, devant environ 240 personnes. Cette cérémonie eut son importance comme condamnation du mariage paien. La princesse fit distribuer plusieurs plats de nourriture; puis nous eûmes les époux à notre table.

La conférence avait autorisé Pauluse et Willie à emmener leurs enfants au Lessouto et à prendre un congé d'un an. Deux autres évangélistes bassoutos avaient dû quitter la mission pour adul- 
tère. Ces évangélistes il faut les remplacer; aussi le moment est-il venu d'éprouver nos élèves évangélistes. Ah! s'il ne s'agissait que de connaissances intellectuelles, de notions élémentaires d'arithmétique ou de géographie, et même s'il n'était question que de la connaissance de la voie du salut, ce serait sans crainte que nous les verrions mettre la main à l'œuvre. Mais quelle sera leur valeur morale et spirituelle? Leur vie depuis leur conversion, et particulièrement depuis leur entrée dans l'école d'évangélistes, a été facile, relativement exempte de tentations. Que vont-ils donner comme ouvriers dans la vigne du Seigneur? Retirés hier du paganisme si corrompu du Zambèze, sans le soutien de parents ou de compatriotes chrétiens... que Dieu leur donne la fermeté et la fidèlité dont ils ont besoin et qu'il les garde de l'orgueil et de la soif de s'enrichir, qui sévit maintenant au bo-Rotsé, depuis les palais royaux jusqu'aux misérables huttes des esclaves. Prions afin qu'ils soient remplis de l'Esprit Saint. Filippi ira à Sefula, Samuele restera à Loatile pour y remplacer Willie. M. Béguin, privé de John, sera aidé par Adèle. Boiteux devant se rendre à Kazungula et être absent de sa station pendant quelques semaines, Pauluse Sesoaïra ira aider M.me Boiteux.

J'avais demandé à nos professants de Léalui de pourvoir aux besoins de l'évangéliste de Sefula. La collecte à cet effet, commencée par les professants de notre station, s'est faite avec entrain. Elle a produit en quelques jours un demi sac de maïs, 5 plats en bois et 6 francs 25 en monnaie. Cette fois encore plusieurs ont prélevé leurs offrandes sur leur propre nourriture, et ceux-là n'étaient pas les moins heureux.

Le samedi 25 mars, mes élèves évangélistes m'amenèrent à Sefula en canot: cette station avait encore l'air plus délabré que jamais; il ne restait que quelques bouts de palissades et la cour était toute envahie de hautes herbes. Le lendemain Pauluse fit ses adieux au premier culte. Au second j’installai Filippi et lui rappelai ses principaux devoirs. Je madressai ensuite aux 340 présents. Filippi fit allusion à ses années d'école à Sefula, puis à notre école d'évangélistes. "Comme Pierre, dit-il en terminant, je n'ai rien autre à donner que la guérison au nom de Jésus 》.

Samuele dit à son tour: "Vous ne me connaissez pas, regardez-moi. Mais ne vous attendez pas à ce que nous vous 
annoncions un autre Evangile que celui que vous avez entendu depuis des années. C'est vieux, mais c'est toujours nouveau.

J'eus Filippi et Samuele à dîner et passai la soirée avec Pauluse.

27 Mars. - Il y a doux ans que notre petit bien-aimé s'est envolé... Il est dans le Séjour de la paix et c'est là que nous le retrouverons.

En partant pour les Mafulo, Lewanika a débarqué à Loatile. Comme les années passées, il a accepté la collation que nous lui avons offerte. Son canot rapide lui a permis d'atteindre bien vite les deux Nalikwanda.

Le 30 le Ngambéla et sa femme nous revinrent à Loatile pour l'examen. Les sept candidats au baptême furent reçus le lendemain, vendredi saint. M. Béguin était venu pour la circonstance. Pauluse et Willie étaient aussi présents avec les membres de l'église. Le baptême, les allocutions, le repas en commun qui suivit, tout nous laissa d'excellents souvenirs. Dans les chants comme dans les prières, l'Esprit de Dieu se faisait sentir. Pendant la cérémonie comme pendant le repas, le Ngam. béla et la fille aînée $d u$ roi, étaient assis à côté de simples esclaves, affranchis par le Seigneur.

Nous bénîmes Dieu pour ces encouragements. La petite église de Léaluï s'agrandissait ainsi peu à peu. Puissent ces quatorze membres faire briller leur lumière à la gloire du Seigneur! Voici les nouveaux noms choisis par nos convertis: Mokamba (le Ngambéla) et Maria sa femme (ex Mpololoa); Yosefa (Moka) et Miriame sa femme (Nanjeke); Daniele (Setumba); Nguanangombe (Sewakutilibebe) et Maretha (Mathe femme de Filippi). Mokamba et Nguanangombe demandèrent à garder les noms qu'il avaient reçus de leurs mères.

$\mathrm{Du} 1^{\text {er }}$ au 11 avril nous fûmes en vacances à Nalolo, jouissant du repos et de la société de nos amis Béguin, Boiteux et Mercier. Nous nous y retrempâmes pour la tâche toujours si lourde que nous avons à remplir à Loatile. Le départ de Willie et celui très prochain de $\mathrm{M}^{\text {lle }}$ Specht, ainsi que les préparatifs pour le retour de notre vénéré M. Coillard, allaient encore ajouter à notre travail. Mais quel beau jour que celui où nous reverrons ce cher ami, et où je pourrai de nouveau me décharger sur lui de la responsabilité de l'œuvre de Léaluï! 
Pauluse et Willie arrivèrent à Nalolo le 8 , tristes du peu de secours qu'ils avaient trouvé auprès du roi, et du manque de sympathie des ma-Rotsé. Ils nous laissèrent à nous un grand vide. Sous son écorce un peu rude Pauluse est un homme de confiance, tel qu'il est rare d'en avoir parmi les indigènes. Quant à Willie, que nous avons eu comme aide depuis 1894, ce que nous avons le plus apprécié en lui ce sont les qualités du coeur, une délicatesse de sentiment que nous n'avons trouvée chez aucun autre noir, si ce n'est peut-être chez la brave Miriame (Nanjeke).

Nous nous délassâmes chez nos chers amis. Nous eûmes aussi nos fêtes spirituelles, les cultes de famille, la communion, le baptême de Blanche et le second anniversaire d'Eglantine Béguin. Que de bienfaits!

Le 12, un jeune chef d'environ 30 ans, dont j'avais déjà appris les bonnes dispositions, Letebele ou Samolila, vint me dire qu'il avait obtenu du roi la demi permission de s'établir sur la station pour apprendre à lire et à mieux connaître le Seigneur. Il avait été jusqu'à ces derniers temps, un des plus grands moqueurs du pays, et un blasphémateur.

Après-midi Elizabetha m'amena Ma-Nalishebo, une femme d'une cinquantaine d'années, travaillée dans son âme depuis plus de deux ans, mais empêchée de se déclarer par Katoka sa mâ̂tresse. Quoiqu'elle n'eût pas reçu la permission de celle-ci, elle ne pouvait plus se contenir. Elle voulait se déclarer ouvertement pour son Sauveur. Advienne que pourra.

Il y avait prière chez Elizabetha, matin et soir; beaucoup de femmes y accouraient, tellement que les deux cours se remplissaient. C'étaient de nouveaux encouragements que le Seigneur nous donnait.

14 AVRIL. - Ce matin à $6 \mathrm{~h}$. on frappait à notre porte pour nous annoncer la mort d'une petite fille, amenèe hier sur la station dans un ètat de délire qui ne l'a plus quittée. C'était une enfant de dix ans que Willie avait confiée à la gardienne de l'établissement de Yakobo. Cette pauvre petite, souffrante depuis le 11 courant, a étẻ laissée par ses cruels protecteurs, en proie à la fièvre, au grand soleil tout le jour et à la belle étoile pendant la nuit. Samuele (Selwendo) et Lumba qui en ont eu pitié, l'ont recueillie hier et l'ont soignée avec amour. Mon mari a fait pour elle tout ce qu'il a pu, mais inutilement. Personne ne pourra jamais dire combien 



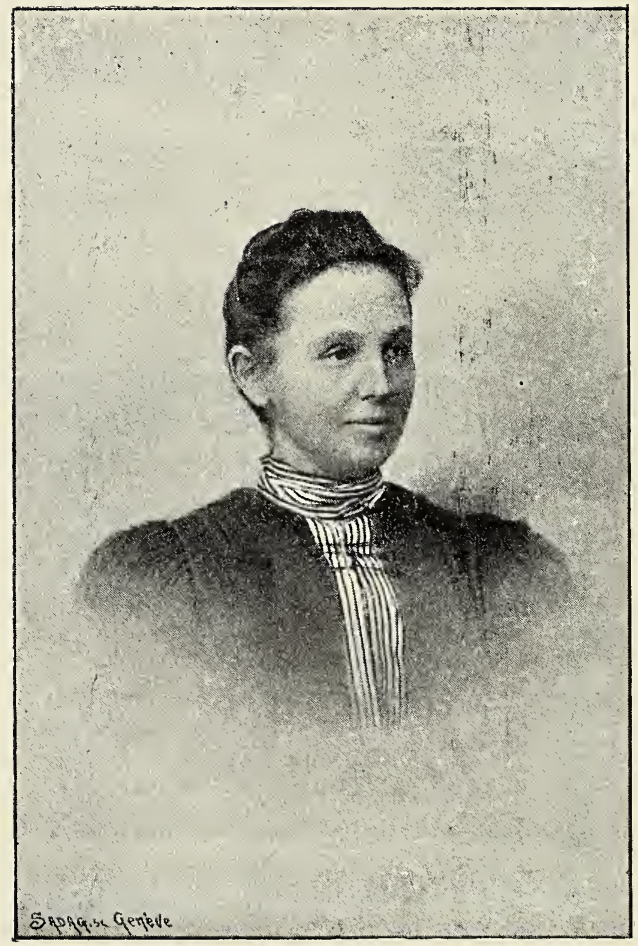

Maıie Jalla 
de pauvres enfants meurent ainsi, victimes innocentes de l'insouciance et de la cruautẻ de ceux qui les entourent. Le malheureux pays! Cette enfant était une mo-Toka, arrachẻe à sa famille, et amenẻe ici en esclavage. Dans ses accès de dẻlire elle appellait sa mère! Après un service funèbre on a été l'enterrer sur une termitière, qui sert de cimetière, à quelque distance d'ici.

Le 13 nous reprîmes, ma femme et moi, nos écoles, nos réunions et nos tournées à Léalui. Nous fûmes frappés de voir le petit nombre de gardiens qu'on y avait laissés, à peine 150 en tout.

Le soir, avec un globe et une lampe, je donnai à nos 3 écoles une leçon sur les phases de la lune, les éclipses et l'alternance des saisons. L'intérêt fut aussi vif que s'il s'était agi d'une séance de lanterne magique. Ce n'eût probablement pas été le cas trois ans auparavant. Cela prouvait le développement de l'intelligence de nos élèves.

\section{XCIII.}

Mort de Madame L. Jalla. - Séparation.

Marie est morte: - sympathie de Lewanika. - Vide immense à Sesheke. semence de vie. - Eenfort des 18. - Cruels contrastes. - Précieux amis. - Mariage de missionnaires. - Responsabilité. - Brave Miriame. Retour. - Inauguration du canal de Seoma. - Hospitalité zambézienne. - Braves rameurs. - Le revoir. - Vaillante femme.

I 18 avril pendant le déjeuner nous reçûmes une lettre 1 de mon frère Louis Jalla nous annonçant la mort de sa femme!

Quel coup de foudre! Nous ne la reverrons plus ici-bas, notre chère Marie, toujours vaillante et gaie nous accueillir avec le chaleureux empressement qui la caractérisait. Que nous avons peine a comprendre pourquoi Dieu prive mon beau-frère de sa prẻcieuse compagne et ses petits enfants de leur tendre mère. Notre mission elle aussi fait une grande perte. Elle était femme missionnaire dans l'àme. Quel affreux chagrin pour sa pauvre mère lorsqu'elle apprendra 
cette nouvelle! Le dernier soir de mon sẻjour à Seshéké, nous avions prié ensemble, Marie et moi, pour nos chers enfants, agenouillées côté à côte, dans l'obscrurite de sa chambre à coucher.

J'écrivis aussitôt au roi pour lui annoncer la triste nouvelle et lui demander un canot et un rameur expérimenté. Lewanika m'exprima sa sympathie pour notre deuil, en disant: "C'est moi qui suis malheureux de ce que nos missionnaires nous laissent, ou sont dans le deuil; c'est par ma faute, moi qui ne me convertis pas $》$.

Le 21 (1) j'arrive à Nalolo le soir même, et le lendemain soir à Senanga. J'y passe le dimanche. Partis de là le 24 avec M. Boiteux, nous arrivons à Sesheke le 29. J'aime le canot, cette vie en plein air me fait toujours du bien, surtout lorsque Dieu nous fait éviter tout ennui, tout retard, comme c'est le cas cette fois. Mais la tête et le cœur n'ont guères qu'une pensée.... J'aborde quelques minutes avant M. Boiteux, je traverse la place et entre dans la maison. Mon frère demande en sessouto: «Qui va là?....» je ne puis que pleurer avec lui. Dieu merci, je ne le trouvai pas abattu comme j'aurais pu m'y attendre; notre Père lui accorde chaque jour la force et la consolation qui lui sont nécessaires. Cependant le vide est là, immense. Tout dans la maison, dans l'œurre, rappelle sa femme; mais ses trésors d'amour et d'activité ne sont plus à notre portée. Le Seigneur l'a appelée au repos, ou bien à un autre service encore plus beau. Ici où mari et femme ont tant besoin l'un de l'autre, où ils ont tout en commun, où chacun des deux est le seul confident de l'autre, ne croyez-vous pas qu'ils sont plus encore l'un pour l'autre que ce n'est le cas en Europe?

Cette mort est un profond sillon creusé par Dieu, dans lequel il jette la semence, une semence de vie, il le fera pour nous, pour mon frère si affligé, mais ne sera-ce pas aussi le cas pour plus d'un Zambézien? Que d'attaches nouvelles avec le ciel! Quels avertissements pour nous qui restons. Veillons et travaillons, il n'y a que douze heures au jour. Elle a travaillé, ma chère belle-sœur, elle a été pour mon frère un aide semblable à lui, ayant tout son cœur à l'œuvre.

5 MaI. - Un courrier nous apprend que M. Bœgner est venu

(1) Extrait du Journal des Missions. 
jusqu'à Bulawayo, et que la nouvelle expédition missionnaire est forte de 18 personnes! Que Dieu bénisse leur arrivée dans ce pays! Qu'il prépare aussi les ma-Rotsé à recevoir ce beau don. Nous recevons encore la nouvelle de la mort de Yakobo l'interprète, survenue peu après son arrivée au Lessouto.

7 MaI. - Je fais le culte du matin. Après la prédication Akanangisoa se lève et déclare vouloir servir le Seigneur, elle s'humilie pour tout le mal qu'elle a fait et demande aux missionnaires et aux professants d'intercéder pour elle afin qu'elle soit fidèle.

11 MaI. - LÉaluï. La vie a de cruels contrastes: pendant qu“a Sesheke un époux pleure sa compagne et qu'un foyer voit disparaitre celle qui en faisait le charme, ici nous faisons des préparatifs pour un mariage.... M. Pickering est arrive hier à $4 \mathrm{~h}$. et son mariage avec M. ${ }^{\text {lle }}$ Specht aura lieu, D. v., le 16.

Il y 8 jours, comme nous achevions tranquillement notre thé, les Mann et moi, nous entendons plusieurs coups de fusil. C'était M. Mercier qui venait m'aider dans mes travaux!.... Quelle fatigue pour recrépir notre maison, mais que tout est frais et joli après!

21 MaI. - Si vous pouviez voir le tas de lettres qui est là devant moi, vous frémiriez avec moi, et pourtant il n'y en a pas une de trop quand il s'agit de les lire. Quels puissants souffles d'amour et de sympathie elles nous apportent, et que nous nous sentons petits devant ce grand concert de voix connues et inconnues qui nous redisent à travers l'espace: Nous sommes avec vous, votre œuvre est la nôtre, vos joies sont les nôtres et nous partageons vos deuils et vos difficultés. Oui, ils portent avec nous le faix du jour ces amis qui font de notre détresse la leur, et qui par un suprême effort arriveront à couvrir les énormes frais de l'expédition de notre vẻnérẻ $M$. Coillard.

Il est donc à la porte du pay's notre ami et notre père, et Dieu voulant, nous allons le revoir sur notre termitière, nous allons jouir encore de sa bienfaisante influence, et de la paix sereine et joyeuse qui entre toujours avec lui. Pourquoi faut-il qu'un voile de deuil assombrisse ce revoir et que notre belle-sceur ne soit plus là pour voir arriver le doyen de notre mission et le puissant renfort qu'il nous amène? Voilà, j'espère, des forces qui renforcent, voilá toute une colonne de jeunes et ardents ouvriers. Que Dieu anime chacun d'eux d'un esprit de zèle et d'amour, et d'entière consécration à l'œuvre!

Le mariage s'est fait le 16 courant. Le 15 j'eus une affreuse 
nèvralgie et ne pus avoir un instant pour m'étendre. Le Ngambela survint avec des lettres à écrire au nom du roi. Puis Madame Bèguin arriva, plus tard ce fut son mari; il fallut confectionner le gâteau de noces, terminer le courrier, bref il était minuit quand nous pûmes, les Béguin et moi, gagner enfin nos chambres.

M. Mercier avait joliment orné la salle à manger de grandes palmes... Les époux entrèrent à l'église à $11 \mathrm{~h}$., suivis de M. Béguin, le pasteur officiant, et de sa femme, M. Mercier et moi, M. et $\mathrm{M}^{\mathrm{e}}$ Mann et notre maisonnée. La cérémonie fut solennelle. Nous avons chanté des hymnes anglais. Le déjeuner qui suivit a été très animé.

Le lendemain tous mes hôtes partirent, je pus enfin jouir d'un peu de calme.

25 MaI. - Que les femmes restẻes à Léaluï ont l'air heureux en l'absence de leurs seigneurs et maîtres. "Que faites-vous donc tout le long du jour? leur demandai-je aujourd'hui. - Nous restons assises », me répondirent-elles. Et en rẻalitẻ ces pauvres crẻatures ne conçoivent rien de plus désirable, que de se chauffer au soleil ou de se tenir à l'ombre, tout le jour, les mains sur les genoux, à bàiller aux corneilles. Elles ne comprennent rien à notre manière de comprendre le repos.

Quelle charmante jeune femme que notre Miriame, toujours douce, gaie, et serviable. Je suis reconnaissante que Dieu l'ait amenée sous notre toit. Elle m'a procuré quelques unes des plus grandes satisfactions de ma vie au Zambèze.

13 mar, Séchéle. - Des messagers nous amnoncent que la nouvelle expédition est plus loin que nous ne le pensions. D'après eux, M. Coillard ne pourrait pas atteindre le Zambèze avant le 27 , et cela semble probable puisque nous n'avons encore rien reçu de notre doyen.

Ce fut les yeux remplis de larmes et la poitrine oppressée, que le 15 je laissai mon frère seul sur la rive. Nous arrivâmes à Seoma le 20. Le dimanche 21 nous eûmes deux cultes avec 70 auditeurs, et allâmes faire un tour aux chutes. Le 22, à la requête des chefs de Seoma et des envoyés de Lewanika, nous allâmes inaugurer et inspecter le canal qu'ils avaient imaginé de faire dans une dépression naturelle. Nous en fûmes agréablement surpris. Le canal proprement dit a environ 1100 mètres de longueur, et ses berges ne dépassent nulle part $\mathrm{m} .1,20$ ou m. 1,30. Sur une longueur d'environ 300 metres, l'eau forme un rapide impraticable d'environ 10 ou 12 mètres de pente, à 


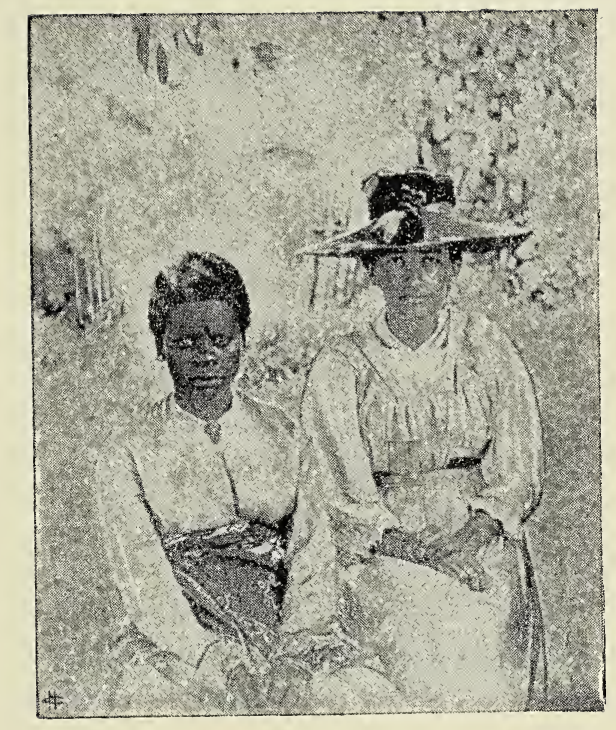

Madame Ad. Jalla et Miriam . 

travers rocs, broussailles et buissons épineux. En aval, l'eau trouve une nouvelle dépression naturelle, puis un petit lac, encore une dépression et un autre lac, de l'extrêmité duquel on atteint le Zambèze par un rapide court et facile. Les gens venaient d'ouvrir le canal, à la prise d'eau, quand nous arrivâmes le samedi; nos canots furent les premiers à y passer le lundi, ils furent amenés sans peine. Je félicitai les chefs pour leur travail, et promis d'en faire au roi un rapport élogieux.

Le 25, laissant nos compagnons de voyage, nous poursuivons avec mon canot, nous nous enfonçons à travers la plaine que mes rameurs ne connaissent que très imparfaitement; nous zigzaguons beaucoup, et une demi heure après le coucher du soleil nous abordons à un petit village où nous demandons l'hospitalité pour la nuit. Aussitôt on met à ma disposition l'abri du Khotla (toit cônique posé sur des pieux). De chaque maison on apporte une natte neuve pour l'entourer, on nous donne du bois (objet précieux qu'on amène de bien loin), et le chef du village offre à mes rameurs un plat de courges et un de bouillie de sorgho. Voilà un bel exemple d'hospitalité zambézienne, donné par le brave Imangolwa et ses gens. Ils s'unirent à nous pour les cultes du soir et du matin.

Le 26, malgré le froid, nous partons à $7 \mathrm{~h}$. Vers midi et demi nous laissons Nalolo à gauche; au coucher du soleil nous sommes à Sebembi, mais sans que j'aie un mot à dire, mes braves gens décident de pousser jusqu'à Loatile, où nous arrivons vers $11 \mathrm{~h}$., après 15 heures de navigation dans la journée.

Toute notre maisonnée est bientôt sur pied, malgré le froid de la nuit, pour souhaiter la bienvenue. Quelle joie de se retrouver après 36 jours d'absence! Seuls les Mann n'ont rien entendu, je les surprendrai le lendemain chez eux. Une tasse de thé me tient lieu de dîner.

Dieu m'avait accordé un voyage rapide et facile. Je n'avais pas eu la moindre difficulté avec mes gens. Gideone et Daniele, Ananyatele, l'officier royal que Lewanika m'avait donné, et les trois autres rameurs, ont toujours été complaisants et prévenants. Est-ce que les gens à cravache pourraient en dire autant de leurs expéditions?

Et pendant toute mon absence, ma chère femme n'avait eu que du plaisir avec sa grande maisonnée, élèves évangélistes, jeunes femmes et jeunes filles, garçons et ouvriers, c'était à 
qui la servirait ou l'aiderait le mieux; bien que ce fût un temps de travaux de toute espèce. Car on a brassé de l'ouvrage en mon absence. Ma vaillante femme a eu l'œil et la main à tout, aux choses matérielles et aux spirituelles, en plus des soins à donner à notre fille souvent malade.

\section{XCIV.}

Lewanika et la polygamie.

Diminution de la fréquentation des cultes. - Le harem. - Razzias.

Conversation avec Lewanika sur la polygamie.

$T^{E}$ trouvai la capitale repeuplée depuis le 25. Lewanika

e me questionna beaucoup sur la mort de ma belle-sœur; il fut très affable. La seule ombre au tableau ce fut que les cultes du dimanche 28 , furent peu fréquentés, et que tous les chefs et officiers y brillèrent par leur absence (les deux chefs chrétiens exceptés). Quelle en était la raison? Etait-ce parce que taut à Loatile qu'aux Mafulo la chaire avait été occupée par nos élèves évangélistes, et que plusieurs considéraient comme au dessous de leur dignité de les écouter? Il pouvait y avoir de cela. Mais la principale cause était probablement autre.

Le roi avait décidé, malgré mon opposition constante, de faire bâtir des maisons rectangulaires pour ses femmes, à commencer par les quatre plus importantes. C'était une profession de paganisme et une manière de dire qu'il était loin de songer à se convertir, c'était un défi au christianisme. Le discours en acte avait été compris par les chefs et officiers et par la nation. Or, pendant des mois on n'avait parlé que de razzias, on voulait en faire trois simultanément, à l'Est, au Nord, et à l'Ouest. Dieu merci, les deux dernières avaient échoué. Nalishua, le chef de la première, était parti en février; son corps expéditionnaire avait dû se former loin des yeux du missionnaire, auquel on avait assuré qu'il ne s'agissait que de rétablir la paix entre deux chefs ma-Toka. Ils avaient coopéré avec les troupes de la police, et amenèrent à la capitale des centaines de têtes de bétail comme butin. 
Le 6 juin, j'eus avec Lewanika une longue et sérieuse conversation: "On travaille beaucoup dans ta capitale, lui dis-je; dans tous les coins j'ai vu des hommes, la hâche à la main, préparant pieux, chevrons et sablières. - Eh oui! - J'en suis bien triste, tu persistes donc dans ton dessein de bâtir des maisons stables pour tes principales femmes. - Tu as bien dit. - Tu entends donc affirmer bien haut que tu es paien et que tu veux le rester, tu es polygame et tu ne songes pas à changer. Ne crains tu pas que ceci ait une mauvaise influence sur la nation? - Beaucoup de mes sujets voient la chose comme le missionnaire. - Oui, mais eux s'en réjouissent. N'est-ce pas pour cela que depuis mon retour de Sesheke je n'ai vu ni chefs, ni officiers aux cultes. - C'est probable, mais ce serait mal de professer ce que je ne suis pas. - Sans doute, mais c'est tout aussi mal de persister à violer la loi de Dieu. Ne sais-tu pas que tu la transgresses? - Je sais très-bien que Dieu condamne la polygamie. - Eh bien, maintenant que tu en as les matériaux, construis une grande maison pour celle qui sera ton unique femme, et convertis-toi ». Sur ce, il changea de sujet.

\section{$\mathrm{XCV}$.}

Pour recevoir M. Coillard.

Le Ngambela a Ia rencontre de M. Coillard. - Notre père est de retour : Salut, missionnaire.

Tokamba partit le 12 pour Sesheke, envoyé par le roi I à la requête de. M. Coillard. Nous avions eu un bon service de communion la veille. Notre Ngambela semblait avoir plus de courage et plus de zèle pour rendre témoignage à son Sauveur. Un dimanche qu'il s'était trouvé aux campements de chasse de Mokwae et il y avait tenu les deux cultes. Il en avait agi de même à deux reprises à ceux du roi, c'est encore lui qui y assemblait les gens alors qu'un élève évangéliste allait y présider les services. 
J'eus aussi de bonnes nouvelles de Sefula. Filippi s'y occupait avec amour de l'école, des classes de catéchumènes et de l'évangélisation.

Nous consacrâmes deux heures par semaine à apprendre les chants de bienvenue que j'avais composés pour $M$. Coillard et les nouveaux missionnaires.

NTAt'A RONA o KHUtLiLe.

1.

Bitso la hao le tume

U sebetsa tse hlollang.

U natlafatsa ba shuang,

Ntat'a rona o khutlile!

Morena ba u trepang,

$\mathrm{Ba}$ fofa yualeka ntsu

Ba tiea le boqhekung

Matla óhle ke a hao

\section{2.}

Lerato ha le fele

Lu u le tselang moeeng,

Ke mollo o sa timeng,

Ntat'a rona o khutlile!

Mollo u o hotetsang

O hloleha Molimo

O tuka le boqhekung,

U liba sá lerato.

3.

Uen'a re lopalotseng

Mohloli oa nyakallo

U n'u mo roese thabo

Ntat'a ronia khutlileng

Moatisetse bana

$\mathrm{Ba}$ holisetse hloekong

A elisoe boqhekung

Thabo e tsua ho uena.

4.

Matla a hao ha a hloloe

U nts'u khantsa lerato

Me re bina ka thabo;

Ntat'a rona o khutlile!

Re boka, re leboha

Molim'o re hauhetseng,

Re re ka ntsue le le leng

Thoko li be ho vena!

\section{LUMELANG, BARUTI!}

Lumelang, baruti, lumelang baruti

Ba tlileng lebitsong la Morena

Rea kandelela, rea le leboha

Re aka letsoho la 'Moloki.

Bontate, le bo' nie,

Molimo le o sebeletsang

0 'no o le boloke

Le hlohonolofale

Lumelang, baruti, lumelang!

\section{NOTrE PÈre EST REVENU.}

1.

Que ton nom retentisse

$T u$ fais des miracles

Tu rends la force aux mourants,

Notre père est revenu!

Seigneur, ceux qui se confient en toi

Volent comme l'aigle,

Ils sont forts meme dans la vieillesse.

La toute puissance t'appartient.

\section{2.}

L'amour n'a pas de fin, Celui que tu verses dans l'ame C'est un feu qui ne s'éteint pas :

Notre père est revenu. Le feu que tu allumes Est durable, ô Dieu, Il brille même dans la vieillesse.

Tu es le puits de l'amour.

4.

Toi qui nous as rachetés

Source de l'allégresse

Pare-le sans cesse de joie

Notre père qui est revenu. Multiplie-lui les enfants, Fais-le croître dans la pureté, Qu'il soit illuminé dans la vieillesse, La joie procède de toi.

\section{4.}

Ta force ne se vainc pas,

Tu fais sans cesse resplendir l'amour, Et nous chantons avec joie:

Notre père est revenu!

Nous louons, nous remercions

Le Dieu qui a eu pitié de nous,

Nous disons d'une seule voix:

Que les louanges soient à toi!

Salut, missionnalres !

Salut missionnaires, salut missionnaires Venus au nom du Seigneur,

Nous battons des mains, nous vous remercions

Nous baisons la main du Sauveur.

Nos pères, et nos mères,

Le Dieu que vous servez,

Qu'il vous garde sans cesse

Que vous soyez heureux:

Salut, missionnaires, salut! 


\section{XCVI.}

\section{À l'œurre avec des constitutions minées.}

Notre joie. - Constitutions minées. - Levée de boueliers - Samuele, Lewanika et la discipline. - Le Lewanika que nous aimons et l'autre. - Mensonge et mendicité des grands. - Mort de Madame Bouchet. - Naissance d'Arnold Mann. - Tournée d'évangélisation. - Le grenier de Léalui. - Bonne øuvre de Filippi. - Travaux compliqués. $\neg$ L'ouvre, ses tristesses et ses joies.

23 JuIN. - Notre vie suit son cours habituel, remplie, régulière, égayée et rafraichie chaque jour par notre brunette bouclée. C'est $\dot{a}$ elle que nous revenons après les déboires et les tristesses, $\dot{a}$ elle dans les ennuis et les lassitudes, qui comme des flots envahissants passent quelquefois sur nous. Mon mari a eu la fièvre toute la semaine, avec insomnies, aussi chacun (même le roi aujourd'hui) est-il frappé de l'altération de ses traits. Malgré son épuisement, il continue à vaquer à toutes ses occupations.

26 Juin. - Je souffre moi aussi d'une lassitude gẻnérale depuis quelques jours et de névralgies accompagnées de fièvre. Après 7 ans de Zambèze, plus de 7 1/2 d'Afrique, la constitution n'est plus forte, et je ne suis ici que depuis 7 ans. Mon mari, malyrẻ son court sejour en Europe, a bientôt 10 ans de séjour, aussi est-il beaucoup changé.

3 JUILLET. - Le major Gibbons a été notre hôte pendant quatre jours. Il est maintenant chez le roi, à la dépendance de Nayuma. Nous l'engageons à venir nous surprendre souvent, mais je suis trop fatiguee et trop occupée pour insister auprès de lui afin qu'il fasse un long sejjour sous notre toit. Son voyage a été interrompu par le mauvais vouloir de ses gens.

Quant à moi, je ne sais si vous me reconnaîtriez. Ici, on n'a de couleurs que celles que la fièvre donne.

J'avais laissé tomber la leçon de composition en sessouto, que Willie donnait à l'école primaire supérieure. Mais j'avais remarqué que l'orthographe et le style des élèves laissait de plus en plus à désirer. Quant à la coordination des idées, ils n'en 
avaient aucune notion. Or ce sont des choses qui ne peuvent être enseignées avec profit que dans une langue que l'on possède. D'accord avec M. Mann, je leur déclarai le 4 juillet que j'allais leur donner une heure par semaine pour la composition. Cela provoqua une levée de boucliers: «À quoi bon le sessouto? nous en saurons toujours assez !... ». Je leur réponds calmement que je ne leur ai pas demandé leur avis. Le 7 ils m'écrivent que non seulement ils ne feront pas ce que je leur ai commandé, mais qu'ils ne veulent plus d'autres leçons que celles d'anglais et d'arithmétique, tout le reste ne leur sert de rien! Le 10 je leur lis la lettre et demande à chacun des onze s'il l'approuve. Sur leur réponse affirmative je leur dis qu'ils sont exclus de l'école, et qu'ils doivent rendre ardoises, livres, cahiers etc. Ces gens, qui depuis des années reçoivent tout, tout gratuitement, il voudraient nous dicter la loi, et quelle loi! Les élèves évangélistes blâmèrent énergiquement cette conduite.

Hélas! ce que j'avais dit au roi quand nous nous proposions de fonder cette école, que l'instruction sans la conversion ne produit pas grand'chose qui vaille, n'était que trop vrai.

Je craignais qu'il ne se sentîssent appuyés par plus d'un chef. Je ne soupçonnais pas Lewanika, qui nous a toujours sontenus dans les questions de discipline, et qui m'avait déclaré avoir confiance en nous pour les programmes des écoles.

Samuele avait frappé une fille du roi, âgée de 12 ans, et avait brisé un de ses bracelets d'ivoire. La princesse avait cru ne pas devoir respect et obéissance à notre évangéliste, elle l'avait poussé à bout, pensant qu'un esclave affranchi ne pouvait avoir d'autorité sur elle. Samuele était venu vers moi craignant les conséquences de son coup de baguette. Que me dit le roi ? Il approuva l'évangéliste et m'exprima sa tristesse de ce qu'une de ses enfants ne se conduisait pas bien. Il chargea un de ses serviteurs personnels d'aider Samuele dans l'exercice de la discipline. Moi, je grondai l'évangéliste. De tels châtiments pour de légères fautes ne pouvaient que nuire à son autorité morale.

A part cet incident, notre brave jeune homme, de nature timide, ne se tirait pas mal d'affaire à cette grande école. Il est vrai qu'il n'était pas seul. M. Mann et moi, nous nous occupions souvent de la première classe, ma femme avait toujours la seconde, et pour les cinq autres les élèves évangélistes donnaient quelquefois un coup de main. 
C'est ainsi que les dispositions de Lewanika (1) sont encore telles que nous les avons décrites plusieurs fois. Pour nous il s'est toujours montré aimable. Il nous a souvent aidés, nous et nos collaborateurs, par des envois de nourriture; dans nos difficultés il s'est montré un ami, et dans nos deuils il nous a manifesté une vive sympathie. Il nous a été d'un grand secours pour l'école de Sefula et pour la fondation de la station de Senanga. Bien que j’aie continué à agir comme si j'étais sa conscience, l'encourageant ou le reprenant, selon le cas, il a toujours été affable tant chez lui que chez nous. C'est grâce à lui que nous n'avons pas encore dû payer le frêt des canots et que $M$. Coillard a pu en obtenir un assez grand nombre. Lors de la mort de l'ancien Ngambela il a empêché qu'on retournât aux pratiques païennes. Dernièrement il s'opposa formellement à ce qu'on fit le massacre des sarcelles et des cigognes pêcheuses un dimanche, quelque pressantes que fûssent lẹs objections de ses conseillers. On se rappelle comment il a motivé le choix de notre Mokamba comme nouveau Ngambela. Voilà le Lewanika que nous aimons.

Hélas! il y a un autre homme en lui, celui qui se laisse posséder par le démon de l'or, celui qui en dépit du contrat voudrait nous obliger à payer ses bœufs qui ont péri à Palapye, et même ceux qu'il y a vendus à un fort prix; c'est l'homme charnel qui, loin d'abandonner la polygamie, l'affirme en donnant plus de stabilité à son harem; c'est l'homme faible qui se laisse diriger par le parti rétrograde, maintient le culte des ancêtres et prétend à l'occasion faire la pluie; c'est l'homme qui résiste aux appels de l'Evangile et en évite souvent la prédication. Mais ne croyons-nous pas au marteau qui brise le roc et à l'efficace du sang de notre Sauveur? Continuons à prier pour cet homme auquel la mission doit tant, et dont la conversion pourrait amener celle de milliers de ses sujets.

13 JUILlET. - Dimanche nous avions au culte quatre femmes du roi ; c'était un véritable évènement. Je leur en marquai ma joie en les saluant à la sortie: "Mes mères, revenez à votre ancienne coutume, venez au culte chaque dimanche! - Oh! mais, me rẻpondit l'une d'elles avec un large rire, nous venons toujours, ma mère». C'est ainsi que nos Zambéziens certifient les choses les plus contraires à

(1) Extrait du rapport de station. 
la vẻrité, sans la moindre hésitation, par habitude et en guise de plaisanterie.

La vieille Ma-Rhosi, mère du roi, nous reçoit toujours avec plaisir et surtout lorsque Graziella est avec nous. Pour nous prouver son attachement, elle envoie parfois à la fillette un plat de maïs ou de patates. Mais elle nous fait aussitôt demander du sucre, du savon, de l'étoffe. À ses yeux, cette demande de sa part est un signe tout aussi certain de son amitié. En effet, le Zambézien croit honorer celui auprès duquel il mendie, mais il admet le refus et reviendra parfois à la charge avec tant d'insistance que l'on cède pour se dẻbarrasser de l'importun. Que de fois j’ai pensé ici à la parabole du juge inique!

Le 14 juillet nous apprîmes la mort de M. ${ }^{\text {me }}$ Bouchet, déjà fauchée moins d'un mois après son arrivée au Zambèze! Et pour son mari quel rude début dans la carrière missionnaire!

Le 15 août, M. Mann et moi, avons fait ensemble une course à cheval. Après avoir présidé un culte dans le grand village mo. Mbunda de Moni-Siengele, nous atteignons enfin le commencement de la forêt et une demi-heure plus tard nous voilà dans la vallée de Nametome. Bientôt nous discernons la hutte d'Elizabetha. Pendant que la brave femme nous prépare des rafraîchissements et que M. Mann repose sa tête fatiguée, je vais à pied au confluent d'un vallon. Nametome est une vallée de près de 3 kilomètres de largeur, se subdivisant en plusieurs vallons pouvant avoir 30 kilomètres de longueur.

Pendant longtemps, cela n'a été qu'une suite de marais inhabitables: mais depuis 1894 et 95 , Lewanika les a fait draîner, avec un double but: alimenter le canal de Lealui, et gagner ce terrain à l'agriculture. Il a pleinement réussi. Dès lors le canal a toujours de l'eau courante et cette vallée a des milliers d'habitants, et est devenue le principal grenier de la capitale.

Après un culte nous rentrons chez nous, harassés et fiévreux. Ma fièvre à moi est commode et me permet de travailler du matin au soir, pour revenir toutes les nuits malgré les cures préventives.

Le 18 je reçois des élèves de l'école primaire supérieure une lettre de rétractation. Ils s'humilient et promettent d'accepter désormais le programme que leur donneront leurs professeurs.

Le 21 nous arrivons à l'improviste à Sefula, M. Mann et moi. Nous y trouvons Filippi dirigeant son école avec ordre et au- 
torité. Les 45 élèves présents sont divisés en 6 classes. Un rapide examen de lecture et de chant pour toute l'école et d'arithmétique pour la $1^{\text {re }}$ classe (multiplication par plusieurs chiffres) nous prouvent que le maître est bien à son affaire. La chapelle a été fraîchement recrépie avec le concours bénévole des élèves et des catéchumènes femmes. Filippi a maintenu la classe de catéchisme du matin. Dieu s'est réservé un levain même à Sefula, qu'il en soit loué! La station est dans un état de propreté que je n'ai jamais vu du temps de Pauluse. On en oublie presque les ruines. Quelques livres de verroterie et la direction de Filippi ont produit ce changement.

Le travail semble s'être accumulé durant l'absence que mon mari a faite pour se rendre auprès de son frère affligé. Tout rèclamait sa présence. Puis ces dernières semaines notre temps a èté encore rempli par toutes sortes de travaux et de préparatifs; il fallait donner le meilleur air possible à notre termitière... mais tout est compliqué par le manque de matériaux: les roseaux, l'herbe, le bois, tout cela n'arrive pas facilement jusqu'ici et l'installation des nouveaux habitants de notre monticule sera moins confortable que nous ne l'eûssions désiré. Cependant chaque bâtiment a été recrépi. Perdue au milieu de la plaine désolée et nue, la station se voit de loin, repose les yeux et parle de civilisation. Elle est presque coquette avec ses grands eucalyptus.

Que dire de l'œuvre? Elle se poursuit avec ses déboires et ses joies. Liesprit de sainteté et de droiture exerce encore peu d'influence sur les cœurs. Nous avons eu bien des déceptions et des chagrins, et nous nous sommes souvent sentis abattus, tristes et fatigués ces derniers mois. Nous avons besoin sans cesse de penser $\dot{a}$ Pierre et aux flots tumultueux qui l'effrayaient. Que Jésus nous enseigne à toujours tenir nos regards fixẻs sur lui!

Satan continue à rôder autour de nos professants, comme un lion rugissant, il en a dévoré plus d'un et nous avons tremblé pour plusieurs. Ce qu'il faut, c'est l'onction céleste, une effusion plus complète de l'Esprit de vie, de sainteté et d'amour.

Les élèves évangélistes ont encore été notre sujet de joie le plus constant. Pendant l'inondation, ils nous ont si bien secondés qu'aucun culte n'a été manqué ni sur la station ni aux Mafulo, et que bien des villages ont été visités. Pendant mon absence, les deux restés à Loatile ont été le bras droit de ma femme: les deux qui ont ramé dans mon canot ont été arec 
moi aux petits soins, comme des fils dévoués. Les trois autres se sont acquittés de leur tâche d'évangélistes à notre grande satisfaction. C'est là une récompense pour laquelle nous bénissons Dieu de tout notre cour.

\title{
XCVII.
}

Le retour de M. Coillard. La maison et les mains pleines.

\author{
A Nalolo, at la rencontre du renfort. \\ Lesprit missionnaire. - Arrivée du renfort. - Sujets d'angoisse. \\ Réception princière. - Willie l'éthiopien, ses menées. - Feulle de route. \\ Nos hôtes.
}

Nalolo 28 aout. - Nous sommes venus ici le 25 pour y rencontrer M. Coillard et nos nouveaux collaborateurs, mais ils tardent. Nous étions bien fatiguès; le changement a coupé la fièvre qu'Adolphe avait toutes les nuits, et cela nous a fait du bien de causer avec nos amis, de nous sortir de notre station, où le travail abonde toujours avec préoccupations et soucis de toutes sortes.

29 Aout. - Je suis fatiguee et cependant mon travail habituel me manque. La perspective du séjour que M. Coillard et nos amis feront chez nous fait tressaillir notre cœur. - Je vous parle de ma fatigue. Fatiguée, hélas! c'est le refrein habituel, mais c'est la vẻrité. Le Zambèze use. Les mois comme ceux que nous venons de traverser comptent double.

Nous sentons vivement et douloureusement l'absence de $\left(\mathrm{M}^{\mathrm{mo}}\right.$ Louis Jalla) Marie, cette femme missionnaire dans l'âme. Il ne suffit pas de venir en Afrique pour être missionnaire. L'esprit missionnaire ne vient pas tout seul, au contact immédiat de ce que le paganisme a de répulsif et de désagréable à nos sens européens et christianisés. Que Dieu suscite parmi nous de vraies femmes missionnaires qui aiment les noirs et fassent du Zambèze leur seconde patrie. - Comme je me rẻjouis d'avoir Madame Liẻnard et Madame de Prosch pendant quelques mois à Loatile! Ce n'est pas le travail qui nous manquera. Quel champ de labeur pour l'activité de femmes missionnaires que ce grand village de Léalui !

Le vent souffle avec violence et contribue à augmenter ma fa- 
tigue. Je ne m'habitue pas à cette atmosphère débilitante, au contraire...

Il y aurait beaucoup à dire sur' notre séjour à Nalolo, l'arrivée du renfort, le revoir avec notre cher M. Coillard, la conférence, notre anxiété pour Mesdames de Prosch et Rittener, et puis l'arrivée de M. Coillard à Loatile, l'accueil princier qui lui fut fait etc... etc. Les descriptions ont paru ailleurs. Je m'en tiendrai à des détails complémentaires extraits de nos lettres.

31 Aout. - Un premier canot s'arrête. C'est M. Coillard qui en sort, M. Coillard toujours le même, mais rajeuni, fortifié. Il nous embrasse. Nous sommes trop émus pour beaucoup parler.

LE 7. - Nous faisons les derniers préparatifs. Je vais chez le roi règler les détails de la réception à faire à $M$. Coillard. À $6,30 \mathrm{~h}$. du soir une lettre de notre cher doyen nous apprend qu'ils passent la nuit près d'ici, et que Madame de Prosch a heureuseument surmonté la crise.

LE 8. - Nos Zambéziens savent mieux se réjouir avec ceux qui sont dans la joie que sympathiser avec ceux qui pleurent. Il ne nous manque qu'un profond réveil parmi eux pour que jous soyons aussi heureux que des missionnaires peuvent l'être ici-bas.

LE 17. - Mort du Natamoyo. Le Ngambela est le seul chef qui vienne sur la station. Malgré cela nous avons 350 personnes au culte principal. Ma femme a 120 enfants à l'école du dimanche.

LE 18. - MM. Mercier et Rittener arrivent de Nalolo et seront nos hôtes pour quelques jours.

Je reçois une bonne lettre de Willie, de Bloemfontein, pleine de remerciments pour tout ce que nous avons fait pour lui depuis 1894, et surtout depuis la mort de sa femme. Il m'écrit combien lui ont été utiles les lettres de recommandation que je lui ai données pour les missionnaires des différentes villes où ils ont passé, et m'en demande d'autres pour les pasteurs et missionnaires de la Colonie du Cap, de l'Etat Libre de l'Orange et du Transvaal.

LE 20. - Lewanika m'envoie une lettre, afin que je la lui traduise par écrit. Je l'ourre et reconnais l'écriture de Willie. 
Je vais la refermer sans la lire, quand mon regard tombe sur ces mots: Ne te fie pas à tes missionnaires..., je poursuis... ils ne t'aiment pas; c'est nous seulement qui t'aimons, nous qui sommes de la même race... Bref, c'est une lettre nous dénigrant, pleine des principes de l'éthiopisme, et promettant qu'ils vont rentrer au bo-Rotsé, bien outillés, prêts à fonder toutes sortes d'écoles, industrielles et autres. Il demande à Lewanika de leur bâtir les établissements dont ils lui ont parlé (lui et Yakobo!) Je fais part de ma triste découverte à toute la famille missionnaire.

Après l'école, je vais chez Lewanika, lui dis que la lettre qu'il m'a envoyée est de Willie, et lui offre de la lui lire, (Lewanika lit très difficilement l'écriture). Il a l'air gêné, mais n'ose pas refuser. Quand ensuite je le questionne, il m'avoue qu'en effet Yakobo et Willie lui ont parlé de leurs projets, mais il avait cru qu'ils les avaient faits avec nous!

LE 29. - Nous avons eu Akanangisoa à dìner. Elle est si agréable, si douce et respectueuse! et comme son expression a changé.

2 OCTOBRE. - Nous avons maintenant chez nous 7 hôtes. Le D. $r$ de Prosch et sa femme nous sont arrivés à $5 \mathrm{~h}$.

LE 9. - MM. Burnier et Verdier sont arrivés le 5, à cheval, pleins d'entrain, après un long et pénible voyage en wagon. MM. Mercier et Rittener sont repartis le 6 pour Nalolo, après avoir creusé un puits dont ils ont doté la station. Quel luxe! - Au. jourd'hui $\mathrm{M}$. et $\mathrm{M}^{\mathrm{me}}$ Liẻnard se sont mis à leur ménage.

Le docteur croit que le moment est tout-à-fait venu pour nous d'aller en Europe, il voudrait même nous voir partir immédiatement; nous ne croyons pas que ce soit possible. M. Coillard voudrait encore nous garder deux ans. Il a demandé à Adolphe de continuer l'œuvre missionnaire comme s'il ny était pas, sauf pour un des cultes du dimanche. Notre tâche n'a donc pas encore diminué, au contraire.

Hier nous avons eu un bon culte le matin, auquel assistaient environ 500 personnes. Après la prédication, mon mari a interprèté le docteur de Prosch, MM. Burnier et Verdier. À notre réunion de missions (en sessouto), j'ai parlé du devoir qui incombe à chacun de travailler pour Dieu. Le soir, excellent service en français, présidẻ par M. Coillard.

Nous aimons tous nos nouveaux collaborateurs et nous croyons que leur venue au milieu de nous sera bénie.

LE 13. - J'ai été fêtée comme une reine; nos hôtez nous ont 
conviès à une charmante fête en mon honneur. La salle où ils nous ont accueillis avait été gracieusement décorée avec des palmiers.

LE 23. - M. Burnier a passẻ de nouveau quelques jours avec nous. Quelle fête pour nous tous, compris notre bébé, dont il a eu vite fait la conquête.

5 Novembre. - MM. Ramseyer et Bouchet nous ont fait l'agréable surprise de nous arriver hier matin, à l'improviste. Adolphe les a présentẻs et interprétés aujourd'hui au culte principal.

\section{XCVIII.}

Fondation de la Station de Mabumbu.

Vne belle situation. - Les ma-Mbunda.

Superstitions combatrues à coups de hâche. - U'installation de M. Manu.

T watile (1), 21 OCtoBre 1899. - Hier nous nous sommes

11 rendus à Mabumbu, à environ seize kilomètres au NordEst de Léaluï, pour choisir l'emplacement de la station dont nous avons confié la fondation à $M$. Mann. L'endroit est des meilleurs, sur la colline, dans les bois, élevé, bien aéré, avec une belle vue sur la plaine. M. et M. ${ }^{\text {me }}$ Mann pourront en faire une de nos plus agréables stations. Nous nous y sommes rendus en wagonnette; nous y avons trouvé le Ngambela et $\mathrm{Na}$ moyamba, qui venaient d'y arriver à cheval, et environ trois cents personnes, hommes et femmes, des villages avoisinants, ma-Rotsé et ma-Mbunda en nombre à peu près égal.

De toutes les tribus que nous connaissons, les ma-Mbunda sont ceux qui ont le plus de pratiques superstitieuses. A cet égard, leur influence sur les ma-Rotsé a été plus grande et plus néfaste que celle des ma-Kololo. Ils ont été des maîtres en empoisonnement et en sorcellerie. A Séfula, nous n'avons pas eu le bonheur de les entamer; il y a eu parmi eux des professants, mais ils sont tous retournés au paganisme. Près de Mabumbu, il y a un grand village ma-Mbunda. La maison du chef rappelle, en petit, l'établissement de Léwanika. Près de là se trouve un

(1) Extrait du Journal des Missions. 
tombeau très fréquenté et très-redoute des ma-Mbunda. Le bosquet est sillonné de sentiers allant dans tous les sens, et toutes sortes de cornes et de bouts de calicct blanc ou de verroterie blanche sont suspendus aux branches des arbres, tout cela pour se rendre propices les mânes.

En allant à la recherche du site de la station, nous avons trouvé un pot brisé, dans lequel on avait préparé de la médecine arec des racines; plus loin, deux cerceaux consultés en guise de dés divinatoires et, à l'endroit même que nous avons choisi, un arbre abattu encore vert, entouré d'une trace faite avec le pied, le long de laquelle sont fixés des bouts de verges avec des racines entortillées ou des verges fendues en deux et fichées dans la trace en forme de $M$.

Naturellement, tous ces objets ont servi à inculquer à ces gens une bonne leçon de choses. Un coup de hâche à été donné à l'arbre des pratiques superstitieuses. L'arbre abattu devait servir à faire des plats. Si quelqu'un franchissait la raie, cela suffirait, disait-on, pour lui faire enfler la tête jusqu'à ce qu'il en mourût.

De retour au pied de la colline, nous nous sommes restaurés sous de beaux ombrages; puis $M$. Coillard a présenté M. Mann à ses futurs paroissiens. Le Ngambéla et moi, avons ajouté quelques mots. C'était comme une installation anticipée.

Le roi s'est montré favorable à la fondation de cette nouvelle station; il la dotera de terrains arables au pied de la colline, et fournira des charpentiers pour la construction des premiers bâtiments.

XCIX.

Santẻs éprouvẻes. - Morts.

Maretha meurt dans Ia paix. - Epuisement. - A Senanga.

Mort de M. Rittener.

14 Novembre. - Nos santés ne sont pas bonnes. M. ${ }^{\text {me Lié- }}$ nard garde le lit depuis quelques jours; le docteur a de fréquents et forts accès de fièvre, et les autres ne vont pas bril- 
lamment, ni M. de Prosch, ni M. Liénard, ni moi, ni surtout M. Coillard, qui n'a jamais été.tout-à-fait bien depuis son retour ici. Mais qui nous donne le plus d'anxiété c'est Maretha, la femme de Filippi. Ne se sentant pas bien depuis la mort de son second enfant, elle a désiré rentrer chez «son père et sa mère »; Hélas! nous n'avons pas pu enrayer sa maladie et maintenant elle est mourante. Mais elle meurt dans la foi. Au milieu de grandes souffrances, elle est calme. Quand je lui ai demandé si elle savait qu'elle allait mourir, elle m'a dit: «Oui. - Et n' as-tu pas peur de la mort? - Oh! non, pourquoi en aurais-je peur? Est-ce que le Seigneur n'est pas là pour me tenir par la main? 》 Oh! quelle consolation pour nous! Qu'il est beau de voir enfin un Zambézien mourir dans la paix des enfants de Dieu! Il valait la peine de tout quitter et de tout supporter pour entendre de telles paroles!

Sénanga, 24 Novembre. - Après la Conférence de Nalolo (1) nous eûmes sans cesse beaucoup d'hôtes, c'était avec plaisir que nous les recevions à notre table, ma femme en jouissait beaucoup, mais sa tâche n'en était pas moins rendue plus lourde, des névralgies presque constantes survinrent, puis une fièvre tenace. Le résultat de tout cela, c'est un état inquiétant d'épuisement extrême de tête et de corps. Les traitements de notre brave docteur apportèrent peu d'amélioration, il fallait du repos, loin de la station où tant de devoirs et de préoccupations s'imposent à nous. Les Boiteux nous invitèrent et nous pressèrent de venir jouir de ce repos chez eux. Ce que nous acceptâmes avec reconnaissance.

LE 16. Nous offrons un dernier déjeuner à nos hôtes, les de Prosch, MM. Coillard, Bouchet et Liénard; et nous partons confortablement établis dans le bateau d'aluminium que M. Coillard a eu la bonté de mettre à notre disposition.

Le 18 vers $2.30 \mathrm{~h}$. nous abordons à Senanga. De leur belvedere les Boiteux avaient signalé notre bateau et son blanc pavillon. Ils nous attendent à l'abordage et le thé est prêt à être servi dans la nouvelle salle à manger inaugurée depuis huit jours.

Nous avons trouré ici la cordiale affection de nos amis, le repos, une belle vue qui repose l'œil, une forêt invitant à la

(1) Extrait d'une lettre à M. Boegner. 
promenade... je voudrais pouvoir dire la santé de ma femme, mais hélas! la névralgie est là chaque jour, tantôt sourde, tantôt aigiie et les forces ne reviennent que bien lentement.

Graziella, heureuse d'avoir trouvé une compagne de jeux dans Marie, s'amuse tant que le jour est long. Moi, j'ai l'école d'évangélistes tous les matins. Ces braves jeunes gens, c'est le dernier voyage que nous faisons avec eux. Ils nous manqueront beaucoup et longtemps.

Le 25 après-midi, M. Bouchet venant de Sefula nous communique les mauvaises nouvelles qu'il y a apprises: Maretha est morte. M. Liénard et Arnold Mann ont été mordus par un chien enragé et $M$. Coillard a été brûlé par de l'ammoniaque. Le dimanche 26 un exprès de M. Liénard nous rappelle à Loatile en toute hâte. On est inquiet pour M. Coillard menacé de cécité et d'étouffement.

Nous quittons les Boiteux, avec beaucoup de regret, le 27 à 7 h. du matin. Notre bateau a une proue trop large pour remonter facilement le courant. Nous n'atteignons Nalolo que le 29 et Loatile le 30.

Seules MM. ${ }^{\text {mes }}$ Liénard et de Prosch viennent à notre rencontre; leurs maris et M. Mann sont au lit avec la fièvre. Nous trouvons M. Coillard assis dans sa chambre obscure, levé pour la première fois depuis l'accident, mieux que nous n'avions osé l'espérer. Sa poitrine est libre, et sa vue est en train de revenir.

5 DÉcEMbre. - Les de Prosch nous quittent aujourd'hui. Ils ont passè deux mois chez nous. Nous les apprécions et nous les aimons beaucoup.

Je vais mieux et j'espère recommencer mes rẻunions et mes classes. J'ai un grand nombre de visites à faire. M.me Liẻnard m'accompagnera. En nous mettant ainsi quelques semaines à l'ẻcart, Dieu nous a fait comprendre la nécessité d'un congẻ. $M$. Coillard lui-même ne parle plus de nous faire prolonger metre séjour ici. Il va mieux. Son accident a eu ceci de bon, qu'il l'a contraint à passer plus de temps étendu, aussi son état général en a-t’il profité.

10 DÉCEMBRE. - Notre cher ami M. Rittener vient de mourir dans la nuit. Malgré les soins du docteur, une dyssenterie avec complication a emporté en moins d'une semaine, celui qui était 
doué d'une force extraordinaire. Cette force il l'avait toute consacrée à la mission. Il a travaillé comme deux hommes de bonne volonté. Nous perdons en lui un excellent charpentier, et un chrétien simple mais conséquent. Pour l'école industrielle la perte nous semble pour le moment irréparable. Nos cœurs saignent en pensant à cette jeune veuve de 24 ans et au frêle petit orphelin.

J'arrive à Sefula à $9 \mathrm{~h}$. Madame Rittener est merveilleusement soutenue. Le docteur est fiévreux et épuisé. M. Verdier fait le cercueil L'après midi M. Liénard arrive, puis M. M. Burnier et Béguin de Nalolo, enfin le Major Harding, Résident Britannique intérimaire. Il ne connait aucun de nous, mais il tient à nous exprimer sa sympathie en assistant à l'enterrement. Nos éléves évangélistes et des envoyés du roi entourent la tombe avec 200 personnes de Sefula.

C.

Investitures et installations.

\footnotetext{
En nouveau Mokulwakashiku. - Mauvaises nouvelles. - Repos tronqué.

Reprise de l'euvre. - Déménagements. - Samolila le surveillant.

A Mabumbu. - Yosefa investi de la charge d'Imasikwana.
}

12 Décembre. - Invités par le roi, M. Liénard et moi, avons été ce matin assister au remplacement de quelques uns des chefs destitués pour ivrognerie. La séance a été assez semblable à celle de l'investiture du Ngambéla, seulement il y a eu beaucoup moins d'orateurs. Monono a été choisi pour remplir la charge de Mokulwakashiku, parce qu'au Lessouto où il avait été envoyé avec Yakobo, il a toujours refusé de boire de la bière forte, même quand les chefs lui en ont offert. Les orateurs ont surtout insisté sur le fait que ces nouveaux chefs et officiers, n'ont pas succédé à des gens enlevés par la mort, mais à des coupables destitués pour avoir bu des boissons enivrantes. Si le jugement a commencé par les plus haut placés, on n'épargnera personne. 
14 Décembre. - Notre brave Samuele nous a quittés avec sa famille pour Sefula, où il remplace Filippi que nous avons dû transférer ici depuis son veuvage. Sa femme et lui étaient émus en nous disant adieu, nous l'étions aussi.

Le 16. Les Mann sont partis pour Mabumbu, leur nouvelle station, dans la wagonnette à ressorts de M. Coillard. Il ne reste plus à Loatile que M. Coillard et les Liénard, avec nous. Nous prenons beaucoup de repas en commun.

Le 21. Je vais à Mongu avec M. Liénard, Lewanika et une nombreuse suite. Ce qui m'intéresse encore plus que le phonographe c'est de voir dans la chambre du Major Harding, sur la table, la photographie de sa mère et la Bible. Le major m'exprime de nouveau son désir d'assister à un de nos cultes indigènes, pour honorer l'Evangile aux yeux du peuple.

Le 22. Après la séance de clôture de l'année scolaire, Lewanika désigne comme surveillant des élèves, un homme auquel il remet une verge, en l'autorisant à en frapper les princes et princesses et tous les enfants, jeunes gens ou jeunes filles qu'il pourrait surprendre faisant l'école buissonnière. Cet homme c'est notre Samolila, auquel le roi permet enfin de venir s'établir sur la station.

Il est exempté de toute corvée, sa seule tâche est désormais celle de surveiller les écoliers.

Le 23. - Nous recevons de mauvaises nouvelles de M. Mann. Madame me demande d'envoyer un évangéliste. Je me décide à y aller moi-même.

Le 24. - Le cheval que Lewanika vient de recevoir du gouverneur du Matebeleland est une bête très fringante que personne n'a encore osé monter. Moi-même je le monte. Il fait d'abord tout son possible pour me faire tomber en se cabrant, puis il se lance à un galop effréné; comme il obéit aux rênes, je n'essaie pas de l'arrêter. Au bout de dix minutes, il cesse de m'éprouver et va délicieusement.

M. ${ }^{e}$ Mann est émue en me voyant arriver, son mari va cependant mieux. Les paurres sont logés dans de petites huttes circulaires, la maison rectangulaire n'étant pas encore crépie. Ce sont des ouvriers du rci qui ont tout construit. Mais nos amis font quand même quelques expériences de la vie de pionniers. Dieu veuille que la maladie ne la leur complique pas trop!

À Loatile je trouve que ma femme a comme hôtes le Major 
Harding et son frère, le roi et M. Coillard. Le Résident a assisté au culte indigène.

Au second culte M. Liénard lit sa première méditation en sessouto.

Comme Lewanika avait élu Mokamba son premier ministre, afin d'avoir un chrétien à la tête du corps des chefs, il tenait à avoir un chrétien dans le corps des officiers, et parmi les principaux. Son choix se porta sur un de nos élèves évangélistes, notre brave Yosefa (Moka! Il nous le demanda, et il l'installa le 28 décembre.

Nous assistâmes naturellement à la cérémonie et y prîmes une part active; après les discours des chefs, le roi fit aligner les officiers selon leur rang. Notre Yosefa, avec le titre d'Imasikwana occupait le $3^{\mathrm{e}}$ rang.

Les derniers mots de l'allocution du Ngambela furent: «Garde la foi et tu seras fidèle au roi. Si tu deviens infidèle à ton Dieu, tu le seras à ton roi. 》

Je m'adresse alors à Yosefa et lui dis: « Nous servons tous la nation, chefs, conseillers et missionnaires. Nous pensions que tu la servirais comme nous en te dévouant à enseigner les grands et les humbles, et à annoncer l'Evangile. Le roi en décide autrement. On peut être grand et chrétien. Comme le Ngambela parmi les chefs, toi parmi les officiers tu dois ouvrir la voie. Vous, les officiers, n'étouffez pas la foi de notre enfant! Toi, Yosefa, sois fidèle! Sois un Joseph par la pureté et la fidèlité. Nous allions te donner le titre d'évangéliste, on te l'a ravi, mais la chose te reste. Il y a quatre ans, le roi t'a amené vers moi pour que je te forme et que tu deviennes un évangéliste. Eh bien, tu n'es plus seulement Yosefa l'évangéliste, mais Imasikwana l'évangéliste. Vous, les ma-Rotsé, ne vous étonnez pas s'il fait des cultes et s'il vous rappelle la loi de l'Evangile. Vous avez voulu un officier évangéliste, vous l'avez. Toi, Yosefa, fortifie-toi par la prière et la lecture de la Bible. Nous t'entourerons de nos prières 》.

M. Coillard s'adressa surtout aux principaux chefs, il leur dit son étonnement qu'ils manquassent d'hommes au point de devoir nous prendre nos évangelistes.

Yosefa et Miriame sa femme, revinrent encore sur la station et ne la quittèrent que le lendemain. Ce fut avec tristesse que nous les vîmes s'établir dans le milieu si païen de Léalui. 


\title{
CI.
}

\section{Nos dernières semaines à Lwatile.}

\begin{abstract}
Les fêtes. - Promotions d'évangélistes. - Lewanika fàché. - Regrets. - Pré. paratifs de départ. - Réconciliation avec Lewanika. - Chez Mokwaé. Dernier dimanche. - La Conférence. - Grande tâche de la mấtresse de maison. - Encore l'afraire des beufs. - Adieux de Lewanika et des principaux. - Adieux émus des professants et de nos cnfants.
\end{abstract}

29 Décembre. - Nous recevons un courrier du bo-Lubale. M. Schindler a eu la fièvre hématurique, un de ses collègues est mort et une demoiselle missionnaire est devenue folle à la suite d'un violent accès de fièvre, il faut la rapatrier.

8 Janvier. - Les Béguin et M. Mercier sont arrivés le 27 et. M. Bouchet le 30. M. Coillard prend de nouveau ses repas avec nous depuis lors (Il s'était mis à son ménage à notre départ pour Senanga). À la St. Sylvestre nous avons veillẻ ensemble jusqu'ả minuit. À 9 h. nous avons eu un culte présidé par M. Coillard et terminé par la Ste Cène. À minuit, après lecture, chant et prière, nous nous sommes réciproquement souhaité une bonne année.

Le 5 JANVIER 1900, nos Messieurs ont fini d'examiner les éléves évangélistes, Kajata, Pauluse (Sesoaïra) et Gideone ont étẻ acceptẻs comme évangélistes, Kaieka et Daniele iront continuer leurs études à Nalolo chez M. Béguin.

Le roi est de nouveau de mauvaise humeur. Il a ramené sur le tapis la question des bœufs morts à Palapye, lors de l'expédition de M. Davit. Il veut qu'on lui en rembourse tout le prix. Et ces Messieurs ne pouvant se rendre à ces exigences, il s'est écrié: «Eh bien! je n'irai plus à l'église! » Il n'a pas paru hier.

Nous avons célébrẻ hier au premier culte, le baptême de Davida (Kajata) et ceux de quatre femmes d'évangélistes. Dans l'après-midi nous avons eu avec ces jeunes nouveaux membres et les autres déjả reçus, un culte de Ste Cène ( 17 indigènes et 8 blancs y participèrent). Ce fut une bonne journée, une fête spirituelle.

Je suis encore souvent peu bien et très fatiguée. Espérons que cette lassitude et ces douleurs presque continuelles passeront avec le changement d'air et de vie. Le voyage à lui seul me sera salu- 
taire. Même dans ce pays, voyager est un repos malgré les fatigues inhérentes au canot et au wagon.

9 JANVIER. - Nous nous réjouissons à la pensẻe de revoir nos parents bien aimés et nos amis connus et inconnus. Mais la pensée de quitter notre œuvre, notre termitière à laquelle nous attachent tant de souvenirs, nous attriste.

LE 10. - Quand M. Béguin a été le saluer, Lewanika lui a parlé très grossièrement. Il lui a dit que nous sommes des trompeurs et des voleurs, nous tous les missionnaires. Qu'est-ce qui se machine dans l'ombre? Mais c'est Dieu qui règne.

LE 12. - Nos braves Pauluse et Rahele nous ont quittés pour Mabumbu, où ils ont été placés comme aides de M. Mann.

LE 21. - Notre maison a déjà l'air vide et désolé. Les gravures, les photographies, les mille riens qui faisaient notre foyer si attrayant, ont disparu des murs et des étagères. Le 17, le major Harding a mis à notre disposition son wagon qui doit partir des Chutes Victoria au commencement de mars. Cette occasion que nous n'avons pas recherchée nous dit que Dieu aplanit le chemin devant nous. Mais d'où viendront les canots?

Le 18, nous prenons un peu de vaisselle, un sucrier, un pot-à-lait et une cafetière, nous y ajoutons un paquet de sucre en morceaux et deux petites boîtes de savon de toilette, et envoyons ce petit cadeau à Lewanika, en demandant à Dieu de changer les dispositions du roi envers nous. Mais Il nous avait exaucẻs avant que la prière fuit sur nos lèvres. Notre envoyé rencontrait en effet le messager du roi qui nous apportait un énorme morceau de viande. Jamais roastbeef ne m'a paru si bon!

Le soir nous allâmes, Adolphe et moi, voir le monarque, laissant Graziella à M.e Liénard, car il y a à la capitale une épidémie de petite vérole volante. Nous nous étions fait annoncer. Le roi vint au devant de nous sur sa porte, deux chaises nous attendaient, lui s'assit à terre, car il souffrait d'une légère atteinte de lumbago. Puis nous causâmes longuement, amicalement. Il aborda lui-même la question des canots. «Comment irez-vous à Kazungula? - En canot. - Et dans lesquels? - Dans ceux que tu nous donneras », lui dis-je. Il se mit à rire. Il nous accompagna jusqu'à la place du Khotla. En nous quittant il nous dit: "Après votre départ nous nous sentirons amoindris ».

Nous nous rendîmes chez Mokwae remplis de joie et de reconnaissance. Une fois de plus nous avons fait l'expérience que le cœur 
des rois est entre les mains de Dieu et qu'il l'incline comme des ruisseaux.

La grosse reine nous accueillit très bien aussi; elle nous fit passer dans sa petite cour intẻrieure, où son mari, souffrant de douleurs rhumatismales, était assis sur une natte et appuyé sur des coussins. Cinq ou six jeunes filles cousaient pour la reine. La machine à coudre ètait là aussi. Mais olle seule veut y toucher. Je l'invitai à venir dîner chez nous le jour suivant. Nous prîrnes congẻ du roi, non sans avoir remonté et règlé sa montre et ses petites pendules.

Mon cœur vole sans cesse auprès de vous et bondit de joie en pensant au revoir, mais il se serre aussi, car nous laissons tant de chers amis ici.... puis nos chers Zambéziens. Oh! c'est maintenant que je sens combien je les aime. Il y en a un si grand nombre auxquels nous sommes attachés. Et notre maison où nous avons tant pleurẻ et souffert, et où nous avons étẻ heureux. Et notre petite tombe.... Miriame me répète presque chaque jour: « Mais que vaisje devenir quand vous serez partis? » Et ses yeux se remplissent de larmes.

28 JANVIER. - Oui, nous l'aimons ce monticule où nous avons passè 6 ans, dans des alternatives de joie et de douleur, de diffcultẻs et de temps faciles.

Louis est ici depuis trois jours. Il est venu pour la confẻrence. Comme sa chère femme nous manque et comme son nom revient souvent sur nos lèvres: il est toujours dans nos cours, mon beaufrère est merveilleusement soutenu par Dieu.

4 FÉVRIER. - Nous voici à notre dernier dimanche sur notre station. Adolphe a fait ses adjeux ce matin, il était très fatigué, après une série de mauvaises nuits, et des accès de fièvre qui ont duré pendant toute la semaine.

Nous sommes en pleine conférence. Nous jouissons beaucoup de cette dernière réunion avec nos amis. C'est trop joli de voir l'entrain des jeunes. Je fais de si bons rires que peu se doutent de la tristesse qui est cependant au fond de mon cœur, quand je songe que nous allons quitter notre œuvre.

6 FÉvRIER. - Nous avons encore la confẻrence rẻunie pour déjeuner ce matin, on se dispersera après; mais notre maison ne se videra pas encore. MM. Verdier et Mercier restent pour monter la cloche; nous aurons les Liẻnard aussi au dîner. Vous voyez que jusqu'au dernier moment j'ai une grande tâche de maittresse de maison. Nous arriverons à l'heure du départ sans avoir eu.le temps de nous recueillir. Nous voulons achever nos emballages ce matin et après midi retourner $\grave{a}$ la capitale faire des visites d'adieux. 
Que Dieu nous conduise dans notre long voyage, que nous sentions toujours sa main paternelle sur nous. Nos gens ont l'air triste de notre départ. Nous penserons souvent à nos enfants et à l'œuvre que nous laissons derrière nous. M. Bẻguin ne parle qu'avec émotion de notre départ. $M^{e}$ Liénard elle aussi est toute émue. Je me suis beaucoup attachée à elle. Dimanche soir nous avons eu un service de Sainte Cène.

Nous emportons de cette réunion le meilleur souvenir. À part les décisions prises, nous croyons qu'elle a beaucoup contribué à resserrer les liens qui nous unissent les uns aux autres.

Ne fallait-il pas qu'au dernier moment le roi réclamât de nouveau le paiement des bœufs de l'expédition de M. Davit? Il déclara le 7 à M. Coillard qu'il voulait $100 £$ st. (2500 francs), puis il descendit à $80 £$. st.

Le 8 février, au moment de partir nous n'avons que 4 canots et presque pas de rameurs. La Commission Exécutive me dit alors d'aller offrir au roi 40 £.st., pour finir la querelle. Ma femme m'accompagne. Nous le trouvons à son chantier avec beaucoup de chefs et d'officiers. Il nous reçoit très aimablement et nous conduit à la dépendance voisine de Naguma. Il accepte l'offre et devient aussitôt très-cordial. Il promet de s'occuper des rameurs et des canots.

Chacun des chefs et des officiers tient à nous serrer la main, ils nous disent presque tous : "Allez et revenez. Revenez-nous bientôt 》. Lewanika est ému en prenant congé de nous.

Nous avons à peine abordé à Loatile que nous recevons une magnifique corbeille couverte, contenant des petits paniers et 5 bracelets d'ivoire. C'est le cadeau d'adieu que le Roi envoie à ma femme.

A 2.30 h., à notre départ, les membres de l'Eglise et autres professants nous saluent avec émotion, plusieurs d'entr'eux pleurent. Nos élèves, garçons et filles sanglotent. Miriame veut nous accompagner jusqu’à Senanga. M. Coillard et les Liénard nous suivent un moment dans la nacelle. Mais il est $2.30 \mathrm{~h}$., nous devons nous hâter, si nous voulons encore atteindre Nalolo.

Louis et nous, y arrivons à $7.45 \mathrm{~h}$. mais M. ${ }^{\text {me }}$ Rittener et Miriame, surprises par la nuit vers Sebembi, doivent y dormir. Nous sommes reçus à la rive par nos chers Béguin, Burnier, Mercier et Verdier... et par les fourmis guerrières qui nous 
font courir vers la maison plus précipitamment que ne ie comporterait notre dignité. Nous eûmes là quelques bonnes journées de repos et de douce communion fraternelle en attendant que notre expédition fût au complet. Nous en partîmes le 12 et arrivâmes à Senanga le soir même. J'y fus saisi par la fièvre. Le 14 nous en repartîmes comblés par les Boiteux et M. Bouchet.

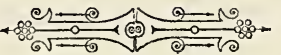




\title{
SIXIÈME PARTIE
}

\section{Notre Retour en Europe.}

\author{
1900
}






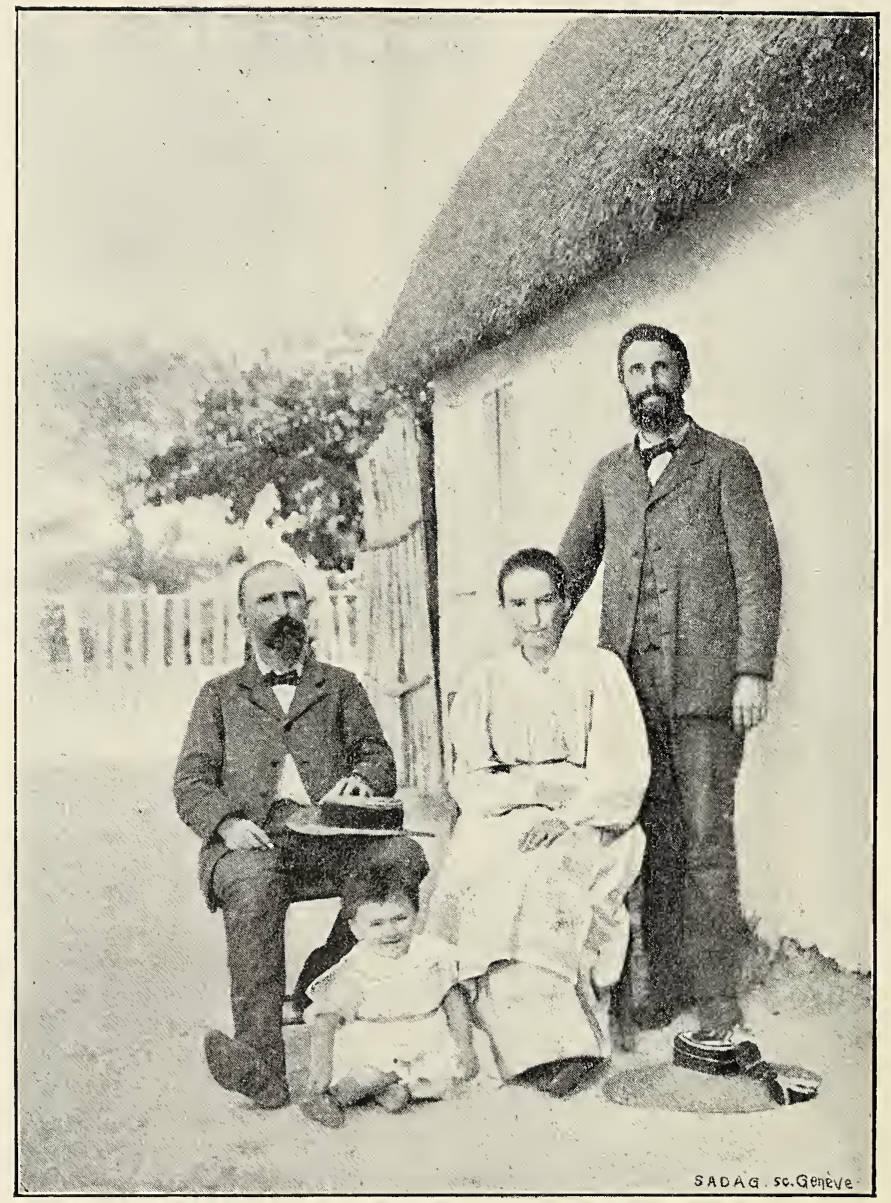

Louis, Adolphe, Emma et Graziella Jalla. 


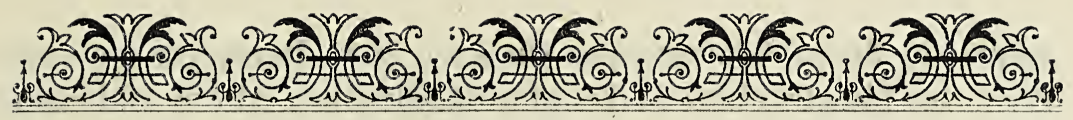

\section{SIXIÈME PARTIE}

CII.

Dix semaines d'attente à Sesheke.

Triste arrivée. - Moustiques et fèvre. - Jésus trasforme le tigre en aguean.'

Un ménage chrétien. - Mort de M.lle Dupuy.

Un joyeux commencement. - Senl:

Tous eûmes une triste arrivée à Seskeke. Le 21, en y abor-

1 dant, nous apprîmes que M. ${ }^{\text {me }}$ Martin y était morte le 18 ! Son pauvre mari faisait profondément pitié.

Le soir du 21, le wagon qui devait nous conduire de Kazungula à Bulawayo quitta Sesheke. Mais dès le lendemain les bourbiers de Simosenkele l'arrêtèrent. Force fut de l'abandonner et de ramener l'attelage à Sesheke. Un des bœufs y périt en deux heures, de la morsure d'un serpent. Nous devions passer à Sesheke dix semaines entières. Nous fûmes reconnaissants d'être arrêtés sur une station et chez notre frère plutôt que partout ailleurs; mais pendant tout ce temps nous ne fîmes guère que passer d'une anxiété à une autre.

Je me bornerai ici encore à donner quelques extraits de nos lettres sur nos épreuves et nos occupations.

13 MaRs. - Nous avons trouvé la colonie de Sesheke bien malade. Depuis notre arrivée ici, M. ${ }^{\text {lle }}$ Dupuy a eu une première at- 
taque de fièvre hématurique (le $5 \mathrm{c}$.), M. ${ }^{\text {me }}$ Ramseyer a eu une crise des plus pénibles et des plus débilitantes. Ah! si seulement ma femme recouvrait ses forces! Elle a eu 7 jours de fièvre à notre arrivée ici et est encore très faible. Elle a eu beaucoup de peine hier à arriver jusque chez Akanangisoa et à en revenir.

Que de moustiques dans la grande maison de Louis! Nous en sommes tourmentés non seulement pendant les veillées, mais toute la nuit dans la grande chambre à coucher que mon frère nous a cédée. La moustiquaire semble servir de cage à ces vilains insectes.

Akanangisoa a été si contente de nous voir qu'elle a voulu nous offrir du thé. Je lui demandai de m'envoyer un jour un peu de lait caillé, et tout de suite elle nous en fit apporter à la station. Elle a une si jolie expression, cette femme autrefois dure, cruelle et moqueuse. Ses gens la disent foncièrement changée. N'est-ce pas là un vivant tẻmoignage de la puissance de l'Evangile? Pourquoi n'est-il pas reçu dans plus de cœurs ce Jésus qui transforme le tigre en agneau? - M.lle Dupuy ne se remet pas, et du Haut nous recevons de graves nouvelles par chaque courrier.

Litia est parti pour la chasse avec la plupart des hommes de Moandi et de Sesheke; nous l'avons vu plusieurs fois avant son départ. Un soir à $5 \mathrm{~h}$. Adolphe, Graziella et moi, nous avons pu aller chez lui en canot. Il nous a montré sa belle maison, meublée à l'européenne et avec infiniment de goût. C'est un spectacle aussi rare que réjouissant de voir un chef zambézien vivre avec une seule femme sur un pied d'égalité et d'intimité comme Litia le fait avec la sienne.

10 AvrlL. - Dieu est bon de nous avoir conservẻ Graziella à travers tous ses accès de fièvre. Mon mari a eu une si forte fièvre $\left(40^{\circ} 8\right)$ dans la nuit du 8 au 9 ! Il en a été terriblement affaibli. L'état de M. ${ }^{l l e}$ Dupuy devient de plus en plus inquiẻtant. Il faudrait pouvoir la faire partir aussitôt. Hélas! le messager que nous avons envoyé en éclaireur est revenu ce soir disant que la route n'est pas encore praticable pour le wagon.

16 AvrIL (1). - Nos épreuves ne font que se multiplier. M. ${ }^{\text {.le }}$ Dupuy a rendu son dernier soupir hier, jour de Pâques, après six semaines de maladie. Elle s'était déjà fait une bonne place dans notre corps missionnaire, étant une de celles qui se sont aus-

(1) Extrait d'une lettre à M. Boegner. 
sitôt mises à l'œuvre. A notre arrivée à Sesheke, nous l'avions trouvée donnant ses leçons à l'école et aux 10 jeunes filles de l'internat, aidant les Ramseyer dans bien des détails du ménage. A partir du 2 avril son état s'aggrava. Le 13 avril au soir elle demanda une fois encore à M. ${ }^{\text {me }}$ Rittener de prier avec elle, puis elle expira subitement.

Ce matin vers $9 \frac{1}{2} h$., nous l'avons ensevelie près de M. ${ }^{\text {me }}$ Martin, une centaine de personnes entourait la fosse. Mon frère, Samuele et moi, nous parlâmes de l'activité de notre sœur, du deuil de notre Mission et des parents de M. ${ }^{\text {Ile }}$, de l'éspérance chrétienne et du sérieux des appels de Dieu.

Quatre tombes creusées à Sesheke en un an, quatre tombes de dames, outre celle de Rittener à Séfula, outre les rapatriements qui s'imposent et la mauvaise santé de plusieurs de ceux qui restent! Que de sujets de tristesse et de préoccupations? Nous les déposons chaque jour aux pieds du Sauveur, le suppliant de nous accorder les délivrances après les épreuves, les joies après les deuils.

Qu'est-ce que Dieu veut nous enseigner par ces coups rẻpétés? Jamais sa main ne s'était appesantie sur notre mission ainsi. Pourquoi? Que de questions se pressent angoissantes sur nos lèvres, et nous tremblons au souffle de la tempête qui passe sur nous.

25 AVRIL. - La poste du bo-Rotsé nous apporte la triste nouvelle de la mort de la petite Hélène Boiteux. Pauvres chers amis!

27 Avril. - Hier Emma a demandé à Akanangisoa si elle ne voudrait pas rassembler dans sa cour des femmes de Sesheke, afin d'y inaugurer une réunion semblable à celle de Mwandi. La princesse a accueilli la proposition avec un joyeux empressement. «Et pour quand? - Viens demain, et tu les trouveras réunies 》. Ainsi fut fait. Emma y a été aujourd'hui. Elle a eu environ 30 femmes. Akanangisoa avait l'air si heureux, elle chantait de tout son cœur et répondait aux questions sans aucune fausse honte. Louis en a été très content et se propose de continuer cette réunion, jusqu'à ce qu'une dame missionnaire puisse s'en charger.

1 Mal. - J'écris une lettre de Sesheke, mais je pense que ce sera la dernière. Notre wagon est de nouveau en route depuis hier; 
passera-t-il tous les mauvais pas? En tout cas, nous devons partir avec l'espoir que ce changement fera du bien à Graziella, car elle a souvent la fièvre, la nuit surtout.

Les Ramseyer sont partis ce matin pour Kazungula. Nous sommes tristes de quitter Louis avant de savoir si et quand on lui enverra un aide. Ce ne serait rien de le sentir seul sur sa station s'il avait encore sa femme. Mais seul à ses repas, seul à ses soirées, seul pour sa tâche!... Là-Haut tous les mystères sont expliqués, les pourquoi angoissants font place à l'adoration et à la louange. Adorer et louer, c'est ce que nous devons faire, bien que les dispensations de Dieu nous étonnent souvent.

CIII.

À Kazungula et à Mosi-wa-thunya.

Arrivée à Kazungula. - Pauve Kazungula. - Le wagon: - Le dimanche.

De Kazungula à Mosi-wa-thunya. - Hospitalité missionnaire.

Bel emplacement, mais vive Lwatile: - Adieu au pays des ma-Rotsé.

Kazungula 7 Mar. - Nous quittions Louis à $8 \mathrm{~h}$. vendredi $4 \mathrm{c}$. K Nous étions tout émus. À $7.30 \mathrm{~h}$. du soir nous arrivions ici ou les Ramseyer nous ont reçus.

La station de Kazungula est méconnaissable. De grandes herbes folles l'ont envahie. Le toit de la grande maison a d'immenses trous et des pans de murs entiers se sont écroulés.

Comme nous finissions de déjeuner sous les arbres, devant la maison, M. Cairncross (notre chef d'expédition) arriva à cheval. Il nous annonçait que le wagon serait jci dans la matinée.

Hier dimanche, Adolphe a dû faire les deux cultes. Léfi était peu bien. Il y avait environ 50 auditeurs, surtout des femmes. Dans l'après-midi nous sommes allés saluer les deux chefs du village, dont l'un, Kwenane, très âgé, nous a parfaitement reçus; sa femme nous a offert deux courges. Ne riez pas. Ces légumes plus ou moins prisés en Europe, sont fort estimés ici.

Nous partîmes de Kazungula le 10 mai. Notre wagon faillit verser deux fois, une autre fois il s'enfonça si bien dans la boue, qu'il fallut le décharger pour l'en retirer. A certains endroits 
rocailleux les secousses furent épouvantables, cependant nous eûmes, en somme, un bon voyage et finîmes par arriver à la station du Mosi-wa-thunya, le 13.

Nous y reçûmes un excellent accueil, et une hospitalité plus qu'africaine, missionnaire. M. Coisson était peu bien.

L'emplacement de la station est très beau, bien ombragé et bien tenu. Le fleuve bleu coule à 2 ou 300 mètres à l'ouest et au sud. Même le jour, mais surtout la nuit on entend les chutes, et par moments on en voit la «fumée 》 bien haut par dessus les grands arbres qui nous entourent, et cependant la station en est à plus de 6 kilomètres. Elle ne possède encore que des huttes circulaires.

Le village de Sekute à 5 minutes de distance est presque désert. Le chef est en route vers Sesheke et la plupart des gens sont aux champs, à quelques heures, dans la forêt. Le dimanche au culte je n'eus comme auditeurs que le personnel de la station, moins l'évangéliste qui était en tournée et les ouvriers qui étaient au bois. Ah! vive Loatile, malgré la plaine unie et la mauvaise eau et le manque de bois! Il y a tout près un Léalui qui satisfait notre besoin d'activité.

Le 17 , naissance du petit Henri Coisson.

20 MaI. - Nous regrettons de quitter les Coisson après demain, mais peu forte comme je le suis, je ne puis rien faire. Cependant nos cœurs se serrent en quittant le Zambèze. Nous y avons vécu huit ans, et c'est notre seconde patrie. Nous y laissons de chers amis, notre home et une petite tombe.

\section{CIV.}

En wagon, à travers le désert.

Pas de confort, mais de lentrain. - Anx Chutes. - Manvais chemins. - Sans can quolque tont près. - Malhenrenx voyage du dimanche. - Notre panve chariot. - Pays houiller. - Yanvaises nouvelles de M. Mamseyer. - De uncilleures routes.

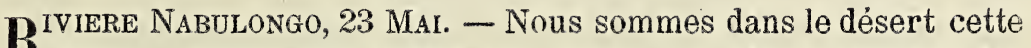
fois, en route vers Bulawayo, mais en route au pas lent des boufs peu dressés du bo-Rotsẻ. Ils ont un talent tout spécial pour 
s'enchevêtrer dans les clés de joug, ou pour s'en débarrasser aux moments les plus critiques. Heureusement, c'est toujours avancer que d'avancer lentement! Vos prières nous enveloppent. Nous arriverons ainsi jusque dans vos bras.

Nous ne voyageons pas dans des conditions très favorables au confort, puisque nous sommes logés dans une demi-tente de wagon (qui ne mesure que 2 mètres sur un mètre soixante-dix de superficie) avec M. ${ }^{\text {me }}$ Rittener et son enfant. Mais nous tâchons de supporter les désagrẻments présents, en pensant à la joie de l'arrivée. Du reste, à la guerre comme $\dot{a}$ la guerre. Et le grand air et les cahots nous donnent un appétit extraordinaire. Nous arriverons au milieu de vous, Dieu voulant, en si bon état que vous direz: "Sontce bien lá ces pauvres Zambéziens sur lesquels nous nous apitoyons?»

Nous avons quitté la station des Coisson hier $\dot{a}$ midi, et d'une première traite nous avons été jusqu'au magasin Geese, près des Chutes. Nous en avons visité une ou deux, mais la nuit et la grande humidité nous ont chassés. Ce matin nous avons fait une longue route (de 5 h. à $81 / 2$ h.) et nous sommes embourbés pour finir en sortant du guẻ de la Nabulongo. Qu'il sera beau le jour où la vapeur favorisera notre impatience.

Point de gibier, pas le plus petit oiseau qui puisse figurer sur notre table.

LE 27. - Personne ne connait la route, ni ne sait par conséquent à quelle distance il faut aller pour trouver l'eau la plus proche. Hier soir il faisait très sombre. Nous nous sommes laissés arrêter par ce que nous croyions devoir être une mauvaise descente. On dẻtelle. N'ayant qu'une goutte d'eau dans le baril, nous dûmes nous contenter de faire un peu de cafẻ. Quel ne fut pas notre étonnement ce matin de trouver un petit ruisseau d'eau courante à moins de 200 pas de là?

LE 28. - La journẻe d'hier n'a pas ẻtẻ bonne. Est-ce parceque les voyages du dimanche portent malheur? Nous déplorons de devoir voyager le dimanche, mais nous ne pouvons agir autrement. A l'étape du matin, après une demi-heure de marche, nous nous sommes embourbés au guẻ du Pokabuvo. Il a fallu décharger le wagon, et changer la disposition des caisses. Le soir, nous repartons á $3.30 \mathrm{~h}$. et un quart d'heure après nous sommes de nouveau arrêtés. Que de travail et de peine pour passer! Quand le wagon se remet enfin en branle, des cris joyeux se font entendre. Mais il taut dételer car il va faire nuit. J'étais brisée de fatigue.

29 MaI. - Ce matin, le chemin était meilleur mais fort resserré entre des arbres. Notre tente en a étẻ complètement abîmée. Nous 


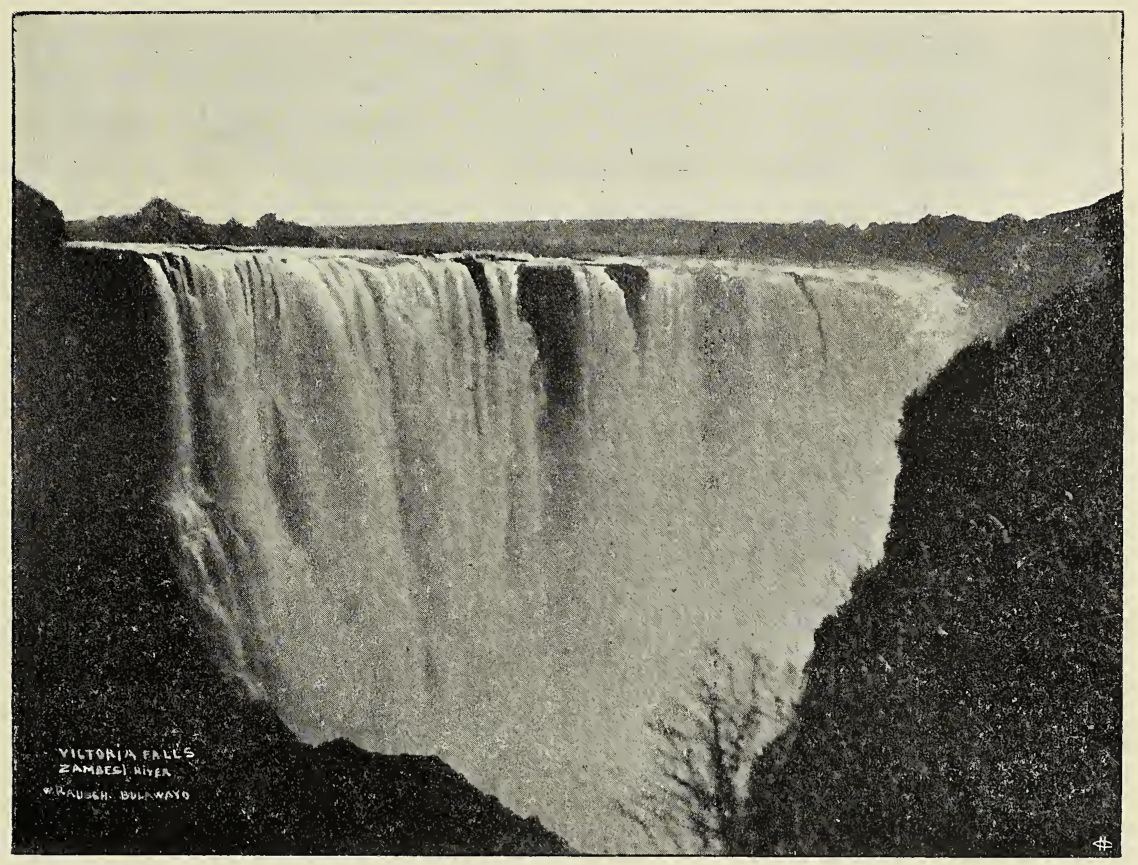

Chutes Victoria (Chute centrale). 

avons tous failli être écrasés. Et nous voilà sains et saufs, mais à la belle étoile. Mon pauvre mari en a la fièvre toute la nuit.

Nous avons passé hier près d'un hameau où nous n'avons trouvé à acheter qu'une courge, en l'échangeant contre un mouchoir. Peu après nous avons passé sans difficultés la Matetsiẻ où les Lemue ont versé il y a quelques semaines.

4 Juin. Gué de la Déka. - Nous sommes arrivés ici hier matin vers $10 \mathrm{~h}$. Nous avions rencontré, peu après nous être remis en route, un chasseur et sa fernme en voyage de plaisir. Ils étaient suivis par une élégante voiture couverte, tirée par des ânes. Notre pauvre wagon tout rafistolé faisait triste figure à côté d'eux. Il me paraît plus lourd et plus inconfortable qu'avant. Et cependant, comme nous sommes heureux de l'avoir! Sans ce véhicule nous serions encore à nous morfondre au Zambèze.

LE 5. Wankie. - Nous sommes arrivés ici hier soir. Ce matin j'ai été, avec Adolphe et Graziella, visiter le solitaire habitant de ce poste, un écossais. Il a de son perchoir une belle vue sur les collines, mais quelle solitude que la sienne.

LE 6. - Nous sommes en plein pays houiller. Nous avons trouvé en rase campagne ce combustible qui brûle sans difficulté. Nous avons vu le puits d'essai. Nous avons été rejoints par un Boer, connaissant très-bien la route. Ce sera une ressource.

LE 7. - Nous avons eu des nouvelles des Ramseyer qui sont en avant et nous attendent. Le 31, Madame à été très malade. Son mari nous supplie de nous hâter.

10 JUIN. Jacob's Kraal. - Nous voici enfin au bout d'une nouvelle étape. Et nous sommes presque à la fin de nos peines. Nous n'aurons plus désormais de mauvaises routes. En arrivant ici à $10 \mathrm{l} / 2 \mathrm{~h}$. nous avons trouvé un billet de M. Ramseyer nous apprenant qu'ils sont obligés de continuer leur route et que sa femme lui a de nouveau donné le 7 une sérieuse alerte.

LE 20 en arrivant au village de Masarwa Kraal nous poussons un nouveau soupir de satisfaction. Comme à Jacob's Kraal nous étions au bout des routes rocailleuses, ici nous eu avons fini avec ces routes sablonneuses dans lesquelles les bœufs traînent péniblement le chariot. Jusque près de Bulawayo le terrain sera argileux. Il faut éviter d'y passer pendant les pluies, et tant que le sol est détrempé, les ornières nous disent qu'il y a eu de terribles luttes pour d'autres voyageurs; mais nous pouvons 
aller sans crainte, car il y a des mois qu'il n'est pas tombé une goutte de pluie. Les villages sont encore espacés, cependant nous en voyons tous les jours.

LE 25 M. Chapman nous rejoint, il est venu à pied de sa station de Nkala, dans le bo-Shukulumbwe. C'est avec lui que nous entrons à Bulawayo le 27 juin à 8 h. du matin.

\title{
CV.
}

\section{De Bulawayo à Torre Pellice.}

\begin{abstract}
Rentres dans la civilisation. - Chez le gouverneur. - En chemin de fer. Mafeking. - Kimberley. - La ville du cap. - La traversée. - Larrlvée.
\end{abstract}

Dìs que nous pouvons apercevoir la ville, je regarde de tous mes yeux. Des maisons en maçonnerie, des voitures confortables, comme tout cela attire nos regards déshabitués de la civilisation. Des passants matinaux considèrent avec intérêt notre équipage. C'est transis de froid que nous franchissons le seuil de l'Hôtel Cecil. Nous faisons bientôt honneur $\dot{a}$ un bon déjeuner, dont le pain blanc et léger nous enchante.

Le capitaine Lawley administrateur, nous invite pour le lendemain.

À midi et demi la voiture de l'Administrateur de la Rhodésia est à la porte. Nous y montons tous les trois. Government House est à 5 kilomètres de la ville. Madame Lawley nous reçoit avec une exquise amabilitè.

Le lunch est bientôt servi. C'est un copieux dẻjeuner où l'abondance de légumes nous fait plaisir. Un chou-fleur en sauce blanche nous semble particulièrement bon. Bébé a cru que c'était du pudding et s'en est regalée. Mais comme vous devez me trouver gourmande, d'après toutes ces réflexions gastronomiques. Que voulezvous? on jouit tant après en avoir étẻ privés si longtemps.

LE 29. - Une lettre de M. Boegner nous a appris la mort du cher petit Guido (fils de Louis Jalla), mais nous n'avons accun détail.

J'eus beaucoup à faire pour trouver un nouvel agent pour notre mission et pour obtenir le rabais accordé à notre corps missionnaire, pour nos effets. Le Capitaine Lawley, qui m'a ac- 



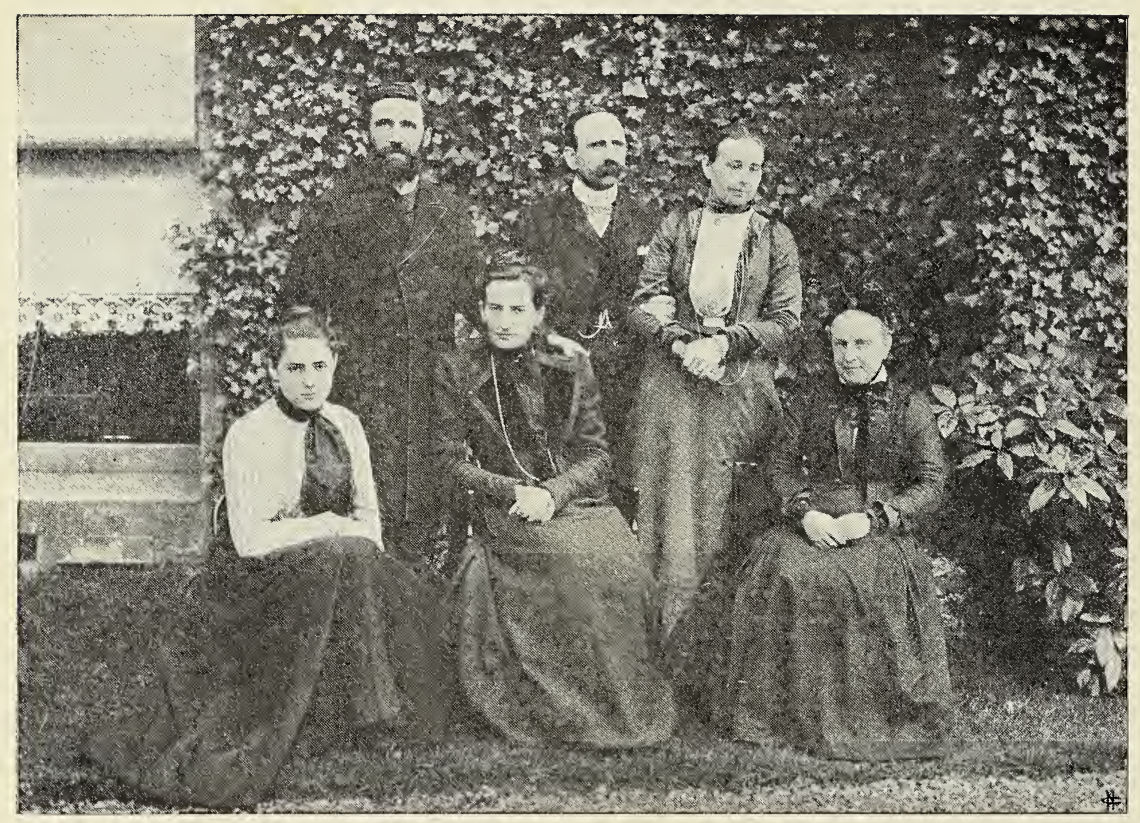

Souvenir d'Edimbourg (1901). 
cordé une longue entrevue, nous fait obtenir le droit de voyager dans le train prochain, avec le rabais des missionnaires.

En arrivant à la gare nous trouvons qu'on nous a réservé un compartiment à trois places, dans le wagon-salon. Nous nous serrerons pour $\mathrm{y}$ faire place à $\mathbf{M}^{\text {me }}$ Rittener qui avait été placée ailleurs, loin de nous. M. Chapman est dans un autre compartiment du même wagon. Kwalela doit se contenter d'un fourgon avec d'autres noirs.

Le 5, à Lobatsé un train blindé vient à notre rencontre et nous précède jusqu'à Mafeking, pour nous protéger. Cette ville est encore à peu près telle qu'au lendemain du siège. À Forteen Streams, le pont du Val ayant été gâté par les Boers, on a posé les rails dans le lit du fleuve, sur des pierres, c'est ainsi que nous passons le fleuve.

Nous arrivons à la Ville du Cap le 8 à 6.30 h. du matin. Des amis nous attendent à la gare. M. ${ }^{\text {me }}$ Rittener est conduite ì Wynberg chez les Cartwright, et nous à Woodstock, la belle résidence du Docteur et $M^{\text {me }}$ Sharp, des amis du Zambèze, s'occupant très activement d'évangélisation et d'œuvres humanitaires. Le 9 nous sommes appelés, ma femme et moi, à parler à une réunion organisée par la Zambézia, dans une grande salle de la Cape Mission.

Le 11, après nous avoir encore comblés de cadeaux, nos excellent amis nous amènent au Briton, où $\mathrm{M}$. Cartwright a obtenu pour ma femme, Graziella et moi, une belle cabine à 4 places.

Kwalela fut encore plus émerveillé du bateau que des villes et du chemin de fer. Il nous dit le premier matin: « Mais ce n'est pas un bateau, c'est une ville! 》 Il fut aussi frappé du fait que, parmi les centaines de passagers, il était le seul noir.

Nous arrivâmes à Paris le 27 juillet.

En sortant du train à la gare du Nord, à 11.10 h. du soir, nous avions la délicieuse surprise d'y trouver M. et M.me Boegner. Ils nous ont reçus avec la chaude affection qu'ils nous ont toujours témoignée.

Le $1^{\text {er }}$ août nous étions au sein de nos familles.

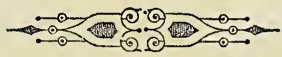





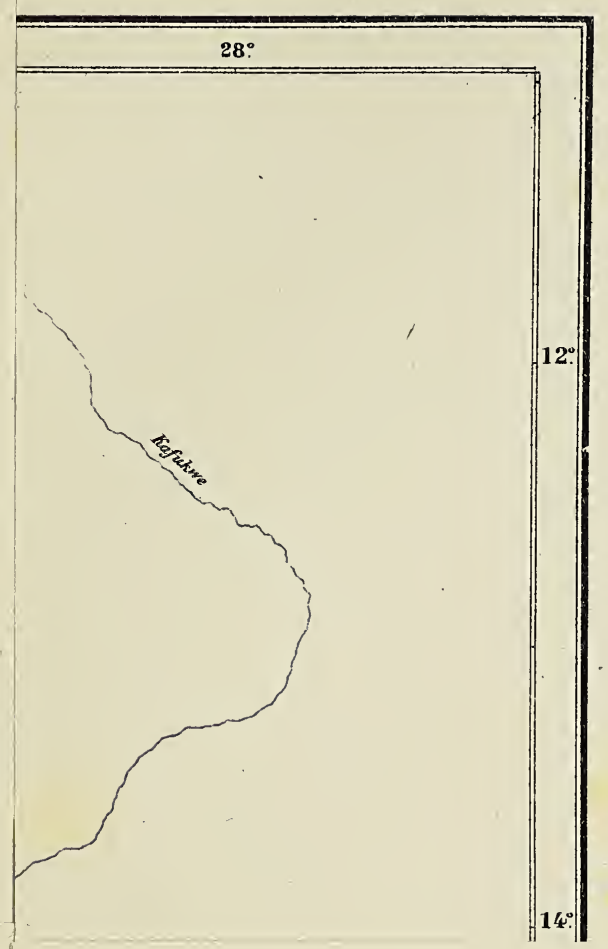





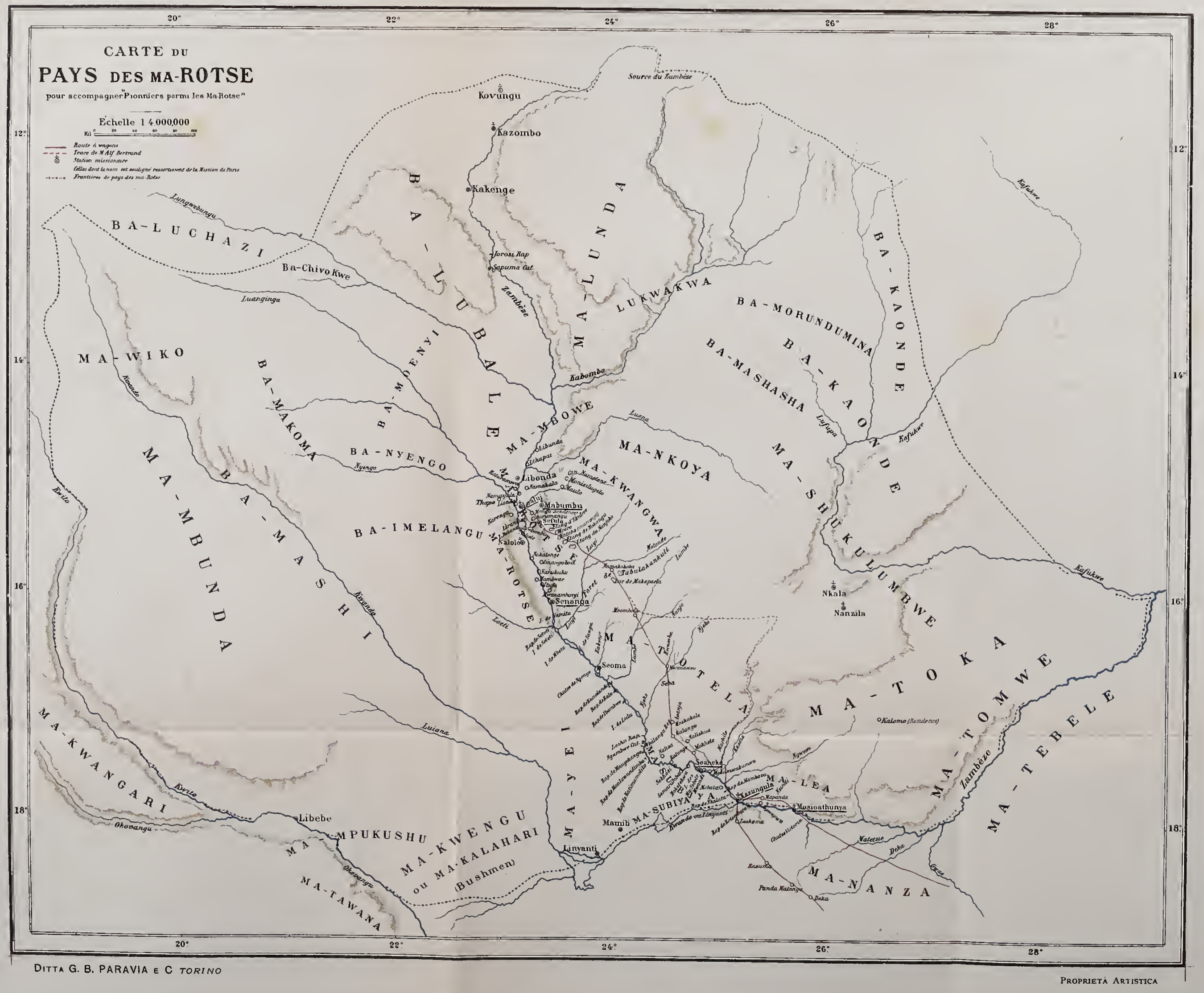





\section{APPENDICE \\ $-\infty \Leftrightarrow \infty-$}

[Je suis heureux de pouvoir renvoyer nos amis à l'excellent livre de M. Béguin, pour les questions géographiques et ethnographiques. Les données qui suivent et la carte que je publie, complèteront l'étude de mon cher collègue.]

\section{L'Histoire des ma-Rotsé.}

A.

Jes Drisines. Tradition de Kanmonu et Nyambe.

Pö̈ne.

Une fois Hamonu (1) arriva chez Nyambe (2).

C'est Kangomba qui amena Kamonu à Sasisho (3) le messager de Nyambe.

Sasisho l'amène à Nyambe.

Kamonu demande où il peut cultiver,

Nyambe lui donne des champs.

Kamonu cultive.

Des buffles viennent dans le champ de Kamonu, de nuit.

Kamonu blesse un buffle.

Il meurt.

L.e jour paraît.

Il s'en va voir et le trouve mort.

(1) Pour les ma-Rotsé, Kamonu est le premier homme et le premier ma-Rotsé.

(2) Nyambe est probablement un héros divinisé. Il est devenu la divinité suprême des ma-Rotsé.

(3) Kangomba et Sasisho sont des intermédiaires entre l'homme et la divinité. 
Il va chez Nyambe: «J'ai tué un buffle!»(1).

Nyambe lui dit: «Qu'il mange!».

La marmite de Kamonu se brise (2).

La marmite où il avait coutume de préparer les médecines.

Elle se brise.

Kamonu va chez Kangomba. Il dit:

«Va parler de moi à Nyambe et dis:

Na marmite s'est brisée ».

Nyambe dit: Mes choses à moi prennent aussi fin » (3).

Kamonu arrive dans son village.

Des élans viennent la nuit dans le champ de Kamonu.

Kamonu blesse là un gros élan mâle.

C'est là ce que Kamonu blesse.

L'élan meurt.

Kamonu en apporte la queue à Kangomba et dit:

«J'ai tué un élan ».

Kangomba va vers Nyambe.

Nyambe lui dit: «Qu'il le mange!

C'est le cadeau d'hospitalité que je lui fais ».

Kamonu revient.

Le chien de Kamonu meurt.

Kamonu va vers Kangomba et dit: « Mon chien est mort! 》

Kangomba l'amène vers Nyambe et dit: «Son chien est mort 》.

Nyambe lui dit: «C'est bien, j'ai entendu 》.

Kamonu s'en retourne de chez Nyambe,

Et dit à sa femme: (4) « J'ai vu le chien chez Nyambe,

Ainsi que la marmite » (5).

La femme nie et dit:

Peut-être qu'il ne vit pas, pas possible! ».

Le soleil se couche.

Des éléphants viennent dans le champ de Kamonu.

La femme réveille son mari.

L'homme se lève, saisit ses lances et blesse un éléphant.

Il le blesse.

L'éléphant meurt.

Le jour parait.

Il va de bon matin et le trouve mort.

Kamonu va chez Kangomba et dit:

«Va parler de moi à Nyambe et dis:

$J$ 'ai tué un éléphant $\gg$.

Nyambe dit: «Tu peux manger ton cadeau d'hospitalité,

Depuis que tu es arrivé chez moi je ne t'en ai pas donné.

Mange!»

Kamonu retourne.

Quand il arrive vers sa femme il lui dit:

(1) Tout le gibier est considéré comme appartenant à la divinité. D'où les pratiques religieuses qui précèdent et suivent les expéditions de chasse.

(2) C'est la vengeance de la divinité.

(3) Allusion au buffle tué par Kamonu.

(4) Kamonu n'a qu'une femme.

(5) Les objets qui se brisent, les bêtes et les gens qui meurent, sont «pris par Nyambe ». 
Nyambe a dit: «Allez manger votre cadeau d'hospitalité ».

L'enfant de Kamonu meurt.

L'enfant meurt.

Kamonu va vers Kangomba et dit: «Va parler de moi.

Dis: Mon enfant est mort 》.

Il vont les deux chez Nyambe.

Là Kamonu trouve son enfant, chez Nyambe.

Il le trouve assis.

Nyambe dit: «Mes choses prennent fin de la même manière 》.

Kamonu arrive chez sa, femme et lui dit:

"J'ai aussi trouvé l'enfant chez Nyambe ».

Kamonu dit à Nyambe:

"Donne-moi une médecine pour que je conserve ce qui m'appartient ».

Nyambe lui dit:

«Non, aussi mes choses prennent fin ainsi ».

Nyambe appelle Sasisho et Kangomba:

«Comment vivrons-nous?

Kamonu sait trop bien venir ici!»

Ils vont dans une île.

Kamonu creuse un canot,

Il va trouver Nyambe dans l'île (1).

Alors Nyambe dit à Sasisho et à Kamgomba:

« Faites bouillir des graines de courge dans une marmite.

Allumez un grand feu,

Qu'on voie qui peut l'enlever du feu » (2).

La marmite est mise sur un grand feu,

Tout le sol en est brûlant.

On appelle les animaux.

Le buffle ne peut approcher de la marmite,

Le lion ne peut pas.

Le léopard si rusé ne peut pas.

La hyène qui le suit pour manger leurs restes ne peut pas.

L'éléphant apporte de l'eau dans sa trompe, mais ne peut pas.

Le crocodile ne peut pas.

L'hippopotame ne peut pas (3).

Les oiseaux ne peuvent pas.

Les poissons ne peuvent pas s'approcher de la marmite,

Ils ne peuvent pas l'enlever du feu.

Nous appelons Kamonu.

Kamonu et les siens vont à l'eau.

Ils puisent de l'eau dans des plats creux,

Ils versent l'eau sur le sol,

Ils versent l'eau sur le feu,

Ils enlèvent du feu la marmite,

La marmite dans laquelle bouillent les graines.

Ils envoient un homme à Nyambe :

«Il y a longtemps que nous avons enlevé la marmite du feu!

La marmite dans laquelle bouillent les graines ».

(1) L'homme est plus fin que la divinité. Ce poëme est comme son panégyrique.

(2) Il s'agit ici de voir lequel des êtres est le plus habile.

(3) Ici le poëme est plus ou moins développé selon l'imagination de qui le récite. La liste des animaux peut s'allonger indéfiniment. 
Nyambe et Sasisho et Kangomba envoient des messagers du pays,

Ils trouvent des hommes dans tous les pays.

Ils appellent les devins

Ils appellent le se-nebukoki: (1)

《Montre-nous le nord, montre-nous le sud »

Ils appellent aussi le nalungwane (la bergeronette),

Le devin de Nyambe.

La bergeronette saisit une araignée et cherche une résidence.

Nyambe envoie à Sasisho eux (les devins) et l'araignée.

Ils vont chercher une résidence pour Nyambe.

Ils traversent la fleuve de ce côté.

La bergeronette dit encore: « Non, il n'arrivera pas 》.

Il va sur l'autre rive à Letoma, la ville de Nyambe.

La bergeronette et l'araignée conduisent Nyambe à Letoma.

Nyambe monte par le fil de l'araignée.

La bergeronette dit: «Aveuglons l'araignée,

Qu'elle ne sache pas retrouver la route,

Qu'elle n'amène pas Kamonu à la ville de Nyambe.».

C'est ainsi que Nyambe s'en alla en haut,

Seul.

Tel est le plus ancien document (2) de la théologie et de l'anthropologie des ma-Rotsé. ll doit être très ancien, car le poëme renferme plusieurs archaïsmes.

La Divinité était parmi les hommes, sous la forme humaine d'un roi.

On pouvait l'approcher par des intermédiaires. Elle monta au ciel par crainte de l'homme, pour ne plus être trouvée par lui. Les champs, le gibier, ce que possède l'homme, l'homme lui-même, lui appartiennent.

Elle est représentée comme craintive, trompeuse, vindicative.

Il y a une vie future auprès de la divinité.

L'homme était monogame. Il est très intelligent, très habile. La croyance aux enchantements et à la divination prouvent sa faiblesse.

\section{B. - Tradition de la famille royale.}

\section{La mène de la dynastie noyale. - Mvananserundui, le noi sage. - Inyambo, le poi loumain. - Ngalama le farouche. - Ngam- bala le conquér'ant. - mbanga, le girand chef et patron de Nalolo. - Décadence.}

Mbuyamwamba donna naissance à des enfants qui n'eurent pas de père, elle fut donc une femme de Nyambe.

Nyambe venait de monter au ciel, lorsque Mbuyamwamba quitta le bo-Rotsé

(1) Le se-mebukoki est un échassier assez commun au bo-Rotsé, il a la particularité de tourner sa tête tantôt d'un côté tantôt de l'autre. Nyambe lui demande s'il doit se diriger vers le sud pour échapper à Kamonu.

(2) C'est à Kalonga et à Sewakutilibebe qui je dois la plupart de ces données sur les traditions et l'histoire des ma-Rotsé. 
pour aller vers Kaumbu, chez les ma-Lunda. Tous la suivirent. Elle s'en repentit et dit: «Retournons au bo-Rotsé, qui est un beau pays. Seoka-nalimanga se sépara d'elle, vint à Lukulu, alla au Mwito. Mange s'en alla avec sa mère au boKwangwa, à la ville de Makala. La fernme (Mbuyamwamba) vint au bo-Rotsé à la ville de Makono (près de Nangulwe). Ils y habitèrent.

Chacun tuait (le gibier et les boeufs) pour soi, mangeait pour soi, sans rien donner à pérsonne, sans rien apporter à la chéfesse. Les enfants de la chéfesse allèrent à la chasse sur l'autre rive à Semonyamge, au lac de Notumgi. Ils y trouvèrent Isimwa qui pêchait. Les ma-Rotsé se contentèrent de boire de l'eau et s'assirent. Quand ils partaient ils envoyèrent des gens ramasser des poissons. Isimba en donna aux fils de la chéfesse, eux se les répartirent. Ils admirèrent cette belle coutume. Ils retournèrent chez eux.

Là les principaux formèrent un dessein, ils dirent: Choisissons un roi parmi les jeunes garçons (princes). Pendant qu'ils discutaient ce projet, une fille, envoyée par la chéfesse, écoutait. Elle retourna vers la chéfesse en retard, elle lui expliqua son retard et lui dévoila le projet. La chéfesse laissa passer du temps, pour qu'on oubliât cette affaire. Ensuite elle rassembla les principaux et leur dit de choisir un roi parmi ses fils. Ils refusent. Elle insiste. Enfin elle leur désigne Mwanaserundui (aussi appelé Mboo) pour qu'il soit roi. Elle ne fut plus que mère du roi (Ma-Natambumu).

Mwana-serunduï alla un jour à la chasse à Mbwa, au pays de Mœnyi. Ses gens craignirent qu'il n'eût méprisé le pays. Ses sœurs le suivirent: Mbwanjikana (dont le tombeau est à Libonda) et Nakatindi (dont le tombeau est à Sesheke, sur la rive gauche du Zambèze, en avant de Libonda). Elles lui demandèrent pourquoi il avait quitté le pays. Il leur répondit: «J'étais venu à la chasse ». De là vient le nom de cour Samwa ta Nangulwe. Il prit encore le nom de ses bœufs, Mumbowa-molonga. Ce fut le premier roi.

Il fit la guerre aux gens de Meshurundu, de Namale, de Malinga, de Upangmma de Liyowa, de Monyi, aux ma-Mbowe et détrôna Imenda leur roi. Il avait sa capitale à Katuramwa. [Son Ngambela était Inguwa, dont le village était Simunji].

Mwana-serundui fut un roi sage. Il fonda beaucoup de villages et les donna à ses frères et sours. A Inyambo il donna le village de Sikuli [près de Likwanga]. À Mwana-wina il donna Sekongo de l'autre côté du Luena: Yeta(1) reçut le village de Mwandi [le régiment dont il était le chef, puis le patron, s'appelait Sweaela]. Il donna à sa sceur Mwanjikana le village de Libonda. [Le régiment dont elle est patronne s'appelle Mbi]. À sa sœur Nakatindi il donna le village de Sesheke [elle etait patronne du régiment de Ngundwana].

[Imbala, fils de Inguwa, succéda à son père comme Ngambela, encore du temps de Mwana-serunduï; il est le häros d'un ancien chant].

Quand Mwana-serunduï mourut, il fut enterré à Katuramwa. La femme du roi qui est le prêtresse de ce tombeau, c'est Marundwelo. [Le régiment dont il est le patron c'est Kabete].

Inyambo lui succéda. Ce fut lui qui établit la loi d'après laquelle il est défendu de tuer un jeune animal à la chasse, et qui exige qu'on le rapporte à sa mère, si on l'a attrapé. [Imaandi fut son Ngambela. Il eut un fils Numwa dont le tombeau est à Moï, sur la rive droite du fleuve]. Le tombeau d'Inyambo est à Liondo. La femme du roi qui en est la prêtresse c'est Maondo.

Le tombeau de Yeta est dans la région de Nambuwata; Namabanda (2) est la femme du roi qui en est la prêtresse.

(1) Litia s'appelle aussi Yeta, et son village s'appelle Mwandi.

(2) La femme de Litia a aussi le titre de Namabanda. 
Ngalama succéda à Inyambo. Jusqu'à ce temps-là les ma-Rotsé n'occupaient que le centre de la plaine proprement dite du bo-Rotsé. Les ma-Kwangwa demeuraient encore au Mokulo (au pied de la forêt qui longe la plaine à l'est). $\dot{A}$ l'inondation les ma-Rotsé amenaient leur bétail à Nalwamba et au Moliulo de Kalwamba.

Avant qu'il fût roi, lorsqu'il était encore jeune homme, Ngalama avait tué une antilope le-tswe, un gros mâle, que les ma-Kwangwa lui avaient disputé comme ayant été tué par eux. Il leur en garda rancune. Dès qu'il eut le pouvoir, il rassembla ses guerriers et fondit sur les ma-Kwangwa. Leur roi Mange s'en alla se noyer dans un petit lac non loin de Mabumbu. C'est là qu'est son tombeau. Dès lors les ma-Kwangwa furent soumis aux ma-Rotsé, at ils demeurèment côte à còte.

Ngalama fit aussi la guerre aux ba-Imelangu.

Il détruisit le pouvoir de Mwana-mbinyi, son frère aîné et son beau-père. Sa femme (la fille de Mwana-mbinyi) avait voulu, coûte que coûte, emporter les tambours de son père et les amener à Likwa, la capitale de Ngalama. Mwana-mbinyi avait enfin cédé. Quand elle arriva près de Likwa elle les battit. Les ma-Rotsé les lui ravirent et décidèrent d'aller faire la guerre à son père. Celui-ci périt avec ses gens, sans coup férir.

Ngalama tuait tous ses enfants mâles. Mais l'un d'eux fut allaité en cachette par Namasiku, une sienne se-endi (concubine de voyage). Cet enfant c'est Ngombala.

Avant de mourir, Ngalama déclara qu'il ferait périr tout mo-Kwangwa qui s'approcherait de son tombeau, et jusqu'à ce jour aucun mo-Kwangwa n'a osé en approcher.

[Iwakumakolwe ou Semonja fut le Ngambela de Ngalama].

Ce roi fut enterré à Kwandu (le village de Semonja). La femme du roi qui en est la prêtresse c'est Ikoma (la même que Ma-Morambwa) la première femme du roi. [Le régiment dont il est le patron est celui de Kalekelwa ou Kawaio].

Ngombala lui succéda. Il alla faire la guerre jusqu'à Sesheke et Kazungula et près du Mosi-wa-thunya. Il en emmena de grands troupeaux de bœufs et de vaches. Il soumit les ma-Lẹa. Il creusa la Noka en ma-Rotsé, en aval de Kazungula, Il remonta en canot le Linyanti, toujours en combattant. Il pénétra jusquau Mashi. Dans la forêt de Mbanga (entre le Mashi et Seoma), il lui naquit Mbanga. Il alla jusqu'au Nyengo. Il guerroya ainsi pendant des années.

Ce fut lui qui fonda la vice-royauté de Nalolo en y plaçant. sa fille Notulu. Celle-ci prit son frère Mbonga pour l'élever, mais quand il fut grand il en chassa sa sœur, et fit exhausser sa résidence.

Nakewe était la capitale de Ngombala. Son tombeau est à Ngundu près de Naliele. La femme du roi qui en est la prêtresse c'est Matondo. [Il est le patron du régiment de Imotaliela].

A la mort de Ngombala les ma-Rotsé allèrent vers Mbanga pour le faire roi, il refusa en disant: "J'ai déjà règné avec mon père, mais je vous donnerai mon fils Yubia.

Yubia établit sa capitale à Namwenda. Il fit beaucoup de terrassements sur lesquels il fonda les villages de Liembe, Nangeme, Nakalata, Namayula (au Mabundo). Il fut enterré à Namayula (ouest-nord-ouest de Léalui). ionga (femme du roi) en est la prêtresse. Mamonda fut son Ngambela.

A sa mort, les ma-Rotsé retournèrent vers le vieux Mbanga, à Nalolo. Celui-ci refusa encore de devenir roi, alléguant son grand âge et leur donna son second fils Mwana-wina.

Mwana-wina fit le terrassement de Naliele et s'y établit. Sous son règne Mbanga 
mourut, à Naliele ou à Nalolo, et fut enterré à Kambai près de Nalolo. Yubia, un autre de ses fils qui lui succéda comme vice-roi de Nalolo, mourut et fut enterré à Namayala au Sud de Nalolo. Il eut comme successeur Nakaembe (enterré à Mwandi) puis Mwana matia qui mourut la même année que Mwana-ivina.

Le tombeau de Mwana-wina est à Lienenu (où l'on fut tristes). Son Ngambela fut encore Namonda.

Mwana-nyanda succéda à Mwana-wina, il s'établit à Liwale; tandis que Kusïo fut fait vice-roi de Nalolo. Mwana-nyanda a son tombeau à Kasika.

Morambwa lui succéda. Il tua Kusio et le remplaça par son fils Mobukwano. Muswa était son Ngambela. De son temps, des tributaires voulurent s'affranchir, mais il leur fit la guerre et les battit. Il vainquit aussi les ba-Lubale et chargea Motakela (le père de Lnchanana. l'Imuwanu actuel) d'en percevoir le tribut.

Le tombeau de Morambiva est à Lirundu. Mokena ( $3^{\circ}$ femme du roi) en est la prêtresse.

Yetamwamba (ou Selume-lume) son fils lui succéda. Son tombeau est à Namawisi.

Il fut remplacé par Mobukwano son frère puîné. En son temps le pouvoir des ma-Rotsé s'était déjà beaucoup affaibli, grâce à des divisions et à de petites guerres civiles. Plosieurs tributaires avaient déjà secoué leur joug. Ce fut sous son règne que les ma-Kololo envahirent le bo-Rotsé.

\section{C. - La tradition de Mwana-mbinyi.}

\section{Métamonplioses et autres prodiğes.}

Mwana-mbinyi, était le frère cadet de Mwana-serunduï, mais l'aïné de Inyambo et de Ngolama. Il alla faire la guerre à Seoka-nalinanga, afin de lui ravir son bétail. Mais les ma-Rotsé furent battus et prirent la fuite. Mwana-mbinyi fait prisonnier se métamorphosa en homme vieux et maigre et transforma de même son garçon. Un jour il prit de la bouse de vache et en jeta tout le long du sentier jusqu'au fleuve, et même il traversa le fleuve. Le bétail suivit son chemin et descendit le fleuve à la nage. Les gens de Seoka-nalinanga en perdirent ainsi la trace. Mwana-mbinyi était perché sur un bœuf métamorphosé en nalwange (oiseau blanc comme neige). Le troupeau aborda à Nakandiana et à Nebungu. Les arbrisseaux qu'on y trouve encore aujourd'hui, ne sont autre chose que les petits pieux auxquels les vaches avaient été attachées pour la nuit. Le lendemain ils rentrèrent dans le fleuve. En arrivant à Katuramwa, la capitale, les vaches et les bœufs remplissaient le Zambèse. Mwana-mbinyi envoya dire à son frère Mwanaserenduï qu'il arrivait amenant le troupeau.

Il n'allait pas d'accord avec le roi. Ils firent une gageure à qui tirerait mieux de l'arc. L'aîné manqua la cible, tandis que le cadet l'atteignit. Ils firent ensuite un combat de taureaux. Nwanga-serunduï amena son taureau Lumbolondo, et Mwana-mbingi le sien, Nabianga. Imafua, la sœur de Mwana-mbinji, lui dit: «Tue le tien avec un poison, dépèce-le, et que la peau soit étendue sur un canot et menée de çà et de là (pour la faire sécher). Quand la peau fut frappée avec une médecine, le taureau ressuscita. Alors le combat eut lieu. Le taureau de 
Nwana-mbinji ne ressentait aucun mal des coups de l'autre, il n'avait que la peau! l'autre mourut. Sur ce, les frères se séparèrent.

Mwana-mbinyi se dirigea vers Mboëla (le sud). Avec tout son bien il descendit le fleuve sur un le-tindi (îlot flottant d'herbes entrelacées) et alla s'établir en aval d'Itufa (non loin de Senanga).

D'après une autre tradition il suivit au contraire le haut de la colline à l'est de la plaine, tandis que son troupeau marchait à travers la plaine inondée. Quand il voulait le surveiller, il faisait surgir de la colline des contreforts (ceux de Mongu, Montwambwa, Nambuwata etc. etc.).

Quand Ngalama, son frère cadet, lui fit la guerre, Mwana-mbinyi s'enfonça sous terre, lui, ses gens, son bétail et tout son avoir, sauf les battoirs de beurre et ses queues d'animaux (ses chasse-mouches), qui devinrent les grands arbres que I'on voit encore sur son tombeau. On y entend encore des bruits souterrains, le roulement des tambours, et les mugissements et les beuglements de son troupeau.

\section{D. - Le ma-Kololo.}

\section{Mignation. - Invasion du pays des ma-Rotsé. - Sebitwane de bon, Sekeleta et Mbololo. - Fin de la domination des mar- Koloho. = Lenn. Hangine neste.}

Les ma-Kololo sont une branche de la nation des Bassoutos, à laquelle s'amalgamèrent des individus d'autres branches. Par crainte de Mosele-Katsi, le terrible chef Zulu, ils quittèrent le Lessouto vers 1824 , avec femmes et enfants, ayant à leur tête Sebitwane.

Ils parcoururent l'Afrique Méridionale au nord de l'Orange. Au bout de quelques années de pérégrinations, ils arrivèrent dans la région du lac Ngami, y battirent Letsulathebe, chef des ba-Mangwato occidentaux, du ba-Riva ou maTawana et leur prirent de grands troupeaux. Is atteignirent Linyanti vers 1835 et s'y établirent.

Ils soumirent ensuite les ma-Kalahari, les ma-Yeï, les ma-Subiya; traversèrent le Zambèze, et battirent les ma-Toka, tribu très importante alors: ll leur prirent troupeaux et esclaves. Ils firent diverses incursions dans leur pays et fondèrent près de Mosi-wa-thunya, le village important de Maswatane. Leur chef-lieu était toujours Linyanti.

Plus tard ils allèrent à Sesheke, s'avancèrent à travers le bo-Totela, et le boKwangwa sans trouver grande résistance. Les ma-Rotsé se rassemblèrent et allèrent les attendre à Kathaba (petit marais). Les ma-Kololo se mirent en embuscade. Ils dirent à leurs femmes et enfants de rebrousser chemin en poussant le bétail devant eux. Les ma-Rotsé crurent à une fuite, ils voulurent les poursuivre et tombèrent dans le guet-apens. Ils furent battus et massacrés.

Les ma-Kololo s'emparèrent du bo-Rotsé proprement dit, mais leur pouvoir ne s'étendit jamais au delà. Beaucoup de ma-Rotsé se réfugièrent au Nyengo, ou Makoma, et surtout au Lukwakwa et n'y furent pas molestés. Même au Lukwakwa ils se reconstituèrent en nation. Les principaux villages de ma-Kololo au ho-Rotsé furent Naliele et I.ibonda. 
Sebitwane fut bon pour ceux qu'il avait vaincus. Il ne les accabla pas de travaux. Il prit plusieurs jeunes ma-Rotsé à son service personnel, comme hergers, rameurs, gardes de corps. Le seul crâtiment qu'il employait était la fustigation avec la cravache. Au Khotla les petit tabourets étaient permis, et il y avait plus de liberté qu'aujourd'hui. Les ma-Kololo introduisirent les grandes huttes «masaela » souvent appelées «ma-tlo a se-Kololo » ímaisons bâties à la façon des maKololo), et une aspèce de nattes de voyage, imperméables à la pluie (mo-seme wa se-Kalolo).

Sebitwane ne resta pas longtemps au bo-Rotsé. Il dut retourner vers Linyanti, afin d'en repousser Letsulathebe qui avait paru pour reprendre son bétail. Il dut aussi se battre avec les ma-Tabele qui essayèrent à plusieurs reprises d'envahir le pays.

En 1850 Sebitwane accueillit Liwingstone avec empressement, mais ii mourut la même année.

Son jeune fils Sekeletu, qui lui succéda, ne marcha pas sur ses traces, et ne sut pas se faire aimer. Il transporta sa capitale à Sesheke et y mourut de la lèpre en 1864.

En ce temps-là Lewanika était avec Litia, son père, dans le village de Semarumba. Son père mourut peu après Sekeletu et Lewanika devint le compagnon de Latlali, fils de Sekeletu.

Mbololo partit de Thapo sa résidence et se dirigea vers Linyanti en septembre 1864, et livra bataille à Mamili qui s'était révolté avec les ba-Kalahari, et les battit. À la fin d'octobre il se rendit à Sesheke. Il confia la direction de ce village à Sepatonyana et à ses ma-Toka. Il y prit les principales familles ma-Kololo et les troupeaux et en partit en janvier 1865. Il arriva à Mongu en mars, et y fut arrêté par l'inondation. Vers la mi-juin il se rendit à Naliele où il passa juillet et août.

Mbololo était hautain et cruel et se suscita bientôt beaucoup d'ennemis parmi les ma-Kololo eux-mêmes.

Sepopa, un des plus jeunes fils de Morambwa, qui avait été fait chef des maRotsé et des ma-Mbunda du Lukwakwa, apprit que les ma-Kalolo étaient divisés. Il envoya contre eux son Ngambela Njekwa (le père de Mokamba le Ngambela actuel), à la tête d'une bande, qui fut rapidement grossie à son arrivée au boRotsé.

Mbololo ne fit pas de sérieuse résistance, il fut blessé et courut se noyer dans le fleuve. On ne retrouva pas son corps. C'était en août 1865 .

Les ma-Kololo hommes furent massacrés. De ceux qui échappèrent, plusieurs furent lâchement tués par les ma-Tawana chez lesquels ils avaient été chercher un refuge.

Les femmes et les filles, eurent naturellement la vie sauve et ce fut de bon ton pour les ma-Rotsé d'avoi des femmes ma-Kololo. Sepopa et Niekwa donnèrent l'exemple. La mère de Mokamba et celle d'Elizabetha (qui, on s'en souvient, est une fille de Sepopa) sont des ma-Kololo. Si le se-Kololo (1), qui s'était imposé comme langue des vainqueurs, resta la langue dominante, c'est aux femmes ma-Kololo que c'est dû en bonne partie.

(1) Le se-Kololo est un sessouto corrompu, appauvri; mais ce qu'il a perdu d'un côté il l'a gagné de l'autre par l'adoption de mots correspondants pris du se-Rotsé, du se-Toka et du se-Chwana. 


\section{E. - Sepopa et Mwana-wina.}

\section{Sepopa, ses changenents de capitales. - Conspination. Fuite et mort. - Count règne de Mwana-wina. - Révolution.}

À la fin d'août, Sepopa arriva lui-même à Naliele et y fut proclamé roi. Il alla à Sola distribuer les bœufs qui avaient appartenu à leurs anciens dominateurs, puis il s'établit à Nangurwe.

A l'ouie de ces nouvelles Sepatonyana et ses gens, voulant s'émanciper, quittèrent Sesheke et rentrèrent au bo-Toka. En 1866 Sepopa les y poursuivit. Il leur livra bataille à Mosamonoyamu (près de Kalomo), les vainquit et les amena au bo-Rotsé comme esclaves.

Sépopa s'établit alors à Léalui jusqu'à l'année 1869, puis il retourna à Nangulowe pour deux ans, après lesquels il se fixa à Sola.

(l transféra enfin sa capitale à Sesheke où il passa les années 1875 et 1876 . (Je tiens tous ces détails de lewanika qui accompagna Sepopa dans toutes ses pérégrinations). Il y avait alors beaucoup d'éléphants dans la plaine basse de Sesheke. Sepopa s'enrichit par la vente de l'ivoire.

Déjà auparavant ses actes de cruauté lui avaient aliéné beaucoup de monde; sa résolution d'abandonner le bo-Rotsé fit encore grandir le mécontentement. Son Ngambela Njekwa était mort et avait été remplacé par Mamili. Celui-ci trama de renverser Sepopa et d'établir Mwana-wina, son neveu.

Sepopa en eut vent et ordonna l'exécution de deux chefs qui avaient pris part à la conspiration. Ce fut le feu mis aux poudres. La révolution éclata. Mwanamachaha, un de ses ma-buto (gardes du corps), le blessa.

Lewanika procura un canot à son malheureux oncle, il entra lui-même dans un autre et ils partirent à la faveur des ténèbres. Mais ils se perdirent de vue. Sepopa alla aborder au village de Semarumba, il en partit à pied suivi de quelques fidèles et se rendit à Mothuametsi sur le Linyanti, et de là gagna Kazungula Mokumba, le jeune Amba et tous les ma-Subiya de Mambova l'y rejoignirent. Ils passèrent quelques jours dans l'île de Mahaha. Mais ses ennemis l'y découvrirent et se préparèrent à l'y assaillir. Il se sauva alors vis-à-vis du village de Koma, sur la rive droite et $\mathrm{y}$ mourut entouré de quatre ou cinq de ses fidèles. Amba était du nombre. Quand ses ennemis le surent enterré, ils allèrent se prosterner sur sa tombe.

Lewanika avait ramé jusqu'au matin et abordé vis-à-vis de Katongo. Il s'enfuit à pied à Semokosi, puis retraversa le Zambèze un peu en amont du rapide de Katimamolilo. Là il rencontra des gens qui lui annoncèrent que son cousin Mwana-wina avait été proclamé roi et qu'il l'appelait vers lui. Lewarika le rencontra à Katango en route vers le bo-Rotsé, à la tête d'une nombreuse expédition de canots.

Ils arrivèrent à Naliele en novembre 1876. Au commencement de l'inondation de 1877 , ils allèrent s'établir à Liandwa, dans l'île formée par le Nokana et le Zambèze. En 1878 Mathaha, secondé par les ennemis de Sepopa, fit éclater une nouvelle révolution. Mwana-wina se sauva sans livrer combat. Il marcha trois jours pour arriver au Mashi, d'où il gagna le bo-Toka avec une dizaine d'hommes. 
F. - Lewanika. (1)

\section{Sa jennesse. - accession an trône. - Premiène expédítion de M. Coillard. - Guerve des ma-Kupe Kupe et mort de Mwana vina. - M. F. S. Arnot. - Les Jésuites. - Mathaha prépare la pévolution. - Elle éclate. - Fuíte de Lewanika. - Mois d'hor- reurs. - Restanmation et vengeances. - M. Coillard et Le- vanika.}

Mathaha appela Lewanika et le fit proclainer roi, en aout ou septembre 1878 . Le jeune monarque (il n'avait alors que 27 à 28 ans) établit sa capitale à Léalui.

Son habileté à la chasse et la bravoure qu'il avait montrée dans les combats qui avaient abouti à l'extermination des ma-Kololo, l'avaient fait connaitre avantageusement. Les osselets divinatoires lui avaient fait ailouer comme récompense une «kapakaï (vache noire sans cornes). Son oncle Sepopa lui en avait ensuite donné un troupeau, et l'avait fait chef d'un village au bord du fleuve, au nord de Libonda. C'est là qu'il aimait à se retirer de temps à autre, loin de la vie tourmentée de la cour royale. Il s'y était marié. Sa première femme avait été MaLitia (la mère de Litia) qu'il dut chasser quelques années plus tard pour cause d'adultère.

Lewanika était occupé à bâtir sa capitale quand il reçut le premier message de M. Coillard qui, à la tête de l'expédition d'exploration avait atteint le Zambèze en août 1878. Il répondit qu'il serait content de recevoir le missionnaire; mais il ajouta que si le missionnaire avait hâte de repartir, à cause des pluies qui étaient proches, il pourrait revenir en hiver. Il envoya des ordres pour qu'à son retour M. Coillard fût aussitôt amené à Léaluï.

Mwana-wina qui avait en vain essayé de susciter des troubles, avait fini par aller au confluent du Zambèze et du Kafukwe; il y avait embauché une bande de chasseurs ma-Kupe-kupe, auxquels s'étaient joints de nombreux ma-Toka, et avait repris la direction du bo-Rotsé à leur tête. À l'ouie de son approche les cheis de Sesheke s'enfuirent, sauf un qui s'y attarda, et y fut tué. Mwana-wina poursuivit sa marche vers le nord. En arrivant à la rive gauche du Lumbe, à la saison de l'inondation de 1879, il y rencontra une armée envoyée par Lewanika, fut battu, mais parvint à se sauver à Ngambwe. Après un mois il y mourut empoisonné.

Même après cette victoire Lewanika ne se crut pas bien assis sur son trône. car les années de guerre civiles avaient déchaîné les passions. Il crut devoir suivre les traces de ses deux prédécesseurs; il agrandit son harem, devint soupçonneux et commença à ordonner des exécutions.

Ce fut en ce temps qn'il vit arriver à Léaluï M. Stanley Arnot (le 19 décembre 1882). Il lui fit d'abord bon accueil, mais bientôt par sa mendicité et ses exigences, il réussit à le dépouiller de tout. Ce ne fut qu'alors qu'il se sentit en quelque sorte obligé de pourvoir aux besoins de son hôte, non toutefois sans lui

(1) Presque tout ce chapitre a été extrait de l'esquisse biographique de Lewa. nika, qui a paru en 1902 comme supplément au n. 2 des Nouvelles du Zambèse. 
faire sentir sa dépendance. Aussi le jugement de M. Arnot sur Lewanika n'est pas flatteur. Il le représente comme mendiant, faux, cruel et sans aucune capacité administrative.

Des Jésuites vinrent aussi planter leurs tentes près de la capitale, mais le souvenir qu'ils ont gardé du roi est encore moins bon. De son côté Lewanika se plait à raconter quelques-unes des causes de leur mésentente. Chaque fois qu'il leur demandait le but de leur mission, ils répondaient: «Autorise-nous d'abord à nous établir dans ton pays, ensuite nous te dirons ce que nous sommes venus y faire ». Lewanika aurait aimé les surprendre à un de leurs repas, ses espions l'avertissaient du moment où ils allaient se mettre à table, vite il se levait... mais dès qu'il était en vue de leur campement, il les voyait faire enlever la table et s'enfoncer dans leurs bréviaires. Chaque fois qu'une femme passait près de là, ils détournaient leurs regards avec horreur. Un jour, en plein khotla, le roi appelle un serviteur et l'envoie vers les Jésuites, demander une aiguille avec scn aiguillée de fil. Ensuite en les recevant, il les montre triomphalement à sa cour en disant: "Voyez leur avarice, ils ont des boîtes et des boîtes d'aiguilles et de fil, mais ils ne me donnent qu'une aiguille aver son aiguillée». Pour ces raisons et pour d'autres, et grâce aux conseils de M. Arnot et du marchand Westbeech, Lewanika n'autorisa pas les RR. PP. à s'établir dans son pays.

Afin de mieux établir son autorité, Lewanika aurait voulu s’allier avec Khama. Dans une lettre qu'il lui écrivait par la plume de M. Arnot, à la fin de 1893, il Iui demande en mariage une de ses filles, et un chien noir, comme preuves d'amit:é. Il le prie aussi de faciliter la voyage du missionnaire Coillard.

Le 29 avril 1884 il reçut une lettre lui annonçant la prochaine arrivée des missionnaires qu'il attendait. Peu après, M. Stanley Arnot le quitta pour aller vers Benguela.

Mais pendant que MM. Coillard et Jemmairet, avec leur expédition, avançaient vers le Zambèze, les troubles allaient en croissant au bo-Rotsé. À mesure que les germes de révolte se développaient, le pauvre Lewanika devenait de plus en plus soupçonneux. Mathaha, son principal chef après Salumbu le Ngambela (frère cadet de Njekwa), tout en protestant de son attachement pour le roi, soufflait sur le feu qui couvait partout sous les cendres, en poussant Lewanika à multiplier les exécutions capitales, et en détachant secrète nent de lui ses meilleurs soutiens et même plusieurs membres de la famille royale. Un jour le roi apprend qu'un de ses frères complote contre lui; il se le fait amener, le fait ligoter de calicot blanc et couvrir de verroterie, puis le fait enfermer dans un enclos non loin de sa résidence, et le fait mourir de faim! Un autre jour il ordonne que sept de ses principaux chefs soient mis à mort.

Au moment même où M. Coillard arrivait à Sesheke et y recevait l'invitation də se rendre à la capitale, Mathaha achevait d'organiser la révolte. Il va jeter le masque. Une nuit Lewanika est reveillé en sursaut par des coups de fusil, des balles traversent sa hutte! C'est la conspiration! Il se lève, saisit ses lances et un fusil, franchit sans obstacle la première enceinte, mais trouve la sortie de la seconde barrée par une bande d'hommes. Il en blesse deux, les autres, effrayés, saisis de crainte superstitieuse, reculent et lui livrent passage; il est poursuivi, mais gràce aux ténèbres, il réussit à sortir de sa capitale. Avant l'aube il a traversé le Zambèze en canot. Il s'enfuit vers Thapo. Là quelques-uns de ses partisans le rejoignent et lui amènent Litia. Ils reprennent leur fuite précipitée à traver's bois et clairières, ils franchissent le Loeti, fuient encore pour ne s'arrêter qu'au bout de quatre ou cinq jours, quand ils ont atteint le Mashi (Kwando) où ils sont bien reçus, et amenés à travers des marécages labyrinthiques, dans une des îles qui servent de refuge aux peureux ba-Mashi. 
Lewanika passa son temps d'exil dans les îles du Kiwanda, puis plus au Sud, chez Libeba, le chef des ma-Mpukushu des bords de Okovangu, célèbre faiseur de pluie.

Mathaha fit nommer roi Alkufuna, un cousin de Lewanika, et règna par la terreur. Les gens de Mboela restés fidèles à Lewanika marchèrent contre lui, mais ils furent battus à Mongu, après un combat acharné. À la suite de cela Mathaha fit une incursion au Mboela et y commit des atrocités. Le régne d'Akufuna fut un temps de désordres et d'horreurs.

Mwauluka, chef de Seoma, groupe les partisans de Lewanika, et lui fait dire de retourner au bo-Rotsé. En juin ou juillet 1883 le roi exilé reparait à la tête d' une bande qui va grossissant chaque jour. Mathaha et Akufuua n'apprennent son retour que quand il est déjà près de Léaluï, ils n'ont plus que le temps de fuir. Lewanika reprend ainsi sa capitale presque sans coup férir.

Mathaha abandonne Akufuna qu'il trouve incapable de règner, mais il revient en octobre 18:35 avec Sekufele, le grand chef du Lukwakwa, l'héritier le plus authentique du pouvoir. La bataille fut longue et sanglante, ce fut à Loatile que la lutte fut le plus acharnée. Voyant que son Ngambela et plusieurs de ses princípaux défenseurs jouchent le sol, et que les autres faiblissent, Lewanika envoie un message à une caravane de ma-Mbari campés non loin de là, il leur promet de favoriser leur commerce s'ils lui procurent la victoire. Ceux-ci accourent armés de fusils et décident la journée. Mathaha, Sekufele et les autres chefs de la révolution sont tués, les survivants de leur parti fuient poursuivis par leurs ennemis. Lewanika nomme Mwauluka son Ngambela.

Hélas, cette victoire, chèrement gagnée, ne marqua pas encore la fin du carnage. Les haines et les passions avaient été déchaînées par cette guerre fratricide, chacun profita de ce temps de désarroi pour piller et égorger ceux qu'il considérait comme des adversaires. Lewanika, lui aussi, aurait voulu assouvir sa soif de vengeance et noyer dans le sang tous ceux qui avaient pris part à la révolution. Il y était poussé par sa mère, ses sœurs et tout son entourage. Ses émissaires parcouraient le pays dans toutes les directions, tantôt massacrant ou faisant massacrer ceux qu'il avait désigné; tantôt se présentant comme des messagers de paix, afin d'accomplir plus sûrement leur mandat de sang.

II semblait que ces débordements devaient fatalement mener ce peuple à sa ruine, mais Dieu avait des desseins d'amour à son égard. M. Coillard, qui avait déjà saisi l'occasion de parler de paix aux chefs turbulents de Sesheke, et a Mathaha lui-même, allait ètre mis en rapport avec Lewanika. Personne n'a oublié le récit de leur première entrevue du 22 mars 1886, pas plus que la longue conversation d'un des jours suivants, qui nous a fait voir un frappant contraste entre la mendicité du roi, son égoïsme, son orgueil, ses enfantillages, et la sagesse et l'amour ferme et digne qui dictait chacune des réponses du missionnaire.

Mais le travail accompli à ces occasions et pendant les années suivantes, ne devait pas porter aussitôt tous ses fruits. Le roi crut avoir fait une grande concession, le jour où il annonça au ministre de Dieu que sur ses conseils, il avait décidé de poser la lance et de ne plus répandre de sang, mais qu'il s'était contenté de faire boire le poison à ses victimes. Plus tard encore, en dépit de l'opposition de M. Coillard, le roi partit à la tête de ses troupes pour faire une razzia contre les ma-Shukulumbwe, voulant ainsi donner une diversion aux idées de révolte, de ses sujets, fatigués de ses actes de violence et de sa méfiance persistante.

Le débordement ne pouvait pas être arrêté tout d'un coup, mais les pierres fondamentales des remparts qui devaient l'endiguer étaient posées.

La suite de l'histoire de Lewanika se confond avec notre récit. 


\section{G. - Généalogie de Lewanika.}
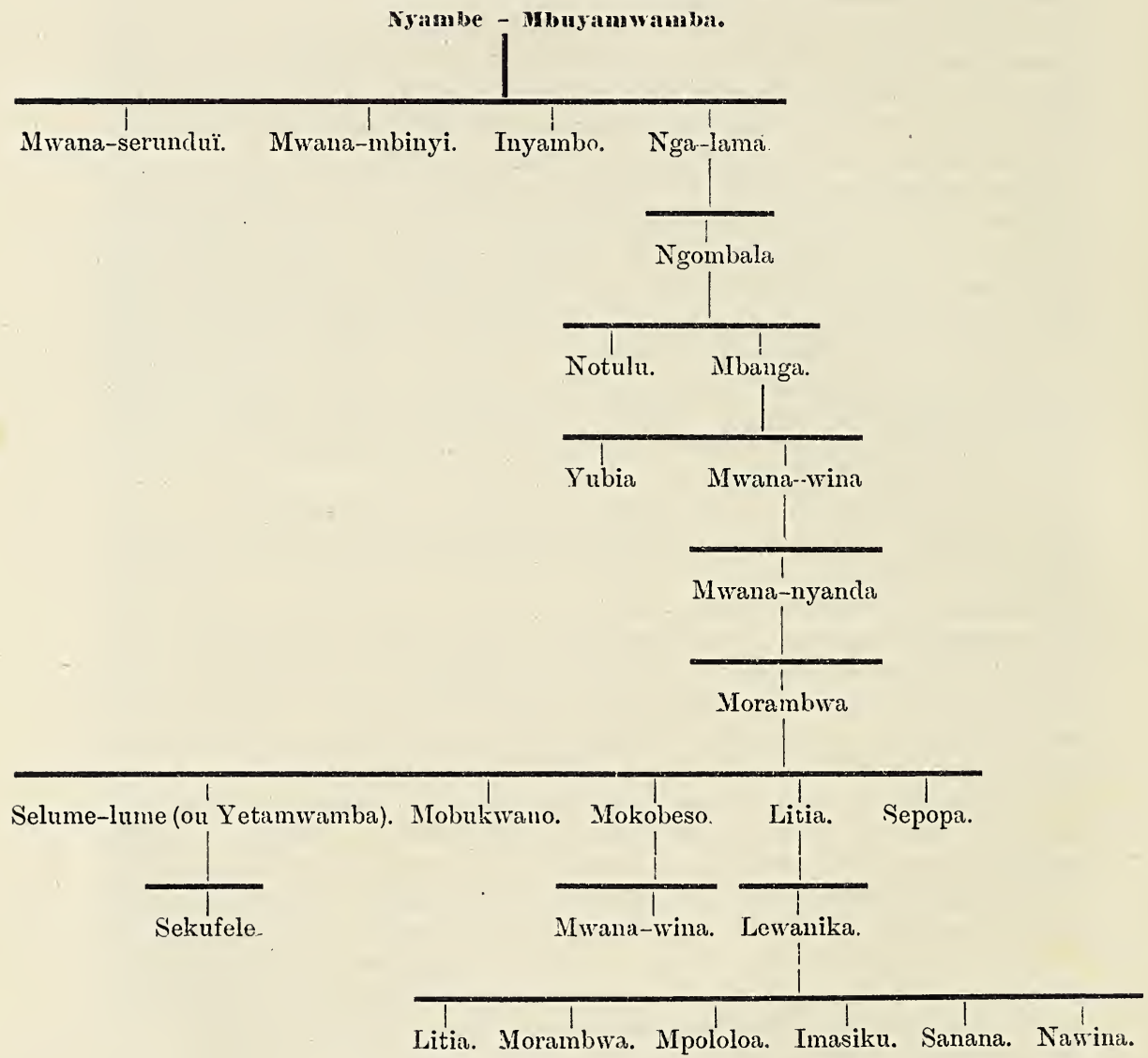

Lewanika a 33 enfants vivants.

J'ai recueilli les noms de 29 enfants (fils et filles) de Morambwa le grand père de Lewanilia. 


\section{H. - Principaux Chefs et Officiers formant la cour de Lewanika.}

\section{D'après lenx' ondre hiénarchique.}

\author{
CHEFS \\ (ma-kwambuin).
}

1 Ngambela ou Sope.

2 Natamoya.

3 Mokulwakashiku.

4 Inyamawina.

5 Liomba.

6 Namoyamba.

7 Nalishua.

8 Kalonga.

9 Namunda.

10 Semonja.

11 Moyumbana.

12 Ingundwana.
OFFICIERS.

(li-kombwa).
OFFICIERS de la maison royale (li-Kombwa)
1 Ingangwana.

2 Imuwana.

3 Imasilkwana.

4 Mobonda.

5 Sekota.

6 Wina.

7 Awami.

8 Ifunga.

9 Alulea.

10 Mubita-Kalundu.

11 Mwaiba.

12 Mokuba.

13 Inguu.

14 Alisheke.

15 Imokondo.

16 Ananyatele.

17 Alwanda.

18 Mafwira.
1 Amba.

2 Kololo.

3 Moranda.

4 Moliokela.

5 Moramata.

6 Yukuyema.

7 Imusho (Andrease).

8 Liambwanamunji

(Seajika).

9.... Les gardes du corps (ma-buto).

Note. Les chefs et officiers de Nalolo, Libonda, Sesheke et Mwandi s'intercalent entre ceux de Léaluï d'après un ordre hiérarchique établi.

Les membres de la famille royale (cousins, neveux...) de Lewanika forment encore une hiérarchie à part. Les principaux sont Mnï-muï, Nameluko, Likokwane, Sasa.

Chacun de ces fonctionnaires a ses attributions spéciales.

Ainsi chaque femme du roi a des chefs et des officiers chargés de veiller sur elle, et de pourvoir à ses besoins. Les chefs qui ont charge d'Ikoma (Ma-Morambwa; la première femme du roi, sont le Ngambela et Liomba. Ses officiers sont Imasikwana (Yosefa) et Salali.

\section{I. - Régiments.}

Les ma-Rotsé qui dépendent de Léaluï sont répartis entre les 5 régiments sui. vants;

1. Njemino - Régiment du roi.

Second chef: Kalonga.

Officiers: Ingangwana. Imasikwana, Mobonda, Wina, Sekota. 
2. Kabeti. - Régiment du Ngambela.

Second chef: Liomba - Troisième: Nawa-serundu.

3. Motakela chefs: Mokulwakashiku, Namoyamba, Monono.

4. Mbanda chefs: Moyumbana, Ingundwana.

5. Ngulubela chefs: Nalishua, Namunda, Semanja.

Les principaux de ces régiments peuvent se subdiviser.

Ils vont par régiments à la guerre, à la chasse, à la pêche et à d'autres travaux tels que creusement de canaux, construction de chaussée....

Les gens de Nalolo, Libonda (chef-lieu du Motulo, nord), Mboela, Sesheke, et Mwandi forment des régiments à part.

II.

La Famille. (1)

\section{I'enfant.}

Quand la femme est près d'avoir un enfant, on l'amène hors du village, dans une hutte construite ad hoc. Ni les gens, ni le mari ne l'y voient. Le bois et la nourriture qu'on lui apporte sont déposés hors de la cour. On lui donne une femme pour la soigner et une petite fille comme servante. Quand l'enfant est né, on annonce que la femme d'un tel est devenue mère. Les gens s'accroupissent, battent des mains et vont baiser la main du père. Le mari ne verra sa femme et, son enfant qu'à la nouvelle lune; la mère est considérée comme souillée. S'il allait la voir, on nous assure qu'il prendrait mal à la poitrine! Personne ne voit l'enfant et on le cache par crainte qu'on ne lui jette un sort. Quand, à la lunaison suivante, on montre l'enfant pour la première fois, le père tue un bœuf, s'il en a les moyens; il en prend le gros nerf de la jambe pour en faire un collier à la mère et à l'enfant. On les en pare. On apporte de la nourriture, on invite les parents et les voisins. Mais personne ne peut prendre l'enfant s'il ne lui met d'abord un collier de perles blanches (verroterie) autour du cou, ou au poignet ou à la jambe.

Les femmes du roi restent cachées quatre mois, et ses enfants quatre ans. Si on doit les faire sortir de l'enclos, on les porte recouverts d'un voile afin que personne ne puisse les voir.

L'enfant ne reçoit son nom que quand il a deux ou trois ans. La personne qui le lui donne habituellement, une grand' mère ou une tante, lui fait, pour l'occasion, cadeau d'un collier de verroterie blanche. Jusqu'à ce moment, l'enfant n'avait qu'un nom de plaisanterie tel que vent, poupon, grenouille. L'allaitement dure deux à trois ans, mais après quelques mois le lait maternel n'est plus la seule nourriture de l'enfant.

On revêt la fillette d'un tablier de franges dès qu'elle apprend à marcher. Ce tablier, dont la forme diffëre d'après les tribus, est fait de petites lanières de peaux de chèvres ou de gazelles, ou bien de simples cordelettes de fibres végétales, ou encore de queues de chats sauvages. Vers douze ans on lui donne sa première

(1) Extrait du Bulletin du Sou du Zambèze, Mars et juin 1902. 
jupe en cuir de bouuf bien assoupli. Le petit garçon va tout nu jusqu'à sept ou huit ans, après quoi on le revêt du setsiba.

Quand l'enfant commence à parler, on se moque de lui, on lui dit des malédictions, qu'il répète à son tour aux gens, même aux grandes personnes, au grand amusement de tous. Il pousse à sa guise, comme un arbre sauvage. La mortalité des enfants est grande. Il est habituellement enlevé à sa mère vers sa quatrième année et placé chez une grand' mère, une tante ou une cousine pour son éducation. Cette règle a des exceptions chez le menu peuple, mais pas chez les gens de bonne famille. Ainsi Litia n'a plus chez lui que le cadet de ses enfants, Daniel, qui n'a que deux ans. Sa fille aînée est élevée par une des femmes de Léwanika; la seconde, Kotoutou, l'est par Mokwaé de Nalolo (la sœur aînée du roi) la troisième par Moliwaé Katoka (la sour cadette du roi). Léwanika nous a promis de laisser à Litia son dernier enfant, un petit garçon, afin qu'il l'élève chrétiennement.

Des enfants du roi, les uns sont chez les Mokwaé susnommées, d'autres chez des femmes du roi, ou encore chez Litia et chez Akanangisoa, mais aucun n'est élevé par sa propre mère.

Les petites filles ne tardent pas à apprendre les travaux des femmes; celui qu'elles préfèrent c'est le smearage. Quel bonheur de pétrir avec les pieds et les mains ce mélange de bouse de vache et d'argile, et puis l'étendre avec art sur le parquet ou sur ies murs. C'est une grande punition que de les en priver! Les petits garçons aiment à paître les troupeaux et à pêcher. Ils s'exercent à jeter des lances de roseaux ou de verges, ils font de l'escrime. La rame et le moulage font passer de bons moments aux fillettes comme aux garçonnets. Les enfants de gens aisés ou des chefs ont des «ba-pepi », portenrs, grands et petits. Chaque enfant du roi en a plusieurs, toujours à son service, le suivant partout, prêts à faire ses caprices, et cependant responsables de tout ce qui peut arriver à leur petit maître. Ces ba-pepi sont les seuls esclaves admis à fréquenter nos écoles, à Lealui et à Nalolo, ils en forment le principal noyau. Les enfants sont rarement grondés par leurs éducateurs et encore plus rarement punis. Hélas! il n'en est pas de même des enfants d'esclaves ou esclaves de naissance, ni des autres petits esclaves, fruit des razzias des tribus ou des amendes.

Les liens de famille sont très-relâchés. Quand quelqu'un nous présente son père ou sa mère. ou nous en parle, nous devons toujours demander si c'est son vrai père ou sa vraie mère, car ce nom a été étendu aux oncles, aux tantes, aux cousins, etc. Il en est de même quand quelqu'un nous parle de son fils ou de sa fille, ce qui peut aussi vouloir dire son neveu ou sa nièce, ou son petit cousin. Tous ces termes ont perdu en profondeur ce qu'ils ont gagné en étendue.

Nous avons été frappés et presque émus au commencement d'entendre nos Zambéziens se traiter réciproquement de pères et nères, et d'être appelés par ces noms qui impliquent le respect et l'affection. Mais plus tard nous avons déploré cette coutume, parcequ'en réalité elle affaiblit la notion de la famille.

Nos Zambéziens n'ont pas de vie de famille proprement dite. Nous n'avons trouvé que très-rarement réunis le père, la mère et les enfants, à moins qu'il ne s'agit que d'un petit enfant. Aucune femme ou jeune fille n'est admise à assister aux repas du roi; s'il y admet un de ses fils, celui-ci ne s'assied pas à table avec son père, mais s'accroupit sur la natte où il attend que son père lui fasse passer le plat par un esclave. Léwanika a longtemps hésité à accepter de dîner chez nous avec Litia; il n'a jamais voulu y dîner avec Mokwaé ni avec aucune autre femme que les dames missionnaires.

On fait passer la jeune fille de treize à quatorze ans par une espèce d'initiation. On lui arrange les cheveux en cordelettes. On lui passe de petites perles 
blanches dans les cheveux au-dessus du front. De jour, des femmes l'emmènent loin des habitations et des lieux fréquentés. Si un homme se hasardait d'en approcher il serait battu de verges. Gare à la jeune fille qui n'aurait pas été obéissante, ou complaisante, ou respectueuse pendant son enfance, elle est battue sans pitié par toute femme qui a eu lieu de s'en plaindre. Vers le soir, avant de la faire rentrer à la maison, on la fait chanter et danser, on la bat de verges même celle à laquelle on ne reproche rien. On la prépare ainsi à souffrir sans se plaindre. De retour chez elle, elle passe au «lushoko ", arrière-cour, où aucun homme ne peut la voir. Après toute une lunaison de ce manège, après quatre lunaisons, s'il s'agit d'une princesse, on la lave, et vers le coucher du soleil, on la ramène au village. Le lendemain on la «shukula》 (on la coiffe en peignant soigneusement chaque mèche de cheveux) on lui recouvre la tête d'ocre et le corps de beurre. on la pare de verroterie blanche. Si elle est fiancée, c'est alors qu'on amene son fiancé vers elle et qu'on les fait se mirer ensemble dans un plat d'eau. Il y a des danses et des chants ce jour-là comme au premier jour de l'initiation. Pour une princesse, le roi devait ouvrir la danse.

\section{Fiançilles et Mariaģe. \\ He man'i er la fenme.}

Le cas le plus intéressant est celui du jeune homme qui en est à ses premières fiançailles. Il préfèrera une enfant de dix à treize ans. Quand il a fait son choix, il va vers le père et la mère de la jeune fille, vers ses maîtres, si elle est esclave, et leur dit: «He kopa molilo», c'est-à-dire: je demande du feu (un foyer). Si la fille est encore petite, les parents refusent, en prétextant son âge. Le jeune homme revient souvent à la charge. Quand enfin il a le consentement désiré, il donne à sa fiancèe des perles blanches, une jupe en cuir de bœuf et une pélerine ou mante, "afin qu'on la respecte ».

Quand la fiancée est en âge de se marier, après les cérémonies du itlhaleha, le fiancé et la fiancée, qui ont laissé pousser leurs cheveux, sont coiffés avec soin; on leur couvre la tête d'ocre, leur corps est reluisant de beurre, on les amène l'un d'un côté, l'autre de l'autre, vers un plat en bois, dans lequel on a mis de l'eau, quelques grains de verroterie blanche, une hachette; tous deux s'y mirent.

Si un jeune a jeté son dévolu sur une jeune fille plus âgée, il s'entend d'abord avec elle, puis la demande à ses parents ou maitres. La fiancée ne prononce jamais le nom de son fiancé et viceversa. Ils se voient rarement, le jeune homme apporte de temps en temps un petit cadeau pour ses beaux-parents ou pour sa fiancée. Quand il va prendre sa fiancée pour l'amener chez lui, il arrive avec une assez forte provision dornements ou autres objets. Il la trouve accroupie sur une natte, entourée de sa famille; mais il ne réussit à la faire se lever que $s^{\prime i l ~ l u i ~ d o n n e ~ u n ~ c o l l i e r ~ d e ~ v e r r o t e r i e . ~ E l l e ~ s e ~ l e ̀ v e ~ e n f i n, ~ m a i s ~ r e f u s e ~ d e ~ l e ~ s u i-~}$ vre. Le fiancé jette à terre un autre collier qui sera ramassé par les parents. Sur le parcours qui la sépare de l'habitation de son mari, elle s'arrête fréquemment, s'accroupit quelquefois sur sa natte et ne consent à avancer que quand le fiancé a jeté à terre d'autres objets que les parents. ramassent. Malheur à lui s'il n'en est pas bien fourni et si des parents ou amis ne peuvent lui venir en aide, sa fiancée pourrait bien rentrer chez elle. A la porte de la cour du jeune homme, nouvel arrêt et nouveau cadeau: elle pénètre dans l'enceinte et y trouve une natte où son fiancé l'invite à s'asseoir; nouveau refus, nouveau cadeau. Elle s'accroupit, le fiancé lui offre un plat de nourriture auquel elle ne touchera que si un nouveau cadeau intervient. Vers le soir, elle refusera, d'entrer dans la hutte si elle n'y trouve une pioche; mais le fiancé a prévu le cas. Le lendemain, 
si le mari en a les moyens ou qu'un sien parent y ait pourvu, on tue un bœuf, on en apporte la viande à la demeure des parents de la femme. Le mari fait à ses beaux-parents une provision de bois à brûler qu'il leur renouvellera d'année en année. La femme cultivera les champs de ses beaux-parents, outre les siens propres et ceux de sa mère.

Quand il s'agit d'une princesse, c'est le roi qui désigne son futur gendre. Le jour où le mariage doit avoir lieu, les envoyés du roi font irruption dans la demeure du fiancé, ils le garrottent avec des colliers de verroterie et le portent dans la hutte de la jeune fille.

La femme est la servante de son mari, elle a seule soin du ménage, elle pile les grains pour en faire de la farine, elle ramasse les herbes qui serviront de légumes; elle ne mange pas avec lui; elle lave les plats et les marmites, elle balaie la maison et la cour, elle cultive les champs et sème, elle bâtit les huttes et les «smeare »; quand elle en a le temps elle fait de la poterie, tresse des nattes ou certaines espèces de corbeilles, etc. Si elle a des esclaves, femmes ou hommes, elle se fait aider par eux. Elle ne sort jamais avec son mari et ne s'assied pas avec lui en public. Le mari, s'il est libre, va chaque jour siéger au khotla; il chasse et pêche, prépare les peaux, les coupe, et les coud; s'il en a le goût, il sculpte; à l'occasion, quand le travail est pressant, il aide sa femme pour les travaux des champs ou les bâtisses. S'il est à la capitale, il est souvent employé aux travaux du roi ou occupé de la chose publique. S'il est esclave, il fera les travaux de son maître.

\section{Lae Polygananje.}

Sous l'ancien régime des ba-Rotsi, il n'y avait de polygames que le roi et les principaux chefs. La polygamie s'est généralisée sous le régime des ma-Kololo. Maintenant quiconque le peut a plus d'une femme et proportionne le nombre de ses femmes à ses moyens de subsistance et à sa dignité. Le vieux Ngambéla en avait cinq, outre les concubines. En 1890 le roi en avait dix-sept, outre les concubines; il en a douze maintenant. Chaque femme a sa hutte et sa cour. Nos Zambéziens prennent souvent de petites filles de dix à quatorze ans qu'ils font élever par une de leurs femmes, et qu'ils épouseront dès qu'elles seront en âge. Les li-endi (se-endi au singulier) sont des «femmes de voyage 》 - que les Zambéziens prennent pour les accompagner dans de longs voyages ou de grandes parties de chasse. Pendant le temps que Litia fut renégat et polygame (de 1893 à 1894) il prit une se-endi pour une expédition de chasse; il en eut un enfant. A la mort de cet enfant, en 1896, il y eut deuil national.

Les femmes noires ne sont pas très-sensibles, hélas! L'amour est rarement le mobile du mariage, cependant la jalousie, l'envie, la calomnie, les complots sont fréquemment la conséquence de la polygamie. La plus ancienne femme est reconnue comme la femme; c'est habituellement chez elle que le Zambézien reçoit ses hôtes; mais elle n'est pas nécessairement la favorite, celle dont le mari prend le plus de soin et qu'il fréquente le plus. Il est assez rare de trouver plusieurs enfants ayant le même père et la même mère. Ainsi nous avons eu dans notre maison :

$$
\begin{array}{ll}
\text { Kajata (Davida) } & \text { frère de Sanzala par père et non par mère } \\
\text { Kajata } & \text { frère de Mwinda par mère et non par père } \\
\text { Mwinda } & \text { frère de Sanene par père et non par mère. }
\end{array}
$$

Kajata et Sanene ne sont pas frères. De même Sanzala et Mwinda ne sont pas frères.

Chacun comprend combien la polygamie sape les fondements de la famille. 


\section{Le Divoree.}

Le divorce est si fréquent, chez nos Zambéziens, que nous pouvons dire qu'il est la règle. Il est peu d'hommes fidèles à leur première femme, et vice versa. Notre brave Mamwenda-Rubi disait vrai lorsqu'elle reconnaissait tristement que les Zambéziennes sont toutes comme la Samaritaine, elles ont eu trois, quatre et cinq maris, et celui qu'elles ont actuellement n'est pas leur mari, puis-qu'il a d'autres femmes; c'est même le cas de la plupart des fenımes du roi. Les Zambéziens ont réalisé la théorie uu mariage libre. Le mariage est une union à terme indéfini, que chacune des deux parties contractantes peut rompre à plaisir. Si le mari est mécontent, il ramasse les hardes de sa femme, les roule dans sa natte et la renvoie vers ses parents ou ses maîtres, et tout est dit. Elle est libre à son égard, et peut se remarier à qui elle veut. Si c'est la femme qui est mécontente, elle quitte simplement son mari. Celui-ci conserve, dans ce cas, certain droit sur elle et particulièrement celui d'exiger une compensation de qui veut la prendre comme femme. Quand il a reçu cette compensation, le divorce est consommé, la femme est libre de se remarier à qui elle veut. En 1890, à Séfula, nous vîmes un apprenti de M. Waddell s'emparer de la femme, à trois-quarts divorcée, de son voisin. Il ne donna que quelques lances comme compensation au mari précédent.

Quand le roi renvoie une de ses femmes (maori) il lui envoie deux ou trois de ses officiers. Ils trouvent la femme dans sa cour, ne sachant rien du message qui va lui être communiqué. Elle s'accroupit sur sa natte, fait apporter des nattes aux officiers qui s'accroupissent à leur tour. On bat des mains, on se salue de part et d'autre, on cause de la pluie et du beau temps, ou dit les «mots pour rire ». Tout à coup le principal dit: "Mon père, qu'elle s'en aille de la natte du roi ». La femme a compris. Interdite, triste, ella se hâte de quitter la natte, et s’accroupit à côté, à terre, elle dépose ses bracelets et autres ornements d'ivoire sur la natte. Bientôt après, elle sort de la cour pour aller se mettre au rang des esclaves chez une de ses ex-rivales. Mais elle n'est pas libre. On ne tardera pas à la donner comme femme à quelque membre de la famille royale. Beaucoup plus tard, ella pourra quitter ce deuxième mari et prendre qui elle veut, à quelque rang qu'il appartienne. Elle n'a aucun droit sur les enfants qu'elle a eus du roi. En ceci encore elle diffère des autres femmes. Habituellement quand il y a divorce, le mari garde les filles et la femme les fils. Dans certains cas les petits enfants restent avec la mère, tandis que les grands vont au père.

\section{v. La famille chrétlenne.}

La famille chrétienne apparut au Zambèze à l'arrivée des couples missionnaires. Tout dans nos mœurs les frappait, mais rien ne les étonnait plus que la position que nous faisons à nos femmes, en famille et en public. C'était amusant de les voir nous suivre avec un air ébabi, et d'entendre leurs remarques, quand ils nous voyaient traverser les villages avec notre femme au bras. Quelques uns ricanaient, d'autres disaient: Voyez comme ils s'aiment!

Les premiers temps, les femmes zambéziennes n'étaient admises à nos cultes que si elles s'y réfugiaient sous un abri où personne ne pouvait les voir; cela même avait marqué un progrès sur les temps antérieurs, alors qu'aucune femme ne pouvait paraitre sur la place publique, à moins que ce ne fût pour les procès. Quelle révolution dans leurs idées quand ils y virent nos dames, assises à nos côtés, et qu'ils furent témoins des égards que nous avions peur elles, égards que le roi ne tarda pas à leur prodiguer avec empressement. Quelle révélation de voir dans nos intérieurs, nos femmes partager les repas et présider à la table; puis 
de voir le roi s’asseoir à côté d'elles, et, dans la vie de tous les jours, de voir la place faite à la femme missionnaire, dans la maison et sur la station; de remarquer qu'elle n'est pas une servante mais une aide et que nous lui évitions tous les travaux pénibles. Leur surprise n'était guère moindre quand, à la naissance de nos enfants, nous admettions notre maisonnée á les voir, et que, bientôt, nous les sortions à la vue de tout le monde, ou qu'après quelques jours la mère paraissait en public et qu'elle assistait au culte quelques semaines plus tard. L'éducation de nos enfants donna lieu, de même, à toutes sortes de réfléxions. La vie de la famille missionnaire est une leçon de choses renouvelée à chaque instant. Cette leçon a été apprise de plusieurs.

Dans le haut bo-Rotsé, le premier mariage célébré chrétiennement fut celui de Litia. C'était en 1892, à Séfula. La foule qui y assista, en fut impressionnée. Ce qui frappa le plus, ce furent les promesses de fidèlité et d'égards réciproques, qui ne devaient cesser qu'à la mort de l'un des deux époux. Mpututu, un jeune homme qui venait de faire profession de foi chrétienne, en fut tellement effrayé qu'il se hâta d'aller se marier en cachette, à la façon du pays. Ce mariage fut ratifié publiquement avec celui du Ngambéla actuel, en mars 1899. Mpututu, baptisé du nom de Gideone, fit alors, de son plein gré, les promesses auxquelles il avait voulu échapper quelques années auparavant.

Nous avons plusieurs ménages chrétiens au Zambèze. Nous en avons suivi de près, particulièrement ceux des élèves évangélistes, maintenant à l'œuvre. Il ne faut pas croire que tout ait été parfait dans ces nouveaux foyers. Plus d'une fois, et malgré le proverbe qni nous met en garde, nous avons dû intervenir entre le mari et la femme en dispute. - «Il m'a battue 》 - venait dire l'une. - «Elle ne veut pas m'obéir 》 - disait l'autre. Alors on reprenait, conseillait, montrant a chacun son tort et les suppliant tous deux de tout sacrifier à la paix du ménage et à l'édification de l'entourage. Un autre plus prudent vint un jour nous dire: - «Puis-je battre ma femme? - Vous devinez la réponse. C'était déjà un progrès. Quelle joie pour nous que de voir ces chers couples zambéziens n'être heureux qu'ensemble, soupirer l'un après l'autre quand ils sont obligés de se séparer, et, ensemble, s'occuper avec amour de deux ou trois fillettes, dont ils avaient animé le foyer auquel Dieu avait refusé un enfant.

Que c'était joli de voir un mari et une femme piocher ensemble le même champ, chose inouie au Zan:bèse et accueillie par les moqueries des passants; ou bien encore de les voir ensemble, assis sur la même natte, pour partager le frugal repas. Le 6 juin 1897 nous avions pris note de la date de naissance d'Haokhese (il næ méprise pas) mais nous ne savions pas que ses parents l'eûssent aussi fait.

A l'anniversaire de la petite, nous nous préparions à la fêter par de petits cadeaux, quand nous vîmes le père, Sesoaïra (Pauluse depuis son baptême) venir vers nous pour nous demander les moyens de fêter sa fillette par un repas plus copieux que d'habitude, auquel il convierait tous les habitants de la station; petit incident de famille qui dans son apparente insignifiance, nous fut bien précieux. C'était la preuve qu'une ère nouvelle avait commencé pour les ménages zambéziens.

Tous les missionnaires qui ont passé à Séshéké ont été frappés par le ménage de Litia. Sa maison, la plus belle du pays, est spacieuse et bien comprise; l'intérieur en est aménagé avec benucoup de goût et de propreté, et le confort y a aussi sa place; mais ce que nous y admirons le plus, c'est la parfaite courtoisie avec laquelle Litia traite sa femme, partageant avec elle toutes ses préoccupations; et elle, de son côté, toujours propre et avenante, règne dans sa maison en femme douce et en mère qui sent la grandeur de son rôie et la belle place qui lui est faite au côté de son mari. Litia, aidé par l'Evangile, a pu élever sa femme jusqu'à lui. 
Quelques échos nous sont parvenus de ce que font nos premiers évangélistes zambéziens, et nous apprenons avec joie, que plus d'un est secondé par sa femme dans l'œuvre scolaire et l'évangelisation.

Puisse l'Evangile, ce puissant agent de tout véritable progrès, manifester de plus en plus sa puissance, émanciper l'esclave, relever la femme, ennoblir l'homme, inspirer l'éducation de l'enfant et reconstituer la famille.

\section{Climat.}

\section{A. Tennpénenture.}

Degrés centigrades. Résultat de nos observations de 1890 à 1897 .

Mois. Maximum. Minimum. Moyenne. Ecart min. ${ }^{m}$ Ecart max. ${ }^{\mathrm{m}}$ Ecart moyen.

\begin{tabular}{|c|c|c|c|c|c|c|c|c|}
\hline Janvier & $35^{0}$ & $32^{\circ}$ & $16^{0} 5$ & $19^{0}$ & $25^{07}$ & 805 & $15^{0} 5$ & $12^{03}$ \\
\hline Février & $39^{\circ}$ & $32^{02}$ & $16^{0}$ & $19^{0} 8$ & $26^{0}$ & $8^{0}$ & $17^{0}$ & $11^{08}$ \\
\hline Mars & $36^{0}$ & $33^{03}$ & $19^{0}$ & $20^{\circ}$ & $26^{07}$ & $8^{0}$ & $18^{0}$ & $13^{0}$ \\
\hline Avril & $36^{\circ} 5$ & $31^{04}$ & $10^{0}$ & $15^{07}$ & $23^{0} 4$ & $13^{0}$ & $22^{0}$ & $17^{0}$ \\
\hline Mai & $33^{0}$ & $29^{07}+$ & $6^{0}$ & $13^{01}$ & $21^{0} 6$ & $14^{0}$ & $20 \%$ & 1702 \\
\hline Juin & $29^{\circ}$ & $25^{0} 8+$ & $1^{0}$ & 809 & 1703 & $8^{0}$ & $21^{0}$ & $16^{08}$ \\
\hline Juillet & $33^{0} 5$ & $2607 \div$ & $3^{0}$ & $8^{0} 6$ & $18^{\circ}$ & $12^{0}$ & 2605 & $21^{0}$ \\
\hline Août & $36^{0}$ & $30^{0} 3+$ & 305 & 1207 & 2009 & $13^{0}$ & $27^{0}$ & 1807 \\
\hline Septembre & $39^{\circ}$ & $33^{09} \div$ & $3^{0}$ & $13^{04}$ & $23^{\circ} 03$ & $13^{0}$ & $26^{0} 5$ & $19^{\circ} 9$ \\
\hline Octobre & $43^{03}$ & $36^{0}+$ & $8^{0}$ & $16^{0} 5$ & $26^{03}$ & $12^{\circ}$ & $29^{\circ}$ & 1908 \\
\hline Novembre & $43^{\circ}$ & $33^{2} 5$ & $10^{\circ}$ & $16^{0} 5$ & $24^{05}$ & 705 & $23^{\circ}$ & $16^{0} 6$ \\
\hline Décembre & $40^{\circ}$ & $30^{\circ}$ & $13^{0}$ & $17^{0} 5$ & $23^{0} 8$ & $4^{0}$ & $21^{0}$ & $12^{0}$ \\
\hline
\end{tabular}

Maximum absolu de 1889 à 1900: + $47^{\circ}$ à Kazungula en novembre 1889.

Minimum absolu à Nalisa le 10 juillet 1898: $-8^{0}$. Nous eûmes alors 12 centimètres de glace dans notre seau.

Nous eûmes encore un peu de glace au Lumbe en Août 1892.

Le plus petit écart de température a été de $4^{0}$, le 4 décembre 1895 et le 5 décembre 1896.

Les plus grands écarts ont été: $29^{0}$ le 5 octobre $1898\left(\mathrm{de}+8^{0} \mathrm{a}+37^{\circ}\right)$.

$27^{\circ}$ le l.r août 1895 .

$26^{0} 5$ le 4 juillet 1890 et le 23 septembre $189 \pi$.

\section{B. Vent.}

Janvier

Février

Mars

Avril

Mai

Juin

Juillet

Aoû́t

Septembre

Octobre

Novembre

Décembre

Moyenne des journées de vent.

Les moyennes sont celles de Léaluï et peuvent servir pour Nalolo. Kazungula est aussi très exposé au vent. Sesheke un peu moins. Senanga, Mabumbu et Mosi-wathunya encore moins. Sefula le moins de toutes.

Ce sont surtout les bois qui font la différence.

Par vent j'entends un vent assez fort, et pas la brise qui est à peu près constante. Le vent dominant souffle du Nord-est. 


\section{c. Pluie.}

En millimètres.

Année Août. Sept. Oct. Nov. Déc. Janv. Févr. Mars Avril. Totaux

$\begin{array}{lllllllllll}1895-96 & 0.00 & 0.00 & 16.25 & 66.05 & 208.08 & 147.06 & 312.70 & 79.08 & 56.24 & 885.46\end{array}$

$\begin{array}{lllllllllll}1896-97 & 2.32 & 0.77 & 4.64 & 28.64 & 273.48 & 321.73 & 52.12 & 208.72 & 8.51 & 900.93\end{array}$

$\begin{array}{lllllllllll}1897-98 & 2.84 & 0.00 & 52.12 & 73.79 & 169.48 & 165.00 & 139.71 & 173.38 & 3.61 & 779.93\end{array}$

$\begin{array}{lllllllllll}1898-99 & 0.00 & 1.29 & 9.03 & 153.12 & 152.48 & 79.72 & 423.64 & 93.01 & 25.54 & 937.83\end{array}$

$\begin{array}{lllllllllll}\text { Totaux } & 5.16 & 2.06 & 82.04 & 321.60 & 803.52 & 713.51 & 928.17 & 554.09 & 93.90 & 3504.15\end{array}$

$\begin{array}{llllllllll}\text { Moyennes 1.29 } & 0.52 & 20.51 & 80.40 & 200.88 & 178.38 & 232.04 & 138.55 & 23.47 & 876.04\end{array}$

On peut avoir très exceptionnellement de la pluie même en mai, juin et juillet. Nous en eûmes les 7 et 28 mai 1890 et le 18 mai 1897; le 20 juin 1899 et les 11 et 12 juillet 1899 .

Maximum absolu de pluie tombée en 24 heures (de minuit à minuit) $103 \mathrm{~mm}$. On a rarement des pluies continues. 11 est rare qu'une journée se passe sans qu'on voie le soleil.

J'eus 5 ou 6 fois de la grêle: La plus forte à Manyekanga à la mi-novembre 1891.

\section{Les Saisons.}

Saison

Mois

Pluie Vent Tempér. Maxim. Minimum.

$\begin{array}{lllllll}\text { Naria (l'hiver) Juin à août } & 1.30 & 45 & 18^{07} & 30^{\circ} 9 & 9^{04}\end{array}$

Mbumbi (la sécheresse) Sept. à Nov. $\quad \begin{array}{lllll}101.48 & 72 & 24^{\circ} 8 & 344^{5} & 15^{\circ} 5\end{array}$

\section{E. Maladies des Lamibéziens ").}

Environ $50 \%$ des malades que nous soignons ont des maux d'yeux de diverses natures. Les autres maladies, dans leur ordre de fréquence, sont les suivantes:

Maladies de la peau: lèpre, gale...

Maladies des voies digestives: diarrhée, constipation, dyssenterie...

Fièvres intermittentes.

Maladies des voies respiratoires: coryza, bronchites, pneumonie, influenza, un cas de phthisie importé des mines d'or.

Rhumatismes.

Névralgies. Odontalgies (dents arrachées)...

Maladies épidémiques ou contagieuses: variole en 92 , varicelle en 99, espece de diphthérie en 98 et 99 .

Maladies cardiaques...: palpitations, évanouissements, vertiges...

Corps étrangers dans le pharyngs..., dans les oreilles, le nez...

Membres démis ou luxations.

Epilepsie, hystérie, crises nerveuses.

Dysurie, anurie, syphilis...

Folie.

Dystocie.

De 1895 à 1900 j'ai eu en moyenne 8 cas par jour.

a) Ce tableau n'a comme source que mes propres observations et notes. 


\section{A LA MÉMOIRE BÉNIE...}

Quelques souvenirs de la vie de Mad. Emma Jalla.

A.- Les premières (1) années de Madame Ad. Jalla, née Emma Pons, s'écoulèrent à Guastalla, où elle est née, à Rome, à Côme et à Venise, où son père actuellement conducteur de la paroisse de Torre-Pellice et Modérateur de l'Eglise vaudoise, était alors pasteur. C'était une enfant d'une vivacité extrême, mais réfléchie, que les choses de Dieu intéressaient et touchaient singulièrement. Ame foncièrement droite, ses parents ne se souviennent pas qu'elle leur ait jamais déguisé, même lontainement, la vérité. Intelligence sans cesse en éveil et s'assimilant, sans effort, tout ce qu'on lui enseignait, elle eut de bonne heure le goût de l'étude, où elle devait toujours se distinguer également par une application qui lui permit d'acquérir plusieurs langues, qu'elle parlait et écrivait avec autant de pureté que son idiome maternel. Ceux qui l'ont entendue plaider, en français, en italien et en anglais, la cause de la Mission, dans les divers pays qu'elle visitait avec son mari, comparaient volontiers ses causeries faites dans d'humbles salles d'école, dans d'immenses halls ou dans des salons accueillant l'élite de la societé protestante de Suisse et de Grande Bretagne, au cours limpide d'un ruisseau que la déclivité du terrain change parfois en torrent qui balaie tous les obstacles sur son passage, tant il y avait dans cette parole nette, colorée et convaincue, de passion et de chaleur commucative.

$\dot{A}$ huit ans, Emma Pons suit sa famille aux Vallées et jusqu'à seize ans son temps se partage entre ses études, les siens et ses amies, années heureuses de travail consciencieux et joyeusement accompli, de pures et saintes émotions. Très populaire parmi ses compagnes de classe, elle n'eut guère que deux ou trois amies intimes. Celles-ci, chose singulière, devaient toutes se trouver auprès d'elle pendant ses derniers jours, dans cette belle propriété des Airals Blancs appartenant au pasteur Appia de Paris, où son âme, éprise des beautés de la nature, jouissait doublement, après les privations de dix années d'Afrique, de la vue enchanteresse sur les Alpes Cottiennes et sur la plaine du Piémont, de la fraîcheur du grand parc et des fleurs qui font de cette retraite un petit paradis terrestre.

Son éducation terminée, Emma Pons se consacra aux membres de sa famille qui avaient le plus besoin d'elle. Son activité égalait seule sa gaieté. Secrétaire de son père, elle écrivait rapidement, sous dictée, et dans plusieurs langues, sans que jamais une faute ou une rature vînt se glisser sous sa plume alerte, heureuse de pouvoir, entre deux lettres de caractère administratif, avoir quelques instants de conversation avec celui que ses occupations multiples enlevaient presque totalement aux siens. Tous les sujets y étaient abordés et l'intimité croissait

(1) Extrait de l'Eglise Libre, $N^{0}$ du 14 novembre 1902. Je voudrais recommander à tous ceux qui ont aimé ma femme, la brochure de M.lle M. A.: Madame Aclolphe Jalla. Souvenirs d'une amie d'enfance. - Vals-les-Bains. E. Aberlen et Co. 1903. 



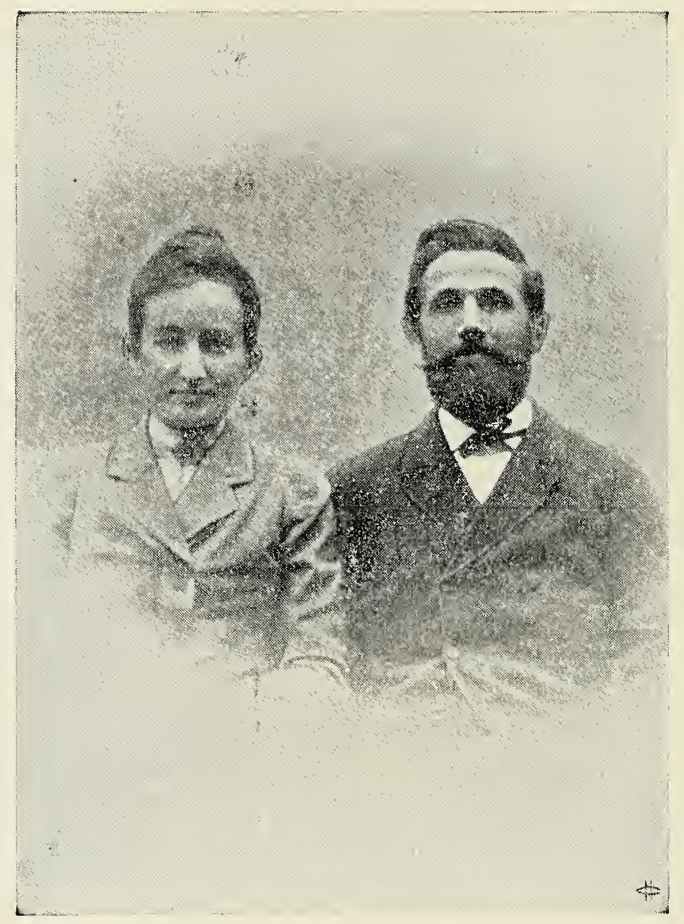

En tournée missionnaire (Spezia, Novembre 1901). 
entre ces deux caracteres si bien faits pour se comprendre. Précepteur de son frère, elle se mit courageusement à l'étude du latin pour faciliter la tâche à l'écoiier. Elle suivait régulièrement les cours du Lycée. En outre elle était le bras droit de sa mère, plus qu'une sœur pour la fillette aux grands yeux dont la venue l'avait ravie, et s'occupait de l'éducation de leux petits cousins, trouvant encore moyen de beaucoup lire, de faire de l'allemand avec une amie, sans négliger aucun des travaux féminins où elle excellait, et de collaborer à tout ce qui se faisait de bon'et d'utile dans la vaste paroisse de son père. Quelques séjours chez des amis en Italie, et des parents en France, développaient toujours plus l'amour du beau dans cette âme éprise d'idéal et que le sérieux de l'existence avait toujours empoignée. Tout ce qu'il y avait de plus intellectuel et de plus généreux comme culture et aspirations, soit aux Vallées, soit parmi les visiteurs étrangers de ce pays historique, éprouvait une vive admiration pour cette personnalité si tranchée et si oublieuse d'elle-même. Elle allait droit au but et mettait autant d'impétuosité et de promptitude à réparer des torts qu'elle en mettait à affirmer ce qu'elle croyait être la vérité.

En 1888, la jeune fille était fiancée au pasteur missionnaire Adolphe Jalla, qui se rendait sur le Haut-Zambese pour y devenir le collaborateur de M. Coillard. On se représente facilement la douleur des siens à la pensée de la future sépara. tion. La jeune fille ne s'occupa plus, durant les trois années qui la séparaient de son mariage, qu'à adoucir la coupe que devaient boire ses bien-aimés, et à se préparer à la tâche qui l'attendait. Pendant un séjour de plusieurs mois en Ecosse, chez des amis, elle suivit entr'autres avec assiduité un cours de médecine, passant ensuite avec plein succès, un examen sur cette branche. Elle plaisantait volontiers sur ses connaissances thérapeutiques.

Le moment du départ arriva. Le 29 octobre 1890 le jeune couple - M. Ad. Jalla était revenu aux frais de sa famille, chercher sa compagne en Europe quittait le pays de leurs pères pour se rendre sur les bords du fleuve géant, en plein cœur africain, suivi des bénédictions générales. Déjà alors dans les visites d'adieux, Madame Jalla gagna tous les cœurs.

Il est impossible de retracer ici, dans cette rapide esquisse de la vie et de l'œuvre de Madame Jalla, les travaux, les joies et les peines des dix années vécues au Zambèse, aux côtés de l'homme de son choix, dont elle fut l'aide admirable, dépensant sans compter des trésors d'énergie, de forces physiques et morales, dans les diverses branches de l'activité missionnaire, à la capitale, et cela a travers des angoisses et des crève-cœur quotidiens, malgré la maladie et les deuils. Aucune épreuve n'entamait son courage. Ses lettres à sa famille et à ses amis, dispersés dans le monde entier, respirent une foi indomptable, et jamais Madame Jalla ne parlait de ce pays qui devore ses habitants, quavec un amour intense: «C'est ici, disait-elle, que Dieu nous veut. Le Zambèze est pour nous une seconde patrie 》.

LE $I^{r}$ Août 1900, M. et Madame Jalla rentraient au milieu des leurs, après deux lustres de cette vie de pionniers qui affaiblit terriblement lorsqu'elle ne les détruit pas, lès organismes les plus résistants. Chacun sait de quels soins ils furent entourés et quelle affection on leur témoigna partout, ainsi qu'à leur fillette. Leurs congés furent des plus actifs, des plus agités même, et cela, malgré les prières de ceux qui les aimaient. L'œuvre qu'ils portaient dans leurs cœurs sollicitait leur activité, et ils ne reculèrent devant aucune fatigue pour la servir. Et, d'ailleurs, tous ceux qui ont bien connu Madame Jalla, savent qu'elle était une de ces personnes qui ne savent pas et qui ne peuvent peut-être pas se reposer. À peine avait elle repris quelque force, elle se prodiguait aux siens, à son entourage, reprenait sa plume, ses livres, son aiguille. ses voyages. 
Dieu l'a rappelée soudainement à Lui au moment où elle se praparait avec une consécration renouvelée, à retourner au poste. Quelle perte pour son mari. pour ses fillettes, pour tous les siens, pour la Mission du Zambèse! Le sacrifice était dur. Après quelques minutes de combat intérieur, la vaillante jeune fenme s'écria: «Le Maître m'appelle et Il m'accueillera! 》 À l'âge de 33 ans, ce Dieu auquel elle était et qu'elle avait fidèlement servi, la faisait entrer dans le repos des saints. Qu'Il soit la consolation et la force de ceux pour qui la journée de labeur n'est point encore terminée!

A. B.

B. - Il faut, comme M. Jalla, avoir goûté par la vie commune, ou par la correspondance, l'intimité de son âme, pour mesurer la perte que nous venons de faire et pour comprendre notre douleur.....

Mais ce qui, en Mme Jalla, l'emportait encore sur les qualités intellectuelles, c'étaient les dons de l'âme. On s'en apercevait bien vite, dans sa société, dont nous voudrions pouvoir rendre tout le charme. L'enveloppe physique était frèle; mais l'énergie se lisait dans ces yeux au regard si pur et presque enfantin, sur ces traits où la netteté des lignes s'alliait aux plus délicates couleurs; sur tout ce visage transparent, à l'intense vie intérieure. C'était là ce qui séduisait: cette droiture, ce naturel parfait qui excluait dans l'expression et jusque dans le ton, tout apprêt et toute affectation. Telle nous la vîmes aux Vallées Vaudoises en 1889, alors que fiancée à $M$. Ad. Jalla, elle se préparait à la vie missionnaire, telle nous l'avons retrouvée dans ses lettres, telle nous l'avons revue, il y a deux ans, à son retour d'Afrique.

Arrivée au Zambèze, elle manifestait à une amie la volonté de l'associer entièrement à sa vie par une correspondance active et détaillée: "Je vous écrirai tant que vous finirez par connaître notre œuvre comme si vous y étiez vous-même associée ». Cette force passionnée de volonté et d'intérêt était le trait dominant de son caractère. Elle suppléait à ce qui, originairement, eût pu lui manquer comme aptitudes pratiques. ( 1$)$

\section{Derniers mois et derniers moments.}

Le séjour de congé des missionnaires est un changement d'air et d'occupations plutôt qu'un repos. Il en sera ainsi tant que les églises n'auront pas compris leur responsabilité à l'égard des millions de païens qui périssent. Comment jouirionsnous du repos, nous qui avons vu combien est grande la misère des peuples qui sont sans Christ, et combien est grande aussi chez la plupart des chrétiens l'indifférence à l'égard de l'ordre du Maître, d’évangéliser toutes les nations? Nos tournées missionnaires ont été pour nous un devoir et un besoin. L'accueil de nos amis en fait une source de bénédictions. Ma femme a été beaucoup moins éprouvée par les déplacements fréquents que par l'inaction à laquelle elle a été condamnée pendant des semaines et des mois, tandis que je parcourais les églises d'Alsace, de Hollande, de Belgique et de France. Aussi je remercie vivement les amis et parents qui ont rendu possibles les voyages de ma femme en Suisse, en Grande Bretagne et en Italie, sans que cela coûtât quoi que ce soit à la Société des Missions.

A la fin de 1901, aprè notre tournée en Italie, dont elle avait très bien supporté les fatigues, nous nous réjouissions à la pensée de reprendre kientòt le chemin du

(1) Extrait du Journal des Missions de décembre 1902. 
Zambèze. Cependant la sommité médicale que nous consultâmes, sans s'opposer catégoriquement à notre départ, demanda pour nous une année de plus en Europe, année que le Comité accorda. En janvier 1902 nous allâmes à Milan, Bergame et Novare. Le 20 février eut lieu la séance d'adieux à M. et Mme Georges Volla. Le soir même je partis pour la Vallée de la Dordogne.

Trois semaines après mon retour auprès de ma compagne, je fus appelé à aller rencontrer Lewanika en Angleterre. Ma femme qui allait remarquablement bien, m'y rejoignit bientôt. Tant à Londres qu'à Paris et aux Vallées Vaudoises, nos amis remarquèrent une grande amélioration dans sa santé.

Le 26 Octobre, à $2 \mathrm{~h}$. 15 de l'après-midi, son troisième enfant, pour lequel elle avait choisi le nom de Letizia, naquit normalement, mais laissant sa mère dans un état de faiblesse fort inquiétant. Nous espérions cependant; mais quelques heures plus tard, de nouveaux symptômes alarmants apparurent (probablement ceux d'une embolie). Ma chère femme vit mon anxiété, elle comprit quelle était la volonté du Seigneur, et dit: "N'est-ce-pas que Dieu m'appelle? J'aurais tant aimé rester encore avec toi, faire encore un peu de bien ».... Après avoir répandu encore une fois son cœur si chaud dins celui de ceux qui l'entouraient, elle ajouta avec calme: "Il m’appelle et Il m'accueillera!» Elle nous dit encore une dernièrs fois: "Il m’appelle! » et sans agonie, elle nous quitta à $7 \mathrm{~h} .15 \mathrm{du}$ soir.

\section{Les funẻrailles}

A. - Cette nouvelle foudroyante (1) impressionna grandement toute la population vaudoise, qui se sentait liée à la chère défunte par une sympathie toute spéciale. Aussi les funérailles (29 octobre) (2) furent-elles imposantes par le nombre de ceux qui s'y trouvèrent; le deuil de deux familles aimées devint ainsi celui de la population toute entière. Des allocutions telles que la triste circonstance les requérait, furent prononcées par MM. les pasteurs A. Jahier, H. Tron, D. Peyrot et C. A. Tron, à la maison mortuaire; et au cimetière par MM. J. Weitzecker et J. P. Micol, ainsi que par le capitaine Bertrand, explorateur africain. L'Echo du Vallon exécuta quelques beaux chœurs. La cérémonie fut émouvante, le regret et la douleur se lisaient sur tous les visages.

B. - Fragments de l'Allocution de M. le pasteur $H$. Tron, prononcée aux Airals-Blancs le 29 Octobre 1902. (Actes xx. 17, 27).

Réunis autour de la dépouille mortelle de notre sœur Emma Jalla née Pons, qui a consacré sa vie à l'oeuvre missionnaire, nous éprouvons une grande consolation en méditant les paroles dites par le premier et le plus grand des missionnaires, au moment où il allait être lié de chaînes, et alors qu'il pouvait considérer comme proche le terme de sa course terrestre. Les missionnaires, hommes et femmes, lui reconnaissent le droit de parler au nom d'eux tous.

L'œuvre missionnaire est un ministère, que le Seigneur Jésus confie aux disciples qu'il choisit pour cela. C'est une grâce ajoutée à celle du salut personnel...

Oui, mais ce ministère ne peut s'accomplir qu'en acceptant tous les sacrifices, toutes les privations, et en exposant constamment sa propre vie. Voici encore sur ce point si sérieux, les paroles du missionnaire: « Je ne me mets en peine de rien et ma vie ne m'est point précieuse, pourvu que j’achève ma course et le

(1) Extrait de l'Avvisatore Alpino.

(2) C'était le 1l.me anniversaire de notre mariage.

Pionners 
ministère que j"ai reşu du Seigneur Jésus ». Ce ministère et si beau et si grand, il procure de telles joies, que les liens, les affections, la mort même sont des choses dont il ne vaut pas la peine de tenir compte. Celui qui le dit n'est pas un enthousiaste, un jeune homme qui se nourrit d'illusions, les souffrances il les a endurées, il a vu la mort en face. Il sait que la prison, les afflictions, et la mort l'attendent. Je ne me mets en peine de rien, dit-il, ces paroles font vibrer nos cœurs. C'est bien cela, ce n'est pas trop de souffrir, et mourir pour Christ mort et ressuscité pour nous. "Nous avons connu la charité en ce que Jésus Christ a mis sa vie pour nous, nous devons donc aussi mettre notre vie pour nos frères ». "Sois fidèle jusqu'à la mort et je te donnerai la couronne de vie ». Les souffrances et la mort ne sont plus rien au service du Prince de la vie. La fidélité est tout.

Là devant nous se trouve le corps inanimé d'une épouse, d'une mère, d'une fille, d'une sœur, d'une parente, d'une personne que plusieurs personnes aimaient. mais il y a plus - c'est le corps d'une servante de Jésus-Christ, d'un ministre, d'une missionnaire; au dessus des liens de la famille terrestre il y a les liens de la famille céleste. Il y a ici l'enfant de Dieu, l'ouvrière du Seigneur. Le Dieu qui l'a rachetée a tout droit sur elle, et c'est lui qui l'a prise à son service.

Pour la famille terrestre, la mort d'un de ses membres est une perte irréparable. Pour la famille du Père celeste il n'y a point de perte, il y a gain. «Pour moi, vivre c'est Christ et la mort m'est un gain ». « Et si je sers d'aspersion sur le sacrifice et l'offrande de votre foi, j'en ai de la joie et vous aussi réjouissez vous avec moi ». Quel langage! Si nous regardons à la terre nous sommes dans le deuil; si nous regardons au royaume de Dieu nous pouvons nous réjouir. C'est une servante du Seigneur que le Seigneur couronne. Ici ou là, toujours avec le Seigneur!

Cher frère Jalla, vous aussi vous avez dit: Je ne me mets en peine de rien. ma vie ne m'est point précieuse, vous êtes allé et retourné. Quand vous ave\% amené avec vous votre jeune épouse, vous saviez que la fièvre et les privations l'attendaient, et vous avez fait le sacrifice de sa vie comme de la vôtre; vous êtes dans l'ordre. Vous alliez repartir, elle vous a précédé. Dieu console les siens dans toutes leurs afflictions, et vous irez consoler les cœurs affligés. Dieu prendra soin de vos enfants et vous bénira dans votre œuvre.

Chers M. et M.me Pons, Dieu vous a honorés en choisissant votre fille aînée pour en faire une missionnaire. Vous la lui avez donnée. Il l'a employée comme il l'a voulu. Elle a été fidèle.

Jeunes gens, jeunes filles, le Seigneur a besoin de serviteurs et de servantes en Afrique, en Italie, aux Vallées pour travailler au salut des âmes. Entrez dans la moisson. Frères et sœurs, qui vous intéressez aux missions, hâtez-vous avant que la nuit vienne! Serviteurs et servantes du Seigneur, servez-le avec larmes, pour arracher à la mort ceux qui ne se sont pas donnés à Christ.

Nous tous qui honorons le dévouement des serviteurs de Dieu, ne négligeons pas nous-mêmes son grand salut. Rendons grâces à Dieu qui nous a donné la victoire sur le péché et sur là mort!...

\section{Extrait de l'Echo des Vallées: Torre-Pellice 8 Novembre 1902.}

... Puisque pas un passereau ne tombe en terre sans la volonté du Seigneur, ne croirons-nous pas comme elle que c'est Dieu qui l'a appelée? - Ce qu'elle était, le Seigneur l'a vu mieux que nous. Il a vu l'amie, la sœur, la fille, la mère, l'épouse bien-aimée, la femme missionnaire; ses qualités du cœur et de l'intelligence, son amour des noirs, que tant d'amis ont remarqué, le Seigneur les a vus. Lui qui les avait donnés et vivifiés par la puissance du Saint-Esprit. Elle avait 
accompli son œuvre puisqu'il l'a appelée. Sa journée a été courte mais bien remplie.

Ce qu'elle a été pour moi, quelques-uns l'ont entrevu. C'est un don de Dieu pour lequel je le bénirai toujours. Vous ne vous attende\% pas à ce que je vous dise ma douleur, elle est trop sacrée. Nous avons tout pleinement partagé... Son bonheur actuel m'éclairera encore. Ce qu'il en sera quand je devrai laisser mes deux fillettes et reprendre le chemin du Zambèze?... Dieu le sait. Vous le devinez. chers amis, et je compte sur vos prières pour nos enfants et pour moi: j'en ai besoin. Ce que je sais, c'est que dès à présent les choses invisibles sont plus réelles, le ciel est plus beau et plus près. Dès à présent le Seigneur m'est devenu plus précieux. Il me donnera de saisir toujours mieux ses richesses incompréhensibles et m'accordera la grâce de les annoncer aux païens encore mieux que par le passé; ce sera de la semence répandue avec larmes... Bientôt viendra la moisson avec les chants de triomphe.

Adolphe Jalla.

\section{Echos du ministère de ma femme en Europe.}

\section{FLEURS SUR SA TOMBE}

\section{A. - La vocation missionnaire.}

Paroles prononcées par ma femme le 20 férrier 1902 à Torre Pellice, à la séance d'adieux de .M. et M. ${ }^{m}$ Grorges Volta.

C'est ma qualité de vieille Zambézienne qui me donne le couraye de parler ici. Nous avions rêvẻ autre chose pour cette journẻe. Vous le savez bien, vous, chers amis, avec lesquels nous avions fait de si jolis projets de voyage en commun. L'an passé, en disant adieu à M. et M.e Lageard, dans une circonstance analogue à celle-ci, nous avions espéré, oui, je le dis du fond du cœur, espéré, que ce serait à nous, cette année, qu'on dirait: Adieu! Dieu en a jugẻ autrement. Nous devons rester un an encore dans la vieille Europe - et quelques-uns nous en fẻlicitent - cette Europe très-belle et où l'on a des bénédictions inconnues au Zambèze, mais où pourtant nous nous sentons désormais comme des visiteurs, des étrangers. Notre vraie patrie terrestre, maintenant, c'est le Zambèze! Nous le disons à la gloire du Dieu fidèle, dont toutes les promesses sont véritables.

Je me souviens mon étonnement et presque mon scandale lorsque M. Coillard, dans notre premier culte de famille, à Sefula, pria pour moi disant: «Fais qu'il en soit pour elle, comme pour Joseph, qu'elle oublie la maison de son père ». M. Coillard sourit quand je lui fis part de mon sentiment et m'expliqua que, dans ce cas-ci, 
oublier ne veut pas dire effacer de son cœur et de sa mémoire, mais y pouvoir penser sans regrets. Je n'avais pas été longtemps au Zambèze sans éprouver la réalité de cette chose, inouie pour le cœur humain livré à lui-même: la patrie de l'enfant de Dieu est partout où le Seigneur l'appelle, et tous les hommes, même les pauvres Zambéziens dégradés, sont nos frères, nos mères et nos sœurs. Vous le sentez dès à présent, ces Zambéziens, pour lesquels vous quittez tout, vous sont chers; ils le deviendront toujours plus quand vous aurez vécu au milieu d'eux, quand vous les aurez vus si malheureux, sans Dieu et sans espérance, quand aurez encore plus souffert à cause d'eux, et quand, au milieu des innombrables épines, vous aurez cueilli une rose.

C'est là-bas, dans ce pays de cruauté, de mensonge et d'égoïsme, qu'on apprend à apprécier le plus petit acte de charité; comme il est suave le parfum des rares fleurettes qui croissent sur notre sentier! On l'a assez dit pour que vous le sachiez bien, les Zambéziens sont comme des enfants et de méchants enfants, mais c'est à cause de cela même qu'il est plus facile de leur pardonner des fautes qu'on ne tolèrerait pas chez des blancs. Ils ont si peu reçu qu'on attend très peu d'eux. C'est, sans doute, cette pensée constante qui donne à M. Coillard la grande indulgence qui a fait dire au célèbre voyageur Serpa Pinto: «M. Coillard n'a qu'un défaut, c'est de trop aimer les noirs ».

Cependant, je ne resterais pas dans le vrai si je ne disais pas qu'il y a des circonstances ou les péchés grossiers de nos paurres Zambéziens, en faisant verser des larınes amères, nous repoussent et nous éloignent presque. Oh! alors, notre amour seul ne suffit pas; il nous faut puiser à pleine âme, dàns l'amour divin, et nous rappeler que Jésus est venu chercher et sauver ce qui était perdu. Il n'a pas craint, lui, de se mêler aux péagers et aux gens de mauvaise vie, et nul péché n'a été trop grand pour qu'il pût l'effacer. Si je voulais, je pourrais, moi aussi, et malgrẻ mon grand amour pour le Zambèze, vous faire un nuir tableau de choses que j'ai vues et que vous verrez aussi; mais c'est justement parceque vous savez ces choses que vous partez.

Quelqu'un nous disait un jour: «Les missionnaires sont des enthousiastes!»- «Il faut autre chose», ajouta un autre. Et c'est vrai. Je plaindrais celui ou celle qui partirait pour le Zambèze avec son enthousiasme seul. Mais il en faut, et une dose assez forte pour qu'il dure à travers la mer et ses vagues houleuses, dans le désert avec ses lenteurs, ses retards, son soleil cuisant et ses bourbiers. Il en faut pour se confier à ces frêles coquilles de noix qu'on appelle canots, et il en faut encore, une fois installés 



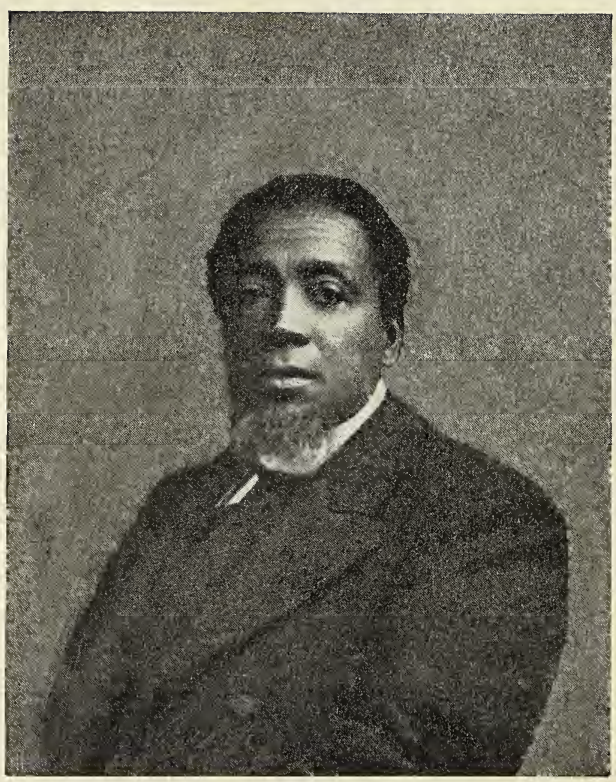

Le roi Lewanika à Londres. 
sur une station solitaire, souvent aux prises avec la fièvre, toujours avec toutes sortes de difficultés, avec un travail débordant et le sentiment de ne pouvoir faire assez. Cette petite perle a son prix. Il le savait ce grand ami des missions (M. Bœgner) qui disait $\dot{a}$ un « revenant» d'Afrique: «J'espère que vous n'avez pas perdu votre enthousiasme ». Partez donc, chers amis, avec tout l'ẻlan de votre vocation, pleins d'enthousiasme et de joie, décidés à ne les perdre jamais. Vous savez la source où on les renouvelle chaque jour.

Mais parler du Zambèze, c'est parler de maladie, de mort, de nombreuses places vides. Que de foyers mutilés depuis trois ans! Vous ne trouverez plus à son poste notre sœur Marie, qui, pour moi, demeure le type de la femme missionnaire, et qui nous accueillait avec tant de bonheur en 1892. En voilà une de ces consécrations entières, simples, joyeuses. Elle avait su conserver son enthousiasme au travers d'épreuves répétées, et nous était revenue la même, après le sacrifice qui, peut-être, lui a coûtẻ la vie; avec quel amour, quel entrain elle s'était remise á son œuvre, à la tâche surtout d'élever ses jeunes Zambéziennes qu'elle a toujours vues meilleures qu'elles ne le sont. Et après la sienne, que de tombes creusẻes sur le bord du grand fleuve! «Mais je suis plein de confiance en l'avenir, nous écrit M. Coillard, vous verrez encore de grandes choses ici», et je vous le répète de sa part, à vous qui serez là-bas avant nous. Oui, que ce vœu se réalise! Qu'une grande et belle moisson suive ces pénibles semailles! Vous trouverez dẻjà quelques épis, maigres quelques-uns, mais des épis pourtant, des tisons arrachés du feu.

Ce n'est pas adieu que nous vous disons, mais au revoir; au revoir au Zambèze, si Dieu le veut! Nous aurions étẻ si heureux de, vous en faire les honneurs, de vous initier à cette œuvre, mais c'est vieux Zambéziens d'un an que vous nous accueillerez, et peutètre même sur notre chère termitière de Léaluï. Quand nous la quittions, il y a deux ans, tous les ma-Rotsé nous disaient: «Revenez ». Dites-leur que nous ne les oublions pas, et que notre vœu le plus cher est de retourner vers eux.

\section{B. - Lewanika en Angleterre (1)}

Torre Pellice, 2 Septembre 1902.

Le nom de Lewanika a été sur toutes les bouches et dans les ceuurs, d'une façon spéciale, ces derniers mois; et, pendant qu'il ro-

(1) Lettre de ma femme, extraite des Nouvelles du Zambèze, 1902, n. 3, p. 93. C'est un précieux souvenir de la fin de son ministère auprès des ma-Rotsé. 
gue sur les grandes eaux, nos pensées et nos prières le suivent et l'entourent.

On a déjà beaucoup écrit sur ce monarque africain. Mon désir est simplement de présenter une fois encore au public cette figure sympathique et aimée, en parlant de lui tel que nous avons eu le privilège de le voir en Angleterre. Ce voyage, que nous avions tant redouté pour lui, a peut-être contribué, entre les mains de Dieu et sous l'influence bienfaisante des amis chrétiens qui, de près et de loin, l'ont entouré, à l'amener plus près du Sauveur. C'est plus tard qu'on pourra juger du bien qu'il s'est fait, pour le moment nous pouvons seulement dire ce que nous avons vu: J'aime à me rappeler l'expression de sa physionomie, son visage adouci et paisible, dans les salons où il était reçu. Le despote cruel et abruti ètait bien loin, c'était le roi avec le sentiment de sa dignité, mais aussi l'homme prévenant et poli, l'ami heureux de nous voir, que nous avions devant nous. Tout son visage, quelquefois soucieux et triste, s'épanouissait en nous voyant entrer, et si Graziella était avec nous: «Oh! bẻbé, viens me saluer, s'écriait-il de suite avec joie». « Misisi », me dit-il une fois que j'employais une expression toute zambézienne, «tu me fais penser au bo-Rotsẻ ». Il jouissait de la vie civilisée, s'émerveillait de tout ce qu'il voyait, mais son cœur était bien resté lả-bas, parmi son peuple, dans la grande plaine. Les honneurs dont on l'a comblẻ ne semblent pas l'avoir enorgueilli: « Je vois bien la diffẻrence entre ceux qui ne me reçoivent que comme roi et ceux qui m'accueillent en ami » disait-il à mon mari à Glasgow. Tout était pour lui sujet d'observation et d'émerveillement: «Que de monde, que de voitures, disait-il à Londres, on dirait que les gens déménagent tous. Et les maisons (ẻtages) les unes au dessus des autres!» - «Oh! les mots nous manqueront pour dire ce que nous avons vu», disait le Ngambéla, à l'œil intelligent, au visage ouvert et aimable.

« Ici, je suis sur terre étrangère, nous dit un jour Lewanika; si j'avais pu aller de l'autre côté du canal, je me serais senti chez moi, parmi les miens. N'est-ce pas de là que me sont venus tous mes missionnaires? » Il a saisi toutes les occasions de dire son grand désir d'en voir beaucoup dans son pays. C'est cet appel que nous posons sur le cœur de tous les chrétiens. Qui y répondra? Que Dieu envoie Lui-même ceux qui doivent aller, qu'll choisisse ses serviteurs et ses servantes, qu'll garde ceux qui sont là-bas à la brèche, qu'Il prépare à nouveau ceux qui doivent aller reprendre leur poste!

M. Stanley Arnot, aucien missionnaire, nous écrivait il y a quelques jours: «J'ai eu le privilège de passer avec Lewanika sa dernière soirée en Angleterre. Il paraissait très heureux à la perspec- 



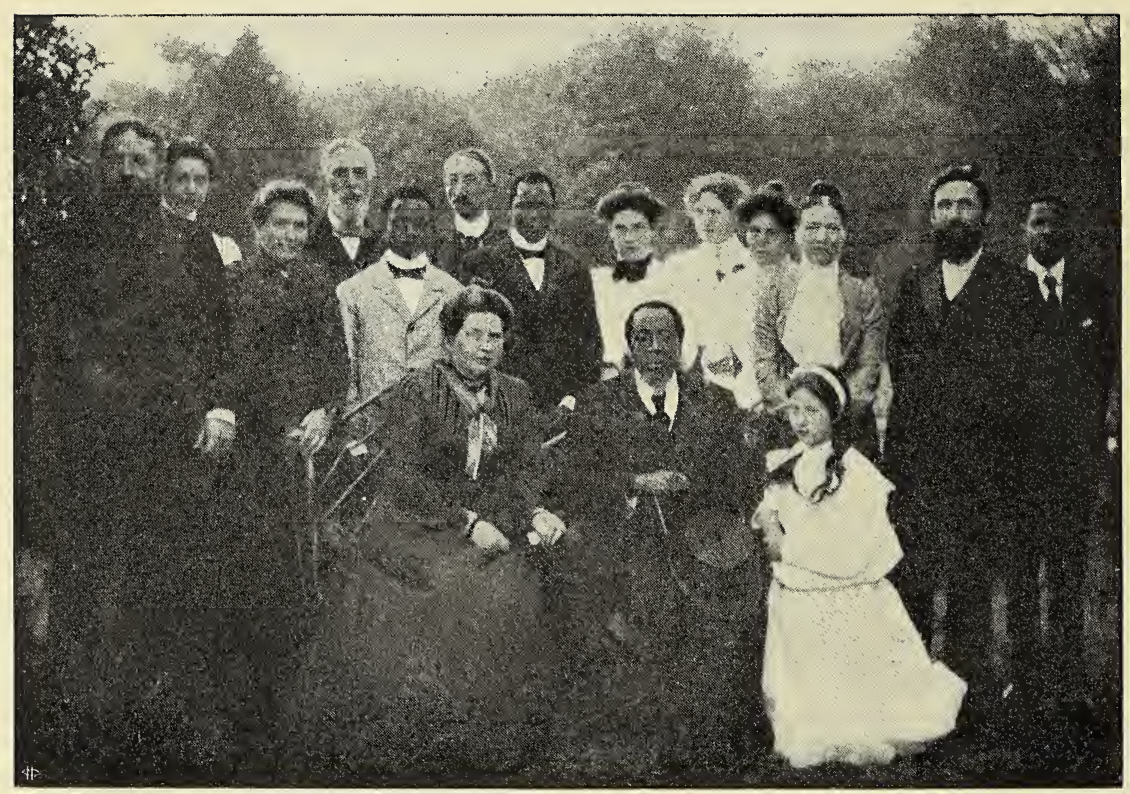

Souvenir de Glentyan (Glasgow) 
tive de retourner chez lui. Après une longue conversation avec lui et le Ngambela, Lewanika dit: «Oui, Monare, je ne suis qu'un noir, chez nous la lumière se fait lentement, mais je puis dire que j'ai appris à prier Dier, et si tu ne viens jamais me voir dans mon pays, j'espère que, comme tu l'as dit, je te rencontrerai dans le royaume de Dieu.

Nous ne voulons pas donner à ces paroles plus d'importance qu'il ne le faut, et nous devons tenir compte que le roi était peut-être en proie à des émotions profondes, à la veille de quitter la vie civilisée et ses jouissances, pour rentrer dans l'Afrique tẻnébreuse et le pays qui lui prépare un accueil frénétique qu'on ne peut s'imaginer en Europe. Cependant n'est-il pas permis d'espérer qu'une ceuvre solide et salutaire s'est faite dans ce cœur depuis si longtemps èclairé, mais encore rebelle et partagé? Ne serait-ce pas le commencement de la conversion véritable de cet homme, changé déjà à tant d'égards, mais qui ne s'est pas encore entièrement donné? En tout cas notre devoir à nous, est de continuer à prier, à lutter pour que cette âme soit sauvée, et que par elle, plusieurs soient amenées à la lumière et à la croix.

\section{C. - Fragments de lettres de condoléance.}

Les fragments de lettres de condoléance que je transcris ici, témoignent du bien qu'il a été donné à ma femme de faire dans ses tournẻes. Est-ce un abus de confiance de ma part? Que nos chers amis me le pardonnent. Les lignes qui suivent sont pour moi un écho de son ministère en Europe, des fleurs que je voudrais déposer sur sa tombe!

\section{Membres du Comité des Missions.}

Votre compagne a été aimée et appréciée comme elle le mérite, et nous pleurons en connaissance de cause. Elle nous avait gagné le cœur au premier abord, aux Vallées - par sa chaleur de cœur, sa spontanéité, l'originalité primesautière de sa nature. Elle n'avait rien de convenu dans sa manière d'être, dans sa façon d'écrire. Tout jaillissait de la source de son âme trempée, délicate et que Dieu avait conquise, sans que rien en elle eût été faussé ou mutilé... Unis comme vous l'étiez à un degré tout à fait exceptionnel, le déchirement doit dépasser tout ce que l'on peut imaginer..

Je sais combien vous étiez la vie l'un de l'autre... Une de vos consolations sera de penser que vous l'avez rendue parfaitement heureuse. Une union aussi tendre que la vôtre rayonne sur d'autre vies...

Chère et noble fille des Vallées, nourrie par les siens des traditions pures des pères, intelligence, travail, simplicité, foi, cette enfant du presbytère vaudois a déposé sa vie entre les mains de Celui à qui elle l'avait consacrée. 
C"est un grand sacrifice qui nous a été demandé. Notre œuvre perd une servante éprouvée et distinguée: mais nous perdons aussi une amie, une sœur.

On nous a retracé le caractère, la belle intelligence et le dévouement de celle que vous pleurez. Un hommage plus beau ne peut être rendu à la femme d'un missionnaire. Il doit y avoir dans votre deuil une grande douceur à constater la place que votre femme bien-aimée tenait dans l'estime et dans l'affection de vies amies. Nous nous sentons tous appauvris par votre perte.

\section{Echos des derniers jours.}

Comme sa figure illuminée m'apparaît douce et belle! Je sens qu'elle ne s'effacera pas, que je ne pourrai jamais l'oublier. Elle restera pour moi un exemple vivant de paix, de calme, d'amour. Je demande à Dieu la force de vivre une vie lumineuse comme la sienne et de passer tranquillement, joyeusement dans son sein.

Si pleine de vie, de charmes, de dons de toute espèce! Il me semble toujours la voir si fraîche et jeune, captivant, par ses récits si vivants, toute la jeunesse qui l'entourait. Elle revivra dans l'âme des Zambèziennes qu'elle a amenées à la foi, dans le cœur de tous ceux qui l'ont chérie et qui continueront à s'inspirer de son exemple si pur et si noble... Je la cherche au pays de la lumière où ses incomparables facultés continuent à s'épanouir, où ses ailes se déploient sans se heurter aux contradictions de la vie.

\section{De la Suisse.}

Dieu nous a frappés en plein cœur, nous tous qui aimions celle qu'on ne pouvait pas ne pas aimer.

Elle avait tout pour être aimée et appréciée: sa chaleur de cœur, son amour pour l'œuvre, à laquelle elle s'était donnée toute entière... Elle semblait si utile, si indispensable à votre foyer, au Zambèze, auprès de ces noirs qu'elle aimait tant et qui le lui rendaient.

Elle n'était pas une femme ordinaire. Partout où elle passait elle se faisait des amis.

Nous gardons un souvenir lumineux et bienfaisant de son trop court séjour chez nous... Elle était une femme missionnaire dans l'âme.

La vie d'Afrique, si dévouée, si active et si belle, doit créer entre un missionnaire et sa femme des liens si intimes, si forts et si doux.

Consacrée avec tant d'ardeur au service de Dieu, elle avait tout quitté pour le suivre où Il l'appelait, dans cette lointaine Afrique... Elle a été gardée alors que tant de compagnons d'œuvre ont succombé là-bas... Se séparer ici en Europe qui nous paraissait un abri contre cette mortalité si active là-bas. Hélas, on meurt partout!

Nous qui avons eu le plaisir de faire sa connaissance, nous gardons d'elle un bienfaisant souvenir. Combien elle nous avait pris le cœur par ses récits, son entiëre consécration au service du Maître; et ses joyeux accents en nous contant sa vie missionnaire au Zambèze, nous ont dès lors bien souvent aidés et fortifiés. Que la foi de celle qui vous a quitté, cette foi courageuse, joyeuse, persévérante, vous soutienne et vous donne de pouvoir regarder en avant où est le devoir, et non pas en arrière pour nourrir les regrets et la douleur du passé disparu à toujours...

Elle avait tant de jeunesse et de charme, tant de zèle et d'intelligence pour le règne de Dieu; tout cela est fini pour la terre. Elle avait conquis bien des cours et sera encore en bénédiction à la cause qu'elle servait.

Nous conservons un souvenir ému de madame Jalla. Sa bonté et son amour de

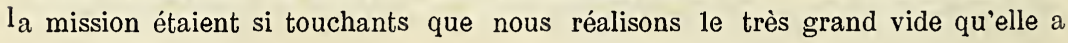


laissé dans votre vie et dans votre œuvre. Vous allez continuer l'évangélisation du peuple que votre bien-aimée compagne a beaucoup aimé et pour lequel elle a donné le meilleur de sa vie.

C'était si intéressant, si émouvant de l'entendre parler de son œuvre et d'apprendre par elle maint petit détail. Elle savait faire vivre devant nos yeux les noirs, petits et grands, dont elle s'était occupée avec dévouement et amour. Son travail n'a pas été vain.

\section{De l'Angleterre.}

C'est une immense perte. Lors de vos deux séjours dans la Grande Bretagne, beaucoup d'entre nous ont appris à la connaître et à l'aimer personnellement, comme nous l'avions déjà connue et aimée par ses lettres, et nous avons su apprécier cette charmante personnalité, si palpitante de vie et d'énergie et qu'on sentait tout spécialement appelée par Dieu à faire son œuvre au milieu des païens. Elle a donné la fleur de sa jeunesse à cette œuvre, elle a renoncé au bonheur de la vie civilisée ainsi qu'aux tendres liens qui l'unissaient $\dot{a}$ la famille, pour porter l'Evangile aux païens dans les ténèbres. Parmi eux elle a fait briller la beauté de la vie de famille chétienne.

\section{De l'Ecosse.}

Elle s'était consacrée à l'œuvre de Dieu avec ses grands dons. Combien son vide se fera sentir là-bas, que de cœurs seront désolés au Zambèze quand ils apprendront qu'elle ne retournera jamais égayer leurs vies! Sa présence même était un encouragement, et sa consécration gaie, joyeuse, inconsciente, avait plus de valeur que bien des sermons.

Sa douce figure vivra dans les cœurs de plusieurs. Sa vie et sa mort porteront des fruits.

Je sais qu'elle a été en bénédiction à plusieurs par sa vie de courage et de rèle, comme par la façon si douce dont elle parlait du Maître et de son œuvre. On ne peut qu'être assuré que l'influence de sa vie se fera encore sentir longtemps.

\section{De la France.}

La voilà auprès de celui qu'elle a fidèlement servi, auquel elle a été heureuse de consacrer sa vie et qui, la couronnant avant la fin de la lutte, l'a recueillie dans son repos. Elle possède ce qu'elle espérait, elle contemple Celui qu'elle aimait sans l'avoir vu, son bonheur est au comble.

\section{De La Haye.}

Je me rappelle cet inoubliable discours d'adieux qu'elle adressait aux missionnaires Volla. Comme elle désirait retourner là-bas au Zambèse reprendre cette belle œuvre où vous avez tous deux mis votre cœur.

\section{De L'Italie.}

Le souvenir de madame Jalla sera toujours dans nos cœurs, et l'œuvre à laquelle elle s'était si entièrement consacrée aura toujours pour nous un grand intérêt.

Nous ne reverrons pas la belle figure de Madame Jalla, qui l'année passée nous transportait, par des paroles aussi simples qu'élevées, dans de lointains parages et, tout en nous modelant des caractères de femmes, elle en imprimait un autre dans nos cœurs, fort, noble, et serein.

Elle était si pleine de cœur, si humaine! Encore l'autre jour comme je visitais à l'hôpital un monsieur qui ne l'a vue qu'une fois, il me dit: «J'ai plus souffert que 
si j'avais perdu ma sœur ». En lisant ces adieux (aux G. Volla) j'ai compris que cœur il y avait chez elle.

Nous nous sentions liés à vous d'une façon toute particulière depuis votre visite. Vous avez laissé un souvenir béni dans mon église... Que le souvenir de vo tre chère femme reste dans nos cœurs à tous, pour nous apprendre comment ou aime les âmes et comment on sert le Maître.

La Zambésia de $\mathrm{R}$. est née après le passage de votre chère femme. Elle est auprès de son Sauveur qu'elle a servi si fldèlement, mais son souvenir est vivant parmi nous et la semence qu'elle a jeté pour la Mission qu'elle aimait tant, germera et portera son fruit.

Nous nous souvenons comme d'une des belles et bienfaisantes choses, de votre passage au milieu de nous, l'an dernier. Elle nous avait beaucoup apporté, beaucoup donné, elle nous avait vraiment fait du bien.

Tous ceux qui l'ont connue l'ont aimée et il vous sera doux de voir le sillon lumineux de sympathie qu'elle a laissé après elle.

Notre douleur est aussi vive et profonde que s'il s'agissait de la perte d'une parente.

Nous avions appris à l'aimer de tout notre cœur, et les quelques jours passés en communion avec elle, ont été un tel privilège pour nous que nous en remercions encore le Seigneur. Oh! elle nous a laissé un souvenir béni et un désir intense de la revoir.

Telle qu'elle est, la carrière de Madame Jalla, comme celle de sa belle-sœur Madame Louis Jalla, a été un splendide témoignage rendu à l'Evangile par le travail (excessif hélas!) accompli en Afrique au milieu des épreuves, et par l'intérêt pour la cause des missions suscité ou accru dans tant de lieux divers en Europe, par la correspondance ou par la parole. Après une journée courte mais très remplie, Dieu l'a rappelée ponr la faire entrer dans son repos.

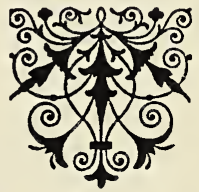






\section{TABLE DES MATIÈRES}

Préface et Préliminaires . . . . . . . . . . . . . . Pag. 4-8

\section{Première Partie.}

Mon Premier voyage au Pays des ma-Rotsé.

INITIATION À LA VIE MissionNAIRE.

1889-1891.

1888 Chap. 1. De Torre-Pellice à la Ville du Cap . . . . . . . Pag. 9

1889 » 2. Séjour dans la Colonie du Cap . . . . . . . . . ” 11

1889 3. De Kimberley à la Ville de Khama . . . . . . . » 13

1889 » 4. A travers le désert . . . . . . . . . . . . . » 16

$1889 » 5$. Sur l'eau et dans les sables . . . . . . . . . . » 22

$1889 » 6$. Onze semaines sous la tente . . . . . . . . . . 》 24

1890 " 7. De Sesheke à Sefula en wagon. . . . . . . . . » 26

1890 8. Débuts à Sefula . . . . . . . . . . . . . ” 28

1890 » 9. Première visite aux capitales. . . . . . . . . . \ 30

$1890 》$ 10. Travaux missionnaires. Mœurs zambéziennes . . . . " 35

1890 » 11. Traité de Lewanika avec la Compagnie à Charte . . » 38

1890 » 12. Chasse au léopard. . . . . . . . . . . . . . » 39

$1890 »$ 13. Chef intérimaire de station. . . . . . . . . . ” 41

1890 11. Dernières semaines de stage . . . . . . . . . . » 44

1890 » 15. Voyage en canot de Sefula à Kazungula . . . . . » 47

1890 » 16. Laissé seul . . . . . . . . . . . . . . 》 51

$1891 \gg$ 17. Du Zambèze en Italie . . . . . . . . . . . . » 53

\section{Seconde Partie.}

SEMAILles LABorIEUSES. RÉveIL DE 1894 ET 1895.

1891-1895.

1891 Chap. 18. Des Alpes à la Tele . . . . . . . . . . Pag. 63

$1891 》$ 19. $\mathrm{Au}$ Lessouto. . . . . . . . . . . . . . . . » 7 7

1892 » 20. Du Lessouto à Mafeking . . . . . . . . . . . » 69

1892 "21. De Mafeking à Kazungula en wagon. . . . . . . " 0

$1892 \gg$ 22. À Kazungula . . . . . . . . . . . . . . . » 74

$1892 \gg$ 23. De Kazungula à Sefula . . . . . . . . . . . » 76

$1892 》 24$. Reprise du travail dans de tristes circonstances . . . \ 79

1892 "25. Chez nous et aux capitales. . . . . . . . . . . » 82

$1892 》 26$. Nos moyens d'action. . . . . . . . . . . . . \ 85

1893 27. Temps de crise. . . . . . . . . . . . . \ 89 
1893 Chap. 28. Ombres et lumière . . . . . . . . . . . . . Pag. 94

1893 " 29. Crainte d'invasion de hordes ma-Tebele. . . . . . 》 98

1894 》30. Paganisme zambézien . . . . . . . . . . . . 》 101

$1894 \gg$ 31. Euvre du Saint-Esprit . . . . . . . . . . . . » 106

$1894 \gg$ 32. Voyage en canot . . . . . . . . . . . . . . \ 109

$1894 \gg$ 33. Temps de rafraichissement . . . . . . . . . . 》 111

$1894 \gg$ 34. Retour à Sefula . . . . . . . . . . . . . . 》 111

1894 \5. Le réveil à Sefula. . . . . . . . . . . . . . \ 113

1894 »36. Dernières semaines à Sefula . . . . . . . . . . 》 116

1894 »37. Nos débuts à Léaluï . . . . . . . . . . . . . » 118

1894 \3. L'opposition s'organise . . . . . . . . . . . . \ 122

$1895 》 39$. Lutte entre les ténèbres et la lumière . . . . . . » 128

1895 » 40. Polygamie et divorce . . . . . . . . . . . 》 133

1895 \1. Des progrès . . . . . . . . . . . . . \ 136

$1895 \gg$ 42. Temps d'arrêt . . . . . . . . . . . . . . . . . . \ 142

1895 \3. Encouragements, secours et difficultés . . . . . . \ 149

1895 \44. Émancipation et profession de Nolianga . . . . . . 》 152

1895 »45. L'opposition gagne du terrain . . . . . . . . . » 153

$1895 》 46$. M. Bertrand, un hôte apprécié et regretté . . . . . 》 155

$1895 \gg$ 47. La traite interdite au bo-Rotsé . . . . . . . . . » 156

$1895 》 4$ 4. La cinquième Conférence de la Mission . . . . . . 》 157

$1895 》 49$. Dernières semaines passées à Lwatile avec M. Coillard 》 158

1895 » 50. De Nalolo à Séoma avec M. Coillard. Retour à Léaluï 》 161

\section{Trosième Partie}

SEUi.s POUR UNE TACHE AGRANdie.

1895-97.

1895 Chap. 5l. Heureuses dispositions de Lewanika . . . . . . Pag. 165

1896 \2. Inauguration officielle de l'école d'évangélistes . . . » 168

$1896 \gg$ 53. Sujets de préoccupations et objets de nos soins . . . 》 172

1896 \5. A la grande chasse royale. . . . . . . . . . . 》 174

$1896 \gg$ 55. Cernés par l'inondation. . . . . . . . . . 》 178

$1896 \gg$ 56. Influences pernicieuses . . . . . . . . . . . » 179

1896 \7. Deuil et autres épreuves . . . . . . . . . . . » 181

$1896 \gg$ 58. Dix jours au chevet de M. Davit . . . . . . . . » 183

$1896 \gg$ 59. Encore des difficultés. . . . . . . . . . . . . » 185

$1896 \gg 60$. Naissance de notre premier-né . . . . . . . . . \ 187

$1896 》 6$ 61. Princesses mises à l'épreuve . . . . . . . . . . . \ 187

1896 \2. Docteurs Zambéziens . . . . . . . . . . . . . \ 189

$1896 \gg$ 63. Sur la station . . . . . . . . . . . . \ 191

1896 » 64 . À la capitale . . . . . . . . . . . . . . . 》 195

$1896 》 65$. Les évangélistes s'éloignent . . . . . . . . . \ 200

1896 \6. Vacances et fêtes agitées et assombries . . . . . . » 201

1897 »67. Toujours la lutte entre le bien et le mal . . . . . » 205

1897 »68. Dernières semaines et mort de Giulio. . . . . . . » 208

$1897 》 69$. Dieu nous accorde des consolations . . . . . . . » 212

$1897 \gg$ 70. Reprise de l'œuvre en plein . . . . . . . . . » 216 


\section{Quatrième Partie.}

Pértode Critique.

1897-98.

1897 Chap. 71. Causes de la crise. . . . . . . . . . . Pag. 221

$1897 \gg 72$. Au jour le jour. . . . . . . . . . . . . . . 》 222

1897 73. Esclavage et guerre esclavagiste . . . . . . . \223

$1897 \gg$ 74. La crise s'accentue . . . . . . . . . . . \ 227

1897 75. Parmi nos ouailles. . . . . . . . . . . . \ 231

1897 76. Délivrance. Sinistre. Démissions. . . . . . . . . \ 332

1897 " 77. Etablissement du Protectorat Britannique. . . . . . 235

1897 》7. L'épidemie d'influenza et ses fruits . . . . . . . » 237

1898 » 79. Nos fêtes . . . . . . . . . . . . . . . . . \ 240

$1898 \gg 80$. Naissance de notre second enfant . . . . . . . . \242

1898 81. L'œuvre pendant l'inondation de 1898 . . . . . . \ 243

1898 \2. Grave maladie de Graziella . . . . . . . . . . \ 248

1898 83. Fragments de notre journal . . . . . . . . . \ 250

1898 » 84. Une mort et un mariage . . . . . . . . . . . » 251

1898 》 85 . Voyage à Kazungula et retour . . . . . . . . . \ 253

1898 » 86. Triste retour sur notre station . . . . . . . . \ 256

$1898 \gg 87$. Mort du Ngambela . . . . . . . . . . . . \ $\gg 258$

1898 »8. Difficultés et encouragements. . . . . . . . . \ 259

\section{Cinquième Partie.}

L'GUVRE PROGRESSE.

1898-1900.

1898 Chap. 89. L'œuvre missionnaire. Ses rouages. . . . . . . Pag. \$65

1898 » 90. Sujets de joie et sujets de tristesse. . . . . . . . . \ 269

$1899 \gg 91$. Un nouveau Ngambéla à Léaluï . . . . . . . . » 271

$1899 \gg 92$. Quelques fleurs et quelques fruits . . . . . . . . \ 275

1899 » 93. Mort de Madame Louis Jalla. Séparation . . . . . » 279

1899 »94. Lewanika et la polygamie. . . . . . . . . . » 284

1899 »5. Pour recevoir M. Coillard . . . . . . . . . . \ 285

$1899 \gg 96$. A l'œuvre avec des constitutions minées . . . . . » 28 \%

1899 》97. Le retour de M. Coillard. La maison et les mains pleines » 292

$1899 \gg 98$. Fondation de la station de Mabumbu. . . . . . . \ 295

1899 »99. Santés éprouvées. Morts . . . . . . . . . . » 296

$1899 \gg$ 100. Investitures et installations . . . . . . . . . . » 299

1900 »101. Nos dernières semaines à Lwatile . . . . . . . . » 302 


\section{Sixième Partie.}

Notre Retour en Europe.

1900.

1900 Chap. 102. Dix semaines d'attente à Sesheke . . . . . . . Pag. 309

1900 》103. À Kazungula et à Mosi-wwa-thunya . . . . . . . 》 312

$1900 \gg$ 104. En wagon à travers le désert . . . . . . . . . » 313

$1900 \gg$ 105. De Bulawayo à Torre Pellice . . . . . . . . . » 316

\section{APPENDICE.}

Carte du Barotsiland. . . . . . . . . . . . . . Pag. 318

I. L'Histoire des ma-Rotsé . . . . . . . . . . . . . . . . 》 319

A. Les origines. Tradition de Kamonu et Nyambe. . . . . . » 319

B. Tradition de la Famille royale . . . . . . . . . » 322

C. La tradition de Mwana-mbinyi . . . . . . . . . . » 325

D. Les ma-Kololo . . . . . . . . . . . . . . \ 326

E. Sepopa et Mwana-wina . . . . . . . . . . \328

F. Lewanika . . . . . . . . . . . . . . . . . . . 》 329

G. Généalogie de Lewanika. . . . . . . . . . . . \ 332

H. Principaux chefs et Officiers la cour de Léaluï. . . . . . » 333

I. Régiments . . . . . . . . . . . . . . . . . » 333

II. La Famille . . . . . . . . . . . . . . . . . . . . . » 334

I. L'enfant . . . . . . . . . . . . . . . . . . . 》 334

II. Fiançailles et mariage. Le mari et la femme . . . . . . » 336

III. Polygamie. . . . . . . . . . . . . . . . . . . 》 337

IV. Le divorce. . . . . . . . . . . . . . . . . . . \ 338

V. La famille chrétienne. . . . . . . . . . . . . . \ 338

III. Le Climat . . . . . . . . . . . . . . . . . . . . . \ 340

A. Température . . . . . . . . . . . . . . . \ 340

B. Vent . . . . . . . . . . . . . . . . 340

C. Pluie . . . . . . . . . . . . . . . . . \ 341

D. Saisons . . . . . . . . . . . . . . . . . . . 》 341

E. Les Maladies . . . . . . . . . . . . . . . . » 341

\section{A LA MÉMOIRE BENIE...}

Quelques souvenirs de la vie de ma femme . . . . . . . . Pag. 342

Derniers mois et derniers moments . . . . . . . . . . . . . 》 344

Les Funérailles . . . . . . . . . . . . . . . . . . . . 》 345

Articles Nécrologiques . . . . . . . . . . . . . . . 》 345

Echos du ministère de ma femme en Europe et Fleurs sur sa tombe . 》 347

A. La vocation missionnaire. . . . . . . . . . . . » 347

B. Lewanika en Angleterre. . . . . . . . . . . . . 》 349

C. Fragments de lettres de condoléance . . . . . . . \ 351 


\section{INDEX DES ILLUSTRATIONS}

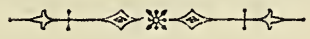

1 Madame Emma Jalla (Décembre 1901). . . . . . Pag. 4

2 Adolphe Jalla (L'Auteur) . . . . . . . . , , 8

3 A travers les fourrés . . . . . . . . . . , , 21

4 Plan de la station de Sefula. . . . . . . . . . . , 28

5 Mokwae. . . . . . . . . . . . , , 34

6 Les Chutes Victoria (Chute de droite). . . . . . . . . . , ,

7 Adolphe et Emma Jalla (Morija, février 1892) . . . . . " 66

8 Wagon embourbé . . . . . . . . . . . . . . . . 71

9 Wagon embourbé . . . . . . . . . . . . . . . .

10 Boeufs en désordre . . . . . . . . . . . . . . . . . . 79

11 A Sefula (1894) . . . . . . . . . . . . . . 102

12 Devant notre chaumière (Sefula 1894). . . . . . . " 102

$13 \mathrm{Kaieka} \mathrm{.} \mathrm{.} \mathrm{.} \mathrm{.} \mathrm{.} \mathrm{.} \mathrm{.} \mathrm{.} \mathrm{.} \mathrm{.} \mathrm{.} \mathrm{.} \mathrm{,} 114$

14 Elizabetha (Nolianga) . . . . . . . . . . . . 152

15 Le Zambèze vis-ì-vis de la station de Mosi-wa-Thunya . . , , 161

16 À Lwatile . . . . . . . . . . . " " 186

17 Nos six évangélistes du Bo-Rotsé et leurs écoles . . . , , 205

18 Brusque tournant du Zambèze à environ $2000 \mathrm{~m}$. en aval des

Chutes Victoria . . . . . . . . . " 234

19 Madame E. Jalla, et Graziella . . . . . . . . " , 248

20 Les Chutes Victoria (Chute de gauche) . . . . . " 250

21 Madame Marie Jalla . . . . . . . . . . , 279

22 Madame Ad. Jalla et Miriame . . . . . . . " , 282

23 Louis, Adolphe, Emma Jalla . . . . . . . , , 308

24 Les Chutes Victoria (Chute centrale) . . . . . . ", 314

25 Souvenir d'Edimbourg (1901) . . . . . . . . , , 317

26 Carte Géographique du Barotsé . . . . . . . . " 318

27 En tournée missionnaire (Spezia, Novembre 1901) . . , , 343

28 Le roi Lewanika à Londres. . . - . . . . . 343

29 Souvenir de Glentyan (Glasgow) . . . . . . . " , 351 





\section{PRIX: Francs 3. 50}

\section{relié toile et or: Francs 5. --}

Dépôt pour la suisse: Chez M. VERnET-WARnERY

21, Florissant, GENEYE.

Dépôt pour la France: À la Maison des Missions Evangéliques 102, Boulevard Arago, PARIS. 

SMITHSONIAN INSTITUTION LIBRARIES 